\title{
Materials Sciences Division 1990 Annual Report
}

\author{
National Center for Electron Microscopy \\ The Groups in Physics, Chemistry, and Materials Sciences \\ Center for Advanced Materials
}

\begin{abstract}
All research described in this report was supported by funds from the Division of Materials Sciences, Office of Energy Research of the U.S. Department of Energy under contract DE-AC03-76SF00098. Portions of this work were also supported by Chemical Sciences Division, Office of Basic Energy Sciences, Office of Conservation and Renewable Energy, Office of Energy Storage and Distribution, Energy Storage Division, Advanced Utility Concepts Division, Energy Blosciences Division, Magnetic Fusion Divison, Fossil Energy Materials Program, Office of Advanced Research and Technical Development in the U.S. Department of Energy; the Department of Defence; U.S. National Aeronautics and Space Administration; U.S. Army; Office of Naval Research; UCSD Center for Recording Materials (NSF); Electric Power Research Institute; National Science Foundation; Morris Research, Inc.; The State of California, Callifornia Competitive Technology Program; Conductus, Inc.; University of Houston; Cargill Corporation; Ford Motor Company; LTV Steel; Digital Equipment Corporation; Hewlett Packard; Sandia National Laboratory.

Cover:

1 Schematic diagram of xenon atoms distributed within the $\alpha$-cages of $\mathrm{Na}$-A zeolite.

2 Benzene adsorbs with notable distortions on Pt(111). Top panel shows side view parallel to surface, exhibiting a buckling (bending) distortion. Bottom panel shows view perpendicular to surface, illustrating location of benzene relative to metal atoms. Note expanded carbon-carbon bond lengths, relative to the gas phase value of $1.40 \AA$. Hydrogen atom positions are guessed.

3 Computer generated structure of the enzyme subtilisin as modified by site-directed mutagenesis to improve iss activity and lifetime. Surface amino acid residue that are practical targets for further modifications are shown.

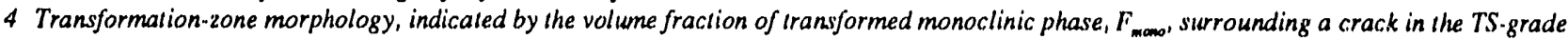
$M g . P S Z$. The extent of transformation is clearly observed to respond to the applied loading conditions.

5 Detail of a stepped interface, showing an edge dislocation, labeled " $d$ ", in which the associated extra haif plane is normal to the inlerface.
\end{abstract}




\section{- CONTENTS-}

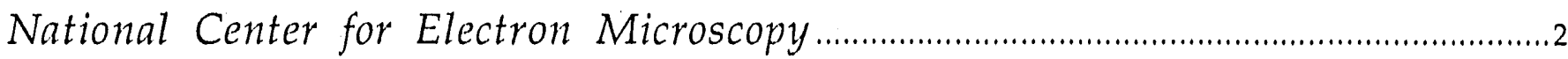

\section{The Groups in Physics, Chemistry, and Materials Sciences}

\section{METALLURGY}

Microstructure, Properties and Alloy Design: Inorganic Materinls

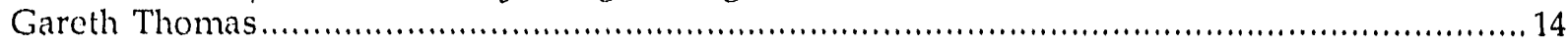

Solid-State Phase-Transformation Mecharisms

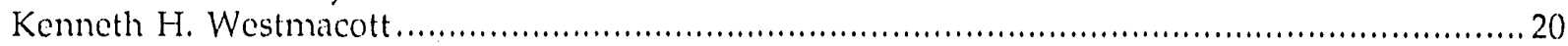

Crystallography of Microstructures

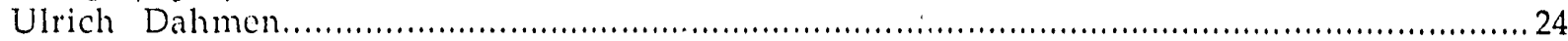

Alloy Phase Stability

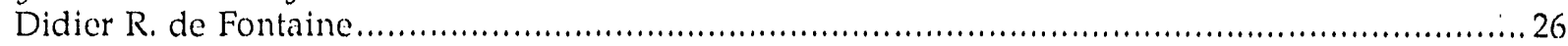

Wastage of Steels in the Erosion Corrosion Enviromments of Fluidized Bed Combustors

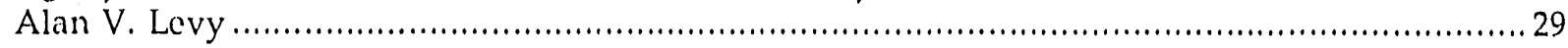

Gas-Solid Reactions

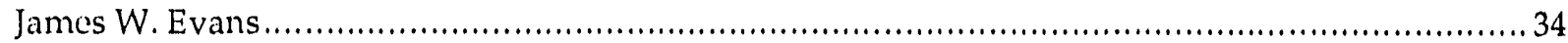

\section{SOLID-STATE PHYSICS}

\section{- Experimental Research}

Far-Infrared Spectroscopy

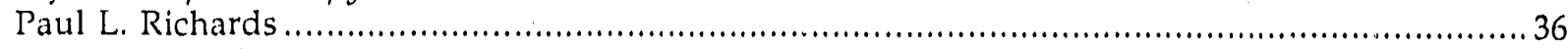

Experimental Solid-State Physics and Quantum Electronics

Y. Ron Shen....

Time-Resolved Spectroscopies in Solids

Peter Y. Yu.....

Superconductivity, Superconducting Devices, and 1/f Noise

John Ciarke.....

- Theoretical Research

Theoretical Studies of Electronic Properties of Solid Surfaces

Leo M. Falicov

Surfaces, Chemisorption, and Theory of Solids

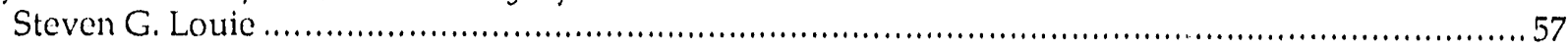

Theoretical Solid-State Physics

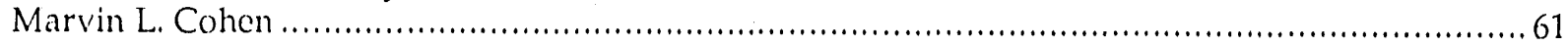

Studies of the Metal/Solution Interface with X Rays

Phillip N. Ross.....

\section{MATERIALS CHEMISTRY}

Low-Temperature Properties of Materials

Norman E. Phillips....

Electrochemical Processes

Charles W. Tobias

High-Temperature Thermodynamics

Leo Brewer.

Materials Chemistry Problems in Nuclear Technology

Donald R. Olander.

Electrochemical Phase Boundaries

Rolf H. Muller 
Nuclear Magnetic Resunance

Alexander Pines.....

- Electrochemical Energy Storage

Electrode Kinetics and Electrocatalysis

Phillip N. Ross.....

Electrical and Electrochemical Behavior of Particulate Electrodes

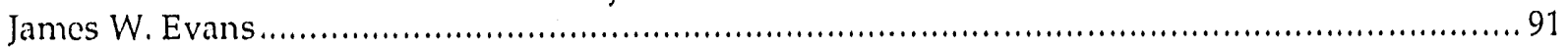

Surface Layers on Battery Materials

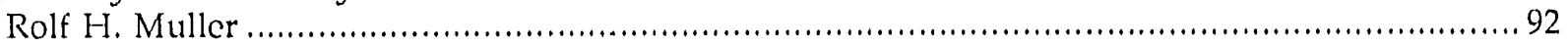

Surface Morphology of Metals in Electrodeposition

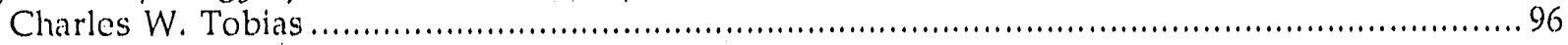

Analysis and Simulation of Electrochemical Systems

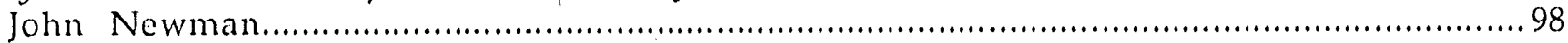

Center for Advanced Materials

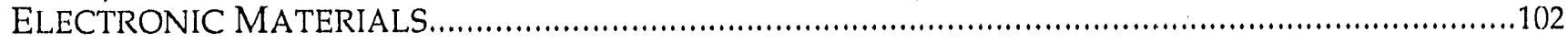

Defects and Impurities in Semiconductors

Bulk Crystal Growth

Thin Films and Interfaces

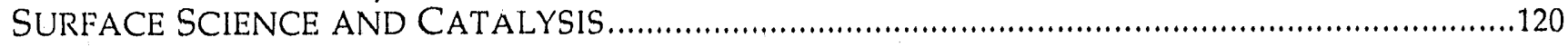

Catalyst Design and Characterization

Surface and Interface Compounds

Instrumentation for Surface Science

CERAMIC SCIENCE

Modeling

Processing

Mechanical Performance

Syrnthesis of Composite Ceramics

HIGH TC SUPERCONDUCTIVITY.

Basic Science

Thin Films and Thin-Film Devices

Electron Microscopy

Ceramic Processing

POLYMERS AND COMPOSITES...

Anisotropic Poiymeric Materials

Polymer Substrate Interactions

Enzymatic Synthesis of Materials

HICH PERFORMANCE METALS......

Metals for Advanced Applications

Mechanical Behavior 


\section{National Center for Electron Microscopy}

High Voltage Electron Microscope

Atomic Resolution Microscope

Analytical Electron Microscope

Computer Image Simulation 


\section{National Center for Electron Microscopy}

The National Center for Electron Microscopy (NCEM) is a DOE-designated User Facility established in 1984 to provide the U.S. electron microscopy community with advanced instrumentation for electron-optical characterization of materials.

At the heart of the NCEM are two unique high voltage microscopes-the $1.5 \mathrm{MeV}$ Kratos HVEM and the $1 \mathrm{MeV}$ JEOL Atomic Resolution Microscope (ARM). The HVEM, which has the highest accelerating voltage available in the United States, is an all-purpose instrument designed primarily for dynamic in situ studies. It is equipped with a variety of heating, cooling, and straining stages and an environmental (or gas reaction) cell for performing experiments in a controlled gaseous atmosphere. An excellent specimen chamber vacuum (cryopumped to better than $10^{-7}$ torr), $\mathrm{LaB}_{6}$ filament, and high resolution, low-light-level $80 \mathrm{~mm}$ television camera complement its other capabilities.

One of the main research objectives at the NCEM is to characterize microstructures at theatomiclevel. This goal motivated the design and construction of the ARM. Sincebeing installed in 1983, its performance has been progressively improved, mainly by mechanical and acoustical vibration suppression, to where atomic columns with spacings less than $0.15 \mathrm{~nm}$ can be resolved. The high-resolution asset of the ARM is enhanced further by the high-angle biaxial tilt goniometer stage which allows images to be obtained (at full resolution) along any zone axis in the stereographic triangle. In these respects the ARM can provide additional structural information not obtainable on its progeny, the JEOL $4000 \mathrm{CX}$.

An essential complement to the instrumental performance is computer image simulation. This component of the NCEM facilities provides users with a variety of services. In addition to user-friendly programs for image simulations from structure models, averaging methods are available for enhancing image quality. Also, links between the computer and various microscopes are being established that streamline the procedures for alignment and performance optimization and greatly increase the microscopist's efficiency.

The third major instrument in the Center is a JEOL 200CX TEM/STEM Analytical Electron Microscope (AEM). Equipped with high-angle and ultra-thin-window $x$-ray detectors and PEELS, the microscope is used both independently and in support of the HVEMs. It provides users with complementary information such as chemical microanalyses, $x$-ray maps, convergent beam electron diffraction patterns, EXELFS, and ELNES.

The resident staff of the Center operate, maintain, design, and develop equipment and software, and provide assistance in supporting the work of its users. In additicn, staff members conduct their own forefront research on problems in the materials sciences.

Guidance for the NCEM is provided by a steering committee chaired by J.J. Hren (North Carolina State University). Its present membership is C.W. Allen (Argonne National Laboratory), R. Geiss (IBM), T. Hayes (LBL), D.G. Howitt (University of California, Davis), D.J.Smith (Arizona State University), L.E. Thomas (Battelle Pacific Northwest Laboratory), M.M. J. Treacy (NEC Research Institute, Inc.), and the investigators on this project. Meetings are held yearly.

Research activities at the Center cover a uroad spectrum of techniques, problems and materials. This is evidenced by the list of currently active projects given in Table 1 . 


\section{Resolution of Oxygen Atoms in Staurolite by \\ Three-Dimensional Electron Microscopy \\ K. H. DOWNING* , H. MEISHENG*, H.-R. WENK ${ }^{\dagger}$ AND M. A. O'KEEFE}

High-resolution electron microscopy has progressed to the point of distinguishing metal atom positions within crystalline specimens. However, the positions of associated oxygen atoms are not seen. The unique capabilities of the NCEM atomicresolution electron microscope (ARM), combined with image processing at the NCEM and Donner Lab, have enabled us to obtain images showing not only the metal atom positions in a silicate specimen, but for the first time, the oxygen atom positions as well. Electron crystallography, in which information from several views is combined, has been developed to obtain three-dimensional information on proteins, generally at resolutions in the $10 \AA$ to $20 \AA$ range. We applied this technique to the mineral staurolite, at a resolution of $1.6 \AA$, using the high-angle tilt stage of the ARM ( $\pm 40^{\circ}$ on two axes) to obtain micrographs in five projections (the three orthogonal directions plus [101] and [310]. Images were processed to reduce noise, confirmed by comparison with simulations, and combined to form a three-dimensional model. Sections through the model (Figure 1) show the metal atom positions as dark spots; in addition, the positions of the accompanying oxygens can be seen as smaller black spots. The final image shows all atom positions in a specimen far too small to be useful for x-ray crystallography.

\section{High Resolution Electron Microscopy Study of the Cationic Disorder in $\mathrm{Al}_{2} \mathrm{TiO}_{5}$ \\ T. EPICIER ${ }^{\ddagger}$, G. THOMAS, H. WOHLFROMM ${ }^{\ddagger}$, AND J. S. MOYA}

As part of a research program devoted to the microstructural characterization of $\mathrm{Al}_{2} \mathrm{TiO}_{5}$-based compounds, high resolution electron microscopy (HREM) has been undertaken in order to study the crystallographic arrangement, especially ordering
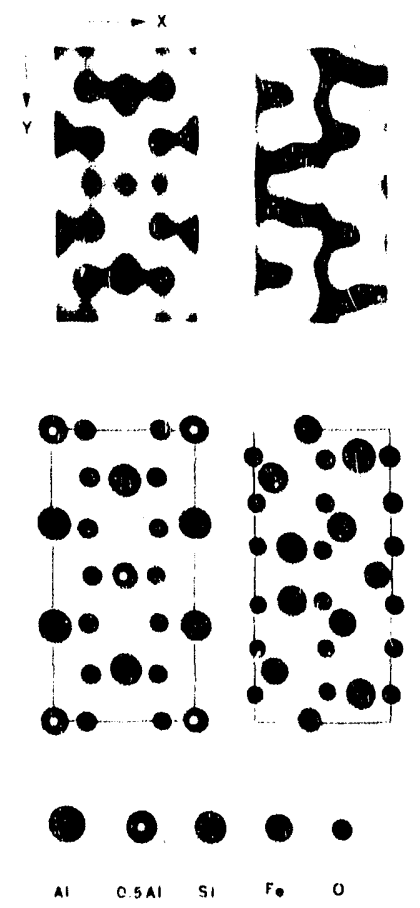

possibilities, of $\mathrm{Al}$ and $\mathrm{Ti}$ cations in the metallic sublattice of aluminium titanate. It is seen that adequate experimental conditions, mainly defocus setting, for a resolution of at least $2.5 \AA$ point-topoint, enable the disordered model to be directly and unambiguously proved on [100]-oriented micrographs, despite the fact that both ordered and disordered structures have the same space group. This work illustrates the good potential for the ARM for structure analysis directly.

Figure 1

Sections displaying the Coulomb potential as derived from the threedimensional structure reconstruction in a full unit cell of staurolite, at a density level that displays all fully occupied cations and oxygens. Sections at $z=0$ and $z=0.25$ are shown above, each corresponding to a slice $0.2 A$ thick. The corresponding crystal structure indicating cation and oxygen positions is shown below. Schematic polyhedral representation with Al octahedra and $\mathrm{Si}$ and Fo tetrahedra is below right. (XBB 900-10026)

" Donner Laboratory, LBL

${ }^{\dagger}$ Department of Geology and Geophysics, University of Californla at Berkeley ${ }^{\ddagger}$ INSA, GEMPPM, Villeurbanne Cedex, France ${ }^{\$}$ Instituto de Ceramica y Vidrio, Madrid, Spain 


\section{Microstructure of $\alpha$-Al Base Matrix/SiC Particulate Composites}

V. RADMILOVIC $*$ G. THOMAS AND S.K. DAS ${ }^{\dagger}$

The microstructures of monolithic Al-Fe-V-Si alloy and $\alpha$-Al base matrix/SiC particulate composites $(\mathrm{MMC})$ have been characterized by conventional and high resolution transmission electron microscopy, microdiffraction and X-ray spectroscopy techniques. Silicide particles of average composition $\mathrm{Al}_{12}(\mathrm{Fe}, \mathrm{V})_{4} \mathrm{Si}$ are present in both of these materials. These particles are unstable under the electron beam at voltages above $200 \mathrm{kV}$, and exhibit radiation induced disordering. $\mathrm{SiC}$ particulates present in the MMC structure are predominantiy of the hexagonal $6 \mathrm{H}$ polytype, but the hexagonal $5 \mathrm{H}$ polytype is also observed. A very thin reaction layer is present between the matrix and $\mathrm{SiC}$ particles. No segregation of alloying elements such as $\mathrm{Fe}$, $\mathrm{V}$, or $\mathrm{Si}$ at the $\mathrm{m} / \mathrm{SiC}$ interface has been observed. The second phase present at the $\alpha-\mathrm{Al} / \mathrm{SiC}$ interface seems to be a disordered silicide.

\section{HVEM Studies of the Sintering of MgO Nanocrystals Prepared by $\mathrm{Mg}(\mathrm{OH})_{2}$ Decomposition \\ N. Thangaraj, K.H. Westmacott and U. Dahmen}

Hot stage high voltage electron microscopy (HVEM) combined with high resolution electron microscopy (HREM) has been employed to study the microstructural evolution during in-situ decomposition of thin $\mathrm{Mg}(\mathrm{OH})_{2}$ flakes and during early stage sintering of the resultant nanocomposite. The decomposition reaction is known to be pseudomorphic and topotactic, resulting in a regular composite of highly aligned nearly cubic $\mathrm{MgO}$ nanocrystals interspersed with a roughly equal volume of pores. This structure was characterized by selected area and optical diffraction techniques as well as by HREM, depending on its microstructural scale. Immediately after decomposition and in the early stages of sintering the fine scale and regular, nearly periodic nature of the microstructure gave rise to diffuse small angle diffraction rings that could be used as a measure of coarsening during in-situ heating in the temperature range $350-900^{\circ} \mathrm{C}$. A series of micrographs recorded during an in-situ heating sequence at $900^{\circ} \mathrm{C}$ in the HVEM is given in Figure 2. The progressive coarsening of the microstructure during sintering is readily apparent. Consistent results were obtained from electron diffraction, optical diffraction and Fourier transforms of digitized images. These measurements were complementary to direct imaging by HREM or conventional imaging techniques.

Sequence of micrographs of a $\mathrm{MgO}$ pseudomorph recorded at $900^{\circ} \mathrm{C}$ for different annealing times showing sintering of microstructure. a) The microstructure of a fully decomposed $\mathrm{Mg}(\mathrm{OH})_{2}$ crystal viewed along [0001] direction immediately after decomposition; b) The same crystal annealed for 40 minutes; c) 90 minutes; d) 120 minutes. (XBB 908-6555)

\footnotetext{
- University of California at Berkeley

${ }^{\dagger}$ Electric Power Research Institute, Palo Alto, CA
}
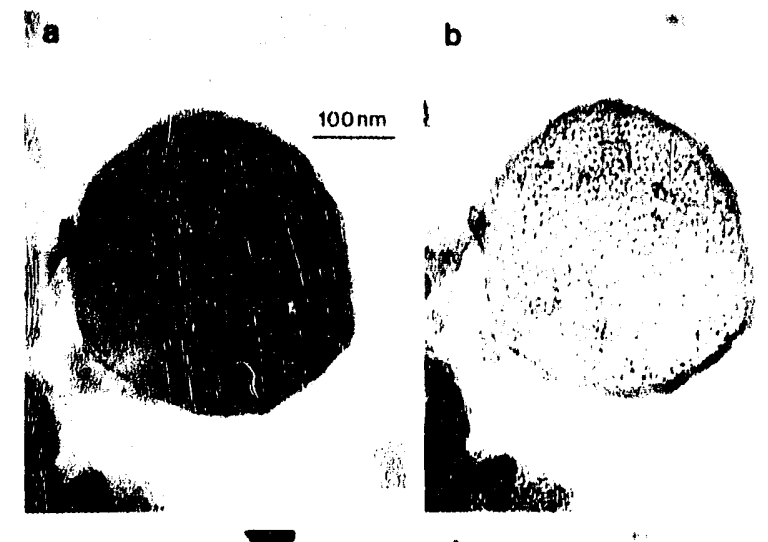

d
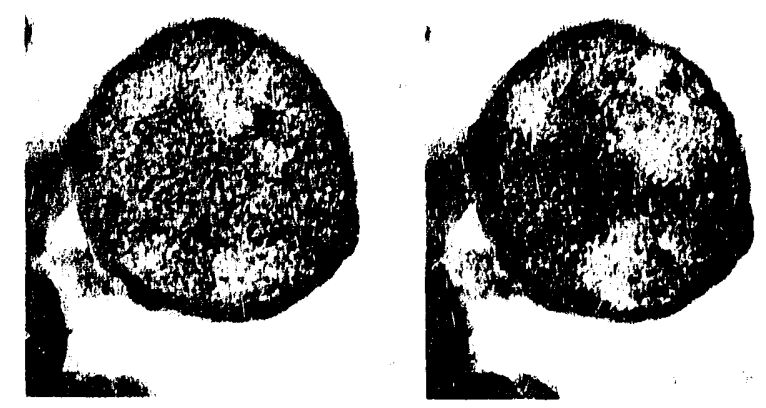
A typical mlcrostructure of thin film diamond synthesized by plasma CVD methods. A high density of microtwins on the (111) planes are observed.

The diffraction pattern (insets) confirms the dlamond orystal structure. The

twin spots are Indexed separately and the streaking is due to the close proximity of neighbouring microtwins. (XBB 894-3261)

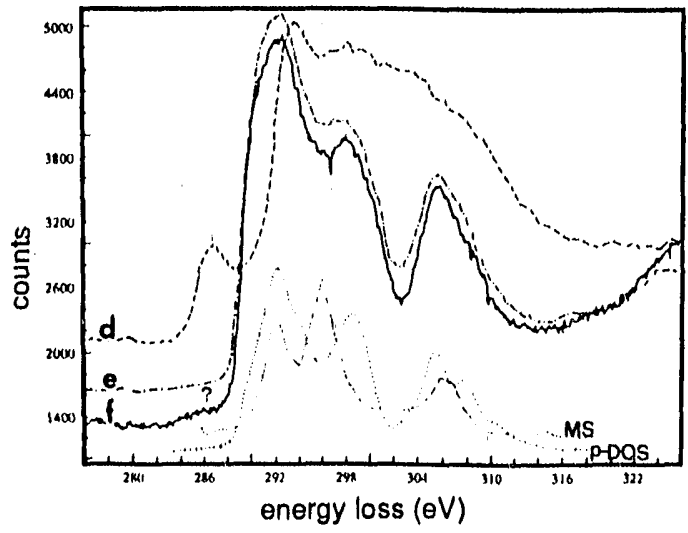

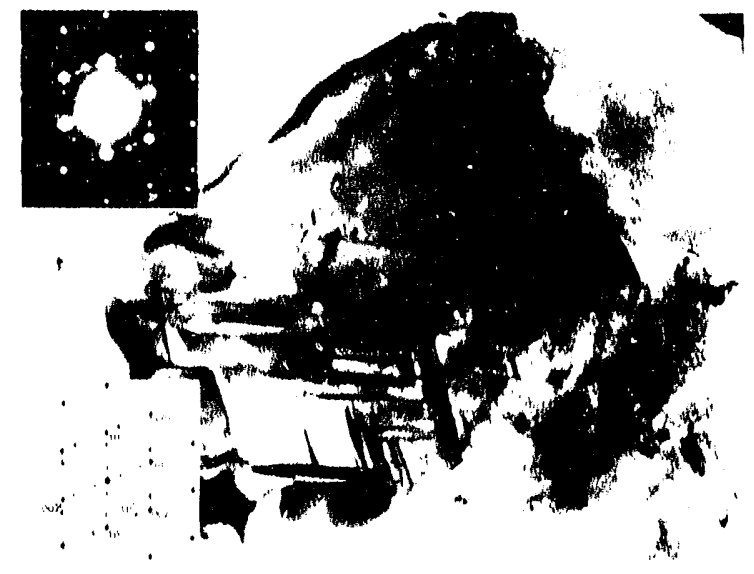

Figure 3b

The C-K edge profiles of plasma CVD diamond, HOPG and natural diamond. The fine structure of the diamond is in good agreement with recent theoretical predictions based on a projected density of states ( $\pi$-DOS) method. However, a fine $\pi^{*}$ peak, representative of $\mathrm{sp}^{2}$ carbon is present. (XBL 894-1465A)

\section{Advances in the Microanalytical Characterization of Optical Materials by Electron Microscopy and Related Spectroscopies}

K. M. KRISHNAN

The fine probe forming capabilities of an analytical electron microscope combined with the develo pment of related spectroscopic (EDXS, EELS), diffraction (CBED) and imaging (phase contrast) techniques, make it possible to obtain structural and chemical information from multiphase materials at high spatial resolution. These microanalytical methods will be described with relevant examples from our studies of compounds in the $\mathrm{Al}_{2} \mathrm{O}_{3}$-AlN pseudobinary system, a potential optical window material, and low-pressure diamond and diamond-like carbon films. In particular, efforts to extend energy dispersion $x$-ray spectroscopy quantification procedures to low atomic number elements $(C, N, O)$ will be discussed. A comprehensive example of the characterization of a novel AlON polytypoid structure, illustrative of both the information content obtainable from these techniques at any particular level of resolution and the need to use all the complementary methods of analysis, will be presented. Finally, our efforts to characterize a variety of diamond and diamond-like carbon films, by the mer drement of both the low-loss plasmon resonances and the fine structure of the corc loss edges observable in their electron energy-loss spectrum, to obtain $\mathrm{sp}^{3} / \mathrm{sp}^{2}$ ratios, will be outlined. As an example of this work, the microstructure and corresponding diffraction pattern from a plasma CVD diamond film is given in Figure 3a. In Figure $3 \mathrm{~b}$ the electron energy loss spectrum tor this material is shown together with spectra from Highly Oriented Pyrolite Graphite and natural diamond for comparison.

\section{Iron $L_{3,2}$ Near Edge Fine Structure Studies \\ K.M. KRISHNAN}

$L_{3,2}$ near edge fine structures of iron in different oxidation states and coordination numbers, measured with a parallel electron energy-loss spectrometer operating at 1.0-1.3 V resolution, show distinct splittings of the white lines. The splittings have been interpreted in terms of a simple atomic approach involving ligand field splitting of the d orbitals. It is shown that Fe(III) fine structure is particularly sensitive to its coordination. 


\title{
Structure and Composition Characterization of Submicronic Mullite Whiskers
}

\author{
N. MERK AND $G$. ThOMAS
}

Analytical, high resolution electron microscopy, and x-ray diffraction has allowed a full characterization to be made of two sets of submic ronic mullite whiskers. One set of whiskers had the metastable tetragonal symmetry which transformed upon heating to the stable orthorhotnbic phase. "The other set was orthorhombic. From these results it is clear that the structure of mullite is very process- and not just composition-dependen!. It may be that fluorine is involved in stabilizing the tetragonal form. Annealing of both sets of whiskers under vacuum results in a continuous loss in silicon and finally the appearance of the $\alpha-\mathrm{Al}_{2} \mathrm{O}_{3}$ phase in the form if sintered powders. Mullite whiskers of composition as high as 79.6 mole $\%$ $\mathrm{Al}_{2} \mathrm{O}_{3}$ were detected. The loss in silica is accompanied by a loss of oxygen. The appearance of antiphase boundaries and twinning indicate the occurrence of oxygen vacaricy ordering. The detection of pure aluminum metal at the tips of single annealed mullite whiskers suggests the existence of a strong ieducing atmosphere. An alternative path for $\alpha$-alumina formation may be through the reoxidation of the aluminum.

Table 1-1

NCEM Research Proposals (active during 1990)

\begin{tabular}{|c|c|c|}
\hline Principal Investigator & Affiliation & Title \\
\hline \multicolumn{3}{|l|}{ HVEM } \\
\hline P. Alivisatos & L.BL & Meling of semiconductor nanocrystals \\
\hline J. Bastacky & LBL/UC Berkeley & Phagocytic process in uptake of coal combustion particulates by pulmonary macrophage cells \\
\hline T. Cass & Hewlett-Packard & Defect structures in semiconductor devices \\
\hline U. Dahmen & LBL & Characterization of nanocrystals by TEM \\
\hline K. Dante & UC Berkeley & Alteration of pyrite to chalcocite \\
\hline J. Dash & Portland State & Phase transformation induced by high pressures and temperatures in a ballistic compressor \\
\hline S. Farrens & UC Davis & NCEM proposal to prepare diamond yilms in the HVEM \\
\hline R. Fisher & LBL/IBM & Microstructure investigations of ceramic model interface \\
\hline \multirow[t]{2}{*}{ D. Frear } & Sandia & Microstructural study of Al thin films \\
\hline & & Microstrusture of solder interconnections in electronic packaging polymers \\
\hline S. Frisia-Bruni & LBL/U. Milano & Microstructural investigation into the diagenetic history of Haupt dolomite of the Southem Alps \\
\hline W. E. Glassley & LBL/LLNL & Investigation of the alpha/beta cristobalite transition in the presence of a vapor phase \\
\hline H. W. Green, II & UC Davis & The olivine to spinel transformation in $\mathrm{Mg}_{2} \mathrm{GeO}_{4}$ \\
\hline J. Heuer & Rockwell Internat. & Miaterials study of mixed composition thin films \\
\hline D. Howitt & UC Davis & Structural study of thin film ceramics \\
\hline M. E. Kassner & Oregon State U. & Delayed failure of $\mathrm{Ag}$-aided diffusion bonds by microvoid coalescence \\
\hline E. Kvam & LBL & Dislocation dynamics in strained epitaxial Ge-Si alloys on (001) silicon \\
\hline Z. Liliental-Weber & LBL & Kinetics of the Au crystallites formation on the periphery of Au Schoult:y contacts \\
\hline A. Meike, C, Ruscher & LBI/U. Hanover & Elementary steps of biotite buffer reactions \\
\hline W. Moberly & Stevens Institute & Martensitic transformations in thin-film TiNi alloys \\
\hline \multirow[t]{2}{*}{ J. W. Morris, Jr. } & LBL/UC Berkeley & Dislocation substructures and work-hardening in BCC polycrystalline metals \\
\hline & & TEM studies of electromigration induced failure in $\mathrm{Al} / \mathrm{Al}$ alloy interconnection \\
\hline D. Noble & Stanford & Misfit dislocation in SiGe/Si heterostructures \\
\hline L. E. Rehn & Argonne NL & Comparison of clectron and ion irradiation-induced grain growth in gold films \\
\hline J. Reyes-Gasga & U. Mexico & In-situ HVEM studies of metal-semiconductor interfaces \\
\hline M. M. Robinson & U. Capetown, S. A. & In-situ straining of $\mathrm{Al}$ and $\mathrm{Al}-\mathrm{Mg}$ alloys within the serrated flow regime \\
\hline A. E. C. Spargo & U. Melbourne & The tuned voltage effect in HREM \\
\hline «. Tanner & LLNL & Study of metastable phase formation in $\mathrm{Cu}-\mathrm{Zr}$ and $\mathrm{Al}-\mathrm{Ni}$ \\
\hline M. A. Taylor & UC Davis & Ilydration of Portland cement in enviromental cell \\
\hline G. Thomas, V. Radmilovic & LBI/U. Belgrade & Critical voltage studies of $P F Z$ in $A l-L, i$ alloys \\
\hline G. Thomas, A. Berkowitz & LBL/UC San Diego & The oxidation-reduciion transitions in $\mathrm{aFe}_{2} \mathrm{O}_{3} / \mathrm{Fe}_{3} \mathrm{O}_{1}$ transformation \\
\hline
\end{tabular}


Table 1-1 (Continued)

\begin{tabular}{|c|c|c|}
\hline Principal Investigator & Affiliation & Title \\
\hline P. Vasconcelos & UC Berkeley & Microstructures in natural gold-Influence of high $\mathrm{Ig}$ and Pd content \\
\hline M. Vittori & ENEA, Rome & Electron irradiation effects on $\mathrm{Ni}-\mathrm{Zr}$ interfaces \\
\hline \multirow[t]{3}{*}{ R. Wenk } & UC Berkeley & Phase transformation in silica minerals \\
\hline & & Deformation mechanisms in dolomite polycrystals as a function of orientation \\
\hline & 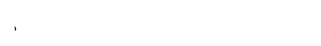 & Influence of defects on $a-b$ quartz transformation and Dauphine twinning \\
\hline K. H. Westmacott & LBL & Dy'namic hot-stage studies of precipitate development in interstitial and substitutional alloys \\
\hline \multicolumn{3}{|l|}{ ARM } \\
\hline S. Chumbley & Ames Laboratory & Analysis of deformed superconductors \\
\hline \multirow[t]{2}{*}{ U. Dahmen } & LBL & Characterization of nanocrystals by HREM \\
\hline & & HREM study of ionized-clu. er beam (ICB) deposited metal clusters \\
\hline \multirow[t]{2}{*}{ G. Thomas, T. Epicier } & LBI ISA, France & Atomic resolution microscopy of light atoms in some ceramic compounds \\
\hline & & HREM study of alumina-based ceramics; aluminum titanate \\
\hline \multirow[t]{4}{*}{ T. Epicier } & INSA, GEMPPM, France & HREM of copper/cordierite interfaces \\
\hline & & HREM of interfaces in alumina-based ceramics \\
\hline & & HREM study of defects in chloritoid \\
\hline & & Electron microscopy study of precipitation in Al-Fe-Mo alloys obtained by rapid solidificatio \\
\hline A. Fitzgerald & U. Dundee & Atomic resolution electron microscopy of amorphous and microcrystalline silicon films \\
\hline J. Goral & SERI & Defect generation and propagation in MBE-grown $\mathrm{GaAs} / \mathrm{GaInAs}$ \\
\hline \multirow[t]{9}{*}{ R. Gronsky } & LBL/UC Berkeley & Atomic mechanisms of precipitate plate growth \\
\hline & & Quasicrystals \\
\hline & & Defects in oxide superconductors \\
\hline & & Defect reduction in ISE SOI material \\
\hline & & HREM of thin film superconductors: epitaxy and metal contact interfaces \\
\hline & & Microstructures of C-implanted and Ge-implanted Si \\
\hline & & Site specific occupancy in $\mathrm{Sb}-\mathrm{Pb}-\mathrm{Bi}-\mathrm{Ca}-\mathrm{Sr}-\mathrm{Cu}-\mathrm{O}$ superconductors \\
\hline & & HREM of VPI-5 and $\mathrm{AlPO}_{4}-8$ \\
\hline & & Studies of $\mathrm{Si} / \mathrm{SiO}_{2}$ interface between $\mathrm{ECR}$ oxide films and [100] Si substrates \\
\hline R. A. Herring & Martin-Marrietta & HREM of $\mathrm{T}_{1}$-type phases in $\mathrm{Al}$ alloys \\
\hline A. Jankowski & LLNL & Characterization of shon period $\mathrm{Au} / \mathrm{Ni}$ and $\mathrm{Ni} / \mathrm{Ti}$ layers \\
\hline K.M. Krishnan & LBL & Interface structure of ultrathin multilayers \\
\hline E. Kvam & LBL & Systematic study of grain boundary structures in fcc[001] tilt boundaries \\
\hline \multirow[t]{2}{*}{ J. Y. Laval } & CNRS, Paris & Atomic structure of internal interfaces in covalent materials \\
\hline & & Atomic structure of coincidence tilt boundaries in $\mathrm{YBaCuO}$ superconductors \\
\hline Z. Liliental-Weber & LBL & The structure of metal contacts to $\mathrm{GaAs}$ \\
\hline J. Mayer & UC Santa Barbara & HREM studies of interfaces between high-temperature superconductors and substrates \\
\hline R. L. McConville & Raychem & A proposal to study grain boundary regions in $\mathrm{ZnO}$ based varistors using the NCEM ARM \\
\hline M. Mills & Sandia, Livermore & Core structure of screw superdislocations in $\mathrm{Ni}_{3} \mathrm{Al}$ \\
\hline G. B. Olson & Northwestem & Fine structure of martensitic interfaces \\
\hline F. Ponce & LBL/Xerox & Structure of early stages of growth in GaAs/Si epitaxy \\
\hline M. Ruhle & UC Santa Barbara & HREM study of $\mathrm{Pd} / \mathrm{Al}_{2} \mathrm{O}_{3}$ interfaces with modulated structures \\
\hline A. Schwartzman & Stanford & Core structure of Lomer dislocations at the $\mathrm{Cd} T \mathrm{e} / \mathrm{GaAs}$ and $\mathrm{ZnTe} / \mathrm{GaAs}$ interfaces \\
\hline A. E. C. Spargo & U. Melbourne & The tuned voltage effect in HREM \\
\hline \multirow[t]{2}{*}{ L. Tanner } & LLNL & HRTEM studies of pretransformation microstructures in metallic alloys \\
\hline & & Study of metastable formation in $\mathrm{Cu}-\mathrm{Zr}$ and $\mathrm{Al}-\mathrm{Ni}$ \\
\hline \multirow[t]{2}{*}{ G. Thomas } & LBL/UC Berkeley & HREM on glasses \\
\hline & & Atomic imaging of structure and defects in high $\mathrm{T}_{\mathrm{a}}$ superconductors \\
\hline \multirow[t]{2}{*}{ G. Thomas } & LBL & Structure and interfaces in $\mathrm{NiO} / \mathrm{CoO}$ \\
\hline & & Formation mechanism of $\delta^{\prime}\left(\mathrm{Al}_{\mathrm{j}} \mathrm{Li}\right)$ \\
\hline M. Wall & LLNL & Characterization of short period $\mathrm{Au} / \mathrm{Ni}$ and Ni/Ti multilayers \\
\hline \multirow[t]{2}{*}{ H. R. Wenk } & UC Berkeley & Superstnucture identification in carbonate mincrals \\
\hline & & Electron crystallography of minerals \\
\hline K. H. Westmacott & LBL & Studies of precipitate morphologies and interfaces \\
\hline
\end{tabular}


Table 1-1 (Continued)

\begin{tabular}{|c|c|c|}
\hline Principal Investigator & Affillation & Title \\
\hline \multicolumn{3}{|l|}{ AEM } \\
\hline \multirow[t]{3}{*}{ K.M. Krishnan } & LBL & Iron $L_{3,2}$ near edge fine structure studies \\
\hline & & Characterization of low pressure diamond films \\
\hline & & Applications and development of channelling enhanced microanalysis \\
\hline K.M. Krishnan, N. Cho & LBL & Characterization of diamond-like carbon \\
\hline K.M. Krishnan, et al. & LBL & White lines in manganese oxides and complexes \\
\hline K.M. Krishnan, C. Echer & LBL & Experimental determination of energy loss cross sections for low atomic number elements \\
\hline C. Ortiz, K.M. Krishnan & LBL/IBM San Jose & Microstructural characterizaition of Fe-oxide magnetic recording media \\
\hline C. Ortiz, et al. & LBL/ABM San Jose & $\begin{array}{l}\text { Microstructural characterization } \\
\text { of laser modified Br-Te-Se thin filns }\end{array}$ \\
\hline \multirow[t]{2}{*}{ R. Shen, et al. } & LBL/UC Berkeley & EELS analysis of B-C-N chemically vapor deposited crystallites \\
\hline & & Characterization of new materials $\left(\mathrm{C}_{\mathrm{x}} \mathrm{ByN}_{2}\right)$ by Electron Energy Loss Spectroscopy \\
\hline \multirow[t]{2}{*}{ D. Blake, C. Echer } & LBL/NASA-Ames & Characterization of carbonaceous phases contained in meteorites and interplanetary dust \\
\hline & & Carbon characterization of Murchison meteorite \\
\hline Z. Lilienta!-Weber, et al. & LBL & Ohmic and Schottky Au contacts on $\mathrm{GaAs}$ \\
\hline Z. Liliental-Weber, et al. & LBL/UC Berkeley & Microstructural characterization of $\mathrm{Zr}$ oxides and nitride interfaces with $\mathrm{GaAs}$ \\
\hline N. Merk, L. Tanner & LBL/LLNL & Characterization of $\mathrm{Ni} / \mathrm{Al}$ and $\mathrm{Cu} / \mathrm{Zr}$ solid state phase transformations \\
\hline \multirow[t]{2}{*}{ N. Merk, G. Thomas } & LBL/UC Berkeley & Characterization of mullite whiskers \\
\hline & & Characterization of metal/ceramic interfaces \\
\hline N. Kijima, R. Gronsky & LBL & Microstructural characterization of $\mathrm{Sb}-\mathrm{Pb}-\mathrm{Bi}-\mathrm{Sr}-\mathrm{Ca}-\mathrm{Cu}-\mathrm{Co}$ superconductors \\
\hline N. Benson, et al. & LBL/Cal State, Hayward & Characterization to determine the presence and valence of reduced selenium in bacteria \\
\hline S. Menon, et al. & LBL/UC Berkeley & Characterization of short range order and long period superstructures in Cu-Pd alloys \\
\hline K. C. Liu, G. Thomas & LBL/UC Berkeley & Reaction sintering: kaolinite \& mullite \\
\hline C. Koehler, G. Thomas & LBLNC Berkeley & Microstructural evaluation to improve high temperature properties of Y-SiAlON \\
\hline C. Leroux, G. Thomas & LBL/UC Berkeley & Characterization of antiferromagnetic $\mathrm{NiO} / \mathrm{CoO}$ films \\
\hline I'. Li, G. Thomas & LBL/UC Berkeley & Characterization of $\mathrm{Co}-\mathrm{Ni}-\mathrm{Cr}$ and $\mathrm{Co}-\mathrm{Ni}-\mathrm{Ta}$ recording thin films \\
\hline M. Cinibulk, G. Thomas & LBL/UC Berkeley & Characterization of silicon nitride/SiAION composites \\
\hline V. Radmilovic, G. Thomas & LBL/UC Berkeley & Interfacial characterization of silicon carbide and aluminum alloys \\
\hline A. Goldstein, P. Alivisato & IIC Berkeley & Elevated temperature characterization of CdS microcrystallites \\
\hline J. Goral & SERI & Characterization of copper containing impurity phases in CuInSe $e_{2}$ polycrystalline thin films \\
\hline S. Bruni, R. Wenk & U. Milano/UCE & Microstructural investigation of Southem Alps dolomites \\
\hline K. Dante, M. Hu, R. Wenk & UC Berkeley & Characterization of copper containing pyrite \\
\hline R. Wenk, et al. & UC Berkeley & Characterization of Amazoniar gold nuggets \\
\hline D. Sinitsyna, R. Wenk & UC Berkeley & Characterization of perovskites and dolomites \\
\hline J. Douin, et al, & LBL & Microstructural characterization of precipitates in aluminum - $1 \%$ germanium alloys \\
\hline M. Witcomb, et al. & LBL/U. Witwatersrand, & Microstructural characterization of chromium rich precipitates in $\mathrm{Cu}-\mathrm{Cr}$ alloys \\
\hline A. Fox & Naval Postgraduate & Microchemical analysis of small precipitates in steels \\
\hline C. Salvadori, K.M. Krishnan & U. Sao Paulo, LBL & Characterization of CVD diamond films \\
\hline C. Gouthama & U. Nevada & Characterization of coated and clad superconductors \\
\hline W. Cao, G. Thomas & LBL/UC Berkeley & Characterization of interfaces and grain boundaries in $\mathrm{Fe}_{-}-\mathrm{SiO}_{2}$ thin films \\
\hline A. Ilutten, G. Thomas & LBL/UC Berkeley & Characterization of hard magnets $\mathrm{Sm}-\mathrm{Fe}$-Ti alloys \\
\hline M. Berkson, G. Thomas & UC Berkeley & Characterization of grain boundary precipitates in Ti-Ni alloys \\
\hline B. Schuler, et al. & LBL/UC Berkeley & EELS analysis of B-C-N graphites \\
\hline N. Thangaraj, U. Dahmen & LBL & TEM study of microstructural evolution during decomposition of magnesium hydroxides \\
\hline R. Spontak & Procter \& Gamble & Correlation of polymer resin/cellulose fiber interactions with nitrogen \\
\hline J.-Y. Laval & CNRS, France & Operational procedures for parallel electron energy loss spectroscopy \\
\hline
\end{tabular}

\section{COMPUTER PROJECTS}

$\begin{array}{ll}\text { R. S. Rai, M. A. O'Keefe } & \text { LBL/UC Berkeley } \\ \text { M. L. Sattler, M. A. O'Keefe } & \text { LLNL/LBL } \\ \text { M. L. Sattler, M. A. O'Keefe } & \text { LLNL/LBL } \\ \text { U. Dahmen, M. A. O'Keefe } & \text { LBL/UC Berkeley } \\ \text { N. Merk } & \text { LBL/LLNL } \\ \text { M. Stampfer } & \text { LBL } \\ \text { C. Hetherington } & \text { LBL } \\ \text { C. Hetherington } & \text { L.BL. }\end{array}$

Simulation of phases in $\mathrm{Y}_{2} \mathrm{Si}_{2} \mathrm{O}_{\text {, }}$

Processing of images of multilayer structures formed from amorphous materials

Simulation of interfaces in amorphous materials

Simulation of metastable phases in zirconia

Diffraction pattern calculation in $\mathrm{CuZr}-\mathrm{NiAl}$

Quantification in energy loss spectroscopy

ARM characterization (CI'F's, on line ODM)

Al grain boundary-processing (SEMPER) 
Tuble 1-1 (Continued)

\begin{tabular}{|c|c|c|}
\hline Principal Investigator & Affiliation & Title \\
\hline C. Hethorington, et al. & LBLNaval Postgraduate & Wedge crystal study of experimental image vs, calculated image \\
\hline C. Hetherington, U. Dahmen & LBL & Hexagonal silicon and hexagonal/cubic interface \\
\hline U. J. Douin, U. Dahmen & LBL & Interface simulation in $\mathrm{Al} / \mathrm{Si}-\mathrm{Al} / \mathrm{Ge}$ \\
\hline T. Epioier, et al. & INSA/LBL & Studies of mullite; studies of $\mathrm{C} 60$ cluster \\
\hline M. A. O'Keefe, et al. & LBLU, Penn & Simulation of $\mathrm{Al}$ grain boundaries \\
\hline M. A. O'Keefe, M. Sattler & LBL/LLNL & Simulation of multilayer structures \\
\hline N. Thangaraj, J. Tumer & LBL & Diff raction pattem profiles of $\mathrm{MgOH}$ \\
\hline J. Tumer, M.A. O'Keefe & LBL $\quad ;$ & Processing ICB aluminum grain boundary images to detcrmine perioxlicity and atom position \\
\hline J. Ulan, M. A. O'Keefe & LBL/UC Berkeley & Simulation of Zeolite images \\
\hline J. Ulan, J, Tumer, & LBL/UC Berkeley & Processing of Zeolite images \\
\hline R. Ramesh, R, Kilaas & LBL/Bell Comm. & Studies of copper vacancies in high $\mathrm{T}_{\mathrm{c}}$ superconductors \\
\hline N. Merk, R. Kilaas & LBLUC Berkeley & Simulation studies of displacement waves and concentration waves in NiAl \\
\hline R. Kilaas & LBL & Development of software algorithms for the construction of general crystal interfaces \\
\hline U. Dahmen, R. Kilaas & LBL & Computer models for cluster formation under vapor deposition \\
\hline M. Hu, et al. & LBL/UC Berkeley & Simulation studies of staurolite \\
\hline M. Hu and J.Tumer & ¿BL/UC Berkeley & Processing of staurolite images \\
\hline M.A. O'Keefe & LBL & Theoretical verification of EREM parameters \\
\hline N. Merk & LBL & Simulations of mullite whisker images \\
\hline T'. Epicier & Lyons, France & Simulations of $\mathrm{BaTiO}_{3}$ images \\
\hline M.A. O'Keefe, T. Epicier & LBL/Lyons, France & Simulations of mullite images \\
\hline T. Nguyen, et al. & LBL/UC Berkeley & Simulations of multilayer boundary images \\
\hline T. Nguyen, J. Tumer & LBL/UC Berkeley & Processing and analysis of multilayer images \\
\hline N. Kijima & UC Berkeley & BiSr superconductor image simulation \\
\hline N. Kijima, J. Tumer & LBL/UC Berkeley & BiSr superconductor image processing \\
\hline N. Thangaraj, M.A. O'Keefe & LBL & Line measurements from diffraction pattem \\
\hline R. Kilaas & LBL & Software development for $\mathrm{X}$-ray image processing \\
\hline R. Kilaas, C. Echer & LBL & $\mathrm{X}$-ray image processing \\
\hline K.M. Krishnan & LBL & SLEEP software for PEELS data processing \\
\hline E.S.K. Menon & UC Berkeley & PEELS data processing \\
\hline J. Tumer, et al. & LBL/UC Berkeley & Diff raction pattem analysis \\
\hline J. Tumer, A. Goldstein & LBL/UC Berkeley & Image analysis of CdS nanocrystals \\
\hline J. Turner, A. Goldstein & LBL/UC Berkeley & Diff raction analysis of CdS nanocrystals \\
\hline J. Tumer, Y. Zhu & LBL/Brookhaven & Image processing of 123 -superconductor boundaries \\
\hline J. Tumer, C. Burmester & LBL/UC Berkeley & Image processing of oxygen deficient $\mathrm{YBa}_{2} \mathrm{Cu}_{3} \mathrm{O}_{7 . x}$ \\
\hline M.A. O'Keefe, et al. & LBL/U. Belgrade & Simulation of $\mathrm{SiC}$ images \\
\hline M. Fendorf, J. Tumer & LBL/UC Berkeley & Image processing of superconductor images \\
\hline C. Leroux & LBL & Simulation of anti-ferromagnetic $\mathrm{NiO} / \mathrm{CoO}$ films \\
\hline P. Lours & LBL & Aluminum bicrystal image simulations \\
\hline C. Burmester & LBL & Image simulation by Monte Carlo method of oxygen ordering of $\mathrm{YBa}_{2} \mathrm{Cu}_{3} \mathrm{O}_{7 \cdot \mathrm{x}}$ \\
\hline
\end{tabular}

Actiny Director*

Ulrich Dahmen

Investigators

Ronald Gronsky

Kannan M. Krishnan

Gareth Thomas

Kenneth H. Westmacott

Staff Scientists

Roar Kilaas

David Loretto

Michael A. O'Keefe

\author{
Postdoctoral Fellows \\ Nam-Hee Cho \\ C.P. Luo \\ M. Cecilia Salvadori \\ Nagappan Thangaraj \\ Principal Technician \\ Douglas Owen \\ Senior Technicians \\ Charles J. Echer \\ John Turner \\ Technicians \\ Cyril Gleeson \\ Doreen AhTye \\ Administrafine Assislance \\ 'îheda Crawford \\ Madeline S. Monre
}

"Effective 1991 


\section{Publications and Reports}

Refereed Joumal Articles

Douin, J., U. Dahmen, and K.H. Westmacott, "A High Resolution Study of Twinned Precipitates in Al-Ge Alloys," J. Phys. 51, Suppl. C1 809, 1990.

K.H. Downing, H. Meisheng, H.-R. Wenk, and M.A. O'Keefe, "Resolution of Oxygen Atoms in Staurolite by Three-dimensional Electron Microscopy," Nature 348, 1990.

Koestler, C., L. Schultz, and G. Thomas, "Microstructure of Mechanically Alloyed Fe78Mo10Sm12-magnets with ThMn12-structure," J. Appl. Phys. 67, 5, 1990.

Kramer, M. J., L.S. Chumbley, R.W'. McCallum, W.J. Nellis, S. Weir, and E P. Kvam, "Deformation Induced Defects in $\mathrm{ReBa}_{2} \mathrm{Cu}_{3} \mathrm{O}_{7-d}$, Physica C 166, 115, 1993.

Motta, A. T., D.R. Olander, and A.,. Machiels, "Electron Irradiation-induced Amorphization of Precipitates in Zircaloy-2," Standard Technical Publication 1046-1990, Amer. Soc. Testing \& Materials, p. 457, 1990.

Pirouz, P., R. Chaim, U. Dahmen, and K.H. Westmacott, "The Martensitic Transformation in Silicon. I. Experimental Observations," Acia Met. 38, 1990.

Pirouz, P., R. Chaim, U. Dahmen, and K.H. Westmacott, "The Martensitic Transformation in Silicon. II. Crystallographic Analysis," Acta Met. 38, 313, 1990.

Pirouz, P.. R. Chaim, U. Da'isnen, and K.H. Westmacott, "The Martensitic Transformation in Silicon. III. Comparison with Other Work," Acta Met. 38, 1990.

Tabbernor, M. A., and A.G. Fox, "The Low-angle Atomic Scuttering Factors and Charge Density nf Zinc,"Phil.Mag. Lettcrs 62, 291, 1990.

Zhu, Y., M. Suenaga, and A.R. Moodenbaugh, "Displacement Wave of the Tweed Str ucture in Y-Ba-Cu-O Oxides," Phil. Mag. Letters $62,51,1990$.

Conference Proceedings

Cho, N.-H., D. Bogy, and K. Krishnan, "Chemical Structure of Diamond-like Carbon Thin Films," i roc. XIIIntl.ICEM, S. F. Press, p. 710, 1990.

Dahmen, U., C. Hetherington, and K.H. Westmacott, "A Technique for Measuring Small Atomic Displacements in HREM Images," Proc. XII Int'l. ICEM, S.F. Press, p. 338, 1990.

Goral, J. P., M.M. Al-Jassim, D. Albin, J.R. Tuttle, and R. Noufi, "TEM Identification of Secondary Phases in Non-stoichiometric Polycrystalline CulnSez thin films," Proc. XIIth Internat. Congress for E. M., San Francisco Press, p. 604, 1990.

Hetherington, C., "High-resolution Image Simulation of a Tilted Crystal," Proc. XII ICEM, p. 68, 1990.

Kilaas, R., "Image Simulation: Concepts/software/hardware," Proc. XII Intl. ICEM, S. F. Press, p. 54, 1990.

Krishnan, K., "Crystallographic Effects in X-ray Microanalysis," Proc. XII Intl. ICEM, S. F. Press, p. 466, 1990.

Menon, E., K. Krishnan, P. Huang, C. Echer, P. Singh, and D. deFontaine, "Electronic Structure of Cu-Pd Alloys," Proc. XIIIntl. ICEM, S. F. Press, p. 38, 1990.

Merk, N., A.P. Tomsia, and G. Thomas, "Analytical and High Resolution Electron Microscopy Study of Crystalline Phases Formed at Metal-ceramic Interface," Proc. XIIth Congress for EM, S.F. Press, p. 426, 1990.

O'Keefe, M. A. and M. Sattler, "HRTEM Simulation of Amorphous Materials," Proc. XII Int'l. ICEM, S. F. Press (1990), p. $112,1990$.

Westmacott, K. H., "In-situ Studies in the High Voltage Electron Microscope," Proc. XII Int'l ICEM, S. F. Press, p. 504, 1990.

LBL Reports (including journal articles submitted or in press)

Cho, N.-H., K.M. Krishnan, D.K. Veirs, M.D. Rubin, C.B. Hopper, B. Bhushan, D.B. Bogy, LBL-28908, "Chemical Structure and Physical Properties of Diamond-like Amorphous Carbon Films Prepared by Magnetron Sputtering," J. Mat. Res. (In press.)

Epicier, T., G. Thomas, H. Wohlfromm, and J.A. Moya, LBL-28569, "High Resolution Electron Microscopy Study of the Cationic Disorder in $\mathrm{Al}_{2} \mathrm{TiO}_{5}, "$ J. Mat. Res. (Submitted.)

Epicier, T., M.A. O'Keefe, and G. Thomas, LBL-27169, "Atomic Imaging of 3:2 Mullite," Acta Cryst.(In press).

Epicier, T., G. Thomas, and M.A. O'Keefe, LBL-29597, "Comments on 'Interpretation of HIREM Images of Mullite'," by S. Hamid Rahman and H.-T. Weichert, Acta Cryst. (Submitted.)

Mayer,J., C.P. Flynn, and M. Ruhle, "High Resolution Electron Microscopy Studies of Nb/ $\mathrm{Al}_{2} \mathrm{O}_{3}$ Interfaces," Ultramicroscopy. (In press.)

Merk, N., and G. Thomas, LBL-29679, "Structure and Composition Characterization of Submicronic Mullite Whiskers," J. Mat. Sci. (In press).

O'Keefe, M. A. and R. Kilaas, LBL-29350, "Comments on 'HIRTEM Bildkontrastsimulation von Strukturen mit Punktdefekten in speziellen Lagen'," Z. Krist. (Submitted.)

Radmilovic, V., G. Thomas, and S.K. Das, LBL-28366, "Microstructure of $\alpha$-AI Base Matrix/SiC Particulate Composites," ). Mat. Sci. and Engrg. (In press.)

Washburn, J., E. Kvam, and Z. Liliental-Weber, LBL-29037, 'Defect Formation in Epitaxial Crystal Growth," J. Elec. Mat. (Submitted.) 
Dahmen, U., Model/Observation Comparisons for Grain Boundaries in Metals and Covalent Materials, Meeting of the American Physical Society, Anaheim, March 1990.

Dahmen, U., Mirrors Make Markers in Microscopy of Materials Microstructures, Spring Meeting of Pacific Northwest Electron Microscopy Socicty, Seattle, April 1990.

Dahmen, U., Comparisons Betueen Models and HREM Ousercations of Near-90 $-110>$ Tilt Boundaries in Aluminum, 'Third Conference on Fronticrs of Electron Microscopy, Oak Brook, May 1990.

Dahmen, U., Of Broken Mirrors and Split Reflections: Summetry in Electron Microscopy of Microstructures, Northwestern Univ., Chicago, May 1990.

Dahmen, U., Interfaces in ICB Al Studied by Transmission Electron Microscopy, 13th Symposilum on ISLAT'90, Tokyo, June 1990.

Dahmen, U., Interfaces in ICB Al Films, Mitsubishi Electric, May 1990.

Dahmen, U., TEM Characterization of Grain Boundaries and Heterophase Interfaces in ICB Al, AMMTRA Meeting, Osaka, May 1990.

Dahmen, U., High Resolution Microscopy as a Tool for the Study of ICB Al Thin Films, Kyoto University, June 1990.

Dahmen, U., Microstructure and Interfaces in ICB Al on Si and Ge Substrates Studied by TEM, Toshiba R\&D Center, Kawasaki, June 1990.

Dahmen, U., HREM Obsercations on the Structure of Tilt Boundaries in Continuous Bicrystals of Al, CENG, Grenoble, France, Oct. 1990.

Dahmen, U., Beobachtungen der Struktur ron Kippgrenzen in Aluminium Bikristallen Mithilfe der Hochauflösenden Elektronenmikroskopi,Max-PlanckInstitut, Stuttgart, Oct. 1990.

Dahmen, U., TEM Analysis of Enclosed Crystal Microstructures and Interfaces, Carnegie-Mellon University, PHittsburgh, Dec. 1990.

Krishnan, K. M., Crystallographic Effects in X-ray Microanalysis, XII ICEM, Seattle, WA, August 1990.

Ramesh, R., D. Hwang, T. Ravi, A. Inam, T. Venkatesan, C. Hetherington, and G. Thomas, Structural Imacitig of Y-Ba-Cu-O Thin Films, MRS Spring Meeting, San Francisco, CA, April 1990.

Thomas, G., Characterization of Artzanced Materials, Spanish Srciety for Electron Microscopy, Madrid, Spain, April 1990.

Thomas, G., 5 lectures, The Applications of Electron Microscopy to Inorganic Materials, Chemistry Department, Univ. of Madrid, Spaun, April 1990.

Thomas, G., Electron Microscopy and Microanalysis of Boundaries in Structural and Superconducting Ceramics, ENEA and Institute for Materials Research, Rome, Italy, May 1990.

Thomas, G., 3 lectures, Electron Microscopy and Design of Adoanced Materials, Postgraduate Summer School on Materials, Holland, June 1290.

Thomas, G., Electron Microscopy of High $T_{c}$ Supercond uctors, CNRS Institute for Cyrstallography, Grenoble, France, October 1990.

Thomas, G., C. Hetherington, R. Kilaas, and M.A. O'Keefe, Atomic Discrimination and Occupancy Measurement by HREM, MRS Spring Meeting, April 1990.

Westmacott, K. H. and U. Dahmen, In-situ Annealing Studies of Aluminum Bicrystals, Frontiers of EM in Mat. Conf., Oak Brook, IL, May 1990.

Westmacott, K. H., Dynamic Studies of Precipitate Shape Changes, Frontiers of EM in Mat. Sci., Oak Brook, Illinois, May 1990.

Westmacott, K. H., In-situ Studies in the High Voltage Electron Microscope, XIIth ICEM, Seattle, WA, August 1990.

Westmacott, K. H., Some Roles for TEM in the Dezelopment of New Materials, New Materials 90 Japan, Osaka, Japan, Octobur 1990.

Cho, N.-H., K.M. Krishnan, and D.B. Bogy, Chemical Structure of Diamond-like Carbon Thin Films, XIIth ICEM, Seattle, WA, August 1990.

Cho, N.-H., K.M. Krishnan, D.K. Viers, M.D. Rubin, B. Bushan, and D. Bogy, Power Density Effects in the Physical and Chemical Properties of Diamond-like Carbon Thin Films, MRS Symposium on Materials Issues in Microcrystalline Semiconductors, April, 1990.

Hetherington, C., U. Dahmen, M.A. O'Keefe, R. Kilaas, J. Turner, . nd K.H. Westmacott, An HREM Investigation Into the Atomic Structure of an Aluminum Grain Boundary, MRS Spring Meeting, San Francisco, CA, April 1990.

Hetherington, C., HREM of Defects in Silicon at Twin Interactions, MRS Spring Meeting, San Francisco, CA, April 1990.

Hutten, A., and G. Thomas, Characterization of Rare Earth Permanent Magnets, 6th Internat. Symp. on Rare-Earth Magnets, Pittsburgh, PA, October 1990

Lowe, T. L., N.Merk, G. Thomas, An Historical Mullite Fiber-Reinforced Ceramic Composite: Characterization of the 'wootz' Crucible Refractory, MRS Spring Meeting, San Francisco, CA, April 1990.

Menon, E. S. K., K.M. Krishnan, P. Huang, C. Echer, P. Singh, and D. deFontaine, Electronic Structure of Cu-Pd Alloys, XIIth ICEM, Scattle, WA, August 1990.

O'Keefe, M.A., and M.L. Sattler, HRTEM Simulation of Amorphous Materials, XIIth ICEM, Seattle, WA, Aligust 1990.

O'Keefe, M.A., and R. Kilaas, Theory and Application of Simulated High-Resolution Electrom Micrographs, Fronticrs of EM in Mat. Sci., Oak Brook, Illinois, May 1990.

Thangaraj, N., K.H.Westmacott, and U. Dahmen, HVEMStudies of the Sintering of MgO NanocrystalsPreparedby $M_{g}(O H)_{2}$ Decompositicm, Fronticrs of EM in Mat. Sci., Oak Brook, Illinois, May 1990. 


\title{
The Groups in Physics, Chemistry, and Materials Sciences
}

\author{
Metallurgy \\ Solid State Physics \\ Materials Chemistry
}




\section{Metallurgy}

\section{STRUCTURE OF MATERIALS \\ Microstructure, Properties and Design-Inorganic Materials \\ G. Thomas, Principal Investigator}

This is a multicomponent, interdisciplinary program investigating the interrelation between processing-structure-properties in technologically significant materials related to energy and conservation. The goals are to understand these relations so it becomes possible to design new or improved materials. The major current emphases are on permanent rare earth alloy magnets to improve energy product properties. A new approach has been to model the magnetization reversal process for nucleation controlled magnets and this method is promising for predicting ideal compositions and microstructures and is related to the methods currently used for processing viz., sintering, melt spinning and mechanical alloying. Work has been initiated to produce idealized composites of single dornain size particles $(\sim 200 \mathrm{~nm})$ in a non-magnetic matrix.

Efforts are continuing to study grain boundary defects in ceramic superconductors resulting from non-ideal oxygen effects which create low $T_{c}$ polytypoids and hence impair performance.

All tasks involve characterization of materials by advanced electron microscopy and microanalytical techniques exploited to their maximum capability. More emphasis is also being placed on the processing of materials.

\section{Characterization of Rare Earth Magnets-Electron Microscopy}

Melt-spun $\mathrm{SmFe}_{10} \mathrm{Ti}$ and mechanically alloyed $\mathrm{Sm}_{28} \mathrm{Fe}_{62} \mathrm{Ti}_{10}$ magnets (Figure 1) have been investigated with $\mathrm{x}$-ray microanalysis and microdiffraction. The microstructure of annealed $\mathrm{SmFe}_{10} \mathrm{Ti}$ ribbons consists mainly of the tetragonal $\mathrm{SmFe}{ }_{11} \mathrm{Ti}$ (1:12) hard magnetic phase with an average grain size of $(30 \pm 20) \mathrm{nm}$ and $\alpha-\mathrm{Fe}$. Comparison of the overall composition measured in the as-quenched specimens with that of the annealed ones shows a significant loss in the Sm content in the latter. This causes a shift of the nominal composition toward the Fe-rich side of the phase diagram and hence an increase in the volume fraction of the $\alpha$-Fe phase. The loss in Sm can be attributed to its high vapor pressure according to calculations of the equilibrium vapor pressure.

Mechanical alloying produces magnets with a grain size comparable to that in melt-spun samples but requires long milling times of the elemental powders and consequently more exposure to oxidation. The microstructure of annealed $\mathrm{Sm}_{28} \mathrm{Fe}_{62} \mathrm{Ti}_{10}$ 

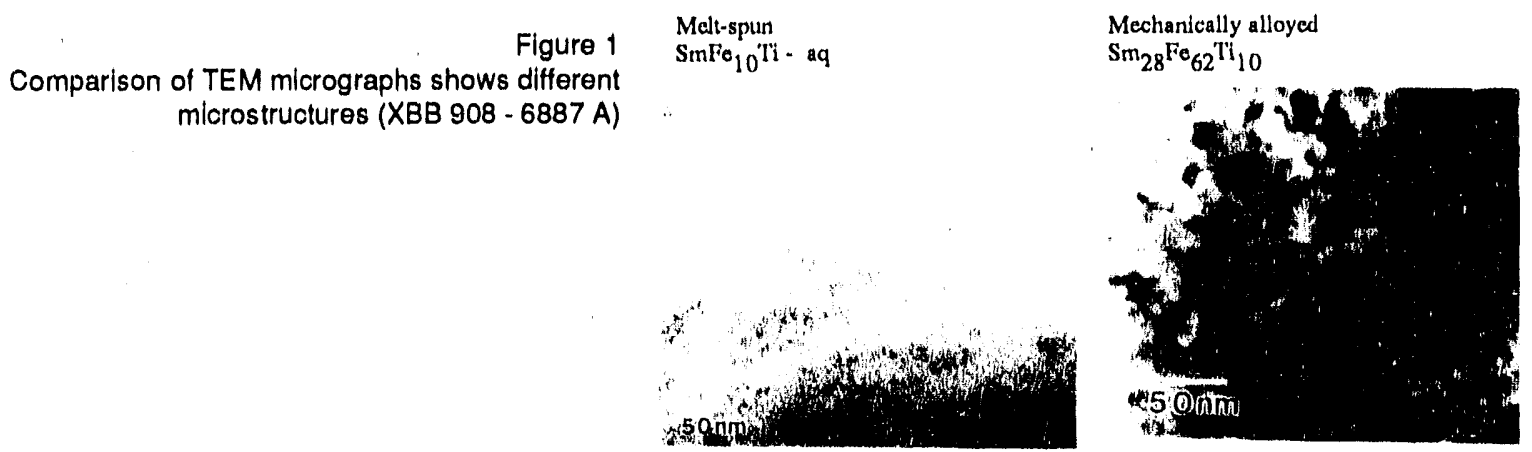

consists of three Fe-rich phases. Grains 100-300 $\mathrm{nm}$ in diameter of nonmagnetic $\mathrm{Fe}_{2} \mathrm{Tl}$, most likely of soft magnetic (Fe, $\mathrm{Ti})_{2} \mathrm{Sm}$ and of $\mathrm{Sm}_{23} \mathrm{Fe}_{73} \mathrm{Ti}_{4}$ are surrounded by a $\mathrm{SmO}$ grain boundary phase. The most striking result is that in these specimens the magnetic properties are not determined by the 1:12 phase but by the new hard magnetic $\mathrm{Sm}_{23} \mathrm{Fe}_{73} \mathrm{Ti}_{4}$ phase with a large anisotropy field. From the com-
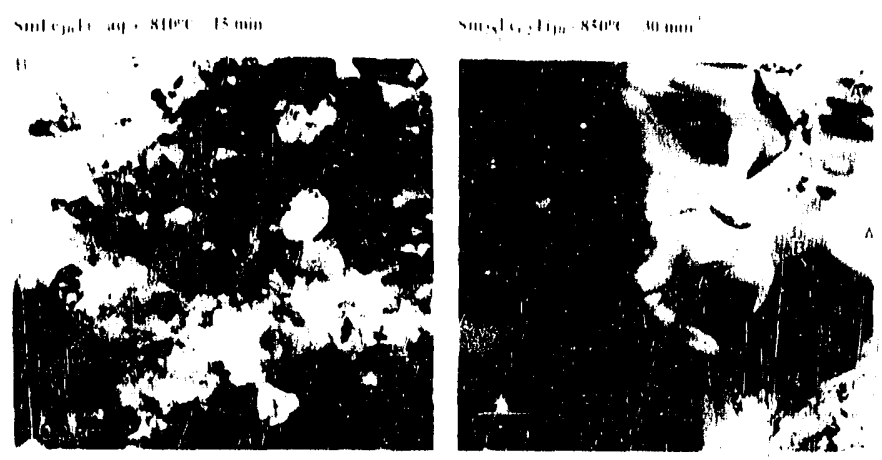
parison of as-mechanically alloyed samples with subsequently annealed ones it can be concluded that $\operatorname{Sm} 0$ was already formed during the milling process.

\section{Microstructuri of Mechanically Alloyed $\mathrm{Fe}_{78} \mathrm{Mo}_{10} \mathrm{Sm}_{12}$ Magnets with the $\mathrm{ThMn}_{12}$ Structure C. KÖSTLER*, L. SCHULZ ${ }^{\dagger}$ AND G. THOMAS}

The $\mathrm{ThMn}_{12}$ - type $\mathrm{Fe}_{78} \mathrm{Mo}_{10} \mathrm{Sm}_{12}$ magnets have been characterized by high-resolution electron microscopy, $x$-ray microanalysis, and microdiffraction. In general, the microstructure of mechanically alloyed and annealed magnets consists of the tetragonal 1:12 matrix phase with an average matrix grain diameter of $200-300 \mathrm{~nm}$ and two rare-earth oxide phases, the $\mathrm{SmO}$ and the $\mathrm{Sm}_{2} \mathrm{O}_{3}$ phases. Microdiffraction data clearly verify the fcc structure of the single and polycrystalline $\mathrm{SmO}$ grains, while the $\mathrm{Sm}_{2} \mathrm{O}_{3}$ phase was found to exist only in a single-crystal hcp and monoclinic structure. In this material, no grain boundary phases at multigrain junctions were observed. The high defect concentration in the matrix grains seems to be responsible for the pinning of the domain walls and the good magnetic properties of the $\mathrm{Fe}_{78} \mathrm{Mo}_{10} \mathrm{Sm}_{12}$ magnets. However, it was not possible to resolve magnetic domains by Lorentz imaging methods.

\section{Improvement in Toughness of Fe-Cr-Mn-C Steels by Thermo-Mechanical Treatments \\ R.RAMESH ${ }^{\ddagger}$, N.J.KIM ${ }^{8}$ AND G.THOMAS}

Using designed guidelines laid out by earlier research on Fe-Cr-Mn-C steels, excellent combinations of strength and toughness have been obtained in an Fe- $0.2 \mathrm{wt}$ pet $\mathrm{C}-10$ wt pet $\mathrm{Cr}-1$ wt pet $\mathrm{Mn}$ steel. It was determined that the ideal microstructure required to obtain high toughness, i.e., primarily dislocated autotempered lath

" Hoechst, Frankfurt, Germany

† Siemens AG Research L aboratories, Erlangen, Germany

${ }^{\ddagger}$ Bellcore, Red Bank, NJ

Postec, Pohang, Korea 

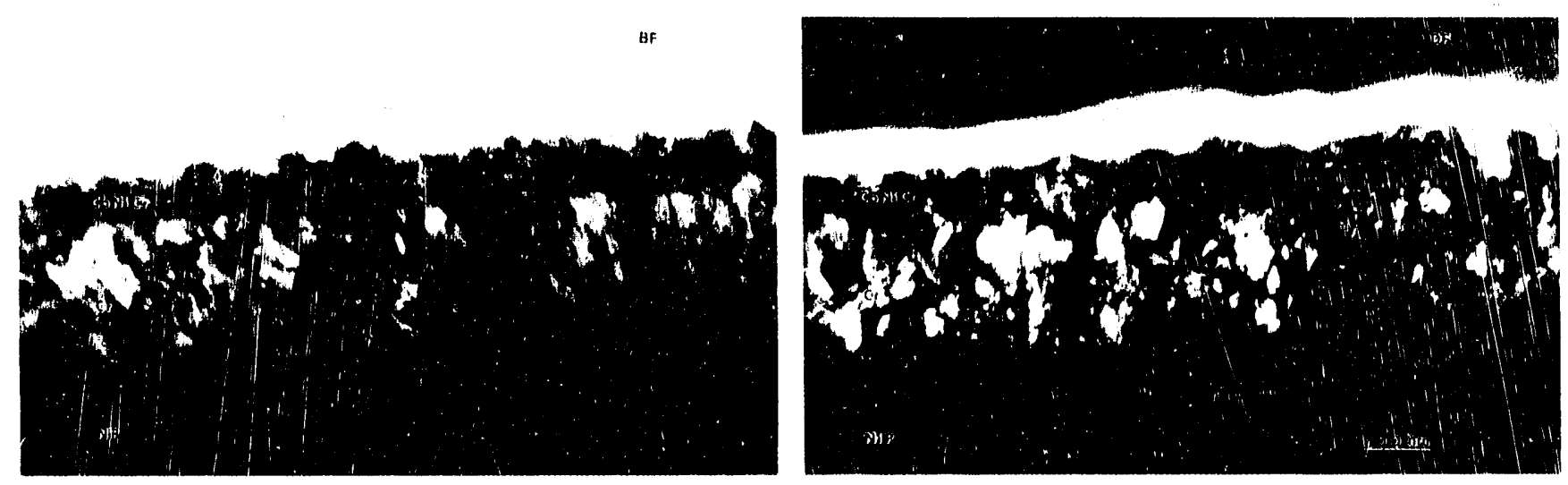

Figure 2

(a, left) Cross section of CoNiCr film deposited on $\mathrm{Cr}$ and NiP. A carbon layer is deposited on the film to protect the film.

(b, right) Dark field Image using part of the 1010 ring pattern of the polycrystalline film. (XBB 908-6962)

martensite, with thin contiguous films of retained austenite at the lath boundaries, can be obtained either by air cooling or by oil quenching from single-phase austenite. Attractive mechanical properties have been obtained by a two-step hot-rolling treatment, with finish rolling between $900^{\circ} \mathrm{C}$ and $1000^{\circ} \mathrm{C}$, followed by air cooling or sil quenching. The rolling conditions have been optimized by examining the effect of finish and start rolling temperature and tempering temperature on the mechanical properties. The mechanical properties of the steels after the two-step rolling treatment are superior to those after thermal cycling treatments. Thus, the alloy appears to be an attractive one for commercial, on-line hot mill production for high-strength, hightoughness, corrosion-resistant applications. The process is economical in that subsequent tempering is not needed to achieve high impact toughness.

\section{Magnetic Properties and Microstructures of Cobalt Based Magnetic Thinfilms \\ L. TANG*, G. THOMAS, S. L. DUAN ${ }^{\dagger}$, M.R. KHAN ${ }^{\dagger}$}

The trend in magnetic recording is towards higher frequencies and larger storage capacities. In rigid-disk data systems thin-film media are used to meet these high demands. The thin films of $\mathrm{Co}$ alloys are deposited on $\mathrm{Ni}$ and $\mathrm{Cr}$ substrates and grow in a polycrystalline array of non epitaxial columnar grains (Figure 2) which shows a cross section. $\left(\mathrm{CoCr}_{14}\right)_{100-\mathrm{x}} \mathrm{Ta}_{\mathrm{x}}$ films $(\mathrm{x}=0,1,1.5$, and 2 at.\%) with or without applying a $-200 \mathrm{~V}$ bias between the substrate ( $\mathrm{Ni}-\mathrm{P}$ coated $\mathrm{Al}$ ) and the ground and heating the substrate at $300^{\circ} \mathrm{C}$ for different time were deposited by DC magnetron sputtering. Possible effects of biasing and heating the substrate are increasing the mobility of atoms sputtered from the target on the substrate. Films of $\mathrm{CoNiZr}$ and $\mathrm{CoNiNb}$ with different compositions of $\mathrm{Zr}(0-4 \mathrm{at} . \%)$ and $\mathrm{Nb}(0-6.5 \mathrm{at} . \%)$ were also deposited. Possible grain boundarv segregation of $\mathrm{Zr}$ and $\mathrm{Nb}$ is suggested due to their small solubility in cobalt. It is found that biasing and heating on the substrate can increase the coercivities of CoCrTa films with relatively high Ta composition $(1.5,2$ at. \%) and coercivity as high as $1000 \mathrm{Oe}$ can be achieved at 2.5 at. \% $\mathrm{Zr}$ and $1-4$ at. $\% \mathrm{Nb}$ for $\mathrm{CoNiZr}$ and $\mathrm{CoNiNb}$ films, respectively. SEM and TEM studies show that the grains of high coercivity films are more equiaxied in shape and more densely packed than that low coercivity films. This may be correlated to the influences of biasing, heating, and alloying on the nucleation and growth mechanism of thin films. Currently, more detailed studies on the microstructures of these films are being carried out.

\footnotetext{
" Partly supported through UCSD Center for Recording Materials (NSF)

t Seagate Magnetics, Fremont, CA
} 

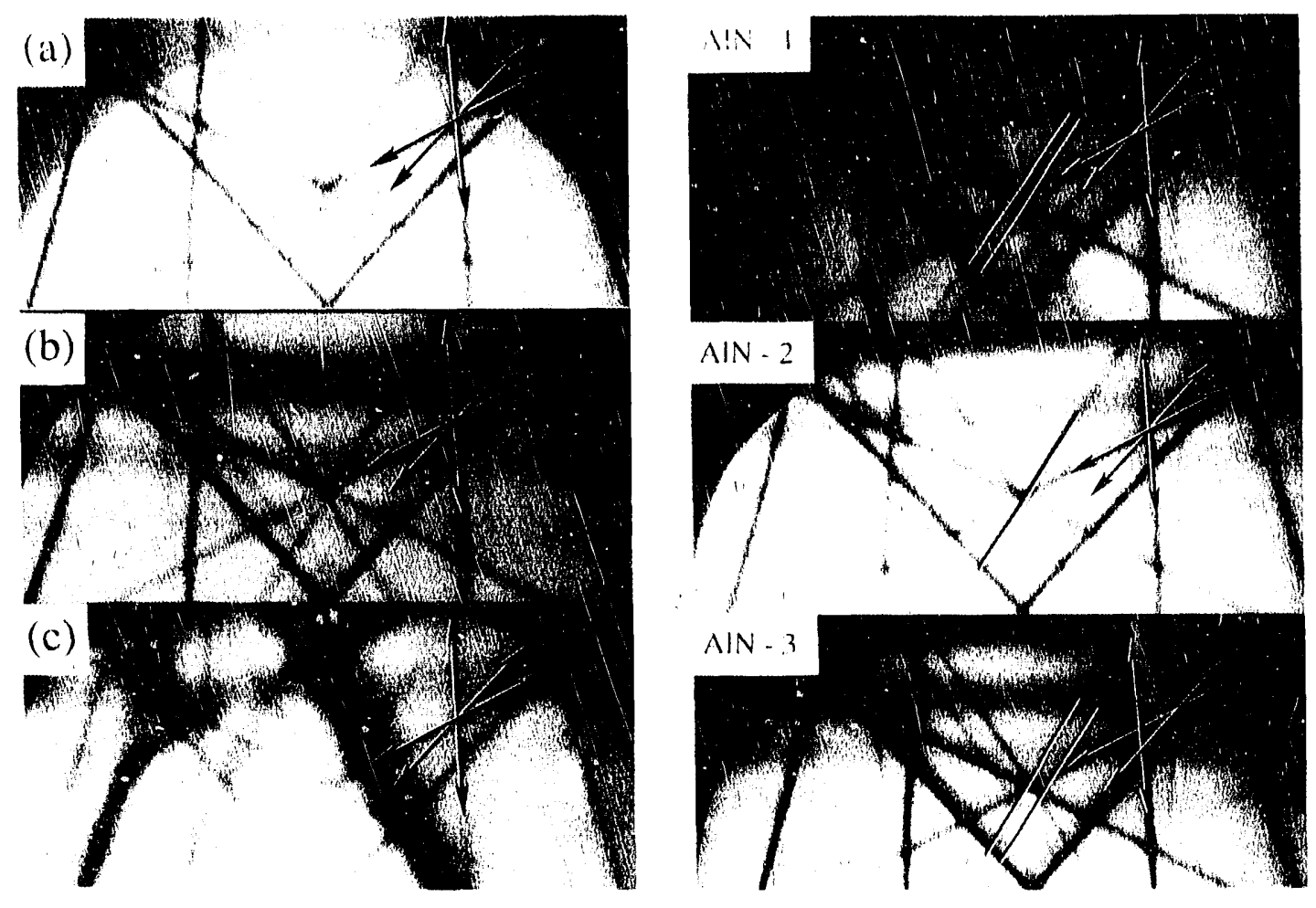

Figure 3

Convergent Beam

Electron Diffraction

Patterns taken from the same polycrystalline AIN ceramic indlcating that the impurity content does not change from (a) the center of a grain, (b) the center of a different grain in the sarne sample (c) and the grain boundary of the previous grain (XBB 890-9535)

\section{Figure 4}

Convergent Beam Electron Diffraction Patterns taken from three types of polyorystalline AIN ; arrowed lines indicate three FOLZ deficiency lines; plain lines indloate two SOLZ deficlency lines. (XBB890-1) 890891))109920)

\section{Impurity Distribution in Polycrystalline Aluminum Nitride Ceramics \\ D.L. CaLLAHAN ${ }^{\ddagger}$ AND G. Thomas}

Convergent-beam electron diffraction (CBED) and diffuse dark field (DDF) imaging transmission electron microscopy were used to obtain qualitative information regarding the distribution of impurities in polycrystalline AlN. Convergent beam electron diffraction analysis shows internal uniformity of lattice parameter and hence uniformity of impurity content throughout the crystalline matrix as shown (Figure 3). Distinct differences in higher-order Laue zone deficiency line symmetries are, however, apparent between the different AlN ceramics as illustrated by Figure 4. The measurement of absolute differences in lattice parameter and hence oxygen content (or total impurity content in solid solution) may be complicated by the competing effects of oxygen and carbon in solid solution. Thin glassy phases $(\sim 1 \mathrm{~nm})$ are found at all grain boundaries, and are believed to be an oxynitride phase of similar origin to that found in $\mathrm{Si}_{3} \mathrm{~N}_{4}$. 


\section{An Historical Mullite Fiber-Reinforced Ceramic Composite- Characterization of the 'Wootz' Crucible Refractory}

T.L. LOWE', N. MERK, AND G. THOMAS

Since at least the sixteenth century, the 'wootz' ultra-high carbon white cast-iron ingot was produced in India by melting or carburising iron in a crucible. This ingot was forced into sword blades of so called 'Damascus' steel. The charged crucible was fired in a long (24 hour) single cycle at high temperature $\left(1150-1250^{\circ} \mathrm{C}\right.$ ) in a strongly reducing atmosphere. Raw materials for the refractory vessel are clay and 'coked' rice husks. At high temperatures, two phases reinfurce the glassy matrix: cristobalite relics of rice husks and a network of mullite crystals. The microstructure and chemistry of the mullite network in the glassy matrix was characterized by means of a combination of techniques: optical microscopy, XRD, SEM, TEM with EDS and HREM.

\section{Staff}

$\begin{array}{ll}\text { Principal Investigator } & \text { Graduate Students } \\ \text { Gareth Thomas } & \text { S. Miyasato } \\ & \text { A. McFayden } \\ \text { Scientists } & \text { A. Nowakowska } \\ \text { W. Cao } & \text { M. Chandramoulı } \\ \text { V. Radmilovic } & \text { B. Simion } \\ \text { Visiting Scientist } & \text { K. Yanagimoto } \\ \text { A. } & \text { M. Berkson }\end{array}$

A. Hütten-T. Lynen Humboldt Fellow

Awards

- M. Cinibulk won the Student Award, American Society of Metals

\section{Publications and Reports}

(See also CAM High- $\mathrm{T}_{\mathrm{c}}$ Superconductivity Program, and CAM High Performance Metals Program.)

\section{Refereed Journal Articles}

Radmilovic, V., A.G. Fox, and G.Thomas,"Spinodal Decomposition of Al-Rich Al-Li Alloys", Acta Met., vol.37, p. $2385,1989$.

Thomas, G., "Research Needs and Opportunities in Magnetic Materials", Materials Sci. E Eng. vol.B5, p. 409, 1990.

Srikrishna, K., G. Thomas, R. Martinez, M.P. Corral, S. DeAza and J.S. Moya, "Kaolinite-Mullite Reaction Series: A TEM Study", J. of Mat. Sci., vol. 25, p. 607, 1990.

Koestler, C., L. Schultz and G. Thomas, "Microstructure of Mechanically Alloyed $\mathrm{Fe}_{78} \mathrm{Mo}_{10} \mathrm{Sm}_{12}$ Magnets with the TinMn $\mathrm{M}_{12} \mathrm{Structure}^{\text {", }}$ J. Appl.Phys. vol.67 p. 2532, 1990.

Ramesh, R., N.J. Kim and G. Thomas, "Improvement in Toughness of Fe-Cr-Mn-C Steels by Thermal-Mechanical Treatments", Met. Trans. A, vol. 21 A p.683, 1990.

Callahan, D.L., and G.Thomas, "Impurity Distribution in Polycrystalline AIN Ceramics", J. Am. Ceram. Soc.,vol, 73, p.2167, 1990.

Cinibulk, M.K.S.M. Johnson, and G. Thomas,"Grain Boundary Phase Crystallization and Strength of Silicon Nitride Sintered with Y-SiAlON Glass", J. of Am. Cer. Soc., vol. 73, p.1606, 1990.

Theses

Callahan, D.L.,Metal-Ceramic Bonding in DiCalcium Silicate Composites with Ni, 1990. (Ph.D. Thesis, Department of Materials Sclence and Mineral Engineering, U.C.Berkelcy. Advisor: G.Thomas). 
K.C. Lin, G. Thomas and G.J.S. Gau, "Effect of Media Propertles on Side Erase Bands", Conf. Proc. M. R.M. '89, Romini, Italy, llilit Trans. of Magnetics, vol.26 p. 132, 1989.

Thomas, G., "Design and Processing of Strong-Tough Microcomposite Stcels", Proc. Conf, on Steel, Krakow, Poland, Archives of Metallurgy, Polish Academy of Sciences Quarterly, vol.35, 1990.

Koehler, C. and G. Thomas, "Characterization of Graln Boundary Phases in S1, $\mathrm{N}_{4}$ Stntered using Y-S1-Al-O-N Addittves", Proc. of XIIth ICEM Conf. in Seattle, Washington, p.1070, 1990.

Chandramoull, M. and G.Thomas, "Microstructure and Microanalysis of Sintered Fe-Nd-B Permanent Magnets", ibid., 1990.

Cinibulk, M. and G. Thomas, "Microstructure and Microanalysis of Silicon Nitride Ceramics in the Y-S1-Al-O-N and Y-SI-O-N Systems", ibid, p.1072., 1990.

Merk, N., A.P. Tomsla and G. Thomas, "Analytical \& High Resolution EM Study of Crystalline Phases Formed at Metal-Ceramic Interface", ibld., p.426.,1990.

Ramesh, R., B.G. Bagley, J.M. Tarason and G. Thomas, "Atomic Imaging and Spectroscopy of Bismuth Cuprate High Temperature Superconductors", ibid, p.60., 1990.

Liu, K.C., G. Thomas, A. Cabellero, J.S. Moya, and S. deAza, "Microstructure and Microanalysis of Mullite Processed by Reaction Sintering of Kaolinite", Proc. 7 th Cimtec World Ceramics Congress, Monte Catini Terme, Italy, 1990, p 177.

Komega, K., M. Komatsu and G. Thomas, "H-ligh Temperature Strength and Microstructures in $\mathrm{Sl}_{3} \mathrm{~N}_{4}-\mathrm{Y}_{2} \mathrm{O}_{3}$ Base Ceramics", ibid.

Tang, L. and G. Thomas, "Magnetic Properties and Microstructures of CoNiCr and CoFeCr Thin Films", MMM Conference, San Diego, California, Journal of Applied Physics, 69, 5166, 1990.

Hutten, A. and G. Thomas, "Characterization of Rare-Earti Permanent Magnets", Proc.6th Internat, Symp. on Magnetic Materials, Pittsburgh, Pennsylvania, p 110, 1990.

Other Publications

Ramesh, R., S.M. Green and G. Thomas, "Microstructure Property Relationships in the Bi(Pb)-Sr-Ca-Cu-O Ceramle Superconductors", in Studies of High Temperature Supcrconductors, Nova Science, vol. 5, ed. A. Narlikar, p. 3611990.

LBL Reports (Including journal articles submitted/in press)

Qayum, H. and G. Thomas, "Crystallization of Glasses and the High Temperature Phases in the Y-S1-Al-O-NSystem", I. Am. Ceram. Soc..(Submitted).

Callahan, D.L., G. Thomas, J.S. Moya and P. Pena, "Reaction Sintering of $\mathrm{Ca}_{2} \mathrm{SIO}_{4}-\mathrm{CaZrO}_{3}$ Composites", J. of Materials Reasearch. (Submitted.)

Radmilovic, V., G.Thomas and S.K. Das, "Microstructure of a-Al Base Matrix/SiC Particulate Composites", J. Mat. Sci. E Eng..(In press.)

Epicier, T. , G. Thomas, H. Wohlfromm and J.S. Moya, LBL-28569, "High Resolution Electron Microscopy Study of the Cationic Disorder in the $\mathrm{Al}_{2} \mathrm{TiO}_{5}{ }^{\prime \prime}$, I. of Muterials Research. (In press.)

Contributed Talks

Callahan, D.L. and G. Thomas, CBED Microanalysis of Oxygen in AIN, 92nd Annual Meeting ACS, Dallas, Texas, April,1990.

Wohlfromm, H. A.P. Tomsla and G. Thomas, Melting and Reaction in the System $\mathrm{Al}_{2} \mathrm{O}_{3}-\mathrm{TiO}_{2}{ }^{\prime \prime}$, ibid.

Thomas,G,and J.S. Moya, Interface Engineering in Ceramic Composites, Workshop, Madrid, Spain, March,1990.

Ramesh, R., D.M.Hwang, T.S. Ravi, A. Inam, T. Venkatesan, C.J.D. Hetherington and G. Thomas, Structural Imaging of $Y$-Ba-Cu-O Thin Films presented at MRS Meeting, San Francisco, Callfornia, March, 1990.

Lowe, T.L., N. Merk and G. Thomas, An Historical Mullite Fiber Reinforced Ceramic Composite: Characterization of the 'Wootz' Crucible Refractory, presented at MRS Meeting, San Francisco, California, March 1990. 


\section{Solid-State Phase-Transformation Mechanisms}

\section{K.H. Westmacott, Paincipal Investigator}

This research is directed towards obtaining an atomic-level understanding of the structural factors that govern phase changes and phase stability. $T$. .nsmission electron microscopy techniques, particularly high-voltage and high-resolution microscopy, are employed to characterize phase changes and to infer the atomic rearrangements occurring during a transformation. By studying alloy systems characterized by strains of different signs and magnitudes the fundamental mechanisms for a broad range of phase transformations are being identified. It has been possible to predict precipitate morphologies (growth directions, habit planes, orientation relationships, substructure, twinning, etc.) from first principles and to relate them to nucleation-and-growth processes. Extension of the principles from simple model alloy systems to more complex materials is now in progress.

\section{An HREM Investigation of the Structure of Carbide Platelets in Platinum}

M.J. WITIOMB*, U. DAHMEN AND K.H. WESTMACOTT

High-purity platinum with only trace amounts of carbon in supersaturated solid solution forms thin precipitate plates on (100) planes during aging after a rapid quench from near the melting point. These plates develop in stages from the single layer $\alpha$ plates through the double-layer $\alpha^{\prime}$ to the four-layer $\alpha^{\prime \prime}$ plates with the transition from one to the next proceeding via a ledge mechanism. The precipitates could be interpreted alternatively as carbon-decorated (100) stacking faults, as combined precipitates of carbon and vacancies, or as platinum carbide precipitates whose excess volume was accommodated by vacancy loops. All three interpretations led to the same structure which was confirmed by micrcdiffraction from single platelets in edge-on orientation. The proposed structures in $<001\rangle$ projection are illustrated schematically in Figure 1. Direct evidence for these models has been obtained by HREM imaging.

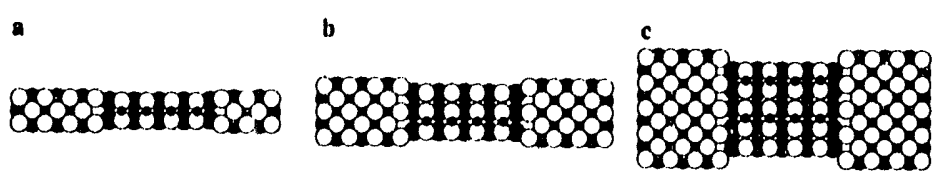

\footnotetext{
"Electron Mlcroscope Unit, University of the Witwatersrand, Johannesburg, S.A.
} 

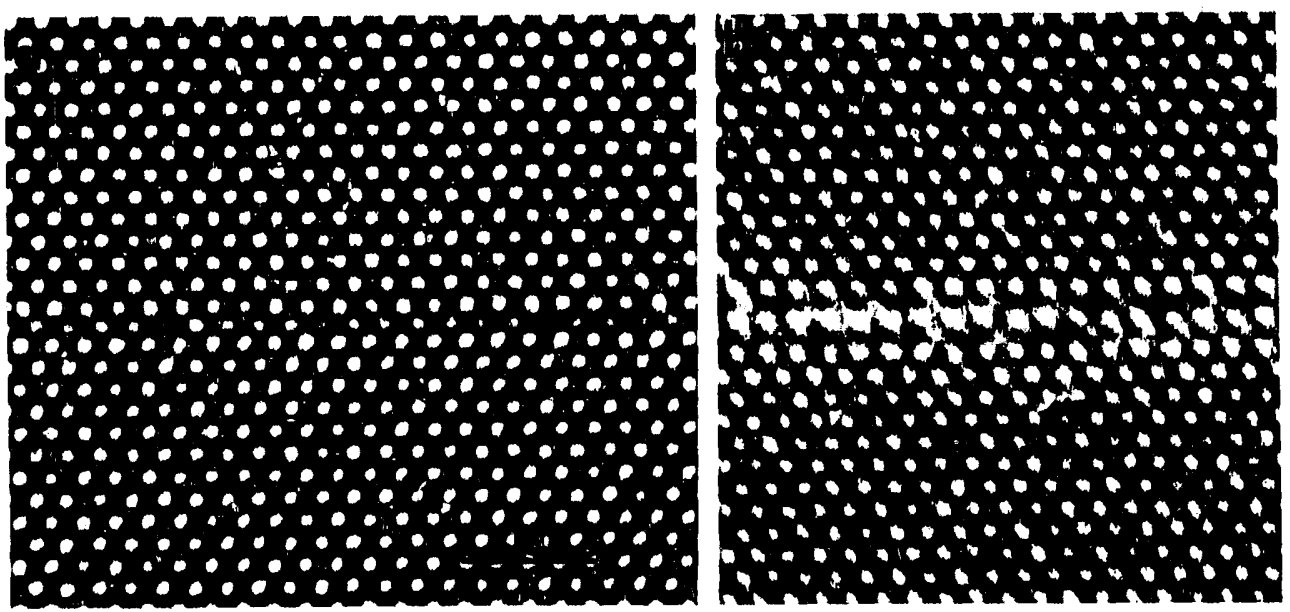

Figure 2

High resolution images of $\alpha$ (a) and $\alpha^{\prime}$ (b) preclpitates seen edge.on $\ln <011>$ orlentation. (XEB 9012-10148)

Figure 2 shows the $\alpha$ and $\alpha^{\prime}$ platelets seen edge-on in a $<011>$ orientation imaged on the JEOL ARM 1000 at $800 \mathrm{kV}$. At a defocus of $-80 \mathrm{~nm}$, the atoms appear as white dots and the contrast level is optimized because the contribution of specimen noise from surface contamination is selectively filtered out. The specimen thickness is estimated to be around $10 \mathrm{~nm}$. Due to a strong $<112>$ texture a $30^{\circ}$ tilt was required to reach a symmetrical $<011>$ orientation. Figure 2 confirms the predicted structure of $\alpha$ and $\alpha^{\prime}$ precipitates as single and double-layer precipitates. Both plates are clearly atomically and uniformly flat along their entire length. The single-layer $\alpha$ precipitate shown in (a) has the appearance of a simple (100) stacking fault. In the collapsed layer, small white dots appear at the position of the carbon atoms. However, whether these are actually due to the presence of the carbon remains to be examined by image simulations. The double-layer $\alpha^{\prime}$ precipitate seen in (b) clearly has the stacking sequence corresponding to that proposed in Figure 2(b). Again, faint white spots are present at the proposed positions of carbon atoms. These observations suggest the potential exists for using high resolution imaging to determine the location of interstitial atoms in ordered precipitate structures.

\section{A Technique for Measuring Small Atomic Displacements in HREM Images \\ U. Dahmen, C.J.D. Hetherington, AND K.H. WestmacotT}

An important problem in materials science is the measurement of elastic strain ficlds, lattice rotations and rigid body shifts. High resolution microscopy is a simple and direct means of mapping displacement fields near defects, interfaces or precipitates. Large and highly localized atomic relaxations such as those found near the core of dislocations or structural units in grain boundaries are sensitive to thickness and defocus conditions and must be interpreted with the use of image simulations. However, displacements of small magnitude or displacement ficlds that vary slowly enough to allow only a gradual change of the periodic interatomic distance avoid artifacts caused by oscillations of the contrast transfer function. Such displacements are accurately reflected in the position of atomic column images under most imaging conditions and can be measured directly and without the aid of image simulations. Spot-to-spot measurements can be performed directly on a high resolution image, but such measurements are tedious and of low accuracy. Plane-to-plane measurements are more accurate but require the use of a microdensitometer. The present contribution introduces an alternative method based on interference effects between two overlaid images or lattices to prodıce moiré patterns that display the displacement field in a graphic and accurate manner. The method makes use of the fact that small 


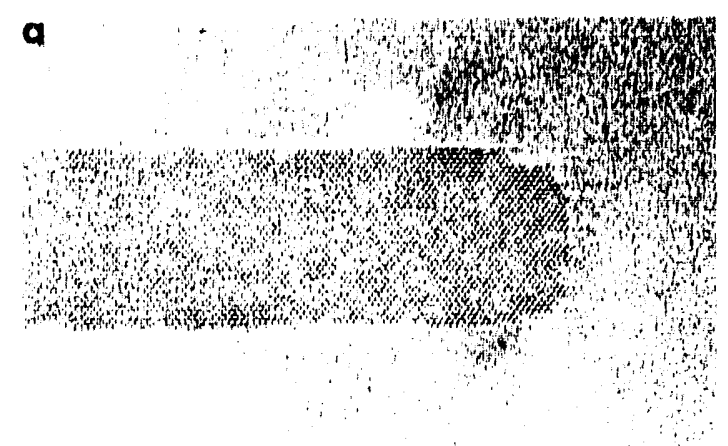

Figure 3a

High resolution mlcrograph of the end of a $\theta^{\prime}$ preclpitate in Al-Cu alloy (a) and Illustration of displacement fleld by superposition of reference lattloo (b).

(XBB-906-4600)

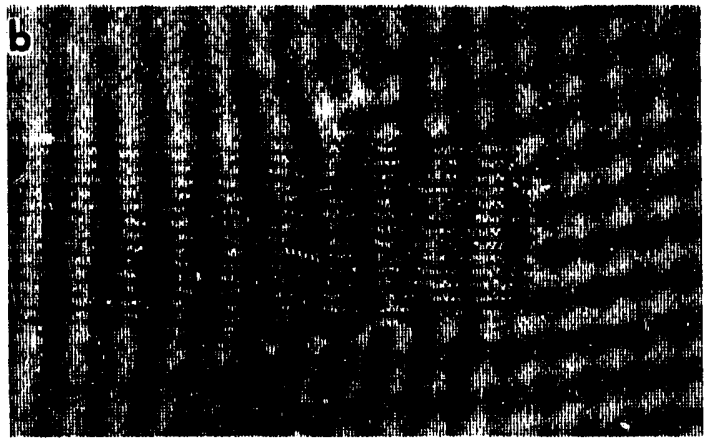

a

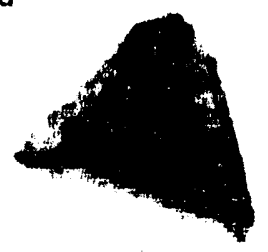

b

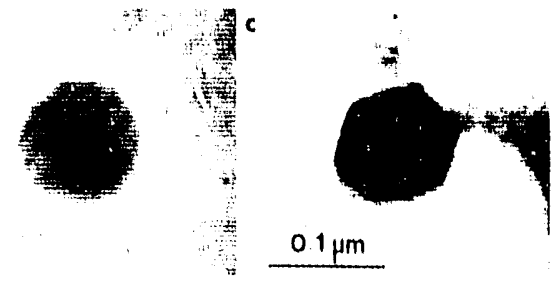

Figure $3 b$ Bright field miorographs taken from video tape showing the transformation, with $B=111$ and $g=220$, of a tetrahedron to an ootahedron during in-situ heating. The temperatures are approximately $250^{\circ} \mathrm{C}$ in (a) $420^{\circ} \mathrm{C}$ In (b) and $250^{\circ} \mathrm{C} \ln (\mathrm{c}) .($ XBB $907-6066)$

violations of perfect translation, rotation and mirror symmetries will give rise to large changes in the periodicity of the moirés.

A strain field is difficult to measure directly by tracing the positions of atomic planes or columns in a high resolution micrograph. But by overlaying an Ideal undistorted lattice with a slightly different lattice parameter, any deviation from perfect translation symmetry will be detected as a large change in the parallel moiré pattern. Figure 3a shows a high resolution micrograph of the end of a $\theta^{\prime}$ precipitate in $\mathrm{Al}-\mathrm{Cu}$. Although present, lattice distortions are difficult to detect. Figure $3 \mathrm{~b}$ illustrates the moiré effect when a smaller reference lattice is overlaid. The distortion ficld around the end of the particle, including a dislocation are now clearly visible. This displacement can be quantificd by using the basic relationships for the spacing and orientation of moirés.

\section{An HVEM Study of Tetrahedral and Octahedral Precipitates in Al-Ge Alloys K.H. WESTMACOTT AND U. DAHMEN}

The shapes of faceted precipitates of Ge in cube-cube orientation relationship within an Al-Ge alloy were investigated by in-si tu high voltage clectron microscopy, which allows observation of bulk behavior in thick foils. It was found that in addition to the regular tetrahedral particles reported by other workers, during bulk aging precipitates also form as regular octahedra. Tetrahedra were generally larger than octahedra but transitional morphologies such as tetrahedra truncated by further (111) planes were also observed as well as truncations of the octahedra by (100)] planes. In situ temperature cycling of a tetrahedron across the phase boundary led to spheroidization followed by refaceting to an octahedron. A series of micrographs taken on the same particle showing these shape transformations is given in Figure 3. It was concluded that the variability of morphologies was a result of the anisotropic grow th kinetics but that temperature cycling led to shapes approaching equilibrium. Possible implications of these observations for different interface structures are discussed. 
Investigators

U. Dahmen

K. Westmacott
Visiting Scientists

C.P. Luo

M.J. Witcomb

P. Lours

\section{Publications and Reports}

Refereed Journal Articles

Pirouz, P., Chaim, R. Dahmen, U, and Westmacott, K.H., "The Martensittc Transformation In Sillcon I. Experimental Observations," Acta Met. 38, 313 (1990) (LBL-27071). Dahmen, U, Westmacott, K.H., Pirouz P., and Chaim, R., "The Martensitic Transformation In Sllicon II, Crystallographic Analysis", Acta Met, 38, 323 (1990) (LBL-27072).

Pirouz, P., Chaim, R., Dahmen, U, and Westmacott, K.H., "The Martensittc Transformation in Silicon 111, Comparison With Other Work," Acta Met. 38, 329 (1990) (LBL-27073).

Dahmen, U.,Witcomb M.J, and Westmacott, K.H. "Aspects of Faceting in the Study of Precipitate Interfaces," |. de Physique, 51, Suppl. C1، 737 (1990) (LBL-27834).

Douln, J. Dahmen, U. , and Westmacott, K.H. "A High Resolution Study of Twinned Precipitates in Al-Go Alloys," I. de Physique , 51 Suppl. C1 809 (1990) (LBL-28389).

Other Publications

Dahmen, U., Hetherington, C.J.D., and Wnstmacott, K.H. ,A Technique for Measuring Small Atomic Displacements in HREM Images," Proc. IFSEM 1990, 4, 330, G.W. Balley, ed. (LBL-28784),

LBL Reports

Witcomb, M.J., Dahmen U., and Westmacott, K.H. , LBL-29882, "An HREM Investgation of the Structure of Carbide Platelets In Platinum," EMSSA Proc. 20. (In press.)

Westmacott, K.H., and Dahmen, U., LBL-30072, "An HVEM Study of Tetrahedral and Octahedral Precipitates in Al-Ge Alloys." Invited Talks

Dahmen, U., Model/Observation Comparisons for Grain Boundaries in Metals and Covalent Materials, Mecting of the American Physical Sodety, Anaheim, March, 1990.

Dahmen, U., Mirrors Make Markers in Microscopy of Materials Microstructures, Spring Meeting of Pacific Northwest Electron Microscopy Soclety, Seattle, April, 1990.

Dahmen, U., Comparisons Between Models and HREM Obseroations of Near-90 $<110>$ Tilt Boundaries in Aluminum, Third Conference on Fiontiers of Electron Microscopy, Oak Brook, May, 1990.

Westmacott, K.H., and Dahmen, U., In Situ Annealing Studies of Aluminum Bicrystal, Frontiers of E.M. In Material Sclence, Oak Brook, IL, May, 1990.

Dahmen, U., and Westmacott, K.H., Interfaces in ICB Al Studied by Transmission Electron Microscopy, 13th Symposium on ISI $\Lambda \mathrm{T}$ ' 90 , Tokyo, June, 1990.

Dahmen, U., and Westmacott, K.H., Interfaces in ICB Al Films, Mitsubishi Electric, May, 1990.

Dahmen, $U_{1,}$ and Westmacott, K.H., TEMICharacterization of Grain Boundaries and Heterophase Interfaces in ICB Al, AMMTRA Meeting, Osaka, May, 1990.

Dahmen, U., and Westmacott, K.H., High Resolution Microscopy as a Tool for the Study of ICB Al Thin Films, Kyoto University, June, 1990.

Westmacott, K.H., In Situ Studies in the High Voltage Electron Microscope, XIIth ICEM, Seattle, WA, August, 1990.

Dahmen U, and Westmacott, K.H., Microstructure and Interfaces in ICB Al on Siand Ge Substrates Studied by TEM, Toshiba R\&DCenter, Kawasaki, June, 1990.

Dahmen U., and Westmacott, K.H., Beobachtungen n'or Struktur von Kippgrenzen in Aluminium Bikristallen Mithilfe der Iochauflösenden Elektronenmikroskopie, Max-Planck-Institut, Stuttgart, Oct., 1990.

Westmacott, K.H., Some Roles for TEM in the Development of New Materials, New Materials '90, Osaka, Japan, October, 1990.

Dahmen, U., TEM Analysis of Enclosed Crystal Microstructures and Interfaces, Carnegie-Mellon University, Pittsburgh, Dec,, 1990. 


\section{Crystallography of Microstructures}

U. DAHMEN, PRINOIPAL INVESTIGATOR

This program is aimed at understanding the fundamental features that underlie the evolution of microstructures in solids by applying crystallographic techniques to the analysis of topology and defects in crystalline materials. Many microstructures possess a degree of order that reflects crystallographic relationships with precursor or parent phases. Such relationships are put to use both analytically, to examine the structure of defects, as well as synthetically, to produce new and unique microstructures with defect configurations reflecting composite symmetries. The aim is to understand and ultimately gain control of the structure and distribution of defects such as inclusions, grain boundaries, domain walls and dislocations. Because of the scale and nature of such microstructures, electron microscopy is an integral part of these investigations, both as an analytical tool and as a subject of technique development. Detalled characterization of the atomic structure of interfaces through extensive use of conventional, "in situ" and atomic resolution microscopy in tandem with computer image simulations allows critical testing of theoretical models.

Atomic Structure of a $\Sigma 99$ Grain Boundary In Aluminum: A Comparison Between AtomicResolution Observation, Pair Potential and Embedded Atom Simulations U. Dahmen, C.J.D. Hetherington, M.A. O'Keefe, K.H. WestmacotT, M.J. Millis*, M.S. Daw* and V. Vitek ${ }^{\dagger}$

An atomic resolution image of a symmetrical $\Sigma 99(557)<110>$ thlt boundary in aluminum is compared with images simulated from models based on atomistic calculations using pair potentials and the Embedded A tom Method. The two merhods for atomistic modelling result in very similar structures, and image simulations based on these structures closely match the experimental results. Because it was possible to liscard unambiguously a number of other structures found in the process of computer modeling as clearly mismatched with the observation, a comparison of this kind is an accurate measure of the quality of the match between theory and experiment. This is an innportant point since it demonstrates that the technique of high resolution microscopy now allows the experimental distinction between different atomic boundary structures in close packed metals. This study shows that high resolution electron microscopy can now assess quantitatively the degree of coincidence between experimental and theoretical atomic structures of high- $\Sigma$ grain boundaries.

"Sandia National Labs

† University of Pennsylvania 
Investigators

U. Dahmen

Scientific Staff

N. Thangaraj

$\therefore$

Publications and Reports

Refereed Journal Articles

Dahmen, U., C.I.D. Hatherington, M.A. O'Keefe, K.H. Westmacott, M.J. Mills, M.S. Daw and V. Vitek "Atomic Structure of a $\Sigma 99$ Grain Boundary in Aluminum: A Comparison Between Atomic-Resolution Observation, Pair Potential and Embedded Atom Simulations," Phil. Mag. Lett., vol. 62, p. 327, 1990.

Other Publications

Dahmen, U., and K.H. Westmacott, LBL- 29034, "Transmission Electron Microscopy Study of ICB Al on Ge and SI (001) Substrates," Proc. ISIAT ‘90.

Witcomb, M.J., and U. Dahmen, LBL-29967, "A Jet Polishing Technique for Thinning Two-Phace Materials," EMSSA Proc. 20.

Penisson, J.M., U. Dahmen and M. Mills, "HREM Study of a $\Sigma=3$ (112) Twin Boundary in Aluminum," Phil. Mag. Lett. (Submitted.) Invited Talks

Dahmen, U. , Of Broken Mirrors and Split Reflections: Symmetry in Electron Microscopy of Microstructures, Northwestern University, Evanston, IL, May 1990.

Dahmen, U., HREM Obseroations on the Structure of Tilt Boundaries in Continuous Bicrystals of Al, CENG, Grenoble, France, October 1990.

Dahmen, U., TEM Analysis of Enclosed Crystal Microstructures and Interfaces, Carnegie-Mellon University, Pittsburgh, PA, December 1990. 


\section{Alloy Phase Stability}

D. de Fontaine, Principal Investigator

Temperature-composition phase diagrams are of great practical interest as they constitute useful "maps" of thermodynamic systems such as binary, ternary alloys. These diagrams are generally determined experimentally, but the exciting possibility now exists of deriving certain classes of phase diagrams virtually from first principles. This possibility rests on the very significant advances that have been made recently in the two relevant areas of alloy theory-electronic-band-structure calculations and statistical thermodynamics. The purpose of this project is to combine the latest electronic structure and statistical thermodynamic techniques in integrated packages in order to produce phase diagrams from a minimum amount of empirical information and to compare with one another various approximate compv ational methods. These methods have been used to derive various binary alloy phuse diagrams, such as $\mathrm{Al}-\mathrm{Li}$ and $\mathrm{Cu}-\mathrm{Pd}$, which agree remarkably well with those determined experimentally. The same theoretical techniques have been applied successfully to vacancy ordering in high- $\mathrm{T}_{\mathrm{c}}$ superconductors.

First-Principles Calculation of Phase Equilibria in the Aluminum Lithium System M. SluITER, ${ }^{\dagger}$ D. DE Fontaine, X.Q. GUO, ${ }^{\dagger} R$. PodlouckY, ${ }^{\ddagger}$ and A.J. Freeman ${ }^{\dagger}$

Volume-dependent total energies of $\mathrm{Al}, \mathrm{Li}$, and various intermetallic $\mathrm{Al}-\mathrm{Li}$ compounds have been calculated by the first-principles full-potential linearized augmented-plane-wave (FLAPW) method. These values have been used to calculate Al$\mathrm{Li}$ phase diagrams according to the cluster variation method in the tetrahedron approximation. Methods for performing lattice-parameter optimization and for including relaxation effects are presented. Truly first-principles-based phase diagrams for solid phases computed without any fitting parameters or empirical formulas are shown to exhibit a remarkable agreement with experimental data. Subsequently, some empirical equations for the free energy of the liquid and the vibrational entropy have been added to the first-principles results and striking similarities with experimental phase diagrams were obtained. Special attention has been paid to the metastable $\mathrm{Al}_{3} \mathrm{Li}$ phase and to the mechanical properties of $\mathrm{Al}$-rich $\mathrm{Al}-\mathrm{Li}$ alloys. Furthermore, the influence of relaxation and vibrational entropy are discussed.

Additional support was provided by the Austrian Ministry of Science, the Air Force Wright Aeronautics Laboratory administered through Los Alamos National Laboratory, the National Science Foundation, and the Air Force Office of Scientific Research.

\section{$A b$ Initio Study of the Cu-Pd One-Dimensional Long Period Superstructure Phase Diagram \\ G. Ceder, D. de Fontaine, H. Dreysse, " D. M. Nicholson, " G. M. Stocks," and B. L. Gyöffy"*}

The f.c.c. superstructure phase diarram for $\mathrm{Cu}-\mathrm{Pd}$ is calculated by means of isotropic effective interactions derived from an ab initio KKR-CPA electronic structure calculation. We prove the existence of a region in which one-dimensional long period superstructures are stable. This region is composed of several single phase fields in which the modulation period is constant and in close agreement with results from High Resolution Electron Microscopy. The change from wavy antiphase boundaries at low Pd concentration to sharp antiphase boundaries at high Pd concentration is

\footnotetext{
" Lawrence Livermore National Laboratory, Livermore, CA.

$\dagger$ Department of Physics and Astronomy, Northwestern University, Evanston, IL.

₹ Present address: Institute for Physical Chemistry, University of Vienna, Austria.

$\$$ Laboratoire de Physique du Solide, Uriversité de Nancy, France.

\# Oak Ridge National Laboratory, Oak Ridge, TN.

" H.H. Wills Physics Laboratory, University of Bristol, England.
} 
related to a significant change of the interactions with $\mathrm{Pd}$ concentration. The role of the Fermi surface and the applicability of the ANNNI model are clarified.

Additional support was provided by grants from the CNRS-NSF (France), the Belgian American Educational Foundation, NATO, and the Division of Materials Science, U.S. Department of Energy, under contract with Martin Marietta Energy Systems, Inc.

\section{A Comparison of the Direct Configurational Averaging and Connolly-Williams Methods of Obtaining Effective Pair Interactions in Substitutionally Disordered Alloys \\ C. Wolverton, H. DReYsSE, ${ }^{\dagger}$ and D. DE Fontaine}

In order to calculate thermodynamic properties of disordered alloys, it is necessary to extract certain parameters (namely effective cluster interactions) from electronic band structure models. Several of these methods exist, thus necessitating a comparison of their accuracy and convergence. Direct configurational averaging is performed in both a canonical (concentration-dependent) and grand canonical (concentration-independent) scheme. These results are compared with those derived from the Connolly-Williams method and "exact" results obtained on a simple, tightbinding, d-band model.

Additional support was provided by grants from NATO and from CNRS-NSF. A large portion of the $\mathrm{FY} 1990$ research effort was redirected to studies of oxygen ordering in the $\mathrm{YBa}_{2} \mathrm{Cu}_{3} \mathrm{O}_{\mathrm{x}}$ high-temperature superconducting compound. Results of this investigation are reported in a special high- $\mathrm{T}_{c} \mathrm{CAM}$ report. The effort paid off as we were awarded the 1990 DOE prize for "Outstanding Scientific Accomplishment in Metallurgy ar.d Ceramics."

Investigator

Didier de Fontaine

Post-Doctoral Fellows

Erik Salomons

Prabhakar P. Singh

\author{
Graduate Students \\ Mark Asta \\ Gerbrand Ceder \\ Mark Kraitchman \\ Ryan McCormack \\ Christopher Wolverton
}

Refereed Journal Articles

\section{Publications and Reports}

(See also CAM High- $\mathrm{T}_{\mathrm{c}}$ Superconductivity Program.)

Ceder, G., M. Asta, W.C. Carter, M. Kraitchman, D. de Fontaine, M. E. Mann, and M. Sluiter, "Phase Diagram and Low Temperature Behavior of Oxygen Ordering in $\mathrm{YBa}_{2} \mathrm{Cu}_{3} \mathrm{O}_{2}$ Using ab Initio Interactions," Phys Rev. B, vol. 41, p. 8698, 1990

de Fontaine, D., G. Ceder, and M. Asta, "Low Temperature Long-Range Oxygen Order in $\mathrm{YBa}_{2} \mathrm{Cu}_{3} \mathrm{O}_{x^{\prime}}$ " Nature, vol. 343, p. 544, 1990.

de Fontaine, D., "Comment on Jtructural Properties of the Tetragonal Superconductors LaBaCaCu $\mathrm{O}_{7-\mathrm{d}}$ " J. less-Common Metals, vol. 160, p. L.5, 1990.

Dreyssé, H., G. Ceder, L.T. Wille, and D. de Fontaine, "Determination of Effective Pair Interactions and Segregation Behavior at Alloy Surfaces," Vacuum, vol. 41, p. 446, 1990.

Sluiter, : 1., D. de Fontaine, X.Q. Guo, R. Podloucky, and A.J. Freeman, "A First Principles Calculation of Phase Equilibria in the AlLi System," Phys. Rev. B, vol. 42, p. 10460, 1990.

Other Publications

de Fontaine, D, "States of Oxygen Ordering in $\mathrm{YBa}_{2} \mathrm{Cu}_{3} \mathrm{O}_{\mathrm{z}}$ " in Oxygen Disorder Effects in High $T_{c}$ Superconductors, ed. J.L. Morán-López. and Ivan K. Schuller, p. 75, Plenum, 1990. 
Menon, E. S. K., K. M. Krishnan, P. Huang, C. Echer, P. Singh, and D. de Fontaine, "Electronic Structure of Cu-Pd Alloys," in Proc. of XIIth Int. Congress for Electron Microscopy, vol. 2, p. 38, 1990.

Huang, P., E. S. K. Menon, G. Ceder, and D. de Fontaine, "Effect of Oxygen on the Stability of 1-D LISS In Cu Pd," in Proc. of XIIth Int. Congress for Electron Microscopy, vol, 4, p. 166, 1990.

LBL Reports

Ceder, G., D. de Fontaine, H. Dreyssé, D. M. Nicholson, G. M. Stocks, and B. L. Györffy, LBL-28404, "Ab Initio Study of the Cu-P'd One-Dimensional Long Period Superstructure Phase Diagram," Acta Metall. Mater. (In press.)

Salomons, E. and D. de Fontaine, LBL-28801, "Monte CarloStudy of Oxygen-Vacancy Ordering in $\mathrm{YBa}_{2} \mathrm{Cu}_{3-x} \mathrm{M}_{x} \mathrm{O}_{6+2 c}(\mathrm{M}=\mathrm{Co}, \mathrm{Fe}, \mathrm{Al}, \mathrm{Ga})$," Phys. Rev. B. (In press.)

Wolverton, C., H. Dreyssé, and D. de Fontaine, "A Comparison of the Direct Configurational Averaging and Connolly Williams Methods of Obtaining Effective Pair Interactions in Substitutionally Disordered Alloys," LBL-29095, Proc. of MRS Spring Meeting, Symp. I: Alloy Phase Stability and Design, San Francisco, CA, April 16-21, 1990. (In press.)

Asta, M., M. Sluiter, D. de Fontaine, T. Hong, A. J. Freeman, and P. P. Singh, "First-Principles Study of Phase Stabillty in the Al-Ti System," LBL-29096, Proc. of MRS S'pring Meeting, Symp. I: Alloy Phase Stability and Design, San Francisco, CA, April 16-21, 1990. (In press.)

Singh, P. P., M. Asta, D. de Fontaine, and M. Van Schilfgaarde, "Ground State Propertles of the Al-Ti System," LBL-29097, Proc. of MRS Spring Meeting, Symp. I: Alloys Phase Stability and Design, San Francisco, CA, April 16-21, 1990. (In press.)

Ceder, G., P. Huang, S. Menon, D. de Fontaine, D.M. Nicholson, G.M. Stocks, and B.L. Györffy, "Ab Initio Calculation of the fcc CuPd Phase Diagram for O<c $<c_{\mathrm{pd}}<0.4$," LBL-29098, Proc. of MRS Spring Meeting, Symp. I: Alloy Phase Stability and Design, San Francisco, CA, April 16-21, 1990. (In press.)

Singh, P. P., "Self-Consistent Electronic Structure of 3d-Transition Metal Impurities in Aluminum Using the Recursion Method," LBL29835, Phys. Ret. B. (In press.)

de Fontaine, D. and S. C. Moss, "Comment on 'Diffuse Scattering from $\mathrm{YBa}_{2} \mathrm{Cu}_{3} \mathrm{O}_{7-d}$ Caused by Magnell-Type Plane Defects'," LBL30123, Phys. Rev. Lett. (Submitted.)

Invited Talks

de Fontaine, D., Towards a First-Principles Thermodynamics of Alloys, Rockwell International Science Center, Thousand Oaks, CA, March 1990.

de Fontaine, First-Principles Alloy Thermodynamics, Dream or Reality? MSME Department Seminar, College of Engineering, University of California, Berkeley, CA, September 1990.

Contributed Talks

Ceder, G., P. Huang, S. Menon, D. de Fontaine, G. M. Stocks, D. M. Nicholson, B. L. Györffy, and H. Dreyssé, Theoretical and Experimental Study of the Cu-Pd One-Dimensional Long Period Superstructure Phase Diagram, March Meeting of the American Physical Society, Anaheim, CA, March 1990.

Dreyssé, H., G. Ceder, D. de Fontaine, C. Wolverton, and R. Riedinger, Electronic Structure of Substitutionally Disordered Alloys: A Direct Configurational Averaging Method, March Meeting of the American Physical Sodety, Anaheim, CA, March 1990.

Salomons. E. and D. de Fontaine, Monte Carlo Study of Tracer and Chemical Diffusion of Oxygen in $\mathrm{YBa}_{2} \mathrm{Cu}_{3} \mathrm{O}_{6+2 c^{\prime}}$ March Meeting of the American Physical Society, Anaheim, CA, March 1990.

Ceder, G., P. Huang, S. Menon, D. de Fontaine, G. M. Stocks, D. M. Nicholson, B. L. Györffy, and H. Dreyzsé, Ab Initio Calculation of the fcc Cu-Pd Phase Diagram for $O<c_{P d}<0.4$, MRS Spring Meeting, San Francisco, CA, April 1990.

Wolverton, C., H. Dreyssé, and D. de Fontaine, A Comparison of the Direct Configurational Averaging and Connolly-Williams Methods of Obtaining Effective Pair Interactions in Substitutionally Disordered Alloys, MRSSpring Meeting, San Francisco, CA, April 1990. 


\title{
Wastage of Steels in the Erosion-Corrosion (E-C) Environments of Fluidized Bed Combustors*
}

Alan V. LEVy, PRINCIPAL InVEstigator

The erosion-corrosion (E-C) of carbon and low alloy steels in environments that simulated those found in fluidized bed combustions $(\mathrm{FBC})$ were studied as a function of variables at levels that were much closer to those that occur in bubbling bed, coal burning fluidized bed combustors than earlier work. Velocities of $2.5 \mathrm{~m} / \mathrm{s}$, the presence of $\mathrm{Ca} \mathrm{SO}_{4}$ in the erodent mixtures, and the use of several different microstructures of mild steel and $2.5 \mathrm{Cr} 1 \mathrm{Mo}$ steel were all investigated. The chemical and mechanical mixture characteristics of the scale/deposit layer that forms on erodedcorroded surfaces were studied further io determine how and why they formed and how they modified the E-C behavior of the target metals. The comparative metal wastage of several alloys that were subjected to as near as possible the same test conditions in gas-solid particle, liquid-solid particle (slurry) anci cavitation erosion were determined. The erosivity of flyash from pulverized coal boilers was determined over a range of test conditions and was compared to the bed materials from FBCs. Additional studies of the erosion behavior of diffusion coatings on steels were conducted. Current and planned research will gain additional understanding of the E-C metal wastage of materials used in fossil fueled boilers. Additional natural gas fired internal combustion engines have been operated with consistent major improvements in durability and operating characteristics.

\section{Effect of Microstructure on the Erosion-Corrosion of Steels}

\author{
B. Q. WANG
}

1018 plain carbon steel and $2.25 \mathrm{Cr} 1 \mathrm{Mo}$ steel, two commonly used boiler tubing steels, wrere prepared in five different conditions, i.e., annealed, hot rolled, normalized, quenched and tempered and cold rolled, and erosion-corrosion tested at room and elevated temperatures using $\mathrm{SiO}_{2}$ particles at $\mathrm{V}=20 \mathrm{~m} / \mathrm{s}, \propto=30^{\circ}$. Static and dynamic oxidation tests were also performed. It was determined that the various microstructures caused measurable differences in the metal wastage from erosion at both room and elevated temperatures and from both static and dynamic oxidation. The oxidation rate was influenced by microstructures in opposing manners. A nonequilibriu m microstructure generally resulted in higher static and dynamicoxidation rates than an equilibrium microstructure. However, the extra phase and grain boundaries and / or finer substructure of the non-equilibrium microstructure sometimes provided greater numbers of short circuit diffusion paths for $\mathrm{Cr}$ and $\mathrm{Mn}$ that increased the amount of these elements in the scale, resulting in the formation of a more protective oxide layer that reduced the oxidation rate.

The influence of microstructures on the room temperature erosion metal wastage depended on the distribution of hard, brittle and soft, ductile phases in the steel, which determined their coinbination of ductility and strength. The erosion metal wastage of steel was not related to its hardness. There was a complex relationship between the microstructure of the steels tested and their elevated temperature erosion-corrosion metal wastage. The influence of ductility and strength, oxidation resistance, and the morphology and behavior of the scale formed at the test temperature combined to establish the metal wastage mechanisms and rates.

\section{Effect of Calcium Sulfate Particles on Erosion and Erosion-Corrosion of Carbon Steel}

G. Q. GENG

Tests were performed to determine the effect of $\mathrm{CaSO}_{4}$ in $\mathrm{FBC}$ bed materials on their erosivity. A series of mechanical mixtures of $\mathrm{SiO}_{2}$ (sand) and calcium sulfate

* This work was supported by the U.S. Department of Energy Fossil Energy $\overline{\text { Materials Program, }}$ Advanced Research and Technical Development Office. 
were used for erodent particles. Both high and low particle velocities were used, i.e., 20 and $2.5 \mathrm{~m} / \mathrm{s} .1018$ plain carbon steel was selected as the target material. The tests were carried out at a temperature of $450^{\circ} \mathrm{C}$ except the tests to determine the effect of temperature, which ranged from $350^{\circ}$ to $450^{\circ} \mathrm{C}$. The impingement angle was $\mu=30^{\circ}$. It was determined that calcium sulfate which occurs in FBC bed materials from the reaction of calcined limestone sorbent with the sulfur in the coal fuel can either protect the base metal against erosion-corrosion or enhance the formation of destructive sulfides. The formation of mixed calcium compound-iron oxide layers on the surface helps to protect the metal surface from E-C attack. Sulfidation, which depends on the calcium sulfate content of the erodent particles and the test temperature, particle velocity, and duration, caused a reaction to occur between calcium sulfate particles and metal substrates that formed iron sulfide under certain test conditions.

\section{Characteristics of Scale Layers on Steels in FBC Service}

B. Q. WANG

The characteristics of scale-deposit layers that form on and protect steel surfaces eroded-corroded at elevated temperature, i.e., composition distribution, morphology, deformation, thickness, porosity, mechanical integrity, were determined and related to metal wastage at various laboratory test and in-service conditions. It was found that in the outer part of the scale layer either straight bed material or a mixture of it and iron oxide can form. Near the scale-metal interface, the bed material content of the layer was markedly decreased and it primarily consisted of iron oxide. The gradation of the constituents through the layer were determincd using line scan and $x$-ray maps. the distribution of iron and calcium had a lineargradient through an inner layer near the substrate interface. The iron, calcium and sulfur in the outer layer were neither linear nor could they be directly correlated with the distance from the outside surface to the scale layer-metal interface. The composition distribution depended on both the chemical and mechanical processes that occurred. In the inner layer the chemical process predominated and in the outer layer only the mechanical process occurred.

The erosion-corrosion (E-C) scales that formed at the test conditions used appeared to be relatively ductile. The microhardness of the scaie layers could not be correlated with the E-C metal wastage. However, single particle impact behavior of a preformed layer could be directly relatcd to the E-C metal wastage.

\section{Erosion-Corrosion of 1018 Steel Eroded at Low Velocities by CFBC Bed Material} G. Q. GENG

The erosion-corrosion (E-C) behavior of 1018 carbon steel eroded by fluidized bed combustor $(\mathrm{FBC})$ bed material particles at low elevated temperatures and low particle velocities was determined in a nozzle type laboratory tester. Bed material erodent particles from operating, circulating fluidized bed combustors were used for tests in air at different temperatures from $25^{\circ} \mathrm{C}$ to $550^{\circ} \mathrm{C}$ for exposure periods up to 100 hours at particle velocities as low as $2.5 \mathrm{~m} / \mathrm{s}$. The lowest velocity test conditions were meant to simulate those experienced by in-bed FBC heat exchanger tubes. Metal wastage rates were determined from thickness loss measurements of the specimens.

It was determined that particle velocity influenced the relationship between metal wastage and test temperature. At the low velocity of $2.5 \mathrm{~m} / \mathrm{s}$, there was a peak in the metal wastage curve at $350^{\circ} \mathrm{C}$. At the higher velocity of $10 \mathrm{~m} / \mathrm{s}$ there was a continuous increase in the curve of metal wastage vs. test temperature. There was a basic difference in the behavior of the scales that formed on the metal surface at low and higher particle velocities. At the lower velocity of $2.5 \mathrm{~m} / \mathrm{s}$ the scale behaved in a pscudoplastic manner. At the higher velocity of $10 \mathrm{~m} / \mathrm{s}$, the scale behaved in a brittle manner. The scale layers that formed on the metal surfaces in low particle velocity $E$ $C$ behaved in a ductile manner with the peak loss rate occurring at $\propto=45^{\circ} \mathrm{impact}$ angle. The scale formed at the lower velocity was thicker, denser and more continuous than that formed at the higher particle velocity. At $450^{\circ} \mathrm{C}$ the former became more 
ductile, resulting in more deformation and retention, while the latter was still brittle and cracked and chipped off.

\section{Ceramic Coatings in Gas Lined Internal Combustion Engines}

A. LEVY

The performance of natural gas fired, internal combustion engines with ceramic coated combustion zone surfaces has continued to be excellent. Sufficient numbers of engines $(>40)$ have now been coated and are in operation to have firmly demonstrated the improved durability and operating characteristics of the coated engines. Reduced fuel consumption, increased power output, reduced engine vibration, and markedly lower exhaust emissions have all accrued from the use of the coating. A combustion research project is planned to determine how and why the many desirable engine operating characteristics modifications occur.

\section{Erosivity of Fly Ash from Pulverized Coal Boilers \\ M. LIEBHARD}

In order to calibrate an erosion model which was designed to predict the erosion or erosion-corrosion metal wastage in pulverized coal boiler power-plants, several tests were run in a laboratory erosion-corrosion tester. Target material from an actual heat exchanger steel tube and flyash from a pulverized coal boiler power plant were used as test specimen and erodent. The parameters in the test equipment were adjusted so the conditions in the actual plant were simulated.

Even at a temperature as low as $300^{\circ} \mathrm{C}$, a scale of $\mathrm{SiO}_{2}, \mathrm{Al}_{2} \mathrm{O}_{3}$ (the main constituents of the flyash) and iron oxide was built up on the metal surface. The metal wastage mechanism was found to be a simultaneous building up of this scale and the removal of it by cracking and chipping. The primary result of the tests was the simulation of a pattern of metal wastage vs. test temperature that occurred in operating boilers but that had never been achieved in laboratory tests. The material underwent high metal wastage at low temperatures and low wastage at higher temperatures in tests at $250^{\circ}$, $300^{\circ}$ and $350^{\circ} \mathrm{C}$. The reason for this behavior was related to the occurrence and nature of the scale deposit layer that formed.

\section{A Study of Bubble Induced Wear of In-Bed Tubes in Fluidized Bed Combustors*}

A. V. LEVY, S. MACADAM

Fluidized bed combustion of coal has many potential advantages over conventional coal burning systems. These benefits stem frum the excellent gas and solid particle mixing that occurs within fluidized environments. However, there are some problems that need to be addressed as fluidized bed combustors (FBCs) become commercially viable. One of these is unacceptable metal wastage of heat exchanger tubes and other internal bed components. The present study is concerned with the development of an understanding of a frequently observed and perhaps intrinsic source of wastage in bubbling FBCs. This is the wastage of submerged horizontal or inclined heat exchanger tubes arising from interactions with bubbles upward from below to impact the bottom of tubes and cause localized wear. This effect is simulated in two specially designed wear rigs by quickly driving a specimen rod downward within a bed of fluidized particles. 


\section{Room Temperature Fluid Bed Wear Tester}

A laboratory scale fluid bed wear tester apparatus was operated at room temperature to study the behavior of aluminum rod shaped specimens exposed to fluidized erodent particle beds having different ratios of $\mathrm{SiO}_{2}$ to bed material from operating AFBC's. The mass and circumferential thickness change distributions of the specimen rods were measured. Only part of the specimen surface was worn while a deposited layer of bed particles and aluminum was formed on other regions of the cylinder's surface that prevented metal wastage. The morphologies and compositions of the deposit layer on several specimen rods were measured. It was determined that the $\mathrm{SiO}_{2}$ constituent in the bed material particles caused the metal wastage while the calcium compounds in the AFBC bed material contributed to the formation of the deposit layers. The more $\mathrm{SiO}_{2}$ in the bed particles, the more metal wastage occurred. The larger the particle size was, the greater was the metal wastage. Direct metallographic evidence was found that both particle impact crosion and 3 body abrasive wear metal wastage mechanisms occurred.

\section{Elevated Temperature Fluid Bed Wear Tester}

Construction of a new high temperature fluid bed wear rig began in 1989. this rig is similar to the room temperature rig except that it is capable of operating at bed temperatures up to $700{ }^{\circ} \mathrm{C}$, and it utilizes a $\mathrm{PC}$ based data acquisition, control, and analysis system. There have been in excess of $700 \mathrm{~h}$ testing with this rig at elevated temperature. Among the early findings is that the maximum wear/oxidation rate at a particular impact energy for $1018 \mathrm{stecl}$ increases exponentially above $400^{\circ} \mathrm{C}$. This is indicative of an oxidation limiting process. Furthermore, the activation energy for the wastage process is considerably lower than for static oxidation, and it varies around the underside of the rod. Near the sides of the rods and near the bottom, the presence of either a complete or discontinuous oxide layer prevented wastage under some conditions above $400^{\circ} \mathrm{C}$. The transition from protected to heavily worn materials was abrupt and discontinuous. Oxide protection showed some relationship to the impact encrgy, with more protection at lower energies. Under the least severe condition tested, there was an almost complete oxide layer over the entire underside. At temperatures below $400^{\circ} \mathrm{C}$, there was no protective oxide. Where loss did occur at the bottom, it was found that the rate relative to the maximum loss increased from $0 \%$ at room temperature up to $80 \%$ at $650{ }^{\circ} \mathrm{C}$. Testing under a wide range of conditions indicated that the impact energy rate (power) controlled the wastage observed. Hence, changing the impact severity and the impact frequency, both of which change the power, have the same effect on wastage.

\section{Publications and Reports}

Refereed Journal Articles

Levy, A.V., Shlu, Z.R., Wang, B.Q., "The Erosivity of Atmospheric Fluidized Bed Combustor Particles $600 \mu \mathrm{m}$ in Diametor", Wear 136 No. 7, pp 359-372, March, 1990.

Levy, A.V., "The Abrasion/Erosion and Erosion-Corrosion Characteristics of Steels", Wear 138 Nos. 1-2, pp 111-124, June, 1990.

MacAdam, S. and Stringer, J., "Devolopment of a Unique Laboratory Scale Fluidized Bed Wear Testing Unit", Wear 135 No. 2, pp 403422, Jan, 1990 .

Wang, B.Q. and Levy, A.V., "Erosion Behavior of SIC Fiber-SiC . Malrix Composites", Wear 138, Nos, 1-2, pp 125-136, Junc, 1990,

Wang, B.G., Geng, G.Q., Levy, A.V., "Surface Behavior of I leat Exchanger Tubes in Fluidized-Bed Combustors", Surface and Coatings Technology 42, pp 253-274, 1990).

Wang, B.Q., Shlu, Z.R., Levy, A.V., "Sliding Wear of Thermal-Sprayed Chromla Coatings", Wear 138 Nos. 1-2, pp 93-110, June, 199(). Other Publications

G.W. Geng, B.W. Wang, A.V. Levy, "Erosivity of Partleles from Operating Fluldized Bed Combustors", NACE Corrosion 90), I'aper No. 288,1990

G.W. Geng, B.Q. Wang, A.V. Levy, "The Effect of Fluldized Bed Combustor Materials Compositions on the Erosion-Corrosion of Carbon Steel," NACE Corrosion 9(), l'aper No, 290, 1990). 
G.Q. Gong, P.Y, How, 13.Q. Wang, A.V. Levy, "The Effoct of Additional Silleon on the Corroston and Erosion-Corrosilon of Low Chromitum Stedls", NACE, Corrosion 90, l'aper No. 292, 1990),

B.Q. Wang, G.W. Geng, A.V. Lovy, W. Mack, "Tho Erosion-Corrosion of Addittonal Silleon, Low Chromlum Alloy Steds", NACE, Corrosion 90, I'aper No. 293, 1990,

A.V. Lovy, B.Q. Wang, G.Q. Geng, "The Wastago of Stools in the Erosion-Corrosilon of Fluidlzed Bod Combustors", Proceedlng,s of the Conference on Fossil Energy Matorials, Oak Ridgo, TN, 1990).

B.Q. Wang, G.Q. Geng, A.V. Levy, "Erosion-Corrosion of Thermal Spray Coatings", 17th ICMC, San Diego, CA, 1990).

Z.R. Shul, B.Q. Wang, A.V. Lovy. "Erosion of Protective Coatings", 17th ICMC, San Dlago, CA, 1990,

Y.J. Lui, A.V. Lovy, "Erosion and Erosion -Corrosion Behavior of Chromized-Aluminized Stainless Steols at Room and Elevated Tomporatures", 17th ICMC, San Diego, CA, 1990,

A.V. Lovy, B.Q. Wang, G.Q. Gong, "Relationship Between Feedstock Characteristles and Erosivilty of FBC Bed Materials," $\triangle$ SME Paper No, 90-GT-249, Gas Turbine and Aoroongine Conforence and Exposition, Brussols, Belglum, 1990).

B,Q. Wang, G,Q, Geng, A.V, Lovy, "Erosion-Corroston of Tubing Steols at Simulated Fluldized Bed Combustor Convectlon l'ass Conditions", Proceedings of the 4th Borkeley Conference, Berkoley, $\mathrm{C} \Lambda, 1990$.

Holloman, L., and Levy, A.V., "The Use of Ceramic Coatings on Combustion Zone Components to Enhance the P'orformance and durabllity of Natural Gas Combustlon Enginos", DOE Coatings 90 Workshop, Castine, ME, 1990.

Levy, A.V., "Use of Zirconia Plasma Spray Coatings on the Combustion Zone Surface of Internal Combustion Englnes", DOE Coatings 90 Workshop, Castine, ME, 1990. 


\section{Gas-Solid Reactions}

James W. Evans, Paincipal Investigator

This rescarch is concerned with reactions between gases and solids in materials science. In many such reactions of actual or potentlal technological significanice (e.g, the reaction of tungsten hexafluoride with sillicon in the chemical vapor deposition of tungsten during silicon semiconductor processing) new solid phases appear. The nucleation, growth, epitaxy and crystallinity of these phases, as well as changes to the microstructure of reactant phases, are the focus of this research.

The principal experimental tools are the transmission electron microscopes at Berkeley which permit the examination of the phases formed both by imaging and electron diffraction, either during in-situ experiments or following ex-situ experiments. Other characterization techniques such as Rutherford backscattering spectroscopy and scanning clectron microscopy are used in this investigation.

\section{Dopant Concentration Influence on Tunnel Formation in Chemlcally Vapor-Deposited Tungsten on Sillcon

\author{
L.M. FENG
}

The effect of dopant concentration on tunncl formation in CVD tungsten was studied. Depositions were carried out in a reduced-pressure, cold-wall reactor in the range of $250-350^{\circ} \mathrm{C}$, temperatures which are commonly used for CVD tungsten. It has long been recognized that under some circumstances, tunnels form in the silicon, to the detriment of the integrated circuit formed on the silicon. Experimentally, it was found that

- Higher substrate dopant concentration tends to cause more tunnels

- Tunnel formation appears not to depend on wafer orientations

- Higher deposition temperature produces more tunnels.

The mechanism for tunnel formation is explained in terms of fluorine etching. Specifically, the effect of doping on the etching rate is considered in terms of its influence on the electronic structure near the surface. The roughness observed along the W/Si interface is attributed to the presence of an oxide layer. Thermodynamic calculations suggest that the particles found in the tunnels are tungsten.

Thermodynamic calculations were performed to find the gaseous species distribution at equilibrium with the most stable condensed phases deposited from gas mixtures of $\mathrm{H}_{2}-\mathrm{WF}_{6}$. Different amounts of reactants and different pressure conditions were used in the temperature range $400-1000 \mathrm{~K}$. The calculations indicated that the gas molecules inside the reactor are predominantly $\mathrm{HF}$ and $\mathrm{SiF}_{4}$.

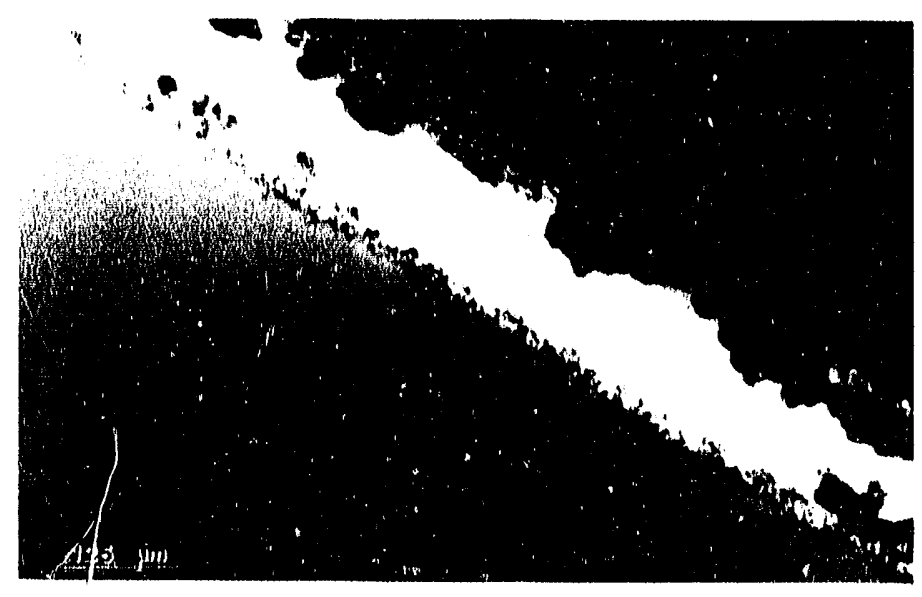

Figure 1

Cross-seotional transmission electron miorograph shows a rough tungsten-silloon interface. Tungsten islands are evident. Most tunnels are not decorated with tungsten partioles at their ends. (XBB 904-3405) 
Principal Investigator

J. W. Evans

Graduate Students

Lucia M. Feng

Brian S, Y. Shieh

\section{Publications and Reports}

LBL Report

Feng L.M., LBL-30080, "Dopant Concentration Influence on Tunnel Formation in Chemically Vapor-Deposited Tungsten on Sillicon." 


\section{Solid-State Physics}

\section{EXPERIMENTAL RESEARCH}

\section{Far Infrared Spectroscopy}

Paul L. RichaAds, Paincifal InVestigator

In this project, improved infrared techniques are being used to do experiments in areas of fundamental and applied infrared physics where their impact is expected to be large. Improved types of infrared sources, spectrometers, and detectors are also being developed. Experiments in progress include: measurements of the far-infrared absorptivity of the new high $\mathrm{T}_{c}$ superconductors, measurements of the infrared spectra of one-dimensional conductors, measurements of the heat capacity of monolayers of adsorbates on metal films, and measurements of lossless quasiparticle tunneling in superconducting tunnel junctions. Improvements in infrared technology include: development of thin film high $T_{c}$ superconducting bolometers for detecting $x$-ray, infrared and microwave radiation, and development of superconducting thin film quasiparticle detectors and mixers for near-millimeter wavelengths that approach quantum limited sensitivity.

\section{Quasiparticle Mixers and Detectors*}

QING HU AND P.L. RICHARDS

The superconducting components that have been developed for infrared and millimeter-wave receivers were reviewed. A brief description is given of the scientific principles on which each device is based, followed by a discussion of the performance that has been achieved in terms of the appropriate figures of merit. Finally, comments are made about the possibility that useful device performance can be achieved by using the new high- $\mathrm{T}_{\mathrm{c}}$ oxide superconductors. This review emphasizes photonassisted quasiparticle tunneling and the SIS quasiparticle mixer, which is the only superconclucting component to find substantial applications at infrared or millimeter wavelength.. Descriptions are given of the SIS quasiparticle direct detector, the Josephson efiect oscillator, the Josephson effect parametric ampilfier, and the various superconducting bolometers, for which practical applications appear possible. The less promising Josephson effect detector and mixer and the various ideas for superconducting pheton detectors are described because of the current interest in possible high- $\mathrm{T}_{\mathrm{c}}$ versions of these devices.

\section{Design Analysis of a Novel Low Temperature Bolometer} M. NAHUM AND P.L.. RICHARDS

A novel antenna-coupled superconducting bolometer which makes use of the thermal boundary resistance available at low temperatures has been proposed. The radiation is collected by a planar self-complementary antenna, as is shown in Figure 1 , and thermalized in a small thin film resistor. The resulting temperature rise is ditected by a transition edge thermometer which can be (but need not be) a separate

\footnotetext{
* Supported in part by the Department of Defense.
} 


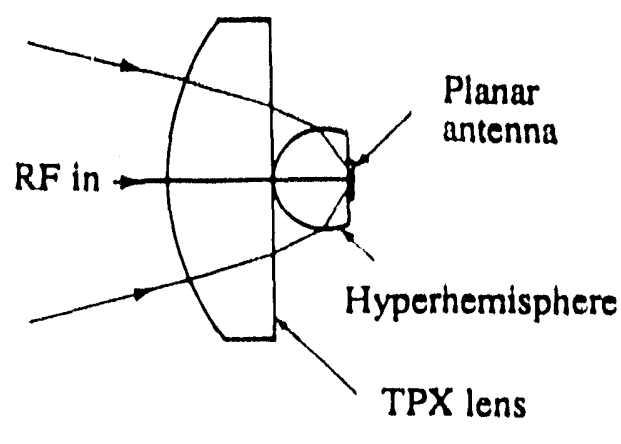

a)

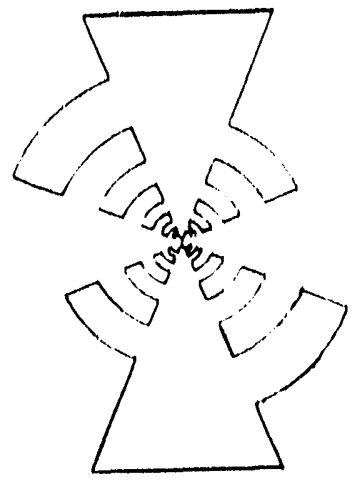

b)
Flgure 1

Quasi-optloal couplly, sheme, a) Cross seotlon. The subsinal:? mounted on the flat side of a hyperhuinispherical lens. A TPX lens lo used to further narrow the beam. b) Planuir log.perlodio antenna. Thls self-complementary struoture glves a Irequenoy-Indefendent real antenna Impedance and very broadband response. In additlon, It has a nearly Gaussian beam pattern. (XBL. 9012.4017)

fllm. All components are deposited directly on a substrate so that arrays can be conveniently produced by conventional lithographic techniques. The active area of the bolometer is thermally decoupled by its small size and by the thermal resistance of the boundaries with the substrate and the antenna terminals. Design calculations based on a $2 \times 2 \mathrm{~mm}$ square film of a superconductor with $\mathrm{T}_{c}=0.1 \mathrm{~K}$ give an NEP $\approx 10^{-18} \mathrm{WHz}^{-1 / 2}$, time constant $\approx 10^{-6} \mathrm{~s}$ and responsivities up to $\approx 10^{9} \mathrm{~V} / \mathrm{W}$. These specifications meet the requirements for NASA's Space Infrared Telescope Facility and Sub-Millimeter Moderate Mission. Useful applications also exist at ${ }^{3} \mathrm{He}$ and ${ }^{4} \mathrm{He}$ temperatures. The calculated NEP scales as $\mathrm{T}^{5 / 2}$, as is shown in Figure 2. Materials, architectures, and readout schemes will be discussed.

\section{The Effect of the Quantum Susceptance on the Gain of Superconducting Quasiparticle Mixers \\ C.A. Mears, QIng Hu, and P.L. Richardos}

A detailed analysis of the effects of the quantum susceptance on the performance of superconductor-insulator-superconductor (SIS) mixers was performed. It was found that the principal effects of the quantum susceptance are to change the dc bias at which optimum coupling of the signal to the mixer occurs, and to change the output admittance at the IF frequency, thus changing the available gain.

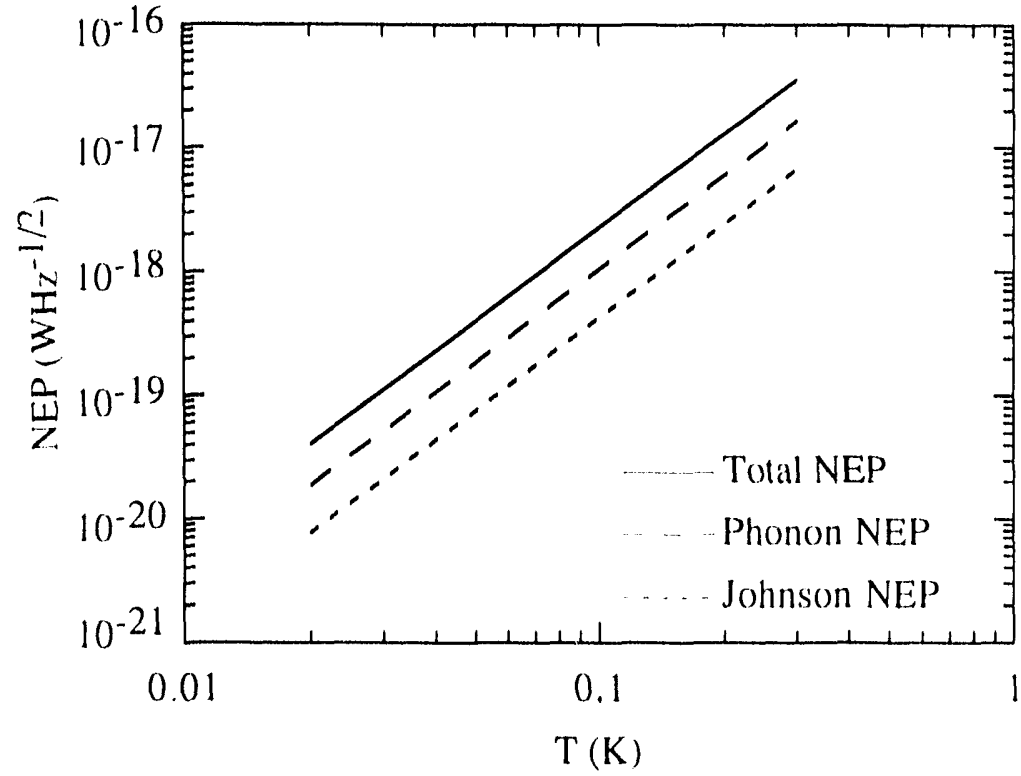

Figure 2

Estimates of the Johnson, phonon and total NEP as a function of operating temperature for the proposed new antenna-coupled low $T_{0}$ superconducting bolometer. We assume the heat flow to be limlted by the thermal boundary resistance from a $2 \times 2 \mathrm{~mm}$ square contact area and pick a boundary resistance coefficient of $B=20 \mathrm{~K}^{4} \mathrm{~cm}^{2} \mathrm{~W}$. The optical efficiency is assumed to be $50 \%$ and the superconducting transition width $10 \%$ of the operating temperature. Under these conditions the sensitivity is limited by the phonon noise. (XBL 9012-4018) 


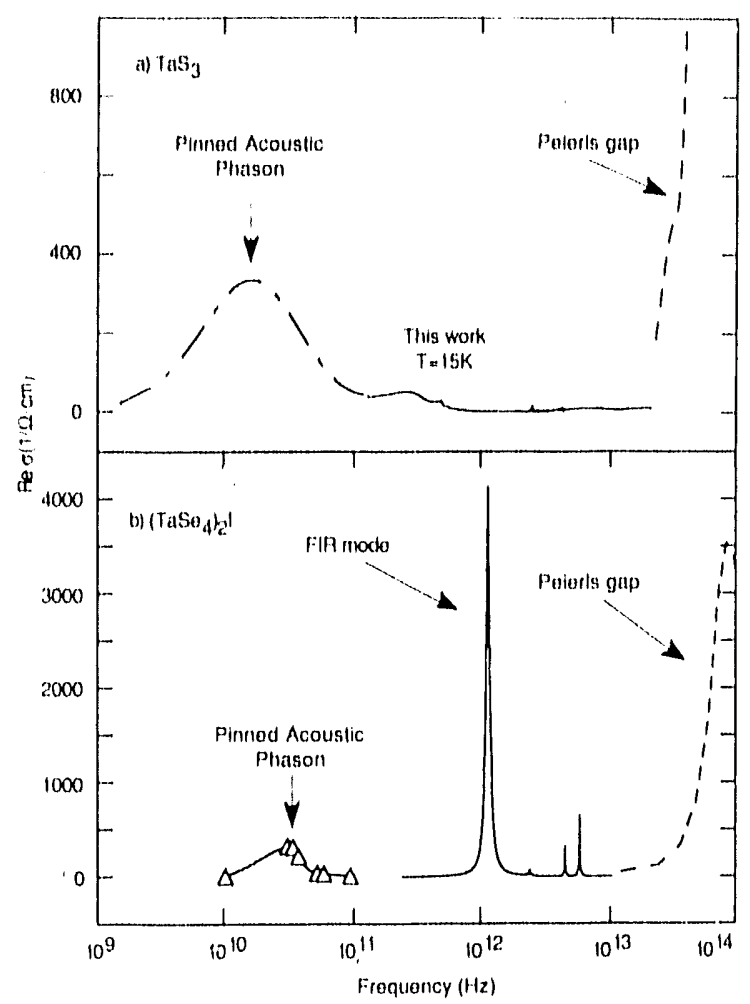

Flgure 3

a) Frequency dependenoe of the real part of the conduotlvity for $\mathrm{TaS}_{3}$ deduced from Infrared and microwave data. b) Frequency dependenoe of the real part of the conduotlvity for $\left(\mathrm{TaSe}_{4}\right)_{2}$ l from our prevlous work combined with work by others. There ls no evidence for a glant far Intrared (FIR) mode in $\mathrm{TaS}_{3}$ comparable to the mode prevlously found in $\left(\mathrm{TaSe}_{4}\right)_{2}$. (XBL 9012-4032)

Far Infrared Conductivity of $\mathrm{TaS}_{3}$ : Identification of the Intrinsic Charge Density Wave Excitation Modes*

W.N. Creager, P.L. Richardos, and A. ZetTl.

The far infrared (FIR) reflectance of the charge density wave (CDW) conductor $\mathrm{TaS}_{3}$ has been measured from 3 to $700 \mathrm{~cm}^{-1}$ over the temperature range from $15 \mathrm{~K}$ to $300 \mathrm{~K}$ as is shown in Figure 3. For incident radiation polarized parallel to the long axis of the crystals, a strong reflection edge correlated with the formation of the CDW appears near $80 \mathrm{~cm}^{-1}$. The associated conductivity shows no dramatic conduction mode in the FIR. These results, which are in sharp contrast to the observed behavior in the related CDW materials $\left(\mathrm{TaSe}_{4}\right)_{2} \mathrm{I}$ and $\mathrm{K}_{0.3} \mathrm{MoO}_{3}$, rule out models of a "generic FIR mode" in CDW excitations.

Staff

$\begin{array}{ll}\text { Investigator } & \text { Graduate Students } \\ \text { P.L. Richards } & \text { John Birmingham } \\ & \text { Carl Mears } \\ \text { Postdoctoral Fellow } & \text { David Miller } \\ \text { Qing Hu } & \text { Michaol Nahum } \\ & \text { Robert Phelps } \\ & \text { Simon Vorghose }\end{array}$

\section{Awards}

- P. L. Richards has been named the Faculty Research Lecturer for the Berkeley Campus for the 199()-91 academic year.

- Qing Hu received an LBL T'echnology Transfer A ward .

" Collaboration with Prof. Zettl, whose research is supported by the NSF 
Refereed Journal Articles

Timbie, P. T., Bernstein, G. M., and Richards, P. L., "Development of an Adiabatic Demagnetization Refrigerator for SIRTF," Cryogenics vol. 30, p. 271, 1990.*

Kenny, T. W., and Richards, P. L., "AC Calorimeter for Measurements of Adsorbed Gases on Metal Films at ${ }^{4}$ He Temperatures," Rev, Sci. Instrum., vol. 61, p. 822, 1990.

Kenny, T. W. , and Richards, P. L., "Heat Capacity and Sticking Probability Measurements of ${ }^{4} \mathrm{He}$ Adsorbed on Evaporated Ag Films Bose Statistics in Two Dimensions," Phys. Rev. Lett., vol. 64, p. 2386, 1990.

Hu, Qing, Mears, C. A. , Richards, P. L. ard Lloyd, F. L., "Observation of Non-Dissipative Quasiparticle Tunnel Currents in Superconducting Tunnel Junctions," Phys. Reo. Lett., vol. 64, p. 2945, 1990. ${ }^{\dagger}$

Bernstein, G. M., Fischer, M.L., Richards, P.L., Peterson, J.B., and Timusk, T., "A Measurement of the Spectrum of the Cosmic Background Radiation from $1 \mathrm{~mm}$ to $3 \mathrm{~mm}$ Wavelength," Astrophys. J., vol. 362, p. 107, 1990. *

Other Publications

Bernstein, G. M., Fischer, M. L., Richards, P. L., Peterson, J. B., and Timusk, T., "New Measurements of the Spectrum and Anisotropy of the Millimeter Wave Background," in Submillimetre Astronomy, eds. G.D. Watt and A. S. Webster, p. 79, Kluwer Acade : : Publ., Dordrecht/Boston/London, 1990. *

Timbie, P. T., Bernstein, G. M., Richards, P. L., Gautier, T. N. , Rieke, G. H. , Werner, M. W., "Submillimeter Cosmology with the Multiband Imaging Photometer for SIRTF", in Submillimetre Astronomy, eds. G.D. Watt and A. S. Webster, p. 53, Kluwer Academic Publ., Dordrecht/Boston/London, 1990.*

Richards, P. L. " "Observations of the CMB Spectrum," in The Cosmic Microwave Background 25 Years Later, eds. N. Mandolesi and N. Vittorio, pp. 141-152, Kluwer Acad. Publ. Co. Dordrecht, the Netherlands, 1990. *

Hu, Qing, and Richards, P. L., "Quasiparticle Mixers and Detectors," in Modern Superconducting Devices, eds. Steven T. Ruggiero and David A. Rudman, pp. 169-196, Academic Press, San Diego, California 1990. ${ }^{\dagger}$

LBL Reports

Phelps, R. B., and Richards, P.L., "Heat Capacity of Adsorbed H2 on Evaporated Ag Films," Bull. Am. Phys. Soc., vol. 35, p. 593, 1990.

Hu, Qing, Mears, C. A., Richards, P. L., and Lloyd, F. L., "Observation of Quantum Susceptance in Superconducting Tunnel Junctions," Bull. Am. Phys. Soc., vol. 35, p. 202, 1990, ${ }^{\dagger}$

Mears, C. A., Hu, Qing, Richards, P. L., Worsham, A., and Prober, D. E., "Quantum Limited Quasiparticle Mixers Using Tantalum Junctions," Bull. Am. Phys. Soc., vol. 35, p. 378, 1990.

Miller, D., Richards, P. L., Etemad, S., Venkatessan, T., Nazar, L., Dutta, B., Wu, X.D., Inam, A., Spielman, S. R., and Geballe, T. H., "Infrared Absorptivity Measurement on Thin Film YBa2 Cu3O7-d," Bull. Am. Phys. Soc., vol. 35, p. 719, 1990.

Verghese, S., Richards, P. L., Sachtjen, S. A., Char, K., and Newman, N., "Low Frequency Voltage Noise Measurements in HTSC Thin Films," Bull. Am. Phys. Soc., vol. 35, p. 425, 1990. $\ddagger$

Creager, W.N., Richards, P. L., and Zettl, A., "Far Infrared Transmittance and Reflectance of the Charge Density Wave Material TaS3," Bull. Am. Phys. Soc., vol. 35, p. 353, 1990.

Mears, C.A., Hu, Qing, Richards, P.L., Worsham, A., Prober, D.E., and Räisänen, A.V., "Quantum Limited Heterodyne Detection of Millimeter Waves Using Superconducting Tantalum Tunnel Junctions," Appl. Phys. Lett. (In press.)

Mears, C.A., Hu, Qing, Richards, P.L., Worsham, A., Prober, D.E., and Räisänen, A.V., "Quantum Limited Quasiparticle Mixers at $100 \mathrm{GHz}$," Applied Superconductivity Conf. Proc., IEEE Trans. Magn. (In press.)

Nahum, M., and Richards, P.L., "Design Analysis of a Novel Low Temperature Bolometer," Applied Superconductivity Conf. Proc., IEEE Trans. Magn. (In press.)

Mears, C.A., Hu, Qing, and Richards, P.L., "The Effect of the Quantum Susceptance on the Gain of Superconducting Quasiparticle Mixers," Applied Superconductivity Conf. Proc., IEEE Trans. Magn. (In press.)

Creager, W.N., Richards, P.L., and Zettl, A., Far Infrared Conductivity of TaS3: Identification of the Intrinsic Charge Density Wave Excitation Modes, Phys. Rev. Lett. (In press.)

* Supported in part by the U.S. National Aeronautics and Space Administration

+ Supported in part by the Department of Defense

+ supported in part by LBL Exploratory Research and Development Funds 
Timble, P. T., Searching for Anisotropy in the Cosmic Background Radiation, Seminar, Physics Department, University of Washington, Seattle, WA, March, 1990.

Richards, P.L., Rocket and Balloon Measurements of the CMB,NASA Ames Rescarch Center Colloquitum, Moffett Field, CA, March, 1990.

Richards, P.L., Measurements of the Cosmic Microwave Background, Physical Sciences Colloquium, IBM Thomas J. Watson Rescarch Center, Yorktown Heights, NY, March, 1990.

Richards, P.L., Rocket and Balloon Measurements of the CMB, Physics Colloquium, Univ, of Washington, Seattle, WA, April, 1990.

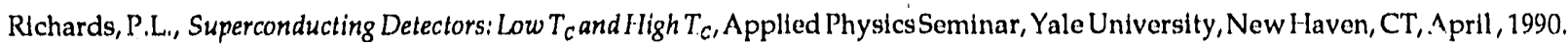

Mears, C.A., Quantum Limited Quasiparticle Mixers at $100 \mathrm{GHz}$, Applied Superconductivity Conference, Snowmass Village, Aspen, CO, September, 1990.

Contributed Talks

Timbie, P. T., CBR Anisotropy Results from Saskatoon, Aspen Winter Physics Conference, Aspen, CO, January, 1990.

Phelps, R. B., Heat Capacity of Adsorbed H 2 on Evaporated Ag Films, American Physical Society March Meeting, Anaheim, C.i, March, 1990.

Hu, Qing, Observation of Quantum Susceptance in Superconducting Tunnel Junctions, American Physical Society March Meeting, Anaheim, CA, March, 1990.

Mears, C.A., Quantum Limited Quasiparticle Mixers Using Tantalum Junctions, American Physical Socicty March Meeting, Anaheim, CA, March, 1990.

Verghese, S., Low Frequency Voltage Noise Measurements in HTSC Thin Films, American Physical Society March Meeting, Anaheim, CA, March, 1990.

Creager, W.N., Far Infrared Transmittance and Reflectance of the Charge Density Waze Material TaS3, American Physical Society, March, Meeting, Anaheim, CA, March, 1990.

Nahum, M., Design Analysis of a Novel Low Temperature Bolometer, Applied Superconductivity Conference, Snowmass Village, Aspen, CO, September, 1990.

Hu, Qing, The Effect of the Quantum Susceptance on the Gain of Superconducting Quasiparticle Mixers, Applied Superconductivity Conference, Snowmass Village, Aspen, CO, September, 1990. 


\section{Experimental Solid State Physics and Quantum Electronics}

Y. R. SHen, PRincipal InVEstigator

The general objective of this program is to study laser interaction with matter and to develop and apply modern optical techniques to studies of materials. Work is being carried out in both theory and experiment. Over the past several years, optical second harmonic generation has been developed as a powerful and versatile probe for surfaces and interfaces in our laboratory. More recently, the method has been generalized to infrared-visible sum-frequency generation used for surface vibrational spectroscopy. Current projects are focused on using these techniques to study orientation, conformation, and interaction of molecules adsorbed at various interfaces and to probe adsorption, desorption, and diffusion of atoms and molecules on metal surfaces in ultrahigh vacuum. Other surface dynamic processes such as surface photon echoes are being explored.

\section{A Nonlinear Spectroscopic Study of Coadsorbed Molecular Monolayers: Conformation and Interaction J.Y. HUANG, R. SUPERFINE, AND Y.R. SHEN}

In recent years, we have demonstrated that surface second harmonic generatic ? (SHG) is a valuable and versatile probe of monolayer systems, and its extension to infrared-visible sum frequency generation (SFG) makes surface vibrational spectroscopy possible. We now show that SHG and SFG simultaneously allow us to learn about the orientation and conformation of pure molecular monolayers and interaction between diffarent molecular species in mixed monolayers.

Figure 1 shows the $\mathrm{CH}$ spectra of a half monolayer of pentadecanoic acid (PDA) on water, a full monolayer of DMOAP $\left[\mathrm{CH}_{3}\left(\mathrm{CH}_{2}\right)_{17}(\mathrm{Me})_{2} \mathrm{~N}^{+}\left(\mathrm{CH}_{2}\right)_{3} \mathrm{Si}(\mathrm{OMe})_{3} \mathrm{Cl}^{-}\right]$on glass, and a 0.7 monolayer of octyl-cyanobiphenyl $(8 \mathrm{CB})$ on a DMOAP-coated glass. It is seen that the spectrum of DMOAP is very similar to that of PDA. This is because

Figure 1

(a) Spectrum of PDA monolayer on water surface at density of $47 \mathrm{~A}^{2} /$ molecules. (b) Comparison of SFG spectrum of SMOAP on clean glass (open circles) and spectrum of same sample after deposition of .7 monolayer of $8 \mathrm{CB}$ (filled circles). (XBL 903-5456)

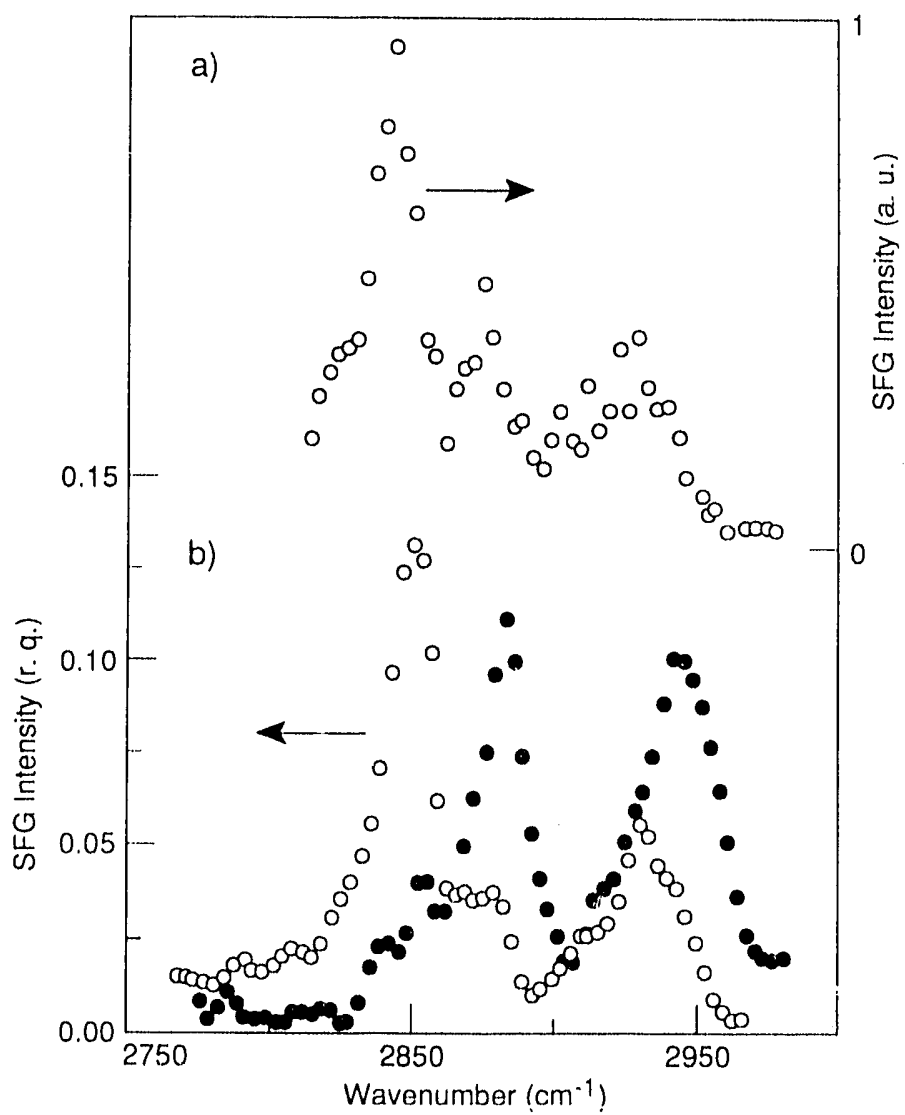


Figure 2

$F G$ spectrum at $\mathrm{CH}_{3}$ vs resonance for PDA monolayer on water. Both curves are from a fit of the SFG intensity to Eq. (3).

(XBL-903-5451)

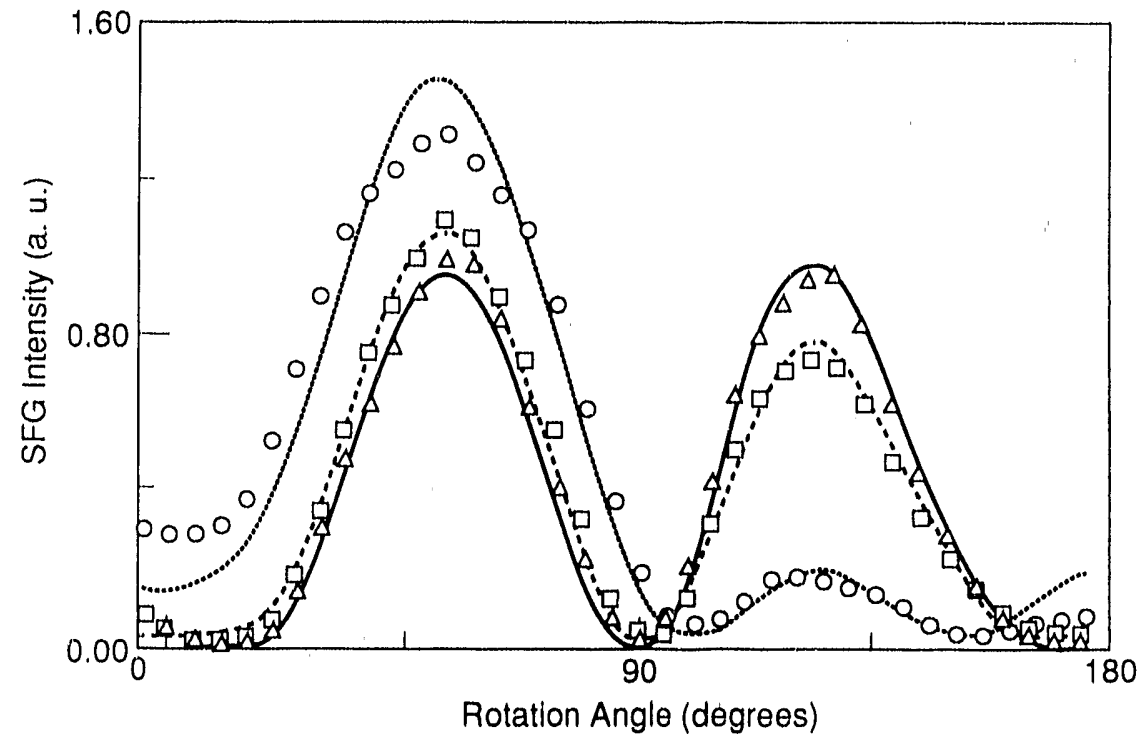

the alkane chain densities of the two cases are nearly the same. Their spectra indicate that the chains have a significant amount of trans-gauche defects. In comparison, the spectrum of $8 C B$ deposited on DMOAP-coated glass (8CB/D) shows clear evidence of interaction between $8 \mathrm{CB}$ and DMOAP. The $8 \mathrm{CB}$ molecules must have penetrated the alkyl chain layer to adsorb on the head groups of DMOAP or glass and via interaction, straighten the alkane chains of DMOAP.

These results together with other SHG and SFG measurements of $8 \mathrm{CB}$ on different substrates provide a detailed picture of the interfacial structure of cyanobiphenyl systems. The existence of interaction between the $8 \mathrm{CB}$ monolayer and the surfactant treated glasses reveals the importance of competing effects of surface polar adsorption sites and surfactant alkyl chains in aligning bulk liquid crystals.

\section{Experimental Determination of the Sign of Molecular Dipole Moment Derivatives- An Infrared Visible Sum Frequency Generation Absolute Phase Measurement Study R. SUPERFINE, J.Y. HUANG AND Y.R. SHEN}

Knowledge of the bond dipole, bond polarizability, and their derivatives with respect to the normal mode coordinates is important for the understanding of molecular structure. They have been intensely studied in the past. Although the magnitudes of these quantities are accessible through standard techniques, the experimental determination of their sign has proven much more difficult. However, it is well known that coherent nonlinear optical techniques can measure the phase of a material response. Knowing the polar orientation of the monolayer, the sign of the surface nonlinear susceptibility $\chi_{\mathrm{s}}$ obtained directly from infrared-visible sumfrequency generation measurements (see Figure 2) directly determines the relative sign of the derivatives of the dipole moment and polarizability, $\partial \mathrm{m} / \partial \mathrm{Q}$, respectively, with respect to the normal mode. When the sign of one of these quantities is well established, the sign of $\chi_{s}$ allows us to determine the sign of the unknown quantity.

We have applied the technique to the determination of signs of $\partial \mu / \partial Q$ for the symmetric $\mathrm{CH}_{3}$ stretch of the $\mathrm{C}-\mathrm{CH}_{3}$ group and of the $\mathrm{O}-\mathrm{CH}_{3}$ group. For the alkane methyl group $\left(\mathrm{C}-\mathrm{C}-\mathrm{H}, \mathrm{sp}^{3}\right)$, our result of $\partial \mu_{\xi} / \partial \mathrm{r}<0$ is in agreement with the ab initio calculations. ${ }^{2}$ For the methoxy group $\left(\mathrm{O}-\mathrm{C}-\mathrm{H}, \mathrm{sp}^{3}\right)$, we have $\partial \mu_{\xi} / \partial \mathrm{r}>0$, but the corresponding $a b$ initio calculation is not yet available. The different signs of $\partial \mu_{\xi} / \partial \mathrm{r}$ in the two cases are consistent with the trend noted in theoretical studies of $\partial \mu_{\xi} / \partial \mathrm{r}$ becoming more positive with the increasing electronegativity of the substituent $X$ in $\mathrm{X}-\mathrm{C}-\mathrm{H} .{ }^{3}$ To our knowledge, this represents the most direct determination of the sign $\partial \mu / \partial Q$ by experiment. 


\section{Phase Measurement for Surface Infrared-Visible Sum-Frequency Generation \\ R. SUPERFINE, J.Y. HUANG, AND Y.R. SHEN}

Coherent nonlinear-optical measurements have allowed us to deduce separately the amplitude and phase of a nonlinear susceptibility $\chi^{\mathrm{NL}}$ of a material system, both of which carry useful information about the material. For example, infrared-visible sum-frequency generation (SFG) spectroscopy can yield the vibrational spectrum of a surface monolayer of molecules and the orientation of a group of atoms in these molecules through $\left|\chi^{\mathrm{NL}}\right|$, and the phase of $\chi^{\mathrm{NL}}$ determines the polarity of the orientation of the atomic group. The latter information, though important for the understanding of many problems in surface science, cannot be obtained by the more conventional techniques. While phase measurements on surface $\chi^{\mathrm{NL}}$ have been reported with surface second-harmonic generation by a number of researchers, none has so far been attempted in surface SFG.

We have developed two nonlinear interference techniques that can determine the phases of $\chi^{\mathrm{NL}}$ in surface SFG and hence the polar orientations of specific atomic groups in the adsorbed molecules. We have used the techniques to find out that the alkane chains of cyanobiphenyl molecules adsorbed on water or glass are pointing away from the surface.

\section{Surface Photon Echoes in the Infrared Range \\ X.D. ZHU AND Y.R. SHEN}

We have explored the possibility of using infrared photon-echoes to study surface vibrational relaxations. As is well known, the technique has been widely adopted for studies of relaxations of excitations in bulk samples. Applications of the same technique to surface excitations, however, have not yet been demonstrated. The main difficulty lies in the fact that the total number of excited molecules in a surface monolayer is much smaller than in a bulk. This, together with the lower oscillator strengths of vibrational excitations compared to electronic excitations, results in rather weak IR photon echoes which are difficult to detect because of the lack of sensitive IR detectors. Nevertheless, our estimates show that photon echoes from surface vibrational excitations should be detectable. We consider three different schemes that could work with a sufficient signal-to-noise ratio: one with a sensitive IR detector, one with an in-situ up-conversion scheme, and one with an external upconversion of the signal.

Up-conversion is inherently an optical gating process, and is naturally suited for detection of surface echoes. The external up-conversion scheme converting the IR echo signal in a nonlinear crystal is most promising because the high conversion efficiency could lead to a very high signal-to-noise ratio. However, it is not capable of providing discrimination against bulk emission. The in-situ up-conversion at the surface has the advantage of being an inherently surface-specific process. Although the signal-to-noise ratio is worse because of the greatly reduced conversion efficiency, this latter scheme will be far superior in cases where bulk emission is overwhelming.

\section{Multipolar Contributions to Optical Second-Harmonic Generation in Isotropic Fluids} $X . D . Z H U$ AND Y.R. SHEN

In this work we have demonstrated that higher-order multipole, especially electric-quadrupole contributions to SHG in an isotropic bulk medium are generally nonvanishing, and the' $y$ are usually present in surface SHG from such a medium. 


\author{
Investigator \\ Y. R. Shen \\ Visiting Scientists \\ J. Y. Huang \\ W. Daum
}

Graduate Students

R. Superfine

M. B. Foller

$X . D$. Xiao

X. D. Zhu

Administrative Assistant

R. Jonos

\section{Awards}

- Y.R. Shen was elected to American Academy of Arts and Sciences.

- Y.R. Shen was elected to Academia Sinica, Rep. of China.

- Y.R. Shen was appointed to the International Scientific Advisory Board for the Max-Planck-Institut fur Quantenoptik.

- J. Y. Huang received an IBM Postdoctoral Fellowship.

\section{Publications and Reports}

Refereed Journal Articles

Zhu, X. D. and Y. R. Shen, "Multipolar Contributtons to Optical Second-Harmonic Generation in Isotropic Fluids," Phys, Rev. A (Comment), vol, 41, p.4549, 1990. Zhu, X. D. and Y. R. Shen, "Surface Photon Echoes in the Infrared Range," Appl. Phys. $B$ vol. 50, p.535, 1990 .

Superfine, R., J.Y. Huang, and Y. R. Shen, "Phase Measurement for Surface Infrared Sum-Frequency Generation," Optics Lett., vol.15, p.1276, 1990.

Huang, J. Y., R. Superfine, and Y. R. Shen, "Nonlinear Spectroscopic Study of Coadsorbed Liquid Crystal and Surfactant Monolayers: Conformation and Interaction," Phys. Rev. A (Rapid Commun.), vol.42, p.3660), 1990.

Superfine, R., J. Y. Huang, and Y. R. Shen, "Experimental Determination of the Sign of Molecular Dipole Moment Derivatives: An Infrared Visible Sum Frequency Generation Absolute Phase Measurement Study," Chem. Phys. Lett. vol.172, p.303, 1990.

Shen, Y. R., "Laser Studtes of Polaritons," Mod. Phys. Lett. B vol.4, p.159, 1990.

Other Publications

Shen, Y. R., "Nonlinear Optical Techniques for Surface Studies," in Spectroscopic and Diffraction Techniques in Interfacial Lilectrochemistry, eds. C. Gutterrez and C. Melendres, p.281, Kluwer Academic Publishers, Dordrecht, 1990.

Superfine, R., J. Huang, and Y. R. Shen, "Phase Measurements of Surface Infrared-Visible Sum-Frequency Generation: Determination of Polar Orientation of Molecules at Surfaces," Tech. Dig. Series, vol. 8, p.256,1990).

Zhu, X. D., W. Daum, X. D. Xiao, and Y. R. Shen, "Interference Method for Studles of Molecular Adsorption at Surfaces by Second Harmonic Generation," Tech. Dig. Series 1990, vol.8, p.258, 1990.

Zhu, X. D., W. Daum, X. D. Xiao, and Y. R. Shen, "Optical Second-Harmonic Generation from a Clean and CO-Covered Ni(110) Surface," Bull. Am. Phys. Soc,, vol. 35, p.218, 1990.

Superfine, R., J. Huang, and Y. R. Shen, "Polar Ordering of Molecules at a Neat Liquid Surface," Bull. Am. Phys. Soc., vol. 35, p,347, 1990.

Shen, Y.R., "Return to the Classics," in Resonances, eds. M. D. Levenson, E. Mazur, P. S. Pershan, and Y. R. Shen, p.99, World Scientlflc Pub., Singapore, 1990.

LBL. Reports

Shen, Y. R., LBL-28526, "Nonlinear Optical Studies of Molecular Adsorbates," in Laser Optics of Condensed Matter. (In press.)

Shen, Y. R., LBL-29266, "Surface Nonlinear Optics and Applications," in Proceedings of les Houches Summer School. (In press.)

Shen, Y. R., LBL-29268, "Wave Mixing and Coherent Transient Spectroscopy," in Proceedings of Les Houches Summer School. (In press.)

Shen, Y, R., LBL-29269, "Multiphoton-Photon Ionization of Atoms," in Proceedings of Les Houches Summer School. (In press.)

Superfine, R., J. Y. Huang, and Y. R. Shen, LBL.29686, "Nonlinear Optical Studies of the Pure Liquid/Vapor Interface: Vibrational Spectra and Polar Ordering," Phys. Rev. Lett. (In press.)

Zhu, X. D., W. Daum, X. D. Xlao, R. Chin, and Y. R. Shen, LBL-30018, "Coverage Dependence of Surface Optical Second Harmonic Generation from CO/NI (110): Investigation with a Nonlinear Interface Technique," Phys. Rev. B. (In press.)

Xiao, X. D., X. D. Zhu, W. Daum, and Y. R. Shen, LBL-30019, "Anisotropic Surface Diffusion of CO on Ni(11())," Phys. Rev. Lett. (In press.) 
Shen, Y. R, "Nonlinear Optical View of Surfaces," Physles Colloqulum, Univ, of Michigan, Ann Arbor, MI, February 1990.

Shen, $Y, R_{1}$, "A Nonlinear View of Molecules Bounded to a Surface," Pittsburgh Conforonce on Analytical Chemistry and Applled Spoctroscopy, New York, NY, March 1990.

Shen, Y. R., "Nonlinear Optical Study of Materials," Combustion Dynamics Facillty Workshop, Borkeley, CA, April 1990.

Shen, Y. R., "Surface Studies with Nonlinear Optical Techniques," Seminar, Univ, of Callf, Riverside, CA, April 1990.

Shen, Y. R., "Probing Surfaces Nonlinearly," French-Israell Symposium on Nonlinear Optlcs, Tiberlas, Israel, April 1990.

S.uperfine, R., J. Huang, and Y. R. Shen, "Phase Measurements of Surface Infrared-Visible Sum-Frequency Generation: Determination of Polar Orientation of Molecules at Surfaces," XVII International Quantum Electronles Conference, (Paper QThK2), Anahelm, CA, May 1990,

Superfine, R. and Y. R. Shen, "Monolayer Studies by Nonlinear Optical Techniques," XIII Surface/Interface Research Meeting of the NCCAVS, Menlo Park, CA, June 1990.

Shen, Y, R, "Surface Nonlinear Optics and Applications, "Les Houches Summer School on "Fundamental Systems in Quantum Optics," Les Houches, France, June-July 1990.

Shen, Y. R., "Wave Mixing and Coherent Transient Spectroscopy," Les Houches Summer School on "Fundamental Systems in Quantum Optics," Les Houches, France, June-July 1990.

Shen, Y. R., "Multiphoton-Ionization of Atoms," Les Houches Summer School on "Fundamental Systems in Quantum Optics," Los Houches, France, June-July 1990.

Shen, Y. R., "Surfacc Nonlinear Optics for Material Studies," Plenary talk, Conference on Nonlinear Optissi Materials, Phenomena, and Devices," Kauai, HI, July 1990.

Feller, M. B., W. Chen, and Y. R. Shen, "The Study of Surface-Induced Molecular Allgnment by a Non-linear Optical Technique," Appllod Optics and Opto-Electronics Conference, Nottingham, England, September 1990.

Shen, Y. R., "Surface Instrumentation and Laser Optics," Advisory Board Review on Surface Science, Lawrence Berkeley Laboratory, Berkeley, CA, October 1990.

Shen, Y. R., "Nonlinear Optical Characterization of Surface Molecular Monolayers," International Symposium on Nonlinear Optical Materials, El Paso, TX, October 1990.

Shen, Y. R., "Nonlinear Optical Techniques for Investigation of Surfaces and Interfaces," Annual Meeting of the Optical Society of America, Boston, MA, November 1990.

Shen, Y. R., "Nonlinear Optics," Seminar, Raychem Corporation, Menlo Park, CA, November 1990.

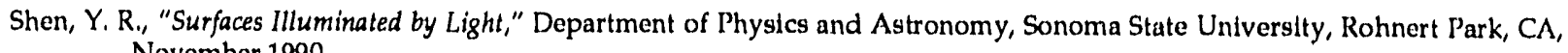
November 1990.

Contributed Talks

Zhu, X. D., W. Daum, X. D. Xlao, and Y. R. Shen, "Optical Second-Harmonic Generation from a Clean and CO-Covered Ni(110) Surface," March Meeting of the American I ysical Society, Anaheim, CA, March 1990.

Superfine, R., J. Huang, and Y. R. Shen, "Polar Ordering of Molecules at a Neat Liquid Surface," March Meettng of the American Physical Soclety, Anaheim, CA, March 1990,

Shen, Y. R., R. Superfine, and J. Huang, "Up or Down? Molecular Polar Orientation Determined by Infrared-Visible Sum-Frequency Generation Phase Measurement," March Meeting of the American Physical Soclety, Anaheim, CA, March 1990.

Huang, J., R. Superfine, and Y. R. Shen, "Conformation, Orientation, and Interaction in Liquid Crystul Monolayers," March Meeting of the American Physical Society, Anaheim, CA, March 1990.

Zhu, X. D., W. [Jaum, X. D. Xiao, and Y. R. Shen, "Interference Method for Studies of Molecular Adsorption at Surfaces by Second Harmonic Generation," XVII International Quantum Electronics Conference, Anaheim, CA, May 1990. 


\section{Time-Resolved Spectroscopies in Solids}

Peter Y. YU, Principal InVestigator

\section{Relaxation of Photoexclted Hot Electrons and Phonons in Semlconductors D.S. KIM, P.Y, YU}

The purpose of this project is to study ultrafast processes in bulk semiconductors and in semiconductor quantum wells fabricated from $\mathrm{GaAs}$ and related compounds. Short laser pulses are used to excite dense electron-hole plasmas in the sample. The dynamics of the excited hot electron and hot optical phonons are studied by timeresolved Raman scattering or photoluminescence.

The cooling of hot electrons in bulk GaAs and InGaAs has been studied with subpicosecond Raman scattering. In both materials the cooling of hot electrons within one picosecond has been shown to be dominated by intervalley scattering. The strength of the intervalley electron-phonon interaction has been determined for the first time in InGaAs. The generation of hot phonons by hot electrons in GaAs/AlAs quantum wells have been studied as a function of well width. It has been found that the phonon generation efficiency decreased as the well width was decreased. This result is in good agreement with theory based on the Frohlich electron-phonon interaction.

\section{Defects in Semiconductors \\ M.F. LI, P. SEGUY AND P.Y. YU}

The objective of this project is to study the properties of defects in semiconductors using optical and electrical techniques in conjunction with uniaxial and hydrostatic stress.

A new metastable level related to the DX center have been observed in SI doped $\mathrm{GaAlAs}$ but not in Te doped samples. The properties of this level can be explained by a complex consisting of a substitutional Siand an adjacent As atom displaced into an interstitial site.

The effect of uniaxial stress on the DX center in GaAlAs alloy doped with Te has been measured. The results are consistent with a model of the DX center proposed by Chadi and Chang but not with models in which the DX center does not have large lattice relaxations.

\section{Properties of Matter under High Pressure \\ T. CHEN AND P.Y. YU}

In this project diamond anvil cells are used to apply high pressure to materials in order to modify their properties. Many materials undergo structural phase transitions under pressure. As a result of such structural phase transition, insulators often transform in metals. Some of these high pressure metallic phases possess interesting properties such as superconductivity.

A technique has been developed to perform four-terminal resistivity measurements inside the diamond anvil cell. This techniques has been applied to determined the insulator to metal transition in an anti-ferrromagnet $\mathrm{NiI}_{2}$ at pressures above 190) kilobars. Associated with this transition $\mathrm{NiI}_{2}$ changes from an antiferromagnet to a diamagnet. The unusual feature of this phase transition is that the $\mathrm{NiI}_{2}$ crystal structure remain unchanged. This transition has been explained by a pressureinduced Mott transition of the $\mathrm{Ni}$ ions. As the Ni ion separations are reduced by their pressure, the $\mathrm{Ni} 3 \mathrm{~d}$ electrons changed from their localized magnetic state to a diamagnetic delocalized state. The transition is purely electronic and therefore involves no change in crystal structure. 
Principal Investigator

Peter Y, Yu

Visiting Scientists

Prof. Ming-fu Li (Beljing, China)

Graduate Students

Toblas Ruf

Patrice Seguy (Gronoble, Franco)

Dai-sik Kim

Tony Chon

Kolth Wald

Awards

- Peter Yu was awarded a Millor Research Profossorship, Millor Instituto for Basic Research in Science, Unlversity of Californla at Borkoley.

\section{Publications}

\section{Refereed Journal Articles}

KIm, D.S, and P.Y. Yu, "Phonon Temperature Overshoot in GaAs exclted by Subplcosecond Lasor Pulses," Phys, Rev. Lett. Vol. 64, p.946, 1990.

$\mathrm{KIm}$, D.S, and P.Y, Yu, "Study of Cooling of Hot Carriors and Intervalloy Scattoring $\operatorname{In} \operatorname{In} 0.53 \mathrm{Ga}$. $47 \mathrm{As}$ by Subpicosecond Raman Scattering," Appl. Phys. lett. Vol.56, p.1570, 1990.

Goldstein, H.F, D. S. Kim, Peter Y. Yu, L. C. Bourne, J-P. Chaminade and Leon Nganga, "Raman Study of CuO Single Crystals," Phys, Rev. B Vol.41, p.7192, 1990.

KIm, D.S. and P.Y. Yu, "Subplcosecond Cooling of Photoexcited Hot Carrlers Studied by One-beam Exclte-and-probe Raman scattering," Appl. Phys. Lett. Vol. 56, p.2210, 1990.

Pasternak, M., R.D. Taylor, A. Chen, C. Meade, L. M. Falicov, A. Glesekus, R. Jeanloz, and P.Y. Yu, "Pressure Induced Metallization and the Collapse of the Magnettc State in the Antiferromagnettc Insulator NiI2," Phys, Rev, Lett. Vol. 65,p, 790, 1990.

Seguy, P., P.Y. Yu, M. F, LI, R. Leon and K. T. Chan, "Effect of Light on the DX Contors In S1 and Te Doped GaAlAs," Appl, Phys, Lett. Vol.57, p.2469, 1990.

Refereed Comference Proceedings

KIm, D.S, and P.Y, Yu, "Study of Hot Carrior Relaxation in Quantum Wells by Subplcosecond Raman Scattoring, Ultrafast Laser Probe Phenomena in Bulk and Microstructure Semlconductors III, ed. by Robert R. Alfano SP'IE Proceeding Serles, Vol. 1282, p.39, 1990.

Thesis

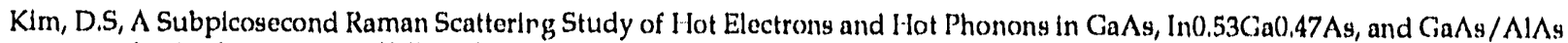
Multiple Quantum Wolls, (Ph. D. Thesis, Department of Physies, University of Callfornia, Berkeley. Advisor: P.Y, Yu.)

LBL. Reports

KIm, D.S, and P.Y. Yu, "Subpicosecond Raman Study of Hot Electrons and Hot Phonons In GaAs," Proc. of NATO Advanced Research Workshop Light Scattering in Semiconductor Structures and Superlattices, ed, by J.F. Young and D.L. Lockwood (In press.)

KIm, D.S. and P.Y. Yu, "Study of Hot Electron Relaxation and Hot Phonons in GaAs by Subplcosecond Raman Scattering," Phys, Rev, (In press.)

Seguy, I' and P.Y. Yu, "Optical Excitation of DX Centers in GaAlAs Alloys doped with SI and Te," proprint LBLL-29886.

Yu, P. and M.F. LI, "Pressure dependence of deep centers by capacitance spectroscopies inside the dlamond anvil cell," preprint LBL29888.

Li,M.F., P.Y, Yu, E. Bauser, W.L. Hansen and E. E. Haller, "Deep Level Transient Spectroscopy of DX Centers in A10,38Cia0,62 As:Te under Uniaxial Stress," Preprint LBL-29887.

LI,M.F, P.Y. Yu, Y.B. Jia, J. Zhou and J.L. Gao," Reply to "Comment on 'Negative U Property of the DX Center in AlxCa1-xAs:Si'," Phys. Rev. (In press.) 
Yu, P,Y, Studying Hot Electron Relaxation and Ilot Phonons in Bulk and MQW of GaAs with Subpicosecomd Raman Scatterins, Clarondon Laboratory, Oxford Unlvorsity, Oxford, England, July, 1990.

Yu, Y.Y, Studying Hot Electront Relaxation and Hot Phonons in Bulk and MQW of GaAs with Subpicosacond Raman Scatlaring, Cavondish Laboratory, Cambridgo Univorsity, Cambridgo, England, July, 1990,

$Y_{u}$, P,Y, Pressure Dependence of Deep Centers by Capacitance Spectroscoptes inside the Diamond Anvil Cell, Fourth Intornational Conforonco on Hilgh Pressuro In Somlconductor Physliry, Porto Carras, (Grooco, August 1990.

$Y_{u}, P_{1} Y_{1}$, Studying Hot Electron Relaxation and Hot lhonons in Bulk and MQW of GaAs with Subplcosecond Raman Scaltering, Dopartmont of Physles, Brown University, Providunce, R.1, Oct, 1990,

Yu, P,Y, DX Centers in AlGaAs Have Small or Large Latlice Relaxations?, Xorox Palo Alto Research Contor, Palo Alto, Ca, Oct, is,90,

Yu, P,Y, Condensed Matler Physics under High Pressure, Colloqulum, Dopartmont of Physlcs, Univorslty of Mistourl-Columbla, Columbla, Missourl, Doc, 1990. 


\section{Superconductivity, Superconducting Devices, and 1/f Noise}

This program is focussed on understanding fundamental phenomona in suporconductors, and on the application of these phenomena to novel devices and the measurement of ultrasmall signals. At present, the program has threc major compononts. The first involves tunnel functions of submicron dimensions, and the novel effects that occur when the energy associated with the transfer of a single electron $\left(\mathrm{c}^{2} / 2 \mathrm{C}\right.$, where $\mathrm{C}$ is the capndtance) is much less than the thermal energy $\left(\mathrm{k}_{11} \mathrm{~T}\right.$, where $\mathrm{T}$ is the temperature). The second is concerned with low-transition temperature $\left(T_{c}\right)$ Superconducting QUantum Interference Devices (SQUIDs) and their applications to ultrasonsitive measurements that are inaccessible to any other device. The third component of the program is focussed on fundamental noise properties of high- $\mathrm{T}_{\mathrm{c}}$ thin-films and the application of these films to prototype devices and is discussed in the section devoted to the CAM High- $T_{\mathrm{a}}$ Superconductivity Program.

\section{Resonant Tunneling in a Current-Blased Josephson Junction J. SCHMIDT, A. CleLLAND AND J. Cl.ARKE}

A current-biased Josephson junction has been shown to be a macroscopic system which exhibits quantum effects. The phase difference $\phi$ between the supcrconducting condensates in the electrodes obeys an equation of motion identical to that of a particle moving in a cosine potential that is tilted in proportion to the bias current. Quantized energy levels exist in the potential wells, and a particle initially trapped in a well can tunnel through the potential barrier to run frecly down the potential, resulting in a nonzero junction voltage. Recently it has been predicted that in addition to this tunneling to the free running state, tunneling will occur resonantly between states of adjacent wells for values of blas currents where the energles of these states are equal.

We have undertaken a theoretical study to determine the experimentally observable effects resulting from resonant tunneling. We have shown that resonant tunneling provides a new mechanism by which the particle can make the transition to the free running state, and have calculated the rate of this transition as a function of the bias current. Peaks which correspond to the alignment of energy levels occur in this distribution. This non-monotonic behavior is distinct from that resulting from thermally induced switching or direct quantum tunneling, and provides a unique signature for the existence of resonant tunneling in this system.

We are now carrying out low temperature $(20 \mathrm{mK})$ experiments on $\mathrm{Al}-\mathrm{Al}$-oxlde-Al tunnel junctions in an attempt to observe these switching characteristics.

Figure 1

Sohematio representatlon of resonant tunneling in a current-blased Josephson Junotion. Path $B$ represents a sequence of resonant tunnellng events whloh causes the junction to switch to the tree running state. (XBL 906-5537)

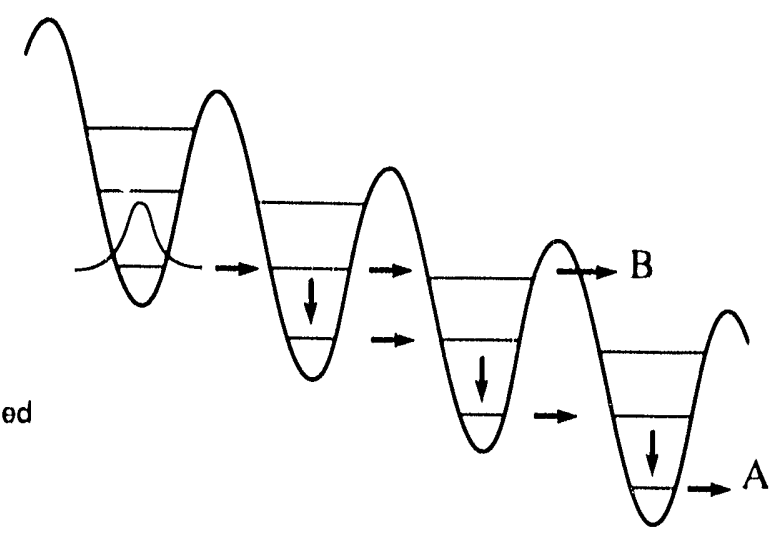



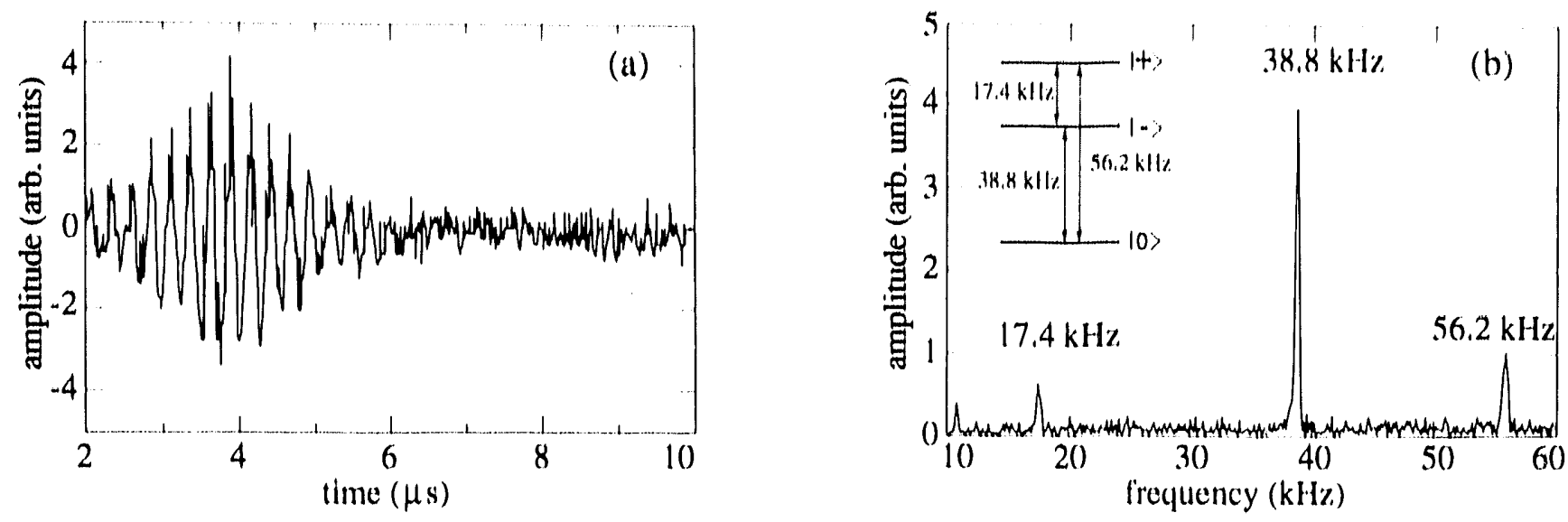

Flgure 2

(a) Spin echo of ${ }^{14} \mathrm{~N}$ nuolel in $\mathrm{NH}_{4} \mathrm{ClO}_{4}$ obtained from real-4lme slgnal demodulated with $35 \mathrm{kHz}$.

(b) Fourler transform of spin echo. The three resonant peaks are due to transitlons between energy levels (shown inset) of ${ }^{14} \mathrm{~N}$ nuclel in presenoe of eleotrlo fleld gradlent $\ln \mathrm{NH}_{4} \mathrm{ClO}_{4}$. In Inset, $|0>=| 10>$ and $\mid \pm>=(|11> \pm| 1-1>) \sqrt{2}$, where symbol $\mid 1 \mathrm{~m}>$ is the elgenstate of

${ }^{14} \mathrm{~N}$ nuolel $(I=1)$ with $I_{2}=\mathrm{m}$. (XBL 906-5595A)

\section{Zero Fleld NMR and NQR with a do SQUID}

N. Fan, M. Hürlimann, C. Pennington and J. Clafke

NMR spectra of powdered sollds in a strong applied magnetic field are broadened by the anisotropic frequency shifts that result from magnetic dipole-dipole and electric quadrupole interactions. The random orientation of crystallites with respect to the applied field gives a broad spread of resonance frequencles, often obscuring important information. In zero applied ficld such broadening is not present, since in the absence of an applied field all crystallites are equivalent. We have developed a versatile spectrometer for pulsed zero field NMR and NQR studies in the frequency range $10-200 \mathrm{kHz}$. Because the signals generated at these low frequencles are extremely weak, we use a low- $\mathrm{T}_{\mathrm{c}} \mathrm{dc}$ SQUID as an amplifier; this amplifier has much lower nolse than any other amplifier in this frequency range.

As an example of the sensitivity of our spectrometer, we have measured the zero field spectrum of $\mathrm{NH}_{4} \mathrm{ClO}_{4}$ at $1.5 \mathrm{~K}$ (Figure 2). The spectrum consists of three sharp ${ }^{14} \mathrm{~N}$ nuclear quadrupole resonance lines at $17.4 \mathrm{kHz}, 38.8 \mathrm{kHz}$, and $56.2 \mathrm{kHz}$, cach with a linewidth of about $0.5 \mathrm{kHz}$. These lines do not display splitting by the neighboring protons, indicating that the ammonlum lons undergo fast quantum tunneling. We have found that even low levels of deuteration strongly affect the ${ }^{14} \mathrm{~N}$ resonance frequencies and relaxation times. For example, $4 \%$ deuteration results in an increase in the transverse relaxation rate from $(42 \pm 4) \mathrm{sec}^{-1}$ to $(80 \pm 10) \mathrm{sec}^{-1}$.

This spectrometer offers a new window on low frequency magnetic resonance as a probe of weak spin-spin and electric quadrupole interactions. We are currently developing a second spectrometer that will allow us to vary the temperature of the sample between $4.2 \mathrm{~K}$ and $100 \mathrm{~K}$ and to apply a smail, stable magnetic ficld (up to 10mtesla).

Principal Investigator John Clarko

Postdoctoral Fellows Martin Hürlimann Charles Pennington

\author{
Graduate Students \\ Androw Cloland \\ Non Fan \\ Michad Hoanoy \\ John Schmidt
}

Administrative Assistant

Barbara Sallsbury 


\section{Publications and Reports \\ (Sec also CAM High-T, Superconductivity Program.)}

Referead Journal Articles

Cloland, A, N, J, M. Schmidt, and J, Clarko, "Chargo Fluctuatlons In Small Capadtanco Junctions," I'hys, Rev, Lelt, 64, 1565 (1990),

Theses

Fan, N., Low-lirequency NMR and NQR Spectrometer wilh a de SQUIID Amplifier, Novembor, 1990) (I'h. D. Thosls, Physlcs Dopartmont, U.C. Borkoloy, Advisor: J, Clarka.)

Hoanoy, M, B., Nuclear Magnetic Resonance lixperiments with da SQUID Amplifiers, Novombor, 1990)(Ph. D. Thosis, Physics Departmont, U.C. Borkeley, Advilsor: J, Clarke.)

Othar Publications

Clarko, J," "SQUIDs: I'rincifies, Noiso, and Applications," chaptor in Superconducting Devices, ods, S, T. Ruggloro and D. A. Rudman, p. 51, Acadomic Press, Inc, Boston, 1990.

LBL Reports

Bindslev Hanson, J., T. Holst, F. C. Wollstood, and J. Clarko, LBL-28891, "Low Froquoncy Nolse in Resonant Josephson Sollton Osclllators," IEIEE Trans. Magn. (Submitted.)

Cloland, A. N., J. M. Schmidt, and J. Clarke, LBL-29364, "Resonant Tunneling In Small Curront-Blased Josophson Junctlons," Ihys. Rev. B1 (In juess.)

Fan, N.Q, and J, Clarke, LBL-30090, "Low-Frequency NMR and NQR Spectrometor Based on a de SQUID," Rev, Sci. Insiru. (Submitted.)

Invited Talks

Forrari, M. J, SQUIDs: Principles, Applications, and Prospects, IEEE nstrumontation and Measurement Technology Conference, San Joso, Callfornia, Fobruary 1990.

Cleland, A. N., J. M. Schmidt, and J. Clarko, Coulomb Blockade in Single, Small Tunnel Junctions, Quantum Fluctuattons In Mesoscopic and Macroscopic Systems, Triesto, Italy, July 1990.

Fan, N. Q., Fourier Transform Zero Field NMR and NQR with de Sh UIDs, sominar at Schlumberger-doll Rosearch, September 1990.

Clarke, J., SQUID Magnetometers, Applicatlons of Metallic and Ceramle Superconductivity, NATO Advanced Study Institute, Fort Collins, CO, Septomber 1990.

Hoaney, M, Direct Detection of Transterse NMR at 32 MHz with a dc SQUID, seminar at IBM Almadon Research Center, San Jose, CA, Septomber 1990.

Fan, N. Q., Fourier Transform Zero Field NMR and NQR with de SQUIDs, sominar at Illowlett-Packard Laboratory, HIlgh-Speed Devlces Divislon, October 1990.

Heaney, $\mathrm{M}_{1}$, Direct Detection of Transverse NMR at $32 \mathrm{MH} / \mathrm{z}$ with a dc SQUID, seminar at Raychom Corporatlon, Monlo Park, CA, October 1990.

Clarke, J., Closing summary at Third International Symposium on Suporconductlvity, Sendal, Japan, November 1990.

Heanoy, M., Direct Detection of Transverse NMR at 32 Ml lz with a de SQLIID, seminar at Quantum Magnetics, San Dlego, CA, December 1990.

1 leancy, M., Direct Detection of Transwerse NMR at $32 \mathrm{Ml} / \mathrm{z}$ with a de SQUID, sominar at Intel Corporation, Santa Clara, CA December 1990.

Contributed Talks

Cleland, A. N., J. M. Schmidt, and J. Clarke, The Effect of Charge Fluctuations on the Coulomb Blockade in Small Tunnel Jumations, March Meeting of the Amorican Physical Soclety, Anaheim, CA, March 1990.

Fan, N. Q., M. D. Hilrlimann, J. Clarke, A. Pines, and E. L. Hahn, Fourier Transform Zero Field NMR and NQR with a de SQLID, March Meeting of the Amorican Physical Soclety, Anaholm, CA, March 1990.

Fan, N. Q, M. D. Hürlimann, J. Clarke, E. L. Hahn and A. P'nes, Fourier Transform Pulsed NQR with a SQLIID Detector, The Exporimental Nuclear Magnetic Resonance Conference, Monterey, CA, April 1990.

Cleland, A. N., J. M. Schmidl, and J. Clarke, Quantum Fluctuations and Coulomb Blockade in Small Tunnel Junctions, XIX International Conforence on Low Temperature ['hysics, Brighton, England, August 1990. 


\section{THEORETICAL RESEARCH \\ Theoretical Studies of the Electronic Properties of Solids and Solid Surfaces}

L. M. Falicov, Painoipal InVEgtigatoh

The purpose of this program is to study properties of solids and solld surfaces. In particular, the interest is in determining (a) structural properties, namely the organization and arrangement of atomic constituents at equilibrium; (b) constitutional properties of the bulk and surface, in particular the segregation properties of alloys at the surface as a function of crystal structure, surface orientation, nominal chemical composition, and temperature; (c) electronic structure of solids and surfaces, in particular electron states and electron densities at particular sites; (d) vibronic properties; (e) magnetic properties of solids, surfaces, thin film layers and interfaces, both in magnetic solids (ferromagnetic and antiferromagnetic) and in nonmagnetic solids that may develop a magnetic layer; and (f) chemical properties of solids - in particular their catalytic propertles - as they are related to all the basic physical properties listed above.

A variety of theoretical techniques and models have been developed to focus on the various properties (band-structure models, many-body electron physics, numerical relaxation techniques), but the emphasis is on physical aspects and their implication to experiments rather than on techniques per se.

Since 1978 a collaboration has been established with Dr. Eugene Haller and his group to study a set of unusual impurities in very pure semiconductors. These impurities include hydrogen complexes, lithium-based complexes, carbon-nitrogen complexes, and ordinary substitutional impurities in an unusual charge state.

Fiessure-Induced Metallization and the Collapse of the Magnetic Stato in the Antiferromagnetic Insulator $\mathrm{Nil}_{2}$

M. P. Pasternak, R. D. Taylor, A. Chen, Chafles Meade, L. M. Falicov, A. Giesekus, R. Jeanloz, and P. Y. Yu

The first observation of a pressure-induced metallization accompanied by the spontaneous collapse of magnetic ordering was reported. This isostructural concurrence was observed in the layered antiferromagnetic insulator $\mathrm{NiI}_{2}$. Electrical transport, $x$-ray-diffraction, and ${ }^{129} \mathrm{I}$ Mössbauer studies were carried out in diamondanvil cells. The evidence points to a mechanism by which the originally filled $5 p$ lodide band shifts and overlaps with the partially filled nickel-3d states. The formation of a hybridized conduction band at $P>19 \mathrm{GPa}$ results in the onset of a diamagnetic metallic ground state.

\section{Exact Many-Body Solution of the Perlodic-Cluster t-t'-J Model for Cublc Systems: Ground-State Proparties \\ J. K. Freericks and L. M. FalicoV}

The $t-t^{\prime}-\mathrm{J}$ model (strongly interacting limit of a particular Hubbard model) was solved exactly on small clusters of eight sites with periodic boundary conditions for the simple-, body-centered-, and face-centered-cubic lattices and for the two-dimensional square lattice. The symmetry, $k$ vector, and spin of the ground state were studied as functions of crystalline environment, interaction strength, and electron concentration. Phase diagrams are presented for stable solutions, and regions of parameter space that exhibit ferromagnetism and heavy-fermionic behavior are identified.

\section{Superconducting Vortex-Line Configurations in Materials with Twin Boundaries H. SVEnSmark and L. M. Falicov}

We have studied numerically the classical states of equilibrium, stable and metastable, of magnetic-field vortex lines in a type-Il superconductor in the presence of twin boundaries which attract the vortex lines. Depending on the value of the magnetic field and the density of the twin boundaries, a variety of situations are found. 
Among them are Abrikosov lattices, anisotropic structures in which the vortex lines are mostly localized at the twin boundaries, and a consistently large regime of disordered structures. Statistical analysis of the distributions, their energies, and their pair-correlation functions are presented.

Principal Investigator

L. M. Falicov

Postdoctoral Fellow

H. Svensmark
Graduate Students

James K. Freericks

Amitesh Maiti

Randolph Hood

Secretary

Sandra Ewing

\section{Publications and Reports}

Refereed Journal Articles

Coleman, R. V., M. P. Everson, H-A Lu, A. Johnson, and L. M. Falicov, "Effects of High Magnetic Fieids on Charge-Density Waves in NbSe3," Phys. Rev. B, vol. 41, p. 460, 1990.

Freericks, J. K. and L. M. Falicov, "Two-State One-Dimensional Spinless Fermi Gas," Phys. Rev. B, vol. 41, p. $2163,1990$.

Chrzan, D. C., L. M. Falicov, J. M. MacLaren, X.-G. Zhang, and A. Gonis, "Magnetic Structure of (111) Stacking Faults in Nickel," J. Appl. Phys., vol. 67, p. 4558, 1990.

Falicov, L. M., D. T. Pierce, S. D. Bader, R. Gronsky, K. B. Hathaway, H. J. Hopster, D. N. Lambeth, S. S. P. Parkin, G. Prinz, M. Salamon, I. K. Schuller, and R. H. Victoria, "Surface, Interface, and Thin-Film Magnetism," J. Mater. Res., vol. 5, p. $1299,1990$.

Pasternak, M. P., R. D. Taylor, A. Chen, C. Meade, L. M. Falicov, A. Giesekus, R. Jeanloz, and P. Y. Yu, "Pressure-Induced Metallization and the Collapse of the Magnetic State in the Antiferromagnetic Insulator Nil 2," Phys. Rev. Lett., vol. 65, p. 790, 1990.

Freericks, J. K. and L. M. Falicov, "Exact Many-Body Solution of the Periodic-Cluster t-t'-J Model for Cubic Systems: Ground-State Properties," Phys. Rev. B, vol. 42, p. 4960, 1990.

Svensmark, H. and L. M. Falicov, "Superconducting Vortex-Line Configurations in Materials with Twin Boundaries," Phys. Rev. B, vol. 42, p. 9957, 1990.

Chen, C., "Surface Magnetism in an Exactly Soluble Many-Body Periodic-Cluster Model of bcc Iron," Phys. Reo. B, vol. 41, p. 1320, 1990; LBL-28961.

Other P:dblications

Falicov, L. M. and D. C. Chrzan, "Incommensurable Surface Spin Structure in MnO-Type Antiferromagnets," In Magnetic Propertics of Low-Dimensional Systems II, eds. L. M. Falicov, F. Meji'a-Lira, and L. J. Morán-López, p. 86, Springer-Verlag, 1990.

Falicov, L. M., "Impacto de la Fisica en la Comprension del Mundo Contemporaneo," in Proc. of the Chilean Academy of Sciences, 1990.

Heyman, J., A. Giesekus, L. Falicov, and E. E. Haller, "Ground State Splitting of the Beryllium Double Acceptor in Silicon," Bull. Am. Pnys. Soc., vol. 35, p. 279, 1990.

Svensmark, H. and L. M. Falicov, "Superconducting Vortex Line Configurations in Materials with Twin Boundaries," Bull. Am. Phys. Soc., vol. 35, p. 260, 1990.

Freericks, J. K. and L. M. Falicov, "The Two-State One-Dimensional Spinless Fermi Já: " Bull. Am. Phys. Soc., vol. 35, p. 692, 1990.

Chrzan, D. C. and L. M. Falicov, "Magnetic Structure of (111) Stacking Faults in Nickel," Bull. Am. Phys. Soc., vol. 35, p. 374, 1990.

Bernaola, O., V. Grunfeld. and L. M. Falicov, "Enrique Gaviola" (obituary), Physics Today, vol. 43, No. 11, p. 105, 1990.

Falicov, L. M., book review, "Workshop on First-Order Displacive Phase Transformations," MRS Bulletin, vol. XV, No. 12, p. 57, 1990.

LBL Reports

Svensmark, H., LBL-29771, "Dynamical Squeezing,"

Maitl, A. and L. M. Falicov, LBL-29080, "Local Chemical Potential Approach to Small-Cluster Many-Body Systems," Phys. Rev. B. (ln press.)

Freericks, J. K. and L. M. Filicov, LBL-29922A, "Exact Many-Body Solutions of Ordinary and Magneti : "ix Frustrated Hubbard Models on a Periodic Eight-Site Square-Lattice Cluster." 
Invited Talks

Falicov, L. M., Pressure-Induced Mott Transition in NiI2, presented at: H.C. Ørsted Institute, University of Copenhagen, Denmark, June 1990; Iustitute for Thecretical Physics, University of Lund, Sweden, June 1990; I'hysics Department; Rise National Laboratory, Denmark, June 1990; Department of Physics, University of Callfornia, Berkeley, September 1990; Department of Physics Colloquium, University of California, San Diego, October 1990; Sandia National Laboratories, October 1990.

Falicov, L. M., Electron Spectroscopy of Highly Correlated Metals, ALS Workshop, Lawrence Berkeley Laboratory, August 1990.

Falicov, L. M., Ginzburg-Landau Theory of Deformable Superconductors, Lawrence Berkeley Laboratory, October 1990.

Falicov, L. M., Solid State Theory, Society of Physics Students, University of California, Berkeley, October 1990. 


\section{Surfaces, Chemisorption, and Theory of Solids}

S.G. LOUIE, PRINCIPAL INVESTIGATOR

The goal of this work is to further basic understanding of the electronic and structural properties of materials. First-principles quantum mechanical calculations are carried out to investigate real systems at a microscopic level. The research effort cncompasses the study of bulk materials, surfaces and interfaces, and defects in crystals. New theoretical methods for ab initio treatment of many-electron effects in calculating the ground-siate and excited-state properties are developed. Current projects include work on surface atomic and electronic structures, insulator-metal transition and properties of materials under high pressure, structural and vibrational properties of solids, electronic excitation spectra of semiconductor superlattices and heterojunctions, impurity centers in quantum wells, optical properties of high $\mathrm{T}_{c}$ superconductors, and metal clusters.

\section{Quantum Monte Carlo Study cf Materials Properties \\ S. FAHY, X. W. WANG, AND S. G. LOUIE}

The recently developed quantum Monte Carlo pseudopotential approach was applied to study the properties of crystals. Accurate results for binding energy and structural properties of diamond, graphite, and silicon were obtained. The use of correlated many-electron wavefunctions allowed a detailed investigation of electron correlation effects in these materials. The calculated electron pair-correlation function reveals striking anisotropy and spatial-dependent structures that result from the crystal structure and chemical bonding of the real material. The effects of correlation on the occupation of single-particle states has also been calculated, as well as quasihole energies within a single-mode approximation.

Quasiparticle Band Offset at the (001) Interface and Band Gaps in Ultrathin Superlattices of GaAs-AlAs Heterojunctions

S.B. Zhang, M.L. Cohen, S.G. LoUie, D. Tomanek, and M.S. Hybertsen

First-principles quasiparticle theory is used to calculated the band offset at the (001) interface and band gaps in $1 \times 1$ and $2 \times 2$ superlattices of GaAs-AlAs heterojunctions. We find a sizable many-body contribution to the valence-band offset which is dominated by the many-body corrections to bulk GaAs and AlAs quasiparticle energies. The resultant offset $\Delta \mathrm{E}_{v}=0.53 \pm 0.05 \mathrm{eV}$ is in good agreement with the recent experimental values of $0.50-0.56 \mathrm{eV}$. Our calculated direct band gaps for ultrathin superlattices are also in good agreement with experiment. The $X_{1 c}$-derived state at point $\bar{\Gamma}$, is however, above the $\Gamma_{1 \mathrm{c}}$-derived states for both the $1 \times 1$ and $2 \times 2$ lattices, contrary to results obtained under the virtual-crystal approximation (a limiting case for the Kronig-Penny model) and some previous local-density approximation (corrected) calculations. The differences are explained in terms of atomicscale localizations and many-body effects. Oscillator strengths and the effects of disorder on the spectra are discussed.

\section{Negative-Donor Centers in Semiconductors and Quantum Wells}

The negative-donor centers $D^{-}$in a magnetic field in semiconductors and quantum wells are studied by an effective-mass model which is solved exactly by a diffusion quantum Monte Carlo method. For $\mathrm{D}^{-}$in bulk GaAs, excellent agreement is found between theory and magneto-optical experiments. For $D^{-}$in a $100-\AA \mathrm{GaAs} /$ $\mathrm{Ga}_{0.75} \mathrm{Al}_{0.25} \mathrm{As}$ quantum well, a sevenfold increase in binding energy over that of the bulk case is predicted at zero field and the calculated field-dependent ground-state energy is in good agreement with the interpretation of recent high-field magnetooptical data. 

an Electron Self Energy Approach

X. J. ZhU, M. S. Hybertsen, AND S. G. Louie

A conceptually complete formalism for the quasiparticle effective masses in semiconductors was proposed. Our approach is based on a generalized form of the $\mathbf{k} \cdot \mathbf{p}$ theory, including the effects of the nonlocal, energy dependent electron self energy operator $\Sigma$, which accounts for the electron-electron interaction. This introduces two important effects on the expression of the effective mass: an explicit energy renormalization and an extra contribution to the matrix elements that enters the usual k - p-perturbation. Our preliminary numerical results for prototypical GaAs show promising improvements over the results from the local density approximation for the calculated electron effective mass compared to experimental data.

Metal-Insulator Transition in Solid Xenon at High Pressures

H. Chacham, X. J. ZhU, AND S. G. LOUIE

Under megabar pressures, solid hcp-Xenon underwent a metal-insula or transition without a concomitant structural phase transition. We have performed a firstprinciples quasiparticle calculation to investigate the properties of this transition resulting from the band gap closure. The theory places the transition pressure at 128 GPa. The many body correction to the LDA band gap is found to decrease significantly as the pressure increases. This is tied with an increase of the dielectric screening.

Magnetic Structure and Equation of State of BCC Solid Hydrogen:

A Variational Quantum Monte Carlo Study

X.W. WANG, J. ZHU, S.G. LOUIE, AND S. FAHY

Solid hydrogen in the atomic bcc structure was studied using a variational quantum Monte Carlo (VQMC) approach. Various magnetic phases were investigated at densities between Wigner-Seitz radius of $r_{S}=1.6$ and $r_{S}=3.0$ a.u. Correlated wavefunctions of the Jastrow-Slater form were used with their antisymmetric part constructed from the Kohn-Sham self-consistent orbitals. A transition from paramagnetic to anti-ferromagnetic phase at lower density is found at $r_{S}=2.4$. There is, hovsever, no evidence for metastable partial ferromagnetic structure.

\section{New Method for Determining Excitation Spectra of Many-Body Systems: Formalism and Application to Small Alkali-Metal Clusters}

S. SAITO, S.B. ZhANG, S.G. LOUIE, AND M.L. COHEN

A new general formalism for determining the excitation spectrum of interacting many-body systems was developed. The basic assumption is that the number of the excitations is equal to the number of sites. Within this approximation, it is shown that the density-density response functions with two different pure-imaginary energies determine the excitation spectrum. The method is applied to the valence electrons of sodium clusters of differing sizes in the time-dependent local-density approximation (TDLDA). A jellium-sphere background model is used for the ion cores. The excitation spectra obtained in this way represent well the excitation spectra given by the full TDLDA calculation along the real energy axis. Important collective modes are reproduced very well. 


\section{Many-Body Calculation of the Surface State Energles for $\operatorname{Si}(111) 2 \times 1$}

J.E. NoRTHAUP, M.S. HYBertSEN, AND S.G. LOUIE

The surface state excitation energies for $\mathrm{Si}(111) 2 \times 1$ were calculated via a first principles self-energy approach. Results for the quasiparticle surface state energies are in excellent agreement with photoemission and inverse photocmission experiments. We find that excitonic effects are important in obtaining a qualitatively correct surface optical absorption spectrum.

- S. G. Loule recelved a John S. Guggenheim Fellowship.

Awards

\section{Publications and Reports \\ (See also CAM High- $\mathrm{T}_{\mathrm{c}}$ Superconductivity Program.)}

Refereed Journal Articles

Zhang, S. B., M. L. Cohen, S. G. Louie, D. Tomanek, and M. S. Hybertsen, "Quasl narticle Band Offset at the (001) Interface and Band Gaps in Ultrathin Superlattices of GaAs-AlAs Heterojunctions," Phys. Rev. B, vol.41, p.10058, 1990.

Hybertsen, M. S. and S. G. Loule, "Self-Energy Approach to Quasiparticle Energies Using a Density Functional Treatment of Dielectric Screening," in Density Functional Theory of Many-Fermion Systems, ed. S. B. Trickey, Advances in Quantum Chemistry, Vol.21, p.155, 1990.

Louie, S. G., "Variational Quantum Monte Carlo Calculation of Electronic and Structural Properties of Crystals," in Quantum Simulation of Condensed Matter Phenomena, ed. J. Gubernatis, p.168 (World Scientific, Singapore, 1990).

Fahy, S., X. W. Wang, and S. G. Loule, "Variational Quantum Monte Carlo Nonlocal Pseudopotential Approach to Solids: Formulation and Application to Diamond, Graphite, and Sllicon," Phys. Rev. B, vol.42, p.3503, 1990.

Zhu, X. J., S. B. Zhang, S. G. Loule, and M. L. Cohen, "Reply to Anisotropy in the Optlcal Spectrum of the GaAs (110) Surface," Phys. Rev. Lett., vol.65, p.938, 1990.

Fahy, S., X. W. Wang, and S. G. Loule, "Pair-Correlation Function and Single-Particle Occupation Numbers In Diamond and Sillcon," Phys. Rev. Lett. , vol.65, p.1478, 1990.

Pang, T. and S. G. Loule, "Negative Donor Centers in Semiconductors and Quantum Wells," Phys. Rev. Lett., vol.65, p.1635, 1990.

Zhu, X., M. S. Hybertsen, and S. G. Loule, "Theory of the Quasiparticle Effective Masses in Semiconductors Based on an Electron Self Energy Approach," Mat. Res. Soc. Symp. Proc., vol.193, p.113, 1990.

Saito, S., S. B. Zhang, S. G. Loule, and M. L. Cohen, "New Formalism for Determining Excitation Spectra of Many-body Systems," Phys. Rev. B, vol.42, p.7391, 1990.

Saito, S., S. B. Zhang, S. G. Louie, and M. L. Cohen, "Quasiparticle Energles in Small Alkali-Metal Clusters," J. Phys, Cond. Matt., vol.2, p.9041, 1990. LBL-28406.

Wang, X. W., J. Zhu, S. G. Loule, and S. Fahy, "Magnetic Structure and Equation of State of BCC Solld Hydrogen: A Variational Quantum Monte Carlo Study," Phys. Rev. Lett., vol.65, p.2414, 1990.

Other Publications

Wang, X. W., S. Fahy, J. Zhu, and S. G. Loule, "Variational Quantum Monte Carlo Calculation of Atomic and Crystalline Si," Bull. Am. Phys. Soc., vol.35, p.418, 1990.

Wang, X. W., J. Zhu, S. Fahy, and S. G. Louic, "Electron Correlation in Solld Hydrogen: A Variational Quantum Monte Carlo Study," Bull. Am. Phys. Soc., vol. 35, p.439, 1990.

Surh, M. P. and S. G. Loule, "Quasiparticle Energies in Elemental Copper," Bull. Am. Phys. Soc., vol.35, p.574, 1990.

Saito, S., S. B. Zhang, M. L. Cohen, and S. G. Loule, "New Method for Excitation Spectrum of the Many-Body Systems: Application to the Metal Clusters," Bull. Am. Phys. Soc., vol.35, p.709, 1990.

LBL Reports

Louie, S. G., LBL-27945, "Theory of Electronic Excitations in Solids," in Electronic Materials: A New Era of Materials Sciences, eds. J. R. Chelikowsky and A. Franciosi, Springer-Verlag. (n press.)

Surh, M. P., M-F. LI, and S. G. Loule, LBL-29009, "Spin-orbit Splitting of GaAs and InSb Bands near G," Phys. Rev. B (In press.)

Chacham, H., X-J. Zhu, and S. G. Loule, LBL-29137, "Metal-insulator Transition in Solid Xenon at High Pressures," Europhys. Lett. (In press,)

Louie, S. G., LBL29273, "Quasiparticle Excitations and Photoemission," in Angle-Resolved Photoemission, eds. S. D. Kevan (Elsevier Sclentific Publ, Amsterdam, 1990) (In press.) 
Northrup, J. E, M. S. Hybertsen, and S. G. Loulo, LBL,-29444, "Many Body Calculation of the Surface State Energles for SI(111)2x1," Phys, Rev. Lett. (Submitted.)

Chacham, H. and S. G. Loule, LBL-29463, "Metallization of Solid Hydrogen at Megabar Pressures: A First-[rinclples Quasiparticle Study," Phys. Rev. Lett. (In press,)

Wang, X. W., S, G. Loule, and M. L. Cohen, "Predlcting High Pressure and Exicted State Properties of Real Materials," Int. J. of Supercomputer Applications . (In press.)

Zhu, X.J. and S, G. Louje, LBL-30083, "Quasiparticle Band Structure of Thirteen Semiconductors and Insulators," Phys. Rev. B (Submitted.)

Loule, S. G., Predicting the Electronic and Structural Properties of Solids, General Seminar, CNRS Service National des Champs Intenses and Max-Planck-Institut für Festkorperforschung Hochfeld-Magnetlabor, Grenoble, France, February 1990.

Loule, S. G., Quantum Monte Carlo Studies of Materials Properties and Electron Correlations, Solld State Seminar, University of Trondheim, Trondheim, Norway, April 1990.

Loule, S. G., Recent Progress in Predicting Materials Properties, Physics Department Colloquium, University of'Trondheim, Trondhelm, Norway, April 1990.

Loule, S. G., Quantum Monte Carlo Simulations of Materials Properties, Theoretical Physles Seminar, Max-Planck-Institut, Stuttgart, West Germany, May 1990.

Loule, S. G., Quantum Monte Carlo Studies of Electronic and Structural Properties of Solid-Siate Systems, Intcrnational Workshop on Monte Carlo Methods in Theoretical Physics, Marciana Marina (Isola d'Elba), Italy, July 1990.

Loule, S. G., Recent Progress in First-Principles Studies of Materials Properties, Physies Department Seminar, Scuola Normale Superiore, Pisa, Italy, July 1990.

Loule, S. G., Quasiparticle Energics in Semiconductors and Insulators, Conference on Electronic Correlations in Condensed Matter, Ascona, Switzerland, July 1,y0.

Loule, S. G., Correlated Wavefunction (')uantum Monte Carlo Studies of Materials Properties, Conference on Electronic Correlations in Condensed Matter, Ascona, Switzerland, ',uly 1990.

Loule, S. G., Superconducting Gap in $\mathrm{Bi}_{2} \mathrm{Sr}_{2} \mathrm{CaCu}_{2} \mathrm{O}_{8}:$ Reflectipity Measurements and Theoretical Analysis, Solid State Seminar, University of Paris South, L.U.R.E., Orsay, France, July 1990.

Louie, S. G., Recent Progress in Predicting Materials Properties, Solid State Physics Colloquium, University of Antwerp (RUCA), Antwerpen, Belgium, July 1990.

Louie, S. G., Electron Correlations and Quasiparticle Excitations in Crystals, $65^{\text {th }}$ We-1 Heracus-Seminar on Electronic Structure in the 1990's, Bad Honnef, West Germany, July 1990.

Loule, S. G., Quantum Monte Carlo Simulation of Materials Properties, Symposium on Applications of Quantum Monte Carlo and Molecular Dynamics to Condensed Matter Systems, University of Callfornia, Davis, CA, December 1990. 


\section{Theoretical Solid State Physics}

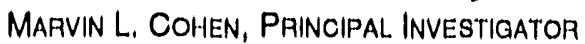

The major areas of focus for our theoretical research this past year have been:

- high temperature superconductivity, discussed in section devoted to CAM High- $T_{c}$ Superconductivity Program

- the use of the total-energy pseudopotential method to predict and explain properties of solids at low and high pressures

- studies of excited states and quasiparticles using formalism developed by S. G. Louie

- solid hydrogen at high pressures

- metallic clusters

In much of this work, we are trying to collaborate with experimentalists. Some of the research is purely theoretical, but the motivation for developing the formalism is usually connected with attempts to understand existing data or to predict new properties and new materials.

\section{Prediction of New Materials and High Pressure Properties}

A first-principles study examined the structural and electronic properties of a hypothetical superhard material $\beta-\mathrm{C}_{3} \mathrm{~N}_{4}$ and of $\beta-\mathrm{Si}_{3} \mathrm{~N}_{4}$. A calculation of the high pressure properties of lead was done, and comparison with high-pressure melting properties was made. This study bears on problems in planctary science and condensed matter physics. The high-pressure structures of InSb were examined using the total energy pseudopotential method. An examination of the high density phases of BN included structural transformation paths, electronic structure, and the exploration of possible high pressure phases of $\mathrm{BN}$.

\section{Quasiparticles and Excited States of Solids}

The formalism introduced by Professor Louic and his collabortors was applied and extended. In particular, a study of the quasiparticle band offset at the (001) interface of GaAs-AlAs heterojunctions determined the role of many-body effects. A new formalism was developed for determining the excitation spectrum of many-body systems. The method was applied to a study of sodium clusters.

\section{Predicting Properties of Metallic Hydrogen}

Our studies of the possible properties of hydrogen at high pressures continue. We predict that molecular hydrogen, which is an insulating solid at low pressures, can become a "molecular" metal or semimetal because of band overlap at pressures in the range of 150-200 GPa. At higher pressures, the calculations indicate that hydrogen will become an atomic metal. In both metallic forms, we expect hydrogen to be a superconductor with a high transition temperature.

\section{Properties of Metallic Clusters}

The jellium model was used several years ago by our group to explain the abundance spectra of alkali metal clusters as observed by Professor Knight's experimental group. Current experiments on optical properties have motivated more elaborate theoretical studies of excited state properties. To do this, it was necessaryto develop a new formalism. The results of the application of this new approach are promising, and the applications to sodium and potassium clusters indicate that the new theory constitutes a significant improvement over the local density approximation which was used previously. 
Principal Investigator

M.L. Cohen
Graduate Students

Troy Barbee III

Jennifor Corkill

VIn Crospl

Alberto Carcia

Steve Lewis

Amy Llu.

\section{Awards}

- M. L. Cohen was awarded a Guggenhelm Followshlp.

- M.L. Cohen was awarded the U.S. Department of Energy Award for Sustained Outstanding Research in Solid State Physics.

\section{Publications and Reports}

(See also CAM High- $\mathrm{T}_{\mathrm{c}}$ Superconductivity Program.)

\section{Refereed Journal Articles}

Zhang, S. B., M. L. Cohen, S. G. Loule, D. Tomanek, and M. S. Hybertsen, "Quasiparticle Band Offuet at the (001) Interface and Band Gaps in IItrathin Superlattices of GaAs-AlAs Heterojunctions," Phys. Rev. B, vol. 41, p. 10058, 1990.

Liu, A. Y. and M. L. Cohen, Structural Properties and Electronic Structure of Low-Compressibility Materials: b-Si, $\mathrm{N}_{4}$ and Hypothetical b- $\mathrm{C}_{3} \mathrm{~N}_{4}$ " Phys. Rev. B, vol, 41, p. 10727, 1990

Godwal, B. K., C. Meade, R. Jeanloz, A. Garcia, A. Y. Liu, and M. L. Cohen, "Ultrahigh-Pressure Melting of Lead: A Multidisdplinar Study," Science, vol. 248, p. 462, 1990.

Zhu, X., S. B. Zhang, S. G. Loule, and M. L. Cohen, "Reply to 'Comment on "Quasiparticle Interpretation of Photoemisslon Spectra and Optical Properties of GaAs(110) [1'hys. Rev. Lett. 63, 2112 (1989)]'," Phys. Rev. Lett., vol. 65, p. 938, 1990.

Xlang, X.-D., S. McKernan, W. A. Vareka, A. Zettl, J. L. Corkill, T. W. Barbee III, and M. L. Cohen, "Iodine Intercalation of a HighTemperature Superconducting Oxide," Nature, vol. 348, p. 145, 1990.

Garcia, A., M. L. Cohen, and S. B. Zhang, "Theoretical Study of a New Transition Sequence in IIl-V Compounds: High-Pressure Phacs of InSb," Mat. Res. Soc. Symp. Proc., vol. 193, p. 89, 1990.

Liu, A. Y. and M. L. Cohen, "Theory of Structural and Electronic Properties of Silicon Nitride and Carbon Nitride," Mat. Res. Soc. Symp. Proc., vol. 193, p. 95, 1990.

Garcia, A., T. W. Barbee III, M. L. Cohen, and I. F. Silvera, "Band Gap Closure and Metallization of Molecular Solid Hydrogen," Europhys. Lett., vol. 13, p. 355, 1990.

Salto, S., S. B. Zhang, S. G. Loule, and M. L. Cohen, "New Formallsm for Determining Excitation Spectra of Many-Body Systems," Phys, Rev, B, vol. 42, p. 7391, 1990.

Saito, S., S. B. Zhang, S. G. Loule, and M. L. Cohen, "Quasiparticle Energies in Small Alkali-Metal Clusters," I. Phys. Cond. Malter, vol. 2, p. 9041, 1990.

Cohen, M. L. and W. D. Knight, "The Physics of Metal Clusters," Phys. Today, vol, 43, p. 42, 1990.

Other P'ublications

Lam, P. K., R. M. Wentzcovitch, and M. L.Cohen, "High Density Phases of BN," Mat. Sci. Forum, vols, 54/55, p. 165, 1990.

Garcia, A., T. W. Barbee III, M. L. Cohen, and I. F. Silvera, "Solid Molecular Hydrogen: Structures and Band Gaps," Bull. A.P.S., vol 35, p. 195,1990

Liu, A. Y. and M. L. Cohen, "Prediction of New Low Compressibility Sollds," Bull. A.P.S., vol. 35, p. 573, 1990.

Saito, S, S. B. Zhang, S. G. Loule, and M. L. Cohen, "New Method of the Excitation Spectrum of the Many-Body Systoms: Application to the Metal Clusters," Bull. A.P.S., vol. 35, p. 709, 1990.

LBL Reports

Zhang, S. B., M. L. Cohen, and S. G. Loule, LBL-29782, "Chemical Shift and Zone-Folding Effect on the Energy Gaps of GaAsAlAs(0)1)," Phys. Rev. (In Press.)

Salto, S., S. B. Zhang, S. G. Loule, and M. L. Cohen, LBL-28406, "Quasiparticle Energies in Small Alkall-Metal Clsuters," I. I'hys, Cond. Matter. (In Press.)

Liu, A. Y., A. Garcia, M. L.Cohen, B. K. Godwal, and R. Jeanloz, LBL-28577, "Theory of Illgh-Pressure Phases of Pb," Phys, Rev. (In Press.) 
Lut , A, Y, M. L. Cohen, K, C. Hass, and M. A. Tamor, LBL-29582, "Structural Proportlos of Novol All-up" Phaso of Carbon," Phys, Rev. (In Pross,)

Cohon, M. L., LBL-29583, "Predicting Now Solldy and Thoir Propertlos," PhIl. Trans, Roy. Soc, London, (In Prosy,)

Surh, M, S. G. Loule, and M. L. Cohen, LBL-29816, "Quasipartlcle Energles for Cuble BN, BP', and BAs from a Modol GW Calculatlon," Phys. Rev. (In Press.)

Corkill, J, L., A. Garcla, and M. L, Cohon, LBL-29986, "Theorotical Study of High Prossuro Phases of Sn," Phys, Rev, (In Pross.) Inviled Talks

Cohen, M. L., Predicting New Solids and Superconductors, Intornational Conforonco on Total Enorgy Mothods and Physlcs of III-V Semicondcutors, Parls, France, January 1990.

Cohen, M. L., Predicting Properties of Solids and Superconductors, Ecolé Polytechnique do Lausanno, Lausanne, Switzerland, January 1990.

Cohon, M. L., Predicting Properties of Solids, Clusters, and Superconductors, Lawronce Livormoro Laboratory, Livormore, CA, Fobruary 1990.

Cohen, M. L., Evidence of the Claimts of Metallization of Hydrogen, Departmont of Physics, University of Callfornla, Borkoley, CA, February 1990.

Cohen, M. L., Quantum Theory of Materials, Annual Roview of the Materials and Chemical Sclences Divislon, Lawronce Berkoloy Laboratory, Berkeley, CA, March 1990.

Cohen, M. L., Predicting Properties of Solids, Clusters, and Superconductors, Department of Physics, Arizona State University, Tempo, AZ, March 1990.

Cohen, M. L., Predicting New Solids and Their Properties, V.M. Goldschmidt International Conference on Geochemistry, BaltImore, MD, May 1990.

Cohen, M. L., Predicting New Solids and Their Properties, The Royal Society Discussion Meeting on Bonding and Structure of Sollds, London, England, September 1990,

Cohen, M. L, Predicting Properties of Solids, Clusters, and Superconductors, Dupont Contral Research and Dovelopment Department, Experimental Station, Wilmington, DE, November 1990.

Cohen, M. L., Predicting Properties of Solids, Clusters, and Superconductors, Geophysical Laboratory, Carnegle Institution of Washington, Washington, D. C., November 1990. 


\section{Studies of the Metal/Solution Interface with X-rays}

P.N. Rogs, Paincipal InVEgtiaAtor

During the last two decades there have been great advanees in the dovelopment of methods for the analysis of the structure of surfaces in ultrahigh vacuum (UHV), which has led to a detalled understanding of the chemistry of free surfaces. Further advances of comparable magnitude will be necessary to develop an equivalont lovel of understanding of structure at interfaces, particularly the technologically important cases of interfaces between condensed phases. In thls work, we address the problem of structure determination at the metal/solution interface. Study of the motal/ solution interface is relevant to technologies like metal corrosion, electrochomical encrgy conversion (fuel cells), and storage dovices (battorics), and the rapidly growing new technology of electrolytic epllayers for photovoltaics, magnetle recording, and electro-optic devices.

The problem of structure determination at the interface between condensed phases is a difficult one. Most of the techniques developed for the study of solid surfaces in UHV cannot be applied to the interface between condensed phases, since they rely on the diffraction, scattering, or emlssion of electrons. The electrons scattered or emitted from the interface are too severely attenuated by the condensed phases for external detection and anal;'sis. New techniques must be developed that utilize more penetrating, higher momentum photons like $x$-rays, gamma-rays, or neutrons. We are pursuing the use of $x$-rays, and especially $x$-ray diffraction, for structure determination at the metal/solution interface.

In recent years there have been several approaches to the development of surfacesensitive $x$-ray diffraction, Including $x$-ray standing waves, direct-transmission diffraction from thin substrates, and grazing incidence Bragg diffraction at the critical angle for total reflection (GID). The grazing-Incidence geometry appears to be the most generally applicable technique for our purposes. GID is a very new surface tool that has been used only a few times, for some solld/solid interfaces (multilayers) and submonolayer metal/metal surfaces in UHV. Prior to this study, the application of GID to a solid/liquid interface was a totally new experiment.

The Role of Defects In the Specific Adsorption of Anlons on Pt(111) P.N. Ross

The specific adsorption of anions from hydrochloric and sulfuric acids was studied on $\mathrm{Pt}(111)$ surfaces containing a variety of deliberately induced defects. One type of defect was an ordered step array produced by cutting a Pt(111) crystal a few degrees off the [111] zone axis. Another was a randomly stepped surface produced by ion bombardment and annealing. In all cases, the structure of the defects was determined by low energy electron diffraction (LEED) in a UHV system directly coupled to an electrochemical cell. The vacuum work function of the surfaces was determined by UV photocmission. The potential of the pseudocapacitive charging from anion adsorption/desorption was found to corrclate with the work function of the surface. All the step defects of the type studied lowered the work function of the surface in proportion to the step density, indicative of a local dipole at the step. The processes of hydrogen adsorption and anion desorption are coupled on Pt surfaces having relatively low work functions $(5,2-5.4 \mathrm{cV})$, while the hydrogen adsorption and anion desorption processes become decoupled on the high work function $(5.7-5.8 \mathrm{eV})$ surface of Pt(111) having no steps detectable by LEED. An electrostatic model for selectlve adsorption of anions at the step due to the intrisic dipole is proposed to explain these observations. 
Investlgator

l'hlllip N. Ross

Stuff Scitentists

E. Moltzor

A. Thompson
Visilling Sctuntlst

W. Halloy

Resenrch Associntes

P. L.Indborg

L. Johnson

\section{Publications and Reports}

LBL, Report

P.N. Ross, LBL.29941, "Tho Rolo of Dofocts In tho Spocific Adsorption of Antons on P'(111)," 1. Cham. Phys, (In pross.) 


\section{Materials Chemistry}

\section{SYTHESIS AND CHEMICAL STRUCTURE}

\section{Low.Temperature Properties of Materials}

Norman E. Phillips, Prinoipal. InVestigator

This program is directed to obtaining information that contributes to an understanding of the behavior of materials by the measurement of their low-temperature propertics, particularly specific heats, and including measurements in magnetic flelds and under pressiure. There are numerous special cases in which specific-heat data provide either a test of theoretical models or values of important parameters that could not otherwise be obtained. Since much of the work is in the region below $1 \mathrm{~K}$ where the temperature scale is not well established, an accurate laboratory temperature scale that extends to $5 \mathrm{mK}$ has been developed. The interest in high-T, superconductors has led to an extension of the measurement capabilities to above $100 \mathrm{~K}$. Recent measurements have been made on a number of heavy-fermion compounds, including heavy-fermion superconductors, and on high- $\mathrm{T}_{\mathrm{c}}$ superconductors. The High- $\mathrm{T}_{\mathrm{c}}$ work is discussed in the section devoted to the CAM High- $\mathrm{T}_{\mathrm{c}}$ Superconductivity Program.

\section{Pressure and Magnetlc Fleld Dependence of the Specific Heat of} Heavy Fermion $\mathrm{YbCu}_{4.5}$

A. Amato* R.A. Fisher, N.E. Phillips, D. Jaccaro and E. Walker ${ }^{\dagger}$

The specific heat of a polycrystalline sample of $\mathrm{YbCu}_{4.5}$ has been measured between 0.3 and $20 \mathrm{~K}$ at pressures to $8.2 \mathrm{kbar}$, and, at zero pressure, in fields to " $T$. Unlike cerlum-hased

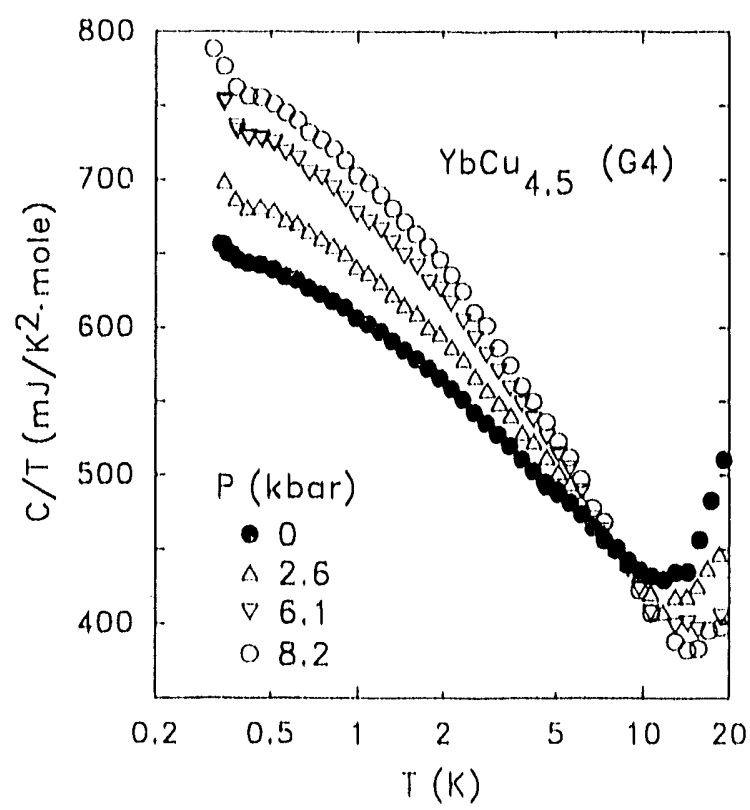

heavy-fermion compounds, an increase of $\mathrm{C} / \mathrm{T}$ is observed

Figure 1

Pressure dependence of $\mathrm{C} / \mathrm{T}$ for $\mathrm{YbCu}_{48}$

(XBL 903-833)

\footnotetext{
- Laboratorlum fur Festkorperphyslk, ETH Honggerberg, Zurloh, Swlizerland

$\dagger$ Department of Physics, University of Geneva, Geneva Switzerland
} 


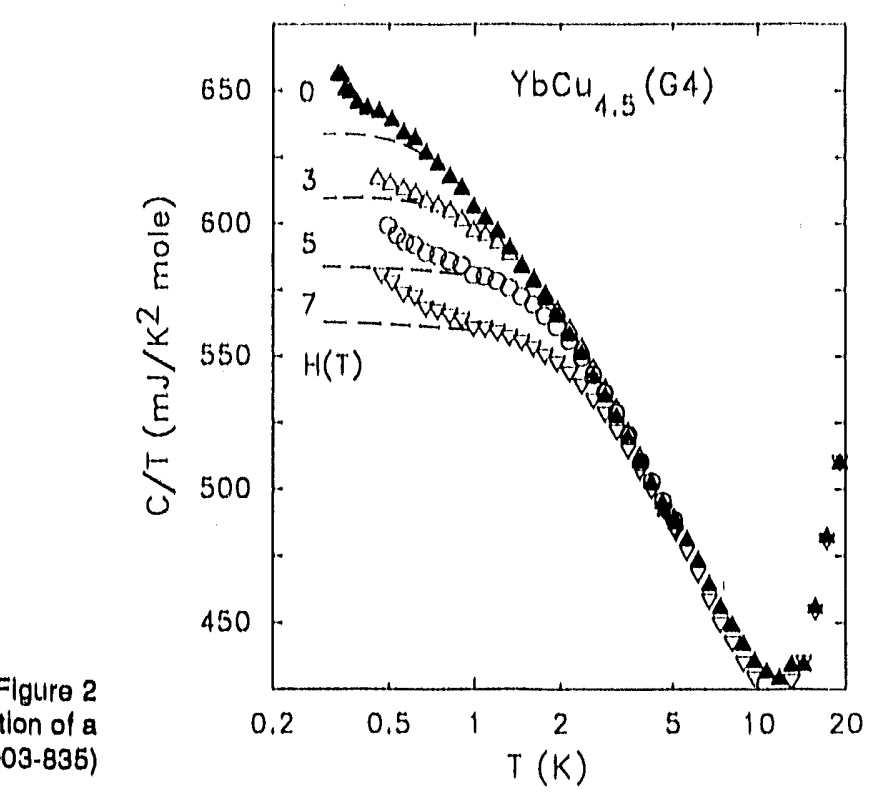

with increasing pressure, with the linear term enhanced by about $16 \%$ at $8.2 \mathrm{kbar}$. Above $7 \mathrm{~K},(\partial \mathrm{C} / \partial \mathrm{P})_{1}$ is negative. The nuclear contribution observed at $P=0$ is increased by roughly a factor of two at $8.2 \mathrm{kbar}$. At zero field a minimum in $\mathrm{C} / \mathrm{T}$ is observed near $11 \mathrm{~K}$. Below that temperature $\mathrm{C} / \mathrm{T}$ increases and below $0.5 \mathrm{~K}$ exhibits an upturn ascibed to a hyperfine contribution. The increase in $\mathrm{C} / \mathrm{T}$ below $11 \mathrm{~K}$ is reduced by a factor 1.5 for $\mathrm{H}=7 \mathrm{~T}$, whereas the hyperfine term is enhanced due to the contribution of the ${ }^{6.3} \mathrm{Cu}$ and ${ }^{65} \mathrm{Cu}$ nuclei.

Investigators

Norman E. Phlllips

Robort A. Fishor

\author{
Graduate Students \\ Brian Woodficld \\ Daniel Wright \\ Jeffrey Emorson
}

\section{Publications and Reports}

(See also CAM High- $\mathrm{T}_{\mathrm{c}}$ Superconductivity Program.)

\section{Reftered Journal Articles}

Flsher, R. A., S. KIm, Y. Wu, N.E. Phillips, M.W. McElfresh, M.S. Torikachvili and M. B. Maple, "Specific Heat of URu, S1, Effect of Pressure and Magnetic Flold on the Magnetic and Suporconducting Transitions", Physica B, vol. 163, p. 419, 1990.

Amato, A, R.A. Fisher, N.E. Phillips, D. Jaccard and E. Walker, "Magnetic Fleld Dependence of the Specifle Heat of Heavy Formion $\mathrm{YbCu}_{4.5}$ ", Physica B, vol. 165-166, p. 389, (1990).

Amato, A., R.A. Flsher, N.E. Phillips, D. Jaccard and E. Walker, "I'ressure Dependence of the Specifle: Heat of Heavy-Fermlon $\mathrm{YbCu}_{4.5}{ }^{\prime \prime}$, Physica $B$, vol. 165-166, p. 425, (1990),

L.BL. Reports

Flouquet, J, P. Halln, P. Lejay, P. Morin, D. Jaccard, J. Schwolzor, C, Vottlor, R.A. Flshor and N.E. Phlllips, LBL-30119, "Mngnotlc Instabillty in Ce Heavy Formion Compounds", presented at Yamada Conference XXV on Magnetlc ['hase Transiltions, Osaka, Japan, April 1990. (In press)

Invited Talks

Flouquet, J, P. Haen, P. Lejay, P. Morin, D. Jaccard, J. Sch wlozer, C. Vettler, R.A. Flsher and N.E. Phillips,"Magnetic Instability in Ce lleavy Fermion Compounds", Yamada Conference XXV on Magnetlc Phase Transltions, Osaka, Japan, April 1990. 


\section{Electrochemical Processes}

C.W. Tobias, Painolpal Investigator

This program is designed to ad vance the scientific foundations of electrochemical engineering and to broaden the useful applications of electrochemical transformation. Electrochemical processes have inherent advantages over thermochemical methods with respect to material ylold and energy efficiency. However, in splte of their long history of economically significant applications, cell processes haven't achleved their potential with respect to performance and range of applications in chemical synthesis, nor in energy conversion and storage, A major rcason for this condition is the complex nature of transport phenomena in ionic media, as they are coupled to charg: transfer processes at the electrode surface.

For the elucidation of reaction mechanisms assoclated with the co-deposition of iron-nickel alloys, a new method, including theoretical underpinnings, has been developed for the in situ measurement of interfacial $\mathrm{pH}$. The method uses a rotating disk electrode as the site of deposition and? a ring electrode on open circuit as the measuring element. The $\mathrm{pH}$ at the interface is a critical parameter in the deposition of iron-nickel magnetic alloys.

In a project jointly directed with R. H. Muller, reduction of mass transfer boundary layers by means of suspended inert solids in moving electrolytes is investigated using a rotating cylindrical electrode as an experimental vehicle. This technique for increasing limiting rates of metal deposition is of particular promise in electroforming, and in electroorganic synthesis.

Applied research on the "Surface Morphology of Metals in Electrodeposition", and on "Engineering Analysis of Gas evolution" is supported by the Assistant Secretary of Conservation and Renewable Energy, Office of Energy Storage and Distribution of the U.S. Department of Energy under Contract No. DE ACO3-76SF00098. Results are presented in this Report in the "Electrochemical Storage" Section.

\section{In Situ Measurement of Interfacial pH Using a Rotating Ring-Disk Electrode.}

\section{S. HessamI AND C.W. TOBIAS}

A non-Intrusive technique for the in situ measurement of interfacial $\mathrm{pH}$ and current efficiency has been developed. A ring electrode, operated potentiometrically at open circuit is used to measure the $\mathrm{pH}$ change at a rotating disk electrode. The technique takes advantage of the well-characterized hydrodynamics at the rotating disk electrode and has the added advantage that the $\mathrm{pH}$ probe, the ring electrode, is not interfering with the flow field and the current distribution on the disk. To determine

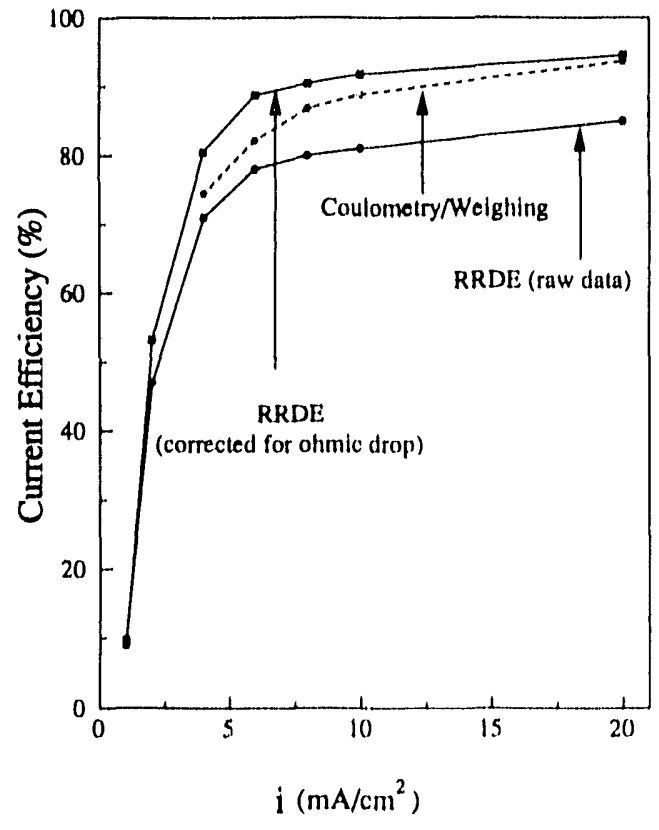

Figure 1

Current efflciency of nickel deposition as 1) measured with the rotating ringdlsk eleotrode and 2) by weighing the deposit, bulk $\mathrm{pH}=2.9,0.2 \mathrm{M} \mathrm{NiCl}_{2}, 900$ $\mathrm{rpm}$. The ring electrode, monitored at open circult, responds to the concurrent hydrogen evolution reaction. (XBL. 9011-3669) 
the $\mathrm{pH}$ at the disk electrode by measuring the potential of the ring, the radial transport of hydronium ions across the insulating gap and on the ring is analyzed, taking into account the effect of homogeneous dissociation reactions of water, metal-hydroxide complexes, and buffering agents. Shifts in the ring potential caused by hydrogen super-saturation and by ohmic drop in the electrolyte are also evaluated.

A platinized piatinum electrode in a hydrogen-saturated electrolyte provides a stable and reproducible sensor with a Nernstian response to changes in the bulk $\mathrm{pH}$. Performance of the ring is evaluated by generating hydrogen at the disk electrode from a dilute acid solution, in the absence of other electrochemical reactions. The technique is then applied to determine the interfacial $\mathrm{pH}$ and the current efficiency in the electrodeposition of iron and nickel, with concurrent hydrogen evolution. (Figure 1)

\section{Mass Transport to Cylindrical Electrodes Rotating in Suspension of Inert Microspheres C.W. TOBIAS, D.W. GiBBons, AND R.H. MULLER}

Mass transfer enhancement produced by the addition of inert microspheres was investigated on a rotating cylinder electrode operating in the turbulent regime. The effects of rotation speed, rotor radius, paxticle size, solids volume fraction, and particle density on the rate of mass transfer were determined by limiting current measurements for ferricyanide reduction. In comparison to transport rate observed with clear electrolytes, up to two and a half fold higher limiting currents were observed in concentrated suspensions containing 5-80 micron diameter spheres with densities ranging from 0.7 to $2.1 \mathrm{~g} / \mathrm{cm}_{3}$. Transport enhancement is attributed to the microconvective eddies produced by particle rotation in the shear field adjacent to the spinning electrode, and to the increased shear rate caused by the formation of a particle free-wall layer.

Experimental data could be correlated in the form: $S h=\alpha \operatorname{Re}^{\beta} \mathrm{Sc}^{1 / 3}$ where $\mathrm{Sh}, \mathrm{Re}$, and Sc are the Sherwood, Reynolds, and Scilmidt numbers, respectively, and are empirical function of solids volume fraction, determined from mass transport rate measurements (Figure 2).

Addition of appreciable volume fractions of inert particles to the electrolyte results in significant improvements of production capacity when the latter is limited by transport : ates. The use of suspended particles to achieve a given increase in limiting current density is shown to require far less power than simply increasing electrode rotation speed to enhance mass transport.

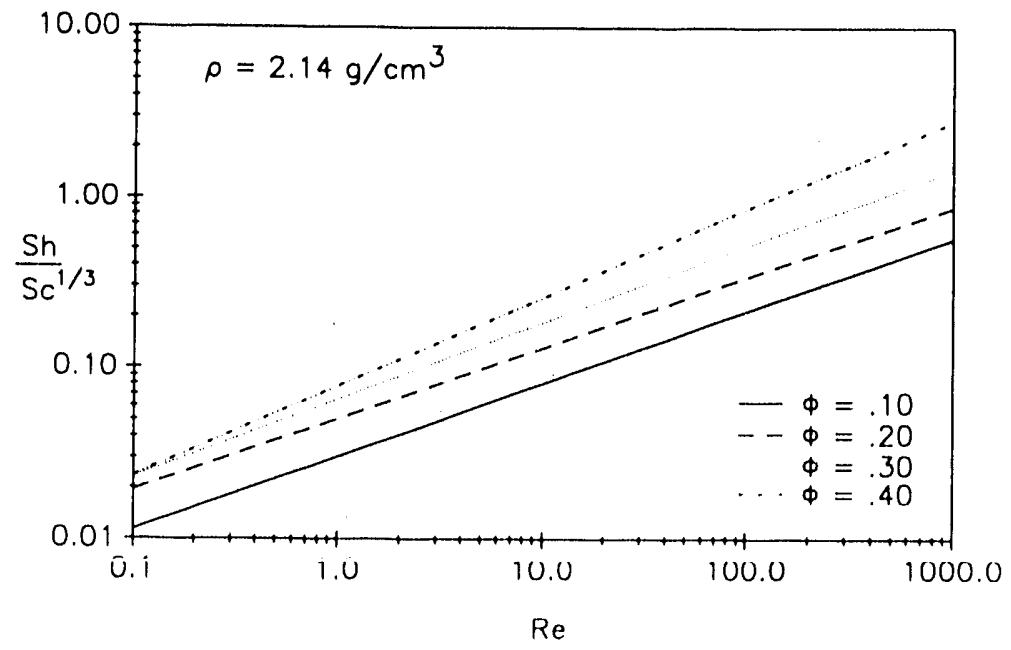

Figure 2

Summary of mass transfer correlation results as a function of $\phi$ for various sizes of elctrodes and microspheres $\left(\rho_{s}=.14 \mathrm{~g} / \mathrm{cm} 3\right)$. Sh, $R e$, and Sc are the Sherwood, Reynolds and Schmidt niunituetis, iespeciively. The lines represent a least squares fit to the data at each respective volume fraction. (XBL 9011-3813) 


\section{Staff}

Investigator

Charles W. Toblas
Graduate Students

Sholeh Hessaml

Danile Gibbons*

Awards

- Charles W. Tobias received the Vittorio de Nora-Diamond Shamrock Award of the Electrochemical Society, for his seminal contributions to the field of electrochemical engineering.

- Sholeh Hessami recelved an IBM Manufacturing Research Fellowship for a second year.

- Davor Sutija received a Herz Scholarship for a third year.

\section{Publications and Reports}

Refereed Journal Articles

Tobias, C. W. R. Andersen and Muller, R. S., "Porous Silicon for Vapor Sensing" Sensors and Actuators, vol. A21-A23, p.835-839,1990.

Refereed Conference Proceedings

Tobias C. W., and Hessami S., "A Mathematical Model for Anomalous Codeposition of Nickel-Iron on a Rotating Disk Electrode", Proceedings of the Symposium on Magnetic Materials, Processes and Devices, vol. 90-8, p. 449-450, The Electrochemical Soclety, 1990.

LBL Reports (including journal articles submitted or in press

Tobias, C. W., Anderson, and Muller R. S., "Investigations of the Electric Properties of Porous Sillicon," J.Electrochem. Soc. (In Press.)

Tobias, C. W. and Hessami, S., LBL 30031, "Method for the In Situ Measurement of pH at a Rotating Ring-Disk Electrode," AICHE J. (In press.)

Tobias, C. W., Gibbons, and Muller R. S., LBL 29846, "Mass Transport to Cylindrical Electrodes Rotating in Suspensions of Inert Microspheres," J. Electrochem. Soc. (In press.). 


\section{High-Temperature Thermodynamics}

LEo BREWER, INVESTIGATOR

The understanding of high-temperature chemistry is not only important for processes carried out at high temperature such as those of fusion and fission reactors and fossil-fuel power generators, but it is also important for the preparation and fabrication of ceramics, metals, semiconductors, superconductors, and many other materials. The understanding of high-temperature behavior is complicated by the occurrence of unusual species and phases that are often unstable at conventional temperatures. It is difficult to carry out measurements to obtain the data needed for design of high-temperature systems. Thus, it is most important to develop broad predictive models that provide reliable prediction of high-temperature behavior. The experiments in progress are aimed at the testing or development of such predictive models.

Previous research of this program has led to the development of a variety of successful models of predictive capability for the bahavior of gases, refractory containment materials, and of many metallic systems. At the present time the main thrust of the research is aimed at providing quantitative predictive models for the strongly interacting transition-metal alloys exhibiting generalized Lewis acid-base behavior. A variety of experimental methods are being used to characterize the thermodynamics of these systems.

\section{Generalized Lewis Acid-Base Reactions of Metals}

L. Brewer, B. Ebbinghaus, K. Kruschwitz, S. Leonard, and R. Reddy

This general program was initiated during the Manhattan Project when it was necessary to predict the high-temperature properties of plutonium and other substances, so that materials could be developed for their high-temperature processing when they became available. A combination of chemical bonding theory with a framework of thermodynamics was used to predict high-temperature behavior and to point the way to new materials that could be developed to carry out the hightemperature processing.

This program has been quite successful in the following areas: (1) characterization of important molecular species in high-temperature vapors; (2) development of improved refractory materials that can withstand rigorous high-temperature environments; and (3) improvement of understanding of the chemical interactions between atoms and molecules in solutions, particularly metallic alloys. Models based on this background, together with spectroscopic information and thermodynamics, have provided for the successful prediction of multicomponent phase diagrams of the metals. This information has been valuable for the development of new materials to meet the design criteria of new applications.

The present emphasis on strongly interacting combinations of metallic acids and bases is aimed at improving the predictive ability for these systems, which have unique properties of importance for many applications. However, work is continuing toward the improvement of understanding of the behavior of all types of materials at high temperatures.

The present research could be described as the study of two types of acid-base titrations. For one, the acid is an electron deficient element such as $\mathrm{Ti}, \mathrm{Zr}, \mathrm{V}$, or $\mathrm{Nb}$, while the base ir a metal, such as $\mathrm{Rh}, \mathrm{Ir}, \mathrm{Pd}$, or $\mathrm{Pt}$, which has excess nonbonding electrons. For tre other type, all of the transition metals are bases and nontransition metals such as $\mathrm{Al}$ or Si are acids. One procedure for studying the titration is to use an electrochemical cell with solid electrolytes such as thoria doped with yttria. By repeating the electrochemical potential measurements for a series of compositions, the partial molal Gibbs energies of the components can be characterized. This method is limited to rather low temperatures, in the $8(0)$ to $1200^{\circ} \mathrm{C}$ range. The many oxide phases of $\mathrm{Ti}, \mathrm{V}$, and $\mathrm{Nb}$ have been used by equilibrating a pair of adjoining oxides such 
as $\mathrm{NbO}_{2}$ and $\mathrm{Nb}_{12} \mathrm{O}_{29}$, with fixed $\mathrm{Nb}$ and $\mathrm{O}$ thermodynamic activity, with $\mathrm{Rh}$, for example, and analyzing the $\mathrm{Nb}$ content in the equilibrated $\mathrm{Rh}$ phase.

Sufficient data are now available for combinations of $\mathrm{Ti}, \mathrm{V}, \mathrm{Nb}$, and $\mathrm{Zr}$ with $\mathrm{Ru}, \mathrm{Rh}$, $\mathrm{Pd}, \mathrm{Os}, \mathrm{Ir}$, and $\mathrm{Pt}$ to characterize the main features of the variation of base strength of $3 \mathrm{~d}$ to $4 \mathrm{~d}$ to $5 \mathrm{~d}$ electron pairs. These data are being used for development of a crystal field model. Data are being obtained for the enthalpies of formation of intermetallics of $\mathrm{Al}$ and $\mathrm{Ga}$ and other nontransition metals with the transition metals to extend the acid-base bonding models with aluminum as a base interacting with transition metals acting as acids by changing their electronic configurations to $\mathrm{d}^{\mathrm{n}}$ for most of the transition metals but also to $\mathrm{d}^{\mathrm{n}-\mathrm{p}}$ for left-hand transition metals. The elimination of electrons from the s orbitals of the transition metals allows $\mathrm{Al}, \mathrm{Ga}, \mathrm{Si}$, and other nontransition metals with $s^{2} p^{n-2}$ ground electronic states to use all of their valence electrons in bonding without having to pay promotion energy to promote one of the $s$ electrons. The interaction of aluminum with transition metals is particularly important, as intermetallics with unique high-temperature properties can be produced. Experiments are under way to characterize the binary Ti-Al system between $\mathrm{TiAl}$ and $\mathrm{TiAl}_{3}$. This work will be extended to ternary systems. A published paper discusses the relation between the character of bonding in binary aluminum alloys and the structure and stability of the resulting phases.

\section{Staff}

$\begin{array}{ll}\text { Investigator } & \text { Graduate Students } \\ \text { Leo Brewer } & \text { Bart Ebbinghaus } \\ & \text { Karen Krushwitz } \\ \text { Visiting Scientist } & \text { Susan Leonard } \\ \text { Ramana Reddy } & \end{array}$

\section{Publications and Reports}

Refereed Journal Articles

Brewer, L., "The Nature of Bonding in Transition Metal Aluminides," J. Phys. Chem., vol, 94, p. 1196, 1990.

Brewer, L., "Ionic Metallic Solutions," I. Phys. Chem., vol. 94, p. 7839, 1990.

Other Publications

Brewer, L., Bibliography on the High Temperature Chemistry and Physics of Materials, Vol. 34, Part 2: Gases: a: Spectroscopy of Interest to High-Temperature Chemistry; B: Reactions Between Gases and Condensed Phases M. G. Hocking and V. Vasantasree, Eds., IUPAC Commission on High Temperatures and Refractory Materials, London, 1990.

LBL Reports

Brewer, L., LBL-29847, "Unusual High-Temperature Behaviour of Neptunium and Plutonium Systems."

Brewer, L., LBL-29848, "High Temperature Chemisi.,."

Invited Talks

Brewer, L., and K. Krushwitz, Amphoteric Palladium Metal, High-Temperature Cordon Research Conference, Meriden, NH, July 1990.

Brewer, L., Unusual High-Temperature Behavior of Neptunium and Plutonium Systems, American Chemical Society, Washington. D.C., August 1990. 


\section{Materials Chemistry Problems in Nuclear Technology}

D.R. Olander, Paincipal InVestigator

This experimental research program has two princlpal objectives. The first is concerned with the chemical and physical behavior of materials of nuclear reactor systems, both fission and fusion. The experiments are designed to explore the fundamental processes that underlie the performance of these materials in their service environments, which are characterized by combinations of high temperature, intense radiation fields, and reactive gases or liquids. Leaching of actinides from minerals for nuclear and high-temperature vaporization of nuclear ceramics are investigated in this program. The effects of radiation on the microstructure of Zircaloy and hydrogen solubility in nonmetals are also studied.

The second direction of the project is the study of gas solid chemical reactions such as corrosion or etching by the method of modulated molecular beams coupled with mass spectrometry. The objective of these studies is to understand the kinetics and mechanisms of such reactions in clean, well-characterized systems. Systems studied include hydrogen etching of uranium dioxide.

\section{Laser-Pulse Vaporization of Refractory Materials D.R. OLANDER}

Recent experimental and theoretical developments concerning the interaction of laser light with refractory solids were reviewed, with emphasis on long, low-power density pulses. Compared to short, high-power density irradiation, long pulses produce principally thermally-driven evaporation that can be related to the thermochemical properties of the heated surface. Surface temperature measurement and calculation methods were outlined and the use of mass spectrometry to analyze the vapor was reviewed.

\section{Hydrogen Dissolution in and Release from Nonmetals-Crystalline Sillicon}

J. ABREFAH AND D.R. OLANDER

The solubility of hydrogen in crystalline silicon from $1363-1473 \mathrm{~K}$ and from 1.7-9.2 atm has been measured using the method of high-temperature, highpressure infusion followed by high-temperature vacuum outgassing with mass-spectrometric detection. The measured solubilities were in the range 1$5 \times 10^{16}$ atoms $/ \mathrm{cm}^{3}$ and exhibited a temperature dependence consistent with a heat of solution of $30-40 \mathrm{kcal} / \mathrm{mole}$. The pressure dependence of the solubility was consistently smaller than the square-root dependence characteristic of simple interstitial solution. The release rate curves showed multiple peaks, which are incompatible with the classical diffusion model of release. Instead the peaks correspond to trapping of hydrogen at distinct binding sites in the silicon lattice. The release kinetics were modeled as detrapping processes.

\section{Reduction of $\mathrm{UO}_{2+\mathrm{x}}$ Atomic Hydrogen J. ABREFAH, D.F. DOOLEY AND D.R. Olander}

The modulated molecular beam technique with in situ mass spectrometric phase sensitive detection was used to study the kinetics of atomic hydrogen reduction of hyperstoichiometric liranium dioxide. The atomic hydrogen portion of an incident mixed-collisionless $\mathrm{H} / \mathrm{H}_{2}$ beam chemisorbed onto urania surface with a sticking probability of $0.7 \pm 0.1$. A major fraction of the chemisorbed $\mathrm{H}$ atom recombined to produce $\mathrm{H}_{2}$ gas, and only a small fraction entered the parallel channel leading to water production. Both the recombination and the water production processes were linear with respect to the incident $\mathrm{H}$-atom beam intensity. The recombination step was rapid, but a slow desorption-like step controlled the kinetics of water production. A phenomenological model was fitted to the data. 
Concentration Profiles of Neutron-Induced Radioactivities in $\mathrm{UO}_{2}$ Fuel Specimens F. E. Osalsal, S. G. Prussin And D. R. Olander

A chemical etching technique has been developed to measure concentration profiles of neutron-induced activities in specimens of $\mathrm{UO}_{2}$ fuel. Tests on material with an average grain diameter of about $20 \mu \mathrm{m}$ in thickness were performed. Deviations from planarity of the etched surface were generally hidden within the surface roughness. The quality of concentration profiles afforded by the overall procedure was demonstrated by nearquantitative agreement between experimental and calculated ${ }^{239} \mathrm{~Np} /{ }^{95} \mathrm{Zr}$ activity ratios which exhibit marked peaking near a specimen surface from intense resonance absorption in ${ }^{238} \mathrm{U}$. The method has been used for measurement of fission product distributions after high-temperature annealing of irradiated $\mathrm{UO}_{2}$.

\section{Electron Irradiation-Induced Amorphization of Precipitates in Zircaloy-2 A.T. Motta, D.R. Olander, and A.J. Machiels*}

The crystalline-amorphous transformation of $\mathrm{Zr}_{2}$ (Ni, $\mathrm{Fe}$ ) precipitates in Zircaloy by electron irradiation has been studied in the high voltage electron microscope at temperatures ranging from 92 to $283 \mathrm{~K}$ and dose rates between $10^{-3}$ and $4 \times 10^{-2} \mathrm{dpa} / \mathrm{s}$. The dose-to-amorphization was found to increase exponentially with temperature and to decrease with increasing dose rate. The occurrence of the transformation was modeled by calculating the increase in free energy because of irradiation effects: accumulation of point defects and lattice disordering. The time-dependent diffusion equation with recombination was solved to find the interstitial and vacancy concentrations as functions of dose, dose rate, and temperature. Random recombination was the assumed disordering mechanism. The transformation was assumed to occur when the free energy increase of the crystalline phase became equal to the difference in free energy between the amorphous state and the unirradiated crystal. The doseto-amorphization predicted by the model agreed well with experimental results for reasonable values of the fitting parameters.

\section{Leaching of Uranium and Thorium from Monazite D.R. Olander AND YeHUdA EYaL ${ }^{\dagger}$}

Interaction of three natural monazite specimens with a bicarbonate-carbonate solution was investigated for times up to 6.8 years. Dissolution was observed to be incongruent with respect to ${ }^{238} \mathrm{U}$ and ${ }^{232} \mathrm{Th}$ as well as their radiogenic daughters ${ }^{234} \mathrm{U}$, ${ }^{230} \mathrm{Th}$, and ${ }^{228} \mathrm{Th}$. Leaching was divided into a very rapid initial stage lasting a few hours and a slower process active for the remaining time. The initial stage was modeled as the sum of a contribution from a mechanico-chemically damaged portion of the specimen. Data on the leaching of $U$ and $T h$ from monazite are analyzed by a solid-state, moving-boundary diffusion model with a surface reaction boundary condition. Nonstoichiometric leaching of the actinide elements with respect to each other and to the matrix is due to different transport properties of the former in the near-surface layers of the mineral and to the interplay of the diffusion process with mineral dissolution, which causes surface motion. Surface chemical kinetics (i.e., the rate of actinide element detachment from the surface into the solution) is rapid compared to diffusion in the solid, except for Th in an annealed monazite specimen. Diffusion coefficients between $10^{-23}$ and $10^{-19} \mathrm{~cm}^{2} / \mathrm{s}$ are deduced from comparison of the model to the data. These mobilities represent movement of the actinide elements along various high-diffusivity pathways rather than true lattice diffusion.

The solid-state diffusion model is also applied to leaching of radiogenic daughters of the actinide decay chains. For an untreated natural monazite, the direct leaching component of ${ }^{228} \mathrm{Th}$ release is larger than for ${ }^{232} \mathrm{Th}$ because of enhanced solid-state

\footnotetext{
"Electric Power Research Institute, Palo Alto, CA

'Dept. of Chemistry. Technion, Haifa, Israel
} 
mobility for ${ }^{228} \mathrm{Th}$ provided by ${ }^{228} \mathrm{Ra}$-recoil tracks. A significant portion of the ${ }^{228} \mathrm{Th}$ which appears in the leachate, however, is attributed to decay of insoluble ${ }^{228} \mathrm{Ra}$ which is continually released from the mineral by matrix dissolution and recoil ejection.

\section{Y-Ba-Cu-O Superconducting Films by Pulsed Laser Vaporization M. Balooch ${ }^{*}$, D.R. Olander, R.E. RUSSO ${ }^{\dagger}$, ANo W.J. SiekHaus*}

The quality of superconducting thin films evaporated from $\mathrm{YBa}_{2} \mathrm{Cu}_{3} \mathrm{O}_{7}$ targets has been improved using a long-pulse (ms) Nd-glass laser with $50 \mathrm{~J} /$ pulse energy. The film produced on $\mathrm{SrTiO}_{3}$, held at $690^{\circ} \mathrm{C}$, and post-annealed at $880^{\circ} \mathrm{C}$ for about three hours began the transition to superconductivity at $85 \mathrm{~K}$ and had zero resistance at 79 $\mathrm{K}$. The observed variation in film thickness corresponded to diffuse emission from the target, and no significant variation in composition as a function of angle of emission up to $40^{\circ}$ with respect to surface normal was seen. (See section on High- $\mathrm{T}_{c}$ Superconductivity Research.)

Investigators and Scientific Staff

Donald Olander

Mehdi Balooch

John Abrefah

Mehran Moalem
Graduate Students

Wei-E Wang

Y.S. Kim

U. ElSaid

H. Abreu

\section{Publications and Reports}

(See also CAM High- $\mathrm{T}_{\mathrm{c}}$ Superconductivity Program.)

\section{Refereed Journal Articles}

Abrefah, J., M. Balooch, and D.R. Olander, "Hydrogen Dissolution in and Release from Nonmetals. II. Crystalline Sillcon," J. Appl. Phys., vol. 67, p. 1, 1990.

Eyal, Y. and D.R. Olander "Leaching of Uranium and Thorium from Monazite: I. Initlal Leaching, Geochim. et Cosmochim. Acta, vol. 54, p. 1867, 1990.

Motta, A.T. and D.R. Olander, "Theory of Electron-Induced Amorphization," Acta Metall. Mater., vol, 38, p. 2175, 1990.

Olander, D.R., "Laser-Pulse-Vaporization of Refractory Materials," High Temp. Sci., vol. 27, p. 411, 1990; also published in Pure E Appl. Chem., vol. 62, p. 123, 1990.

Olander, D.R., J. Abrefah, and D.F. Dooley, "Reduction of UO ${ }_{2+\times}$ by Atomic Hydrogen," J. Phys. Chem., vol, 94, p. $1937,1990$.

Olander, D.R. and Y. Eyal, "Impact of Alpha-Decay on Incongruent Actinide Isotope Leaching From Monazite," J. Nucl. Mater., vol. 170, p. 117, 1990.

Olander, D.R. and Y. Eyal, "Leaching of Uranium and Thorium from Monazite: II. Elemental Leaching" Geochim. et Cosmochimi. Acta, vol. 54, p. 1879, 1990.

Olander, D.R. and Y. Eyal, "Leaching of Uranium and Thorium from Monazite: III. Leaching of Radiogenic Daughters," Geochim. et Cosmochim. Acta, vol. 54, p. 1889, 1990.

Osalsai, F., S.G. Prussin, and D.R. Olander, "Concentration Profiles of Neutron-Induced Radioactivities in UO ${ }_{2}$ Fuel Specimens," J. Nucl. Mater., vol. 173, p. 149, 1990.

LBL Reports

Balooch, M., D.R. Olander, W.J. Siekhaus, and D.E. Miller, LBL-29529, "Reaction of Chlorine and Molybdenum by Modulated Molecular Beam Mass Spectrometry." 
Moalem, M. and D.R. Olander, LBL-29130, "The High-Temperature Sxolubllly of llydrogen in l'uro and Oxygen-Contalning Zlrcaloy."

Moalem, M. and D.R. Olander, LBL-30094, "Oxidation of Zircaloy By Steam."

Park, K, and D.R. Olander, LBL-29801, "Dofect Moduls for tho Oxygon Potentials of Gadolinlum- and Europlum-Doped Uranla."

Park, K. and D.R. Olander, LBL-29859, "Hydrogon Dissolution In and Rolease from Nonmotals III-Tetragonal Zirconium Dioxlde,"

Park, K. and D.R. Olander, LBL-30093, "Oxygen Diffuslon in Single-Crystal Totragonal Zirconla."

Thesis

Abrou, H, lodine Absorption on Oxidized Stainless Steel, 1990. (M.S. Thesls, Dopartmont, of Nucloar Enginooring D.R, Olander, Advisor).

Invitcd Talks

Olander, D.R., Corrosion of Zirconium by Steam, Meeting of the National Assoc, of Corrosion Englneors, Las Vogas, NV, April 1990.

Olander, D.R., Nuclear Materials Research and Development in Japan, Report at the Japan Technology Evaluation Contor Nuclear Power Panel Workshop, Washington, D.C. February 1990.

Olander, D.K., Nuclear Materials, Special Summer Program for DOE Interns, Mass, Instttute of Technology, Cambridge, MA, August 1990.

Olander, D.R., Nuclear Power in the U.S, and Japan - A Comparison, Nuclear Engineering Department Colloquim, University of Callfornla, Berkeley, CA, March 1990.

Olander, D.R., Prospects for Nuclear Power - Japan and the U.S, Rossmoor Engineer's Club, Walnut Creek, CA, April 1990).

Contributed Talks

Olander , D.R., Cluster Formation during Laser Vaporization of Ceramics, 27th Bay Area High Temperature Sclence and Technology Symposium, Lawrence Berkeley Laboratory, Berkeley, CA, November 1990.

Olander , D.R., Etching of Silicon Carbide by Chlorine, Electrochemical Society Meeting, Seattle, WA, October 1990.

Olander, D.R., High-Temperature Oxidation of Zircaloy, Electrochemlcal Society Meeting, Seattlo, WA, October 1990,

Olander, D.R., Oxygen Diffusion in Single-Crystal Zirconia, Electrochemical Socioty Mecting, Seattle, WA, October 1990. 
Nucleation and growth processes in the clectrosolidification of metals and polymers from aqueous medla are investigated to advance the understanding of the development of deposit properties from the first atomic layers to macroscopic thicknesses. Parameters of electrochemical kinctics and mass transfor are studied in the early stages of deposition to gain insight into the action of leveling and brightening agents that control deposit properties. The results of measurements are used to develop theoretical models for prediction of microstructure and surface morphology.

New experimental techniques are developed and used for determining microtopography and composition of deposit surfaces, particularly during their formation while immersed in the electrolyte.

Studies of electrochemical surface layers on battery materials are reported in the section "Electrochemical Energy Storage" of this report. Research on electrochemical mass transfer, conducted in collaboration with C.W. Toblas, is reported in his section "Electrochemical Processes."

\section{The Role of Inhibltors During Electrodeposition of Thin Metallic Films} M.J. Armstrong and R. H. Muller

The role of brightening agents during the deposition of thin metal films was analyzed. The brightness of a surface, characterized by a low intensity of scattered light is related to its topography. Additives are used in plating baths to reduce the roughness. The model brightening system studied was copper deposition in the presence of benzotriazole (BTA). Emphasis was placed on the early stages of deposition. Brightening was found to occur when the concentration of BTA is greater than $100 \mu \mathrm{M}$ and the current density is greater than $50 \mathrm{~mA} / \mathrm{cm}^{2}$. Benzotriazole was not incorporated into the copper deposits, as determined by x-ray photoelectron spectroscopy and secondary ion mass spectroscopy. Benzotriazole altered the morphology of the deposited Cu. Deposits from BTA free electrolyte consisted of flat planes terminated by ledges with growth occurring at the ledges (Figure 1). Deposits
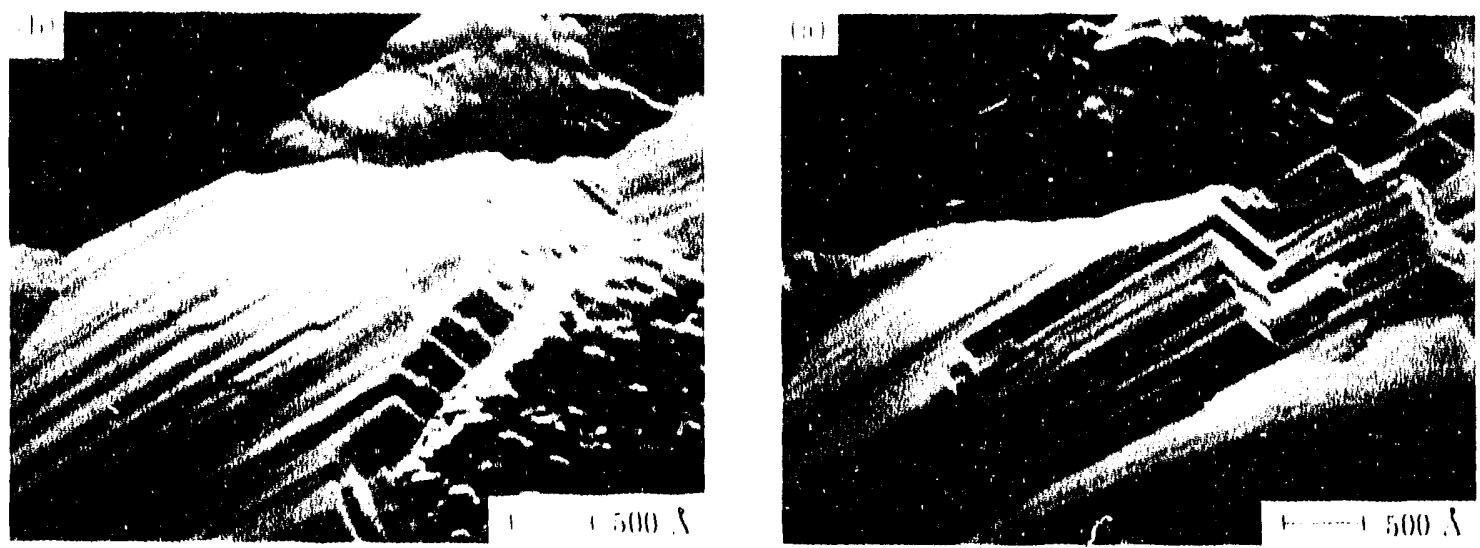

Flgure 1

STM images of a Cu deposit formed by a $30 \mathrm{~s}$ pulse to $-500 \mathrm{mV}$ followed by a step to $-25 \mathrm{mV}$ vs Cu in BTA-free $10 \mathrm{mM}$ $\mathrm{Cu}\left(\mathrm{ClO}_{4}\right)_{2}, 0.5 \mathrm{M} \mathrm{NaClO}_{4}, 0.1 \mathrm{M} \mathrm{HClO}_{4}$ electrolyte; displayed with a derivative-coded grey scale, a) initial deposit and b) following 30 seconds at $-25 \mathrm{mV}$ vs Cu. Propagation of crystal facets ( $2 \mathrm{~nm}$ height) from lower left corner of a) to center of b). (XBB 880-11214-A) 


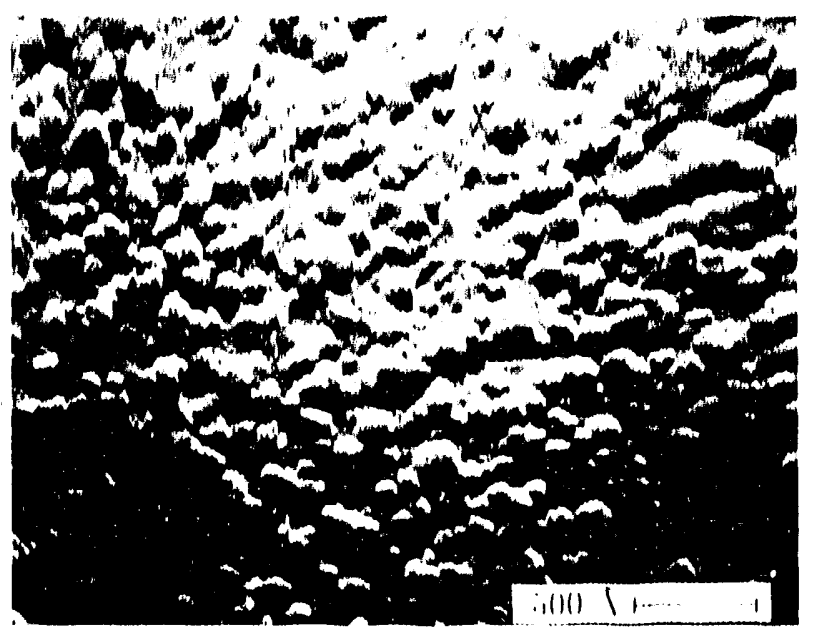

Figuro 2

STM Imago of a $20 \mathrm{mC} / \mathrm{om}^{2} \mathrm{Cu}$ doposit on a PI substlato displayod with a derlvative-codod groy soale. Doposit lormod by a $100 \mathrm{~mA} / \mathrm{om}^{2}$ pulso in $0.6 \mathrm{M} \mathrm{CuSO}_{4}, 0.6 \mathrm{M} \mathrm{H}_{2} \mathrm{SO}_{4}$, with $100 \mu \mathrm{M}$ BTA. FFT of the daposit contour Indloatos perlodlolty of nuclel of $32 \mathrm{~nm}\left(9.8 \times 10^{10}\right.$ nuelol $\left./ \mathrm{om}^{2}\right)$. (XBB 901-654)

from BT'A containing electrolyte consisted of hemlspheres with growth occurring uniformly on the surface (Figure 2): The brightening of copper deposited in the presence of BTA for a given current density is a result of an increased nucleation rate.

\section{In Situ Scanning Tunneling Mlcroscopy of Copper Deposition with Benzotriazole}

\section{J. Armstrong and R. H. MUllek}

The sub-micron topography of $\mathrm{Cu}$ deposits has been studied with scanning tunneling microscopy to investigate the effect of benzotriazole in the initial stages of deposition. The presence of benzotriazole results in a marked increase in overpotential for the deposition (Figure 3). The number density of nucled, determined from Fourier transforms of the surface profiles of $7 \mathrm{~nm}$-thick films, is found to increase with increasing overpotential of the deposition but is independent of the presence of the inhibitor (Figure 4).

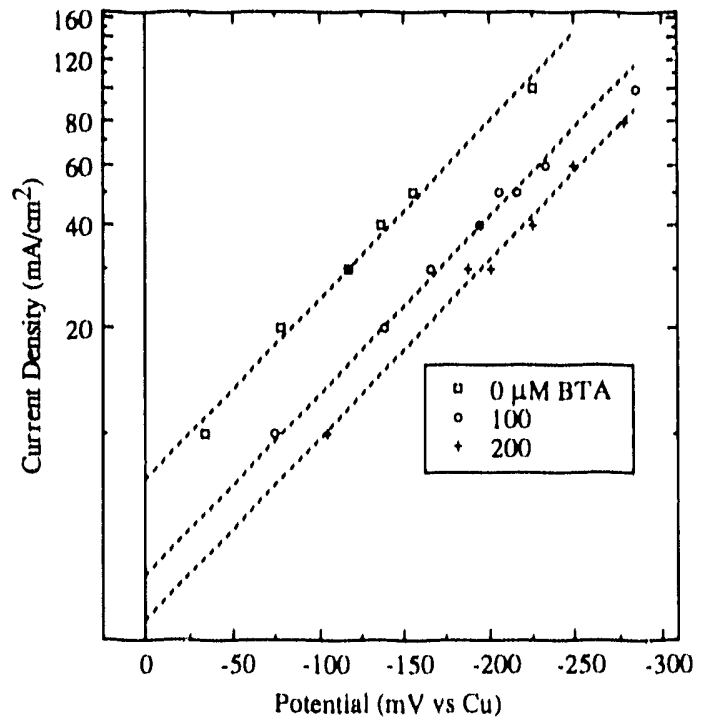

Figure 3

Tafel plot of the potential-ourrent relationship for $\mathrm{Cu}$ deposition from $0.5 \mathrm{M} \mathrm{H}_{2} \mathrm{SO}_{4}, 0.5 \mathrm{M} \mathrm{CuSO}_{4}$, with 0,100 , and $200 \mu \mathrm{M}$ BTA. Rotating disk, $700 \mathrm{rpm}$. Potential corrected for a $2.3 \Omega$ ohmic drop through the cell. (XBL 902.610)

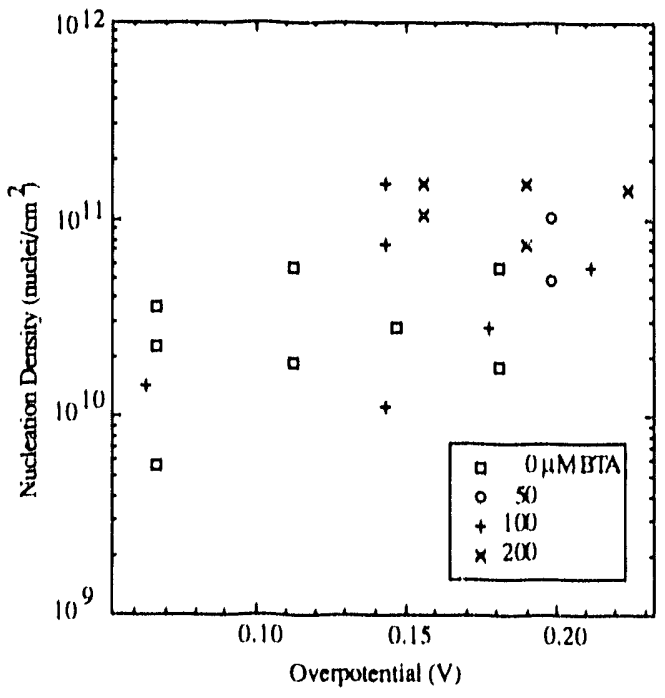

Flgure 4

Effect of overpotentlal and BTA concentratlon on the number densities of nuclel of $20 \mathrm{mC} / \mathrm{cm}^{2} \mathrm{Cu}$ deposits on Pt. Number densities of nuclel derived from FFT of the deposits. Cu deposits formed from $0.5 \mathrm{M}$ CuSO $_{4}, 0.5 \mathrm{M} \mathrm{H}_{2} \mathrm{SO}_{4}$, with (I I) $0,(0) 50,(+) 100$, and (x) $200 \mu \mathrm{M}$ BTA. (XBL 906-2301) 


\section{Effect of Suspended Partleles on Mass Transfer to a Rotating Cylinder Electrode \\ D.W. Gibeong, R.H. Mullean ano O.W. Tobias}

Mass transfor onhancement produced by the addition of inort microsphores was investigated on a rotating cylinder electrode operating in the turbulent regime. Tho effects of rotation speed, rotor radius, particle size, sollds volume fraction, and particle density on the rate of mass transfor were determined by limiting curront measurements for ferricyanide ion reduction. In comparison to transport rates observed with clear electrolytes, up to two and a half fold higher limiting currents were obtained in concentrated suspensions containing 5 80 $\mu \mathrm{m}$ diametor microspheres with densttics ranging from 0.7 to $2.1 \mathrm{~g} / \mathrm{cm}^{3}$. Transport onhancement is attributed to the microconvective eddies produced by particle rotation in the shear ficld adjacent to the spinning electrode, and to the increased shear rate caused by the formation of a particle-free wall layer. The use of suspended particles to achieve a given increase in limiting current donsity is shown to require far less power than increasing electrode rotation speed to obtain the same transport enhancement.

\section{Composition Modulated Alloys Plated in Fluctuating Flow}

D.T. SCHWARTZ

Soft magnetic alloy fllms for data storage devices are typically electrodeposited in a fluctuating flow fleld. Experimental and theoretical results show that time-periodic modulation of the flow field and potential at a rotating disk electrode induces periodic deposition rates for a mass-transfer-1imited species and an activation-1imited species, respectively. The time-periodic deposition of either alloy species can result in a deposit with nanometer-scale periodic composition variations; a composition modulated alloy (CMA) is formed. Nanoscale CMAs often exhibit material properties that are dramatically different from the properties of the homogeneous alloy. Dimensionless groups are formulated to characterize the operating regimes where CMAs deposit from a single electrolyte, and where fluctuating flow influences the composition distribution of the alloy. It is shown that the phase angle difference between the flow and potential modulation waveforms is an important parameter in determining the interfacial character of the resulting CMA.

$\begin{array}{ll}\text { Investigator } & \begin{array}{l}\text { Graduate Students } \\ \text { Foliz Kinad }\end{array} \\ \text { Rolf H. Mullor } & \\ \text { Postoctoral Fellow } & \\ \text { Daniol Schwartz } & \end{array}$

l.BL. Reports

Armstrong, M.J., and R.H. Mullor, L.BL.-29476, "In Situ Scanning Tunnoling Microscopy of Coppor Deposltion with Benzotrlazolo," J. Eilectrochem. Soc. (Sidbmitted.)

Glbbons, D.W., with R.H. Muller and C.W. Toblas, "Mass Transport to Cylindrical Eloctrodes Rotating In Suspenslons of Inert Microsphores," (submitted to 1. Electrochem. Soc.),

Theses

Armstrong, M.J., "The Role of Inhibitors during Electrodoposition of Thin Motallic Films," (Th.D Theyis),

Gibbons, D.W., "The Effect of Susponded Particles on the Rate of Mass Transfor to a Rotating Cylinder Electrode," (MS Thesly). Invited Talks

Schwartz, D.T, Composition-modulated Alloys Plated in a Fluctuating Flow Field, S.F, Section, Electrochom, Soc, Stanford, CA, Octobor 1990.

Contributed Talks

Armstrong, M.J, and R.H. Mullor, Nucleation of Coppar Fillms on Platinumi liffect of Benzotriazole, Eloctrochom. Soc, Mooting, Scattlo, WA, October 1990, ext, abs, no, 633. 


\section{Nuclear Magnetic Resonance}

A. Pineg, Painolpal InVEgtigatoa

The goals of this program are the development of novel theory and exporiments in magnotic rosonance and the domonstration of their application to materials resoarch. Recont tochniques doveloped in our laboratory include multiple-quantum spectroscopy, zero-ficld nuclcar magnetic resonance (NMR), iterative maps, double rotation (DOR), dynamic-angle spinning (DAS), optical pumplng, and SQUID magnetic resonance. Materials appliciations includo clusters, semiconductors, oxides, liquild crystals, zoolites, and intercalated graphite.

\section{Atomlo Distrlbutlon Statistlos In Zeolltes}

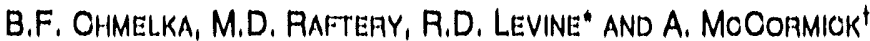

${ }^{129}$ Xe NMR spectroscopy has been used to probe directly the distribution of xenon atoms confined in atomic-size NaA zcolite cavitles. For mean xenon occupancles less than about three $X e$ atoms per $\alpha$-cage, the guest populations are well described by binomial statistics. At higher guost loadings the finite volumes of the xenon atoms become significant, as reflected by a fit of the experimental populations to a hypergeometric distribution. The data and hypergeometric analysis indicate a maximum occupancy of seven Xe atoms/cage. At the highest xenon loadings the experimental distribution is narrower than hypergeometric.

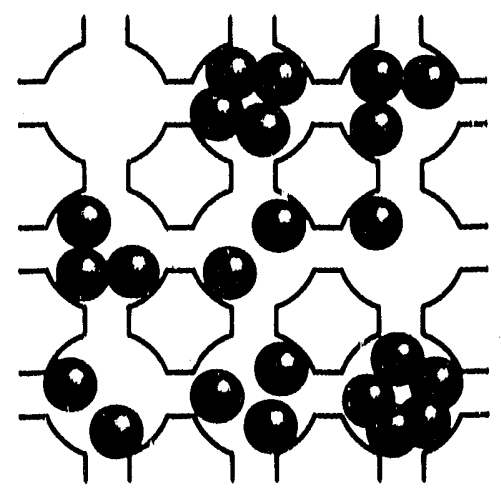

Flgure 1

Sohomallo dlagram of xonon aloms distrlbuted within the (L-cagos of Na-A zoollte. (XBL 0011-3828)

\section{NMR Studies of Molecular Clustering In Zeolites}

M. D. Rafteay, B. F. Chmelka, J. G. Pearson, C. J. Radke $\$$, S. F. Pedersen ${ }^{\ddagger}$, and A. Pines

Macroscopic and local distributions of aromatic molecules adsorbed within $\mathrm{NaY}$ zeolite samples have been investigated using ${ }^{129} \mathrm{Xc}$ and multiple-quantum NMR. Room temperature xenon-129 NMR is a sensitive probe of macroscopic adsorbate distributions, allowing the obscrvation of adsorption fronts and other intercrystalite adsorbate hetrogenelties. Multiple-quantum NMR has been used to measure the intracrystalite adsorbate distributions by "counting" the number of spins (hydrogen nuclei) present in each adsorbate cluster. We are also investigating the use of dipoledipole coupled spin network growth rates in the determination of homonuclear dipole coupling strengths, and therefore distances, between molecular clusters. Low temperature $(123 \mathrm{~K})$ xenon-129 NMR is also being used to determine local adsorbate distributions within NaY zoolite.

Flgure 2 (soe page 79, top)

a) Graph of the apparent cluater size, $N$, as a funotion of preparation time for a NaY zeolite sample containirig a bulk average of one bonzone molecule per two supercages. Data was acquired at room temperature. $N \rightarrow 6$ as preparation $t$ me $\rightarrow \infty$, Indicating a random distribution of benzene moleoules between the zoolite supercages. b) is a ${ }^{120} X_{\theta}$ spectrum of a simllar sample at $160 \mathrm{~K}$, with ${ }^{120} X_{\theta}$ added. The two poaks in the ${ }^{129} \mathrm{Xe}$ speotrum Indlcate two a!stinot environments, supercages with and without benzene guests. (XBL 918-1905)

\footnotetext{
" Hebrew University of Jerusalem, |srael

† Department of Chemical Engineering, University of Minnesota, Minneapolis, MN

‡ Department of Chemical Engineering, University of Callfornia at Berkeley
} 
a)

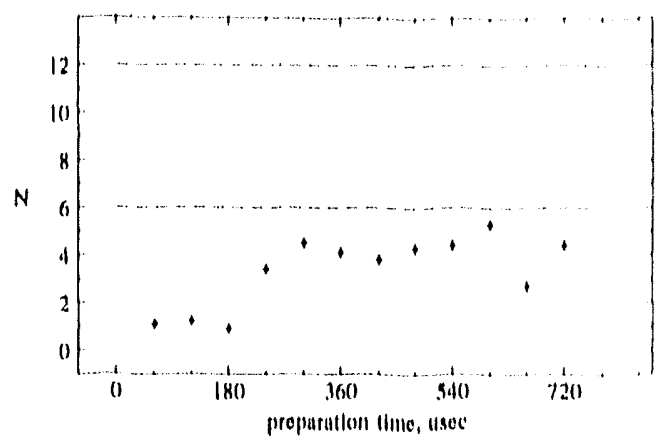

b)

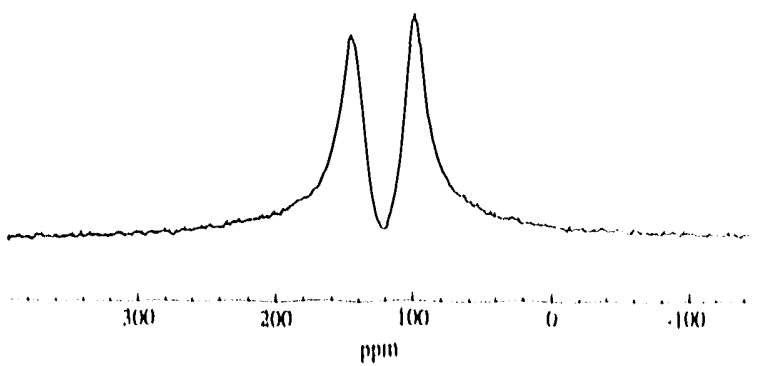

\section{Conformations and Motion of Tetrahydrofuran (THF) in Graphite \\ C. SOHMIDTS, M. E. ROSEN, D. F. CAPLAN, M. F. QUINTON\#}

The orientation and motion of THF in the ternary graphite intercalation compounds $\mathrm{Cs}(\mathrm{THF})_{13} \mathrm{C}_{24}$ and $\mathrm{K}(\mathrm{THF})_{2.5} \mathrm{C}_{24}$ has been determined by proton NMR. Simulations of the NMR spectra indicate that the THF molecules in $\mathrm{Cs}(\mathrm{THF})_{13} \mathrm{C}_{24}$ are oriented with their mean planes parallel to the layers of the host lattice. $\operatorname{In} \mathrm{K}(\mathrm{THF})_{2.5} \mathrm{C}_{24}$ the THF molecules appear to be oriented with their mean planes between 50 and $75^{\circ}$ relative to the graphene layers. The spectra show evidence of rotation of the THF molecules about the layer normal and also a degree of orlentational disorder which corresponds to a mosaic spread of the samples, as determined by X-ray diffraction. The conformation of THF in $\mathrm{Cs}(\mathrm{THF})_{13} \mathrm{C}_{24}$ was studied by modelling its intramolecular motion and simulating the experimental NMR data. Good agreement was found for THF interconverting between two conformations with $\mathrm{C}_{\mathrm{B}}$ symmetry and a puckering amplitude of $0.30 \AA$ or for just one conformation with $\mathrm{C}_{\mathrm{a}}$ symmetry and a puckering amplitude of $0.32 \AA$. Free or slightly hindered pseudorotation as observed in free $\mathrm{THF}$ does not seem to occur. For $\mathrm{K}(\mathrm{THF})_{2.5} \mathrm{C}_{24}$ reasonable agreement is found for elther one or two conformations with $\mathrm{C}_{\mathrm{s}}$ symmetry.
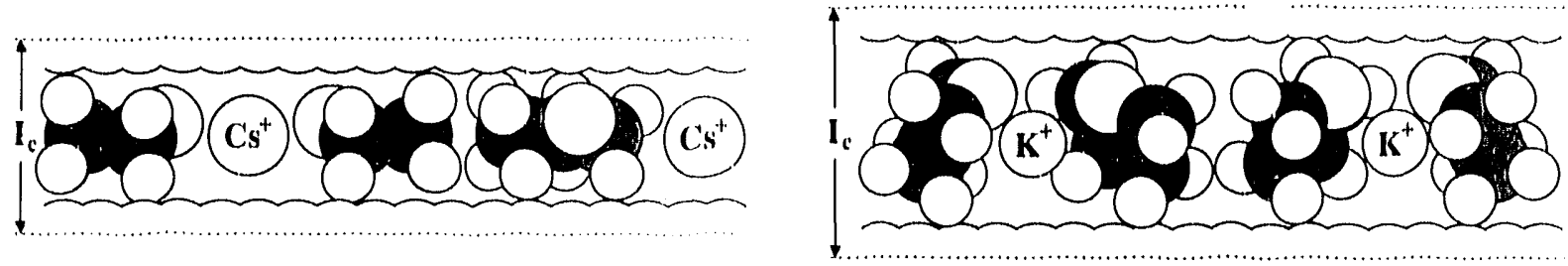

Flgure 3

Schematic plotures of $\mathrm{Cs}(T H F)_{1.3} \mathrm{C}_{24}$ and $\mathrm{K}(T H F)_{2.5} \mathrm{C}_{24}$ that are consistent with the results of the simulations of the proton NMA speotra. The values of $l_{0}$ determined by $x$-ray diffraotion are $7.1 \mathrm{~A}$ for $\mathrm{C} 8(T H F)_{1.3} \mathrm{C}_{24}$ and $8.9 \mathrm{~A}$ for $\mathrm{K}(\mathrm{THF})_{2.8} \mathrm{C}_{24} \cdot(\mathrm{XBL}$ 018-1906)

\section{NMR Imaging of Flow and Turbulence}

G. C. Chingas, L. FAYDMAN, AND J, S. HARWOOD“"

A variety of novel multidimensional NMR sequences have been developed which provide a history of the displacements affecting fluid samples. This macroscopic characterization of motions was applied to investigate the behavior of fluids undergoing diffusion, Poiseuille flow and Taylor flow; the observed results have shown very good agreement compared with the known statistics of the motions. This way of describing complex fluid behavior is based on Fourier principles which show that 


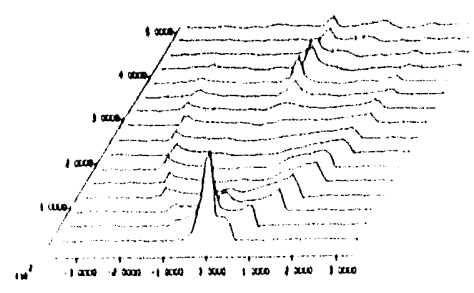

gradient strengths can bo used to extract the statistical distribution of displacements in a way intimately related to NMR signal formation. Figure 4 presents an application of this technique to vortex motion in a Taylor column. The plot shows a series of displacement distributions for an initial fluld slice selected midway between a cell wall and center. Right and left branches indicate the presence of motion in both upward and downward directions in the column, while the re-appearance of the central peak shows return of some fluid to the initlal slice plane after reversing direction after encountering the cell wall. This indication of cyclic return of portions of the fluid to their initial positions is unique to this technique, and distinguishes it from laser methods where only velocities are available.

Flgure 4

NMF characterization of Taylor flow. The horizontal scale is given in mm, whereas the second dimension is giveri in milliseconds. (XBL 918-1907)

\section{Isotropic Time Reversal in Zero-Field NMR}

A. LLOR*, Z. OLEJNICZAK', AND J, SACHLEBEN

Coherent magnetic field pulses applied in zero-field NMR have been used to selectlvely average the zero-field Hamiltonian while preserving the intrinsic orientational invariance of the spectrum. General theoretical results have defined the limits of isotropic zero-field scaling for first and second rank

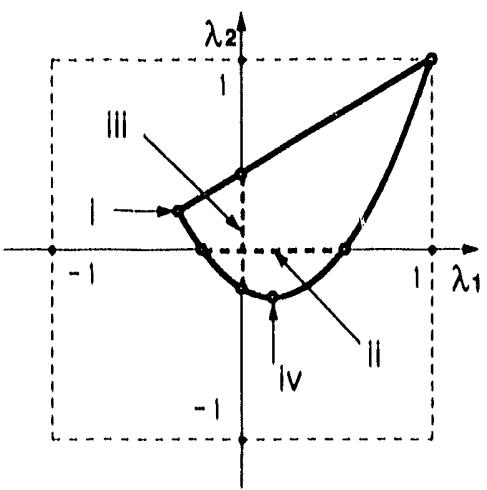
interactions. From these general theoretical results, it was found that negative scalings are possible allowing isotropic time-reversal of the zero-ficld Hamiltonian. Experimental realizations of two such time-reversal sequences have been observed by the formation of a magnetization echo. These sequences generated the following combined zero-field scalings for first and second rank interactions: $(-1 / 3,1 / 5)$ the optimum first rank time reversal, and $(1 / 5,-1 / 5)$ a second rank time reversal.

Figure 5

The allowed combinations of isotroplo scalling faotors for first and second rank tensors, $\lambda 1$ and $\lambda 2$, are limited by the thiok solle line $\ln$ the $\lambda 112$ plane. Some combinations of special importance in appllcations are: (I) $(-1 / 3,1 / 5) ;\left(\right.$ (II) $\left(\left(1-5^{1 / 2}\right) / 6,0\right)$ to $\left.\left(1+5^{1 / 2}\right) / 6,0\right) ;$ (iil) $(0 .-1 / 5)$ to $(0,2 / 5) ;($ IV) $(1 / 6,-1 / 4)$. (XBL 918-1908)

\section{Icosahedral Sequences in the Laboratory and Rotating Frame}

Z. OLEJNICZAK $\neq, Z$, Y. PENGS, B. SUN, AND A. SAMOSON"

The icosahedral symmetry provides a sufficient approximation to a fuil spherical symmetry when it is imposed on the internal nuclear spin Hamiltonian, which contains the irreducible spherical tensors of maximum rank equal to four. Therefore a stroboscopically observed internal Hamiltonian can be made to look isotropic in the Average Hamiltonian Theory approximation. An icosahedral sequence of de magnetic field pulses applied in zero-ficld NMR is

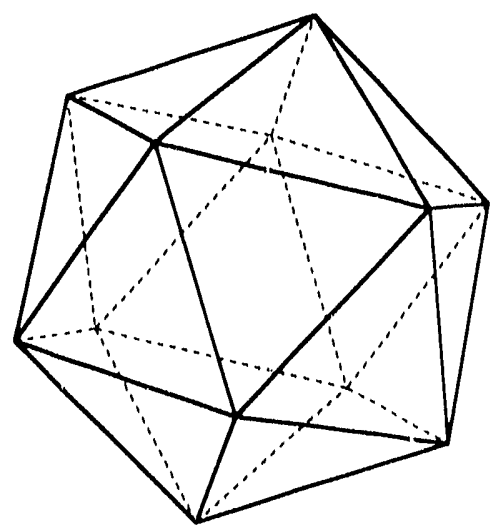
the most efficient way to produce fully isotropic and selective scaling, decoupling or time reversal of the internal Hamiltonian. Similarly, a sequence of $\mathrm{rf}$ pulses that have the icosahedral symmetry in the rotating frame can be applied to the spin part of the truncated Hamiltonian in high magnetic field. When it is combined with a synchronous reorientation of the sample along the icosahedral vertices, an isotropic zero-field Hamiltonian will be recovered which contains structural information about interacting spins.

\section{Figure 6}

A set of discrete configurations of the internal nuolear spin Hamiltonlan which consists of twelve vertices of lcosahedron Is the minimum number necessary to remove the anisotroplo effects in the NMR spectrum. (X.BL 918-1909) 
The Dynamic-Angle Spinning (DAS) Pulse sequence has been improved. The original DAS pulse se, Irence did not allow pure absorption lineshapes to be obtained. Through cons i ration of the coherence transfer (CT) pathways involved in the experiment, two pure phase pulse sequences have been developed which yield significantly narrower lines. In addition, one of these new sequences allows the high resolution DAS dimension to be correlated with an MAS dimension. Since DAS can now be correlated with MAS, the second dimension lineshape is independent of chemical shift anisotropy (CSA), and the powder patterms in the F2 dimension can be easily simulated to give quadrupolar parameters for each site. By performing DAS experiments at two different fields, separation of the total shift into the isotropic chemical and second-order quadrupolar shift contributions is possible. ${ }^{17} \mathrm{O}$ labelled alanine, leucine, and tyrosine in high yield and high ${ }^{17} \mathrm{O}$ incorporation have been obtained, and initial ${ }^{17} \mathrm{O}$ DAS spectra of these have also been obtained. The attempt is now being made to obtain better spectra with increased resolution by working at higher field. This will allow chemical and quadrupolar shifts as described above to be obtained.

Figure 7

${ }^{17}$ O DAS spectra of diopside at two different field strengths showing field dependent shifts of the resonances corresponding to the three crystallographic oxygen sites. From the shifts at the two fields the contributions of the isotropic chemical shift and the second-order isotropic quadrupolar shift to the total shift can be determined. (XBL 918-1910)

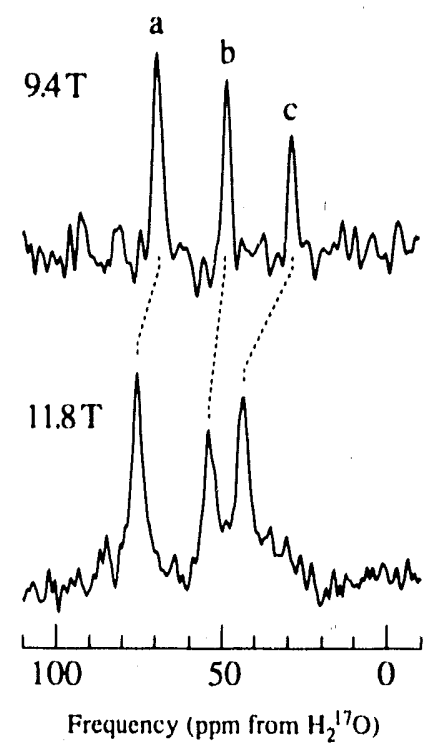

Oxygen-17 NMR in Silicates

K.T. Mueller, Y. Wu, B. F. ChmelKa, AND J. STeBbins ${ }^{\dagger \dagger}$

Until recently it has been difficult to resolve NMR resonances from distinct oxygen environments in polycrystalline and amorphous solids. Individual spectral lines from oxygen- 17 can now be distinguished in a variety of compounds containing from one to nine distinct sites. Several oxygen-17 enriched sclids have been studied using Dynamic-Angle Spinning (DAS) and Double Rotation (DOR) nuclear magnetic resonance spectroscopy. These methods average away second-order quadrupolar interactions by reorienting a sample about a time-dependent axis. A narrow spectral line is observed for each distinct oxygen site at the sum of the isotropic chemical shift and the field-dependent isotropic second-order quadrupolar shift, and resolution is increased by up to two orders of magnitude compared to conventional magic-angle spinning (MAS). New sets of experiments are also being performed using DAS at two field strengths to retrieve the isotropic chemical shifts (which are independent of the field strength) and the quadrupolar parameters for each oxygen site. These parameters teach us about the environments of the oxygen sites in important materials.

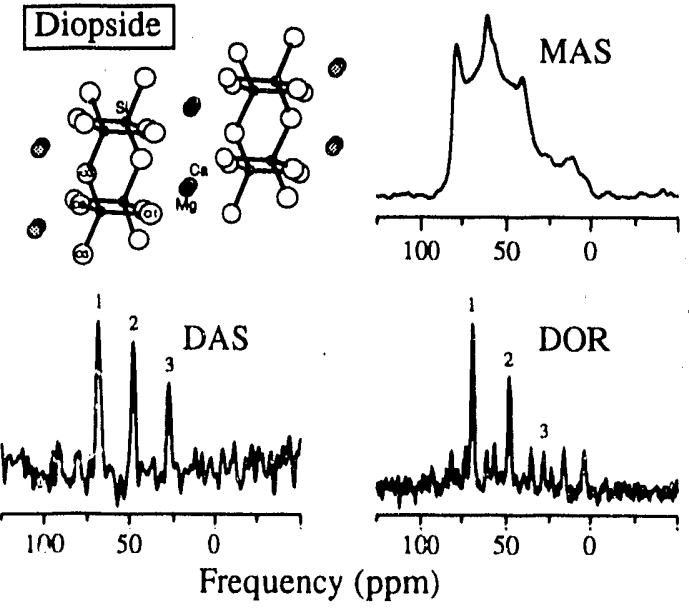

Figure 8

Resolution of the three crystallographically inequivalent oxygen-17 sites in a polycrystalline sample of the silicate diopside $\left(\mathrm{CaMgSi}_{2} \mathrm{O}_{\theta}\right)$ using DAS and DOR NMR spectroscopy. (XBL 918-1911) 
Aluminum-27 NMR in Aluminophosphates

Y. WU, B. F. ChMELKA, AND R. JELINEK

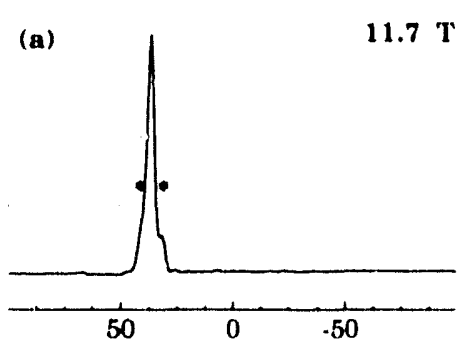

Unprecedented high resolution Al-27 NMR spectra of the aluminophosphates AIPO, -5,8,21,25 and VPI-5 are obtained using Double-Rotation (DOR). Physical adsorption of water molecules onto the framework causes structural changes which are demonstrated by the shape and position of the resonances. Less short-range order, leading to broader spectral lines, is observed for $\mathrm{AIPO}_{4}$ 5 and AIPO4-8 upon dehydration. The two tetrahedral aluminum sites of the AlPO,-25 framework are not resolved in a 11.7 Tesla field. The isotropic resonances, however, are distinguished in 4.2 Tesla because the difference between the isotropic quadrupolar shifts of the two sites is bigger at a lower magnetic field. The quadrupolar parameters extracted for the two sites at the dehydrated and hydrated $\mathrm{AIPO}_{4}-25$ samples, indicate a less distorted frame-

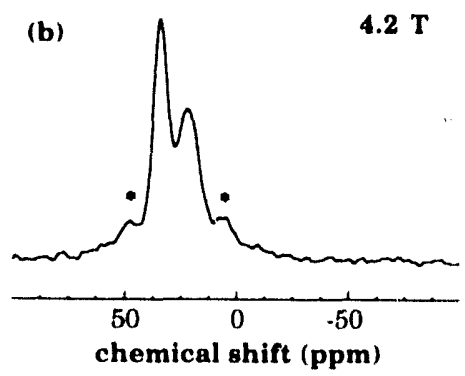
work aluminum environment in the presence of water molecules. In VPI-5, the novel-18-membered-ring molecular sieve, several tetrahedral aluminum environments are detected during the hydration process.

\section{Figure 9 \\ ${ }^{27} \mathrm{Al}$ DOR spectra of dehydrated AIPO,-25: (a) Acquired at 11.7T; (b) Acquired at 4.3T. Outer rotor spinning speod for both spectra was $750 \mathrm{~Hz}$. (XBL. 9010-3383)}

\section{NMR Study of Multi-Site Structures in Quasicrystals Y. Wu, T. H. Chang, Z. M. STANIK}

The sharp X-ray diffraction patterns with fivefold rotational symmetry which are observed in icosahedral crystals, are incompatible with the concept of periodicity in crystals but can be reproduced, however, by quasicrystal model as well as by glass model. The former contains both long-range transitional - although nonperiodic-and orientational orders whereas the latter contains only long-range orientational orders. Instead of multi-site structures as required by quasicrystal model, only broad distributions of local environments have so far been observed by local probes such as Mossbauer spectroscopy and NMR which indicate the glassy features of icosahedral crystals. These distributions, however, may i ot be intrinsic to the icosahedral crystals like in the glass model but rather are the consequences of defects in quasicrystals. Using high magnetic field (11.7 Tesla) and magic angle spinning technique, multi-site structures in various icosahedral crystals were observed. NMR resolutions comparable to those obtained in crystals have been achieved in annealed $\mathrm{Al}_{65} \mathrm{Cu}_{20} \mathrm{Fe}_{15}$ icosahedral crystals (Figure 10a). The Knight shifts, the spin-spin relaxation times

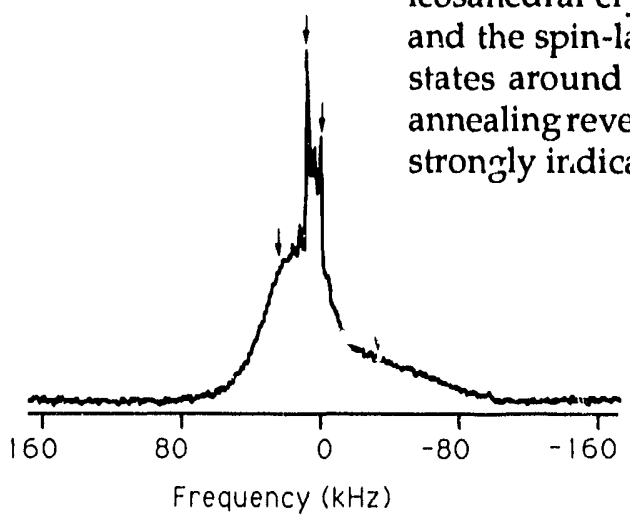

Figure 10

Al-27 MAS spectrum of annealed $\mathrm{Al}_{65} \mathrm{Cu}_{20} \mathrm{Fe}_{15}$ icosahedral crystal. The arrows indicate the distinct resonance peaks. (XBL 918-1912)

\footnotetext{
"Department of Physics, University of Ottawa, Ottawa, Ontario, Canada
} 


\section{Nitrogen-14 Effects in ${ }^{13} \mathrm{C}$ and ${ }^{14} \mathrm{~N}$ NMR Spectroscopy \\ Y. LeE, P. GRandinetti, and M. EAstman}

DAS and DOR sample reorientation methods known to increase resolution in spectra of quadrupolar nuclei with spin $n / 2$ in polycrystalline solids, are being developed for application to structural studies on peptides and proteins. The quadrupolar nucizus of interest in these materials is ${ }^{14} \mathrm{~N}$. Dipolar coupling between ${ }^{19} \mathrm{C}$ and directly bonded ${ }^{14} \mathrm{~N}$ results in splitting and broadening of the lines in the $13 \mathrm{C}$ spectrum. By removing this broadening, DAS should allow accurate measurement of the splitting of the ${ }^{13} \mathrm{C}$ resonances due to ${ }^{14} \mathrm{~N}$, which can then be correlated to local molecular structure. Currently, $w^{13} \mathrm{C}$-DAS technique is also being applied to amino acids and peptides. Also being pursued is the possibility of observing ${ }^{14} \mathrm{~N}$ directly in these compounds by combining the DOR technique, for removal of second order quadrupolar line broadening, and observation of overtone transitions, which, unlike fundamental transitions, are not affected by first order broadening.

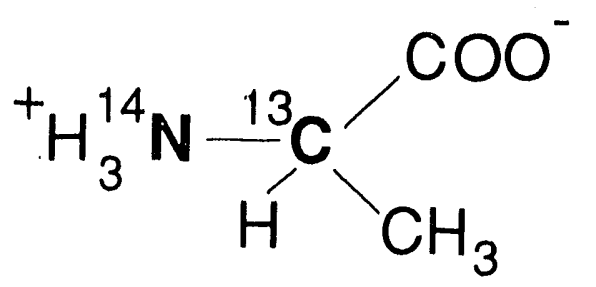

Figure 11

The $\mathrm{C}-\mathrm{N}$ bond shown here in alanine, is present in all amino acid residues. Quadrupolar parameters for ${ }^{14} \mathrm{~N}$, which are indicators of local molecular structure, can be determined using the ${ }^{13} \mathrm{C}$-DAS and ${ }^{14} \mathrm{~N}$ overtone-DOR methods.

\section{Boron SQUID Resonance in Crystalline and Glassy Borates J. ChANG, C. CONNOR AND B. BLACK}

A magnetic resonance SQUID (Superconducting QUantum Interference Device) spectrometer has been used to detect Boron-10 and Boron-11 NQR (Nuclear Quadrupole Resonance) in crystalline $\mathrm{B}_{2} \mathrm{O}_{3} \mathrm{Q} \times \mathrm{H}_{2} \mathrm{O}$ (where $\mathrm{x}=0,1$, and 3 ) and vitreous $\mathrm{B}_{2} \mathrm{O}_{3}$. The observation of ${ }^{10} \mathrm{~B}$ and ${ }^{11} \mathrm{~B}$ resonances in the crystalline borates has allowed the calculation of the quadrupolar parameters and given structural information on the boron sites. The ${ }^{11} \mathrm{~B}$ signal in vitreous $\mathrm{B}_{2} \mathrm{O}_{3}$ had a linewidth of about $70 \mathrm{kHz}$, showing that he SQUID spectrometer has the ability to detect quadrupole resonances even when there is a distribution of nuclear sites as is expected in an amorphous system. This opens up the possibility of performing some hole-burning experiments to determine the spatial discribution of these varying sites.

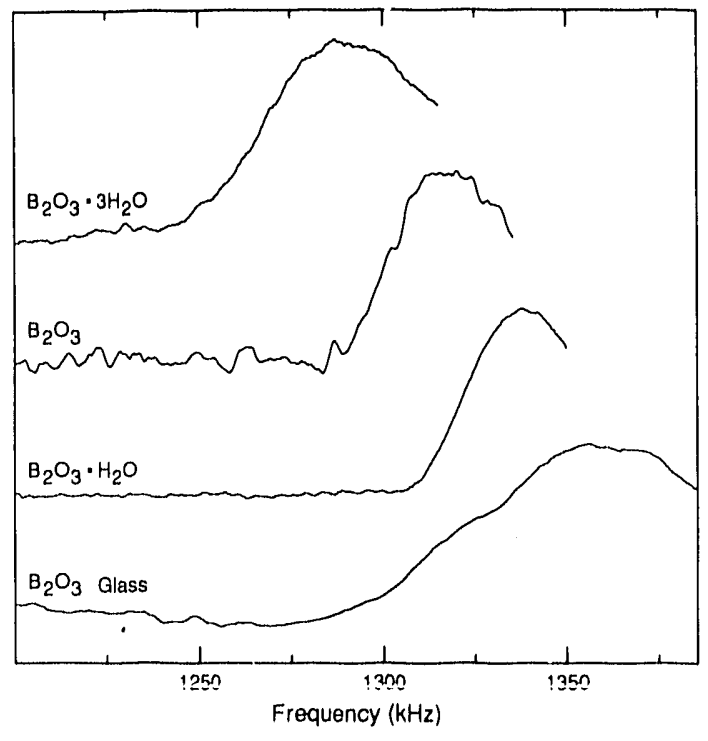

Figure 12

Boron- 11 in 3 crystalline and glassy $\mathrm{B}_{2} \mathrm{O}_{3}$. (XBL 918-1913)

" M.P.I. fur Metallforschung, Institut fur Physik, Stuttgart, Germany 


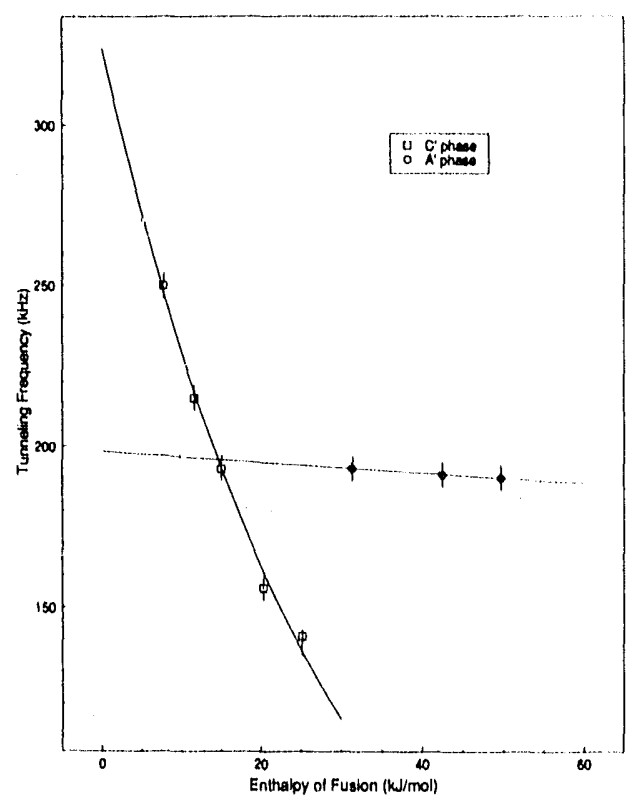

a)

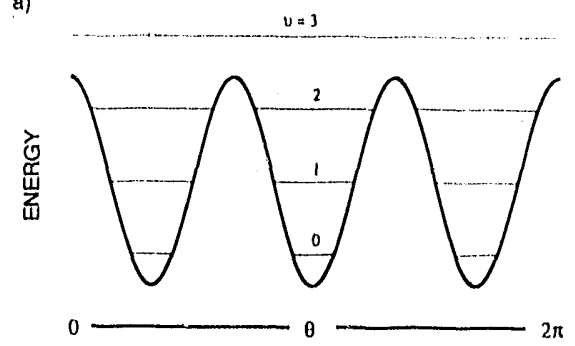

b)
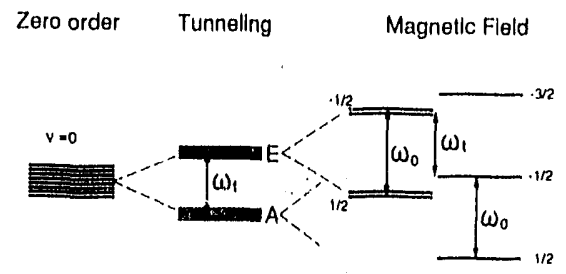

Figure 13a (left)

Plot of the correlation between tunnellng frequency and enthalpy of fusion for the stralght-chained carboxylic acids with an odd number of carbon atoms. The two distinct crystallographic phases, $A^{\prime}$ and $C^{\prime}$, show different correlations. (XBL 918-1914)

Figure 13b (right)

a) Rotational energy levels of a methyl group in a triple well potential, where no tunneling is allowed, b) The eight spin states of the $n=$ 0 rotational state are degenerate in zero order. When tunneling is allowed, the spin states are spitt into two manifolds consisting of four degenerate states each. The splitting between these manifolds is the tunneling frequency, wt. When a magnetic field is applied, the $\mathrm{A}$ states split into a spin $3 / 2$ manifold and the $E$ states split into a double degenerate spin $1 / 2$ manifold. The energy level diagram corresponds to the experimental situation. (XBL 918-1915)

\section{Methyl Quantum Tunneling and Molecular Packing at $4 \mathrm{~K}$}

B. BLACK AND G. MAJER"

Rotational tunneling of methyl groups has been studied by a low magnetic field nuclear magnetic resonance (NMR) spectrometer utilizing a Superconducting QUantum Interference Device (SQUID) as a magnetic flux detector. The tunneling frequencies for the series of straight-chained carboxylic acids, from propanoic acid to hexadecanoic acids, were measured at $4.2 \mathrm{~K}$. All the tunneling frequencies were observed between 80 to $250 \mathrm{kHz}$ and, in some cases, tunneling frequencies were obtained for two separate crystallographic phases of a given sample. A correlation between the enthalpy of fusion and the tunneling frequency were also found. Such a correlation exists because of the dependence of both quantities on the intermolecular and intramolecular interactions of the methyl group.

NMR of Adsorbed Xenon Polarized by Laser Pumping

M. D. Raftery, it. Long, T. Meersman, B. F. J. Grandinetti, and L. Reven

Optical pumping has been used to enhance the pulsed NMR signal of ${ }^{129} \mathrm{Xe}$, allowing the detection of low pressure xenon gas and of xenon adsorbed on powdered solids. An increase in sensitivity of more than two orders of magnitude over conventional NMR is observed, the current limitation being the laser power. Adsorbed xenon is observed at $298 \mathrm{~K}$ on graphitized carbon (about $10 \mathrm{~m}^{2} / \mathrm{g}$ ) and on powdered benzanthracene $\left(\sim 0.5 \mathrm{~m}^{2} / \mathrm{g}\right)$ below $170 \mathrm{~K}$. The increased sensitivity of this technique allows the study of a large class of amorphous materials with surface areas below $10 \mathrm{~m}^{2} / \mathrm{g}$ including semiconductors, polymers, metal oxides, and catalysts.

\footnotetext{
- Institute for Physical and Theoretical Chemistry, University of Tübingen, Germany.
} 
Figure 14a (left)

Schematic dlagram of the experimental apparatus a) and timing dlagram b). Cirsularly polarized $794.7 \mathrm{~nm}$ laser light is fooused onto the optlical pumping cell. A silloon photo detector is used to detect the rubldlum absorption. The oven used to heat the pumping cell, and the nitrogen cooling system for the sample reglon are not shown. Shim coils can be used to oancel gradlents or reduce the overall magnetic fleld in the pumping coll. (XBL 918-1916)

Figure 14b (right)

NMR spectra of enriched ${ }^{129} X_{\theta}$ in the presence of powdered benzanthracene following optical pumping: a) xenon gas peak only, $T=298 \mathrm{~K}, P=20$ torr; $b$ ) xenon gas and adsorbed, $T=158 \mathrm{~K}, P=21$ torr; c) $x \in$ non gas and adsorbed, $T=153 \mathrm{~K}, P=22$ torr; $d$ ) solld xenon, $T=123 \mathrm{~K}$. (XBL 918-1917)

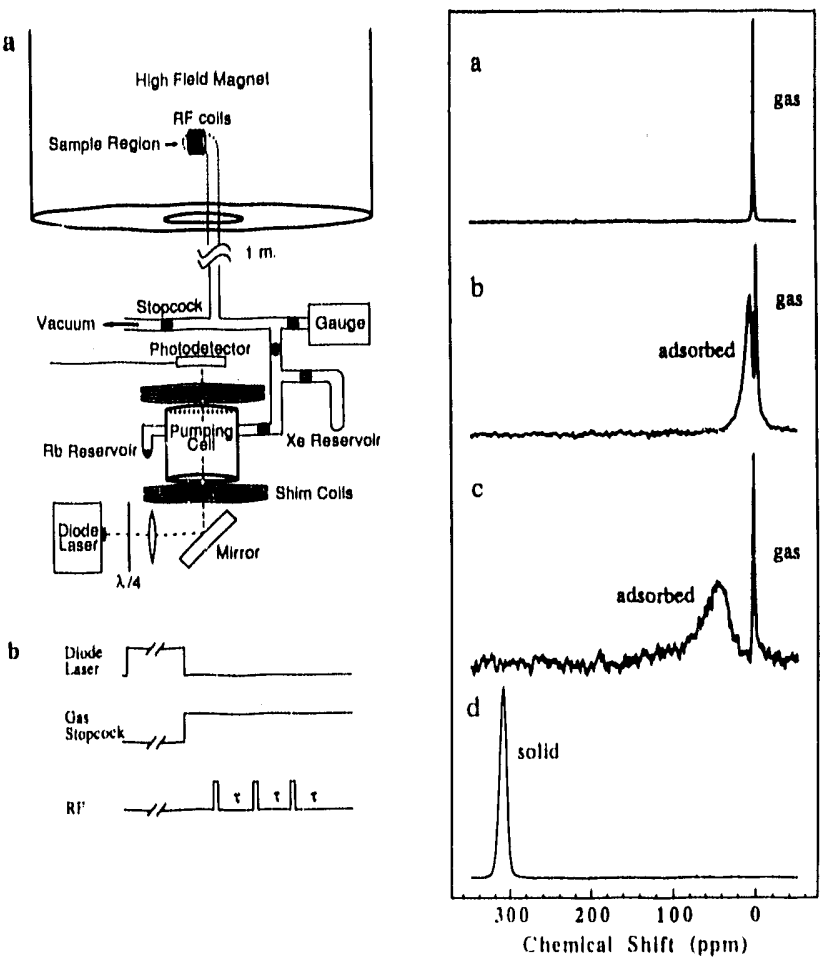

\section{Berry's Amplitude and Nonadiabatic Rapid Passage J. W. ZWanziger ${ }^{\dagger}$, S. P. Rucker, G. C. Chingag, AND K. T. Muellef}

By performing rapid passage experiments outside the adiabatic regime, we have succeeded in observing a component of the nonadiabatic transition probability $\mathrm{P}$ that is independent of the sweep rate through resonance. In a two-level system, the longitudinal magnetization after a sweep is given by (2P-1)Iz, so that $P=0$ corresponds to :omplete inversion. For a linear frequency sweep $P$ is described by LandauZener thec ry, which predicts that $P$ is exponentially small in the sweep rate. For more complicated sweep profiles (such as the spiral shown in Figure 15) Berry has predicted that, near the adiabatic limit, $P$ is a product of two factors, one which is exponentially small in the sweep rate, and one which is constant. The constant factor is predicted to depend only on the shape of the sweep profile. P was measured as a function of sweep rate for the $13 \mathrm{C}$ resonance in carbon disulfide, for selected sweep profiles, and showed that it can indeed be so factored. The results confirm the existence of a geometric part of the transition probability, and show that its form is as predicted by Berry's theory.

Figure 15

Certain trajectories for the nonadiabatic inversion of a two-level system manifest a Berry's amplitude. (XBL 918-1918)

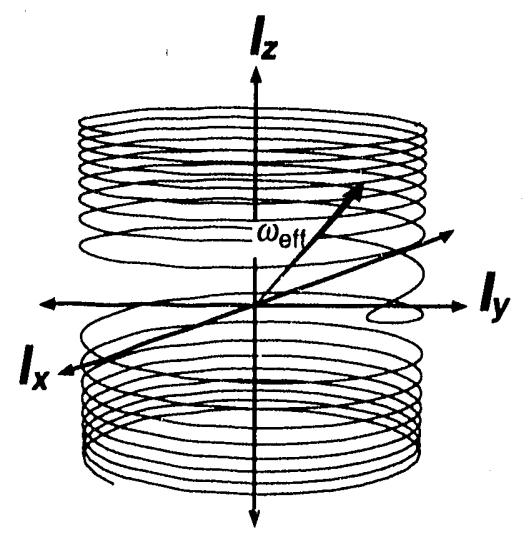

${ }^{\dagger}$ Department of Chemistry, Indlana University, Bloomington, IN 
Principal Investigator

Alexander Pines

Staff Scientist

Cerard Chingas

Postdoctoral Fellows

Lucio Frydman

John Harwood

Z.Y. Peng

Linda Reven

Wu Yue
Graduate Students

David Anvar

Jay Baltisgerger

Geoffrey Barrell

Bruce Black

Jeff Chang

Sheryl Gann

Raz Jelinek

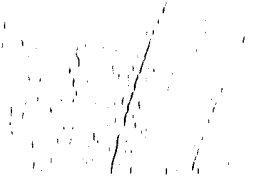

Henry Long

Karl Meuller

John Pearson

Mark Rosen

Dan Raftery

Joe Sachleben

Steve Rucker

Boqin Sun

\section{Visitors}

Tsong-huel Chang-National Tsing Hua University, Taiwan

Margaret Eastman-University of North Carolina, NIH Postdoctoral Fellow

Philip Grandinetti-University of Illinois, NIH Postdoctoral Fellow

Martin Hurliman-University of British Columbia, Swis NSF Fellow

Antoine Llor-University of Paris

Zbig Olejniczak - University of Krakcw

E. Wren Wooten-Oxford University, NIH Postdoctoral Fellow

Administrative Assistant

Dione Carmichael

\section{Publications and Reports}

\section{Refereed Journal Articles}

Chmelka, B.F., D. Raftery, A.V. McCormick, L.C. de Menorval, R.D. Levine, and A. Pines, "Measurement of Xenon Distribution Statistics in NaA Zeolite Cavities," Phys. Rev. Lett., vol. 66, p. 580, 1991.

Connor, C. , J.W. Chang, and A. Pines, "NQR and NMR Spectrometer with a dc SQUID Detector," Rev. Sci. Instrum., vol. 61, p. 1059, 1990.

Connor, C., J.W. Chang, and A. Pines, "Aluminum and Boron Nuclear Quadrupole Resonance with a Direct Current SuperconductIng Quantum Interference Device," J. Chem. Phys., vol. 93, p. 7639, 1990.

de Menorval, L., C. D. Raftery, S.-B. Liu, K. Takegoshi, R. Ryoo, and A. Pines, "Investigations of Adsorbed Organic Molecules in NaY Zeolite by Xenon-129 NMR," J. Phys. Chem., vol. 94, p. 27, 1990.

Gochin, M., A. Pines, M.E. Rosen, S.P. Rucker, and C. Schmiat, "Two-Dimensional NMR Studies of Flexible Molecules in Liquid Crystals: Orientational Order and Conformational Probabilittes of n-Hexane," Mol. Phys., vol. 69, no. 4, p. 671, 1990.

Muellei, K. T., 3. Q. Sun, G.C. Chingas, J.W. Zwanziger, T. Terao, and A. Pines, "Dynamic Angle Spinning of Quadrupolar Nuclei," J. Magn. Reson., vol. 86, p. 470, 1990.

Mueller, K.T., Y. Wu, B.F. Chmelka, J. Stebbins, and A. Pines, "High Resolution Oxygen-17 NMR of Solid Silicates," I. Am. Chem. Soc., vol. 113, p. 32, 1991.

Pines, A, and Y. Wu, "Nuclear Magnetic Resonance," Spectroscopy, vol, 5, no. 9, p. 34, 1990.

Raftery, D.M., H. Long, T. Meersman, P. J. Grandinetti, L. Reven, and A. Pines, "High-Field NMR of Adsorbed Xe Polarized by L/aser Pumping," Phys. Rev. Lett., vol. 66, p. 584, 1991.

Shykind, D.N., G.C. Chingas, A. Pines, and A.J. Shaka, "A Fast, Stable Quadrature Phase Generator for M1 tiple-Pulse NMR," Rev. Sci. Instrum., vol. 61, no. 5, p. 1474, 1990.

Werner, U., W. Muller-Warmuth, and A. Pines, "A Suggestion for Detecting Rotational Tunnelling of CD3 - Groups by MultipleQuantum Spectroscopy," Bull. Mag. Reson., vol. 12 (1/2), p. 9, 1990.

Wu, Y., B.Q. Sun, A. Pines, A. Samoson, and E. Lippmaa, "NMR Experiments with a New Double-Rotor," I. Magn. Reson., vol. 89, p. 297, 1990.

Wu, Y., M.E. Davis, B.F. Chmelka, P.J. Grobet, P.A. Jacobs, and A. Pines, "High Resolution 27Al Double-Rotation NMR in VPI-5," Nature, vol. 346, p. 550, 1990.

Zwanziger, J. W., M. Koenig, and A. Pines, "Non-Abelian Geometric Phase in a Quadrupole System Rotating Around Two Axes," Phys. Rev. A., vol, 42, p. 3107, 1990.

Zwanziger, J.W., M. Konen!g, and A. P!nes, "Berry's Phage," Ann!. Rov, Phys. Chem., vol. 41, p. 601, 1090. 


\section{Refereed Conference Proceedings}

Pines, A, "NMR in Physics, Chemistry and Blology: Illustrations of Bloch's Legacy" In Proceedings of the Bloch Symposium, W. Little, Ed., Int. J. Modern Phys، B, Vol, 4, p. 1241, 1990.

Pines, A. and K.T. Mueller, "Abellan and Non-Abelian Holonomy in NMR Interferometry," in Proceedings of the Conference on Fundamental Aspects of Quantum Theory, J, Anandan, Ed, World Scientiflc Press, 1990.

LBL Reports

Chmelka, B.F., J,G. Pearson, S.B. Liu, R. Ryoo, L.C. de Menorval, and A. Pines, LBL-28538, "NMR Study of the Distributlon of Aromatic Molecules in NaY Zeolite," J. Phys. Chem. (In press.)

Chmelka, B.F., S.B. Lilu, R. Csencsits, L.C. de Menorval, R. Ryoo, C.J. Radke, E.E. Petersen, and A. Pines, LBL-28539, "Distribution of Platinum Guests in NaY Zeolites," Journal of Catalysis. (Submitted.)

Goldman, M., P. Grandinettl, A. Llor, J. Sachleben, J. Zwanziger, LBL-30271, "Theoretical Aspects of Higher-Order Truncations in Solld-State NMR," J. Magn. Reson. (Submitted,)

Harwood, J. S. and G. C. Chingas, LBL-29707, "Application of NMR to the Study of Taylor Vortex Motion."

Harwood, J. S., L. Frydman, and G. C. Chingas, L.BL_-29708, "One- and Two-Dimensional NMR Imaging of Motion Statistics."

Jelinek, R., B.F. Chmelka, Y. Wu, A. Pines, P.J. Biarte, and J. Klinowskl, LBL-29916, "Study of the Aluminophosphates AlPO4-21 and AlPO4-25 by 27Al Double Rotation NMR," J. Am. Chem. Soc. (In press.)

Llor, A., Z. Olejniczak, J. Sachleben, A. Pines, LBL-30272, "Isotropic Time Reversal in Zero Field NMR," Phys، Rev. Lett, (Submilted,) Mueller, K. 1', E. W. Wooten, and A. Pines, LBL-29043, "Pure Absorptlon Phase Dynamic-Angle Spinning," J. Magn. Reson. (In press.) Mueller, K.T., G.C. Chingas, and A. Pines, LBL-29042, "A Dynamic-Angle Spinning NMR Probe," Rev. Sci. Instrum. (Submitted.)

Pearson, J.G., B.F. Chmelka, D.N. Shykind, and A. Pines, LBL-30263, "Multiple-Quantum NMR Study of the Distribution of Benzene in NaY Zeolite."

Peng, Z., B.Q. Sun, and A. Pines, LBL-30269, "Iterative Treatment of the Density Operator with a Time Dependent Hamiltonian." Samoson, A., B.Q. Sun, and A. Pines, LBL-30266, "New Angles in Sample Spinning."

Schmidt, C., M. E. Rosen, D. Caplan, M.F. Quinton and A. Pines, LBL-28537, "Orientation and Motion of Tetrahydrofuran in Graphite Intercalation Compounds: Proton NMR Spectra of Cs(THF)1.6C24 and K(THF)2.5C24," I. Phys. Chem. (Submitted.)

Sun, B. Q, and A. Pines, LBL-30267, "An Approximate Method of Sideband Intensity Calculation in Magic-Angle Sample Spinning NMR."

Sun, B.Q., A. Pines, and R. Levine, LBL-30268, "Information Theory Treatment of Multiple-Quantum NMR."

Sun, B.Q., Z.Y. Peng, Y. Wu, and A. P'ines, LBL-30265, "Theory of Zero Field NMR in Rotating Frame: Exact Solution."

Wooten, E.W., K.T. Mueller, and A. Pines, LBL-30270, "Motional Averaging in Solld State NMR," Acc. of Chem. Res. (Submitted.) Wu, Y., T.C. Chang, Z. M. Stadnik, and A. Pines, LBL-30264, "Direct Observation of Multi-Site Structures in Icosahedral Crystals." Wu, Y., Z-Y Peng, and A. Pines, LBL-30262, "Phase-Reversal in a Homogeneous Spin System."

Zwanziger, J.W., S.P. Rucker, and G.C. Chingas, LBL-30261, "Measurement of the Geometric Component of the Transition Probability in a Two-Level System," Phys. Rev. A. (In press.)

Invited Talks:

Pines, A. and J. S. Harwood (presenter), New NMR Experiments for Investigating Motion Statistics, Picker International, Cleveland, Ohio, Invited Talk, September 1990.

Pines, A., B.F. Chmelka (presenter), Y. Wu, M.E. Davis, P.J. Grobet, P.A. Jacobson, High Resolution NMR of Quadrupolar Nuclei in Molecular Sieves, Rocky Mountains Conference, Denver, Colorado, Invited Lecture, July-August 1990.

Pines, A., Berry's Phase for Pedestrians Vegetables, Physics Colloquium, Stanford University, February 1990.

Pines, A., Berry's Phase for Vegetables, Department of Physics, Rice Universi:y, Department Seminar, October 1990.

Pines, A., Berry's Phase in Magnetic Resonance Interferometry, Departmental Seminar, Physics Department Seminar, Georgia Institute of Technology, February 1990.

Pines, A., C. Schmidt (presenter), M. E. Rosen, S. P. Rucker, D. Caplan, and M. F. Quinton, NMR of Oriented Flexible Molecules, 25th Congress Ampere on Magnetic Resonance, Stuttgart, Germany, September 1990.

Pines, A., C. Schmidt, S. P. Rucker, and M. E. Rosen (presenter), Two-Dimensional NMR Studies of Flexible Chain Molecules in Liquid Crystals, 13th Liquid Crystal Conference, Vancouver, Canada, July 1990.

Pines, A., C. Schmidt, S. P. Rucker, and M.E. Rosen (presenter), Two-Dimensional NMR Studies of Flexible Chain Molecules in Liquid Crystals, Invited Talk, 17th Annual Meeting of the Federation of Analytical Chemistry and Spectroscopy Socictles, Cleveland, Ohio, October 1990.

Pines, A., Chemistry Department Seminar, University of Washington, Seattle, March 1990.

Pines, A., Distribution of Aromatic Molecules in NaY Zeolite: ${ }^{129}$ Xe and Multiple-Quantum NMR Results, B. F. Chmelka (presenter), J. G. Pearson, C. J. Radke, and E.E. Petersen, American Institute of Chemical Engineers, Chicago, November 1990. 
Pines, A., Dynamic-Angle Spinning and Double Rotation NMR Applied to Quadrupolar Nuclel and 13C Bonded to 14N, Renssolaer Polytechnic Instltute, Chemistry Department Seminar by M.A. Eastman, Troy, New York, October 1990.

Pines, A., Evening Lect ure, Royal Institution of Great Britain, London, May 1990.

Pines, A., Experimental Strategies for Dynamic Angle Spinning and Double Rotation, 31 st Experimental Nuclear Magnetic Resonance Conference, Asilomar, Callfornia, Invited Lecture, April 1990.

Pines, A., Fourier Transform Pulsed NQR with a dc SQUID, (N.Q. Fan, M.D. Hurliman, J. Clarke, A. Pines, E. L. Hahn); Direct Detection of Low-Field NMR and NQR, (B. Black, J. Chang, C, Connor, E.L. Hahn, J. Harwood, G. Majer, A. Pines); Theoretical Aspects of Higher-Order Effects in High Resolution NMR of Solids, (P. Grandinettl, A. Llor, Z, Olejniczak, and A. P'ines); DOR and Spinning Sidebartds, (A. Samoson, E. Luppmaa, and A. Pines); Monopoles and Instantons: A Connection between Magnetic Resonance and Jahn-Teller Systems, (M. Koenig, K. T. Mueller, A. Pines, and J. W. Zwanziger); 31st Experimental Nuclear Magnetic Resonance Conference, Asilomar, California, April 1990.

Pines, A, From SQUIDS to ICOSAHEDRA: Recent Developments in NMR, Physical Chemistry Seminar, Colorado State University, Fort Collins, Colorado, November 1990; Chemical Physics Seminar, University of Colorado at Boulder, November 1990; Department of Physies Colloqulum, Rice University, Houston, Texas, October 1990; 10th European Experimental NMR Conference, Veldhoven, The Netherlands, May-June 1990; Chemistry Department Colloqulum, Universilty of Callfornla, Rlverside, October 1990; Ernst D. Bergmann Memorial Meeting, The Hebrew University of Jerusalem, Invited Lecture, April 1990.

Pines, A., Hinshelwood Lecturer, Oxford University, 8 Lectures -Coherence, Motional Narrowing, and Magic Angle Spinning, Symmetry, Icosahedron, Dynamic Angle Spinning, Double Rotation, Oxygen-17 and Aluminum-27, Zero-Field NMR, SQUID, Tunneling, Adiabatic Demagnetization, Low-T, Multiple-Quantum Spectroscopy, Counting Clusters, Time Reversal, Berry's Phase, Topology, Geometry, NMR, Iterative Maps, Chaos and Fractals, Decoupling, Bistable Maps, Two-Dimensional NMR, Conformations of Flexible Molecules, Oxford, England, April-May 1990.

Pines, A., Icosahedral Symmetry and Spectroscopy, Department of Chemistry, University of Callfornia, Irvine, February 1990.

Pines, A., Magnetic Moments, Chemistry Department Seminar, Wichita State University, Kansag, January 1990.

Pines, A., Magnetic Moments, Icosahedral Averaging in NMR, Venerable Distinguished Lecturer Series, University of North Carolina, Chapel Hill, March 1990.

Pines, A., Motional Narrowing, Physics Department Seminar, Wichita State University, Kansas, January 1990.

Pines, A., Near Myths in NMR, NMR In-Vivo Spectroscopy Meeting, University of Callfornia, San Francisco, March 1990.

Pines, A., New Applications of NMR Techniques to Catalysis, Catalytica's 1990 Advances in Technologies (ACT) Seminar, Santa Clara, California, October 1990.

Pines, A., New Developments in NMR and Applications to Materials, Amoco Research Center, Naperville, Illinols, April 1990.

Pines, A., New Developments in Solid State NMR: SQUIDs and Icosahedra, 25th Congress Ai. pere on Magnetic Resonance, Stuttgart, Germany, Plenary Lecture, September 1990.

Pines, A., P.J. Grandinetti (presenter), M.A. Eastman, Y. Wu, and R. Jelinek, Applications of Second-Order Effects in Solid-State NMR, Rocky Mountain Conference, Denver, Colorado, July-August 1990.

Pines, A., Recent Adoances in NMR, 1990 Gordon Research Conference on Analytical Chemistry, New Hampton School, Invited Speaker, August 1990.

Pines, A., Recent Developments in NMR and Application to Materials, Lecture, Distinguished Visitor Series, Ford Motor Company, Dearborn, Michigan, March 1990; Company Seminar, Dow Chemical U.S.A., Midland, Michigan, March 1990.

Pines, A., Recent Deoelopments in NMR: SQUIDs and Icosahedra, Departmental Seminar, Chemistry Department Seminar, Georgia Institute of Technology, February 1990.

Pines, A., Some Recent Developments in Solid State NMR at Berkeley, Kanert Festkolloquium, Physics Department, University of Dortmund, Germany, May 1990.

Pines, A., Some Thoughts on Irreversibility, Watkins Visiting Professorship Lecture Series, Wichita State University, Kansas, January 1990.

Pines, A., There's No Free Induction, Zero-Field NMR and SQUIDs, Motional Averaging Over an Icosahedron, A.R. Gordon Distinguished Lecturer Series, Department of Chemistry, University of Toronto, March 1990.

Pines, A., Topology and Spectroscopy, Max Born Lecture, University of Jerusalem, July 1990. 


\section{ELECTROCHEMICAL ENERGY STORAGE Electrode Kinetics and Electrocatalysis*}

P.N. Ross, PaINCIPAL INVESTIGATOR

Carbon blacks are important materials used in a varicty of battery systems, and each system often makes 1 se of a specific property of the carbon, c.g., conductivity, corrosion resistance, capacitance, catalytic activity, etc. In spite of their importance and wide use, the relation of their chemical propertles to precursor and treatment history is not well understood, and considerable advancement in technologles using carbon materials appears possible.

In the case of air electrodes in metal-air batteries, the carbon is used as a support for the active catalyst, l.e., to achieve and maintain high dispersion, and as a current collector, since the active catalyst may not have high bulk. conductivity and may be relatively expensive and/or heavy. Thus, the unique properties of carbon of interest in this application are conducti vity, surface area, and corrosion resistance. It is known that dramatic changes in structure and chemical properties occur when carbon blacks are heat-treated in an inert atmosphere at temperatures varying from 1000 to $3000^{\circ} \mathrm{C}$. Heat-treatmen: conditions can be combined with selection of the carbon precursor to tailor the properties of the carbon black to suit the application. The particular technical challenge in air electrodes is to develop a rarbon with sufficient corrosion resistance, conductivity, and surface area to meet the lifetime and performance requirements for electric-vehicle applications.

The best known catalysts for the direct oxidation of methanol are platinum surfaces modified by underpotential deposition (UPD) of certain admetals, most especially tin. The state of the admetal, valence, number and type of ligand, coordination to the platinum surface, are all unknown even for the most studied systems like tin. Some studies have speculated that the "active" state of admetal on platinum is an alloy state produced by electrodeposition from the admetal ions in electrolyte, others have suggested the active state is an adsorbed (complexed) ion. We have addressed this question initially by preparing single crystal surfaces having adatoms in known chemical state and atomic position, more specifically, by using ordered $\mathrm{Pt}_{3} \mathrm{M}$ alloy surfaces prepared by UHV methods. In the bulk-alloy $\mathrm{Pt}_{3} \mathrm{M}$ structure, $\mathrm{M}$ atoms are substituted for Pt at the corners of the unit cell. In vacuum, the surfaces of the alloy would ideally have $\mathrm{M}$ atoms substituted in an ordered manner for $\mathrm{Pt}$ atoms in the surface. It is postulated that the intermetallic bonding in these substitutional positions will stabilize the admetal (M) in these positions in the surface when emersed in electrolyte, and that they will remain in these positions by equilibrium with admetal ions in solution. Study of methanol electro-oxidation kinetics on these ordered surfaces of known composition and structure will enable us to determine the "active" state of the adatom in platinum bimetallic catalysts. This study uses modern surface analytical methods [(e.g., low-energy electron diffraction (LEED), Auger electron spectroscopy (AES), $x$-ray photoelectron spectroscopy (XPS), ion scattering spectroscopy (ISS)] coupled with electrochemical methods to determine the dependance of catalytic activity on the composition and structure of modificd platinum surfaces.

\section{The Electrochemical Oxidation of Methanol on Tin-Modified Platinum Single Crystal Surfaces A.N. HANeR and P.N. Ross}

To understand the role of tin as a promoter in the electrochemical oxidation of methanol, we have studied the geometric and electronic effect of tin atoms in different chemical states on/in the platinum surface by using single crystal faces of the ordered

\footnotetext{
"This work was supported by the Assistant Secretary, Conservation and Renewable Energy, Offlce of Energy Storage and Distribution, Energy Storage Division of the U.S. Department of Energy
} 
alloy $\mathrm{Pt}_{3}$ Sn and single crystal faces of pure $\mathrm{Pt}$ modified by electrodeposited/adsorbed tin, l.e. the so-called adatom state. We found that none of the alloy surfaces were more effective catalysts than any of the pure platinum surfaces under the conditions of measurement employed here, and that alloying platinum with tin to any extent significantly reduced the activity. As reported previously by others, we observed tin to spontaneously adsorb on platinum surfaces from dilute sulphuric acid supporting electrolyte containing $S n$ (II) in concentrations above ca. $5 \mu \mathrm{M}$. At a given concentration, the coverage by tin decreased as the atomic density of the platinum surface increased. However, we did not observe any enhancement methanol oxidation of any platinum modified by this irreversibly adsorbed tin. We did observe a diffusion limited enhancement on $\mathrm{Pt}(111)$ and on $\mathrm{Pt}(100)$ due to $\mathrm{Sn}(\mathrm{II})$ in the electrolyte at $1 \mu \mathrm{M}$ concentration. At this concentration, tin did not appear to be adsorbed to any observable extent, and the catalysis appeared to occur via the direct interaction of a dissolved tin species with the surface. We propose a mechanism of catalysis that is a hybrid homogeneous-heterogenenus sequence based on known homogeneous $\mathrm{Pt}$ Sn talysts.

\section{The Surface Structure and Composition of $\langle 111\rangle,\langle 100\rangle$, and $<110>$ Orlented Single Crystals of the Ordered Alloy $\mathrm{Pt}_{3} \mathrm{Sn}$ \\ A.N. HANER, P.N. Ross and U. Bardi}

The surface composition and structure of $\langle 111\rangle,\langle 100\rangle$, and $\langle 110\rangle$ oriented crystals of the ordered alloy $\mathrm{Pt}_{3} \mathrm{Sn}\left(\mathrm{L}_{2}\right.$ or $\mathrm{Cu}_{3} \mathrm{Au}$-type) were determined using the combination of low energy electron diffraction (LEED) and low energy lon scattering spectroscopy (LEISS). The clean annealed surfaces displayed LEED patterns and Sn/ Pt LEISS intensity ratios consistent with the surface structures expected for bulk termination. In the case of the $<100\rangle$ and $<110\rangle$ crystals, preferential termination in the mixed $(50 \% \mathrm{Sn})$ layer was indicated, suggesting this termination to be the consequence of a thermodynamic preference for tin to be at the surface.

$\begin{array}{lll} & \begin{array}{l}\text { Investigator } \\ \text { Phillip N. Ross, Jr. }\end{array} & \begin{array}{l}\text { Postdoctoral Research Associate } \\ \text { Alexandra Haner }\end{array} \\ & \text { Staff Scientist } & \text { Research Associate } \\ \text { Harvey Sokol } & \text { Lee Johnson }\end{array}$

\section{Publications and Reports}

Refereed Jourmals

Bardl, U., B.C. Beard, and P.N. Ross, "COChemisorption on [111] and [100] Oriented Single Crystals of the Alloy Col't," ]. Catalysis, vol. 124, p. 22, 1990 .

Beard, B.C., and P.N. Ross, Jr., "The Structure and Activity of Pt-Co Alloys as Oxygen Reduction Electrocatalysts," J, Electrochem. Soc., vol. 137, p. 3368, 1990 .

Inviled Talks

Haner, A., P.N. Ross, and U. Bardl, Anomalous Surface Phase Formation on Pt3Sn $<110\rangle$, Third Int. Conf. on Structure of Surf., Milwaukee, WI, June 1990.

LBL Reports

Haner, A., and P.N, Ross, LBL-28399, "Electrochemical Oxidation of Methanol on Tin-Modified Platinum Single Crystal Surfaces", J. Phys. Chem. (In press.)

Ross, P.N., LBL-29435"Characterization of Alloy Electrocatalysts for Direct Oxidation of Methanol," Electrochim. Acta. (In press.)

Ross, P.N., "Novel Air Electrode for Metal-Metal-Air Battery with New Arbon Materials and Method for Making Same," (U.S. Patent No. 4,927,718), Official Gazette of U.S. Patent and Tradeniark Office.

Haner, A., P.N. Ross and U. Bardi, LBL-28074, "The Surface Structure and Composition of the $<111>$ and $<100>$ Oriented Single Crystals of the Ordered Alloy P'3Sn," Surf. Sci. (In press.

Haner, A., P.N. Ross and U. Bardi, LBL-29788, "The Surface Structure and Composition of the Low Index Faces of the Ordered Alloy $\mathrm{Pt}_{3} \mathrm{Sn}$," Catalysis Letters, (In press.)

TDepariment of Ćnemistry, University of Fiorence, Fiorence, italy. 


\section{Electrical and Electrochemical Behavior of Particulate Electrodes*}

J. W. Evang, PainoIPal. InvEstiantola

A zinc-air cell wherein the zinc is prosent as particles has been invented and a patent will have been issued when the annual roport is published. The coll employs a commorcially avallable air electrode and electrolyte flow, which is necessary for mass transport and replenishment of electrolyte, is due to solutal natural convection, rather than the usual external pumps. Investigation of the performance of the cell during discharge has been carried out on a laboratory scale and the performance extrapolated to predict that of a full scale battery for an eloctric vehicle.

\section{A Mechanically Recharged Zlno Air Cell for Electrlo Vehicle Applicatlons J.W. EVANS AND G. SAVASKAN}

A mechanically rechargeable zinc-air cell has been studicd on a laboratory scale (up to $400 \mathrm{~cm}^{2}$ air electrode area). Zinc is present in the cell as particles. The cell employs no pumps, relying on solutal natural convection for circulation of the electrolyte through the bed of zinc particles. Results of discharge experiments have been used to perform a preliminary battery design and calculated results suggest that such a battery would be competitive with other battery technologies for electric vehicles.

The laboratory cell has been tested under the SFUDS discharge regimen where the power drawn from the cell is varied to simulate that required by an electric vehicle under various traffic conditions. Figure 1 shows the results of these tests and the cell is seen to respond quickly to step changes in power requirement. The results from the SFUDS discharge were used to design a battery meeting criteria set by DOE for a battery for an electric vehicle: maximum mass $700 \mathrm{~kg}$, maximum volume 600 liters, minimum peak power 55 $\mathrm{kW}$, minimum energy $21 \mathrm{kWh}$. The significant results of the design are: mass $=565 \mathrm{~kg}$, volume $=600$ liters, peak power $55 \mathrm{~kW}$ or greater, energy $62 \mathrm{kWh}$, specific energy $110 \mathrm{Wh} / \mathrm{kg}$, specific peak power $97 \mathrm{~W} / \mathrm{kg}$ or greater.

Figure 1

Results of discharging laboratory zino-air cell under SFUDS power profile (modified to eliminate regenerative braking) a) start of discharge b) At 3 hours o) at 6.9 hours. (XBL 9012-4031)

Principal Inzestigator J. W. Evans
Visiting Scientist

T. Huh

Graduate Students

G. Savaskan

S. Slu
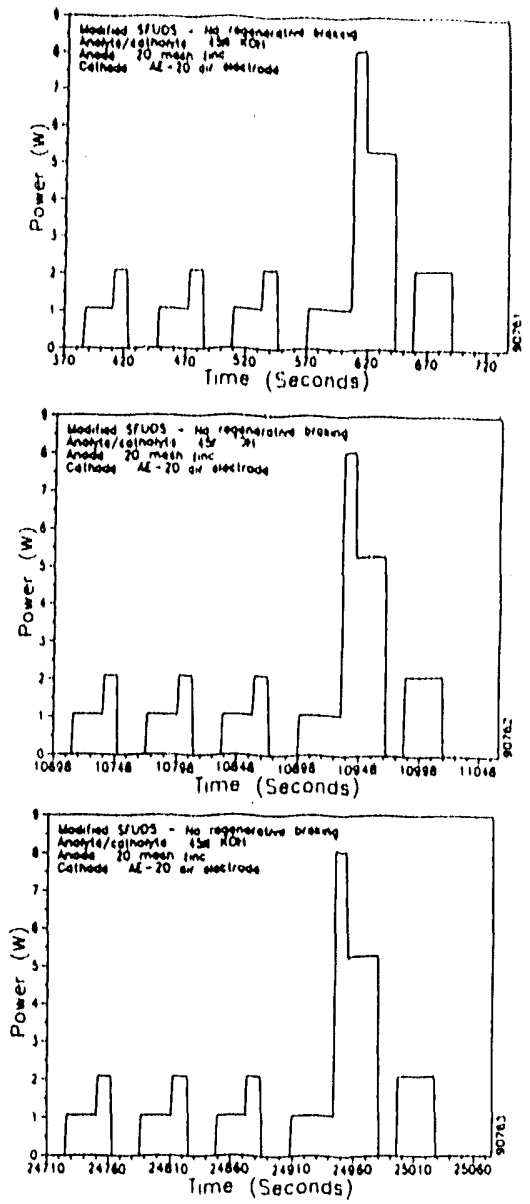

Staff

LBL Reports

Evans, J. W. and G. Savaskan, LBL-30079, "A Zinc-Air Cell with a Packed Bed Anode, Intended for Electric Vehicle Applications."

Evans, J. W. and G. Savaskan, "A Mechanically Recharged Zlnc- Air Cell for Electric Vehicle Applications", Extended Abstracts, 178 th Meeting of the Electrochemical Society, Seattle, Washington, 1990.

"Thls work was supported by the Assistant Secretary, Conservation and Renewable Energy, Oftice of Energy Storage and Distributlon, Energy Storage Division of the U.S. Department of Energy. 


\section{Surface Layers on Battery Materials *}

H.H. Mullea, PRinoipal. InVEgTIGator

The structure, composition, and mode of formation of electrochemical surface layers on olectrodes for rechargeable galvanic colls are dotermined in order to find moans to control film propertics that result in high powor donsity, cycle life and onergy efficiency. Anodic oxide formation and cathodic metal depositton of interest for battery applications in aqueous media are prosently investigated.

Experimental measuroments are centered on in situ optical tochniques sensitive to surface microtopography and composition. Results aro employed in theoretical models for the quantitative description of the formation of surface layers.

Studies about the effect of adsorbed materials on the electrocrystallization of metals and the exploration of new means to accelerate clectrochemical mass transfor for high-rate metal deposition are reported in "Electrochemical Phase Boundarles."

\section{An In Situ Study of the Anodlo Film Formation of $\mathrm{Cu}, \mathrm{Ag}$, and $\mathrm{Zn}$ in Alkallne Medla} S. T. Mayen AND R. H. MulLeen

The anodic film formation on $\mathrm{Cu}, \mathrm{Ag}$, and $\mathrm{Zn}$ in alkaline solutions was investlgated using several in sitw as woll as ex situ techniques. These included angular resolved elastic light scattering, Raman spectroscopy, spectroscopic ellipsometry, scanning tunncling microscopy: scanning electron microscopy, and x-ray diffraction. A discussion of the apparatus and theory of in situ elastic light scattering and Raman spectroscopy for studying thin-film nucleation and growth is presented.

The mechanisms of film formation were inferred from the observations. The solubility and conductivity of the oxides/hydroxides formed strongly influence the morphology and reversibility of the electrochemical reactions. Low solubility tends to favor solld-state, planar film growth. However, planar film growth was generally accompanied by a formation of soluble reaction products.

$\mathrm{Ag}_{2} \mathrm{O}$ formation begins with the production of a planar precursor layer (primary layer) in which nucleation of three-dimensional crystals occurs after a critical thickness is reached. After nucleation, a redistribution of material among the growing crystals causes the number density of growth sites to decrease. The redistribution occurs via the transport of oxide material through the electrolyte from small crystals to larger ones.

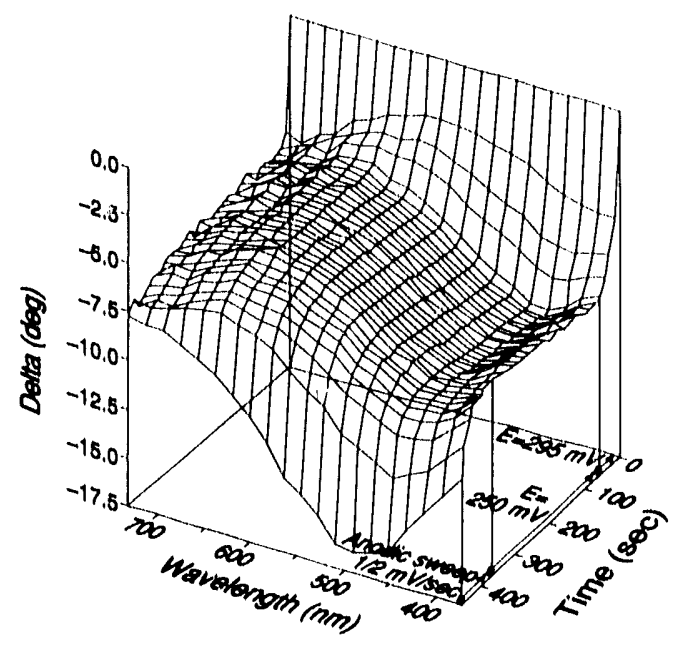

The formation of cuprous oxide is controlled by diffusion. $\mathrm{Cu}_{2} \mathrm{O}$ is less soluble than $\mathrm{Ag}_{2} \mathrm{O}$ and forms a compact layer that does not exhibit three-dimensional nucleation. At higher potentials, the formation of the divalent cuprite ion from the $\mathrm{Cu}_{2} \mathrm{O}$ film results in the precipitation of $\mathrm{Cu}(\mathrm{OH})_{2}$. The thermodynamically more favored $\mathrm{CuO}$ is formed only at higher potentials and longer periods of time from the underlying $\mathrm{Cu}_{2} \mathrm{O}$ layer. At potentials near oxygen evolution, a broad Raman band, which we associate with the formation of a trivalent copper species, is observed at around $550 \mathrm{~cm}^{-1}$.

The oxides of zinc are much more soluble than those of silver and copper. The major soluble zinc species at all

Figure 1

3-dimensional plots of measured ellipsometer parameter $\Delta$ vs time for the anodization of $\mathrm{Ag}$ in $1 \mathrm{M} \mathrm{KOH}$. Potential stepped from -50 to $295 \mathrm{mV}$ at time zero. Potential held at $295 \mathrm{mV}$ from 0 to $60 \mathrm{seo}$. From 60 to 360 $\mathrm{sec}$, potential held at $250 \mathrm{mV}$. After $360 \mathrm{sec}$, potentlal Increased at 0.5 $\mathrm{mV} / \mathrm{sec}$. (XBL 899-7297)

\footnotetext{
"Thls work was supported by the Assistant Secretary, Conservation and Renewable Energy, Otflice of Energy Storage and Distributlon, Energy Storage Dlvision of the U.S. Department of Energy under contract No. DE-AC03 76 SF00098.
} 
concentrations (including supersaturated solutions) is the tetrahedral $\mathrm{Zn}(\mathrm{OH})_{4}^{-2} \mathrm{lon}$. This ion does not polymorize or form polynuclear aggregatos at highor concontraHons. Solutions containing silicate show no now Raman bands, therofore, sllicate does not radically alter the $\mathrm{Zn}(\mathrm{OH})_{4}{ }^{2}$ envitronment.

\section{In Situ Laser Raman Spectroscopy of Zlno Film Formation In Alkallne Media \\ S.T. MAYer AND R.H. MULLER}

Anodic surface films formed on zinc in $1 \mathrm{M} \mathrm{KOH}$ were studied using Raman spectroscopy. During a potential sweep, evidence has been obtained for the formathon of an $\varepsilon-\mathrm{Zn}(\mathrm{OH})_{2}$ film during the active portion the anodic potential sweep. In this region the rate of $\varepsilon-\mathrm{Zn}(\mathrm{OH})_{2}$ forrnation is balanced by its rate of dissolution, and therefore most of the charge ends up as products in the electrolyte and not in the film. Near the active/passive transition potentlal, the diffusion of hydroxide to the metal/ film interface becomes rate limiting, and a film containing kinetically less favored $\mathrm{ZnO}$ is formed. The conductivity of this layer is small and therefore causes a marked decrease in the observed current once the layer is formed. The low rate of dissolution of $\mathrm{ZnO}$ is balanced by its rate of formation.

\section{Copper Oxidation Under Intense Illumination-Effects of a Raman Probe Beam \\ D. T. SCHWARTZ, S.T. MAYER, AND R.H. MULLEE}

High intensity illumination, which is common in Raman spectroscopy, is shown to modify the interfacial electrochemistry of $\mathrm{Cu}$ oxidation in alkaline media. The cathodic photodecomposition of semiconducting $\mathrm{CuO}$ to form $\mathrm{Cu}_{2} \mathrm{O}$ is observed using Raman spectroscopy and intensity modulated photocurrent techniques. The reduction of $\mathrm{Cu}_{2} \mathrm{O}$ to $\mathrm{Cu}$ is also facllitated by illumination. The results indicate that the $\mathrm{Cu}(\mathrm{II})$ valence state is present as a thin film containing both $\mathrm{CuO}$ and $\mathrm{Cu}(\mathrm{OH})_{2}$ phases, at least when oxidation occurs under intense illumination.

\section{Photoelectrochemical Evidence for Saturated Optlcal Absorption in Electrolytic Cuprous Oxide D.T. SCHWARTZ, AND R.H. MULLER}

An illuminated cuprous oxide-covered electrode immersed in alkaline media exhibits a nonlinear dependence of photocurrent on the intensity of $488 \mathrm{~nm}$ laser illumination. Results from intensity modulation experiments show that the differenthal efficiency for converting photons to photocurrent in the p-type cuprous oxide film is inversely proportional to the square root of illumination intensity (Figure 2). A charge transfer model that includes intensity-dependent optical absorption in the

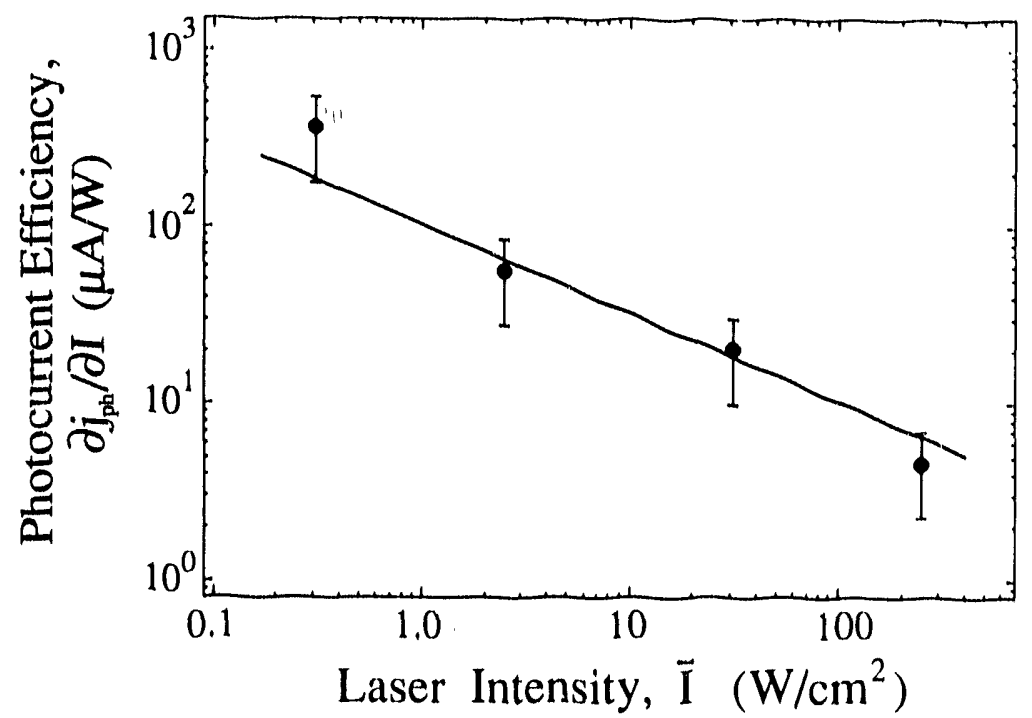

Figure 2

Decrease of photon-to-photocurrent conversion efflolency with increasing laser illumination intensity. Experimental points are obtained from the peak helghts of ao photocurrent density, the solld llne is calculated. (XBL 909-3159) 
cuprous oxide layer is found to be consistent with the observed photocurrent rosponse. Analysls of the experimontal rosults using the charge transfor model shows that the saturation intensity for cuprous oxide is approximately $100 \mathrm{~mW} / \mathrm{cm}^{2}$. Photochemical charge transfor is found to be efficient in the potential region where the nonlinear photocurrent response is obsorved, with noarly all photo-injected minority cartiers being consumed by the interfactal charge transfer roaction rather than recombination.

\section{Oxidation Films on Copper In Alkallne Medla- Intensity Modulated Photoelectrochemlcal and Raman Spectroscopy Studles} D.T. SOHWARTZ AND R.H. MULLER

The composition of thin surface layers on copper oxidized in alkaline media has beon determined by combining in situ intensity modulated photocurrent moasurements and laser Raman spectroscopy with cyclic voltammetry. Photocurrent measurements showed that the high intensity $\left(\$ 250 \mathrm{~W} / \mathrm{cm}^{2}\right)$ laser Raman probe beam facilltated reduction of the oxidized surface. Laser-factlitated reduction was used to identify the presence of $\mathrm{CuO}$ and $\mathrm{Cu}_{2} \mathrm{O}$ and, when combined with Raman spectroscopy, to differentlate between the formation of $\mathrm{CuO}$ and $\mathrm{Cu}(\mathrm{OH})_{2}$ films. Raman spertra confirmed that a thin $\mathrm{Cu}_{2} \mathrm{O}$ film formed as oxidation of the copper surface was Initlated. Increasing the potentlal produced a $\mathrm{Cu}(\mathrm{OH})_{2}$ layer on top of the $\mathrm{Cu}_{2} \mathrm{O}$ film. Further oxidation at higher potentlals converted the $\mathrm{Cu}_{2} \mathrm{O}$ film to a $\mathrm{CuO}$ underlayer that coexisted with the $\mathrm{Cu}(\mathrm{OH})_{2}$ overlayer (Figure 3).

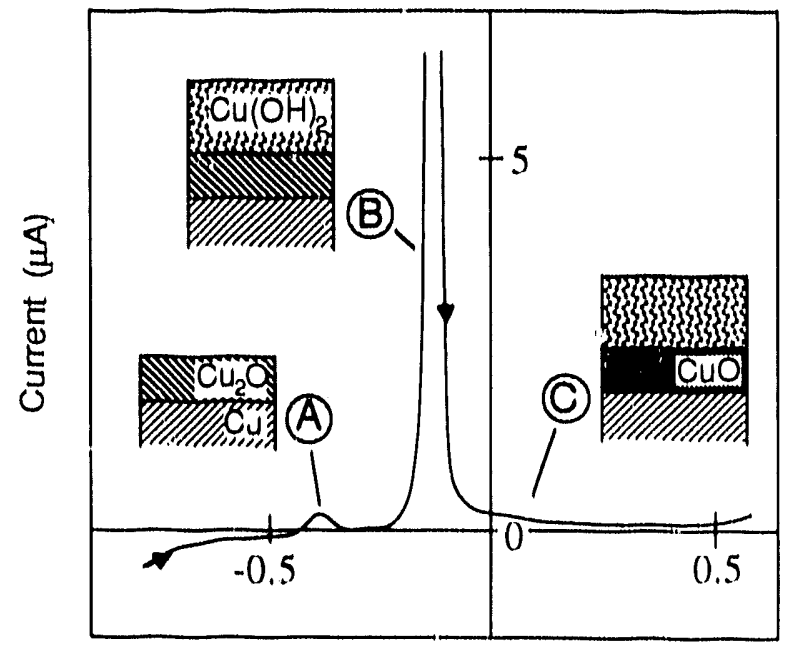

Potentlal (volts vs. HgO)
Figuro 3

Eleotrochemically oxidizing oopper in alkallne media oreates a thin film on the copper surface. The valence and struoture of the film depends on the electrode potential: (A) ouprous oxide layer forms; (B) cuprio hydroxida overlayer covers cuprous oxide fllm; (C) solld-state conversion of ouprous oxide (underlayer) to ouprio oxide. (XBL 911-18)

\section{In situ Observation of Electrochemlcally-Formed Surface L.ayers}

R. H. MULLEA

Propertles of electrochemically-formed surface layers, such as microtopography, porosity, or conductivity are of interest in many applications. They also reflect the mechant: $m$ of film formation. Thus, means for the control of film properties can be derived. Farly stages in the formation of metallic and oxidic thin filmis have been investigated in situ by spectroscopic ellipsometry, elastic light scattoring, Raman spectroscopy and scanning tumeling microscopy in combination with electrochemical measurements and several ex situ techniques for surface analysis. Information on nucleation and grow th of oxide layers on silver and copper and deposition of copper on platinum has been derived from the measurements. 


\section{Application of Videomicroscopy to In situ Studies of Electrodeposition \\ L. MoVay, R. H. Mulleg, and C. W. Tobias}

A videomicroscope has been set up for the continuous observation and recording of the developing surface morphology of electrodeposited metals in a channel flow cell. With a reciprocating, motor-driven traveling stage moving in the flow direction, quasi-simultaneous observation of several electrode areas is possible over extended periods of time. A dual eye-piece enables the experimenter to either observe the experiment in progress or to record still photos without affecting the video camera's alignment. With fiber-optic illumination, adequate light for good quality micrographs is provided. With a maximum magnification of $375 \mathrm{X}$, an area of $300 \mu \mathrm{m} \times 200$ $\mu \mathrm{m}$ can be cbserved at any one time with a diffraction limited resolution of $0.5 \mu \mathrm{m}$.

Staff

Investigator

Rolf H. Muller

Postoctoral Fellow

Daniel Schwartz
Graduate Students

Robert Crocker

Laura McVay*

Gerhard Matzen*

Davor Sutija*

LBL Reports

\section{Publications and Reports}

Mayer, S.T., and R.H. Muller, LBL-28116, "In Situ Laser Raman Spectroscopy of Zinc Film Formation in Alkaline Media."

S.T. Mayer, and R.H. Muller, LBL-28128 "Copper Oxidation Under Intense Illumination - Effects of a Raman Probe Beam."

Schwartz, D.T., and R.H. Muller, LBL-29661, "Photoelectrochemical Evidence for Saturated Optical Absorption in Electrolytic, Cuprous Oxide, " Appl. Phys. Lett., (Submitted.)

Schwartz, D.T., and R.H. Muller, LBL-29563, "Oxidation Films on Copper in Alkaline Media: Intensity-modulated Photoclectrochemical and Raman Spectroscopy Studies," Surf. Sci. (In press.)

Thesis

Mayer, S.T., "In Situ Study of Anodic Film Formation of Cu, Ag and Zn in Alkaline Media", LBL-29085 (Ph.D Thesis). Invited Talks

Muller, R.H., In Situ Obseroation of Electrochemirally-Formed Surface Layers, S.F. Section, Electrochem. Soc., Stanford, CA, Janurary 1990. Contributed Talks

Mayer, S.T., and R.H. Muller, In Situ Laser Raman Spectroscopy of Zinc Film Formation in Alkaline Media, Electrochem. Soc., Montreal, Canada, May 1990.

Schwartz, D.T., S.T. Mayer, and R.H. Muller, Copper Oxidation Under Under Intense Illumination - Effects of a Raman Probe Beam, Electrochem. Soc., Montreal, Canaa., May 1990.

Schwartz, D.'T., and R.H. Muller, In Situ Raman and Photocurrent Spectroscopy of Film Formation on Copper, Am. Inst. Chein. Eng,, Chicago, IL, November 1990. 


\section{Surface Morphology of Metals in Electrodeposition*}

C.W. TOBiAs, PRINCIPAL INVESTIGATOR

The objective of this project is to advance our understanding of the partial processes and their interactions in the deposition and dissolution of metals by electrolysis. Of particular interest is the influence of hydrodynamic flow on electrocrystallization, and the distribution of charge transfer reactions on advancing and receding metal profiles as determined by the electric- and concentration-fields, and by reaction kinetics on the electrode surface. Control of morphology of electrodeposits has been traditionally effected by addition agents that interfere with the crystallization process. This highly empirical practice is curious contrast with modern technologies, moreover, use of such agents is not possible in energy conversion and storage applications, because they adversely affect energy efficiency.

Models are established for the simulation of the effects of inhibitors on developing surface morphology in metal deposition. The ability of a plating system to yield smooth, compact deposits, characterized by levelling efficiency is evaluated as it depends on transport of the additive to microprofiles. Results of simulations are compared to experimental measurements of levelling efficiency. As part of this project, the influence of corrosive agents present in the electrolyte on developing contours during electrodeposition is evaluated.

Rotating disk, rotating cylinder, and planar electrodes in channel type electrolyzers are used for the study of the morphology of zinc deposits in the presence of well characterized hydrodynamic flow. The genesis of surface textures is studied using in situ video-microscopy, and post- mortem examination of deposits by profilometry, SEM, X-ray diffraction, and surface Raman spectroscopy. Quantitative evaluation of morphological features involves Fourier analysis of experimental profiles, and determination of the dependence of characteristic patterns on electric and flow parameters.

\section{Simulation of the Role of Convection in Electrodeposition Microscopic Trenches}

K. G. JORDAN AND C. W. TOBIAS

Levelling or smoothing of a microprofile in electrodeposition is usually accelerated by the addition of so-called inhibitors to the electrolyte. When the inhibitor is present at low concentrations, and hence it is consumed on the electrode, where it is adsorbed at the mass transport limited rate, deposition of more accessible areas is inhibited relative to recessed regions. A theoretical study was undertaken to clarify the role of recirculating flows in small cavities, of various shapes, in the electrode surface. The effect of Couette and Poisieulle flows passing by two-dimensional microscopic cavities was calculated by the finite element technique. Recirculation regions were chararterized as a function of Reynolds number, notch shape and depth. The increase in transport rates caused by convective eddies was assessed relative to the pure diffusion case, for various boundary layer thicknesses. Secondary flows were shown to noticeably enhance transport of inhibitors into microscopic trenches only at high Peclet numbers, i.e. at very high flow velocities.

The effect of Inhibitor Transport on Levelling in Electrodeposition K. G. JoRDAN AND C. W. TOBIAS

The electrodeposition of nickel into an angular trench in the presence of coumarin, a widely used inhibitor, is simulated, using various boundary layer approximations representative of flow parallel or transverse to the groove. Based on the diffusionadsorption mechanism of levelling action, the dependence of developing contours on the Langmuir coefficient and on the metal-ion/inhibitor flux ratio is investigated. Levelling efficiency is shown to be highest for thin, planar boundary layers, and

"This work was supported by the Assistant Secretary, Conservation and Renewable Energy, Office of Energy Storage and Distribution, Energy Storage Division of the U.S. Department of Energy under contract No. DE-AC03 76 SF00098. 
Figure 1

Comparison of simulated profiles for $25 \mathrm{~mm}$, and $5 \mathrm{~mm}$ thick layers, respectively, deposited far away from a trench. Note that the profile following mass transfer boundary layer ylelds the least effective levelling performance.

(XBL 9012-3912)

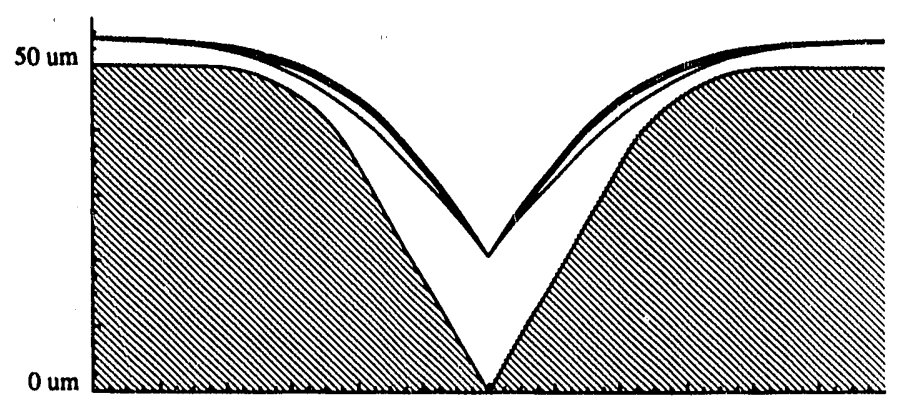

(a) Boundary Layer Thickness $=25$ um

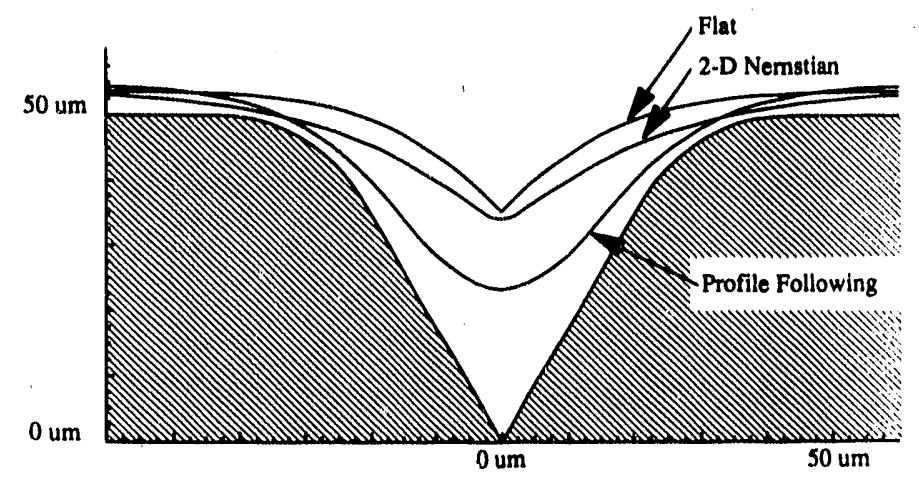

(b) Boundary Layer Thickeness $=10$ um

lowest for contour following boundary layers which result in simple geometric levelling (Figure 1). The model successfully predicts the levelling-off of the inhibitor effect with increasing inhibitor vs. metal ion flux, and that there is an optimal mass transfer boundary layer thickness, or flux of additive which results in superior levelling performance. Agreement was found between the predicted contours, and experimental levelling efficiencies determined by previous investigators.

\section{Investigator Charles W. Tobias \\ Postdoctoral Fellow Eric Egan}

\author{
Graduate Students \\ Kenneth G. Jordan \\ Gerhard Matzen* \\ Laura McVay* \\ Davor Sutija*
}

\section{Publications and Reports}

LBL Reports

Tobias, C. W., and Jordan, K. G., LBL 28342, "The Role of Convection in Electrodeposition into Microscopic Trenches", J.Electrochem. Soc. (In press.)

Tobias, C. W., and Jordan, K. G., LBL 28343, "The Effect of Inhibitor Transport on Levelling in Electrodeposition", J.Electrochem. Soc. (In press.)

Invited Talks

'Tobias, C. W., About Electrolytic Gas Evolution, Vittorio de Nora - Diamond Shamrock, 177th meeting of The Electrochemical Society, Montreal, Canada, May 1990.

"Jointly supervised by R. H. Muller 


\section{Analysis and Simulation of Electrochemical Systems *}

\section{J. NEWMAN, PRINCIPAL INVESTIGATOR}

This program involves fundamental investigations of the transport and interfacial phenomena important in electrochemical systems. Results of this work are used to analyze experimental data, to identify important system parameters, and to aid in the design and scale-up of electrochemical systems. Specific projects include the analysis of transient and steady-state transport processes in solid polymer electrolytes, determination of the diffusion coefficient of sulfuric acid in an aqueous medium, an experimental investigation of the conductivity of sodium polysulfide melts at various conditions, an investigation of the ac impedance behavior of porous electrodes, mathematical modeling of current distributions and its extension into corrosion protection, a mathematical investigation of the transport through and growth of passive oxide films, experimental and theoretical treatment of the electroless deposition of copper, theoretical investigations of inductance effects in high-power batteries, and the rigorous interpretation of cyclic voltammetry and ac impedance experiments.

\section{Determining Current Distributions Governed by Laplace's Equation}

A. C. WEST AND J. NEWMAN

Techniques have been developed for solving Laplace's equation, $\nabla^{2} \phi=0$. An emphasis is placed on analytic procedures and how they can be used with numerical methods to obtain accurate solutions at relatively low computer costs. Analytic procedures are also important because asymptotic solutions provide valuable validations of numerical calculations and insights into how results are best displayed and correlated.

By studying in detail the rotating disk electrode, the framework for determining theoretically the current distribution under the condition where both migration and convective mass transfer are important was established. Other important geometries for which this general problem has been investigated include the flow channcl reactor, the rotating ring-disk electrode system, and the tubular reactor.

\section{Mathematical Modeling of the Sodium/Iron Chloride Battery}

M. SUDOH AND J. NEWMAN

A mathematical model of the sodium/iron chloride battery containing a molten $\mathrm{AlCl}_{3}-\mathrm{NaCl}$ electrolyte is presented. A cylindrical cell consisting of a positive iron electrode, an electrolyte reservoir, a separator, and a negative sodium electrode is considered. The analysis uses concentrated-solution theory within the framework of a macroscopic porous electrode model. The effects of the state of discharge, the cell temperature, the precipitation and dissolution rates of $\mathrm{NaCl}$, and the current density on the current-potential relation during the discharge and charge cycles are discussed. The major influences on battery performance are changes in porosity and component volume fractions during cycling.

\section{Current Distribution Near an Electrode Edge as a Primary Distribution is Approached} A. C. WEst AND J. NEWMAN

When ohmic resistances dominate over electrode kinetic resistances, the distribution of current density on an electrode can be highly nonuniform. In the limit of zero kinetic resistance (i.e., a primary current distribution) the current density at the edge of an electrode will be infinite if the interior angle of intersection between the electrode and insulator is obtuse. In practical cases, nonzero kinetic resistances exist, and the current density remains finite. Previous results demonstrate that, when the ohmic

\footnotetext{
"This work was supported by the Assistant Secretary, Conservation and Renewable Energy, Office of Enerav Storane and Distribution, Energy Storage Division of the U.S. Department of Energy
} 
resistance is large compared to the kinetic resistance, the current distribution can be described by the primary distribution everywhere except the edge region. The purpose of this paper is to describe the deviations from the primary distribution and to show explicitly the manner in which the current density at the edge of the electrode approaches extreme values as the ohmic resistance becomes large. The analysis is valid for any angle of intersection and can be applied in the edge region (for a large ohmic resistance) regardless of the geometric details of the rest of the electrochemical cell. Results are given for linear and Tafel kinetics.

\section{The Effect of Schmidt Number on the Faradaic Impedance of the Dissolution of a Copper Rotating Disk \\ A. K. HAUSER AND J. NewMan}

Frequency-response results, as calculated by the Stefan-Maxwell macroscopic impedance model, are presented for a copper rotating disk in chloride solutions. The working algorithm uses concentrated-solution theory and accounts for multicomponent diffusion, migration, and homogeneous and heterogeneous reactions, as well as a finite Schmidt number and interfacial velocity. The validity of the general program was cliecked by comparing the concentrated-solution model in the limit of dilute solutions, excess of supporting electrolyte, and infinite Sclimidt number to known analytic solutions. Excellent agreement was obtained. Results for copper dissolution are plotted in various forms, enabling the effect of the Schmidt number (Sc) on the frequency-response of the faradaic impedance to be studied. Specifically, plotting the low frequency data according to $\operatorname{Re}\left(Z_{\mathrm{F}}\right\}$ vs $\operatorname{PIm}\left\{Z_{\mathrm{F}}\right\}$ and the high frequency data as $Z_{\mathrm{p}}$ vs $p^{1 / 2}$ allows the entire frequency spectrum to be utilized in the determination of unknown diffusion coefficients for a given electrochemical system. Additionally, the effect of electrode kinetics on the faradaic impedance as applied to the Sc-determination procedure has been studied. Finally, new ways of plotting the dimensionless convective diffusion impedance reduce the Schmidt number dependence of the frequency response nearly to one curve by strctching the abscissa using $\mathrm{pSc}^{1 / 3}$ and $\left(\mathrm{pSc}^{1 / 3}\right)^{1 / 2}$. These plots confirm that the slope of the low-frequency linear region is proportional to $\mathrm{Sc}^{1 / 3}$ and that the slope of the high-frequency linear region is proportional to $\mathrm{Sc}^{1 / 2}$.

\section{Differential Diffusion Coefficients of Sodium Polysulfide Melts \\ D. THOMPSON AND J. NEWMAN}

The method of restricted diffusion has been applied to sodium polysulfide melts in order to determine differential diffusion coefficients spanning the composition range of the single-phase liquid region $\left(\mathrm{Na}_{2} \mathrm{~S}_{3}\right.$ to $\left.\mathrm{Na}_{2} \mathrm{~S}_{5}\right)$, at temperatures between $300^{\circ}$ and $350^{\circ} \mathrm{C}$. Molybdenum electrodes at the ends of the cell gave open-circuit potentials in response to the transient concentration difference. The shape of the potential vs. time plots showed the expected dependence on the initial concentration profile. The following expression summarizes the experimental data $D=0.0153 \exp (-5890 /$ $T) \exp \left(5.30 \mathrm{x}_{\mathrm{e}}\right) \mathrm{cm}^{2} / \mathrm{s}$. The diffusion coefficients showed a temperature dependence in harmony with viscosity data, but not conductivity data.

Potential and Concentration Variations of a Reacting, Supporting Electrolyte

A. K. HAUSer and J. Newman

Steady-state electrolytic mass transfer to a rotating disk has been characterized in dilute solutions, with an excess of supporting electrolyte, for systems where the major ions of the supporting electrolyte participate in the electrochemical reaction. Although it is difficult a priori to predict accurately concentration variations of the electrolyte, the analytic model that has been developed can be used to calculate concentration-difference ratios enabling the concentration profiles next to the disk to be sketched qualitatively. In three of the four electrochemical systems investigated, the model predicts unexpected maxima in the counterion concentration profile. An 
explanation for this interesting behavior is presented in terms of the speed at which the species move, according to the magnitude of their diffusion coefficients. Alternatively, examination of the diffusion potential yields insight into this occurrence and the corresponding minima in the potential.

\section{Staff}

\section{Publications and Reports}

Refereed Journal Articles

Sudoh, M. S. and J. Newman, "Mathematical Modeling of the Sodium/Iron Chloride Battery," J. Electrochem. Soc., vol. 137, p. 876, 1990.

West, A. C., J. H. Sukamto, and J. Newman, "A Criterion to Verify Current Distribution Calculations," J. Electrochem. Soc., vol. 137, p. $2745,1990$.

LBL Reports

West, A. C. and J. Newman, LBL-28045, "Current Distribution on Recessed Electrodes," J. Electrochem Soc. (Submitted.)

West, A. C. and J. Newman, LBL-28075, “Determining Current Distributions Governed by Laplace's Equation."

Theses

Grabowskd, A. J., Current and Potential Distributions on a Cylinder Electrode. (M.S. Thesis.)

Shain, P., Cyclic Voltammetry at a Rotating Disk, Electroreduction of Nitrate in Acidic Nickel Solutions, and the Frequency-Response Analysis of Porous Electrodes. (Ph.D. Thesis.)

West, A. C., Effects of Nonuniform Current and Potential Distributions in Electrochemical Systems. (Ph.D. Thesis.) Invited Talks

Fuller, T. F. and J. Newman, Transport in Solid Polymer Electrolyte Fuel Cells, Electronics Research Laboratory, Los Alamos National Laboratory, Los Alamos, New Mexico, March 1990. 


\section{Center for Advanced Materials}

Ceramic Processing

Surface Science and Catalysis

High-T Superconductivity

Electronic Materials

Polymers and Composites

High Performance Metals 
Basic Studies of Defects and Impurities in III-V Semiconductors

Bulk Crystal Growth

Thin Films and Interfaces

Growth Mechanisms at Heterointerfaces

\section{Electronic Materials Program}

The CAM Electronic Materials Program concentrates on scientific problems impeding the development of large scale digital integrated circuits and optoelectronic devices based on gallium arsenide and related III-V semiconductors. Research is focused in four main areas.

BASIC STUDIES OF DEFECTS AND IMPURITIES IN III-V SEMICONDUCTORS - the study of the structural and electronic properties of defects and impurities and the mechanisms of their incorporation. Many of the properties of compound semiconductors are determined by intrinsic imperfections of the crystal lattice introduced during crystal growth and processing. These must be understood and controlled. Recent results in this area include:

- First measurements of magnetic properties of deep DX donors in $\mathrm{Al}_{\mathrm{x}} \mathrm{Ga}_{1-\mathrm{x}} \mathrm{As}$ semiconductors. These strongly indicate that the deep donors bind only one electron rather than two.

- Excess As in GaAs has been shown to be present in the layers just under an evaporated metal contact layer and has been related to the Schottky barrier height.

BULK CRYSTAL GROWTH - the development of advanced techniques for the growth and characterization of gallium arsenide crystals. Studies rely on the close coupling of crystal growth and the characierization of those crystals in order to gain an understanding of the relationships between growth conditions and the structural and electronic properties of the crystals.

Results achieved during the past year include:

- The vertical gradient freeze growth of $\mathrm{GaAs}$ crystals using total liquid encapsulation with $\mathrm{B}_{2} \mathrm{O}_{3}$. The process eliminated detrimental effects of PBN crucible wetting by liquid $\mathrm{GaAs}$. 
THIN FILMS AND INTERFACES-the study of dislocations, interfaces and point defect structures in thin films and solid state devices, their origin, processing dependence, and effect on properties. The approach emphasizes high resolution electron microscopy combined with microanalytical techniques. Recent results include:

- The mechanism of misfit dislocation generation has been shown to undergo a dramatic change for epitaxial thin films depending on whether the misfit with the substrate is above or below $2 \%$.

- Deposition of metal layers on GaAs by evaporation or sputtering has been shown to cause damage in the first few layers of the semiconductor.

- Progress has been made toward the development of a stable metal contact to $\mathrm{In}_{53} \mathrm{Ga}_{47}$ As.

GROWTH MECHANISMS AT HETEROINTERFACES- a new initiative at LBL aimed at probing the process of interface formation between disparate materials. As materials are more dissimilar in their electrical and structural properties, the formation of stable heterostructures becomes increasingly difficult. Basic research with these systems is vital for establishing a firm scientific foundation on which to base the rational exploitation of these materials in emerging technologies. Such technologies inciude, for example, integrated multi-component devices, high temperature electronics, and protective coatings. As an exploratory research program, however, we do not limit ourselves to specific device applications which have already been proposed, and our motivation in selecting specific experiments and systems for study is based on scientific issues. Systems chosen for initial study include: epitaxial growth of silicide-fluoride heterostructures; formation of interfaces between boron nitride and disparate materials; and growth of the polar semiconductor InP on single crystal Pt using various techniques. 


\title{
BASIC STUDIES OF DEFECTS AND IMPURITIES IN III-V SEMICONDUCTORS
}

\author{
Saturation of Free Hole Concentration and the Impurity Lattice Location in $\mathrm{Zn}$ - \\ Diffused GaAs and InP Single Crystals \\ K.M. Yu, L.Y. Chan, M. Ben-Tzur, E.E. Halleg, J.M. Jaklevic* and W. Walukiewicz
}

Understanding of the physical and chemical processes limiting incorporation of electrically active impurities is one of the basic issues of semiconductor materials science. It has been recognized for some time that the maximum free hole concentration in $\mathrm{GaAs}$ is almost two orders of magnitude higher than in InP. Up to the present time there is no clear explanation of the disparity in the incorporation of electrically active acceptors in both materials. To shed light on the issue we have undertaken an investigation of the relationship between this free carrier saturation and the lattice location of the impurity atoms in single crystal GaAs and InP.

Highly doped GaAs:Zn $\left(\sim 10^{20}\right.$ atoms $\left./ \mathrm{cm}^{3}\right)$ and InP:Zn $\left(\sim 6 \times 10^{19}\right.$ atoms $\left./ \mathrm{cm}^{3}\right)$ samples were obtained by closed-ampoule diffusion with a $\mathrm{Zn}$ solid source. Combined particle induced X-ray emission (PIXE) and ion channeling, Hall effect and capacitance-voltage measurements, and transmissic n electron microscopy (TEM) were performer on these samples. For the GaAs:Zn system, the free hole concentration is close to the total $\mathrm{Zn}$ concentration in the sample. PIXE channeling results indicate that over $95 \%$ of the $\mathrm{Zn}$ atoms occupy substitutional Ga sites. The free hole saturation in this system is therefore believed to be due to the solubility of limit of $\mathrm{Zn}_{\mathrm{Ca}}$ in GaAs.

For the InP:Zn system, the free hole concentration saturates at mid $10^{18} / \mathrm{cm}^{3}$ and is not limited by the solubility of $\mathrm{Zn}$ in InP. Precipitates of $\mathrm{Zn}_{3} \mathrm{P}_{2}$ and of $\mathrm{Zn}$ are found by TEM and they appear to be partly responsible for the hole saturation. However, ion channeling results on a quenched sample indicate that some $\mathrm{Zn}$ atoms $(\sim 20 \%)$ may remain on the interstitial sites after diffusion. Therefore, the presence of these interstitial donors also reduces the hole concentration through compensation. Figure 1 shows a comparison of the channeling PIXE angular scan along the $<111>$ channel from the GaAs: $Z n$ a nd InP:Zn samples. A very good substitutionality of $Z n$ atoms in $\mathrm{GaAs}$ is observed, while in InP the $\mathrm{Zn}$ is only partly substitutional. These results have been analyzed in terms of the amphoteric native defect model. We found that the difference in the free hole saturation phenomenon in $\mathrm{GaAs}$ and InP can be attributed to the difference in the Fermi level stabilization energy in the two materials. It was also found that in InPit is energetically more favorable for atoms to reside in the interstitial site or form precipitates rather than substitute Ga atoms to form acceptors.
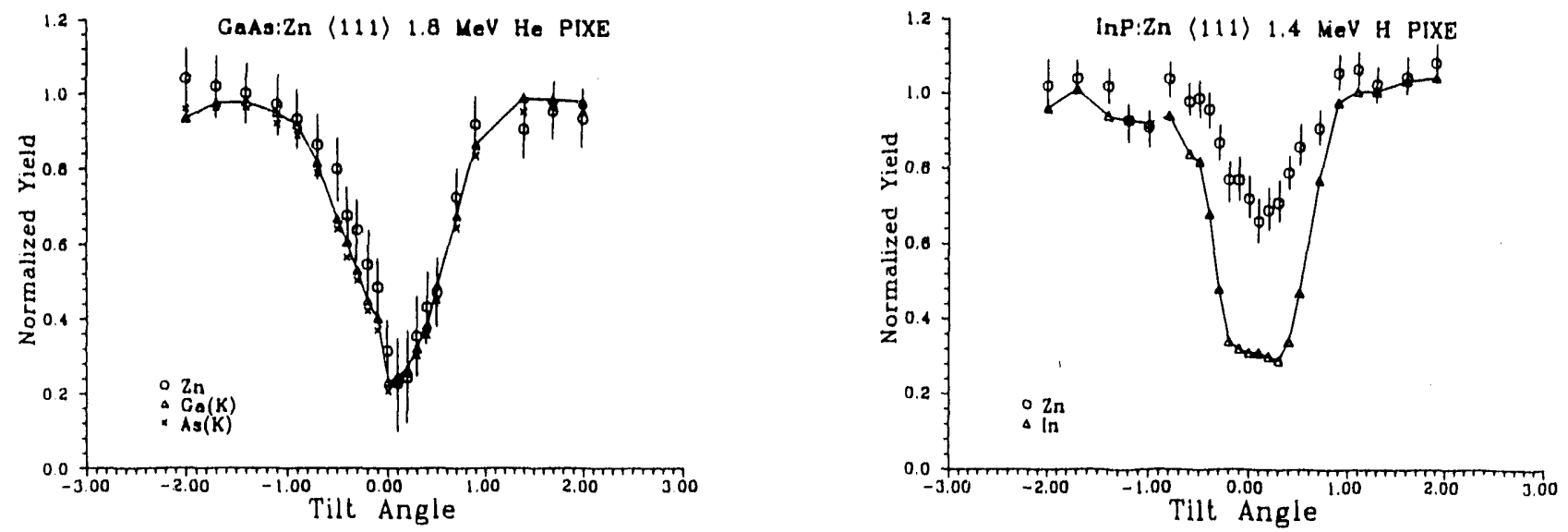

Figure 1

Comparison of the channeling PIXE angular scan along the $<111>$ channel for GaAs: $Z n$ and InP:Zn samples. Note that most of the $\mathrm{Zn}$ is substitutional in GaAs while in InP a substantial concentration of $\mathrm{Zn}$ is the interstitial or random position in the chiannel. (XBL 905.1975)

"Engineering Division 


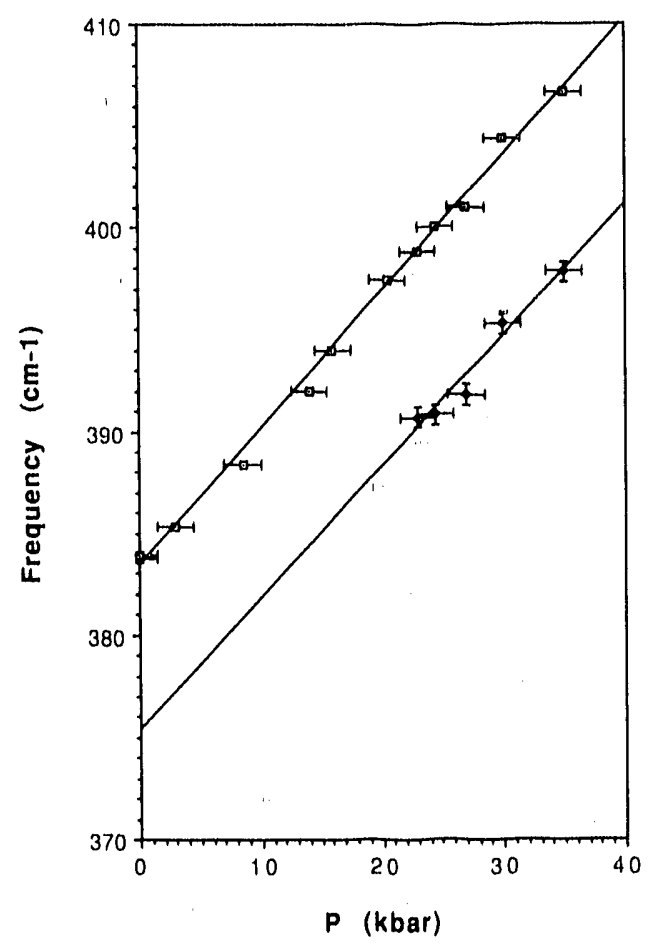

Flgure 2

The shift of frequenoy of LVM modes with pressure for the SI on a Ga site peak (D) and for the pressure induced DX defoot (•). (XBL 918-1717)

\section{Effects of High Hydrostatic Pressure on Local Vibrational Modes of Substitutional Impurities in GaAs \\ J.A. Wolk, M. Kruger, J. Heyman, W. Walukiewilcz, R. JEANLOZ, AND E.E. HALLER}

We have successfully performed Fourier transform infrared absorption spectioscopy of impurities in semiconductors in a diamond anvil cell (DAC). DACs are valuable tools for studying semiconductors because they provide the only means available for studying solids under large, hydrostatic pressure in a cell which allows optical access. Although this technique is commonly used to study absorptions involving intrinsic lattice effects (i.e., $10^{22}$ atoms $/ \mathrm{cm}^{3}$ ), this is the first reported application of this technique to studies of semiconductor phonon spectra associated with defects, where typical concentrations are $10^{18} \mathrm{~cm}^{-3}$. The most important problem for this new approach is the signal-to-noise ratio. We have achieved a sufficient ratio ( 10:1) by using a cone to concentrate incoming light on the diamond cell, which is only 200-300 $\mu \mathrm{m}$ in diameter, and placing a specially designed detector directly behind the DAC to efficiently capture all light passing through the sample.

The first application of this technique has been to study DX centers in GaAs doped with Si. Si normally forms a shallow donor in GaAs, but when hydrostatic pressures of greater than approximately $20 \mathrm{kbar}$ is applied, deep levels related to the Si donor atoms appear. These defects are known as DX centers, and they are seen in many ntype, III-V compound semiconductors and their alloys. After many years of debate, there is still no widely accepted microscopic model for this class of defects. Our contribution to solving this puzzle comes from studying how the local vibrational mode (LVM) of the Si atom changes when it transforms into a DX center. The frequency of the LVM is an invaluable clue in determining how the atom is bonded to its nearest neighbors. Figure 2 shows the shifts in the LVM frequencies with pressure for two peaks observed in our spectra. The shifts are linear, and are both approximately $0.65 \mathrm{~cm}^{-1} / \mathrm{kbar}\left(8.1 \times 10^{-2} \mathrm{meV} / \mathrm{kbar}\right)$. The peaks above $20 \mathrm{kbar}$ were observed in a GaAs:Si with $n=3 \times 10^{18} \mathrm{~cm}^{-3}$. The sample is opaque below this pressure due to free carrier absorption, which is eliminated when the shallow levels transform into the deep DX levels. The peaks below $20 \mathrm{kbar}$ were observed in an electron irradiated GaAs:Si sample with $\mathrm{n}=6 \times 10^{17} \mathrm{~cm}^{-3}$. Irradiated samples are transparent at all pressures, but their donors cannot undergo a DX transformation. The peak which occurs at $384 \mathrm{~cm}^{-1}$ at zero pressure is the LVM of a Si atom sitting substitutionally on a Ga site. We have identified the second peak as the LVM of the DX center. We expect that an analysis of the LVM peak intensities combined with the results of electrical measurements will provide information on the charge state of the defect. The information is crucial for all theoretical models of the DX center. 


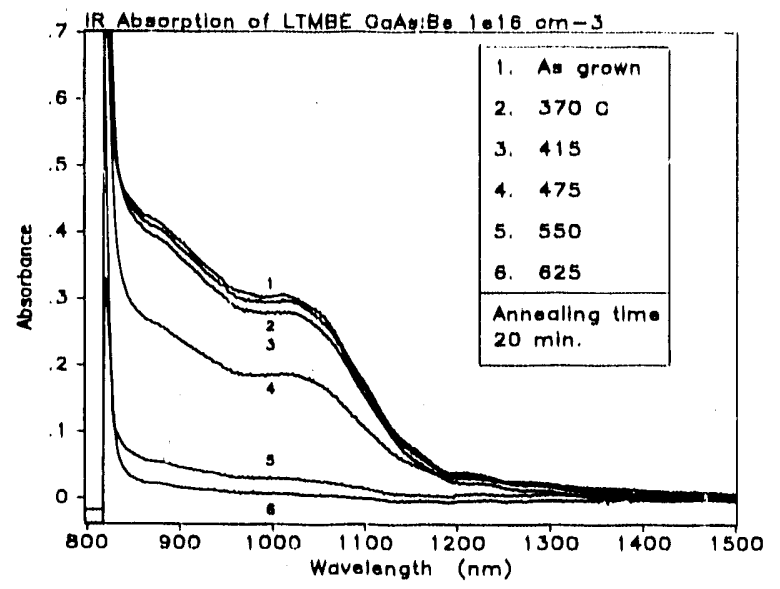

Figure 3

Infrared absorption as a funotion of the wavelength for LTMBE GaiAs annealed at different temperatures. The absorption at 1000 $\mathrm{nm}$ is proportional to the concentration of the midgap native defeots. A very strong reduction of the concentration of native defeots for annealing in the temperature range $415^{\circ} \mathrm{C}-550^{\circ} \mathrm{C}$ is observod. (XBL 918-1718)

\section{Studies of Native Defects in p-Type Doped Low Temperature Grown GaAs Buffer Layers \\ D. Bliss, K. Chan*, E.E. Haller, and W. Walukiewicz}

We are investigating a newly developed GaAs buffer layer grown by molecular beam epitaxy at a low substrate temperature (LTMBE) of $300^{\circ} \mathrm{C}$. Such low temperature grow th results in the formation of a high concentration, $10^{20} \mathrm{~cm}^{-3}$, of native defects associated with excess As. The material is unique since roughly $1 \%$ of all atomic positions are occupied by defects, while the GaAs layer remains crystalline. Compared to bulk grown GaAs, the concen tration of defects in LTMBE layers is four orders of magnitude higher. Because of the high concentration of native defects the LTMBE layers offer a unique opportunity to study native defect formation and defect reactions with intentionally introduced impurities. For our studies, a series of $\mathrm{Be}$ doped samples, $10^{16}-10^{19} \mathrm{~cm}^{-3}$, were grown to investigate defect-impurity interactions. Impurities are intentionally introduced into semiconductors to increase the electrical conductivity. We are interested in finding out how the defects in LTMBE material reduce the free carrier concentration to make highly resistive GaAs. Do the defects form complexes with impurities, or do they just compensate the charge? Photoluminescence spectra show an acceptor-exiton peak, indicating a fraction of the Be is incorporated as an isolated substitutional atom on Ga sites. Electrical and IR absorption measurements show that the Be is fully compensated by native defects for all doping concentrations studied. We find that the conduction occurs through hopping via nearest neighbor native deep level defects. Figure 3 shows IR absorption spectra for the sample doped $10^{16} \mathrm{~cm}^{-3}$ after increasing temperature anneals. The absorption at $1000 \mathrm{~nm}$ is due to As antisite defects and is proportional to the defect concentration. The annealing study indicates the defects begin to anneal away at $450^{\circ} \mathrm{C}$. High temperature annealing at $800^{\circ} \mathrm{C}$ is required to fully activate $\mathrm{Be}$ acceptors.

\section{Paramagnetic Relaxation of Substitutional Defects in III-V Semiconductors \\ M. HoINKIS AND E.R. WeBER}

Arsenic antisite defects (As atoms on Ga sites, $\mathrm{As}_{\mathrm{Ca}_{\mathrm{a}}}$ ) in GaAs and their relationship to the technologically important EL2 defect have been a controversial subject for the last decade. Recently, we have shown through studies of the Electron Paramagnetic Resonance (EPR) signal intensity versus temperature that a range of $\mathrm{As}_{\mathrm{CI}}{ }^{+}$defects exists in $\mathrm{GaAs}$ and that EL2 is an $\mathrm{As}_{\mathrm{Cia}}{ }^{+}$-related defect in the lowest possible strain field with the longest spin-relaxation times of this class of defects.

\footnotetext{
"Hewlett Packard, Microwave Technology Division, Santa Rosa
} 
Signal Intensity versus (Microwave Power) ${ }^{1 / 2}$

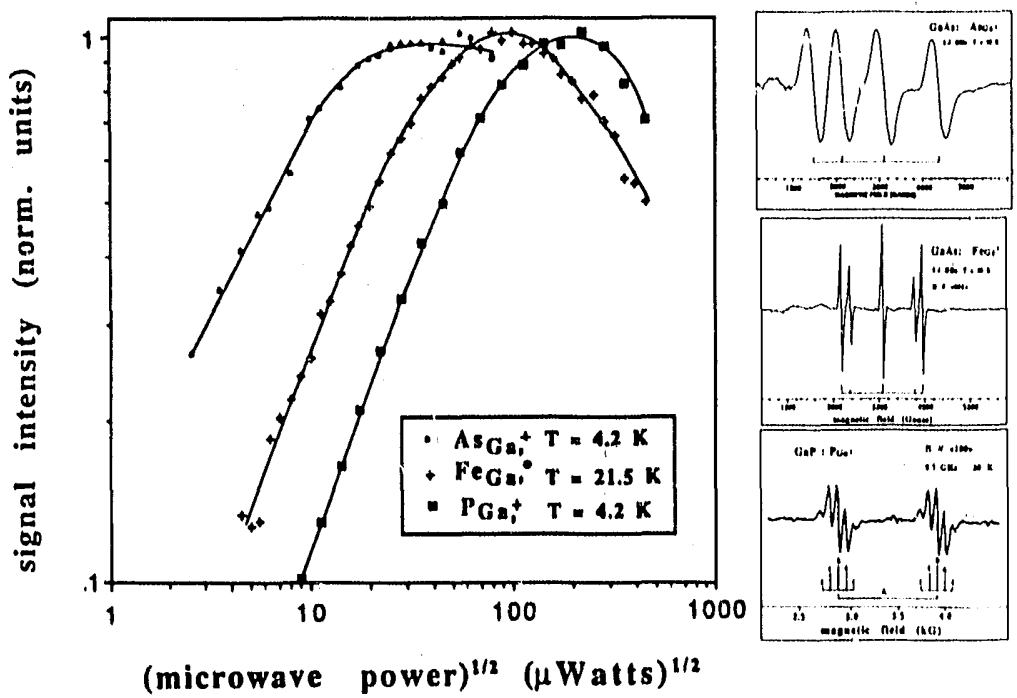

These previous studies developed empirical relationships between strain fields and relaxation times. Specifically, increasing distortion fields were found to result in decreasing spin-relaxation times. Therefore, it appeared to be necessary to investigate further the correlation between spin-relaxation times and the paramagnetic electron wavefunctions.

To address this issue, quantitative spin-relaxation studies were performed on several defects in III-V semiconductors. The cornmon feature between the defects studies was that the defect atom substitutionally occupied the Ga lattice site in the host crystal. Specifically, we compared the $\mathrm{As}_{\mathrm{Ga}^{+}}{ }^{+}$defect in $\mathrm{GaAs}$ with the $\mathrm{Fe}_{\mathrm{G}}{ }^{\circ}$ defect in GaAs, and the $\mathrm{P}_{\mathrm{Ga}}{ }^{+}$defect in $\mathrm{GaP}$.

Many qualitative features of the saturation behavior of these three defects are very similar. Figure 4 shows the relationship between EPR signal intensity and microwave power for these spectra, taken at $4.2 \mathrm{~K}\left(\mathrm{As}_{\mathrm{Ca}}{ }^{+}\right.$and $\left.\mathrm{P}_{\mathrm{Ga}}{ }^{+}\right)$and $21.5 \mathrm{~K}\left(\mathrm{Fe}_{\mathrm{Ga}}{ }^{\circ}\right)$, respectively. A detailed quantitative analysis found the $\mathrm{P}_{\mathrm{Ga}}{ }^{+}$spin relaxation time constants to be $\mathrm{T}_{1}=10^{-7}$ sec. and $\mathrm{T}_{2}=10^{-9} \mathrm{sec}$. at $4.2 \mathrm{~K}$, those of the $\mathrm{Fe}_{\mathrm{C}_{\mathrm{ia}}}{ }^{\circ}$ defect at $21 \mathrm{~K}$ were $\mathrm{T}_{1}=6.1 \times 10^{-5}$ sec. and $\mathrm{T}_{2}=1.5 \times 10^{-8}$ sec., and the product, $\mathrm{T}_{1} \cdot \mathrm{T}_{2}$ of the $\mathrm{As}_{\mathrm{Ga}}{ }^{+}$spectrum (=EL2 in the positive charge state) was $2 \times 10^{-14} \mathrm{sec}^{2}$ at $4.2 \mathrm{~K}$. As relaxation times increase strongly with decreasing temperature, this result demonstrates a much weaker coupling of the $\mathrm{Fe}_{\mathrm{Ga}}{ }^{\circ}$ wavefunction to the lattice than those of the two anion antisite defects. The similarity of relaxation behavior of the antisite defects in $\mathrm{GaAs}$ and $\mathrm{GaP}$ suggests that both spectra are likely due to corresponding atomic configurations, which for the GaP case was shown to be isolated, undistorted antisite defects.
Figure 4

Relationship beiween the EPR signal intensity of $\mathrm{As}_{\mathrm{Ga}^{+}}{ }^{+}$in GaAs, $\mathrm{He}_{\mathrm{Ga}_{a}}$ in GaAs, and $\mathrm{P}_{\mathrm{Ga}}{ }^{+}$in $\mathrm{GaP}$ vs. squice root of the microwave power, which is proportional to the microwave magnetic field strength. Typical EPR spectra for these defects are shown in the side panels. (XBL 918-1715)

\section{CRYSTAL GROWTH RESEARCH}

\section{Studies of Semi-Insulating GaAs Grown by Vertical Gradient Freeze \\ E. Bourret, J. Guitron, and E.Merk"}

It has been demonstrated that the vertical gradient freeze method produces single crystals of $\mathrm{GaAs}$ of improved electrical homogeneity and low dislocation densities. Reproducible growth of semi-insulating crystals has been achieved by using total liquid encapsulation by $\mathrm{B}_{2} \mathrm{O}_{3}$. The effect of $\mathrm{B}_{2} \mathrm{O}_{3}$ water content on the structural and electrical characteristics of the crystals was investigated.

The crystals grown by total liquid encapsulation do not exhibit the highly inhomogeneous dislocation distribution typically found in crystals grown by LEC. A Wshape pattern can be identified, but the absence of slip systems at the periphery of the

\footnotetext{
* Postdoctoral fellow supported by the Swiss National Science Foundation
} 


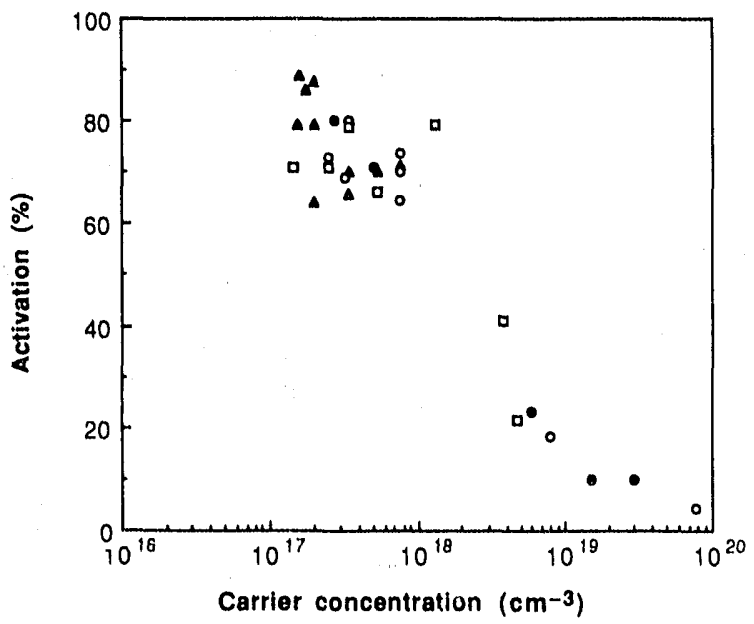

Figure 5

Activation of silicon impiants on wafers from crystals grown with dry $\mathrm{B}_{2} \mathrm{O}_{3}(\bullet)$. Data are compared with activation obtained by others on semi-insulating LEC grown crystals. $(\Delta, 0,0)$. (XBL 907-2359)

Figure 6

New experimental set-up for growth of n-type Te doped $3^{n}$. diameter GaAs crystals: view of the growth chamber which can be operated in a vertical gradient freeze or vertical Bridgman mode. (BBC 902-1507)

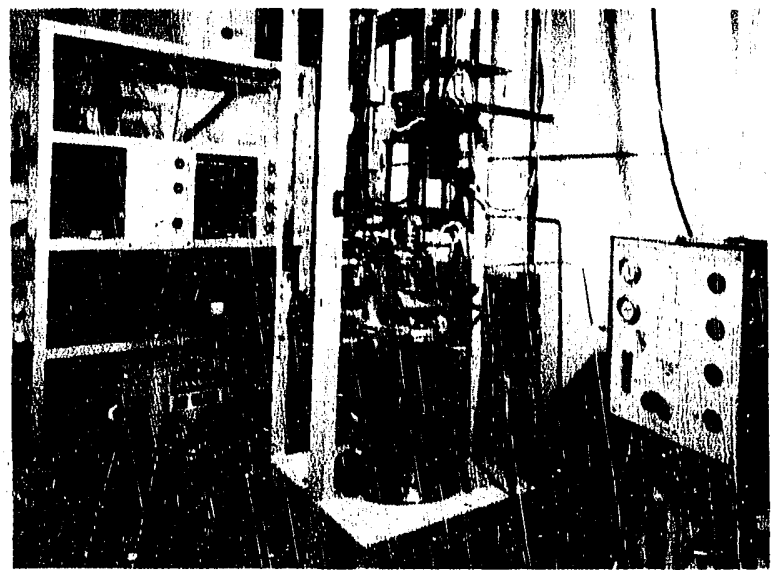

wafer is encouraging. The crystals grown with wet $\mathrm{B}_{2} \mathrm{O}_{3}$ have a lower dislocation density distributed in a less pronounced $W$-shape than the crystals grown with dry $\mathrm{B}_{2} \mathrm{O}_{3}$.

Total encapsulation with wet $\mathrm{B}_{2} \mathrm{O}_{3}$ results in crystals with a low concentration of boron $\left(10^{15} \mathrm{~cm}^{-3}\right)$ and carbon $\left(<10^{14} \mathrm{~cm}^{-3}\right)$. The silicon contamination however is increased by the use of wet $\mathrm{B}_{2} \mathrm{O}_{3}$. Wet $\mathrm{B}_{2} \mathrm{O}_{3}$ oxidizes $\mathrm{SiO}$ released by devitrification of the quartz ampoule which in turn is released to the $\mathrm{GaAs}$ by reaction of the silicon oxide with $\mathrm{Ga}$. Dry $\mathrm{B}_{2} \mathrm{O}_{3}$ is always a good barrier to ambient contamination since it is extremely stable up to high temperatures. Therefore by using toial encapsulation with dry $\mathrm{B}_{2} \mathrm{O}_{3}$ in a PBN crucible, crystals of purity comparable to crystals grown by Czochralski can be obtained even in the presence of a quartz chamber.

The crystal grown with wet $\mathrm{B}_{2} \mathrm{O}_{3}$ shows a sharp drop in resistivity toward the tail end which is due to an increase in both $\mathrm{Si}$ and Ga concentrations. The EL2 concentration of these crystals is slightly lower than those of crystals grown with dry encapsulant and drops toward the end of the crystals. Using As-rich charges, semiinsulating crystals of a resistivity up to $3 \times 10^{8} \Omega \mathrm{cm}$ and a mobility of about $5500 \mathrm{~cm}^{2} /$ $V s$ have been obtained using dry $\mathrm{B}_{2} \mathrm{O}_{3}$ as the encapsulant.

The activation efficiency of implanted $\mathrm{Si}$ has been investigated to assess the suitability of the crystals for doping by cirect implantation techniques. Silicon ions ${ }^{28} \mathrm{Si}$ were implanted at a $6^{\circ}$ angle off $<100>$ to prevent channeling. The implants were activated by a one step, capless proximity method, rapid thermal annealing of the samples at $950^{\circ} \mathrm{C}$ for 7 seconds. The implantations were performed under various conditions with an energy range from 120 to $140 \mathrm{keV}$ and a dose range from $5 \times 10^{12}$ to $10^{14} \mathrm{~cm}^{-2}$. The activation efficiency is defined as the ratio of the carrier concentration obtained by Hall measurements to the atomic concentration of a particular implant. The results are reported in Figure 5 and compared to results obtained by others for silicon implants on undoped LEC grown crystals. The activation efficiencies for implants in our crystals are similar to those of implants in LEC crystals. This demonstrates that total liquid encapsulation for the vertical gradient freeze technique, even in the presence of a quartz chamber, is a viable technique for producing semi-insulating crystals. 


\title{
Vertical Bridgman growth of 3" Diarneter Te-Doped GaAs Crystals \\ R. MiH, E. Bourfet, J. Guithon, A. St. Amour, and A.G. Elliot*
}

A new experimental set-up (Figure ú) has been implemented for growth of $n$-type Te doped 3" diameter GaAs crystals. The apparatus can be best described as a Czochralski puller converted into a computer-controlled vertical gradient freeze/ vertical Bridgman furnace. The heating element is a graphite "picket-fence" type heate: . It is surrounded by layers of graphite and low density alumina shaped to provide proper insulation and so that a temperature' environment suited for the crystal growth is achieved. The seeding and growth conditions have been determined experimentally by using a BN dummy charge to simulate the GaAs since the two materials have close thermal conductivities. The equipment is now ready for the growth experiments.

\section{THIN FILMS AND INTERFACES: METAL CONTACTS TO III-V SEMICONDUCTORS}

\author{
Stability of $\mathrm{Pt} / \mathrm{lnGaAs}$ Contacts \\ D.A. Olson, K.M. YU, J. WASHBurn, and T. SANos
}

Many metal/AIIIBV systems react to form layered structures, with a metal-BV or metal-Alll phases present at the substrate/reacted layer interface. The reaction rate is usually üiffusion limited, i.e., exhibits a parabolic dependence on time. The product phases often exhibit an orientation relationship with the substrate. By varying the composition (and hence lattice parameter) of the semiconductor, the misfit between the product phase and the substrate can be added. The impact of this change in misfit on the morphology of the dipnictide product phase and the reaction kinetics was the forus of this study.

The interactions between $\mathrm{Pt}$ and $\ln _{\mathrm{x}} \mathrm{Ga}_{1-\mathrm{x}}$ As for different values of $\mathrm{x}$ were investigated using $70 \mathrm{~nm} \mathrm{Pt}$ films. $\mathrm{Pt} / \mathrm{In}_{53} \mathrm{Ga}_{47} \mathrm{As}$ was shown to form many of the product phases encountered in the $\mathrm{Pt} / \mathrm{GaAs}$ and $\mathrm{Pt} / \mathrm{InP}$ reactions: $\mathrm{PtGa}, \mathrm{Pt} \mathrm{t}_{3} \mathrm{Ga}, \mathrm{Pt} \mathrm{In}_{2}$, and $\mathrm{PtAs}_{2}$. The reaction products showed a layered structure, especially for higher temperatures and longer annealing times. However, unlike the binary cases, the $\mathrm{PtAs}_{2}$ phase was randomly oriented and was intermingled with a significant amount of $\mathrm{PtIn}_{2}$. For this ternary composition, the PtIn $\mathrm{Pt}_{2}$ product phase developed a particularly strong orientation preference on the substrate, despite its large mismatch ( $8 \%)$ and the reaction progressed at a rate lower than $\sqrt{t}$. This reduced reaction rate is of interest for achieving more stable contacts for use in solid state devices.

\section{The Influence of Near-Interfacial Stoichionietry on the Barrier Height of Schottky Contacts to GaAs ${ }^{\dagger}$ \\ Z. LILIENTAL-Weber, E.R. Weber, J. WAshburn, J.H. Weaver}

One of the fundamental unresolved questions in electronic materials research is the mechanism of Schottky barrier formation at metal/semiconductor interfaces. We found consistently that metal deposition on GaAs causes an accumulation of excess As in the semiconductor near the metal interface. The stoichiometry near the interface depends on the deposited metal and the annealing history of the sample.

A confirmation of this mechanism was achieved by studying contacts formed without the disruption of the semiconductor surface typical of atom-by-atom deposition. These contacts were prepared using a novel method of depositing pre-formed clusters on the semiconductor surface, a method that minimizes surface disruption. In these structures, the interface between the clusters and the substrate was abrupt, and no reconstruction in the GaAs beneath the ciusters was found. Analytical

${ }^{\dagger}$ Supported in part by the SDIO/Innovative Science and Technology program administered through ONR 
electron microscopy performed in the semiconductor below the clusters did not show any deviation from stoichiometry of the sort observed for atom-by-atomi deposition of metals onto the GaAs surface. The Fermi-level positions of these structures determined in-situ by photoemission spectroscopy showed pinning distinctly different from the pinning positions near the midgap determined for the same metals deposited atom-by-atom by normal evaporation.

This contribution represents a major breakthrough in the fundamental understanding of Schottky barrier formation.

\section{Characterization of Thin Epitaxial Films High Resolution Study of Quantum Well Interfaces}

Z. LILIENTAL-WEBER

Samples with differing thicknesses of AlGaAs/GaAs were investigated. A special technique, chemical imaging, was applied to study the roughness at the AlGaAs/ $\mathrm{GaAs}$ and $\mathrm{GaAs} / \mathrm{AlGaAs}$ interfaces. It was found that the interfaces where AlGaAs was grown on GaAs were abrupt (roughness not larger than $2.8 \AA$ ) but the interface where GaAs was grown on AlGaAs was much broader (up to $9 \AA$ ). The roughness of the interfaces was found not to depend on the thickness of the quantum wells.

\section{Structure of MBE GaAs Layers Grown at Low Temperatures}

Z. Liliental-Weber, E.R. Weber, J. Washburn, W. Gwider, K.M. Yu, K. Kortright, F.W. Smith" and A.R. Calawa*

A systematic study of the change in structural qualicy of GaAs layers grown at temperatures between $180^{\circ} \mathrm{C}$ and $210^{\circ} \mathrm{C}$ by molecular beam epitaxy (MBE) was performed by transmission electron microscopy (TEM). It was found that the crystal quality is related to the growth temperature. At lower growth temperatures a higher amount of As was incorporated and larger changes in the lattice parameter were observed. 'These layers have high resisitivity, a large trap density, and a dielectric breakdown strength about ten times that of semi-insulating GaAs, and they can be used to eliminate sidegating in GaAs MESFE'T circuits.

LT GaAs of high crystalline perfection can be grown by MBE when the lattice parameter difference between the layer and the substrate is not larger than $0.1 \%$ for layer thicknesses as large as $2.7 \mu \mathrm{m}$. This can be achieved with a growth temperature of $200^{\circ} \mathrm{C}$ or above. At lower growth temperatures $\left(190^{\circ} \mathrm{C}\right.$ and below), pyramidal defects with polycrystalline cores surrounded by microtwins, stacking faults, and dislocations are formed if the layer exceeds a certain critical thickness. Their formation is due either to high As incorporation in the LT-GaAs layer related to lattice strain $(0.45$ $\mathrm{eV}$ per atom) due to the lattice parameter change, or to poor growth morphology at lower temperature. A $600^{\circ} \mathrm{C}$ anneal of LT GaAs epilayers grown at $200^{\circ} \mathrm{C}$ leads to the formation of As precipitates, which removes a iarge part of the excess As from the GaAs unit cell, leading to a decrease of the lattice parameter of the layers. In the absence of structural defects, these precipitates are small $(\sim 2 \mathrm{~nm})$. In contrast, structural defects may serve as nucleation sites for the excess As, leading to the formation of large precipitates $(20 \mathrm{~nm}$ :).

\section{Structure of Photodectors with InGaAs/GaAs Graded Superlattices ${ }^{\dagger}$ \\ Z. Liliental-Weber and R. Marielle}

The study between vertical electron transport and crystal defects at strained InGaAs/GaAs layers were investigated. The samples were grown on GaAs substrate doped by $\mathrm{Si}\left(1 \times 10^{17} \mathrm{~cm}^{-3}\right)$ followed by $\ln _{x} \mathrm{Ga}_{1-\mathrm{x}}$ As/GaAs strained-layer-superlattices (SLSL) finished by p-type GaAs. The SLSL consisted of two or three parts: a region with average bandgap decreased from that of $\mathrm{GaAs}$, and a region with bandgap larger than GaAs.

\footnotetext{
* MIT Lincoln Laboratory

${ }^{\dagger}$ Work sponsored by Lawrence Livermore National Laboratory
} 
TEM siudy showed formation of large half loops beneath SLSL, but no threading dislocations can be seen in the SLSL region. The layer with constant SLSL exhibit more strain. The P-i-N devices exhibited useful detection efficiencies for light wavelength from 0.9 to $1.15 \mathrm{~mm}$.

\section{Variation of Dislocation Morphology with Strain in GexSi1-x Epilayers on (100) Si \\ E.P. Kvam, D.M. Maher, C.J. Humphreys, J. Washbuan}

A change in microstructure, including dislocation Burgers vector, length, and behaviour has been observed to occur when the epilayer mismatch is varied in GexSi1-x grown on (100) Si. At low mismatches $(<1.5 \%)$, there is an orthogonal array of very long $60^{\circ}$ misfit dislocations. At higher mismatches $(>2.3 \%)$ there is a mixture of $60^{\circ}$ and edge dislocations. The nature of the microstructure has a pronounced effect on the density of threading dislocations in the epilayer, which increase by a factor of $\sim 60 \times$ through a relatively small range of mismatch (1.7 to $2.1 \%$, corresponding to $x$ ranging from 0.4 to 0.5 ).

The production of misfit $60^{\circ}$ dislocations in the low-mismatch materials examined was shown to be due to an internal faulted loop (the diamond defect) operating as a modified Frank-Read source. The resultant microstructure was very inhomogeneous, with dislocations highly clustered (in comparison to the random spacing of the array of edge dislocations at high mismatch). Further, despite extensive dislocation, very little of the dislocation content at low mismatch was edge type. Typical lowmismatch and high mismatch epilayer microstructures are shown in Figure 7.

The gradual change from $60^{\circ}$ to edge type interfacial dislocations with increasing mismatch has been documented, as has the concurrent rapid increase of epithreading dislocation density.

A two-stage process of dislocation introduction is proposed to explain the transition in misfit dislocation morphology which occurs in $\mathrm{Si}$-Ge on Si(001) epilayers, with preäominantly $60^{\circ}$ type at low mismatch to predominantly edge iype above about $45 \%$ Ge ( $2 \%$ bulk mismatch). This transition seems to be associated with a point of critical strain for surface nucleation of $60^{\circ} \mathrm{misfit}$ dislocations, followed by a cooperatively-induced nucleation and propagation of a second, complementary dislocation to form a pure sessile edge dislocation. The subsequent locking up of dislocations in a sessile state results in a rapid increase in the number of threading dislocations in the epilayer. 


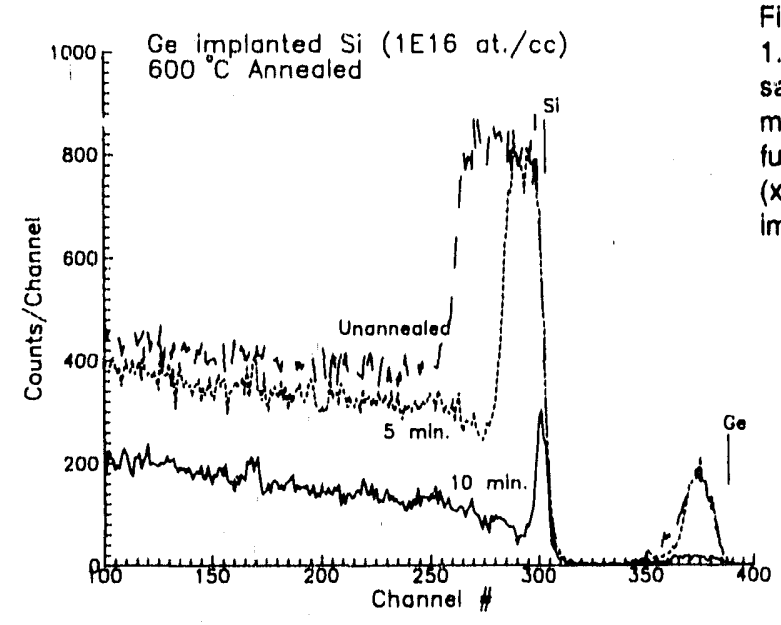

Figure 8.

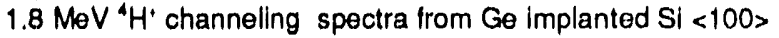
samples as implanted and annealed at $600^{\circ} \mathrm{C}$ for $5 \mathrm{~min}$. and 10 $\mathrm{min}$. Note that the amorphous $\mathrm{SI}$ created by the implantation is fully regrown after annealing at $600^{\circ} \mathrm{C}$ for $10 \mathrm{~min}$. The $\mathrm{SI}_{1 \cdot x} \mathrm{Ge}_{\mathrm{x}}$ $(x=0.05)$ layer is also regrown epitaxially in the Si. The implantation dose is $\approx 1 \times 10^{16}$ atoms $/ \mathrm{cm}^{2}$. (XBL 918-1716)

Size Effect in Parabolic Quantum Wells

W. Walukiewicz, P.F. Hopkins", M. Sundram*, A.X. Gossard*, ano R.M. Westervelt ${ }^{\dagger}$

Recently, new semiconductor heterostructure devices, the remotely-doped wide parabolic wells, have been introduced. These structures have been demonstrated to contain thick layers ( $>1000 \AA$ ) of high mobility $\left(>200,000 \mathrm{~cm}^{2} / \mathrm{Vs}\right)$ electron gas with roughly uniform three- dimensional electron densities.

We have studied three different, remotely doped parabolic well structures. Experimentally, low temperature electron mobility as high as $3 \times 10^{5} \mathrm{~cm}^{2} / V$ s has been found in the parabolic well with electron concentration $\mathrm{n} \approx 10^{16} \mathrm{~cm}^{-3}$. This mobility is much higher than the electron mobilities in uniformly doped GaAs crystals with the same electron concentration. However, it is still at least one order of magnitude lower than mobilities of 2D-electron gas in high quality modulation doped heterostructures. We have found that lower than expected electron mobilities can be attributed to electron scattering from rough walls of the wells. This phenomenon is an equivalent of the so-called "size effect," which has been extensively studied in thin metal films. However, this is the first observation of the size-effect in a semiconductor system.

In order to quantitatively explain the electron mobility in these structures we assumed that the roughness of the walls is related to screening length of the 3dimensional electron gas in the walls. Incorporation of the size effect reduces the electron mobility by the factor 2 to 3 . Also, as is shown in Figure 8 , the absolute value as well as temperature dependence of the experimental mobility, can be only understood if scattering from rough walls is accounted for.

\section{Formation of Buried Strained $\mathrm{Si}_{1-x} \mathrm{Ge}_{x}$ Layer in Single Crystal Si by High Dose Ge Ion Implantation \\ K.M. YU AND I.G. BROWN ${ }^{\ddagger}$}

Recently, there was a renewed interest in $\mathrm{Si}_{1-x} \mathrm{Ge}_{\mathrm{x}}$ alloys. The alloy in the composition range $\mathrm{x}=2$ to $30 \%$ have been grown on Si by molecular beam epitaxy (MBE), chemical vapor deposition (CVD) and limited reaction processing. In our study we have adopted a different approach. We have investigated the formation of $\mathrm{Si}_{1-\mathrm{x}} \mathrm{Ge}_{\mathrm{x}}$ alloy by high dose Ge implantation and solid phase epitaxy.

The implantation was carried out with the high current metal vapor vacuum arc (MEVVA) ion source developed by researchers at LBL. Ce ions with a total dose of $\approx 10^{16}$ atoms $/ \mathrm{cm}^{2}$ were implanted into a $<100>\mathrm{Si}$ wafer at an average energy of $90 \mathrm{kV}$. The implanted wafer was annealed at temperatures ranging from $500-600^{\circ} \mathrm{C}$. Ruth-

\footnotetext{
- University of California at Santa Barbara

+ Harvard University, Cambridge

* Accelerator and Fusion Research Division, LBL
} 
erford backscattering spectrometry (RBS) measurements show that the as-implarited sample has a Ge range at $\approx 400 \AA$ below the Si surface with maximum Ge concentration of $\approx 5$ atomic $\%$. The width of the Ge distribution is measured to be $\approx 700 \AA$. Solid phase epitaxy of the amorphous $S i$ and the $\mathrm{Si}_{1-x} \mathrm{Ge}_{\mathrm{x}}$ layer was found to start at $500 \infty \mathrm{C}$. Figure 8 shows the RBS spectra in the $\langle 100\rangle$ alignment from a series of samples unannealed and annealed at $600^{\circ} \mathrm{C}$ for $10 \mathrm{~min}$. The low backscattered yicld from the $\mathrm{Ge}$ in the regrown sample indicates that a coherent layer of $\mathrm{Si}_{1-x} \mathrm{Ge}_{x}$ is formed below $\approx 400 \AA$ of single crystal Si.

\section{GROWTHMECHANISMS AT HETEROINTERFACES}

Important scientific issues in heteroepitaxy include the role of the differing departures from thermodynamic equilibrium exhibited by different growth techniques in controlling the interface formation; the role of interface stoichiometry in the growth of compound materials; the difference between the growth of one material (A) on another $(B)$ and the inverse process ( $B$ on $A)$; the role of the substrate in controlling the structure of polyrrorphic materials; the role of interdiffusion across growing interfaces in controlling defect properties. Our goal is to determine the roles of various structural, chemical, electronic, and kinetic constraints in controlling thin film heterostructure growth and properties. This multifaceted, multidisciplinary program involves a variety of approaches to common materials systems. To study the role of the growth process, we are investigating the growth of boron nitride films by sputtering, electrochemical and chemical beam methods. To study the role of stoichiometry and interface dipole formation, as well as the order of deposition $(A / B$ or $B / A)$, in controlling the properties of metal/semiconductor and metal/insulator interfaces, we are studying the growth of silicides $\left(\mathrm{CoSi}_{2}, \mathrm{NiSi}_{2}\right)$ and alkaline-earth fluorides $\left(\mathrm{CaF}_{2}, \mathrm{SrF}_{2}\right)$ by souttering, evaporation and molecular beam epitaxy. We also aim to investigate the growth of II-VI materials by chemical vapor deposition and compare that with alternative growth means, possibly including electrochemical and molecular or chemical beam methods. The resultant thin films in all of these projects are studied both in situ and ex situ with high resolution characterization of structural and electronic properties.

Boron Nitride Heterointerface Formation

J. Kortaight, M. Olmstead, J. Porter. J. Lo, F. Echegaray, P. Cullen

Boron nitride is commonly found in two polymorphs, cubic and hexagonal, with highly disparate properties. The cubic form is similar to diamond, while the hexagonal form is structurally similar to graphite, although an electrical insulator. We are investigating means to stabilize cubic and hexagonal boron nitride phases a low defect density by studying growth on cubic and hexagonal substrates with sputtering, electrochemical and chemical beam deposition techniques. The comparison of low temperature solid (electrochemical) and plasma (sputtering) deposition as well as higher temperature UHV chemical beam deposition will allow us to explore directly the influence of growth kinetics and mechanism upon order and disorder in thin films, as well as their electrical and optical properties. 
Sputter Depositton of Boron Nitride Films

J. Kortaight, J. Lo, P. CULLEN

The energetic lons which form the source material in sputter deposition can overcome kinetic barriers to the formation of metastable structures, and it is hoped that these processes may lead to growth of the the metastable cubic form of boron nitride. Our initial experiments of RF magnetron sputtering from a compound $\mathrm{BN}$ target onto unheated substrates confirm literature reports that amorphous, boron-rich films result. Using Rutherford back scattering (RBS) for composition analysis confirms that nitrogen added to the sputtering gas reacts during the growth process to increase the nitrogen content in the films, even making them nitrogen-rich. Future work will further investigate this method to control stoichiometry and investigate the effects of substrate temperature and the possibility of inducing epitaxy by using different substrates. The sputter deposited films will be compared and contrasted with films deposited by other means. Characterization methods will include $x$-ray scattering, near-edge soft $x$-ray absorption, RBS, and various photon and electron spectroscopies.

\section{Electrochemical Deposition of Boron Nitride Fllms}

J. Porter, F. Echegaray

Unlike more traditional high-temperature methods, the low-temperature synthetic processes in electrochemical deposition often produces materials which are far from their equilibrium state. We are able to utilize a wide variety of conducting substrates and non-traditional synthetic precursors to explore the influence of specific interfacial interactions upon thin film structure and properties. By working at low temperature, we can effectively freeze out species or structures which may be transient, reactive intermediates at higher growth temperatures, allowing precise kinetic measurements. Manipulation of the oxidation state of the reagents allows us to generate reactive intermediates on the growing surface of the heterostructure in sub-monolayer quantities. Working with dilute solutions of oxidized solid reagents, these experiments pose enormously reduced safety and health hazards when compared to the more traditional synthetic precursors for III-V materials. To date, we have studied the electrochemistry of several chemical systems, including compounds of boron, gallium, indium, thallium, nitrogen, phosphorous, arsenic and antimony. We have designed and constructed specialized apparatus and electrochemical cells with which to handle moisture-sensitive reagents and we have developed methods to purify and dry the solvents and reagents.

Figure 9 shows a result related to the reduction of a boron containing compound of possible use in BN film growth. An oxidized precursor, in this case borontrifluoride $\left(\mathrm{BF}_{3}\right)$ is reduced at a copper surface in two steps to produce a polymeric deposit consisting mostly of elemental boron. In the first step (A in Figure 9) a soluble reactive intermediate, probably the $\mathrm{BF}_{2}$ radical, is produced by reductive elimination of fluoride ion. Step $B$ is associated with the reductive elimination of fluoride ion from the surface of the growing film to produce local boron radical sites. The film probably grows by a radical coupling mechanism. the resulting film is black, and sufficiently conductive to allow growth to continue indefinitely.

Figure 10 shows an Auger spectrum of the outer surface of the deposit after it has been exposed to humid air. Terminal fluorides have been largely replaced by oxygen, and the presence of copper indicates that the film is discontinuous. In the coming year, our emphasis will be upon physical characterization of the ele- mental and alloy thin film heterostructures which we can produce by these novel low-temperature routes. Determination of the physical structure of the films will be performed using $x$-ray and Raman scattering methods as well as microscopic study using SEM, TEM and STM. Thermal and/or photochemical processing will be explored as a method of producing films with controlled disorder. Optical spectroscopies and electrical characterization will be used to determine the electronic properties of the materials. 


\section{Reduction of Borontrifluoride}

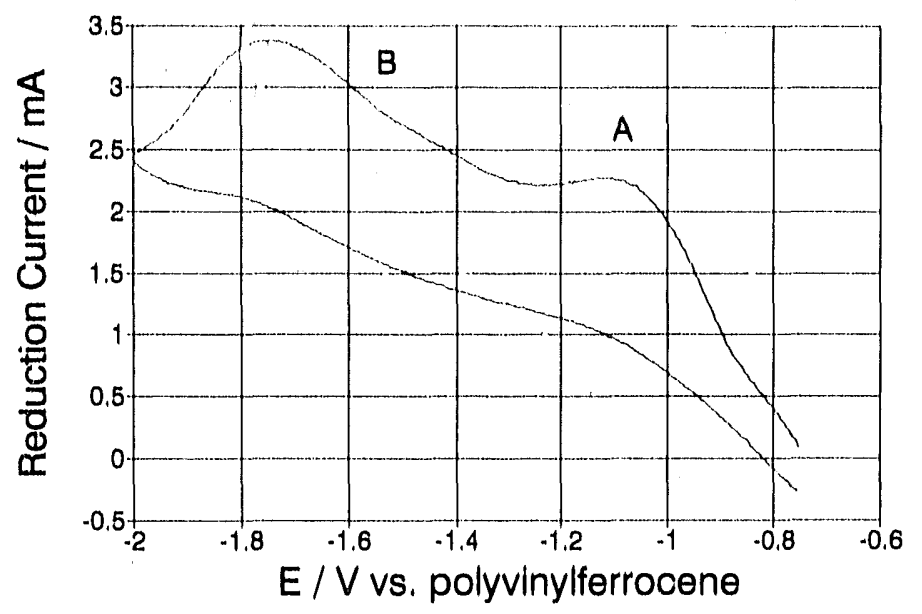

Figure 9

The electrochemical reduotion of $\mathrm{BF}_{3}$ in dry acetonitrlle at room iemperature is shown. The rate of the reaction Is proportional to the reduotion current, and the drlving force for the reaction can be controlled through the temperature $\left(25^{\circ} \mathrm{C}\right)$ and the electrode potential. The reactlon proceeds in two steps on a copper electrode surface. $A$ soluble reactive intermediate is produces in process $A$, probably the $B F_{2}$ radial. $A$ blaok, conduotive thin fllm is deposited on the electrode surface during process $B$, probably by reduotive ellmination of FP ion from the surface of the film followed by radioal-radical coupling with $\mathrm{BF}_{2}$. The struoture, composition and properties of these thin film heterostruotures are being studied. ('KBL 9011-3502)

\section{Chemical Beam Deposition of Boron Nitride Films \\ M. OLMSTEAD, P. CuLlen}

The standard process for the chemical vapor deposition of boron nitride films involves the decomposition of gaseous diborane $\left(\mathrm{B}_{2} \mathrm{H}_{6}\right)$ and ammonia $\left(\mathrm{NH}_{3}\right)$. It is difficult to control the stoichiometry of the films deposited in this manner, and the constituent gases are also toxic, requiring special handling. We are developing novel chemical precursors which are solids or liquids at room temperature and can be easily contained and controlled; a likely candidate is $\mathrm{F}_{3} \mathrm{~B}: \mathrm{N}\left(\mathrm{CH}_{3}\right)_{3}$. Initial experiments in a quartz ampule furnace to determine the reaction products are in progress. When appropriate molecular precursors are se- lected, they will be utilized in the chemical beam epitaxy chamber in the AML to grow boron nitride films.

\section{Epitaxial Semiconductor/Metal/Insulator Systems Sillicide and Fluoride Growth on Sillicon Substrates \\ M. Olmstead, G. Wong, P. Cullen}

The growth of epitaxial metal/insulator interfaces is not well characterized, in spite of its significant technological implications. Complications in the growth of such complex heterostructures include the variable stoichiometry at the interface and the extreme differences in typical surface and electronic energies between the metals and the insulators. Both factors influence the difference between metal-on-insulator and insulator-on-metal deposition as well as the kinetic approach to thermodynamic

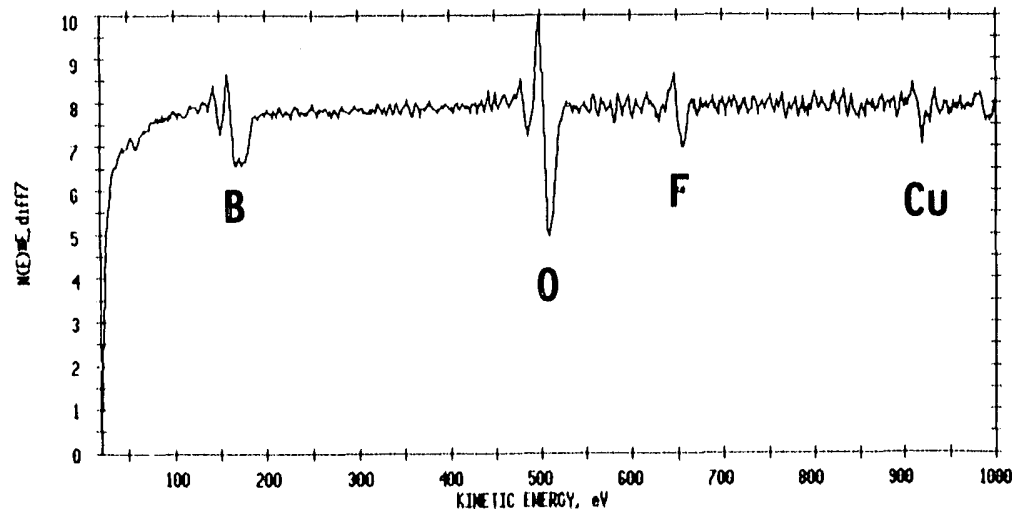

Figure 10

Auger spectroscopy reveals that the thin films produces by reduction of $\mathrm{BF}_{3}$ on $\mathrm{Cl}$ consist primarily of elemental boron. This figure shows an Auger spectrum of the outer surface of an electrodeposited film which has been exposed to humid air. It is likely that the pristine fllms are fluorine terminated on the surface, but hydrolysis of this surface has resulted in displacement of fluorine by oxygen. The composition of the outer surlace of this deposit is $B(52 \%): O(36 \%) F(12 \%)$. The film grew as islands, as indicated by the presence of a signal for Cu. (XBL 9011-3503) 
stability or metastability. We plan to investigate the growth of such epitaxial metal/ insulator interfaces, with $\mathrm{COSI}_{2}$ and $\mathrm{NiSl}_{2}$ as the metal layer ar.d $\mathrm{CaF}_{2}$ as the insulator, and with silicon as the substrate. We are completing the de sign for the evaporation system within the $\mathrm{CBE} / \mathrm{MBE}$ chamber and are doing theuretical simulations of the expected experimental results. In the next year we expect to grow silicide/silicon and fluoride/sillide interfaces and investigate them with photoclectron and $x$-ray speciroscopies. We have submitted a proposal to the Stanford Synchrotron ivadiation Laboratory to perform photoelectron diffraction on these systems once SSRL returns to full operation.

\section{$X$-ray Characterization of Interface Formation $X$-ray Scattering, Diffraction and Reflectanco \\ J. KORTAIGHT, C. LUCAS}

We are developing $x$-ray scattering, diffraction and reflectance techniques to investigate structural aspects of interface formation. Grazing-incidence techniques which enhance sensitivity to just the near surface region will be employed, as will more traditional diffraction techniques to study thicker films. Early experimental developments will include development of the capability to transfer samples from the MBE/CBE system in UHV into x-ray experiments either at LBL or at SSRL. Subsequen t developments will include compact vacuum deposition experiments which will allow structural aspects of plasma-assisted interface formation processes to be studied in situ by $x$-ray techniques, and the application of similar techniques to study interface formation by electrochemical techniques. We are also involved in the design and development of an x-ray wiggler beamline at the ALS.

\section{Growth of Wide Band Gap II-VI Materials}

J. Porter, M. Aandt, F. Echegaray

The non-equilibrium conditions which exist near a heterointerface during growth have been shown to influence the generation and concentration of native defects, as well as the lattice location and solubility of impurities on either side of the interface. Group II-VI compounds are particularly attractive for fundamental studies because of their promise as optical materials, and because the understanding of interface structure at the atomic level is still very limited for this class of materials. In preparation to form II-VI compound interfaces, we have started to evaluate available compounds with regard to toxicity, purity, and physical parameters for use in the existing metal-organic chemical vapor deposition (MOCVD) system in the AML building. The synthesis and purification of new low toxicity compounds is being cilscussed with members of the chemistry department at UCB. Depending on the progress regarding the location of acceptable liquid organometallics of zinc and the in situ generation of gaseous group VI compounds, we plan to grow the first layers in the coming fiscal year.

Program Leader

Eugene E. Haller

Project Leaders

Eugene E. Haller-Semiconductors

Marjorie A. Olmstead-Thin Film Heterostructures

Jack Washburn-Structure Property Relationships

Investigators

Edith D. Bourret

Nathan W. Cheung

Joseph B. Guitron

William L. Hansen
Joseph M. Jaklevic

Jeffrey Kortright

Zuzanna Liliental-Weber
John Porter

Wladyslaw Walukiewicz

Eicke R. Wober

Kin-Man $\mathrm{Yu}_{\mathrm{u}}$ 
Postdoctoral Fellow

Christopher Lucas

Graduate S^udeits

David E. Bliss

Jonathan Denlinger

Francisco J. Echegaray

Mark D. Hoinkis

Jennifer K. Lo
Senior Research Assoctate

I'hillip Cullon

Rebecca D, Mih

Dale A. Olson

Jeffrey A. Wolk

Gerard C. Wong
Industry Collaborations

Review Board
Arthur Gossard

Tom Picraux

R. Noel Thomas
University of Callfornia, Santa Barbara

Sandia National Laboratory

Westinghouse R\&D Center

\section{Technology Transfer}

Patents

- Patent \# S.N. 071551,433 for "Controlled growth of semiconductor crystals" has been granted.

Refereed Journal Articles

\section{Publications and Reports}

\section{Semiconductors}

Bliss, D.E., D.D. Nolte, W. Walukiewicz, E.E. Haller, and J. Lagowski, "Absolute Pressure Dependence of the Second lonization Level of EL2 in GaAs," Appl. Phys. Lett. 56, 1143, 1990.

Bourret, E.D., J.B. Guitron, M.L. Gallano, and E.E. Haller, "Vertical Seeded Melt-Growth of GaAs," 1. Crystal Growth 102,877, 1990.

Lee, B.-T., Jeong Yong Lee, and Edith D. Bourret, "Atomic Structure of Twins in GaAs," Appl, Phys, Letl. 57, 346, 1990.

Waluklewicz, W., "Carrier Scattering by Native Defects in Semiconductors," Phys. Reo. B41, 10218, 1990.

Y'u, K.M., and K.T. Chan, "Characterization of Stralned InGaAs Single Quantum Well Structures by Ion Beam Methods," Appl. Phys. Lett. 56, 45, 1990.

Yu, K.M., and K.T. Chan, "Growth Studies of Pseudomorphic GaAs/InGaAs/AlGaAs Modulation-Doped Field Effect Transistor Structures," Appl. Phys. Lett. 56, 2202, 1990.

Yu, K.M., H.P. Lee, and S. Wang, "Lattice Location of Sn Atoms in MBE GaAs by Ion Channeling Methods," Appl. Phys. Lett. 56, 1784, 1990.

Yu, K.M., H.P. Lee, and S. Wang, "Ion Channeling Investigation of the Lattice Location of Sn Atoms in GaAs Thin Films Grown by Molecular Beam Epitaxy," Appl. Phys, Lett. 56, 1784, 1990.

Refereed Conference Proceedings

Bliss, D.E., W. Walukiewicz, D.D. Nolte and E.E. Haller, "Absolute Pressure Dependence of the Second Ionization Level of EL.2 in GaAs," March 1989 Meeting of the American Physical Society, St. Louls, Mar. 20-24, 1989; Bull. Amer. Phys. Soc. 34, 685, 1990.

Haller, E.E., "Hydrogen in Semiconductors," Proc. 20th Conf, on the Physics of Semiconductors, E.M. Anastasakis and J.D. Joannopoulos, eds, Singapore, World Scientific Publishing Co.,, 1990, p. 29.

Merk, E., J. Heyman, and E.E. Haller, "Infrared Absorption Study of Zinc-Doped Sillcon," Proc. Fall Meeting of the Materials Research Society, Boston, Nov. 27-Dec. 2, 1989; Mat. Res. Soc. Symp. Proc. 163, 815, 1990.

Walukiewicz, W., "Electron Scattering by Native Defects in Uniformly-and Modulation-Doped Semiconductor Structures," Invited paper, 1989 Fall Meeting of the Maierials Research Society, Boston, Nov. 27-Dec. 2, 1989; Mat. Res. Soc. Symp. Proc. Vol. 163,845, 1990.

Walukiewicz, W., and E.E. Haller, "Carrier Scattering by Wative Defects in Modulation Doped Heterostructures," E.M. Anastasakis and J.D. Joannopoulos, eds., Singapore, 1990 p. $165 \%$. 
Bourret, E.D., "Effects of Total Liquid Encapsulation on the Charactoristies of CaAs Single Crystals Grown by Vortical Gradlent Freoze," submitted to J. Crystal Growth, LBL-28488.

Chan, L. Y., Kin Man Yu, M. Ben-Tzur, E.E. Haller, J.M. Jaklevic, W. Waluklewicz, and C.M. Hanson, "Lattice Location of Diffusod Zn Atoms in GaAs and InP Single Crystals," submitted to J. Appl. Phys. LiBL-29638.

Merk, E., and E.E. Haller, "Piezospectroscopic Study of the Ground and Excited Stutes of Zinc Double Acceptors In Sillicon," submitted to Phys. Rev. B. LBL-29332.

Waluklowicz, W., and E.E. Haller, "Effect of Scattering by Native Defects on Electron Mobillty in Modulation-doped Heterostructures," submitted to Appl. Phys. Lett. LBL-29751.

Waluklewicz, W., P.F. Hopkins, M. Sundaram, A.C. Gossard, and R.M. Westervelt, "Size Effect in Parabollc GaAs/AlxGa1-xAs Quantum Wells," submitted to Phys, Rev. Lett. LBL-29729.

Yu, K.M., H.P. Lee, and S. Wang, "Ion Channeling Investtgation of the Lattice Location of Sn Atoms in GaAs Thln Films Grown by Moiccular Beam Epitaxy," Appl, Phys, Lett. 5618, 1784, 1990, LBL-27921.

Yu, K.M., B. Katz, I.C.Wu and I.G. Brown, "Formation of Iridlum Sllicide Layer by High Dose Iridlum Ion Implantation Into Sillcon," submitted to Nucl. Inst. \& Meth. LBL-27544.

'I'U, K.M., K. Khachaturyan, E.R. Weber, H.P. Lee, and E.G. Colas, "Substitutionallty of Te and Sn Related Dx Centers in AlxCa1-xAs," Phys, Rev. Lett. submitted). LBL-27952.

Yu, K.M., M.L. Cohen, E.E. Haller, W.L. Hansen, A.Y. Llu, and I.C. Wu, "Observation of the Theoretically Predicted Crystalline I'hasos of C3N4," submitted to Phys. Rev. Lett. LBL-26358.

Invited Talks

Bourret, E.D., "Gradient Freeze Growth of GaAs Single Crystals," Department of Chemical Engineering, University of Callfornla at Davis, Davis CA, February 5, 1990.

Bourret, E.D., "Growth of Semi-Insulating and Doped GaAs Single Crystals using the VGF Technique," poster presentation, Gordon Research Conference on Crystal Growth, Oxnard, CA, March 11-16, 1990.

Haller, E.E., "Hydrogen in Semiconductors," Plenary talk, 20th International Conf, on the Physics of Semiconductors, Thessalonikl, Greece, Aug, 6-10, 1990. LBL-28691.

Haller, E.E., "Semiconductor Materials and Devices," IEEE Short Course, San Francisco, CA, January 16, 1990.

Haller, E.E., "Hydrogen in Semiconductors," Physics Department, University of Illinols Urbana-Champagne, March 29, 1990 and Purdue University, West Lafayette, IN, March 30, 1990.

Haller, E.E., "Hydrogen in Crystalline Semiconductors," Philips Laboratories, Briarcllff Manor, NY, April 17, 1990.

Haller, E.E., "Hydrogen in Semiconductors," Plenary talk at the 20th Int. Confr, on the Physics of Semiconductors, Thessalonikl, Greece, August 7, 1990.

Haller, E.E., "Electronic Properties of Hydrogen-Related Complexes in Pure Semiconductors," 6th Trieste Semiconductor Symposlum, Trieste, Italy, August 29, 1990.

Haller, E.E., "Semiconductors," Miller Institute for Basic Research, Berkeley, CA, October 16, 1990.

Walukiewicz, W., "Native Defects in III-V Semiconductors," Varian Associates Technical Seminars, Palo Alto, CA, August $20,1990$.

Walukiewicz, W., "Amphoteric Native Defects in Compound Semiconductors," Stanford University, Stanford, CA, Nov. 7, 1990.

Yu, K.M., "Ion Beam Analysis of GaAs Buffer Layers Grown by Molecular Beam Epitaxy at Low Temperature," Workshop on Low Temperature GaAs Buffer Layers, San Francisco, April 20, 1990.

Contributed Talks

Ben-tzur, M., K.M. Yu, and E.E. Haller, "Interfacial Reactions between Thin Films of Co and InP 100),", 1990 Fall Meeting of the Materials Research Soclety, Boston, Nov, 26-Dec. 1, 1990; Mat. Res. Soc. Symp. Proc. Vol, 202, 719 1991). LBL-29270.

Bourret, E.D.,"Vertical Bridgman and Gradient Freeze Growth of III-V Compound Semiconductors," F. Weinberg Symp. on Solidification Processes, Hamilton, Canada, Aug. 26-29, 1990. LBL-28408.

Bourret, E.D.,"Effects of Total Liquid Encapsulation on the Characteristics of CaAs Single Crystals Grown by Vertical Gradient Freeze," Eighth American Conference on Crystal Growth, Vail, Colorado, July 15-20, 1990. LBL-28488.

Haller, E.E.,"Electronic Properties of Hydrogen-Related Complexes in Pure Semiconductors," 6th Trieste Semic. Symp. on "Hydrogen in Semiconductors: Bulk and Surface Properties," Trieste, Aug. 28-31, 1990; LBL-29292, to be publ, in I'hysica B.

Walukjewicz, W.,"Electron Scattering by Native Defects in Modulation Doped Heturostructures,", 1990 Meeting of the American Physical Society, Anaheim, Mar. 12-16, 1990; Bull. Amer. Phys. Soc. 35, 571, 1990. LBL-28418.

Walukiewicz, W., M. Sundaram, P.F. Hopkins, A.C. Gossard, and R.M. Westervelt, "Slze Effect in Wide Parabolic GaAs/AlxGa1xAs Quantum Wells," Fall, 1990 Meeting of the Materials Research Society, Boston, Nov, 26-Dec, 1, 1990. LBL-29342.

Wolk, J.A., and E.E. Haller, "Donor Excited-State Spectroscopy of Ultra-Pure GaAs in Zero Magnetic Ficld," March, 1990) Meeting of the American Physical Sodety, Anaheim, Mar. 12-16, 1990; Bull. Amer. Phys. Soc. 35, 413, 1990. LBL.-28433. 


\section{Refereed journal Articles}

\section{Structure-Property Relations:hips}

George, T., Z. Lillental-Wober, E.R. Wobor, and F.H. Pollack, "Charac erization of polish-Induced damage in $\langle 110\rangle$ Ga $A s ; \Lambda$ Comparison of Transmission Eloctron Microscopy and Raman Spectroscopy," J. Appl. Phys. Lett., 67, 4363, 1990.

Shin, J., K.M. Geib, C.W. Wilmsen, and Z. Lillental-Wober, "Tho Chemilstry of Sulfur Passivation of GaAs Surfaces," I. Vac. Sci. Technol., A8, 1894, 1990.

Waddill, G.D. , I.M. Vitomirov, C.M. Aldao, S.G. Anderson, C. Capasso, I.H. Weaver, and Z. Lillental-Weber, "Abrupt Interfaces with Novel Structural and Electronic Properties: Metal Cluster Depositton and Metal-Semlconductor Junctions," Phys. Rev. B41, 5293, 1990 ,

Nauka, K., G.A. Reid, and Z. Lillental-Weber, "EBIC and CL. Imaging of the Antlphase Domain Boundarles in GaAs Grown on St," Appl, Phys, Lett, 56, 376, 1990.

Lillental-Wober, Z, E.R. Wober, J. Washburn and J.H. Weaver, "Schottky Barrier Contacts on Defect Froo GaAs," Appl, Phys. Lett., $56,2507,1990$.

Kramer, M.J., L.S. Chumbley, R.W. McCallum, W.J. Nelles, S. Weir, and E.P. Kvam, "Deformation Induced Defects in $\mathrm{YBa}_{2} \mathrm{Cu}_{3} \mathrm{O}_{7 . d}$ ", Physica, C 166, 115, 1990.

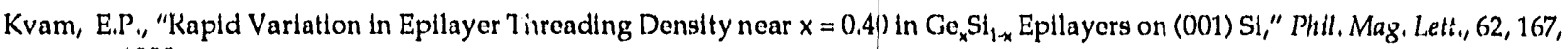
1990.

Kvam, E.P., D.M. Maher, and C.J. Humpreys, "Varlation in Dislocation Morphology with Strain in Ge $\mathrm{SI}_{1-x}$ Epilaycrs on (100) Si," J. Mater, Res., 5, 1990, 1990.

V'ashburn J. and E.P. Kvam, "Possible Dislocation Multiplication Source in (001) Semiconductor Epitaxy", Appl. Phys, Lett, 57, 1637, 1990.

Wung, H., J. Lou, N.W. Cheung, E.P. Kvam, K.M. Yu, D.A. Olson, and J. Washburn, "XTEM Study of Carbon Implantod Layors in Sllicon", Appl. Phys, Lett., 57, 798, 1990.

Refereed Conference Proceedings

Liliental-Weber, Z., "Application of Electron Microscopy for the Detection of Point Defects in MBE GaAs Layers Grown at Low Temperature," Proc, 48th Annual Meeting of the Electron Microscopy Society of America (EMSA), Ed. J.W. Balley, p.588, San Francisco Press 1990.

Kvam, E.P. D.M. Maher, and C.J. Humpreys, "Diqlocation Behaviour in Ge $\mathrm{Si}_{1-x}$ Epllayers on (001) Sl," MRS Symp. Proc.,160,71, 1990.

Kvam, E.P., "Modifled Dislocation Structures in Ge SI $_{1-x}$ Duuble Epilayers on (001) S1," MRS Symp. Proc., 160, $107,1990$.

Kramer, M.J., E.P. Kvam, and L.S. Chumbley, "Determination of the Formation of the 1/6[031] ExtrinsicStacking Faults In Deformed $\mathrm{YBa}_{2} \mathrm{Cu}_{3} \mathrm{O}_{7-d}{ }^{\prime \prime}$, MRS Symp. Proc. Vol. 183, p. 375, 1990.

Kvam, E.P., "Surface-Nucleated Half-Loops in Strained Epllayers", Proc. XII International Conf, on Electron Microscopy, Seattle, WA, ed. G.W. Balley, Vol. 4, p. 560, San Fransico Press, 1990.

Other Publications

Lillental-Weber, Z., E. R. Weber, J. Washburn, "Heteroepitaxy of GaAs on S1: Methods to Decrease The Defect Density in the Epilayer," in Defect Control in Semiconductors, ed. by K. Sumino, p. 1295, Elsevler Sclencu Publishers B.V. (North-Holland) 1990.

Theses

Olson D. A. "Thin Film Reactions on Alloy Semiconductor Substrates," Ph. D. Thesis, Department of Materials Science and Engineering University of California, Berkeley, Advisor: J. Washburn. 
Catalyst Design, Characterization and Application

Surface Structure and Interface Compounds

Instrumentation for Surface Science

\section{Surface Science and Catalysis Program}

The CAM Surface Science and Catalysis program pursues interdisciplinary, basic research studies of surface and interface materials, phenomena, and processes at the molecular level. The research is focused on the chemical and mechanical properties of surfaces and on the development of new surface instrumentation to permit atomic level characterization of interfaces. Current research tocuses on three areas.

The aim of the CATALYST DESIGN, CHARACTERIZATION AND APPLICATIONS project is to develop a fundamental understanding of the factors governing synthesis and performance of catalysts for a variety of processes. The focus is on the synthesis and characterization of novel microporous materials, including zeolites and transition metal nitrides, carbides, and oxides; the preparation and characterization of single-crystal, model catalysts; and the investigation of the fundamental aspects of methane conversion and char gasification. Recent research results irclude several new findings:

- The nucleation of $\mathrm{NaY}$ zeolite depends on the formation of a high Al- content seed material (Si/Al 1).

- Grand canonical ensemble Monte Carlo simulations provide an accurate description of the adsorption isotherm for methane in silicalite over a wide range of pressures.

- Molybdenum modified by the deposition of cobalt and sulfur exhibits superior hydrodesulfurization activity over clean molybdenum single crystals.

- Chlorine is found to disperse platinum over aluminum oxide.

- Titania deposited on rhodium can increase the catalytic activity of rhodium manyfold for the hydrogenation of acetone, carbon monoxide, and carbon dioxide.

- A catalyst has been discovered to oxidatively couple methane to $C_{2}$ and higher olefins and paraffins with close to $100 \%$ selectivity, producing essentially no $\mathrm{CO}_{2}$.

The SURFACE STRUCTURE AND INTERFACE COMPOUNDS project consists of three closely-linked efforts. The objective of the Surface Structure and Bonding group is the development of the molecular science of surface phenomena by means of the understanding of atomic-scale surface structure and chemical bonding of adsorbed monolayers; the Coatings and Tribology effort produces surface filins that impart novel mechanical properties (scratch resistance, hardness) 
and investigates the buried interface (solid-solid, solid-liquid) on the molecular level. In addition to interface structure, tribological properties (friction, lubrication and wear) are measured on the atomic scale using the atomic force microscope. The Surface Compounds effort involves studies on submonolayers of atomic and molecular adsorbates, as well as metal oxides $\left(\mathrm{TiO}_{2}, \mathrm{ZrO}_{2}\right.$ and $\left.\mathrm{FeO}\right)$, which can modify the chemical and mechanical properties of metal surfaces. During the past year:

- New two-dimensional phases of sulfur adsorbed on $\operatorname{Re}(0001)$ have been discovered by scanning tunneling microscopy studies. The new phases consist of aggregates of $S$ in the form of trimers. They form when the local concentration exceeds 0.25 monolayers.

- Disordered benzene molecules bonded to a Pt(111) surface have been found to exhibit marked bending of their carbon rings.

The INSTRUMENTATION FOR SURFACE SCIENCE project is concerned with the development of new techniques and instruments for the study of surfaces. These iriclude the scanning tunneling (STM) and atomic force (AFM) microscopes, nonlinear optical techniques, laser and electron spectroscopies, and low energy electron diffraction (LEED). A surface analysis facility that provides service for the entire division is also part of this project. During the past year:

- An atomicforce microscope operating at $143 \mathrm{~K}$ has been used to image ferritin, a spherical protein, adsorbed on polylysinetreated mica.

- Unenhanced surface Raman scattering was observed from a physisorbed film of methane on highly ordered pyrolytic graphite at $12.1 \mathrm{~K}$. The coverage is estimated to be about three monolayers.

- Ar ultra-low current scanning tunneling microscope has been used to image large polymer and biological molecules. It avoids the typical problems of tip induced displacements of the deposited molecules.

- Electrodeposition processes are imaged in situ on the atomic scale with a newly developed solid-liquid interface STM. 


\title{
CATALYST DESIGN, CHARACTERIZATION AND APPLICATIONS Microporous Materials
}

\author{
Zeolite Synthesis \\ A.T. Bell, D.M. Ginter, W.M. Hendaicks and R.F. Mortlock
}

Zeolites are widely used in industry as catalysts for petroleum processing and chemical synthesis. The aim of this project is to understand the chemical and physical transformations occurring during the synthesis of zeolites from highly alkaline aqueous gels and the function of these processes in determining the structure and composition of the zeolites formed. These questions are being pursued through the use of such modern spectroscopic techniques as nuclear magnetic resonance (NMR) spectroscopy, Raman spectroscopy, $x$-ray diffraction, and electron microscopy, some of which were specifically modified for these studies at CAM.

Changes in the composition and structure of the solid and liquid phases of $f r$ ujasite synthesis gels were measured over time using elemental analysis, NMR spectroscopy, vibrational spectroscopies and $x$-ray diffraction. Initial mixing of the colloidal silica, caustic and aluminate has no noticeable chemical or structural effects beyond gelation via flocculation and adsorption of aluminum and sodium onto the silica surface. The colloidal silica dissolves with room-temperature aging through the successive breakage of siloxane bonds in a kinetically limited reaction. The presence of aluminum slows the rate of siloxane bond breakage and suppresses the appearance of dissolved silica through the precipitation of aluminosilicate species. Once the dissolved aluminum is depleted from the liquid phase, the remaining colloidal silica dissolves away, leaving only an aluminosilicate solid phase which can then rearrange i hrough interaction with silicates in solution.

An investigation was conducted of the effects of gel aging on the rate of $\mathrm{NaY}$ formation, and the structure and composition of the final zeolite. The kinetics of crystallization were followed by powder $x$-ray diffraction with supplemental information provided by elemental analysis, NMR spectroscopy, vibrational spectroscopies and scanning electron microscopy. The rate of crystallization and the composition of the crystalline products are affected and strongly influenced by the composition of an amorphous aluminosilicate solid produced during aging, Initial aging produces an Al-rich aluminosilicate solid which readily reacts to form nuclei upon heating. The number of nuclei is directly related to the amount of aluminosilicate precipitated. Prolonged aging leads to incorporation of additional Si into the aluminosilicate solid, which appears to decrease the amount of coalescence of nuclei. Compositional heterogeneities in the initial gel are reduced by aging. This serves to increase the yield of $\mathrm{NaY}$ zeolite and to suppress the formation of $\mathrm{NaR}$ and $\mathrm{NaS}$ zeolites.

Studies of the reactions of aluminate anions with silicate anions in highly alkaline solutions were continued as part of an ongoing effort to understand the fundamental physical and chemical factors governing the formation of alumino-silicates. ${ }^{29} \mathrm{Si}$ and ${ }^{27} \mathrm{Al}$ NMR spectroscopies have been used to character.ze dilute, highly alkaline tetrapropylammonium aluminosilicate solutions. The solution compositions ranged from 0.1 to 2 mole $\% \mathrm{SiO}_{2}$, silicate ratios $\left(\left[\mathrm{SiO}_{2}\right] /\left[(\mathrm{TPA})_{2} \mathrm{O}\right]\right)$ from 0.05 to 1 , and $\mathrm{Si} / \mathrm{Al}$ molar ratios from 0.25 to $5 .{ }^{29} \mathrm{Si}$ NMR resonances were observed for $\mathrm{Al}$ incorporation into the dimer, linear trimer, cyclic trimer, branched cyclic trimer, double three membered ring (D3R), and double four membered ring (D4R) anions. In aluminosilicate solutions with 2 mole $\% \mathrm{SiO}_{2}$ silicate ratios of less than 1.5 lead to the stabilization of D3R (1 Al) anions. The addition of DMSO (dimethylsulfoxide) to TPA (tetrapropyl ammonium) aluminosilicate solutions provides the solutions with a high concentration of D3R (1 Al) and D4R(1 Al) anions. Semi-empirical quantum mechanical calculations were performed to caiculate the partial charge on $\mathrm{Si}$ atoms in silicate and aluminosilicate anionic structures. A correlation between the $\mathrm{Si}$ atom partial charge and its experimentally observed chemical shift assists in the assignment ${ }^{29} \mathrm{SiNMR}$ peaks due to soluble aluminosilicates (see Figure 1). 


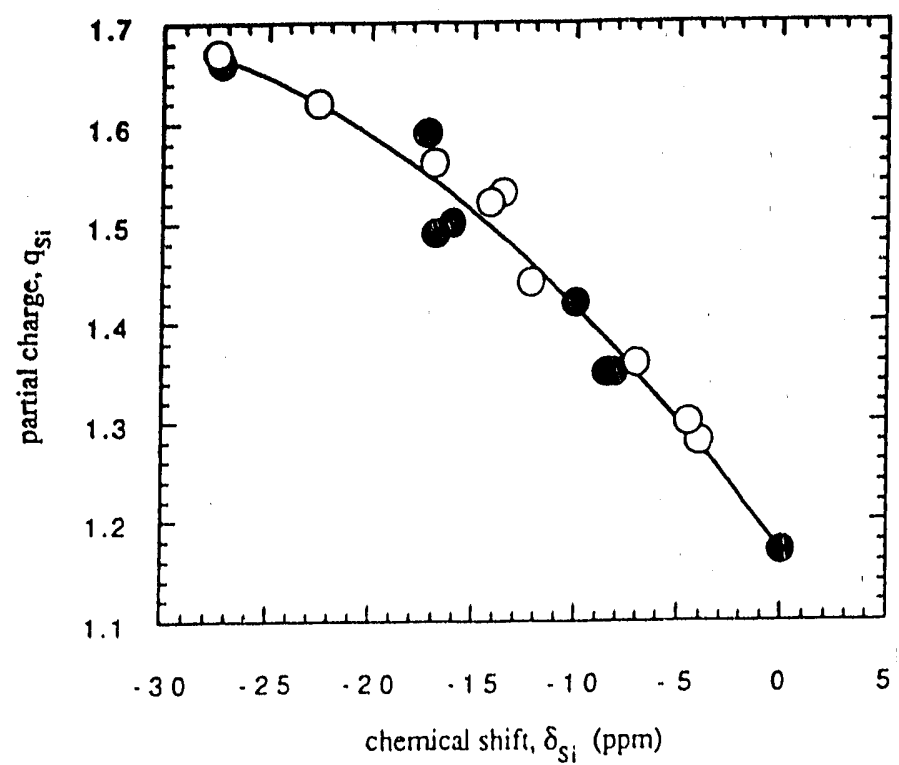

Flgure1

Correlation between the ${ }^{20} \mathrm{~S} /$ chemioal shift of SI atoms in silloate and aluminosillcate anions and the partial charge on the $\mathrm{Si}$ atom. (XBL 918-1709)

In a separate investigation, the effects of tetraalkylammoaium (TAA) cations on the equilibrium distribution of silicate oligomers in aqueous alkaline silicate solutions were investigated using ${ }^{29} \mathrm{Si}$ NMR spectroscopy. The results indicate that intrinsic differences exist in the interactions involving TAA cations and those involving alkali metal cations. The large size of the TAA cations precludes significant ion-pairing, however, hydrophobic solvation and ion-crowding play important roles in determining silicate speciation at equilibrium.

Effects of solvent structure on the equilibrium distribution of silicate oligomers in mixed organic/aqueous solutions of tetramethylammonium hydroxide (TMAOH) were investigated using ${ }^{29} \mathrm{SiNMR}$ spectroscopy. The results indicate that the presence of organic molecules leads to condensation of the silicates, particularly to double-ring structures. Equilibrium calculations indicate that the observed extent of silicate condensation exceeds what would be expected from mass action. The variety of organic solvents used allowed elucidation of structure effects due to the following: carbon chain length, carbon chain morphology, functional group, and placement of the functional group. The structure effects of organic solvents can be attributed to the ordering of water around the solvent molecules.

Transition Metal Nitride Catalysts

K.S. Lee, P.A. Afmstrong, A.T. Bell, and J.A. Reimer

Hydrodenitrogenation of model compounds has been investigated over $\mathrm{Mo}_{2} \mathrm{~N}$. Unsupported $\mathrm{Mo}_{2} \mathrm{~N}$ was prepared by temperature-programmed reduction of $\mathrm{MoO}_{3}$ in ammonia. The BET surface area of the final product was $\sim 150 \mathrm{~m}^{2} / \mathrm{g}$. The reactions of quinoline over $\mathrm{Mo}_{2} \mathrm{~N}$ were studied in a microreactor at a total pressure of $1 \mathrm{~atm}$. Above $250^{\circ} \mathrm{C}$, quinoline was observed to undergo hydrogenation to $1,2,3,4$ tetrahydroquinoline, the extent of hydrogenation being determined by equilibrium. At temperatures above $325^{\circ} \mathrm{C}$, hydrogenolysis occurred to yield a variety of alkylanaline derivatives. Further increase in temperature resulted in the release of ammonia and the formation of alkylbenzene products. At no stage was any evidence found for alkyl cyclohexanes. The observed selectivity to alkylbenzene products is significant and distinctly dificient from that observed for Ni-promoted $\mathrm{MoS}_{2}$ catalysts now used industrially. Preliminary experiments with pyridine suggest that this molecule undergoes hydrogenation to piperidine and subsequent hydrogenolysis to form ammonia and pentane. Investigations of the structure of pyridine adsorbed on $\mathrm{Mo}_{2} \mathrm{~N}$ using ${ }^{2} \mathrm{D}$ NMR spectroscopy have recently been initiated. 
Supported Vanadia Catalysts

G.T. Went, S.T. OYAMA, AND A. T. Bell

Supported vanadia catalysts were studied using Raman spectroscopy to establish the effects of vanadia loading and support composition on the structure of the dispersed vanatia species. Three types of vanadia species were found to be present on $\mathrm{SiO}_{2}, \mathrm{TiO}_{2}$ and $\mathrm{Al}_{2} \mathrm{O}_{3}$ supports: monomeric vanadyls, one-and two dimensional vanadate chains, and crystallites of $\mathrm{V}_{2} \mathrm{O}_{5}$. Monomeric vanadyls are characterized by a narrow Raman band in the region of $1026-1042 \mathrm{~cm}^{-1}$; the position being sensitive to the identity of the support. The terminal $V=O$ groups of polyvanadate chains give rise to a broad feature in the region of $800-1000 \mathrm{~cm}^{-1}$ which, in the case of $\mathrm{TiO}_{2}$-supported $\mathrm{V}_{2} \mathrm{O}_{5}$, shifts to higher frequency as $\mathrm{V}_{2} \mathrm{O}_{5}$ loading increases. Crystalline $\mathrm{V}_{2} \mathrm{O}_{5}$ was detected at higher loading on three si pports. Evidence from Raman spectroscopy and $\mathrm{O}_{2}$ chemisorption indicate that the dispersion of vanadia increases in the order $\mathrm{SiO}_{2}>\mathrm{Al}_{2} \mathrm{O}_{3} \sim \mathrm{TiO}_{2}$. Raman spectra taken after the catalysts were exposed to ethanol and water show that only the monomeric species interact with the adsorbates. For $\mathrm{SiO}_{2}$-supported $\mathrm{V}_{2} \mathrm{O}_{5}$, these interactions result in a reduction in the extent of bonding between the vanadyl groups and the support. Similar experiments conducted with $\mathrm{TiO}_{2}$ - and $\mathrm{Al}_{2} \mathrm{O}_{3}$-supported $\mathrm{V}_{2} \mathrm{O}_{5}$ show no evidence of a reduction in the extent of vanadyl bonding to the support.

\section{Catalytic Hydrogenation of $\mathrm{CO}^{*}$}

The purpose of this project is to develop an understanding of the fundamental processes involved in the catalytic conversion of carbon monoxide and hydrogen to gaseous and liquid fuels. Attention is focused on defining the factors which limit catalyst activity, selectivity, and resistance to poisoning, and the relationship between catalyst composition/structure and performance. To meet these objectives, a variety of surface diagnostic techniques are used to characterize supported and unsupported catalysts before, during, and after reaction. The information is combined with detailed studies of reaction kinetics to elucidate reaction mechanisms and the influence of modifications in catalyst composition and/or structure on the elementary reactions involved in carbon monoxide hydrogenation.

\section{Deactivation of Ru/TiO ${ }_{2}$ Catalysts During Fischer-Tropsch Synthesis* K.R. KaISHNa AND A.T. BeLL.}

An investigation of the causes of catalyst deactivation during Fischer-Tropsch synthesis over $\mathrm{Ru} / \mathrm{TiO}_{2}$ catalysts has been carried out. The effects of Ru dispersion, $\mathrm{TiO}_{2}$ phase, and $\mathrm{TiO}_{2}$ surface area on catalyst activity and selectivity were examined. $\mathrm{CO}$ chemisorption capacity and carbon species accumulation were determined as a function of reaction time using isotopic tracer techniques in conjunction with temperature-programmed surface reaction. The results of this investigation show that all of the catalysts undergo deactivation with time, with no change in product selectivity. Initially, deactivation is very rapid followed by a slower activity loss. The long-term rate of deactivation is proportional to the initial CO turnover frequency, obtained by extrapolation of the long-term activity data. Deactivation is accompanied by a progressive loss in $\mathrm{CO}$ chemisorption capacity as well as an accumulation of various types of carbon species. The activity and the $\mathrm{CO}$ chemisorption capacity can be restored to their initial values by reduction in $\mathrm{H}_{2}$ or $\mathrm{D}_{2}$. Differences in the initial activity (measured at 1 min after start-up of reaction) of Ru supported on anatase and Degussa P-25 titania ( $70 \%$ anatase, $30 \%$ rutile) can be ascribed to differences in $\mathrm{Ru}$ dispersion; Ru supported on rutile exhibits a lower initial activity than the anatasesupported catalyst with the same dispersion. $\mathrm{TiO}_{2}$-supported $\mathrm{Ru}$ has a higher activity than $\mathrm{SiO} \mathrm{V}_{2}$ or $\mathrm{Al}_{2} \mathrm{O}_{3}$ supported $\mathrm{Ru}$, and the formation of $\mathrm{Ti}^{3+} f f$ sites at the adlineation of $\mathrm{Ru}$ and titania is proposed to be the cause for this. Carbidic carbon, $\mathrm{C}_{\mathrm{a}}$ and

\footnotetext{
"This work was supported by the Division of Chemical Sciences, Office of Basic Energy Sciences, U.S. Department of Energy
} 


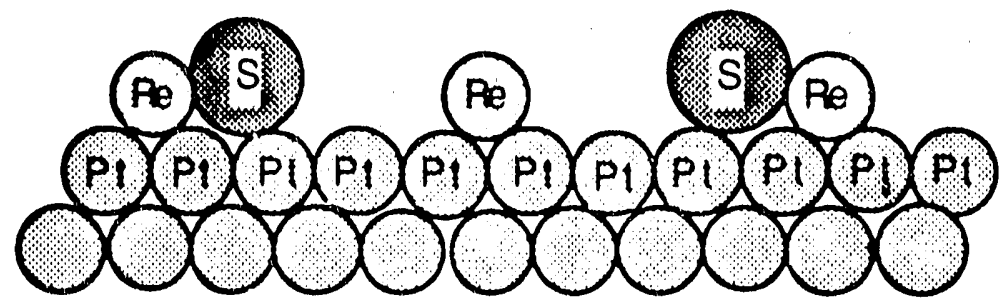

Figure 2

Sohematio of a Pt-Pe bi metallio surface with the coadsorbed sulfur. (XBL. 918-1710)

alkylcarbon chains, $C_{b}$, were observed to accumulate as reaction proceeds. $C_{b}$ consists of two species $\mathrm{C}_{\mathrm{b}^{\prime}}$, which is the precursor to $\mathrm{C}_{2+}$ hydrocarbons, and $\mathrm{C}_{\mathrm{b}^{\prime \prime}}$, which consists of longer alkyl chains and does not participate in the production of gas phase products. The inventory of the reactive $C_{a}$ and $C_{b}$ passes through a maximum in the first 10 min of reaction, while the longer chain $C_{b}$ "grows monotonically. Both types of carbon result in a loss in $\mathrm{CO}$ chemisorption capacity. The rapid initial loss in activity in the first ten minutes correlates with the $C_{a}+C_{b}$ accumulation; the long-term loss in $\mathrm{CO}$ uptake and catalyst activity are probably due to $\mathrm{C}_{\mathrm{b} \text { ".. }}$. The alkyl chains comprising $\mathrm{C}_{\mathrm{b}}$ "do not undergo hydrogenolysis under reaction conditions, probably due to inaccessibility to hydrogen.

\section{Metal and Bimetallic Single Crystal Catalyst Systems: (Pt, Pt-Re, Mo-Co, Ni, Rh)}

Fundamental aspects of catalysis are investigated by the use of well-characterized single crystal metal surfaces. Bimetallic surfaces are produced in ultra-high vacuum by deposition of a second metal. Additives, such as sulfur, chlorine or oxygen are added from the vapor phase when appropriate.

\section{Platinum-Rhenium Bimetallic System \\ C. KIM and G.A. Somorjal}

A pulsed metal vapor vacuum arc plasma gun was developed and applied to deposit rhenium and platinum from submonolayer to multilayer quantities (Figure 2). The co-deposition of sulfur onto the Pt-Re bimetallic system has been investigated in order to develop a Pt-Re-S model catalyst that was found to have superior activity and selectivity for dehydrocyclization in the petroleum refining technology. The bonding and desorption of sulfur was studied in high pressures of hydrogen and nhexane. It was found that the presence of the co-adsorbed hydrocarbon enhanced the sulfur removal rate but the desorption mechanism did not change.

\section{Selective Reduction of Nitric Oxide Using Ammonia}

T. Katona and G.A. Somorjal

NO reduction by $\mathrm{NH}_{3}$ to produce $\mathrm{N}_{2}$ and $\mathrm{H}_{2} \mathrm{O}$ over $\mathrm{V}_{2} \mathrm{O}_{5}$ - $-\mathrm{TiO}_{2}$ catalysts in the presence of excess oxygen is an important chemical process to reduce $\mathrm{NO}_{x}$ emission from stationary combustion based power plants. We explored platinum as a catalyst for this reaction and it proved to be a much more active one by at least two orders of magnitude than the oxide system. We found that NO inhibits ammonia oxidation by 
Figure 3

Rate oscillation of NO consumption at $310^{\circ} \mathrm{C}$.

(XBL 918-1711)
Rate Oscillation of NO Consumption

at $310 \mathrm{C}$

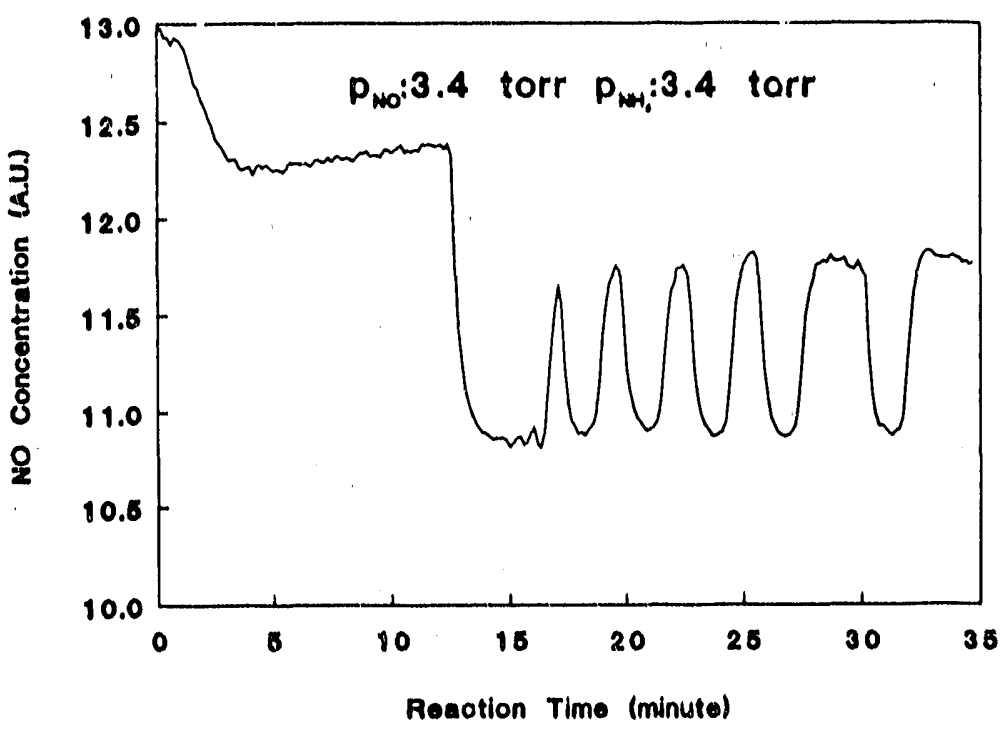

$\mathrm{O}_{2}$ below $250^{\circ} \mathrm{C}$. Oxygen appears to catalyze the $\mathrm{NO}-\mathrm{NH}_{3}$ reaction probably by converting $\mathrm{NH}_{3}$ to reactive $\mathrm{NH}_{2}$ surface species. An oscillatory reaction between $\mathrm{NO}$ and $\mathrm{NH}_{3}$ was uncovered at $300^{\circ} \mathrm{C}$ in certain partial pressure regimes of nitric oxide and ammonia (Figure 3).

The Surface Science and Catalytic Behavior of Cobalt and Sulfur Covered Molybdenum Crystals

C. KniGHT AND G.A. Somorjal

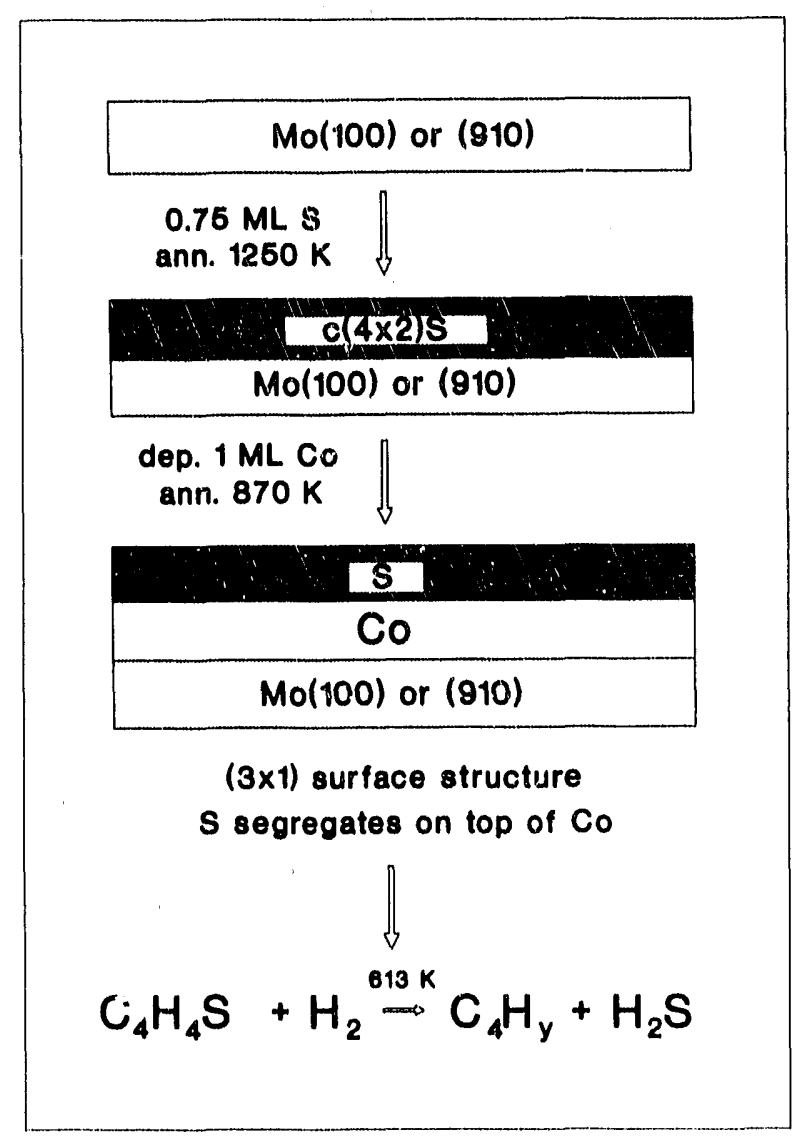

Molybdenum modified by the deposition of cobalt and sulfur was utilized for the hydrodesulfurization of thiophene to butenes and butane (Figure 4). When cobalt is deposited on a stepped molybdenum crystal surface, the reaction rate increases over that of clean Mo. The structures and chemisorption properties of cobalt and sulfur are explored to develop a model catalyst that is superior for the HDS reaction utilized in the petrochemical technology. 
The selective hydrogenation of polyolefins and the hydrogenation of nitriles to amines are facile reactions that readily occur near $25^{\circ} \mathrm{C}$ either in the vapor phase or in a liquid solvent. We aim to understand the mechanisms of these important reactions by studying model singlecrystal nickel [Ni(111)], rhodium (stepped surfaces) and palladium $[\mathrm{Pd}(111)]$ catalysts of low $\left(1 \mathrm{~cm}^{2}\right)$ surface area and by developing a catalytic cell for the combined liquid phase rate studies and uhv surface characterization. While our reaction cell is under construction, we are investigating the structure of chemisorbed ethylene and propylamine on the metal single crystals by thermal desorption techniques, high resolution electron energy loss spectroscopy and low energy electron diffraction.

\section{Oxide and Oxide-Metal Single Crystal Catalyst Systems: Pt/Al $\mathrm{O}_{3}$, Rh/TiO, Pt/ZrO, Cu/ZnO, Cu O, Y-Zeolite}

Oxides and oxide-metal systems have unusual chemical properties and are often used as catalysts. These model studies are aimed to explore how their structure and composition relates to their catalytic activity and selectivity. Oxide layers are deposited in submonolayer coverages on single crystal surfaces or on polycrystalline foils of transition metals by depositing the metal from the vapor and subsequently oxidizing it. The surface coverage of the oxide is monitored by selective chemisorption, electron photon and ion spectroscopies (AES, XPS, ISS). The structure of the oxide-metal system is studied by LEED, XPS and scanning tunneling microscopy. The chemisorption and catalytic behavior of oxide-metal systems is compared with that of the clean metal.

\section{The Role of Chlorine in Controlling the Surface Area and Catalytic Activity of Platinum in Hydrocarbon Conversion \\ I. Böszörmenyi and G.A. Somorjal}

Chlorine, when added to platinum hydrocarbon conversion catalysts is known to cause redispersion of the metal on the high surface area alumina support during catalyst preparation or regeneration. In order to explore the mechanism of this important phenomenon, model catalysts consisting of $\mathrm{Pt}-\mathrm{Al}_{2} \mathrm{O}_{3}-\mathrm{Cl}$ have been prepared by 1) depositing $\mathrm{AlO}_{x}$ on an atomically clean platinum foil which had been exposed to chloroform and 2) depositing $\mathrm{Pt}$ followed by chlorination on $\mathrm{AlO}_{\mathrm{x}}$ prepared on a polycrystalline gold foil (Figure 5).
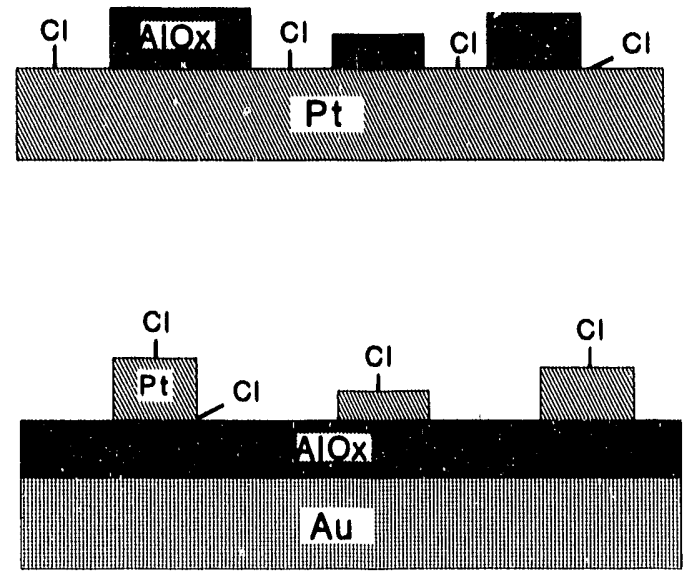

Figure 5

Fabrication of the $\mathrm{Pt}-\mathrm{Al}_{2} \mathrm{O}_{3}-\mathrm{Cl}$ catalyst system on small area $\left(\sim 1 \mathrm{~cm}^{2}\right)$ platinum or gold folls. (XBL 9010-3354) 


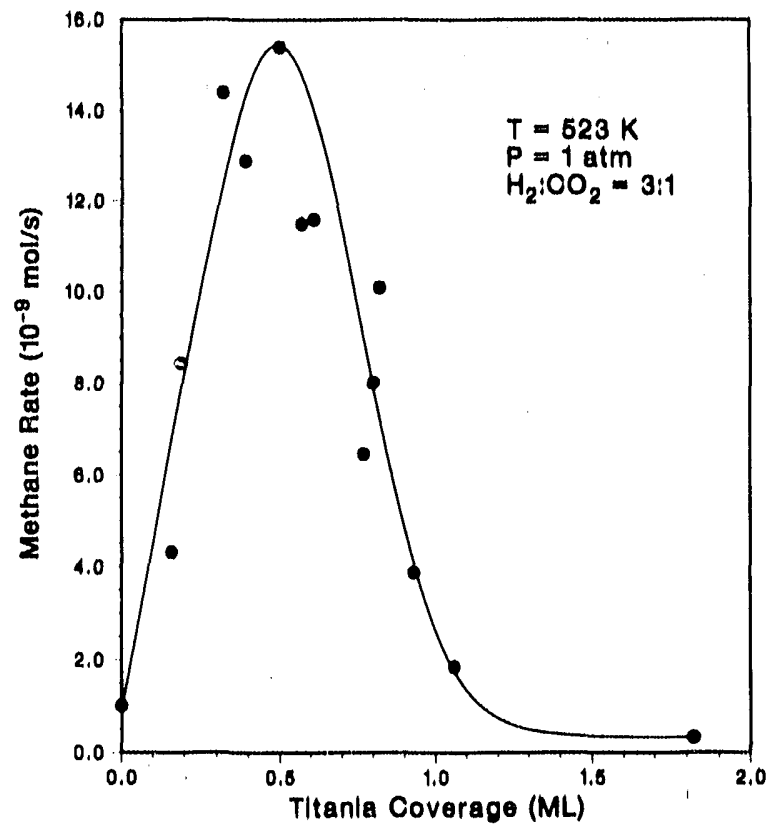

Flgure 6

The hydrogenation of $\mathrm{CO}$ as a function of TiO, coverage over

the Rh-TIO, oatalyst system. (XBL 905-1978)

Our results indicate that $\mathrm{Cl}$ aids the redispersion of $\mathrm{Pt}$ on $\mathrm{AlO}_{\mathrm{x}}$ and an enhancement of mobility of surface species is observed in the $\mathrm{AlO}_{x} / \mathrm{Cl} / \mathrm{Pt}$ system. $\mathrm{AlO}_{\mathrm{x}}$ appears to simply block $\mathrm{Pt}$ sites, and no shifts in the methyl cyclopentane toward a more statistical ring opening can be observed.

CO TPD results show that $\mathrm{Cl}$ and $\mathrm{O}_{2}$ are both aiding the redispersion of the metal on sintered model $\mathrm{Pt} / \mathrm{AlO}_{\mathrm{x}} / \mathrm{Au}$ catalysts, although the presence of $\mathrm{Cl}$ produces a new $\mathrm{CO}$ adsorption site. We found no differences in the catalytic properties between catalysts redispersed by $\mathrm{O}_{2}$ and $\mathrm{CHCl}_{3}+\mathrm{O}_{2}$ treatments.

TiO on Rhodium

A. Boffa K. Williams, H.-C. Wang, D.F. Ogletree, M. Salmefon, G.A. Somorjal and A.T. Bell.

The growth and structure of atomically thin films of $\mathrm{TiO}_{2}$ on $\mathrm{Rh}$ is studied by AES, ISS, XPS and STM. The catalytic properties of the noble metal-titania system are investigated by reactivity and selectivity studies of hydrogenation reactions involving $\mathrm{CO}$ bond activation. Examples include $\mathrm{CO}_{2}$, acetone, and $\mathrm{CO}$ hydrogenation.

Titania has been found to promote all three of the hydrogenation reactions, with each reaction exhibiting a maximum rate at a titania coverage of 0.5 monolayer (Figure 6). The maximum rate of $\mathrm{CO}_{2}$ hydrogenation is 15 times that of the bare $\mathrm{Rh}$ surface. Acetone hydrogenation shows a 6-fold rate enhancement, while CO displays a 3-fold increase. Changes in the selectivities for each reaction are also observed upon titania promotion. The effects of titania on these reactions are attributed to an interaction between $\mathrm{C}-\mathrm{O}$ bonds and $\mathrm{Ti}^{3+}$ ions located at the Rh-titania interface.

Scanning tunneling microscopy has been used to study the structure of the monolayer of titanium oxide. After reduction with $\mathrm{CO}$, titania is shown to form two dimensional patches of atomic thickness nucleating at the steps. These patches are composed of smaller structures with diameters around $20 \AA$. Enhanced electronic conductivity at the periphery of the strictures is revealed by the STM and is associated with the presence of $\mathrm{Ti}^{+3}$ species.

\section{Surface Science Studies of Catalyzed Methanol Synthesis on Copper and Cu-Zn-O Surfaces}

S. Fu AND G.A. SOMORJAI

The Cu- $\mathrm{Zn}-\mathrm{O}$ system is important as a catalyst for methanol production from $\mathrm{CO}$, $\mathrm{CO}_{2}$ and $\mathrm{H}_{2}$. Submonolayers to multilayers of zinc and oxygen deposited in UHV on $\mathrm{Cu}(110)$ were characterized by Auger Electron Spectroscopy (AES), Low Energy 
Electron Diffraction (LEED), and Temperature Programmed Desorption (TPD) of $\mathrm{CO}, \mathrm{CO}_{2}$ and zinc (Figure 7). Carbon monoxide adsorbs well on copper at $150 \mathrm{~K}$ but only poorly on the oxides of copper and zinc. Carbon dioxide adsorbs on zinc oxide at $150 \mathrm{~K}$ but not on copper or oxidized copper We used a combination of $\mathrm{CO}$ and $\mathrm{CO}_{2}$ adsorption to follow the initial grow th of two-dimensional $\mathrm{ZnO}_{x}$ islands and the effect of heat and oxygen treatments on these two-dimensional islands. It is shown that heating above $300 \mathrm{~K}$ leads irreversibly to three-dimensional island formation.

The interaction of methanol with $\mathrm{Cu}-\mathrm{Zn}-\mathrm{O}$ surfaces are modeled by zinc oxide islands on $\mathrm{Cu}(110)$ covered with various amounts of chemisorbed oxygen. Methanol reduces the zinc oxide, as seen by zinc Temperature Programmed Desorption (TPD) and confirmed by Auger Electron Spectroscopy (AES), and takes oxygen away from copper as confirmed by Low Energy Electron Diffraction (LEED) and AES. The decomposition temperature of the formate and methoxy species from the separate components of $\mathrm{Cu}(110)$ or oxygen covered $\mathrm{Cu}(110)$ and $\mathrm{ZnO}_{x}$ are unaffected by the presence of the other component.

\section{The Catalytlc Activity and Characterization of Sputter Deposited Sillca-AlumIna ThIn Fllms \\ T. Nakayama, I. BozörmmenyI and G.A. SOMORJal}

These studies attempt to investigate the acid catalytic propertles of thin $(<100 \AA)$ silica-alumina films prepared on polycrystalline gold foil by sputter deposition using zeolite $\mathrm{Y}$ catalysts with different $\mathrm{Si} / \mathrm{Al}$ ratios. We found that using this method the thin film of silica-alumina and the target zeol ite $Y$ have a very similar composition and chemical $\mathrm{Al}, \mathrm{Si}$, and $\mathrm{O}$ environments. To clearly distinguish the activity of these model catalysts from the background in cumene cracking as test reaction, a glass reactor and a geometric surface area of at least $20 \mathrm{~cm}^{2}$ was needed. Catalytic properties of the sputtered films using zeolite $Y$, silica and alumina as targets correlated well with that of the corresponding target materials. Thus, it appears that this is a promising technique for exploring the surface science of microporous oxide catalysts.

\section{Modeling}

\section{Theoretical Models of Adsorption, Diffusion, Desorption,} and Reaction of Gases on Metal Surfaces ${ }^{\star}$

S. J. Lombardo and A. T. BeLL.

A review is presented of the theoretical approaches available for describing the kinetics of gas adsorption, diffusion, desorption, and reaction on metal surfaces. The prediction of rate and diffusion coefficients based on molecular dynamics, transitionstate theory, stochastic diffusion theory, and quantum mechanics are discussed, and the success of these theoretical approaches in representing experimental observation is examined. Consideration is also given to the effects of lateral interactions between adsorbates and to the ability of lattice-gas models to provide a representation of the dependences of rate and diffusion cocfficients on adsorbate coverage. Finally, the utility of continuum and Monte Carlo models for describing the kinetics of complex surface processes in terms of elementary processes is addressed.

\section{Monte Carlo Simulations of Adsorption-Assisted Desorption of CO*}

S. J. Lombafido AND A. T. BeLL

A Monte Carlo simulation technique is presented for describing the adsorption, surface diffusion, and desorption kinetics of molecules from metal surfaces. Lateral interactions between adsorbed molecules are taken into account using the BondOrder-Conservation-Morse-Potential method. The rate of desorption observed in the presence of a gas-phase species is higher than that observed in a vacuum. The increase in the apparent rate coefficient for desorption with increasing pressure can be 
ascribed to the effects of repulsive lateral interactions on the activation energy for desorption. The simulated kinetics are in good agreement with the experimentallyobserved kinetics for the isothermal desorption of $\mathrm{CO}$ from polycrystalline $\mathrm{Pd}$ and for the temperature-programmed desorption of $\mathrm{CO}$ from $\mathrm{Ni}(1(0))$.

\section{Analysis of Flscher-Tropsch Synthesls by the BOC-MP Approach" \\ E. Shustorovioh and A. T. Bell.}

The BOC-MP (bond-order-conservation-Morse-potential) approach has been used to calculate the heats of chemisorption of adspecles and activation barriers for elementary reaction steps envisioned to occur during Fischer-Tropsch (F-T) synthesis over the periodic series $\mathrm{Fe} / \mathrm{W}(110), \mathrm{Ni}(111), \mathrm{Pt}(111)$, and $\mathrm{Cu}(111)$. Dissociative adsorption of $\mathrm{CO}$ to form carbidic carbon is projected to occur spontancously on $\mathrm{Fe} /$ $W(110)$ and with a small activation barrier on Ni(111). The calculated barrier heights for this reaction on $\mathrm{Pt}(111)$ and $\mathrm{Cu}(111)$ are high enough to preclude appreclable dissoclation of $\mathrm{CO}$. Hydrogen-assisted dissociation of $\mathrm{CO}_{8}$ is found to have an even smaller activation barrier on $\mathrm{Fe} / \mathrm{W}$ and $\mathrm{Nl}$, but not on $\mathrm{Pt}$ or $\mathrm{Cu}$. On thll the metal surfaces, the energeticallypreferred path for initiation of alkyl chain growth is via insertion of a $\mathrm{CH}_{2}$ group into the carbon-metal bond of a $\mathrm{CH}_{3}$ group. The activation barrier for $\mathrm{CO}$ insertion in to the metal-carbon bond of a $\mathrm{CH}_{3}$ group is greater than that for $\mathrm{CH}_{2}$ insertion. As a consequence, the acetyl group formed by $\mathrm{CO}$ insertion serves mainly as a precursor to oxygenated products. On $\mathrm{Fe} / \mathrm{W}, \mathrm{Ni}$, and $\mathrm{Pt}$ the activation barrier for termination of alkyl chain growth by b-elimination of hydrogen is found to be lower than that for a-addition of hydrogen, and, as a consequence, olefins are projected to be formed more readily than paraffins. By using as examples $\mathrm{Fe}(100)$ and $\mathrm{Fe}(100)-\mathrm{c}(2 \times 2) \mathrm{C}, \mathrm{O}$, it is shown that carburization of an $\mathrm{Fe}(100)$ surface reduces the heats of adsorption of $\mathrm{C}, \mathrm{O}$, and $\mathrm{CO}$, resulting in non-dissociative chemisorption of $\mathrm{CO}$, similar to that on $\mathrm{Pt}(111)$. The BOC-MP model projections are consistent with the available experimental data and contain claims that can be tested experimentally in the future.

\section{Analysis of Methanol Synthesis from $\mathrm{CO}$ and $\mathrm{CO}_{2}$ by the BOC-MP Approach* E. Shustorovioh AND A.T. BeLL}

The mechanisms of methanol synthesis from $\mathrm{CO}$ and $\mathrm{CO}_{2}$ on $\mathrm{Cu}(111)$ and $\mathrm{Pd}(111)$ have been analyzed using the BOC-MP (bond-order-conservation-Morse-potential) approach. The analysis was based on calculations of the heats of chemisorption, $Q$, for all adsorbed species and the activation barriers, $\mathrm{DE}^{*}$, for all elementary reactions believed to be involved in the synthesis of methanol from $\mathrm{CO}$ and $\mathrm{CO}_{2}$. The relevant experimental values of $Q$ and $D^{*}$, although scarce, agree well with the BOC-MP estimates. The formyl and formate routes to methanol were compared. On $\mathrm{Cu}(111)$, the activation barrier for hydrogenation of $\mathrm{CO}_{\mathrm{s}}$ to $\mathrm{HCO}_{\mathrm{s}}$ is found to be much larger than that for the desorption of $\mathrm{CO}_{\mathrm{s}}$ which makes formyl formation noncompetitive. By contrast, on $\mathrm{Pd}(111)$ the two barriers are calculated to be practically equal, making it very likely that formyl groups are formed. In the presence of $\mathrm{OH}_{8}$ groups, formate formation via the reaction $\mathrm{CO}_{\mathrm{s}}+\mathrm{OH}_{\mathrm{s}} \approx \mathrm{HCOO}_{\mathrm{s}}$ is found to have a low activation barrier, particularly on $\mathrm{Cu}(111)$, where the formate route to methanol is preferred. The rate determining step in this case is projected to be the hydrogenolysis of formate groups to form formaldehyde and atomic oxygen. $\mathrm{On} \mathrm{Cu}(111)$ the formate route also appears to be efficient for the hydrogenation of $\mathrm{CO}_{2}$ to methanol, since the activation barrier for $\mathrm{H}_{\mathrm{s}}+\mathrm{CO}_{2} \approx \mathrm{ECOO}_{\mathrm{s}}$ is calculated to be smaller than that for desorption of $\mathrm{CO}_{2}$. The reverse is true for $\mathrm{Pd}(111)$, which makes the formate route to methanol energetically unfavorable in this case. The mechanism of the WGS reaction has also been considered. It appears that the reaction does not proceed via the formate intermediate, and the rate-determining step for this reaction is projected to be the dissociation of water. On $\mathrm{Cu}(111)$, the reverse WGS reaction is found to be competi-

"Thls work was supported by the Division of Chemical Solences. 
tive with methanol formation. The BOC-MP projections are generally consistent with the observed features of hydrogenation of $\mathrm{CO}$ and $\mathrm{CO}_{2}$ on $\mathrm{Cu}$ and $\mathrm{Pd}$ catalysts, Some apparent inconsistencles are pointed out and discussed.

\section{Molecular Simulations of Methane Adsorption in Sillcallte ${ }^{\dagger}$ \\ R.Q. SNURA, R.L. JUNE, A.T, BELL. AND D.N. THeOdorOU}

Grand canonical ensemble Monte Carlo (GCMC) simulations of methane in the zeolite silicallte have been used to predict adsorption isotherms over a wide range of occupancles at several temperatures (see Figure7 next page). The zeolite has been modeled using a detailed atomistic description, as have the methane molecules. Lennard-Jones parameters for the atomic interactions have been taken from the Itterature. Adsorption isotherms and heats of sorption have been predicted in good agreement with experiment. Structural features of the intracrystalline fluid have also been studied. In a complementary study, the test particle insertion method has been used to generate isotherms from molecular dynamies simulations. The results are in excellent agreement with those from GCMC.

\section{Kinetlc Model for Cooperative Dissoclative Chemisorption and Catalytic Actlvity Vla Surface Restructuring

A kinetic model for catalytic reactions involving metal surface restructuring has been developed. The model is an extension of the equilibrium model for cooperative dissociative chemisorption and provides a possible explanation as to: (a) why strong binding sites (e.g. those at high surface roughness) can also exhibit a high turnover rate resulting in efficient catalytic activity, (b) why bond breaking occurs preferentially over a narrow temperature range and, (c) why this range is lower for more open surfaces.

All these and other conclusions derive from the central result of the model that dissociative chemisorption of the physisorbed molecules is a cooperative process. This behavior is due to the cooperative rearrangement of the substrate metal atoms upon the chemisorptive dissociation of the absorbate and not to the weaker forces that may operate among the adsorbates.

The model is a kinetic one and depends on input from experiment. In particular, we take two general results as given. One is the well documented restructuring of the surface upon bond breaking. The other is that upon a bare, defect-free, smooth surface, the probability for dissociative chemisorption of an isolated physisorbed molecule is low.

\section{Real-Space Multiple Scattering Theory Calculations of LEED Intensities for Stepped Surfaces}

X.-G. Zhang, P.J. Rous, J.M. Maclahen, A. Gonis, M.A. Van Hove and G.A. Somorjal

We have applied an extension of a newly developed real-space multiple scattering theory (RS-MST) to calculate low-energy electron diffraction (LEED) intensities from stepped surfaces. This will open up the possibility of determining the structure of steps on single crystal surfaces, a major advance is understanding catalytic reactions. In this new calculation the electron wave functions are expanded in terms of an angular momentum basis, utilizing the property of removal invariance of systems with semi-infinite periodicity. This strongly reduces the dependence of the calculation on the interlayer spacing and thus opens up the possibility of treating more open surfaces. This includes in particular, stepped surfaces, to which conventional methods cannot be applied. Applications of the formalism to various stepped surfaces confirrs the value of this new approach. Numerical techniques which can improve the convergence as well as the speed of the RS-MST approach have been investigated as well.

TThis work was supported by the Division of Advanced Industrlal Concepts 
Figure 7

Comparison of predloted and measured lsotherms for methane in silloalite. The predloted Isotherms were determlned using the Grand Canonleal Monte Carlo mothod.

(XBL 918-1713)

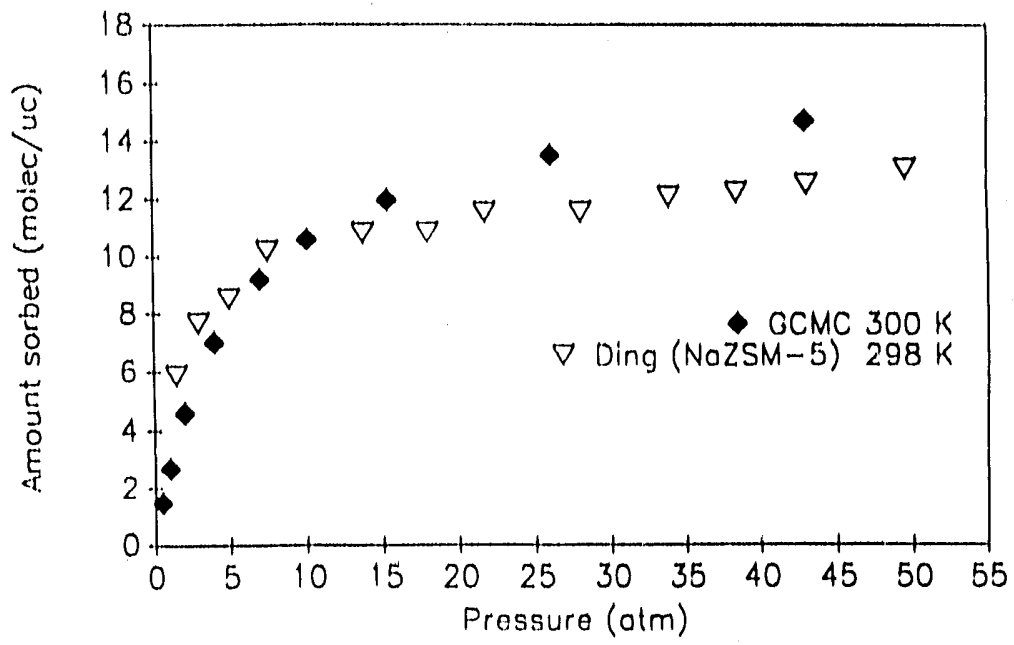

\section{Composition of the Reconstructed $\alpha \operatorname{SIC}(000-1)$ Surface}

\section{P. BADZIAQ}

The structure of a silicon carbide surface has been explored theoretically. Selfconsistent total energy quantum chemical calculations were performed on clusters modelling unreconstructed as well as $(\sqrt{3} \times \sqrt{3}) R 30^{\circ}$ reconstructed a $\operatorname{SiC}(000-1)$ surfaces. In order to preserve the partially ionic nature of the bonds terminating the clusters in bulk-like positions, the investigated clusters were saturated by two different types of hydrogen-like pseudoatoms. The approach was first tested on clusters modelling the bulk and then it was applied to model the surface. Calculated surface energles clearly favor the $S i$ adatom terminated $(\sqrt{3} \times \sqrt{3}) R 30^{\circ}$ reconstructed surface with the Si atoms directly under adatoms (second layer in the unreconstructed surface) substituted by carbon (Figure 10). The mechanism which favors this particular composition is found to be a more stress-free combination of bond lengths and bond angles.

\section{Prediction of the Effect of the STM Sample Blasing and of Surface Defects on the Observed Character of the Dimers in the Si(001)-(2x1) Surface \\ P. Badziag, W.S. Verwoerd and M.A. Van Hove}

Various experimental and theoretical studies have given rise to a controversy about whether or not the dimers in the $\mathrm{Si}(001)-(2 \times 1)$ reconstruction are buckled; i.e., tilted asymmetrically. We have performed selfconsistent quantum chemical cluster calculations to address (his controversy. The results indicate that biasing the surface, as in the scanning tunneling microscopy (STM) experiment, is likely to produce a relatively symmetric STM image even if dimers in the unblased surface are buckled, as deduced from scattering experiments. We have also investigated a dimer close to a surface defect, such as a step, and propose a mechanism which makes the dimer there appear buckled to STM. This explanation would also satisfy the other results that predict a buckling. 


\section{Fundamental Studies of Catalytic Gasification \\ Selective Conversion of Methane to Higher Hydrocarbons* \\ H. Heinemann, P. Pereira ano G.A. Somorjal}

In the 1989 Annual Report some early exploratory work was reported which showed that coal gasification with steam in the presence of alkali-alkall earth oxide catalysts could be applied to the conversion of methane to $\mathrm{C}_{2}$ hydrocarbons. It was found that when methane and oxygen were introduced during the last stages of gasification, yiclds of about $10-15 \%$ of $\mathrm{C}_{2}$ hydrocarbons were formed at the relatively low temperature of $600^{\circ} \mathrm{C}$.

During the current year, the discovery was made that the alkall-earth alkall oxide catalysts could be modified with transition metal oxides and can act as methane conversion catalysts in the absence of external carbon. It was found that methane could be oxidatively and catalytically coupled to $C_{2}$ and smaller amounts of $C_{3}$ and $C_{4}$ hydrocarbons at close to $100 \%$ selectivity at about $10 \%$ methane conversion per pass. At this high selectivitly oxygen consumption is minimized as is the need for purification of recycle methane.

It appears that the reaction path is catalytic and there is no evidence for homogeneous gas phase oxidative reaction in contrast to most of the methane conversion studies reported in the literature that are usually performed at higher temperatures (about $800^{\circ} \mathrm{C}$ ) and higher space velocities. The reaction of methane with small amounts of oxygen is carried out in the presence of steam, typically at molar ratios of methane:oxygen:water $=3: 1: 6.5$ at temperatures below $600^{\circ} \mathrm{C}$ and at atmospheric pressure. The role of water is not understood, but it has been shown to be essentlal. In the absence of water, much lower selectivities are obtained and substitution of inert gases, e.g., helium for water, to achieve the same partial pressure of the reactants and products results in lower yields of hydrocarbons. The preferred catalyst used is a calcium-nickel-potasslum oxide and care has to be taken for its formulation. A very active catalyst consists of oxides of calciuminickel:potassium in the atomic ratio of $3: 1: 1$. In the absence of potassium, the catalysts are not nearly as stable as in the presence of potassium oxides. Essentially no carbon oxides are produced over extended periods of time and selectivities are therefore about $100 \%$. The catalyst has to be activated in oxygen at about $680^{\circ} \mathrm{C}$ before being exposed to the methane-oxygensteam mixture at below $600^{\circ}$. The degree of oxidation influences both conversion and product distribution. At about 10-12\% conversion of methane per pass, selectivity to ethane and ethylene is about $86 \%$ and selectivity to $\mathrm{C}_{3}$ hydrocarbons is about $11 \%$ with $3 \%$ selectivity to $\mathrm{C}_{4}$ hydrocarbons. The total olefin to paraffin ration in this case is about 8 .

There is an induction period to the reaction and carbon material balances indicate that some carbon may initially be deposited on the catalyst and that this carbon may play a significant role in the reaction. This and other features of the mechanism as well as optimization of yiclds are currently under investigation. 


\title{
SURFACE STRUCTURE AND INTERFACE COMPOUNDS
}

\section{Surface Structure and Bonding}

This project aims to elucidate the atomic-scale structure and bonding of surfaces, in particular for surfaces covered with adsorbed atoms and molecules. The surfaces of interest are mostly metals, due to their catalytic importance, while other materials are studied in connection with either catalysis (oxides) or tribology (Si and SiC).

The main techniques used in this project are scanning tunneling microscopy (STM), low-encrgy electron diffraction (LEED) to obtain structural information, and electron spectroscopies, primarily high-resolution electron energy loss spectroscopy (HREELS) to determine surface composition.

\author{
Atomic Adsorption on Metal Surfaces: Sulfur on $R \Theta(0001)$ \\ J. Dunphiy, D. Zeglinski, R. Hwang, A. Lopez Vazguez-De-Parga, D.F. Ogletree, G.A. Somorjal and M. Salmeron
}

The structure of sulfur adsorbed on the basal plane of rhenium has been studied in UHV with AES, LEED and STM. At low coverages ( $<0.25$ monolayers) single sulfur adatoms form open structures with $\mathrm{p}(2 \times 2)$ and $\mathrm{c}(\sqrt{ } 3 \times 5)$ rect lattlces see Figures $8(a, b)$ and $9(a, b)$. In these structures both the sulfur adatoms and some of the rhenium substrate atoms are imaged simultaneously, identifying the sulfur adsorption site as a three fold hollow site. At coverages above $0.25 \mathrm{ML}$ sulfur adatoms aggregate into trimers, first disordered and then ordered into a $(3 \sqrt{ } 3 \times 3 \sqrt{3})$ R3 $30^{\circ}$ lattice at a coverage of 0.45 monolayers see Figures 10 ( $a, b-s e c$ page 136). Two types of trimers form that are centered around different substrate sites. Between 0.45 and $0.5 \mathrm{ML}$ diamondshaped sulfur tetramers appear until an ordered $\mathrm{B}\left(\mathrm{ACO}_{2}(3,1,1,3)\right)$ structure forms, as shown in Figure 11 (a, b-see page 136). With further exposure to $\mathrm{H}_{2} \mathrm{~S}$ a final structure is formied, consisting of hexagonal sulfur rings in a $(2 \sqrt{3} \times 2 \sqrt{3}) \mathrm{R} 30^{\circ}$ lattice. All of the sulfur adatoms in the three high coverage structures occupy the same type of three fold hollow sites as in the low coverage structures.

\section{Sulfur-Induced Metal Relaxations in the $R \theta(0001)$ Surface \\ D. Jentz, G. Held, M.A. Van Hove and G.A. Somorual}

Atomic adsorbates have increasingly been found to generate relaxations of the atomic positions at the surface of metal substrates, thanks to accurate modern analyses. Such relaxations are thought to play a significant role in catalytic processes over such surfaces. We studied the case of sulfur adsorption at a quarter-monolayer coverage in a (2x2) lattice on $\operatorname{Re}(0001)$, using low-energy electron diffraction. The measured diffraction intensities were compared with multiple-scattering calculations based on many possible structural models. It is found that cach $S$ atom adsorbs in a 3-fold coordinated hep-type hollow site confirming the STM finding reported above: the 3 adjacent metal atoms relax toward the $S$ atom, while another metal atom, not bonded to any $S$ atom, moves up out of the surface. In the second metal layer, a Re atom directly below the $S$ atom relaxes outward in the direction of the $S$ atom. The atomic displacements are on the order of $0.05-() .10 \AA$. 


\section{A Directed LEED Search for Many Structural Parameters: Substrate Relaxations and Buckling in $\mathrm{Mo}(100)-\mathrm{C}(2 \times 2)-\mathrm{C}$ and $-\mathrm{S}$ \\ P.J. Rous, D. Jentz, D.G. Kelly, R.Q. Hwang, M.A. Van Hove and G.A. Somorjal}

A newly developed automated structural search method has been applied to the determination of as many as 15 unknown structural parameters for two different adsorption structures on $\mathrm{Mo}(100)$. The method is based on tensor LEED coupled with a steepest descent search that locates a minimum in the R-factor in a high-dimensional parameter space. The results are very stable despite the large number of fitted parameters and give very reasonable structures that exhibit adsorbate-induced first and second layer relaxations in the substrate. A second-layer buckling is detected due to $S$ adsorption. It is shown that an experimental angle of incidence accidentally set off-normal by about $1^{\circ}$ can induce artificial lateral relaxations in the surface atoms of about $0.1 \AA$.

\section{A Diffuse LEED Study of the Adsorption Structure of Disordered Benzene on $\mathrm{Pt}(111)$}

A. Wander, G. Held, R.Q. Hwang, G.S. Blackman, M.L. Xu, P. De Andres and G.A. Somorjai

Previous LEED structural stıdies of benzene chemisorption on transition metal surfaces have relied on the presence of coadsorbed carbon monoxide to induce ordering in the overlayer. To investigate the effect of $\mathrm{CO}$ on the benzene structure, the disordered pure benzene layer chemisorbed on $\mathrm{Pt}(111)$ has been studied by diffuse LEED intensity analysis. The diffuse LEED intensity has been measured using a digital LEED apparatus and analyzed using an extension of the beam set neglect method. The benzene is found to chemisorb in a twofold bridge site rotated by $30^{\circ}$ with respect to the site found for the ordered phase formed in the presence of coadsorbed $\mathrm{CO}$ (Figure 12 see page --). In addition, the benzene ring is found to be distorted. Parallel distortions are subject to large error bars, but perpendicular spacings have been more accurately determined. These include a buckling distortion not previously seen for benzene chemisorption on transition metal surface.
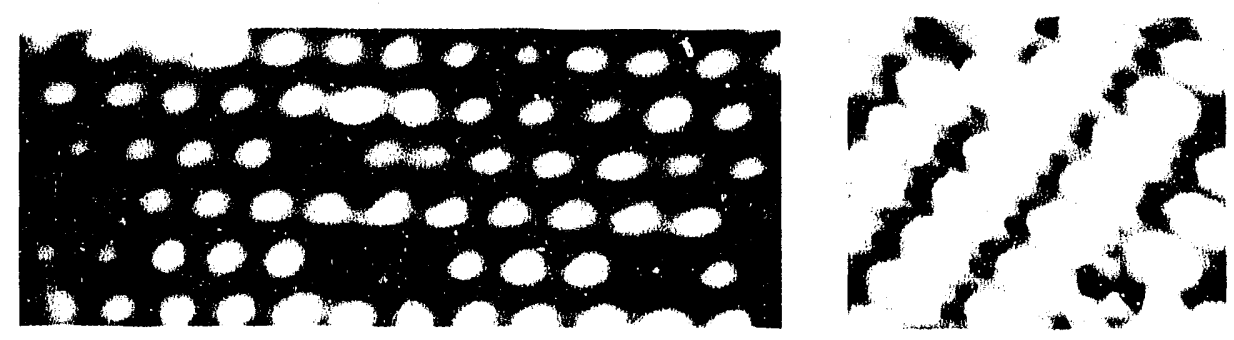

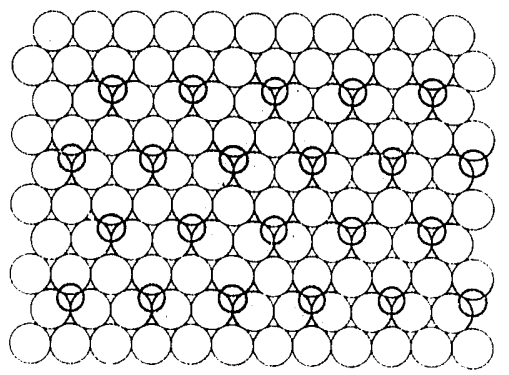

Sulfur $2 \times 2$ on $\operatorname{Re}(0001)$

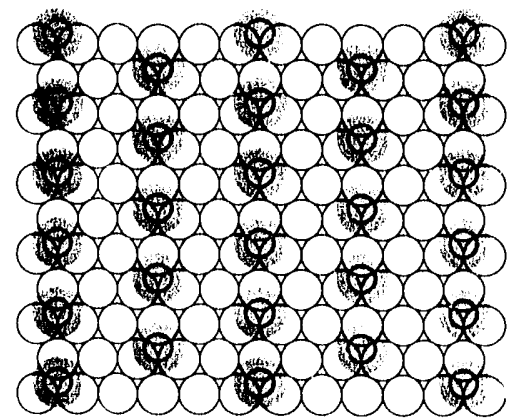

Sulfur $\mathrm{c}(\sqrt{3} \times 5)$ rect on $\mathrm{Re}(0001)$ 

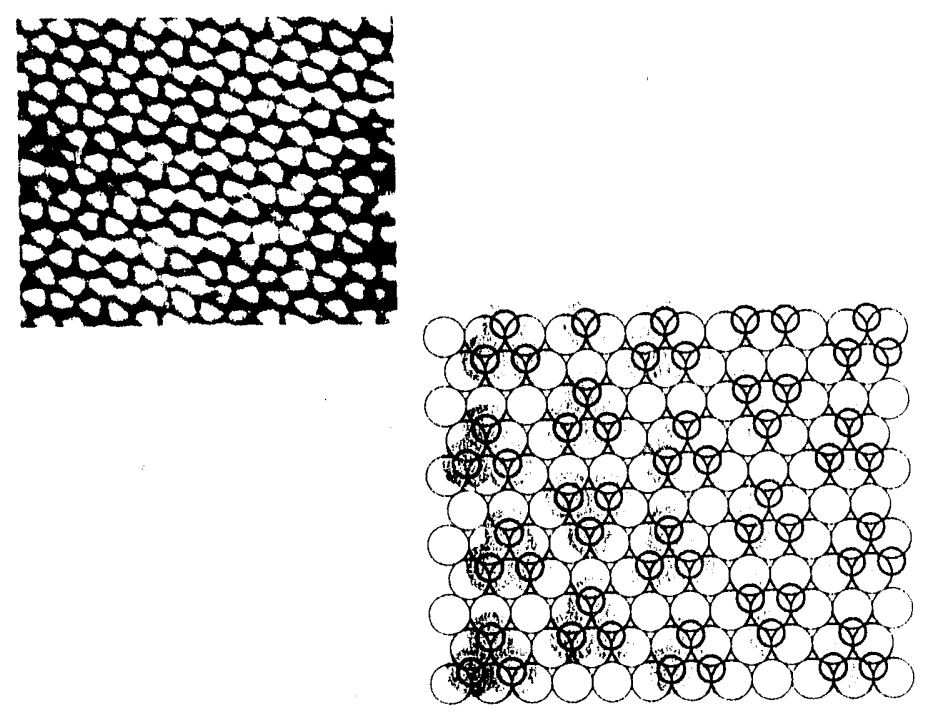

Sulfur $(3 \sqrt{ } 3 \times 3 \sqrt{ } 3) R 30^{\prime}$ on $\operatorname{Re}(0001)$

Figure 10

(a) Topographic image formed by $S$ trimers in the $(3 \sqrt{3} \times 3 \sqrt{3}) \mathrm{R} 30^{\circ}$ structure on $\operatorname{Re}(0001)$. Each triangle in the figure is made of 3 sulfur atoms as shown in the model in (b). Notice defects in the form of $S$ monomers surrounded by trimers and tetramers.

(XBB 907-5511, XBL 907-6445)
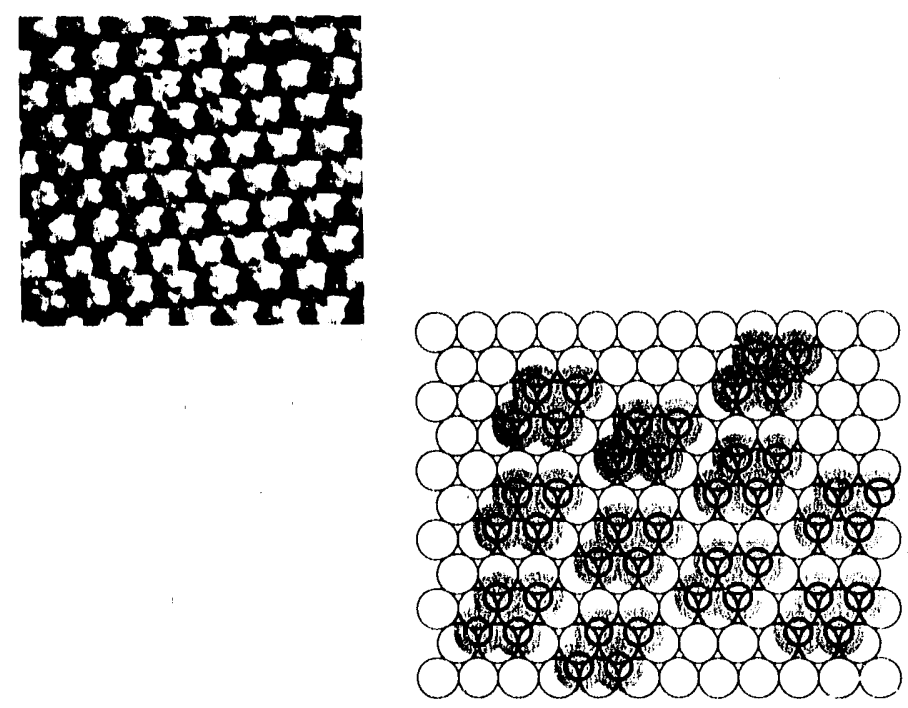

Sullur $\left(\begin{array}{l}3 \\ 1 \\ 1\end{array}\right)$ on $\mathrm{Re}(0001)$

Figure 11

(a) Periodic arrangement of $S$ tetramers in a $B(A C O 2(3,1,1,3))$ lattice on $\mathrm{Re}(0001)$. Although one $S$ atom appears brighter than the other three, it does not necessarily imply a higher elevation over the surface. This is due to electronic effects.

(b) Schematic representation of (a). (XBB 907-5508, XBL 907-6446)

Induced Ordering of Ethylidyne on the Pd(111) Surface by the Pre-Adsorption of Oxygen: A LEED and HREELS Study P.A.P. Nascente, M.A. Van Hove and G.A. Somohual

Overlayers of oxygen coad sorbed with acetylene and ethylene on a $\mathrm{Pd}(111)$ surface were studied by low-energy electron diffraction (LEED) and high-resolution electron energy loss spectroscopy (HREELS) in the temperature range 150)-320 $\mathrm{K}$. Low temperature adsorption of both $\mathrm{C}_{2} \mathrm{H}_{2}$ and $\mathrm{C}_{2} \mathrm{H}_{4}$ resulted in nondissociatively chemisorbed molecules, and the pre-adsorption of oxygen did not change the LEED or HREELS data. At room temperature both $\mathrm{C}_{2} \mathrm{H}_{2}$ and $\mathrm{C}_{2} \mathrm{H}_{4}$ formed ethylidyne $\left(\mathrm{C}_{2} \mathrm{H}_{3}\right)$, which poorly ordered in a $(\sqrt{ } 3 \times \sqrt{ } 3) \mathrm{R} 30^{\circ}$ structure. We found that pre-adsorption of oxygen induced better ordering for $\mathrm{C}_{2} \mathrm{H}_{3}$ formed from acetylene exposure, but not for $\mathrm{C}_{2} \mathrm{H}_{3}$ derived from ethylene adsorption. We propose that pre-adsorbed oxygen helped the ordering of the $\mathrm{C}_{2} \mathrm{H}_{3}$ overlayer by (a) efficiently removing surface hydrogen and (b) attractively interacting with $\mathrm{C}_{2} \mathrm{H}_{3}$ to give coadsorbate induced ordering.

The Surface Structure of $\mathrm{SiC}(100)-\mathrm{C}(2 \times 2)$ from a LEED Intensity Analysis

J. Powers, R. Kaplan, V.M. Bermudez, A. Wander, M.A. Van Hove and G.A. Somorjal

$\mathrm{SiC}$ possesses important mechanical and electronic properties. In particular, it is nearly as hard as diamond (9.2 on Mohs scale vs. 10 for diamond) and hence can be used as a hard coating. We have initiated the first detailed structural study of the surface of SiC, starting with the (100) crystallographic face. Several ordered structures occur, depending on the ratio of $\mathrm{C}$ and $\mathrm{Si}$ in the near-surface region. Utilizing Auger electron spectroscopy (AES) and video low energy electron difraction (LEED), we have examined the stoichiometric Si-terminated $\mathrm{b}-\mathrm{SiC}(100)-(2 \times 1)$ surface and the $\mathrm{C}$-rich $\mathrm{b}-\mathrm{SiC}(10())-\mathrm{c}(2 \times 2)$ surface. The latter surface structure may be produced by $\mathrm{Si}$ sublimation from a $(2 \times 1)$ surface or by ihermal decomposition of $\mathrm{C}_{2} \mathrm{H}_{4}$ on a $(2 \times 1)$ surface. Both routes produce the same surface structure, although the $\mathrm{C}_{2} \mathrm{H}_{4}$ decomposition produces a better ordered surface. The $(2 \times 1)$ surface is presumed to be similar to the $\mathrm{Si}(10))-(2 \times 1)$ surface, in which adjoining surface atoms bend towards each other (dimerize), reducing the number of unsaturated surface bonds. Our dynamical LEED study concentrated on the carbon-rich $\mathrm{c}(2 \times 2)$ structure. Preliminary findings strongly suggest that $\mathrm{C}-\mathrm{C}$ dimers bridge adjacent pairs of $\mathrm{Si}$ atoms with an otherwise bulk-like 


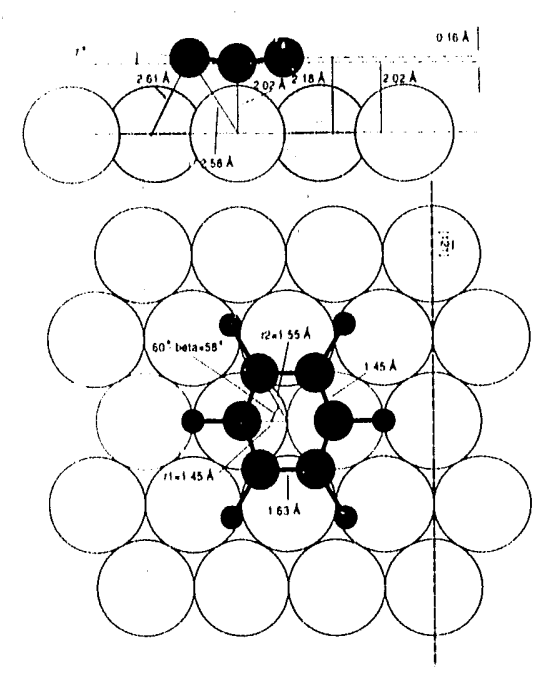

Figure 12

Benzene adsorbs with notable distortions on $\mathrm{Pt}(111)$. Top panel shows side view parallel to surface, exhibiting a buckling (bending) distortion. Bottom panel shows view perpendlcular to surface, illustrating location of benzene relative to metal atoms. Note expanded carboncarbon bond lengths, relative to the gas phase value of $1.40 \mathrm{~A}$. Hydrogen atom positions are guessed. (XBL 9011-3575)

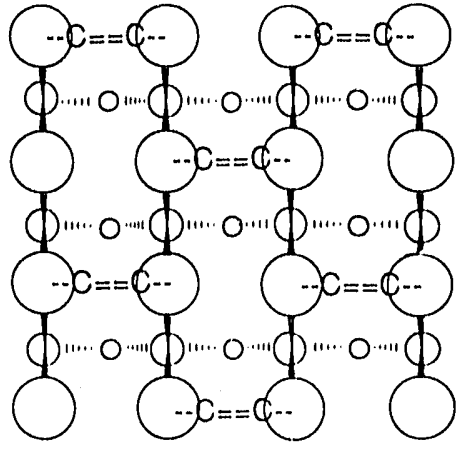<smiles>C[SiH2]C=CC=[18O]</smiles>

Figure 13

Expecled structure of $\operatorname{SiC}(100)-c(2 \times 2)$, from a dynamical LEED analysis. Top panel shows view perpendicular to surface, with C-C dimers between uppermost Si atoms. Bottom panel shows critical dimensions. (XBL 918-1714)

substrate (Figure 13). Reasonable Si-Cand C-C bond lengths are found. Investigation of possible relaxations in the $\mathrm{SiC}$ substrate is underway.

\title{
Coatings
}

\section{Zirconium Oxide on Platinum}

\author{
V. Maurice, K. Takeuchi, M. Salmeron and G.A. Somorjal
}

Zirconium oxide films were deposited onto a $\mathrm{Pt}(111)$ surface by resistively heating a $\mathrm{Zr}$ wire under oxidative conditions. The composition and structure of the surface was determined by AES, ISS, XPS and LEED. Below 700K, the growth of the oxide films is $2 \mathrm{D}$ up to the completion of a monolayer. $\mathrm{Zr}$ is in the $3+$ oxidation state. Upon brief annealing above $900 \mathrm{~K}$ in oxidative conditions, ordered $\mathrm{ZrO}_{2}$ films are formed with the fcc structure of bulk $\mathrm{ZrO}_{2}$. The (111) planes of the $\mathrm{ZrO}_{2}$ films grow parallel to the (111) substrate plane. Multilayer ordered films can be grown with a thickness of at least 7 monolayers, although with a substantial amount of defects.

The schematic drawing in Figure 14 shows the atomic arrangement of $\mathrm{O}$ (large circles) and $\mathrm{Zr}$ (small circles) as seen from above the crystal surface. This model is based on LEED studies. Notice the periodic $O$ vacancies on the last surface plane.

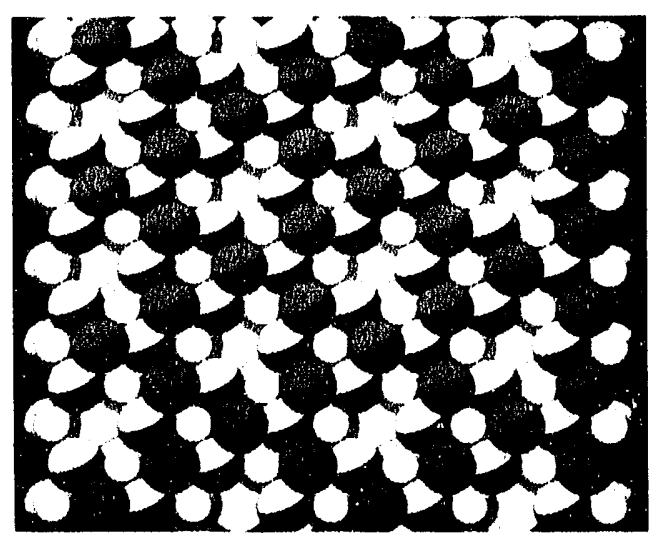

Surface Science and Catalysis. Program
Figure 14

Schematic model of the atomic arrangement of oxygen (big spheres) and zirconium (small spheres) at the surface of a multilayer deposit on the $\mathrm{Pr}(111)$ surface. Notice the oxygen vacancies. The model is based on the LEED symmetry and cell dimensions. (XBC 903-2062) 
Bonding Properties of Perfluorinated Ethers on Zirconium Oxide Thin Films

V. Maurice, K. Takeuchi, M. Salmeron, G.A and Somorjal

The ordered zirconium oxide thin films grown on platinum (111) crystal surfaces are used as model systems of $\mathrm{ZrO}_{2}$ hard coatings. Their surface chemisorption properties have been explored. Ethers and fluorinated ethers that are used as lubricants on $\mathrm{ZrO}_{2}$ have low heats of adsorption, $11 \mathrm{kcal} / \mathrm{mole}$. While the chemisorption of ethers is sensitive to the presence of surface defects that present higher binding energy sites, the heat of adsorption of fluorocarbon ethers remain unchanged. The coadsorption of water decreases the binding energy of fluorinated ethers on $\mathrm{ZrO}_{2}$ while ethers are unaffected in this circumstance.

The Structure, Interface and Mechanical Properties of Hard Carbon Thin Film Produced by Plasma Assisted Chemical Vapor Deposition (PACVD)

K. Kobayashi, G. Vandentop and G.A. Somorjal

Hard, amorphous carbon films are produced from methane by PACVD. The coatings contain hydrogen $(\mathrm{H}: \mathrm{C}=1)$ and their hardness is proportional to the ion power (number of ions times their kinetic energy) of the plasma. They adhere well to the substrates (silicon, glass, gold) only if a silicon carbide layer is formed at the substrate-carbon interface during the film deposition. These studies are extended to produce diamond films that require different experimental conditions (high $\mathrm{H}_{2} / \mathrm{CH}_{4}$ ratio, higher substrate temperatures) for its formation.

\section{The Preparation and Characterization of SiC Thin Films Prociuced From Methyl- Silane by Plasma Assisted Chemical Vapor Deposition \\ M.P. Delplancke, J.M. Powers, G.J. Vantop and G.A. Somorjal}

$\mathrm{SiC}$ hard coatings were produced from $\mathrm{CH}_{3} \mathrm{SiH}_{3}$ plasma. The films contain hydrogen (H:Si 1) but their $\mathrm{Si}: \mathrm{C}$ ratio is that in silicon carbide. Silicon carbide films were deposited by plasma enhanced chemical vapor deposition (PECVD) utilizing monomethylsilane $\left(\mathrm{CH}_{3} \mathrm{SiH}_{3}\right)$. Silicon (100) and polycrystalline gold were used as substrates. A mass spectrometric analysis of the monomethylsilane plasma showed that the majority of the Si-C bonds were preserved in the gas phase. The composition, the density and morphology of the amorphous $\mathrm{SiC}: \mathrm{H}(\mathrm{a}: \mathrm{SiC}: \mathrm{H})$ films were studied as a function of substrate temperature, composition of the ion flux bombarding the surface and the kinetic energy of these ions. The surface science techniques utilized for these investigations include XPS, AES, SEM , FTIR and Raman spectroscopies.

It was observed that films formed at the powered electrode at high temperature $(573 \mathrm{~K})$ exhibited superior properties compared with films formed at the grounded electrode under the same conditions. The density of the powered electrode films formed at $573 \mathrm{~K}$ was high $\left(3.2 \mathrm{~g} / \mathrm{cm}^{3}\right)$ and close to the bulk value. A large amount of compressive stress was developed in these films, but their adhesion to the substrates (gold or silicon) suggested the formation of strong chemical bonds at the interfaces.

The differences between the powered and the grounded electrode films could be attributed to the energetic ion flux bombarding the surface of the powered electrode. This bombardment was responsible for the lower hydrogen incorporation, for the purity of the films grown at this electrode, and for the possible formation of interfacial bonds.

The substrate temperature also controlled the properties of the films. Its increase reduced the hydrogen concentration as well as the oxygen contamination.

The mass spectrometric analysis of $\mathrm{CH}_{3} \mathrm{SiH}_{3}$ plasma showed clearly the advantage of this gas in the preparation of $\mathrm{SiC}$. The majority of the $\mathrm{Si}-\mathrm{C}$ bonds were preserved in the gas phase, increasing the probability to include this type of bonds in the films. Differences in the ion flux composition were observed between the two electrodes and could explain the difference in the film composition. 


\title{
INSTRUMENTATION FOR SURFACE SCIENCE \\ Scanning Probe Microscopy
}

Scanning probe microscopes such as the scanning tunneling microscope (STM) and the atomic force microscope (AFM) are powerful tools for the determination of the atomic and electronic properties of surfaces. We describe six different novel applications of these microscopes.

\author{
STM of Charge Density Waves \\ J. Clafke, R. E. Thomson, A. Zettl and B. Butk
}

There has been a continuing debate concerning the commensurability of charge density waves (CDW) with the underlying atomic lattice. The layered material $1 \mathrm{~T}$ $\mathrm{TaS}_{2}$ has a complex series of phase transitions and exhibits a $\mathrm{CDW}$ at all temperatures at which the material is stable $(T<600 \mathrm{~K})$. This CDW undergoes several rotations relative to the atomic lattice and in recent years the phase known as the nearlycommensurate $(\mathrm{NC})$ phase has been particularly controversial. This phase is present when $1 \mathrm{~T}-\mathrm{TaS}_{2}$ is cooled from $350 \mathrm{~K}$ to $180 \mathrm{~K}$, and the average CDW wavevector (as measured by $x$-ray diffraction) is incommensurate with the underlying atomic lattice. However, a theory has been proposed in which the CDW arranges itself into small commensurate domains which are separated by discommensurations. At the discommensuration, the CDW undergoes a phase slip which corrects for the mismatch between the average CDW wavevector and the commensurate CDW wavevector, thus insuring that the average CDW wavevector is the measured incommensurate value.

Several STM studies have been performed on the NC phase of 1T-TaS 2 to answer the question of whether these commensurate domains and accompanying discommensurations exist in this phase. Most groups have tried to analyze the STM images directly for evidence of commensurate domains or phase slips. These analyses have been unconvincing because they were quite subjective and there was no consensus about the existence and character of the domains. We have performed a careful study using not only the real space STM images but also the Fourier transform of the images. The theory that first proposed the domain model predicted satellite peaks surrounding the CDW peaks in the Fourier transform. We have analyzed the Fourier transform of our data in the NC phase and found these satellite points. This is the first clear demonstration of this discommensuration in the NC phase of $1 \mathrm{~T}-\mathrm{TaS}_{2}$ by any technique.

\section{Low Temperature Force Microscopy of Blological Materials J. ClaAke, M. G. L. Gustafsson and K. A. FisheA*}

Biological systems are not in general conductive enough to be imaged with STM. Since the atomic force microscope (AFM) does not require the sample to be conducting, it is a more suitable instrument for such samples. At room temperature, large biomolecules undergo strong thermal motion, which limits the possible resolution of any microscopy. These molecules are also mechanically soft, and are thus easily deformed or moved even by the weak forces applied by the AFM tip. These problems are all alleviated by lowering the temperature. However, work at low temperatures must be done either in ultra high vacuum or under a suitable liquid, to avoid condensing contaminants onto the surface. For these reasons, we have developed an AFM system which operates at $143 \mathrm{~K}$ immersed in n-pentane.

Figure 19 (see next page) shows a demonstration of sample stabilization at low temperature. The sample is ferritin, a $10 \mathrm{~nm}$ spherical protein, adsorbed on polylysine-treated mica. At room temperature, (a), the ferritin molecules are severely deformed and moved by the tip. As shown in (b), they can be immobilized by applying a $2 \mathrm{~nm}$ amorphous carbon coating, but the coating prevents high resolution. At $143 \mathrm{~K}$, the sample is stabilized without any coating (c). These results demonstrate graphically the improvements in rigidity gained by cooling biological samples. We are now working towards higher resolution. 
$200 \mathrm{~nm}$

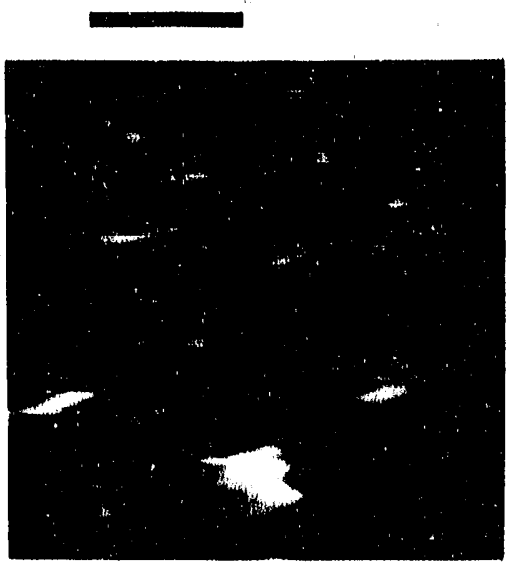

a)
$200 \mathrm{~nm}$

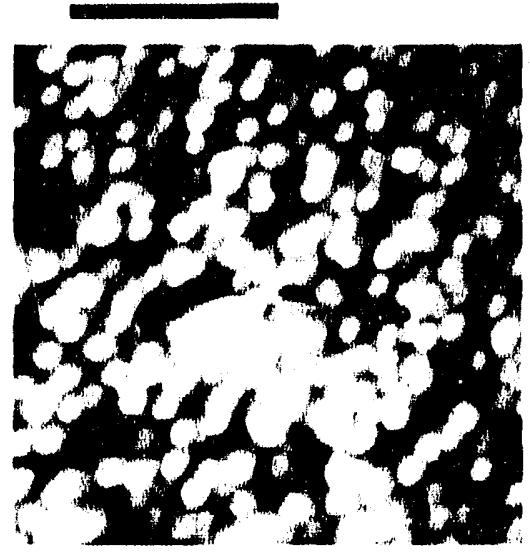

b)
$200 \mathrm{~nm}$

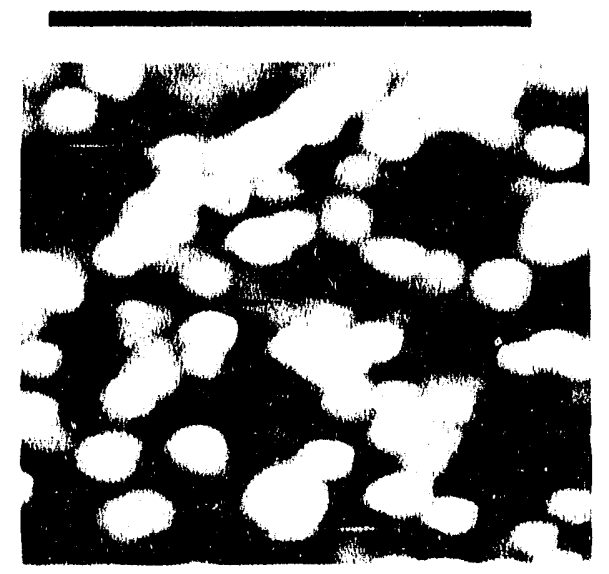

c)

Figure 15

AFM images of indlvidual molecules of ferritin (a $10 \mathrm{~nm}$ spherical proteln), demonstrating stablilzation at low temperature. Image (a) is acquired at room temperature, and is severely blurred by sample deformation. In (b), the sample has been stabilized at room temperature by a $20 \mathrm{~nm}$ carbon coating, but the coating prevents high resolution. At $143 \mathrm{~K},(\mathrm{c})$, the molecules are stable without the need for coating. (XBL 900-9004)

\section{Atomic Force Microscopy (AFM) Studies of Organic Overlayers}

G. Neubauer, W. Kolbe, D.F. Ogletree and M. Salmeron

The AFM is applied to the study of the forces exerted by the tip as it approaches a layer of organic molecules bound to a silicon substrate. These molecules include octadecilsilane (OTS) that forms self-assembled monolayers. As the tip approaches the film, it experiences first an attractive force (van der Waals) and then a repulsive one as it contacts the top of the film and later the hard Si substrate as shown in Figure 16. Simultaneously the tunnel current is being measured. The objective is to understand the mechanism of electron transport through the non-conducting molecular layers of polymers and biomolecules.

\section{Application of STM to Studies of Blo-Organic Materials: Low Current STM}

T. Wilson, M. Murray, D.F. Ogletree, M. Bednataski, C. Cantor and M. Salmeron

The existence of repulsive forces between the tip and the surface in the STM is responsible for many of the difficulties encountered when merging biomolecules. These molecules are usually weakly bound to the surface and are displaced by the scanning tip. In addition, these large molecules are poorly conducting. To solve some of these problems we have modified our STM in such a way that they can operate at lower currents on the picoampere range. This is three orders of magnitude lower than typically used in standard STM instruments.

In this manner we can operate the STM with the tip moved farther away from the substrate as to allow imaging of large molecules without displacement. When the same area is imaged at lower gap resistances only the graphite substrate structure is visible, and the organic overlayer is disrupted.

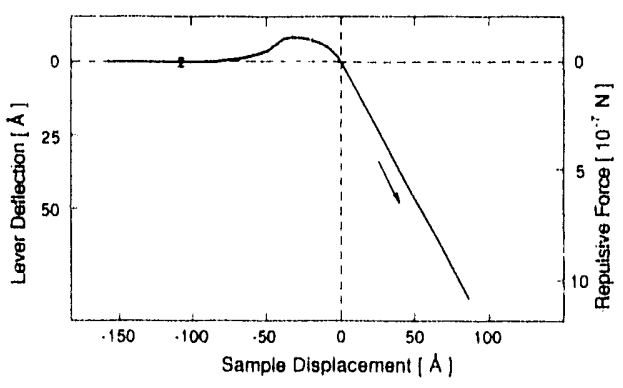

Figure 16

Force exerted on the tip by a SI surface with a self-assembled monolayer of alkylsilane (27A thick). As the tip approaches the surface, first an attraction is felt (upward bending curve). The attraction turns into weak repulsion as the tip contacts the molecular layer, and then into a strong repulsion (straight inclined IIne) as the tip contacts the sillcon substrate. (XBL 909-3062) 
A scanning tunneling microscope designed to operate in controlled environments of temperature $(273-473 \mathrm{~K})$ and pressure $\left(10^{-10}-10^{3}\right.$ torr) has been constructed. With this we plan to study catalyst surfaces in situ in an attempt to obtain atomic level information of phenomerla such as mass transport, adsorbate induced restructuring, and the role of defects and steps in surface chemistry.

\section{ESTM for Solid-Liquid Interface Studies J.-X. Chen, T. Devine, M. Salmeron}

We have develuped an Electrochemical Scanning Tunneling Microscope (ESTM) to study solld-liquid interface phenomena in-situ. We have investigated the change in surface morphology of a silver electrode that was roughened by an oxidationreduction cycle in $0.1 \mathrm{M} \mathrm{KCl}$. The roughening treatment was known to produce Surface Enhanced Raman Scattering (SERS) signals. Coarsening of this roughened surface was observed after immersion at $-0.2 \mathrm{~V}$ (SCE) for 24 hours. This implies that decrease in SERS signals may be caused by such relaxation phenomena.

We have also investigated the deposition of Ag onto HOPG substrate. The deposition took place at the atomic step. Stripping away the Ag deposits restored the atomic resolution of the substrate.

The in-situ ESTM will be applicd to atomic scale studies of surface process driven by electrochemical reactions, such as chemisoiption, under potential deposition (UPD), etc.

First-principles calculations are carried out to explain and predict the structure and properties of surfaces and chemisorption systems. Emphasis is on providing a microscopic understanding of the scanning tunneling microscopy (STM) and atomic force microscopy (AFM) images and the optical and photoemission spectra of systems of particular relevance to the experimental efforts in CAM. The theoretical methods employed include $a b$ initio pseudopotential density functional calculations for ground-state properties and quasiparticle self-energy calculations for excitation spectra. These methods allow accurate determination of solid state and surface properties from those of the atoms. Systems under investigation include hydrogen chemisorption on Pd surfaces and diamond surfaces, atomic-scale friction of Pd layer on graphite, and limits of resolution in AFM images of graphite.

$A b$ initio density functional calculations have been carried out to investigate the interaction of hydrogen with the $\mathrm{Pd}(001)$ and $\mathrm{Pd}(110)$ surfaces and with bulk palladium. The results for the H-Pd systems are further complemented by calculations for the $\mathrm{H}_{2}$ molecule, the bulk and the clean (001), and (110) surfaces of Pd. In the case of $\mathrm{H}$ in bulk $\mathrm{Pd}$, the equilibrium geometry and electronic structure are determined, and the nature of the $\mathrm{Pd}-\mathrm{H}$ bond elucidated. For the adsorption systems $\mathrm{H}$ / $\mathrm{Pd}(001)$ and $\mathrm{H} / \mathrm{Pd}(110)$, the calculations from first-principles yielded the preferential adsorption sites, bond lengths, and vibration frequencies of the adsorbate. The $\mathrm{H}$ induced softening of $\mathrm{Pd}$ surface phonon frequencies is related to a corresponding softening of Pd-Pd interactions in the bulk hydride phase.

The atomic scale friction associated with a layer of Pd atoms moving across a graphite substrate is investigated by performing ab initio total energy calculations. The friction energy caused by variations of the chemical bond strength and work against an external force (load) due to variations of the bond length along the trajectory is evaluated. It is found that there is only a very small dependence of the Pd-graphite interaction on adsorption site which gives rise to a very small friction coefficient $m \approx 10^{-2}$ for loads near $10^{-8}$ newtons. The computed $m$ is shown to increase with load in agreement with recent (AFM) experiments. 
Hydrogen plays an important role in determining the structure and properties of diamond surfaces and in the growth of diamond films. First-principles calculations are being carried out to study the electronic and structural properties of clean and hydrogenated diamond surfaces. This is the theoretical part of a coordinated effort to investigate these systems. On-going experimental work includes clectron-stimulated desorption measurements at Sandia Livermore and surface phonon measurements using Second Harmonic Generation techniques at LBL. For the (100) surface, the calculated results yleld a dimer surface geometry with structural parameters analogous to the Si(100) surface. The theoretical objectives for the monophydride and dihydride surfaces include the determination of the geometry, hydrogen vibration spectra, and chemisorption energetics.

\title{
Linear and Nonlinear Optical Studies of Interfaces
}

\author{
Probing the Structure of the Adsorption Layer of Soluble \\ Amphiphilic Molecules at the Air/Water Interface \\ VIOLA Vogel, C. S. MULLIN, and Y. R. SHeN
}

Adsorption of soluble amphiphilic molecules from a bulk solution to an air/water interface is a problem of great importance in several disciplines. It is, however, not well studied because of the lack of experimental probes. The surface concentration is determined by the bulk concentration but the relationship (adsorption isotherm) is difficult to obtain experimentally. Whether the excess molecules at the interface form a single monolayer or multiple ordered monolayers of totally or partially polaroriented molecules is also not known. We have found that the recently developed optical second harmonic generation (SHG) technique is ideally sulted for such investigations. The SHG process is forbidden in a system with inversion symmetry, and is therefore particularly sensitive to polar ordering of molecules at an interface.

Figure 17 shows that the adsorbed layer of soluble $\mathrm{C}_{6} \mathrm{H}_{13}-\mathrm{C}_{10} \mathrm{H}_{8}-\mathrm{SO}_{3} \mathrm{Na}$ (C6NS) molecules at the air/water interface of a saturated C6NS solution has the same nonlinear susceptibility $c^{(2)}$ as a fully packed monolayer of insoluble $\mathrm{C}_{18} \mathrm{H}_{37}-\mathrm{C}_{10} \mathrm{H}_{8}$ $\mathrm{SO}_{3} \mathrm{Na}(\mathrm{C} 18 \mathrm{NS})$ molecules, indicating that both have the same surface density and orientational ordering. No ordered surface sublayer can be detected in the C6NS case.

\section{A High-Power, Widely Tunable, Picosecond Coherent Source from Optical Parametric Amplification in Barium Borate}

J. Y. HUANG, J. Y. ZHANG, Y. R. SHEN, C. CHEN", AND B. WU*

In spectroscopic studies and other applications, widely tunable, high-power, psec coherent laser pulses are often desirable. This can be achieved with a psec laserpumped optical parametric amplifier (OPA). We report our preliminary results of

Figure 17
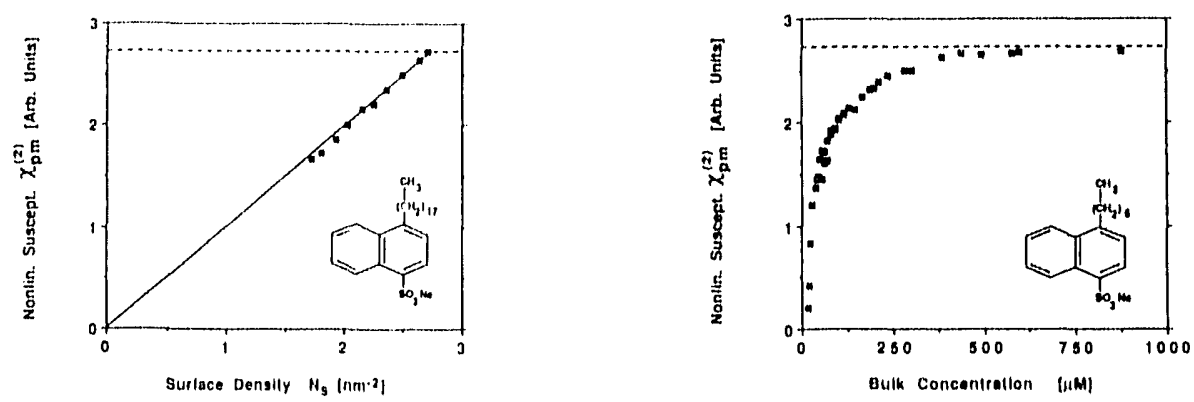

(a) Second-order susceptibility $x F((2), p m)$ versus the surface density of Insoluble $C 18 \mathrm{NS}$ molecules at the air/water interface $(0.5 \mathrm{M} \mathrm{NaCl}$ solution with $\mathrm{pH} 5.6$ at $20^{\circ} \mathrm{C}$ ). The monolayer is close-packed at the surface density of 2.7 molecules per $\mathrm{nm} \mathrm{m}^{2}$ as indlcat $t$ by the broken line. The accuracy of $X F((2), p m)$ is $\pm 2 \%$. (XBL.903-5414Y) (b) Second-order susceptibllity $X F((2), p m)$ versus the bulk cuncentratlon of the soluble C6NS molecules $\left(0.5 \mathrm{M} \mathrm{NaCl}\right.$ solution with $\mathrm{pH} 5.6$ at $\left.20^{\circ} \mathrm{C}\right), \times \mathrm{F}((2), \mathrm{pm})$ of a saturated absorption layer is indicated by the broken line. (XBL901-5415) 
experiments on such a device using a newly discoverod nonlinear optical crystal, barlum borate (BBO). The crystal has not only a large nonlinearty and a high laser damage threshold but also a wide transparent range from near infrared to uv (4-0.2 $\mathrm{mm})$. We show that it is possible to obtain, from angular tuning of $\mathrm{BBO}$, narrow wand $(o(\sim,-) 3 \AA)$ high-energy $(\geq 200 \mathrm{~m})$ ) widely tunable $(0.4-2 \mathrm{~mm})$ psec pulses with a maximum pump-to-signal energy conversion better than $30 \%$.

\section{Study of Copper Diffusion Into Polyimides by Optical Second Harmonlc Generation \\ J. Y, ZHANG, Y, R, SHEN, D. S. SOANE, AND D. PAUSOHINGER}

Optical second harmonic generation (SHG) can be used to study metal cluster formation and diffusion into polyimide (PI) by monitoring the signal in-situ and as a function of time. The highly sensitive SHG and its ability to porform in-situ measurements allow a mechanistic study of diffusion and formation of metal clusters at polyimide surface. We report here some preliminary results on our recent diffusion measurements of $\mathrm{Cu}$ into fully cured polyimide at different temperatures using SHG. It was found that the formatton of Cu clusters on the surface impedes the diffusion of Cuinto polyimide. Figure 18 shows how SHG responds to the diffusion of Cu clusters into polyimide. We also observed the effect of an intermedtate titanlum (Ti) layer as a diffusion barrier at a $\mathrm{Cu} / \mathrm{Pl}$ interface. A monolayer of Ti appears to be sufficient to restrict $\mathrm{Cu}$ diffusion into $\mathrm{Pl}$.

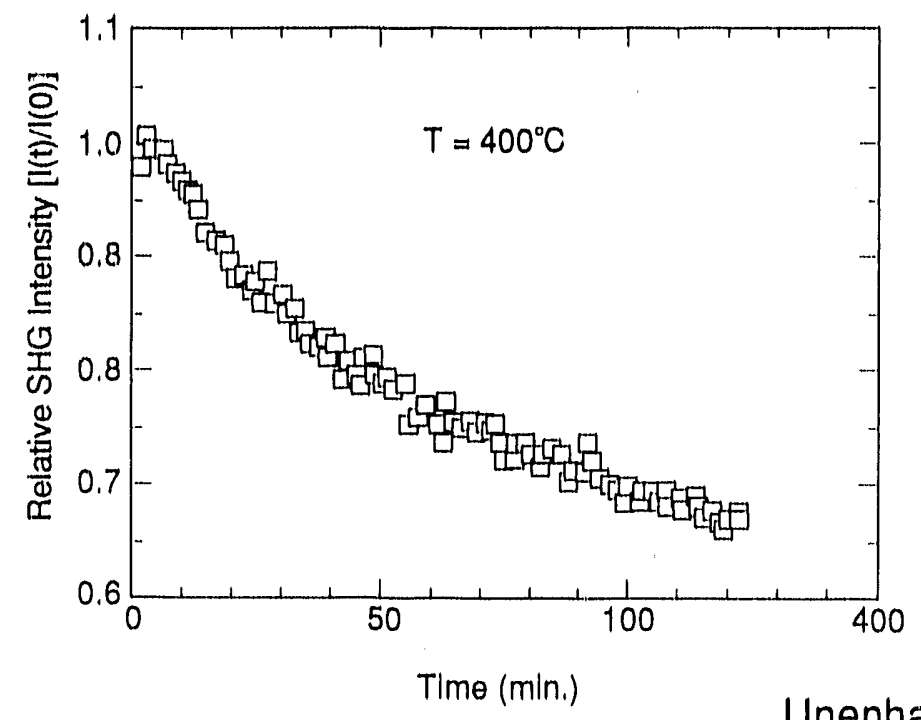

Figure 18

SHG versus time from a polyimlde sample covered with an 8 A Cu layer at $400^{\circ} \mathrm{O}$. The sample was preheated to $350^{\circ} \mathrm{C}$ for 40 houls to remove $\mathrm{Cu}$ atoms and small Cu clusters from the sample surface vla diffusion Into the bulk. (XBL 9010-4704)

\section{Unenhanced Surface Raman Spectroscopy}

D.K. Veirs, J.W. Ager III and G.M. Rosenglatt

Unenhanced surface Raman spectroscopy is used as a vibrational probe of physisorbed and chemisorbed molecules and films on a variety of surfaces from $12 \mathrm{~K}$ to well above room temperature.

Recent developments in two-dimensional low noise detectors as implemented in our laboratory allow unenhanced surface Raman spectroscopy of physisorbed and chernisorbed adsorbates and of thin films. The sensitive Raman apparatus is coupled with an ultrahigh vacuum chamber capable of cooling samples to $12 \mathrm{~K}$ and equipped with LEED/Auger surface characterization and with ion bombardment and heating for surface cleaning. The goal of this work is to study the vibrational-rotational energy levels of molecular adsorbates.

Following the first Raman measurements of a physisorbed system at low, nearmonolayer, coverages- $\mathrm{N}_{2}$ adsorbed on $\mathrm{Ag}(111)$ at $14 \mathrm{~K}$ down to a coverage of 1.7 monolayers-other adsorbates and substrates have been investigated.

In order to investigate adsorbates whose interactions with the substrate are too weak for physisorption at $14 \mathrm{~K}$, the samiple holder and its thermal connection to the cryogenic cooling unit were carefully re-evaluated and redesigned. It is now possible to cool substrates down to $12.1 \mathrm{~K}$. 
Background signal from inclastic scattoring from surface plasmons and Raman scattering from carbon impuritles were observed to limit the abillty to study submonolayer coverages on silver. To avoid these effocts, studies have been initiated on highly ordered pyrolytic graphite (HOPG) substrates. It is relatively easy to prepare an HOPG surface which has a background signal comparable to that of the cleanest $\mathrm{Ag}(111)$ surface away from spectral reglons containing the woll-known first- and second-order HOPG Raman bands. Utilizing the redesigned sample holder the Raman spectrum of a physisorbed film, from an exposture between two and ten Langmuirs ( $2 \mathrm{~L}$ is one monolayer) of $\mathrm{CH}_{4}$ on HOPG at $12.1 \mathrm{~K}$, has been observed. Raman spectra from thicker multilayer $\mathrm{N}_{2}$ and $\mathrm{CH}_{4}$ films on HOPG have also been obtained. During these experiments it was observed that laser powers as low as 10 $\mathrm{mW}$ could drive off $\mathrm{CH}_{4}$ films as thick as 20) monolayers, Laser heating of the substrate requires further investigation.

\section{Raman Studies of Surfaces and Materials *}

Q.M. RosenglatT

The purpose of this project is to utilize and develop Raman and related optical techniques for the study of surfaces and materials. The project uses unenhanced Raman spectroscopy to study surface and near-surface composition; to characterize technologically important materials; to study materl dls systems under both ultrahigh vacuum (UHV) conditions and at chemically important pressures and temperatures; and to provide new information concerning rotational and vibrational energy levels, dynamics, and reactivity of molecules adsorbed on a varicty of surfaces. Raman instrumentation developed for this project uses an imaging photomultiplier detector to achieve the sensitivity required to obtain unenhanced Raman spectra from monolayer films on well characterized surfaces. By explicitly uttlizing the two-dimensional detection capability of the inaging photomultiplier, spatially-resolved Raman spectra are obtained. Combined with automated computer analysis and sample movement, these spectra provide unique, spatially-resolved vibrational data for the mapping of chemical, physical, and mechanical properties at or near the surface of materials, with unprecedented speed. The high sensitivity of the apparatus allows materials studies by Raman spectroscopy which were heretofore impossible.

\section{Mapping Materials Properties with Raman Spectroscopy Utilizing a Two-Dimensional Detector \\ D.K. Veirg, J.W. Agea III, E.T. Louoks, and G.M. Rosenglatt}

Figure 19

Profiles of the monoolinio iraotion, $F_{\text {mon }}$ aoross oraok tips In microenglneered zirconilas having varying degrees of fraoture toughness, obtalned in a spatlally resolved Raman experiment. Upper graph: $\mathrm{MgO}$ stabilized zirconia with $22 \%$ maximum transformation and a zone widih (FWHM) of 1 $\mathrm{mm}$ with a fraolure toughness of $16 \mathrm{MPa} / \mathrm{m}$. Lower graph: $\mathrm{C} \mathrm{O}_{2}$ stabillzed zirconla with $2 \%$ maximum transformation and a zone width (FWHM) of $230 \mu \mathrm{m}$ with a fraoture toughness of $9.5 \mathrm{NiPa} / \mathrm{m}$.

(XBL 903-872)
Raman spectroscopy probes the atomic vibrations of a material and can yicld important information about the chemical, physical, and mechanical properties of materials. Measurements of chemical composition, thermodynamic phase, tempera-

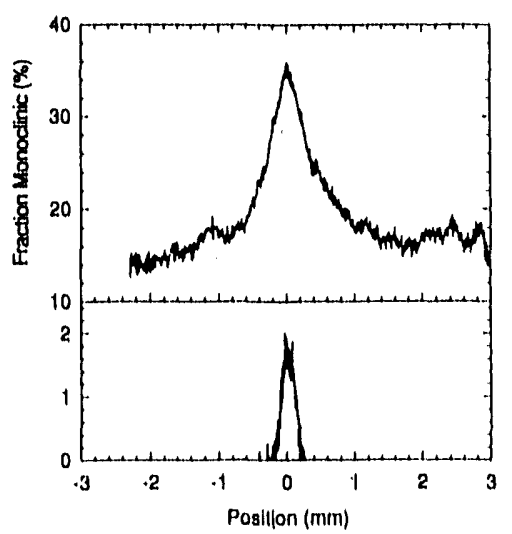

"This work was supported by the Dlrector's Exploratory Research and Development Fund of the Lawrence Berkeley Laboratory 
turc, or stross can be mado with Raman spectroscopy with a spatial rosolution approaching $5 \mu \mathrm{m}$. Wo have developed a techntque that allows us to obtain and analyze many Raman spectra, over a significant area of a sample, in a reasonable perlod of time, in ot der to profile or map the property of interest. Producing a detalled map of the chemical or physical propertios of a materlal may require collection and analysis of tons of thousands of spectra. Proviously, It was not posslblo to produce such maps, because of the time taken to acquire and analyze Raman spectra from many individual points.

In our approach, Raman scattered light is collocted from a slit-like llluminated area on the sample and imaged onto the entrance slit of a monochromator, A twodimensional detector collects the dispersed light. We use a microchannel plate PMT detector with a position-sensitive resistive anode, but the method could also be implemented with a charge coupled device (CCD) detector. Up to 1024 Raman spectra are coliected simultancously; each representing a point along the illuminated line. The data are analyzed to produce a one-dimensional profile of the desired chemical or physical property. Successive sample translations bulld up a twodimensional map of the desired property from successive one-dimensional profiles. The spatial resolution and spectral prectsion are $5 \mu \mathrm{m}$ and $0.16 \mathrm{~cm}^{-1}$, respectivaly. Although our experiments have utilized Raman scattering, the approach can be adapted to the collection and analysis of data from other spectroscopic techniques which disperse light collected from a sample, e.g., photoluminescence.

One application of spatially resolved Raman is the quantitative measurement of phase-transformed zones in phase stabilized zirconias (PSZ's). Phase stabilized zirconias are members of a new class of fracture-resistant ceramics based upon the discovery that the stress-induced martensitic transformation from the tetragonal to the monoclinic phase may be induced in the fine $\mathrm{ZrO}_{2}$ grains in the vicinity of a propagating crack. The degree of toughening is related to the spatial extent and the amount of transformation of the transformed zone. For a complete understanding of these materials, a quantitative measure of the extent of transformation (spatial and amount) is required. These experiments were performed in collaboration with R.O. Ritchile and R. Dauskardt of LBL's Center for Advanced Materials.

Spattally resolved Raman spectroscopy of phase transformations accompanying cyclic-fatigue crack growth in PSZ has revealed zone sizes ranging from 230 to 1500 $\mu \mathrm{m}$ and amounts of transformations ranging from $0.2 \%$ to $20 \%$. Figure 1 shows transformed zones in two zirconla samples. Individual maps have been constructed from the acquisition and analyses of 66,560 Raman spectra in 5.4 hours ( 0.3 seconds per spectrum); the total time includes sample translation, data collection, data analysis, display, and storage of results. Performing the same experiment using a linear multichannel detector and two-dimensional sample translation would take several months; single channel detection extends the required time to many years. The sensitivity of the technique is shown in the first quantitative measurement of the transformation zone in a $\mathrm{CeO}_{2}$ stabilized zirconia $\left(\mathrm{CcO}_{2}-\mathrm{TZP}\right.$, cf. Figure 19). The small amount (ca. $2 \%$ ) and extent $(230 \mu \mathrm{m})$ of the transformed zone would make this analysis very challenging with any other technique.

\section{Laser Heating Effects In the Characterization of Carbon Flbers by Raman Spectroscopy J.W. Agea III, D.K. Veing, J. Shamif, and G.M. Rosenglatt}

Carbon fibers are widely used as a structural material in composites because of their high tensile strength-to-weight ratio (up to ten times that of steel). The firstorder Raman spectrum of single crystal graphite (e.g., highly ordered pyrolytic graphite or HOPG) consists of a single peak at $1581 \mathrm{~cm}^{-1}$ (G-band). In disordered graphites a second peak ( 1 )-band) appears noar $1355 \mathrm{~cm}^{-1}$. Both the L-and G-bands appear in the first-order spectra of the annealed carbon fibers we studied. The ratio of the integrated intensities of the $D$ - and $C_{1}$-bands, $I_{1} / I_{C}$, can be related to the in-plane microcrystallite size, La. The $l_{1} / I_{\mathrm{G}}$ ratios of carbon fibers annealed at successively higher temperatures decrease steadily, indicating that the average microcrystallite 
stze is largor in fibers annoaled at higher tomporatures.

In the Raman characterization of single carbon fit ors, the fiber is heated by the laser in the probed area. Because the frequencles of both the $G$ - and D-bands are temperature dependent, changes in the Raman spectrum occur. At suffictently high laser powers permanent changes in the physical structure of the fibers can be produced. In this work changes in the Raman spectra of carbon fibers caused by different processing conditions are separated from changes caused by laser heating:

The Raman spectra of individual $8 \mu \mathrm{m}$ diameter PAN-derived carbon fibers which had been annealed at five temperatures from $1700{ }^{\circ} \mathrm{C}$ to $28000^{\circ} \mathrm{C}$ wore measured as a function of incident laser power from 1 to $140 \mathrm{~mW}$. In all flbers studied, the frequencles of the C-band and the disordered-Induced D-band shift to lower frequency with increasing laser power. The largest shifts observed before the fiber is physically damaged are about $13 \mathrm{~cm}^{-1}$ at a laser power of $30 \mathrm{~mW}$. The band positions decrease further at higher laser power, up to a maximum of about $20 \mathrm{~cm}^{-1}$ at $40 \mathrm{~mW}$, and at powers above $30 \mathrm{~mW}$ the linewidths and the $I_{1 \mathrm{~b}} / I_{\mathrm{C}}$ intensity ratio change irreversibly as the fiber begins to orode. The irreversible changes extend several hundred $\mu \mathrm{m}$ away from the $2 \mu \mathrm{m}$ spot llluminated by the laser.

To quantify the degree of laser heating the temperature dependence of the Raman shift (G-band) in pure bulk, highly oriented pyrolytic graphite (HOPG) was measured. The present experiments show that a laser power of $30 \mathrm{~mW}$ heats an $8 \mu \mathrm{m}$ fiber to 33()$^{\circ} \mathrm{C}$ and that above 330$)^{\circ} \mathrm{C}$ irreversible changes are produced by crosion of the fiber. Even a laser power as low as $10 \mathrm{~mW}$ causes a temperature increase of ca, $100^{\circ}$ and a G-band shift of $c a .3 .5 \mathrm{~cm}^{-1}$ in a $28000^{\circ} \mathrm{C}$ annoaled fiber. To study the heating effect In more detail, a Raman imaging experiment was carried out in which a $0.1 \mathrm{~mm}$ spot on a fiber is heated by a focused laser beam while the fiber is illuminated for Raman characterization along a $1.6 \mathrm{~mm}$ longth by a low power probe beam. The spatially resolved Raman shifts obtained in this way are combined with the HOPG frequencytemperature callbration to obtain the in situ temperature profile of the laser heated fiber, as shown in Figure 20.

The observations show that reproducible room-temperature characterization of the bonding and microstructure in fine carbon fibers by Raman spectroscopy must be carried out at very low incident laser power and/or by extrapolating measurements back to zero laser power. Upon doing this, the present experimental conclusions are In accord with previous studies that used similarly annealed fibers. For example, for the fibers studied here, the G-band frequency and the $I_{10} / I_{0}$ ratio both decrease with increasing heat treatment temperature. The results also indicate that the $I_{10} / l_{\mathrm{C}}$ ratio may be larger in the interior of the fiber than in the surface layer.

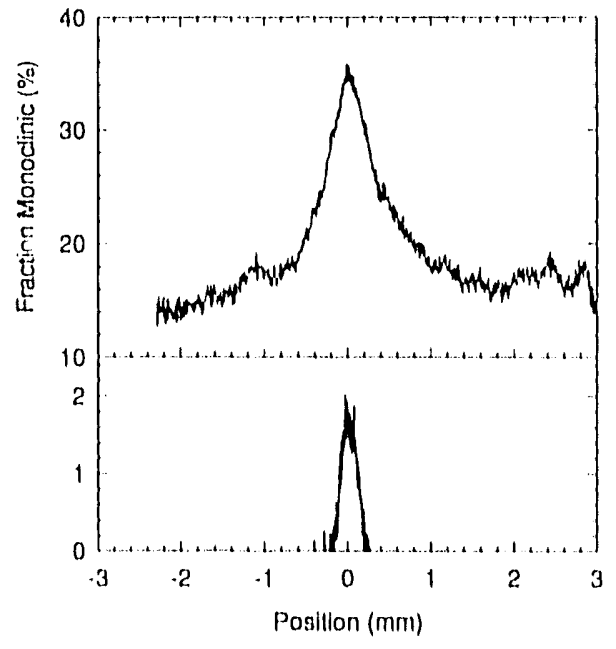

Flgure 20

In situ temperature profile of a high-inodulus carbon floer determined from the measured G-band frequenoy as a function of vertical position along the fiber. The solld line is a fit to a simple heat transfer model with a laser power absorbed by the fiber of $20 \mathrm{~mW}$ and a fiber thermal conduotivilty of $1.1 \mathrm{~W} \mathrm{am}{ }^{-1} \mathrm{~K}^{\prime}$. The Inset shows the experimental geometry, with a point-focused, high power heating laser boam and a line-fooused, lower power, probe beam. (XBL 903-872) 
Project Leaders

Alexls T, Bell-Catalyst Deslgn, Characterization \& Applications

Mlquol B. Salmoron-Surface and Intorfaco Compounds

Yuon-Ron Shon-Instrumontation for Surface Sclonco

Investigalors

Aloxis T, Boll

John Clarko

Holnz Holnotnann

Stovon G, Loulo

Joffroy A. Rolmor

Gord Rosonblatt

Miqual B. Salmoron

Yuon-Ron Shon

Michol A. Van llovo

Postdoctoral leellows

Joel W. Agor, III

Jung $Y$. Huang

Marle-Paule Delplancke

Robort Hwang

Gabl Noubauor

Seong Ha Park

János Raskó

Ulrich Starko

Adrlan Wandor

Xlaoguang Zhang
Graduale Students

Jim Battoas

Jatvan Boszormonyl

Alex Boffa

Jim Dunphy

Sabrina Fu

Donis Gardin

Hoathor Galloway

David Jentz

Glonn Jornigan

Changm In KIm

Colotto Knight

Nick Matoror

Brian Melntyro

Pedro Nasconto

James Powors

Michad Quinlan

Gllroy Vandentop

Hongchuan Wang

Kovin Williams

Troy Wilson

David Zoglinskl

Visiting Scientists and Scholars

Piotr Badziag-University of South Africa (UNISA)

David Clark - ICl, Blllingham, England

H. Bonzel-KFA-julleh

George Comsa-KFA-Jülich

Namhee Cho-

M. Osama

B. Dabbousl-King Fahd University of Potroloum \& Minerals-Saudl Ari' ${ }^{\prime}$ la

Hans-Joachim Fround-Unlv. Bochum, Gormany

Laszlo Guczi-Inst. of lsotopes, Budapest

Tamas Katona-A, Jozsef University; Szeged, Hungary

A. Kawazu-Univorsity of Tokyo

Erno Klss-Yugoslavla

Kazuhisa Kobayash1-Mitsubishl Papor Mills L.td., Japan

C. Dioter Kohl-Aachen, Germany

Sung Han Lee-Yonsel Univ. - Korea

Plerro Laszlo-Lab. do Chimle Rue aux Interfaces-Ecole Polytechnique, France

Oana Leonte-Inst. of Physical Chem. of Romanian Academy

Talsel Nakayama-Mitsubishl, Japan

Makoto Nakazawa-Tokyo, Japan

J. Oudar-University of Paris VI

Pedro Perolra-INTEVEP, Venezuda

J. Potro-Technical Univ. (Dept. Org Chom), Budapest

Koll Takeuchl-Nat'l Rescarch Inst, for P'ollution and Resources, Ibarakl, Japan

Kenzl Tamaru-Sd. Univ, of Tokyo, Dept. of Chomistry

Jose Velasquez-INTEVEP, Venozucla

Mattlas Wuttig-KF!-Julich, Gormany

Julio Gome\%-Unlversity Autonoma, Madrid

Georg Held-Munich, Germany

Vincent Maurice-University P'aris VI

Maurits van Tol-Leidon University-The Netherlands

Staff Sciontist

Frank Ogletree

D. K. Veirs

Technical Support

Winl Hoppler

S. Travis Palomares

I'in Che
Undergraduate Student

E.T. Loucks

Administrative Support

Giloria Osterloh

Brigid Tung 
- Ron Shen was elected to the American Academy of Arts and Scionces.

- Gabor Somorjai was elected an honorary member of the Hungarlan Academy of Sclences.

\section{Advisory Board}

Dr. Roger C. Baetzold, Chairman
Dr. S.K. Alley
Prof. Gary L. Haller
Dr. L. Louls Hegedus
Dr. J.A. Meyer
Dr. Robert M. Nowak
Dr. Kathleen Taylor
Dr. J.J. Wise

Dr, Roger C. Baetzold, Chairman

Eastman Kodak Company

Union Oil of California

Yale University

W.R. Grace and Company

Chevron Research Company

The Dow Chemical Company

Gencral Motors Technical Center

Mobil Rescarch and Development

\section{Industry Interaction}

Gilt

- A gift from Mobil Research and Development will be used for research on petroleum coke gasification.

\section{SURFACE SCIENCE AND CATALYSIS SCIENCE SEMINARS}

Z. Hussain,- KFUIM - Dhahran, and LBL, "Angle-Resolved Photoemlssion Study of Valence Bands of Sollds: Hilgh Angular Resolution and Temperature Dependunce"

:E. Crowell - U.C. San Dlego, "Modol Studies of Thin Film Growth by Chemical Vapor Deposition"

L. Guczl - Instltute of Isotopes, HAS, Budapest, "Bimetallic Catalysts: Factors Controlling Soloctivitlos In CO+H $\mathrm{I}_{2}$ Roaction"

T. Gustafsson - Rutgers University, "Ion Scattering Studles of Reconstruction on Motal Surfaces"

R. Fish - LBL, "Bonding and Regloselective Hydrogenation of Heteroaromatic Nitrogen Model Coal Compounds with Cp"Rh" and CplRu" Complexes"

J. Weaver - University of Minn sota, "Metal/Semiconductor Interface Growth, Evaluation and Irojections"

M. Balkanskl - University of Parls VI, "Solid-State Microbatterles"

K.R. Mitchell - University of Britlsh Columbla, "Recent Surfaco Structural Studies with LEED"

J.). Friplat - University of Wisconsin, Milwauken, "Hydrogen Chemisorption Thermodynamics and Intercalation"

P,R. Norton - University of Western On'ario, "Interaction of Water with NI(110): Static, Dynamic and Catalytic Phenomena"

D. Kohl - University of Aachen, "Surface Science Studies in Relation to Sensors"

W.O. Haag - Mobil Research and Development Corp., "Kinetic and Mechanistic Aspects of Paraffin Cracking with Zeollte Catalysts"

G.L. Haller - Yalo University, "Comparative Dynamics of CO Oxidation of Pt, P'd, and Rh Surfaces"

1'.R. Watson - Oregon State University, "Adsorption, Desorptlon and Etching with Electronegative Atoms on CaAs Surfaces"

J. Petro - Tech. Univ. of Budapest, "Characterization of Mo:al Catalysts for Liquid Phase Hydrogenations"

A. Gellman - University of Illinois, Urbana-Champaign, "Surface-Induced Cyclization Chemistry - Sulfur Abstractlon from Catalytlc Surfaces"

L. Fritsche - Tech. University, Clausthal, "Electronic Structure Studies on Oxygen-Induced Changes of the Ni-Surface Magnetization"

J. Oudar - Ecole Nat, Sup, de Chemle, Parls, "Hydrogenation on Platinum Single Crystals: Mechanlsms and Polsoning by Sulfur"

E. Bauer - Tech. University, Clausthal, "Low-Energy Electron Microscopy"

P.C. Stair - Northwestern Unlversity, "The Production of Gas-Phase Methyl Radicals and their Interaction with Surfaces"

11. Bonzel - KFA-Jullich, "Recent Studies of Surface Roughening and Surface Melting of P"

R. Prins - ETH, Zurich, "Zeolites In the Manufacture of Intermediate Chemicals"

R.). Bertolacinl - Amoco Oll Company, "Resld Hydroprocessing at Amoco"

J.L. Gland - University of Michigan, "In-Sltu Studles of C-S Bond Activation Using FYNES"

P. Cuyot-Stonnest - Orsay, France, "Non-lincar Infrared Laser Spectroscopy of Adsorbates at Interfaces and Ultra-fast Ihenomena"

^. Vertes - Eötvös University, Budapest, "Mössbauor Spectroscopy as a Tool for Electrochemistry and Coating Chemistry"

D. Castner - University of Washington, "XPS and Static SIMS Characterization of Polymeric Biomaterials"

1. Horvath - Exxon Research and Engineering, "Hydroformyhlation of Olffins with Water Soluble Rhodium Catalyst Systems in Supported Aqucous Phase: Is It Really Aqueous?"

D. Theodorou - UC Berkeley, "Molecular Mudeling of Sorption and Diffusion of Alkanes in Zeolites"

M. Hilton - Aerospace Corp., "Structural and Chemical Studles of Lubricants for Space: Advances In MoS"

W. Tysoe - University of Wisconsin, "Hydrocarbon Conversion Reaction Catalyzed by Molybdenum"

V.B. Kazansky - Institute of Organic Chemlstry-Academy of Sciences USSR, "New Ideas on the Mechanlsm of Acidic Catalysis"

J. Scherzer - Unocal, "Application of High Area $\mathrm{SlO}_{2}$ Zeolltes in Catalytic Cracking"

C.D. Chang - Mobil, "On the Mechanism of ZSM-5 Formation" 
M. Jaksic - University of Trondheim, Norway, "Electrocatalysis of Hydrogen Evolution in the Light of the Brewer Intermetallic Bonding Theory"

J. Belloni - Universite de Paris-Sud, "Nucleation Dynamics and Autocatalytic Growth of Silver Aggregates - Simulation of Photographic Development Processes"

G. Cımsa - KFA-Jülich, "Growth and Sputtering-Removal of Surface Films"

M. Altman - Technical University Clausthal, "Low-Energy Electron Microscopy Studies of Surface Phase and Surface Magnetic Structures" K. Tamaru - Sclence Univ. of Tokyo, "Dynamic Processes at Solld Surfaces"

M. Daage - Exxon, Annandale, "Hydrotreating on Transition Metal Sulfides"

M.S. Daw - Sandia, Livermore, "Stability of Small Metal Clusters on Metal Surfaces"

B. Schardt - Purdue University, "Atomic Resolution Scanning Tunneling Microscopy of Adsorbates on Electrode Surfaces"

J. Ulan - NCEM, LBL, "Small-Pore VP15: Stacking Disorder Induced by Thermal Transformation - A HR-TEM Study"

J. Weare - UCSD, "From Van der Waals to Metallic Bonding: Structure and i':onerties of Beryllium Clusters"

B. Ratner - Univ, of Washington, Seattle, "Modification and Characterization of Surfaces for Cell Culture Applications"

R. Hicks - UCLA, "Surface Chemistry and Engineering of Organometallic Chemical Vapor Deposition"

K. Zamaraev - Institute of Catalysis, Novosibirsk, "Catalysis in Conversion of Solar Energy"

H.-J. Freund - Univ. Bochum, "Molecular Adsorption on Oxide Surfaces: Structure and Dynanilcs"

J.N. Armor - Air Products and Chemicals, Allentown, PA, "Catalysts with Permselective Membranes"

R.G. Nuzzo - AT\&T, "Molecular Adsorption Processes on Organic Surfaces"

M. Asscher - Hebrew University, Jerusalem, "Dissociative Chemisorption: A Tunneling Mechanism"

J.N. Israelachvili - UC Santa Barbara, "Static and Dynamic Properties of Molecularly Thin Interfacial Films"

D. Clark - ICI, Billingham, England, "Understanding Surfaces and Interfaces as a Basis for Rational Design of Materials Systems"

J. Haber - Polish Academy of Sciences, "Physical Chemistry of Oxide Monolayer Catalysts"

D.W. Goodman - Texas A\&M, "The Structural, Electronic and Chemical Properties of Ultrathin Metallic Films"

Dr. M. Farcasiu - DOE, Pittsburgh Energy Technology Center, "Carbon Blacks as Catalysts for Selective Carbon-Carbon Bond Cleavage"

T. Huang - Mobil Research and Development Corporation, "Heterogeneous Iso-Paraffin Alkylation Catalysts"

L. Klebanoff - Lehigh University, "Electron Spectroscopy Studies of Atomic Magnetism in Metals"

P. Laszlo-Ecole Polytechnique, Paris and Univ. of Liege, Belgium, "Catalysis of Organic Reactions by Inorganic Solids"

5. Thurgate - Univ, of Murdoch, Australia, "Surface Potential Barrier Determinations from LEED Studies"

\section{Publications and Reports}

Refereed Journiai Articles

\section{Catalyst Design, Characterization, and Applications Project}

Bell, A. T. and E. Shustorovich, "A Comment on the Analysis of COHydrogenation Using the BOC-MP Approach," J. Catal., vol. 121, p. 1, 1990.

Bell, A. T. and E. Shustorovich, "Analysis of the Thermochemistry of $\mathrm{C}_{2}$ Hydrocarbons On Transition Metal Surfaces Using a Refinı $d$ BOC-MP Approach," Surf. Sci., vol. 235, p. 343, 1990.

Bell, A. T., "The Impact of Catalyst Science on Catalyst Design and Development," Chem. Eng. Sci., vol. 45, (8), p. $2013,1990$.

Bourzutschky, J. A. Brown, N. Homs, and A. T. Bell, "Conversion of Synthesis Gas over LaMn1-x $\mathrm{Cu}_{x} \mathrm{O}_{3+1}$ Perovskites and Related Copper Catalysts," J. Catal., vol. 124, p. 52, 1990.

Bourzutschky, J. A. Brown, N. Homs, and A. T. Bell, "Hydrogenation of $\mathrm{CO}_{2}$ and $\mathrm{CO}_{2} / \mathrm{CO}$ Mixtures over Copper-Containing Catalysts," J. Catal. vol. 124, p. 73, 1990.

June, R. L., A. T. Bell, and D. N. Theodorou, "Molecular Dynamics Study of Methane and Xenon in Silicalite," J. Phys. Chem., vol. 94, p. $8232,1990$.

June, R. L., A. T. Bell, and D. N. Theodorou, "Prediction of Low Occupancy Sorption of Alkanes in Silicalite," J. Phys. Chem., vol. 94, p. 1508,1990 .

Rojas, M. L., J. L. G. Fierro, L. G. Tejuca, and A. T. Bell, "Preparation and Characterization of LaMn1-x $\mathrm{Cu}_{x} \mathrm{O}_{3+1}$ Perovskite Oxides," J. Catal. vol. 124, p. 41, 1990.

Somorjai, G.A., "Modern Concepts in Surface Science and Heterogeneous Catalysis," J. Phys. Chem., vol. 94, p. $1013,1990$.

Somorjai, G.A., P. Pereira, R. Csencsits, and H. Heinemann, "Steam Gasification of Graphite and Chars at Temperatures, $<1000 \mathrm{~K}$ Over Potassiurn-Calcium-Oxide Catalysts," J. Catal., vol 123, p. 463, 1990.

Somorjai, G.A., P. Pereira, R. Csencsits, and H. Heinemann, "Steam Gasification of Graphite and Chat r at Temperatures, $<1000 \mathrm{~K}$ over Potassium-Calcium-Oxide Catalysts," J. Catal., vol. 123, p. 463, 1990.

Somorjai, G.A., P. Pereira, S.H. Lee, and H. Heinemann, "The Conversion of Methane to Ethylene and Ethane with Near Total Selectivity by Low Temperature $\left(<610^{\circ} \mathrm{C}\right)$ Oxydehydrogenation over a Calcium-Nickel-Potassium Oxide Catalyst," Catal. Lett., vol. 6, p. 255, 1990.

Went, G. T., S. T. Oyama, and A. T. Bell, "Laser Raman Spectroscopy of Supported Vanadium Oxide Catalysts," I. Phys. Chem., vol. 94, p. $4240,1990$.

Williams, K. J., A. B. Boffa, J. Lahtinen, M. Salmeron, A. T. Bell, and C. A. Somorjai, "Hydrogenation of CO2, A retone, and CO en a Rh Foil Promoted by Titania Overlayers," Catal. Lett., vol. 5, p. 385, 1992.

Other Publications

Zhang, X.-G., P.J. Rous, J.M. MacLaren, A. Gonis, M.A. Van Hove, and G.A. Somorjai, "LEED from Stepped Surfaces: A New Method Based on Removal Invariance in Angular Momentum Space," Bull. Am. Phys. Soc, vol. 35, p. 250, 1990. 
Badzlag, P., W.S. Verwoerd, and M.A. Van Hove, LBL-29058, "Prediction of the Effect of the Sample Blasing in Scanning Tunneling Microscopy and of Surface Defects on the Observed Character of the Dimers in the Si(001) (2x1) Surface," Phys. Rev. B. (In press.)

Chang, C. D. and A. T. Bell. LBL-30011, "Studies on the Mechanism of ZSM- 5 Formation," Catal. Lett. (Submitted.)

Fu, S. and G.A. Somorjai, LBL-29027, "Surface Studies of Zinc Oxide Growth on Cu(110)," Surf. Sci. (Submitted.)

Ginter, D. M., A. T. Bell, and C. J. Radke, LBL-30010, "The Effects of Gel Aging on Faujasite Synthesis," Zeolites. (Submitted.)

Ginter, D. M., G. T. Went, A. T. Bell, and C. J. Radke, LBL-30009, "A Physico-Chemical Study of the Aging of Zeolite Synthesis Gels," Zeolites. (Submitted.)

Hendricks, W. M., A. T. Bell, and C. J. Radke, LBL-30012, "The Effects of Organic and Alkali Metal Cations on the Distribution of Silicate Anions in Aqueous Solutions," submitted to J. Phys. Chem. (Submitted.)

Hendricks, W. M., A. T. Bell, and C. J. Radke, LBL-30013, "The Effects of Solvent Structure on the Distribution of Silicate Cations in Mixed Aqueous/Organic Solutions of Alkaline Tetramethylammonium Silicate," J. Phys. Chem. (Submitted.)

Knight, C.C. and G.A. Somorjal, LBL-28834, "Surface Science Studies of Cobalt Overlayers on Clean and Sulfur Covered Mo(100) Single Crystal Surfaces," Surf. Sci. (Submitted.).

Krishna, K. R. and A. T. Bell, LBL-29427, "An Isotopic Tracer Study of the Deactivation of Ru/TiO 2 Catalysts During Fischer-Tropsch Synthesis," J. Catal. (In press.)

Lewis, K.B., S.T. Oyama, and G.A. Somorjai, LBL-28030, "The Preparation and Reactivity of Thin, Ordered Films of Vanadium Oxide on $\mathrm{Au}(111), "$ Surf. Sci. (In press.)

Lombardo, S. J. and A. T. Bell, LBL-29460, "Monte Carlo Simulations of the Effect of Pressure on Isothermal and TemperatureProgrammed Desorption Kinetics," Surf. Sci. (In press.)

Lombardo, S. J. and A. T. Bell, LBL-29470, "A Review of Theoretical Models of Adsorption, Diffusion, Desorption, and Reaction of Gases on Metal Surfaces," Surf. Sci. Repts. (In press.)

Mortlock, R. F., A. T. Bell, A. K. Chakraborty, and C. J. Radke, LBL-29670, "Effect of Silicate Ratio on the Distribution of Silicate and Aluminosilicate Anions in TPA Aluminosilicate Solutions," I. Phys. Chem. (In press.)

Mortlock, R. F., A. T. Bell, and C. J. Radke, LBL-29327, "NMR Investigations of Tetrapropylammonium Aluminosilicate and Borosilicate Solutions," J. Phys. Chem. (In press.)

Odriozola, J.A., J. Soria, H. Heinemann, J.F, Garcla de la Banda, M. Lopez Granados, J.C. Conesa, and G. A. Somorjal, LBL-26825, "The Adsorption of $\mathrm{NO}$ and $\mathrm{NH}_{3}$ on Vanadia-Titania Catalysts: ESR and XPS Studies of the Adsorption," I. Phys. Chem. (Submitted.)

Oyama, S. T. and G.A. Somorjai, "The Effect of Vanadium Oxide Surface Structure in the Selective Oxidation of Ethanol and Ethane," Proc. TOCAT 1, Tokyo, Japan,1990, LBL-29201.

Oyama, T. and G.A. Somorjai, "Structural Effects in the Selective Oxidation of Ethanol and Ethane on Vanadium Oxide," Boston ACS Meeting. (In Press.)

Shustorovich, E. and A. T. Bell, LBL-29418, "An Analysis of Fischer-Tropsch Synthesis by the Bond-Order-Conservation-MorsePotential Approach," Surf. Sci. (In press.)

Shustorovich, E. and A. T. Bell, LBL-29624, "Analysis of Methanol Synthesis from CO and CC2 on Cu and Pd Surfaces by the BondOrder-Conservation-Morse-Potential Approach," Surf. Sci. (Submitted.)

Snurr, R. Q., R. L. June, A. T. Bell, and D. N. Theodorou, LBL-30014, "Molecular Simulations of Methane Adsorption in Silicalite," Mol. Simul. (Submitted.)

Somorjai, G.A. and S. Ted Oyama, LBL-28055, "The Effect of Structure in Selective Oxide Catalysis: The Oxidation Reactions of Ethanol and Ethane on Vanadium Oxide," J. Phys. Chem., 1990.

Somorjai, G.A., K.J. Williams, LBL-29100, A.B. Boffa, M.E. Levin, M. Salmeron, and A.T. Bell, "Hydrogenation of CO2, Acetone, and CO on a Rh Foil Promoted by Titania Overlayers," Catal. Lett., 1990.

Somorjai, G.A., LBL-29110, "The Structure Sensitivity and Insensitivity of Catalytic Reactions in Light of the Adsorbate Induced Dynamic Restructuring of Surfaces," Catal. lett. (Submitted.)

Somorjai, G.A., S. Ted Oyama, and Ann M. Carr, LBL-29024, "The Kinetics of Ethane Oxidation on Vanadium Oxide," J. Phys. Chem. (Submitted.)

Somorjai, G.A., The Catalyzed Hydrogenation of Carbon Monoxide an Overview and Future Directions, in New Trends in CO Activation, ed. L. Guczi, Elsevier Sci. Publ. Co, Amsterdam, 1990, LBL-29083.

Wang, H.-C., D.F. Ogletree, M.B. Salmeron, and G.A. Somorjai, LBL-29368, "Scanning Tunneling Microscopy Study of TiO $x$ $\mathrm{Rh}(111), " \mathrm{~J}$. Va. Sci. Technol. A. (In press.)

Zhang, X.-G., P.J. Rous, J.M. MacLaren, A. Gonis, M.A. Van Hove, and G.A. Somorjai, LBL-29082, "A Real-Space Multiple Scatttering Theory of Low Energy Electron Diffraction: A New Approach for the Structure Determination of Stepped Surfaces," Surf. Sci. (In press.)

Invited Talks

Bell, A. T., Catalysis by Design: Will It Ever Be Possible?, College of Engineering 75th Anniversary Symposium, The University of $A$ kron, Akron, OH, February 1990. 
Bell, A. T., Characterization and Catalytic Reactioity of Dispersed Transition Metal Oxides, Florida Catalysis Conference, Palm Coast, FL, April 1990.

Bell, A. T., Diffusion in Zeolites, W. R. Grace and Co., Columbia, MD, September 1990.

Bcll, A. T., Mechanistic Studies of Hydrocarbon and Alcohol Synthesis from CO and H2, II International Workshop on Heterogeneous Catalysis, Ensenada, Mexico, October 1990.

Bell, A. T., Prediction of Sorption and Diffusion in Zeolites, Department of Chemical Engineering, University of California, Santa Barbara, CA, May 1990.

Bell, A. T., Simulation of Rate and Transport Processes in Catalytic Systems, Department of Chemical Engineering and Materials Science, University of Minnesota, Minneapolis, MN, April 1990.

Bell, A. T., Studies of CO Hydrogenation over Ru Catalysts Using Transient Response Techniques, AIChEMeeting, Orlando, FL,March 1990.

Bell, A. T., Studies of the Physicochemical Processes Involved in Zeolite Synthesis, Mobil Research and Development Corp., Princeton, NJ, December 1990.

Bell, A. T., The Contributions of Catalyst Science to Catalyst Design of Development, Engineering Foundation Meeting on Chemical Reaction Engineering III, Santa Barbara, CA, February 1990.

Bell, A. T., The Impact of Catalyst Science on Catalyst Design and Development, 11th International Symposium on Chemical Reaction Engineering, Toronto, Canada, July 1990.

Bell, A. T., The Relationship Between Reaction Mechanisms and Kinetics in Heterogeneous Catalysis, Symposium on the Mechanism of Heterogeneous Catalysis, Lawrence Berkeley Laboratory, Berkeley, CA, November 1990.

Heinemann, H., Catalytic Gasification Fundamentals, Tenth Annual Gasification and Gas Stream Cleanup Systems Contractors' Review Meeting, Morgantown, PA, August 1990.

Heinemann, H., Selectize Conzersion of Methane to Higher Hydrocarbons, Methane Conversion Workshop, Pittsburgh, PA, November 1990.

Somorjai, G. A., Activation of Methane by Catalyzed Reaction with Carbon Solids, International Chemical Congress of Pacific Basin Societies PACIFICHEM'89 Symposium, Honolulu, Hawail, December 1990.

Somorjai, G. A., Adsorbate Induced Restructuring of Surface During Catalytic Reactions. The Dynamic Surface Structures Model of Reactivity, TOCAT 1-Tokyo, Japan, July 1990.

Somorjai, G. A., Adsorbate Induced Restructuring of Surfaces Catalytic Implications, The Catalysis Society of Metropolitan New York, December 1990.

Somorjai, G. A., Adsorbate Induced Restructuring of Surfaces. A Mechanism for Reactivity of Organic Molecules on Surfaces, WATOC-90 World Congress of Theoretical Organic Chemists, Toronto, Canada, July 1990.

Somorjai, G. A., L'Institut de Recherches sur la Catalyse, January 12-16, 1990. (1) Case Histories of the Surface Science of Catalytic Reactions $\mathrm{N}_{2} / \mathrm{H}_{2}, \mathrm{CO} / \mathrm{H}_{2}, \mathrm{HDS}, \mathrm{C}_{2} \mathrm{H}_{4} / \mathrm{H}_{2} ;(2)$ Adsorbate Induced Restructuring of Surfaces. Catalytic Implications; and (3) The Structure and Bonding of Organic Molecules Adsorbed on Metal Surfaces. New Techniques of Characterization.

Somorjai, G. A., Materials Science in Berkeley, Universite de Paris-Sud, January 1990.

Somorjal, G. A., Structure Sensitivity and Insensitivity of Catalytic Reactions in Light of the Dynamic Restructuring of Surfaces Under Reaction Conditions, ACS National Meeting, Petroleum Division Symposium on Structure-Activity Relationships in Heterogeneous Catalysis, April 1990.

Somorjal, G. A., Surface Science of Heterogeneous Catalysis, Dalhousie University, Hallfax, Canada, October 1990.

Somorjai, G. A., The Dynamic Restructuring Model of Surfaces. Catalytic Implications, Lehigh University, Bethelem, PA, April 1990.

Somorjai, G. A., The Dynamical Restructuring of Surfaces. A New Model for Forming the Surface Chemical Bond and for Heterogeneous Catalysis, ACS-Boston, Symposium of Past Kendall Laureates, August 1990.

Somorjai, G. A., The Roles of Adsorbate $\mathrm{Al}_{2} \mathrm{O}_{3}, \mathrm{~K}$ and N Induced Restructuring of Iron in Ammonia Synthesis, University of Utah, Sinfelt Symposium, October 1990.

Somorjal, G. A., The Surface Structure Sensitivity of Chemisorption and Catalytic Reactions Over Transition Metal Surfaces, AIChENational Meeting, Orlando, FL, March 1990.

Somorjai, G. A., Why Rough Siurfaces are Important for Chemical Bond Breaking and Catalysis, ACS National Meeting, Boston, MA, April 1990.

Somorjai, G.A.,(1) Solving the Puzzles of Surface Chemistry. The Dynamic View of Surfaces and Their Reactivity; (2) Bridging the Gap Between Homogeneous and Heterogeneous Catalysis; and (3) The Surface Science of Contact, Friction and Lubrication, FM:C Lectures, Princeton University, New Jersey, December 5-7, 1990.

Refereed Journal Articles

\section{Surface Structure and Interface Compounds Project}

Egelhoff, W.F., Jr., J.W. Gadzpk, C.J. Powell, and M.A. Van Hove, "Auger Electron Angular Distributions from Surfaces-Forward Focusing or Silhouettes," Science, vol. 248, p. 1129, 1990.

Kawasaki, M., G.J. Vandentop, M. Salmeron, and G.A. Somorjal, "Analysis of the Interface of Hydrogenated Amorphous Carbon Films on Silicon by Angle-Resolved X-ray Photoclectron Spectroscopy," Surf, Sci., vol. 227, p. 261, 1990. 
Ogletree, D.F., C. Ocal, B. Marchon, T. Beebe, W. Siekhaus, M. Salmeron, and G.A. Somorjal, "Scanning Tunneling Microscopy Study of the Structure of Sulfur $(2 \sqrt{3} \times 2 \sqrt{3})$ R30 $0^{\circ}$ Overlayer on Rhenium (0001)," J. Vac. Sci. Technol., vol. A8, no. 1, p. $297,1990$.

Rous, P.J., D. Jentz, D.J. Kelly, R.Q. Hwang, M.A. Van Hove, and G.A. Somorjai, "A Directed LEED Search for Many Structural Parameters: Asymmetric Sites and Restructuring in C and S Overlayers on Mo(100)," Bull. Am. Phys، Soc., vol. 35, p. 680, 1990.

Somorjal, G.A., "Adsorbate Induced Restructuring of Surfaces. The Surface Thermodynamic Puzzle," in Bonding Energies and the Thermodynamics of Organometallic Reactions, p. 218, 1990.

Somorjai, G.A., "Modern Concepts in Surface Sclence and Heterogeneous Catalysis," J. Phys. Chem., vol. 94, p. $1013,1990$.

Somorjal, G.A., P.J. Rous, and M.A. Van Hove, "Directed Search Methods for Surface Structure Determination by LEED," Surface Science, vol. 226, 15 (1990), LBL-27427.

Van Hove, M.A. , M.-L. Xu, P. de Andres, A. Wander, G.S. Blackman, R.Q. Hwang, and G.A. Somorjal, "Adsorption Structure of Disordered Benzene and Other Molecules on Pt(111) from Diffuse LEED," Bull. Am. Phys. Soc, vol. 35, p. 589, 1990.

Van Hove, M.A., "A Glimpse of Solld Surfaces, in Multiparticle Dynamics," Festschrift for L. Van Hove, eds. A. Glovannini and W. Kittel, World Sci. Publ. Co., Singapore,1990, p. 821, LBL-27158.

Van Hove, M.A., "Theory of Surface Crystallography by Forward Focusing of S, _ondary Electrons," Bull. Am. Phys, Soc,, vol. 35, p. 325, 1990.

Vandentop, G.J,,M.Kawasakl, R.M.Nix, I.G. Brown, M. Salmeron, and G.A.Somorjal, "The Formation of Hydrogenated Amorphous Carbon Films of Controlled Hardness from a Methane Plasma," Phys. Rev., vol. B1, p. 41, (5), 1990.

LBL Reports

Badzlag, P., W.S. Verwoerd, and M.A. Van Hove, LBL-29647, "Prediction of the Effect of the Sample Baising in Scanning Tunneling Microscopy and of Surface Defects on the Observed Character of the Dimers in the Si(001) (2x1) Surface," Phys. Rev. B. (In press.)

Delplancke, M.P, J.M. Powers, G.J. Vandentop, M. Salmeron, and G.A. Somorjai, LBL-29623, "Preparation and Characterization of PECVD Amorphous SiC:H Thin Films, J. Vac. Sci. \& Tech. A. (Submitted.)

Delplancke, M.P., J.M. Powers, G.J. Vandentop, and G.A. Somorjai, LBL-29461, "Preparation of $\mathrm{Si}_{x} \mathrm{C}_{y} \mathrm{H}_{z}$ Films from Methylsilane by Plasma Enhanced Chemical Vapor Deposition," Thin Solid Films.

Hwang, R.Q. and D.M. Zeglinskl, A. Lopez Vazquez-de-Parga, C. Ocal, D.F. Ogletree, M. Salmeron, and G.A. Somorjai, LBL-29333, "Formation of Sulfur Aggregates on Re(0001) Surfaces Observed with the Scanning Tunneling Microscope," Phys. Rev. Lett. (Submitted.)

Maurice, V., K. Takeuchi, M. Salmeron, and G.A.Somorjal, LBL-29487, "The Bonding of Diethyl Ether, Ethanol and Their Fluorinated Analogs to Zirconium Oxide Thin Films," Surf. Sci. (In press).

Maurice, V., M. Salmeron, and G.A. Somorjai, LBL-28699, "The Epitaxial Growth of Zirconium Oxide Thin Films on Pt(111) Single Crystal Surfaces," Surf. Sci. (Submitted.)

Nascente, P.A.P., M.A. Van Hove, and G.A.Somorjai, "Induced Ordering of Ethylidyne on the Pd(111) Surface by the Pre-Adsorption of Oxygen: A LEED and HREELS Study," Surf. Sci. (Submitted.)

Ogletree, D.F., K. Frank, and G.A. Somorjai, LBL-21694, "An Ultra-High Vacuum Sample Manipulator for Angle-Resolved Electron Spectroscopy," J. of Vac. Sci. and Tech. Microelectronics, Center of North Carolina. (Submitted.)

Ogletree, D.F., R.Q. Hwang, and D.M. Zeglinski, A. Lopez Vazquez-de-Parga, M. Salmeron, and G.A. Somorjai, LBL-29367, "Scanning Tunneling Microscopy Studies of Sulfur Overlayers on the Re(000ᄁ\Surface," J. Vac Scl. Tech. A. (Submitted.)

I'owers, J., G.A. Somorjai, LBL-29191, "The Surface Oxidation of Alpha-Silicon Carbide by O2 from 300K to 1373K," Surf, Scl. (Submitted.)

Somorjai, G.A. and M.A. Van Hove, LBL-27397, "Surface Crystallography by Low-Energy Electron Diffraction," in Physical Methods of Chemistry, Vol. 9B, eds. B.W. Rossiter, J.F. Hamilton and R.C. Baetzold, Interscience Publ., 1990. (In press.)

Somorjai, G.A., LBL-29277, "The Puzzles of Surface Science and Recent Attempts to Explain Them," Surf. Sci. (Submitted.)

Van Hove, M.A., "Surface Crystallography at the Metal-Gas Interface," LBL-28688, in Structure of Electrified Interfaces, eds. J. Lipkowski and P.N. Ross, VCH Publishers, New York, 1990. (In press.)

Vandentop, G.J., P.A.P. Nascente, M. Kawasaki, D.F. Ogletree, M. Salmeron, and G. A. Somorjai, LBL-29459, "Observation of the Initial Stages of Growth of Hydrogenated Amorphous Carbon Films by Scanning Tunneling Microscopy," J. Vac. Scl. \& Tech. A. (Submitted.)

Wander, A., G. Held, R.Q. Hwang, G.S. Blackman, M.L. Xu, P. de Andres, M.A. Van Hove, and G.A. Somorjai, "A Diffuse LEEDStudy of the Adsorption Structure of Disordered Benzene on Pt(111)," Surf. Sci. (Submitted.)

Zeglinski, D.M., D.F. Ogletree, T.P. Beebe, Jr., R.Q. Hwang, M.B. Salmeron, and G.A. Somorjai, LBL-28848, "An Ultra-High Vacuum Scanning Tunneling Microscope for Surface Science Studies," accepted Rev. of Sci. Instr. (Submitted.)

Invited Talks

Somorjai, G.A., Computational Methods in Chemical Design, Molecular Modeling, Theory and Experiment, The Development of Models of Surface Structure, Chemical Bonding and Reactivity. The Transition from Static to Dynamic Concepts, Elmau 3 Symposium, Schloss Elmau, Germany, October 1990. 
Somorjal, G.A., Monolayers on Single Crystal Surfaces, New Models for the Surface Chemical Bond Durlng Adsorption and Catalysis, ACS Langmuir Lecture, August 1990.

Somorjal, G.A., Surface as a New Material, The Puzzles of Surface Sclence and Recent Attempts to Explain Them, 26th Yamada Conference, Osaka, Japan, July 1990.

Somorjal, G.A., The Application of New Techniques to Study Surface Structure on the Atomic Scale, LEED, STM, AFM and SIMS, ACS National Meeting-Boston, Kendall Award Symposium II, April.

Somorjai, G.A., The Puzzles of Surface Sclence and the Dynamical Restructuring Model to Explain Them, University of Washington, Department of Chemlcal Engineering, May 1990.

Somorjai, G.A., The Surface Chemical Bond, UC San Diego Colloquia, May 3.

Van Hove, M.A., Challenges to Interface Theory, Univ, of British Columbia, Vancouver, Canada, May 1990.

Van Hove, M.A., Molecular Chemisorption on Metal Surfaces vs, Metal Clusters, Univ, of British Columbia, Vancouver, Canada, May 1990.

Van Hove, M.A., Theory of Surface Crystallography by Forward Focusing of Secondary Electrons, APS Meeting, Anahelm, California, March 1990

Refereed Journal Articles

Instrumentation for Surface Sclence

Ager, J.W., III, D.K. Veirs, J. Shamir, and G.M. Rosenblatt, "Laser Heattng Effects in the Characterization of Carbon Fibers by Raman Spectroscopy," J. Appl, Phys., vol. 68, p. 3598, 1990.

Ager, J. W. III, D. K. Veirs, and G. M. Rosenblatt, "Raman Intensittes and Interference Effects for Thin Films Adsorbed on Metals," J. Chem. Phys., vol. 92, p. 2076, 1990.

Fisher, K. A., K. C. Yanagirnoto, S. L. Whitfield, R. E. Thomson, M. F. G. Gustafsson, and J. Clark, "Scanning Tunneling Microscopy of Planar Blomembranes," Ultramicroscopy, vol. 33, p. 117, 1990.

Fisher, K. A., S. L. Whitfield, R. E. Thomson, K. C. Yanagimoto, M.G. L. Gustafsson, and J. Clarke, "Measuring Changes in Membrane Thickness by Scanning Tunneling Microscope," Biochim. et Biophys. Acta vol. 1023, p. 325, 1990.

Johnson, M. and J. Clarke, "Spin Polarized Scanning Tunneling Microscope: Concept, Design and Preliminary Results from a Prototype Operated in Air," I. Appl. Phys., vol. 67, p. 6141, 1990.

Rosenblatt, G.M. and D. K. Veirs, "Raman Characterization of High Temperature Materials Using an Imaging Detector," High Temp. Sci., vol. 26, p. 31, 1990 .

Salmeron, M., T. Beebe, J. Odriozola, T. Wilson, D.F. Ogletree, and W. Siekhaus, "Imaging of Blomolecules with the Scanning Tunneling Microscope: Problems and Prospects," J. Vac. Sci. Tech. A, vol. 8, no. 1, p. 635, 1990.

Wang, W. arid S. G. Loule, "First Principles Studies of S/Mo(001) Surfaces," Surf. Sci., vol. 226, p. 257, 1990.

Zhong, W., and D. Tomanek, "First Principles Theory of Atomic-Scale Friction," Phys. Rev, Lett., vol. 64, p. 3054, 1990.

Referred Conference Proceedings

Rosenblatt, G.M., D.K. Veirs, J.W. Ager III, and J. Shamir, LBL-27905, "Characterization of Materials with Raman Spectroscopy," in Proceedings of the Symposium on High Temperature and Materials Chemistry, 1990.

Rosenblatt, G. M., J. W. Ager, III, and D. K. Veirs, "Interference Effects in the Raman Spectroscopy of Thin Films," Proceedings of the Twelfth International Conference on Raman Spectroscopy, ed. J. R. Durig and J. F. Sullivan, John Wiley and Sons, p. 334, Chichester, 1990.

Veirs, D. Kirk, J.W. Ager III, and G.M. Rosenblatt, "Mapping Chemical and Physical Properties of Advanced Materials Using Spatially Resolved Raman Spectroscopy," in Proceedings of the XXII International Conference on Raman Spectroscopy, eds. J.R. Durig and J.F. Sullivan, p. 898, Wiley, Chichester, UK, 1990.

Other Publications

Chen, C., Z. Yu, and Y. R. Shen, "Recent Advances in Growth and NLO Characteristics of LiB3O O5," Opt. Soc. of Am. 1990 Tech. DIg. Series, vol. 7, p. 30, 1990.

Mullin, C. S., V. Vogel, M. W. Kim, and Y. R. Shen, "Study of Equilibria and Dynamics of Surfactants at the Air/Water Interface with Optical Second Harmonic Generation," Bull. Am. Phys. Soc., vol. 35, p. 347, 1990.

Rosenblatt, G.M. and D.K. Veirs, "Raman Characterization of High Temperature Materials Using an Imaging Detector," in Materials Chemistry at High Temperature, ed. J.W. Hastle, Vol. 1, Humana Press, Clifton, NJ, 1990.

Shen, Y. R., R. Superfine, and J. Huang, "Up or Down? Molecular Polar Orientation Determined by Infrared-Visible Sum-Frequency Generation Phase Measurement," Bull. Am. Phys. Soc., vol. 35, p. 346, 1990.

Veirs, D.K., J.W. Ager III, E.T. Loucks, and G.M. Rosenblatt, "Mapping Chemical Properties of Advanced Materials Using Imaging Raman Spectroscopy," in Digest of Topical Meeting on Laser Applications to Chemical Analysis, Vol. 2, p. 10, Optical Society of America, Washington, DC, 1990.

Vogel, V., C. Mullin, Y. R. Shen, and M. W. Kim, "Surface Adsorption Studies by Optical SIHG: Soluble Monolayers at the Air/Water Interface," Mat. Res. Soc. Sym. Proc., vol. 177, p. 363, 1990.

Zhang, J. Y., D. Pauschinger, D. Soane, and Y. R. Shen, "Study of Metal/Polymer Interfaces by Second Harmonic Generation," Opt. Soc, of Am., 1990 Tech. Dig. Series, vol. 7, p. 520, 1990. 
Zhang, J. Y., J. Y. Huang, Y, R. Shen, C. Chen, and B. Wu, "Picosecond Tunable Optical Parametric Ampllfication in Barium and Lithium Borates," Opt. Soc. of Am., 1990 Tech. Dlg, Serlos, vol, 7, p. 246, 1990,

LBL Reports

Burk, B., R. E. Thomson, A. Zettl, and J. Clarke, "Charge Density Wave Domains in 1T-TaS2 Observed by Zagellite Structure in Scanning Tunneling Microscopy Images," Phys, Rev. Lett. (Submitted.)

Cho, N.-H., K.M. Krishnan, D.K. Veirs, M.D. Rubin, C.B. Hopper, B. Bhushan, and D.B. Bogy, LBL-28908, "Chemical Structure and Physical Propertles of Dlamond-like Amorphous Carbon Films Prepared by Magnetron Sputtering," J. Mat. Res. (In press.)

Dauskardt, R.H., W.C. Carter, D.K. Velrs, and R.O. Ritchle, LBL-26682, "Transient Subcritical Crack-growth Bohavior in Transformation-toughened Ceramlcs," Acta. Metall. Mater. (In press.)

Marchon, B., N. Heiman, M.R. Khan, A. Laute, J.W. Ager III, and D.K. Veirs, "Raman and Resistlvity Investlgations of Carbon Overcoats of Thin Film Media -- Correlations with Tribological Propertles," I. Appl. Phys. (In press.)

Huang, J. Y., J. Y. Zhang, Y. R. Shen, C. Chen, and B. Wu, "A High-Power, Widely Tunable, Picosecond Coherent Source from Optical Parametric Amplification In Barium Borate," Appl. Phys, Lett. (In press.)

Salmeron, M., D., D.F. Ogletree, C. Ocal, H.-C. Wang, G. Noubauer, W. Kolbe, and G. Meyers, LBL-29714, "Tip-Surface Forces during STM Imaging," J. Vac. Sci. Technol. (In press.)

Salmeron, M., D., M. Zeglinskl, D. F. Ogletree, T. P. Beebe, R. Q. Hwang, and G. A. Somorjal, LBL-28848, "An Ultra-High Vacuum Scanning Tunneling Mlcroscope Providing Interfacing with Standard Surface Sclence Techniques and In Vacuo Tip and Sample Transfer, Rev. Sci. Instrum. (In press.)

Salmeron, M., T. E. Wilson, M. N. Murray, D. F. Ogletree, M. D. Bednarski, and C. R. Cantor, LBL-29737, "STM Imaging at High Gap Resistances and on Chemically Modified Sillicon Surfaces," J. Vac. Sci. Technol. (In press.)

Salmeron, M., X. Godechot, D.F. Ogletree, ]. E. Galvin, R. A. MacGlll, M. R. Dickinson, K. M. Yu, and I. G. Brown, Proceedings Materials Research Society, Spring 1990. (In press.)

Tomanek, D., Z. Sun, and S. G. Loule, "Ab initio Calculation of Chemisorption Systems: H on Pd(001) and Pd(110)." (Submitted.)

Veirs, D.K, J.W. Ager III, E.T. Loucks, and G.M. Rosenblatt, LBL-28369, "Mapping Materials Properties with Raman Spectroscopy Utilizing a Two-dimensional Detector," Appl. Opt. (In press.)

Vogel, V., C. S. Mullin, and Y. R. Shen, "Probing the Structure of the Adsorption Layer of Soluble Amphiphilic Molecules at the Air/ Water Interfaces," Langmuir. (Submitted.)

Xlao, X. D., V. Vogel, Y. R. Shen, and G. Marowsky, "Molecular Monolayers of Charge-Transfer Complexes: Protonation and Aggregation Studied by SHG," I. Chem. Phys. (Submitted.)

Zhang, J. Y., J. Y. Huang, Y. R. Shen, C. Chen, and B. Wu, "Picosecond Optical Parametric Amplification in Lithium Triborate," Appl. Phys. Lett. (Submitted.)

Invited Talks

Cho, N.-H., M.D. Rubin, K.M. Krishnan, D.K.Veirs, B. Bhushan, and D.B. Bogy, Characterization of Diamond-like Amorphous Carbon Thin Films, International Conference on Metallurgical Coatings, San Dlego, CA, March 1990.

Fisher, K. A. and J. Clarke, Quantifying Biological Membrane Thickness with the Scanning Tunneling Microscope, March Meeting of the American Physical Sodety, Anaheim, CA, March 1990.

Fisher, K. A., M. G. L. Gustafsson, R. E. Thomson, S. L. Whitfleld, K. C. Yanagimoto, M. B. Shattuck, and J. Clarke, Low Temperature Scanning Probe Microscopy, 4th International Meeting on Low Temperature Blological Microscopy and Analysis, Cambridge, England, April 1990.

Gustafsson, M., K. A. Fisher, and J. Clarke, Studies with a Cold Atomic Force Microscope, Pacific Conference on Chemistry and Spectroscopy, San Francisco, CA, October 1990.

Rosenblatt, G.M., Recent Developments in the Raman Characterization of Materials, Gordon Research Conference on High Temperature Chemistry, Meridan, NH, July 1990.

Salmeron, M., Observing the Atomic Structure of Surfaces with the Scanning Tunneling and Atomic Force Microscopes, Conference at Texas Instruments, Inc., Dallas, Texas, August 1990.

Shen, Y. R., Nonlinear Optical Characterization of Surface Molecular Monolayers, International Symposium on Nonlinear Optical Materials, El Paso, TX, October 1990.

Thomson, R. E., U. Walter, B. Burk, Z. Zettl, and J. Clarke, Scanning Tunneling Microscopy of Charge Density Waves in 1T-TaS, Paciflc Conference on Chemistry and Spectroscopy, San Francisco, CA, October 1990.

Veirs, D.K., Imaging Using Vibrational Raman Spectroscopy, Gordon Research Conference on Vibrational Spectroscopy, Woifeboro, NH, August 1990.

Veirs, D.K., Spectroscopic Imaging of Materials' Properties, NMT Seminar, Los Alamos, NM, February 1990.Vogel, V., Organic Molecular Assemblies at Interfaces: Structural Investigations by Novel Technique, Department of Bloengineering, University of Bioenglneering, University of Washington, Seattle, WA, Juno 14, 1990.

Vogel, V., X-D. Xlao, and Y. R. Shen, Adsorbates at Interfaces Studied by Nonlinear Optics, Topical Meeting on Laser Application to Chemical Analysis, Incline Village, NV, February 1990. 
Zhang, J. Y, Y. R. Shen, D. S. Soane, and D. Pauschinger, Amorican Society of Metals International's 3rd Eloctronic Matorials and Processing Congress, San Franclsco, Cᄉ, August 1990,

Contributed Talks

Burk, B., U, Walter, R. E. Thomson, M. F. Crommle, J, Clarke, and A. Zettl, Scanning Tunneling Microscopy of the Blue Bronzes $(\mathrm{Rb}, \mathrm{K})_{0,3} \mathrm{MoO}_{3}$ March Meeting of the Amorican Physical Socioty, Anahelm, CA, March 1990.

Chen, $\mathrm{C}_{1}, \mathrm{Z}$. Yu, and $Y$. R. Shen, Recent Adzances in Growth and NLO Characteristics of LiB $3 \mathrm{O}_{5}$, Conforence on Laser and Electro-Optics, Anaheim, CA, May 1990.

Fisher, K. A., S. L. Whitfield, R. E. Thomson, K. G. Yanagimoto, M. G. L. Gustafsson, and J. Clarko, Measuring Changes in Biomembrane Thickness with the Scanning Tunneling Microscope, poster at the 34th Annual Meeting of the Blological Soclaty, Baltimore, Maryland, Fobruary 1990.

Gustafsson, $M_{1}$ and J. Clarke, Microfabricated Springs for Atomic Force Microscopy with Tips Made by Controlled Fracture, March Mocing of the American Physical Society, Anaheim, CA, March 1990.

Johnson, Mark and J. Clarke, Ferromagnet-Air-Ferromagnet Tunneling and Application to a Spin Polarized STM, Moeting of the American Physlcal Soclety, Anahelm, CA, March 1990.

Mullin, C. S., V. Vogel, M. W. Kim, and Y. R. Shen, Study of Equilibria and Dynamics of Surfactants at the Air/Water Interjace with Optical Second Harmonic Generation, Meeting of the American Physical Society, Anaheim, CA, March 1990.

Rosenblatt, G.M., J. W. Ager III, and D. K. Veirs, Interference Effects in the Raman Spectroscopy of Thin Films, 12th Internatlonal Conference on Raman spectroscopy, Columbia, SC, August 1990.

Shattuck, M. B., R. S. Bhatnagar, M. Stewart, S. L. Whitfleld, R. E. Thomson, and J. Clarke, Scanning Tunneling Microscopy of Native Collagen, Meeting of the American Physical Sodety, Anahelm, CA, March 1990,

Shen, Y. R., R. Superfine, and J. Huang, Up or Down? Molecular Polar Orientation Determined by Infrared-Visible Sum-Frequency Generation Phase Measurement, Meeting of the American Physical Society, Anaheim, CA, March 1990.

Zhang, J. Y., D. Pauschinger, D. Soane, and Y. R. Shen, Study of Metal Polymer Interfaces by Second Harmonic Generation, Conforence on Laser and Electro-Optics, Anaheim, CA, May 1990. 
Modeling

Processing

Mechanical Performance

\section{Ceramic Science Program}

The Ceramic Science Program has three linked objectives that aim to provide a science-based framework for the improvement of performance and the development of novel ceramics for energy technologies.

- MODEL STUDIES - the fundamental study of processes that dictate the microstructural changes occurring during processing and utilization of ceramics

- PROCESSING - the definition of quantitative constitutive equations for densification and microstructural evolution of powder compacts and the application of these relationships in the development of improved or novel ceramics with mechanical functions

- MECHANICAL PERFORMANCE-the study and improvement of the mechanical performance of ceramic materials

While the focus of program is the relationship between processing and mechanical properties of single and multiphase structural ceramics, it can be appreciated that mechanical properties, characterized by strength and toughness, often limit the performance of ceramics in functions other than structural. Examples are ceramic electrolytes or dielectric ceramics where limits to performance can be related to the fracture toughness raised to a power higher than one, when failure is accompanied by slow or catastrophic crack growth.

The MODEL STUDIES project focuses on the effects of crystallization, polymorphic phase transformations, and particle substructure on microstructural evolution in powder compacts formed from an "ideal," nominally monodispersed, chemically synthesized titania powder are being examined. Model experiments utilizing photolithographically introduced, microdesigned pore/flaw structures are being used to study high-temperature crack healing in glass.

Recent results include:

- The successful development of a lithography-based procedure for introducing controlled-geometry internal cracklike flaws in glass. Defects introduced in this manner form the basis for high-temperature crack healing studies in isotropic materials.

- The completion of an extensive study of microstructural development during sintering within compacts formed from monosized agglomerates of nanophase $\mathrm{TiO}_{2}$. 
The PROCESSINGproject looks at the important parameters influencing mechanical behavior, reproducibility, and rellability of performance-structural and chemical uniformity. The required uniformity, however, is not readily achieved, and novel or highly controlled processing methods need to be devised to improve significantly to assure the required uniformity. Mechanical behavior, including high temperature creep in particulate composites, R-curve behavior, creeprupture, and fatigue susceptibility, as well as the statistical distribution of performance limits are expected to be strongly dependent on uniformity. Two avenues toward structural uniformity have been developed in this program: the manipulation of the heating schedule to include limited grain coarsening before sintering, and the use of coated powders. With the latter, it has been possible to fabricate aluminum oxide ceramics, containing up to $40 \mathrm{vol} \%$ of SiC whiskers or platelets, by pressureless sintering of coated particles produced in this program.

Recent results include:

- Development of a method to produce coated powders by controlled heterogeneous precipitation in slurries.

- Preparation of special ceramics and homogeneous microcomposites from coated powders.

- Structural mullite made by coating hollow silica spheres with alumina.

The MECHANICAL BEHAVIOR project focuses on the development of improved or novel ceramics with mechanical functions. Ceramics intended for use at high temperature require not only the retention of high strength and high fracture toughness. While chemical stability under operating conditions is the prime factor in determining the utility of a structural ceramic, other, less frequently assessed properties are of concern. For example, while silicon nitride and transformation toughened zirconias can be made with high fracture strength and toughness, these material may suffer slow deterioration under fluctuating load. It has been demonstrated in this program that a number of tough ceramics have significant fatigue susceptibility. The origin of this fatigue susceptibility of tough ceramics is investigated.

Recent results include:

- The first demonstration of cyclic-fatigue crack growth in $\mathrm{SiC}$.

- The Modeling of transient fatigue crack growth following overloads in PSZ. 
Mlorostruotural Evolution in Chemlcally Synthesized Titania

M.L. SHalzz ANo A, M, Glaesea

Chemical synthosis can produce coramic powders of highly controlled particlo size, size distribution, and shape. However, the reaction product is often a chemical procursor to the desired matertal, or it is not the stable crystalline phase. The chemical, physical, and crystallographic changes that produce the dosired form of the powdor occur during heating, and often initiate at temporatures woll bolow the normal sintering temperature of the material. These changes can have a dramatic impact on the ultimate sintering characteristles of the powder, and the microstructure and propertios of the sintered compacts. This research profect has focussed on charactorization of microstructural changes that accompany low-tomperature heat treatmont of a nodel powder, ttania propared by the controlled hydrolysis of titanlum alkoxide solutions.

Electron diffraction suggests the existence of short-range order in as-precipitated titania particles; this short-range order was not detected in prior work. "Crystallization" of this material produces one or more crystalline phases. Anatase and rutile were observed previously; more recent work Indicates that brookite can also be formed. The differing phases that form may reflect local difforences in the degree of order, which in turn may be a consequence of local differences in the nucleation and growth conditions. Differences in degrec of short-range order may also contribute to the batch to batch differences in the heat of transformation indicated by DSC results. Transformation energies also depended upon the reaction atmosphere (-248-284 J/g in argon versus $-337-367 \mathrm{~J} / \mathrm{g}$ in air). Compact surfaces densified before internal porosity was removed, imposing a mechanical constraint on the interior that restricts densification, and causes the interior material to reduce its energy by faceting rather than by densification.

High Temperature Crack Healling in Glass

H. Ackler and A.M. Glaeser

A novel method of introducing controlled-geometry cracklike defects at internal interfaces was developed as part of the Model Studtes research program. The morphological cvolution of such defects at high temperature, high-temperature crack healing, was studied in sapphire. Crack face and crack edge crystallography had a profound impact on the healing mode. It was desirable to complement this work with studies of high-temperature crack healing in an isotropic material.

The lithographic methods and bonding techniques developed to study high temperature crack healing in sapphire have been adapted and successfully applied to glass. Controlled-geometry internal defects can now be produced. Preliminary studies of high-temperature crack healing by viscous flow in soda-lime silica glass have been initiated. In this glass, morphological changes charactoristic of crack healing compete with those accompanying crack enlargement. Gas-evolving reactions become important in the same temperature range within which viscous flow initiates. Experiments utilizing a higher-purity vacuum-degassed glass are in progress. 


\section{Effect of Particle Size on the Creep-Sintering of Narrow Size Alumina \\ F. LIN ANIS L, O,DE: JONGHE}

Alumina powder is classified to produce three narrow size fractions: $1.13 \pm 0.28$ $\mu \mathrm{m},(0.83 \pm 0.21 \mu \mathrm{m}$, and $(0.39 \pm(0,10 \mu \mathrm{m}$. The effect of particle size on the creep sintoring is assessed from the loading dilatomotry. The fine-sized compact has a higher densification strain rate compared with those of the othor two sizod compacts. The ratio of densification strain rate to creep strain rate is inversely proportional to the Inittal particle size, l.c., the driving force, the sintering stress, is proportional to (particle size $)^{-1}$. Under constant heating rate sintoring condition (CHR $=4{ }^{\circ} \mathrm{C} / \mathrm{min}$.), there is negliglble grain growth for all three compacts.

\section{Dopant Effects in Partioulate Ceramlo Composites}

G. BMOWN AND L,C. DE JONGHIE

The achievement of full densification in ceramic matrix composites romains an unsolved problem in ceramic processing. The effects of doping the $\mathrm{ZnO}$ matrix, in $\mathrm{ZnO}-\mathrm{SiC}$ composites, with $340 \mathrm{ppm} \mathrm{Al}$ (a known coarsening inhibitor for $\mathrm{ZnO}$ ) is being investigated. Systematic improvements in isochronal sintered density have been observed in doped samples containing 1,5,10 and 20 volume percent of Inclusions. The competition between densifying and coarsening mechanisms is therefore of importance in the sintering of polycrystalline ceramic materials containing rigid inclusions.

\section{Characterization of Modifled Flbers for use In High Temperature Ceramio Composites \\ C.P. JAOOBSON AND L.O. DE JONGHE}

The purpose of this work is to investigate a process for stabilizing polymer precursor SiC fibers. In parallel to this work is an investigation into the properties of a ceramic matrix composites made from the stabilized SIC fibers and a SIC polymer precursor + SIC filler matrix to determine the mechanical property gains achieved by using these modifled fibers.

Silicon Carbide is a good candidate for making refractory high strength fibers due to its high Young's modulus and strength, high thermal stability, and low cocfficient of thermal expansion. However, the pyrolysis of organometallics to produce SIC ceramics does not convert all the precursor material to sillicon carbide and this leads to thermal instability and fiber degradation beginning around $1000^{\circ} \mathrm{C}$. Fiber degradation and the subsequent reduction in fiber strength has limited these SiC flbers to low or intermediate temperature $\left(\mathrm{T}<10(0) 0^{\circ} \mathrm{C}\right)$ and so their potential for high temperature $\left(\mathrm{T}>1400^{\circ} \mathrm{C}\right)$ applications has not been realized.

This rescarch has focused on the successful development of a simple technique for thermally stabilizing SIC fibers derived from polymer precursor. As-recolved fibers are shown in Figure 1. As-recelved fibers heat treated to 200()$^{\circ} \mathrm{C}$ in an inert atmosphere are shown in Figure 2 (page 60). Stabilized fibers, heat treated $\ln 200()^{\circ} \mathrm{C}$ in an inert atmosphere are shown in Figure 3 (page 60). The stabilized fibers clearly retain their shape even at extrene temperatures. Future work will include mechanical testing of the stabilized fibers and a ceramic matrix composite containing these modifled fibers.

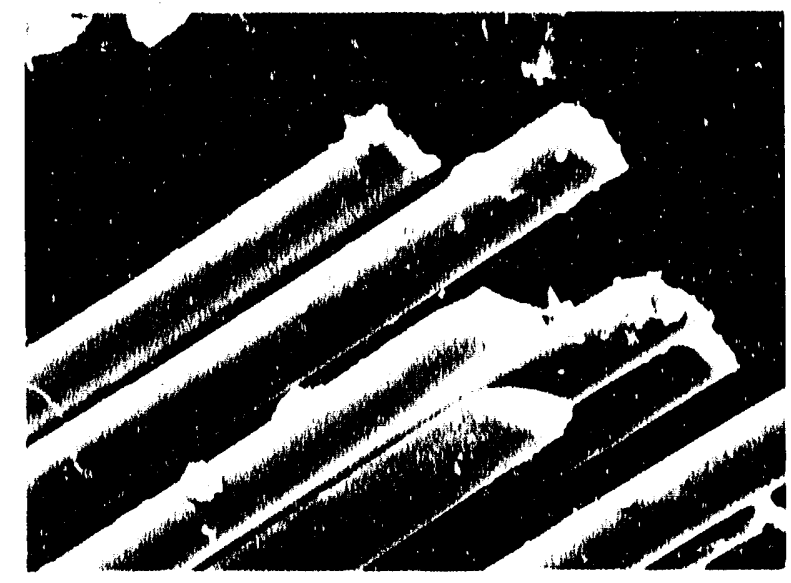




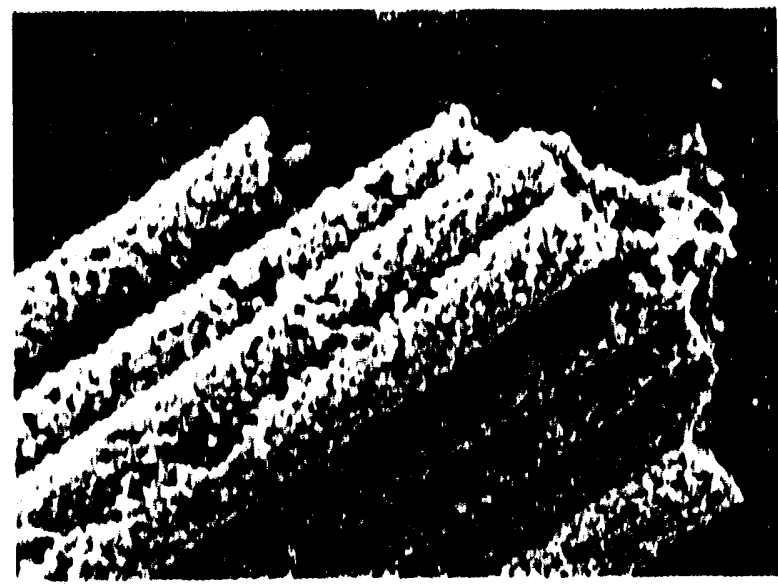

Figuro 2

SEM miorograph of Nloalon fibors troutad at 2020' O in flowing Nitrogan

(Magniflad 780X). (XBB 8110.8140)

Flgure 3

SEM micrograph of stabllized Nicalon flbers treated at 2020' $\mathrm{C}$ in flowing Nitrogen. (Magnifled 760X). (X'3B 9110-8141)

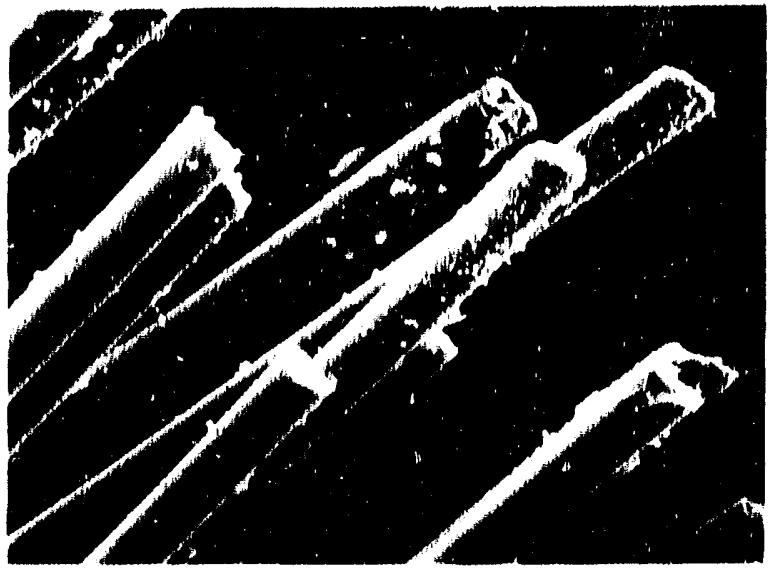

\section{Size Effects In SIC-TIB 2 Composites \\ T. Buchanan AND L.C. DE Jonghe}

The effect of varying $\mathrm{TiB}_{2}$ particle size on the mechanical properties and the microstructure of SiC-TiB ${ }_{2}$ particulate composites was investigated. The $\mathrm{TIB}_{2}$ particles were classified by sedimentation methods into three size ranges: 3,10 , and 15 $\mu \mathrm{m}$. These powders and an as-recelved powder with a 3-10 $\mu \mathrm{m}$ size range were mixed with SIC at 10,20,30, and $40 \%$ volume fractions of $\mathrm{TI}_{2}$ and free sintered. The fracture strength and toughness were tested and the microstructure examined.

Crack deflection, crack pinning and crack branching were observed. The choice of $\mathrm{TiB}_{2}$ particle size determined the primary toughening mechanism. Crack deflection was the primary toughening mechanism in the $S(3 \mu \mathrm{m})$ series and microcracking was the primary mechanism in the other composite series. The 30 vol\% S composite had the optlmum of strength and toughness with values of $421 \mathrm{MPa}$ and $5.8 \mathrm{MPam}^{1 / 2}$, respectively.

\section{Alumina-Sillcon Carbide Composites frorn Coated Powders}

T.D. MitCHELL. AND L.C. DE JONGHE

The purpose of coated particle research is to solve problems in the fabrication of microcomposites caused by the presence of the reinforcing phase. Agglomeration of the reinforcing phase hinders densification of the microcomposite, requiring large external pressures and high temperatures to achieve dense compacts. Second phase distribution is also hindered. These problems were greatly reduced by encapsulating heterogeneous precipitation each roinforcing particle (SiC whisker or platelet) in alumina prior to sintering. Coated whisker composites up to 30) volume percent were pressureless sintered to closed porosity, previously thought to be impossible for microcomposites with greater than 20) volume percent reinforcement. Mechanical testing yielded average fracture toughness values of $7 \mathrm{MPa}$ for these composites. 
Thin film coatings of several matorlals wore propared using sol-gol procossing; polymorized gols wore synthesized from the appropriate metal alkoxidos. The viscosittes of the gols are controlled by the amount of water added. $\mathrm{THO}_{2}, \mathrm{SrCCO}_{3}$, and $\mathrm{ZrO}_{2}$ systems have been studicd. Ind tially, thin films for process characterization woro obtained by dipping a polishod single-crystal silicon wafer into the solution. This substrate was chosen because it provides a clean, flat surface for the study of film morphology, and because the $<100\rangle$ sillicon gives rise to only a single peak in $x$-ray diffraction, making analysis of the film structure casior. Spin coating has also been used, and other substrates under investlgation include soda glass and fused quartz. $X$-ray analysis shows that $\mathrm{THO}_{2}$ and $\mathrm{ZrO}_{2}$ films were successfully deposited, while Initial attempts to form $\mathrm{SrCeO}_{3}$ resulted in $\mathrm{CeO}_{2}$ films with another unidentlfied phase. Further studies are being conducted on the relative gelling rates of corium and strontlum alkoxide solutions.

\section{Effect of Heating Rate on Sinterlng and Coarsening M.-Y, CHU, M.N. Rahaman ANo L,C, DE JONGHE}

The sintering of zinc oxide powder compacts has been investigated at constant rates of heating of $0.5-15^{\circ} \mathrm{C} / \mathrm{min}$. For samples with the same initial relative density $(0.50)$, the temperature derivative of the densification strain versus density fits within a single, relatively narrow band. At low temperatures the densification rate as a function of temperature increases almost linearly with the heating rate. The data, covering a wide density range of $0.5-0.98$, are consistent $w$ ith an analysis that accounts for the coarsening, (defined as an increase in the mean pore scparation) in terms of two classes of microstructural coarsening processes: those assoclated with densifying and with non-densifying mechanisms.

\section{Pre-Coarsening to Improve Mlcrostructure and Sintering of Powder Compacts M.-Y. CHU, L.C. DE JONGHE AND M.K.F. LIN}

$\mathrm{MgO}$ and $\mathrm{Al}_{2} \mathrm{O}_{3}$ were sintered by two types of processes: a conventional isothermal sintering, and a two-step sintering consisting of an initial low temperature pre. coarsening treatment before conventional ssothermal sintering. The final microstructure from two-step sintering is more uniform and finer than that of compacts sintered conventionally.

The differences between two-step and conventional processing are clarified by experiments in pre-coarsened and as-recelved $\mathrm{ZnO}$ powders. These compacts were pre-coarsened at $450^{\circ} \mathrm{C}$ for 90 hours with virtually no increase in the overall density. The resulting grain slze was 1.7 times the starting one, but the standard deviation of the pre-coarsened powder size distribution was narrower than that of the as-received powder. The sintering stress of the pre-coarsened $\mathrm{ZnO}$ is approximately 0.8 that of the as-recelved one. A computational model has been used with two components of coarsening to describe the differences in pore spacing evolution between the precoarsened and the as-recelved system.

The benefit of two-step sintering is attributed to the increase in uniformity resulting from pre-coarsening. The increased uniformity decreases sintering damage and allows the system to stay in the open porosity state longer, delaying or inhibiting additional coarsening (grain growth) during the final stage of densification. Twostep sintering is especially useful for non-uniform powder systems with a wide size distribution and is a simple and convenient method of making more uniform ceramic bodies without resorting to specialized powders or complicated heat schedules. 


\section{SYNTHESIS OF COMPOSITE CERAMICS}

James W. Evang and Lutgaad C. Dejonghe,

Coramic-ceramic composites are ideally suited to high-performance acrospace and gas turbine applications where high-temperature stability, high strength-toweight ratios, and non-catastrophic failure modes are required. Considerable progress has beerl made in chemical vapor infiltration (CVI) of fiber- and whisker-reinforced coramic composites. Silicon carbide/silicon carbilte composites exhibit good fracture toughnoss and high strain-to-fallure. They are damage tolerant, l,e., the energy required for crack propagation increases with the size of the damaged region. They retain a large fraction o! their room temperature strength at high temperatures and are resistant to thermal shock. A slgnificant processing advantage of CVI composiles is the ability to form them in near-net shapes.

The primary obstacle to large-scale commerclal manufacture of these materials by CVI is the long infiltration time requitred to achieve low residual porosity. Infiltration must be carried out at low temperatures and low reactant pressures (where the deposition is controlled $\mathrm{z} ;$ the surface reaction rather than gas diffusion) in order to avold preferential deposition near the exterior of the preform and blocking of the pore entrances.

Improved penetration of the gases to the interior of the preform may be achleved by establishing a temperature gradient within the preform such that the inside is hot relative to the outside. Preliminary mathematical modeling work at LBL has shown that much higher rates of infiltration can occur under these conditions. Microwave heating of the substrate, combined with poor insulation to facilitate heat loss from the surface, produces such a thermal gradient.

\section{A Mathematical Model for Chemlcal Vapor Infiltration with Mlcrowave Heating and External Coolling D. GUPTA AND J. W. EVANS}

A mathematical model has been used to compute temperature profiles in ceramic preforms that are heated by microwaves. The temperature profiles are then Input to a second part of the model describing chemical vapor infiltration of the preform, that is the diffusion of gaseous reactants, heterogeneous reaction and evolution of the pore structure. Equations were solved numerically for parameters corresponding to the

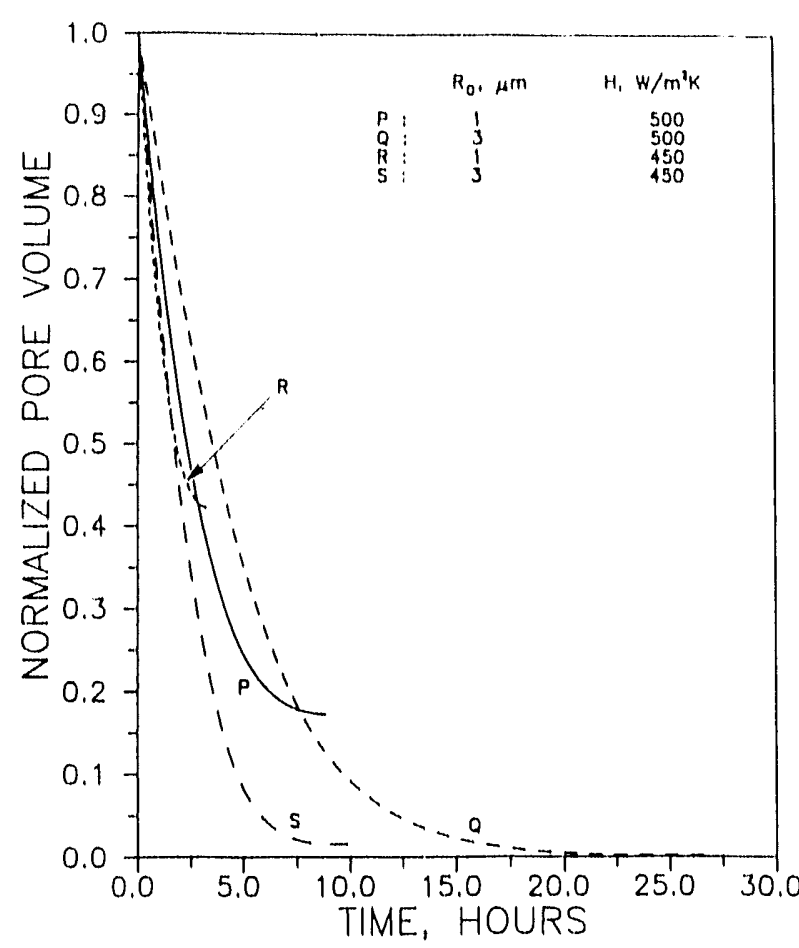
infiltration of SiC preforms by pyrolysis of trichloromethylsilane. While based on some simplifications, the model leads to the conclusion that infiltration procends more rapidly, and to a greater extent, with microwave heating/ external cooling than in isothermal infiltration. The model suggests that infiltration might be optimized by manipulation of microwave power and external cooling. The computed extent of infiltration is seen to be very sensitt ve to the initial pore size. For example, Fig. 1 shows the pore volume (as a fraction of the initial volume) for a pore in a $1-\mathrm{cm}$-thick perform that is being infiltrated in this way. The curves end at the point when the pore mouth closes, and therefore further infiltration is prevented. Parameters in the figure are the initial pore diameter and the heat transfer coefficients at the exterior of the preform. $3 \mu \mathrm{m}$ pores are readily infiltrated to nearly theoretical density while smaller pores are only partially filled.

\section{Flgure 1}

Filling of two different sizes of pores by chemical vapor infiltration under microwave heating and external cooling. Computed results for $2.4 \mathrm{GHz}$ incident microwaves at a power density of $2 \mathrm{MW} / \mathrm{m}^{2}$. Preform $1 \mathrm{~s} 1 \mathrm{~cm}$ thiok and has properties of silicon carbide; infiltration is by decomposition of trichloromethyl sllane. $H$ is the heat transfer coeffiolent external to the prolorm. (XBL 9012-4030) 
This project has two major foci-fatigue of ceramics and the mechanical properties of ceramic/metal interfaces.

\section{Mechanical Properties of Ceramic/Metal Interfaces \\ Cyclic Fatigue-Crack Propagation}

R.M. Cannon, B.J. Dalgleish, R.H. Dauskardt, T.S. OH*, R.O. Ritchie

The integrity of ceramic/metal joints has been investigated under mechanically applied cyclic stresses using double-cantilever-beam and compact-tension sand wich test specimens. Specifically, fatigte-crack propagation rates for interfacial cracks were characterized over a range of velocities from $10^{-9}$ to $10^{-4} \mathrm{~m} / \mathrm{sec}$ for glass/copper and alumina/aluminum-alloy interfaces tested in moist air. Compared to corresponding (stress-corrosion) results under sustained loading, it was found that true interfacial cracks in glass/copper joints were significantly accelerated under cyclic loads. In addition, crack extension force $(G)$ thresholds for interfacial crack growth under cyclic loads were some $46 \%$ lower than under sustained loads, and were typically over 6 times lower than the interfacial toughness $\left(G_{c}\right)$. For the alumina/ aluminum-alloy system, conversely, fracture never occurred in the interface; under monotonic loading cracking progressed near the interface in the ceramic layer whereas under cyclic loading failure occurred either in the ceramic or in the metal (Figure 4). Based on a comparison with fatigue-crack growth data in bulk alumina and bulk aluminum alloys, it was found that near interfacial crack-growth rates in the metal were much lower than those of the bulk ceramic and showed a far higher dependency upon the range of $G$ than behavior in the bulk metal.

\section{Cyclic Fatigue in Ceramics}

Transformation toughening of inherently brittle ceramic materials has been widely studied and a well developed mechanics analysis exists from which the impressive achievements in toughening may be estimated. Compelling arguments for the morphology of the transformation zone based on various martensitic nucleation criterion and stress couplings, the effect of the transformable precipitate shape and orientation on toughening, and resistance-curve behavior between the initial and fully dev sloped zone configurations have been formulated. The objective of this project has been to characterize more completely the extent of transformation ahead of a growing crack, and to consider how this phenomenon influences the growth of cracks under cyclic (fatigue) loading. Initial emphasis has been centered on the fatigue behavior of $\mathrm{MgO}$-partially stabilized zirconia, specifically under variable-amplitude loading and in the presence of small cracks.
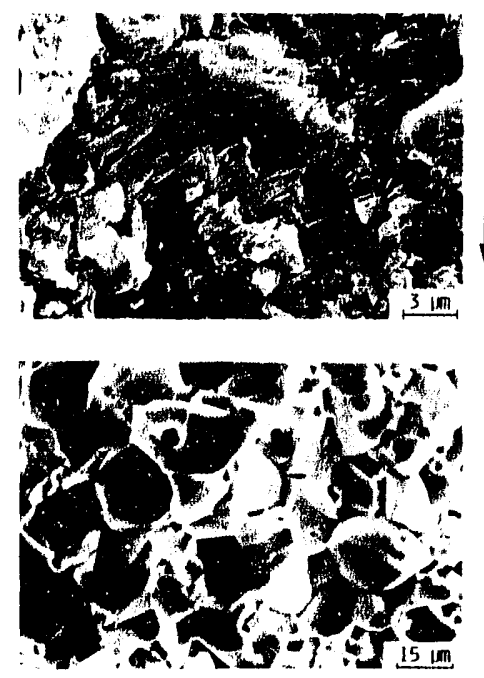

Ceramic Science Program
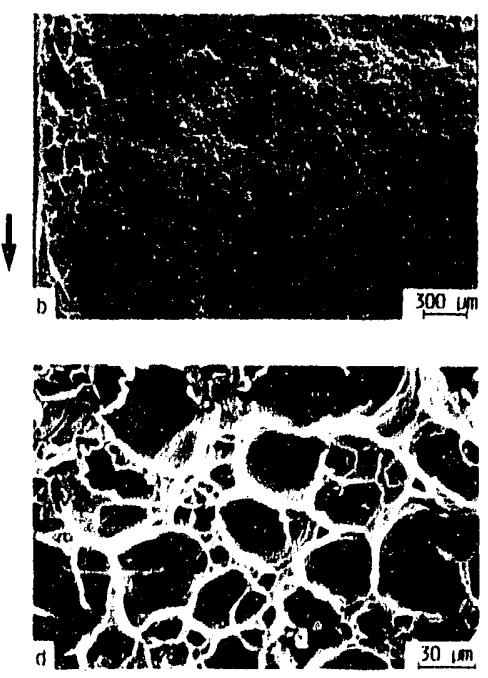

Figure 4

Scanning electron micrographs of the fracture surfaces for interfacial cracking along alumina/aluminum-alloy interfaces, illustrating a) cyclic fatigue failure in the aluminum metal (by ductile fatigue striations), b) low magnification view of the monotonic fracture surface showing intergranular cracking in the ceramic and regions of ductile fracture in the metal, c) monotonic failure in the $\mathrm{Al}_{2} \mathrm{O}_{3}$ (by brittle intergranular fracture), and d) monotonic failure in the metal (by microvoid coalescence). Bold arrow indicates direction of crack growth. (XBB 900-9362)

IPAA, Yorktown Hoighto, NVY. 
Transformation zones surrounding cracks in several toughened magnesia-partially-stabilized zirconia ceramics were characterized by optical interference measurements of surface uplift and by Raman microprobe spectroscopy. The measurements demonstrated that the volume fra. inn of transformation is nonuniform within the zone and that the extent of the frontal zone is approximately the same as that of the wake. Results were used to evaluate the crack-tip shielding stress-intensity factor and to compare with measured fracture-toughness values. The primary conclusions from this study were that frontal zone shapes were approximately circular, in contrast to that of a hydrostatic stress contour which has been previously assumed, that the volume fraction of transformed (monoclinic) material is not uniform within the zone, and that transformation-zone sizes for cyclically-loaded cracks were determined by the maximum stress intensity and not influenced by the cyclic nature of the load. In addition, computations of the reduction in crack-tip stress intensities due to transformation shielding were significantly smaller than measured toughness increases; since these calculations were based on only the dilation component of the transformation, this result implies that other toughening mechanisms may be operating or that the transformation shear strain component is not relieved by twinning.

\section{Transient Subcritical Crack-Growth in Transformation-Toughened Ceramics} R.H. Dauskafdt, W.C. Carter ${ }^{\ddagger}$, D.K. Veirs, R.O. Ritchie

Transient subcritical crack-growth behavior following abrupt changes in the applied load have been studied in transformation-toughened ceramics. A major part of this study - to develop a mechanics analysis - was developed to model the transient nature of transformation shielding of the crack tip, Ks, with subcritical crack extension following the applied load change. Conditions for continued crack growth, crack grow'th followed by arrest, and no crack growth after the load change, were considered and related to the magnitude and sign of the applied load change and to materials properties such as the critical transformation stress. The analysis was found to provide similar trends in $\mathrm{K}_{\mathrm{s}}$ compared to values calculated from experimentally measured transformation zones in a transformation-toughened Mg-PSZ (Figure 5). In addition, accurate prediction of the post load-change transient crack-growth behavior was obtained using experimentally derived steady-state subcritical crackgrowth relationships for cyclic fatigue in the same material.

Figure 5

Transformation-zone morphology, indicated by the volume fraction of transformed monoclinic phase, $F_{\text {mono }}$ surrounding a crack in the TSgrade Mg-PSZ. The extent of transformation is clearly observed to respond to the applied loading conditions. (XBL 904-1303)

\footnotetext{
- Rockwell International Science Center, Thousand Oaks, CA

' Case Western Reserve University, Cleveland, OH

${ }^{\ddagger}$ National Institute of Standards \& Technology, Gaithersburg, MD
}

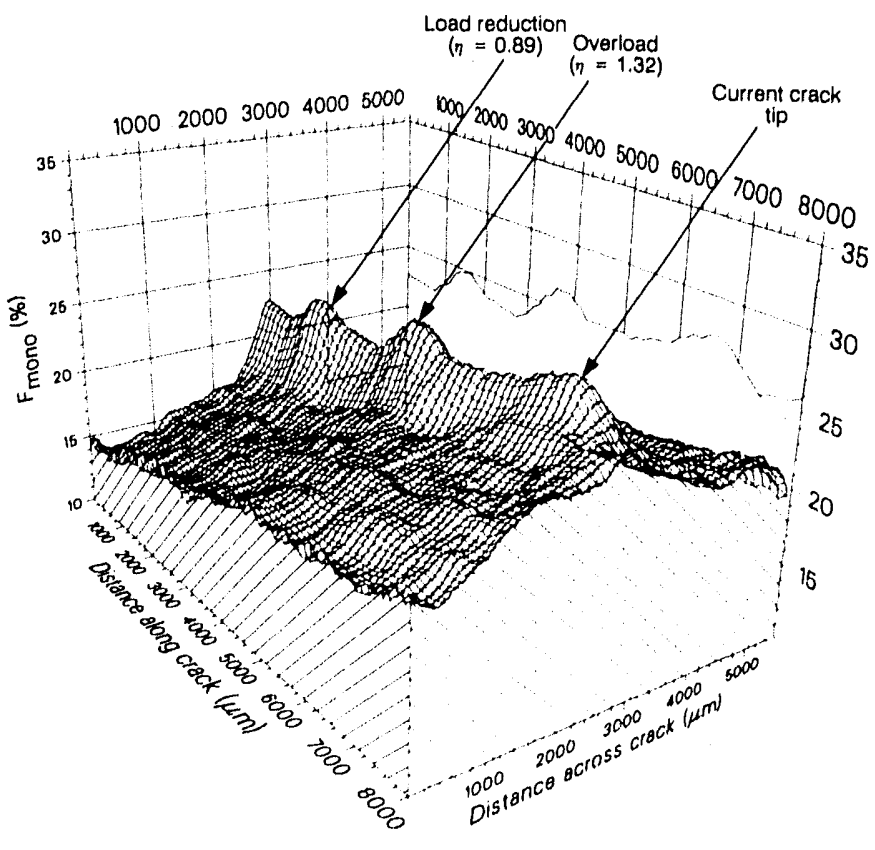




\title{
Cyclic Fatigue Life and Crack-Growth Behavior of Microstructurally-Small Cracks
}

A.A. StefFen, R.H. Dauskardt, R.O. RITCHIE

Cyclic fatigue stress/life (S/N) and crack-growth properties have been investigated in Mg-PSZ in a range of toughened conditions. S/N data from unnotched samples were found to show markedly longer lives under tension-compression compared to tension-tension loading. More importantly, naturally-occurring "small" (1 to $100 \mu \mathrm{m})$ surface cracks were observed to propagate at stress-intensity ranges $(\Delta \mathrm{K})$ some 2 to 3 times smaller than the fatigue threshold $\Delta K T H$ measured for long $(>3 \mathrm{~mm}$ ) cracks. This behavior was rationalized in terms of the restricted role of crack-tip shielding by transformation toughening with cracks of limited wake, analogous to the reduced role of crack closure with small fatigue cracks in metals. The implications of such data for structural design with ceramics was additionally considered.

Program Leader

Lutgard C. De Jonghe

Project Leaders

Andreas M. Glaeser-Model Studies

Lutgard C. De jonghe-Processing

Robert O. Ritchie-Mechanical Performance

Rowland M. Cannon-Interfaces

Investigators and Scientific Staff

Steven J. Visco

Brian J. Dalgleish

R.J. Fisher

Thomas J. Richardson

James Evans

Research Engineer

Reinhold H. Dauskardt

\author{
Graduate Students \\ Harold D. Ackler \\ Yves P. Boiteux \\ Gillian L. Brown \\ Vivek Dutta \\ Deepak Gupta \\ Wan-Shick Hong \\ Seongil Im \\ Craig Jacobson \\ Tim Kueper \\ Frank Lin \\ Tyrone Mitchell \\ Naomi Naito \\ Mark L. Shalz \\ Margaret I. Steinhauser \\ Shun J. Wu \\ Shari Yokota
}

Undergraduate Students

Frank Pennisi

Yvonne Wang

Administrative Assistants

Laura Baxter

Madeleine Penton

\section{Awards}

- Rowland M. Cannon was co-winner of the Ross Purdy Award for best paper in Acta Metall.

- Lutgard De Jonghe was awarded the Humbolt Senior Scientist A ward.

- A. M. Glaeser has been awarded a Miller Research Professorship.

\section{Industry Interactions Contracts}

- The Garrett Auxiliary Power Division of Allied Signal is supporting work by A. M. Glaeser on ine adaptation of lithographic methods to the development of standards fo : nondestructive evaluation.

- A. M. Clacser has received an Alcoa Foundation Crant in support of his work on the application of lithography to funda mental problems of microstructure development in ceramirs. 


\section{Collaborations}

\section{Publications and Reports}

Refereed Journal Articles

Model Studies

Rodel, J. and A.M. Glaeser, "High Temperature Healing of Lithographically Introduced Cracks in Sapphire," J. Am. Ceram Soc., vol. 73, p. 592, 1990.

Other Publications

Rodel, J. and A.M. Glaeser, "Morphological Evolution of Pore Channels in Alumina," in Sintering of Advanced Ceramics, ed. C.A. Handwerker, J.E. Blendell, W.A. Kaysser, p. 243, American Ceramic Society, 1990.

Rodel, J. and A.M. Glaeser, "Pore Drag in Alumina," in Sintering of Advanced Ceramics, ed. C.A. Handwerker, J.E. Blendell, and W.A. Kaysser, p. 280, American Ceramic Society, 1990.

Refereed lourmal Articles

\section{Processing}

Chu, M.-Y., B. Bushan, and L. De Jonghe, "Wear Behavior of Ceramic Sliders in Sliding Contact with Rigid Magnetic Thin Film disks," Trib. and Mech. Magn. Storage Syst., vol. 7, p. 9, 1990.

Garg A. and L. De Jonghe, "Microencapsulation of Silicon Nitride Particles with Yttrla and Yttria-Alumina Precursor," J. Mater. Res., vol. 5, p. 136, 1990.

Naito, N., M.N. Rahaman, and L. De Jonghe, "Pore Size Distribution During Compaction and Early Sintering of Sillcon Nitride," J. Mater. Sci., vol. 25, p. 1686, 1990.

Rahaman, M.N. and L.C. De Jonghe, "Sintering of Spherical Glass Powder under a Uniaxial Stress," J. Am. Ceram. Soc., vol. 73, p. 707, 1990.

Rahaman, M.N., L. De Jonghe, J.A. Voigt, and B.A. Tuttle, "Low-Temperature Sintering of Zinc Oxide Varistors," I. Mater. Sci., vol. 25, p. 737, 1990

Richardson, T.J. and L.C. De Jonghe, "Acoustic Emission Study of Microcracking in 123-Type Ceramic Superconductors," J. Mater. Res., vol. 5, p. 2066, 1990.

Theses

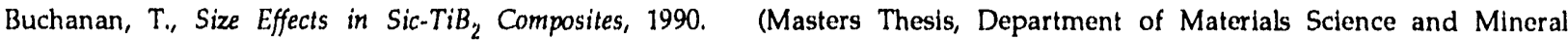
Enginecring, University of California, Berkeley. Advisor: L. De Jonghe.)

Chu, M.-Y, Sintering Stress and Microstructure in Ceramic Powder Compacts, 1990. (Ph.D. Thesis, Department of Materials Science and Mineral Engineering, U.C. Berkeley. Advisor: L. De Jonghe.)

Ghirlanda, M., Sintering of ZnO for Varistor Applications. (M.S. Thesis, 1990, Department of Materials Science and Mineral Engineering, University of California, Berkeley. Advisor. L. De Jonghe

Kanou, O., Powder Processing of Aluminides. (M.S. Thesis, 1990, Department of Materials Science and Mineral Engineering University of California, Berkeley. Advisor: L. De Jonghe.)

Shue, C.H., Crack Crowth Behavior of Encapsulated SiC-PMMA Composites. (M.S. Thesis, 1990, Department of Materials Science and Mineral Engineering, University of California, Berkeley. Advisor: L. De Jonghe.)

I.RI. Reports

Chu, M.Y., L.C. De Jonghe, and M.K.F. Lin, LBL 29144, Pre-Coarsening to Improve Microstructure and Sintering of Powder Compacts.

Rahaman, M.N. and L. De Jonghe, LBL 29085, Sintering of Ceramic Particulate Composites: Effect of Matrix Density.

Rahaman, M.N., L. De Jonghe, and M.-Y. Chu, LBL 29085, Effect of Creen Density on Densification and Creep During Sintering. 
Invited Talks

Brown, G. and L. De Jonghe, Including Size Effects in Coated Powder Composites, Am. Coram. Soc, Seattle, WA, November 1990.

De Jonghe, L., Ceramic Processing Problems, Max-Planck-Instttut Meeting, Tegernsec, Germany, July 1990.

De Junghe, L., Network Formation and Densification, Max-Planck-Institut Meeting, Bad Honnef, Germany, November 1990.

De Jonghe, Lu, The Role of Shape Changes In Ceramic Processing, Max-Planck-Institut Meeting, Tegernsce, Germany, November 1990.

De Jonghe, L., The Science of Ceramic Processing, Rijksuniversiteit Leuven, Leuven, Belgium, October 1990.

Mitchell, T., D. Kapolnek, and L. De Jonghe, Alumira-SiC Whisker Composites from Coated Powders, Am. Ceram. Soc., Dallas, TX, April 1990.

Contributed Talks

Buchanan, T. and L. De Jonghe, $\mathrm{TiB}_{2}$ on Sic TiB ${ }_{2}$ Composites, American Ceramic Society Meeting, Seattle, WA, November 1990.

Chu, N.-Y., L. De Jonghe, and M.K. Lin, Coarsening and Microstructure During Sintering, Am. Ceram. Soc., Dallas, TX, April 1990.

Ghirlanda, M. and L. De Jonghe, Sintering of ZnO Varistor Precursor Powders, American Ceramlc Socdety Meeting, November 1990.

Lin, F.J.T. and L. De Jonghe, Effect of Particle Size on the Creep-Sintering of Narrow Size Alumina, American Ceramic Soclety MeetIng, Scattle, WA, November 1990.

Mitchell, T., D. Kapolnek, and L. De Jonghe, Alumina-SiC Whisker Composites from Coated Powders, American Ceramic Society Meeting, Dallas, TX, April 1990.

Rahaman, M.N. and L. De Jonghe, Factors Controlling the Sintering of Ceramic Particulate Composites, Am. Ceram. Soc., Dallas, TX, April 1990.

Rahaman, M.N. and L. De Jonghe, Reaction Sintering of Zinc Ferrite, Am. Ceram. Soc, Dallas, TX, April 1990.

Shue, C.H., R. Dauskardt, and L. De Jonghe, Fracture and Sub-Critical Growth Behavior of Precipitation Encapsulated SiC/PMMA Composites, Am. Ceram. Soc., Dallas, TX, April 1990.

\section{Mechanical Performance}

Refereed Journal Articles

Dauskardt, R.H., W.C. Carter, D.K. Veirs, and R.O. Ritchie, "Transient Subcritical Crack-Growth Behavior in TransformationToughened Ceramics," Acta. Metall. Mater., vol. 38, p. 2327, 1990.

Dauskardt, R.H., D.B. Marshall, and R.O. Ritchie, "Cyclic Fatigue-Crack Propagation in Mg-PSZ Ceramics," J. Am. Ceram. Soc., vol. 73, p. 893, 1990.

Marshall, D.B., M.C. Shaw, R.H. Dauskardt, R.O. Ritchie, M. Readey, and A.H. Heuer, "Crack-Tip Transformation Zones in Toughened Zirconia," I. Am. Ceram. Soc., vol. 73, p. 2659, 1990.

Conference Proceedings

Steffen, A.A., R.H. Dauskardt, and R.O. Ritchie, "Cyclic Fatigue-Crack Propagation in Ceramics: Long and Small Crack Behavior," in Fatigue 90, ed. H. Kitagawa, and T. Tanaka, vol. 2, p. 745, 1990.

L.BL. Reports

Cannon, R.M., B.J. Dalgleish, R.H. Dauskardt, R.J. Fisher, and R.O. Ritchle, "Ceramic/Metal Interfaces: Monotonic and Cyclic Fatigue Resistance," Fatigue of Advanced Materials, Conference Proc.. (In press.)

Cannon, R.M., B.) Dalgleish, R.H. Dauskardt, T.S. Oh, and R.O. Ritchie, LBL 29626, "Cyclic Fatigue-Crack Propagation along Ceramic/Metal Interfaces," Acta. Metall. Mater. (In press.)

Ritchie, R.O. and R.H. Dauskardt, "Cyclic Fatigue of Ceramics: A Fracture Mechanics Approach to Subcritical Crack Growth and Life Prediction," J. Ceram. Soc. Japan. (In press.)

Steffen, A.A., R.H. Dauskardt, and R.O. Ritchie, LBL 29515, "Cyclic Fatigue Life and Crack-Growth Behavior in Mg-IPSZ, Ceramics: Role of Microstructurally-Small Cracks," J. Am. Ceram. Soc. (Accepted for publication.)

Steffen, A.A., R.O. Ritchie, and R.H. Dauskardt, "Small-Crack Behavior and Safety-Critical Design Criteria for Cyclic Fatigue in Mg-PSZ," Cyclic Deformation, Fracture and Non-Destructive Evaluation of Advanced Materials, ASTM Special Tech. Pub. (Submitted.) 
Basic Science

Thin-Films and Thin-Film Devices

Ceramic Processing

Electron Microscopy

\section{High-T Superconductivity Program}

The CAM High-Temperature Superconductivity Program is directed to advancing the fundamental understanding of the high-criticaltemperature (high- $\mathrm{T}_{\mathrm{c}}$ ) superconductors, by both experimental and theoretical investigations, and directed to building the base of knowledge necessary for the utilization of these unique materials in applications, in electronics and electrical power systems.

The current research areas are:

- BASIC SCIENCE, which includes theory, measurement of physical properties, and materials synthesis.

- THIN FILMS AND THIN-FILM DEVICES

- CERAMIC PROCESSING

- ELECTRON MICROSCOPY

Highlights of the Program during the past year include:

- Normal state electronic properties of $\mathrm{Bi}_{2} \mathrm{Sr}_{2} \mathrm{CaCu}_{2} \mathrm{O}_{8-\mathrm{x}}$ have been determined as functions of $\mathrm{x}$ and temperature; an understanding of these key transport properties may offer important clues to the nature of high temperature superconductivity.

- The jump at $T_{c}$ in the specific heat for $\mathrm{YBa}_{2} \mathrm{Cu}_{3} \mathrm{O}_{7}$ and $\mathrm{La}_{2 \cdot \mathrm{x}} \mathrm{Sr}_{\mathrm{x}} \mathrm{CuO}_{4}$ is found to be significantly larger than the value given by the $\mathrm{BCS}$ theory in the weak coupling limit.

- The new superconducting compound $\mathrm{IBi}_{2} \mathrm{Sr}_{2} \mathrm{CaCu}_{2} \mathrm{O}_{y}$ has been synthesized by intercalating iodine into the $\mathrm{Bi}-2212$ compound; $\mathrm{T}_{\mathrm{c}}=80 \mathrm{~K}$.

- The new superconducting compound $\mathrm{Li}_{x} \mathrm{NbO}_{2}$ has been synthesized. This new material has a layered hexagonal structure and $T_{c}=5.5 \mathrm{~K}$ for $\mathrm{x}=0.45$. 
- The local magnetization of several high- $\mathrm{T}_{\mathrm{c}}$ superconductors has been found to exhibit random telegraph signals (hopping among several discrete values), which is attributed to the thermally activated hopping of individual flux lines.

- A high- $T_{c}$ bolometer has been developed which is already superior to commercial pyroelectric detectors for infrared spectroscopy.

- Bi-Pb-Sr-Ca-Cu-O films doped with Sb have been fabricated by pulsed laser deposition. Even without annealing, these films have $T_{c}=70 \mathrm{~K}$.

- A technique for traveling solvent zone texturing of high-T thick films is under development. It produces films with excellent connectivity and unusual microstructure.

Much of the research is conducted by the staff of the Materials Sciences Division of the Laboratory, but the effort involves very significant participation by investigators in the Chemical Sciences Division (Phillips, Kresin), Applied Science Division (Berdahl, Rubin, Russo), and the Physics Division (D. Morris). Funding sources are likewise diverse. The dominant source is the Division of Materials Sciences (DMS) in the Office of Basic Energy Sciences, Office of Energy Research, US Department of Energy (DOE). Other supporting agencies, cited explicitly in the text which follows, are the Division of Advanced Utility Concepts in the Office of Energy Management, Conservation and Renewable Energy of DOE; the US Department of Education; the Electric Power Research Institute; the Office of Naval Research; the Defense Advanced Research Projects Agency; the National Science Foundation, and private sources. 
The Basic Science research is organized into three parts; Theory, Measurement of Physical Properties, and Synthesis.

Theory

The theoretical work includes fundamental microscopic calculations and phenomenological calculations of superconducting properties, as well as computations of oxygen ordering in $\mathrm{YBa}_{2} \mathrm{Cu}_{3} \mathrm{O}_{7}$. Collaborations with experimentalists are an important feature of the research.

\section{Limitations on Electronic Mechanisms for High-Temperature Superconducting Oxides* M. Cohen, D. Penn, T. Barbee III}

Many authors believe that an electronic mechanism is required to explain the high transition temperatures in certain oxides. In order to constrain the varlous high- $T_{c}$ theories, the effects of these electronic pairing mechanisms upon both the transition temperature and the isotope effect were considered. The calculations utilize the Eliashberg theory for an isotropic Fermi liquid. For the high transition temperature compounds (e.g., $\mathrm{YBa}_{2} \mathrm{Cu}_{3} \mathrm{O}_{7}$ ), the small isotope effect and high- $\mathrm{T}_{\mathrm{c}}$ can be accounted for only by an unrealistically small value of the electron-phonon coupling parameter. Therefore, an electronic pairing mechanism can be excluded for a wide class of theoretical models.

\section{Multigap Structure in the Cuprates ${ }^{\ddagger}$ V. KRESIN}

Some of the cuprate superconductors, especially $\mathrm{YBa}_{2} \mathrm{Cu}_{3} \mathrm{O}_{7}$, are characterized by the presence of different overlapping energy bands. The possibility to observe more than one superconducting gap is raised by the very small coherence length and the presence of two separate systems of carriers, namely, those on the linear chains, and those on the two-dimensional planes. Experimental evidence for two gaps in $\mathrm{YBa}_{2} \mathrm{Cu}_{3} \mathrm{O}_{7}$ may be found in data from NMR, tunneling and transport properties. The theoretical analysis shows that generally, one gap must be larger and the other smaller than in the single gap picture. Furthermore, the multigap analysis is consistent with the NMR data as well as the anomalous critical temperature and magnetic field behavior of $\operatorname{Pr}_{\mathrm{x}} \mathrm{Y}_{1-\mathrm{x}} \mathrm{Ba}_{2} \mathrm{Cu}_{3} \mathrm{O}_{7}$.

\section{Proximity Effect ${ }^{\ddagger}$ \\ V. KRESIN}

Proximity systems containing high- $\mathrm{T}_{\mathrm{c}}$ films as well as conventional materials are promising from the point of view of various applications. For example, the proximity effect makes it possible to induce the superconducting state into a low-temperature superconducting film. Thus one may effectively raise the $T_{c}$ of the low-temperature superconductor, and have its properties (such as high critical current density) available at higher temperatures. Other interesting applications which have been analyzed are three terminal devices (superconductor/semiconductor/superconductor devices), which should show a stronger field effect when high- $\mathrm{T}_{\mathrm{c}}$ materials are employed, and superconductor/normal metal/superconductor Josephsonjunctions.

\footnotetext{
"Supported in part by the National Sclence Foundation

${ }^{\dagger}$ National Institute of Standards, Gaithersburg

¥Supported by the Offlce of Naval Research
} 


\section{Major Normal and Superconducting Parameters of High-T,Oxldes ${ }^{\S}$}

V. KaESIN AND S, WolF"

A theoretical framework has been developed, based largely on a Fermi-liquid approach, which permits the evaluation of many of the normal and superconducting parameters of the high- $\mathrm{T}_{\mathrm{c}}$ oxides, especially the $\mathrm{La}_{1,8} \mathrm{Sr}_{0.2} \mathrm{CuO}_{4}$ compound. The Fermi surface is taken as cylindrical, and the carrier effective mass is consequently found be simply proportional to the Sommerfeld constant. (This constant is the ratio of specific heat to absolute temperature in the normal state.) Taking as input values the observed specific heat and the Hall coefficient, it is then possible to obtain values for the effective mass (about 5 times the free electron mass) and the Formi energy (about 0.1 $\mathrm{eV})$. The very small value of the Fermi energy, compared with conventional metallic values of $5-10 \mathrm{eV}$, is thought to be a key feature of the high- $\mathrm{T}_{\mathrm{c}}$ oxides. The electronphonon coupling constant is obtained, based on a detalled analysis of heat capacity data, and is found to be approximately 2 . This value is not large enough to explain the high value of $\mathrm{T}_{\mathrm{c}}$; additional electronic coupling, for example, to acoustic plasmons appears to be required.

\section{Superconducting Vortex-Line Configurations in Materials with Twin Boundarles \\ L. FALIOOV AND H. SVENSMARK}

In a type II superconductor it is expected that magnetic flux lines in equilibrium make an Abrikosov lattice, i.e., an ordered array with hexagonal symmetry. Therefore it was somewhat surprising that decoration experiments on the new hightemperature superconductors exhibit hexagonal lattices only in some cases. For example observations by Gammel et al. at Bell Laboratories showed a considerably disordered lattice, though pair-correlation functions showed, on the average hexagonal ordering. It is likely, especially at low temperatures, that the disorder of the flux line lattice is due predominantly to crystalline defects. For this reason we have investigated the effects of one important type of defect, namely twin boundaries. The starting point of the analysis is the Ginzburg-Landau (GL) theory, with an additional attractive interaction between flux lines and twin boundaries. Since the coherence length is quite small, the London theory limit of the GL theory is applicable. For the geometry in which the magnetic ficld is parallel to the c-axis, the free energy just assumes a form in which the vortices have mutual repulsion but are attracted to the twin boundaries. The free energy was minimized numerically for various twin configurations. The results show a large number of metastable configurations, resembling a "flux-line glass" with different and sometimes contrasting behaviors which strongly depend on the densities of flux lines (magnetic ficld strength) and twin boundaries (quality of the crystal). While the specific details of the flux line patterns depend on the form, range, and strength of the twin-boundary flux-line attraction, the parameters employed are physically reasonable, and yield results which agree well with experimental observations.

\section{Oxygen Ordering in $\mathrm{YBa}_{2} \mathrm{Cu}_{3} \mathrm{O}_{2}$ D. de Fontaine, M. Asta, G. Ceder, E. Salomons}

The oxygen-ordering phase diagram for $\mathrm{YBa}_{2} \mathrm{Cu}_{3} \mathrm{O}_{2}$ calculated last year by our group has now been shown to agree remarkably well with experimental evidence. Figure 1a shows this diagram calculated by the Cluster Variation Method by means of three effective interaction parameters, $V_{1}, V_{2}$, and $V_{3}$, determined from total energy $a b$ initio electronic structure calculations by P. Sterne at Livermore. The various oxygen structures encountered in various regions of the phase diagram are incilicated and were obtained by Monte Carlo simulation performed with the same interaction

SSupported by the Office of Naval Research

"Naval Research Laboralory 

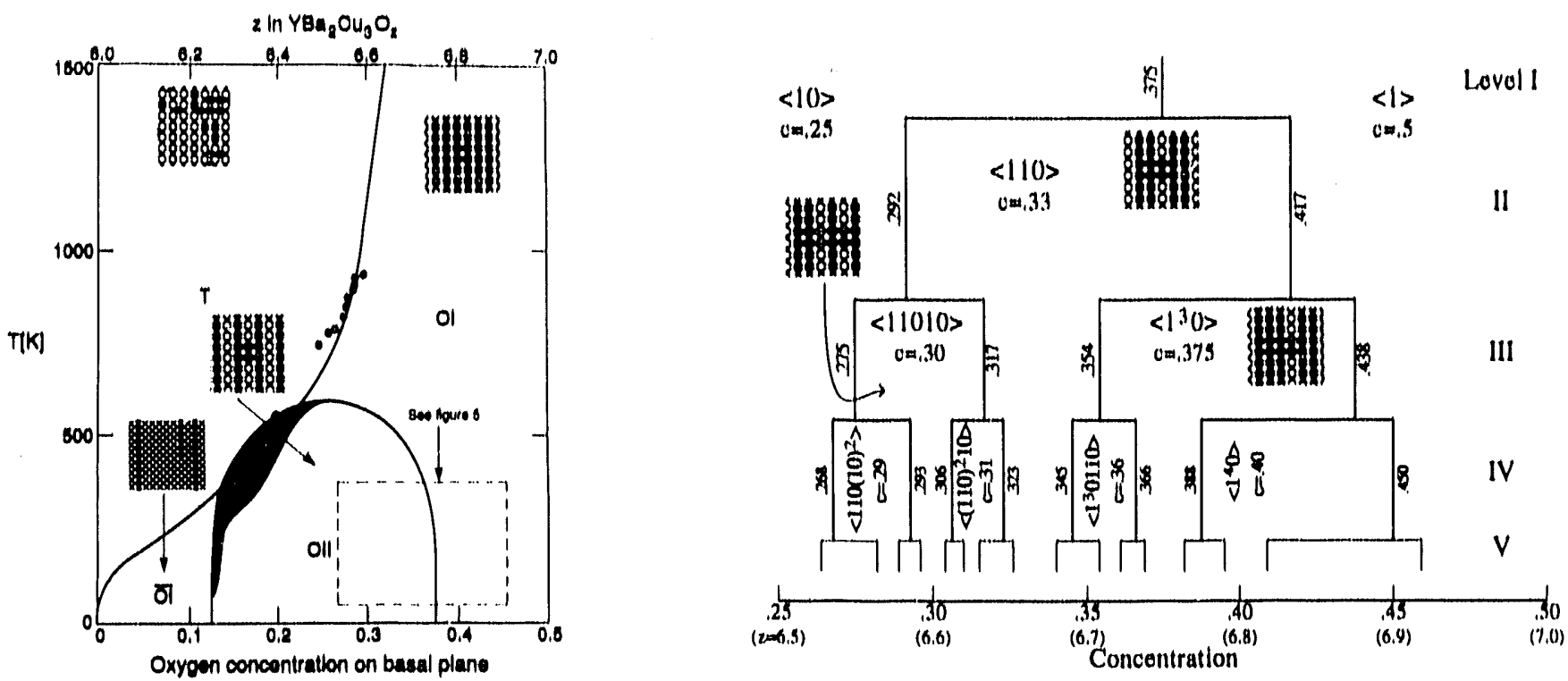

Flgure la (left)

Caluulated phase diagram for $\mathrm{YBa}_{2} \mathrm{Cu}_{3} \mathrm{O}_{3}$ showing the phases and their assoclated patterns of oxygen ordering. Solld dots show

experimental data. 1b, (right) Detall from 1a, showing the varlety of phases with ordered OU-O ohalns, (XBL, 8910-6326A, XBL 905-1728)

parameters $\left(V_{1}, V_{2}, V_{3}\right)$, Large filled circles represent experimental points obtained independently by N.H. Anderson et al, at Ris $\phi$ for the tetragonal (T) to orthorhombic (OI) phase transition, l.e., the $\alpha / \beta$ sublattice ordering. No adjustable parameters whatsoever were used in the phase diagram calculation. Figure $1 \mathrm{~b}$ shows the hierarchy of additional quasi-one-dimensional ordered oxygen superstructures expected to be stable at low temperature when longer-range repulsive interactions are included in addition to the original set of V-parameters. Symbols " 1 ". designate Cu$\mathrm{O}$ chains, "O" designate Cu-vacancy chains. Various structures of this "branching tree" have been observed experimentally.

That oxygen diffusion can occur at room temperatures was shown recently by the Argonne group (Veal, Jorgensen et al.). In these experiments, the measured $T_{c}$ was found to increase markedly in quenched samples of oxygen content $z=6.45$ for samples aged at room temperature over a period of weeks. During this process, it was ascertained that overall oxygen content was not altered. Such behavior can only be interpreted as being due to additional oxygen ordering: $\alpha / \beta$ sublattice ordering is

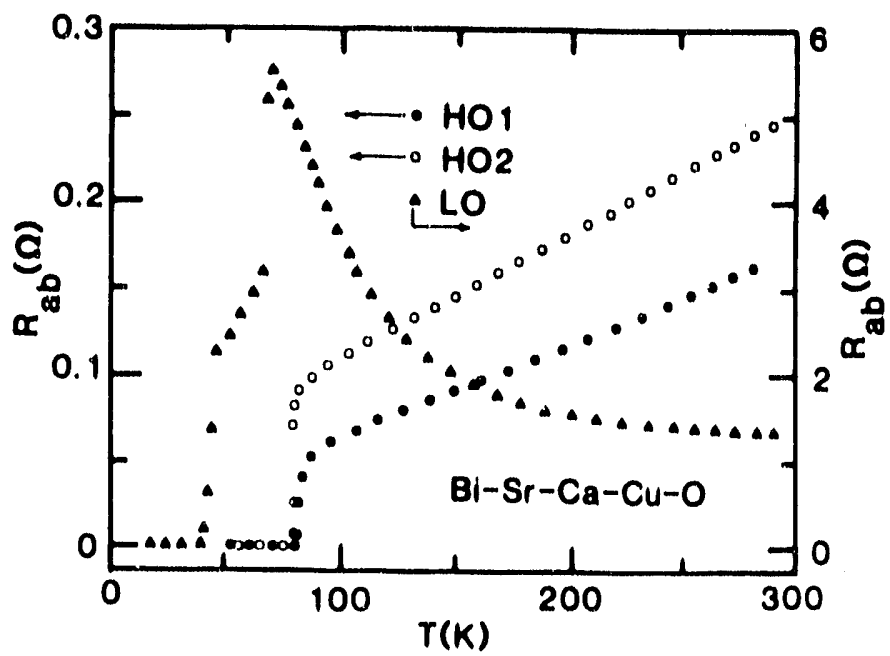

Figure 2

Pesistance in the ab plane of a $\mathrm{Bl}_{2} \mathrm{Sr}_{2} \mathrm{CaCu}_{2} \mathrm{O}_{8 \cdot x}$ orystal with different oxygen conflgurations. HO relers to high oxygen concentration; LO, to low concentration. (XBL 918-1780) 
expected to take place vory rapidly, posslbly during the quonching operation Itsolf, soon followed by the formation of long $\mathrm{O}$-Cu- $\mathrm{O}$ chalns. The additional ordoring that takes place subsequently must bo that of the formation of the quasi-one-dimonsional phases described above. The energettes of the process can be understood quite simply: the $V_{1}$ repulsive intoraction creates $\alpha / \beta$ stublattice ordering, complotely depleting, say, the $b$ sublattlec. The negative (attractlve) $V_{2}$ stablilizes long chains, and the posittive $V_{3}$ promotos Oll ordoring. Additional ropulsivo interactions along the a direction break the degeneracy of $\mathrm{mixed}$ OI-OIl domains, thoroby stabilizing increasingly complex long-period structures at incroasingly lower temporatures.

\section{Measurement of Physical Properties}

Extenslve measurements of transport propertlos of superconductors are per. formod. Transport moasuremonts include resistlvity as a function of crystallographle direction, appliod magnetic field, pressure, frequency, etc., as woll as Hall offect, thermoeinetric power, and thermal conductivity. Electrodynamic propertics of crystalline and granular materlals in bulk and thin film form are examined at $\mathrm{rf}$, microwave, and infrared frequencios. ${ }^{17} \mathrm{O}$ NMR gives information on the chomical neighborhood of oxygen atoms, Mensurements of specific hoat reveal fundamental thermodynamic properties such as the jump in the specific heat at $\mathrm{T}_{\mathrm{c}^{\prime}}$

\section{Varlable Normal-State Electronlc Transport Propertles of $\mathrm{Bl}_{2} \mathrm{Sr}_{2} \mathrm{CaCu}_{2} \mathrm{O}_{8 \cdot x^{*}}{ }^{*}$ \\ A. Zettl, G. Bfioeno, M. Cohien, M. Orommila, ANd A. LIU}

The normal-state resistivity, thermoelectric powor $S$, and Hall coefficlent $R_{1: 1}$ of $\mathrm{Bl}_{2} \mathrm{Sr}_{2} \mathrm{CaCu}_{2} \mathrm{O}_{8-x}$ have been measured, and it is found that these quantitios are all strongly influenced by oxygen concentration. In general the temperature dependences of the coefficients follow simple empirical expressions. For example, Figure 2 shows the ab plane resistance $R$ for an individual single crystal subjected to differing oxygen anneals. The highly oxygenated $(\mathrm{HO})$ cases show a linear $\mathrm{R}$ vs. T plot and sharp transitions into the zero resistance state. In contrast, the low-oxygen (LO) case shows "semiconducting" $R$ vs. ' $T$ behavior and a two-step transition, reaching zero resistance only at $40 \mathrm{~K}$. In each case the normal-state resistance can be fit to the formula $T^{\alpha} \exp \left(\Delta / k_{11} T\right)$, where $\Delta$ depends upon oxygen concentration and $T$ is the temperature. In a similar manner, it is found that both the thermopower and the inverse of the Hall coefficlent $R_{11}{ }^{-1}$ can be fitted as simple linear functions of temperature (c.g, as $A+B T)$. Figure 3 shows a plot of $R_{1:}{ }^{-1}$.

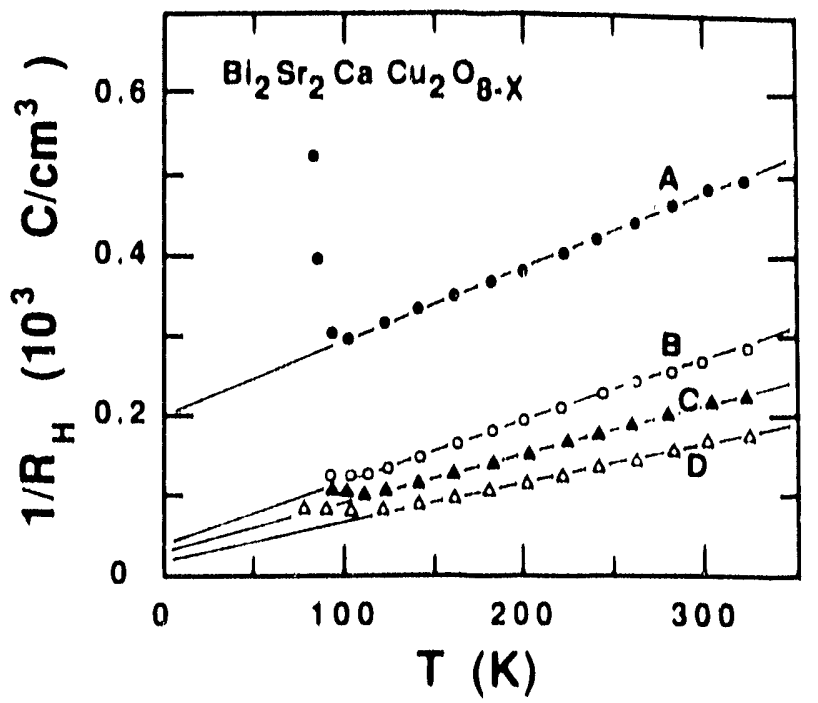

Figure 3

Inverse Hall coefflolent for the ab plane (magnetlo field perpendloular to thls plane). Sarriple $A$ has the hlghest oxygen conoentration; sample $D$, the lowest. The stralght lines are llnear flts to the data. (XBL 018-1781) 
Whild it has been possible to obtain ploasingly simplo fits for the olectronle transport propertios, a fundamontal physteal undorstanding of this transport has not yot been found. In particular, the linear dopendonce of $R_{11}{ }^{1}$ on tomporaturo ts diffledit to reconcilo with simplo motallic (band) behavior. Whillo the transpert propertles in the normal state of $\mathrm{Bl}_{2} \mathrm{Sr}_{2} \mathrm{CaCu}_{2} \mathrm{O}_{\mathrm{B} \cdot x}$ aro unusual, they are quite similar to those of the other high- $\mathrm{T}_{\mathrm{o}}$ superconductors. Consequently, the future undorstanding of these normal-stato propertios is likely to be an essontial step toward understanding hightomporaturo suporconductivity.

\section{Thermal Conduotivilty of Single Crystal $\mathrm{Bl}_{2} \mathrm{Sr}_{2} \mathrm{CaCu}_{2} \mathrm{O}_{3 \cdot x}$} A. ZETTL ANO M. OHOMMIE

The thermal conductivity of single crystal $\mathrm{Bl}_{2} \mathrm{Sr}_{2} \mathrm{CaCu}_{2} \mathrm{O}_{8 \cdot x}$ has been mensured, both in the ab plane $\left(\mathrm{CuO}_{2}\right.$ plano and in the c-axls directions, for samples of varying oxygen configuration. Complomontary olectrical conductivity moasuromonts on the same crystals allow the thermal conductivity to bo accurately decomposed into clectronic and phononcontributions, For metallic samples the electronlc contribution is substantial. The ab plane data $v$ s, tomporature have qualltatively the same shape as prior results by others on polycrystalline samples: below $\mathrm{T}_{\mathrm{b}}$ the thermal conductivity increases and reaches a local maximum at about $62 \mathrm{~K}$. Oxygen deficiont samples are not superconducting (except below $30 \mathrm{~K}$ ) and show no local maximum noar' $62 \mathrm{~K}$; furthermore these samples show a smaller overall value of thermal conductivity (about half) compared to the metallic samples, which is evidence suggesting that the electrons in metallic samples carry a significant portion of the heat. Arguments based on the Wiedemann-Franz law also suggest that electrons carry roughly one third of the heat.

Measurements of the c-axis thermal conductivity show no particular features near $T_{c}$ and $I t$ appears that phonons are responsible for most of the heat flow. In the normal state, the electrical conductivity andsotropy (ab value divided by c-axis value) is of order $10^{4}$ and is strongly temperature dependent, while the corresponding ratio of thermal conductivities is only about 6 and independent of temperature. The detalled analysis of the phonon contribution of the thermal resistivity suggests that phonon scattering from both electrons and impurities are important.

\section{Nonlinear Electrodynamics in Granular $\mathrm{YBa}_{2} \mathrm{Cu}_{3} \mathrm{O}_{7}$ : Measurements and $\mathrm{Models}^{\dagger}$ C. JEFFAIES, Y. KIM, AND Q. LAM}

Magnetic susceptibility of granular cylinders of $\mathrm{YBa}_{2} \mathrm{Cu}_{3} \mathrm{O}_{7}$ is measured with a digital impedance analyzer which provides a controlled ac current to a coll surrounding the sample, and which monitors the inductance and resistance of the coll. The sample is also subject to a de field applied along its axis. The susceptibility is computed from the difference in the impedance due to presence or absence of the sample in the coll. Measured values of its real and imaginary parts are shown in Figures $4 a$ and $4 f$. The complicated behavior as a function of the applied de ficld $\mathrm{H}_{\mathrm{dc}}$ can be replicated, as shown in Figures $4 \mathrm{~b}$ and $4 \mathrm{~g}$, by the well-known Bean critical state model, provided that the field-dependence of the critical current density $\mathrm{J}_{\mathrm{c}}(\mathrm{H})$ is taken Into account. We take $J_{c}(\mathrm{H})$ proportional to $1 /\left(\mathrm{H}+\mathrm{H}_{0}\right)$, raised to the power $\beta$, where $\mathrm{H}_{0}$ and $\beta$ are parameters. The best fit shown corresponds to $\beta=2.25$ and $\mathrm{H}=3.0$ Oersted $(\mathrm{Oe})$. The inferred function $J_{\mathrm{C}}(\mathrm{H})$ thus constructed is in good general agreement with transport measurements of $J_{\mathrm{C}^{\prime}}$

The magnetic susceptibility of granular cylinders of $\mathrm{YBa}_{2} \mathrm{Cu}_{3} \mathrm{O}_{7}$ is also measured with a system consisting of excitation colls for applying both ac and de fields, and a scparate recelver coil to monitor magnetic response of the superconductor. This

\footnotetext{
'Supported In part by the Offloe of Naval Research
} 

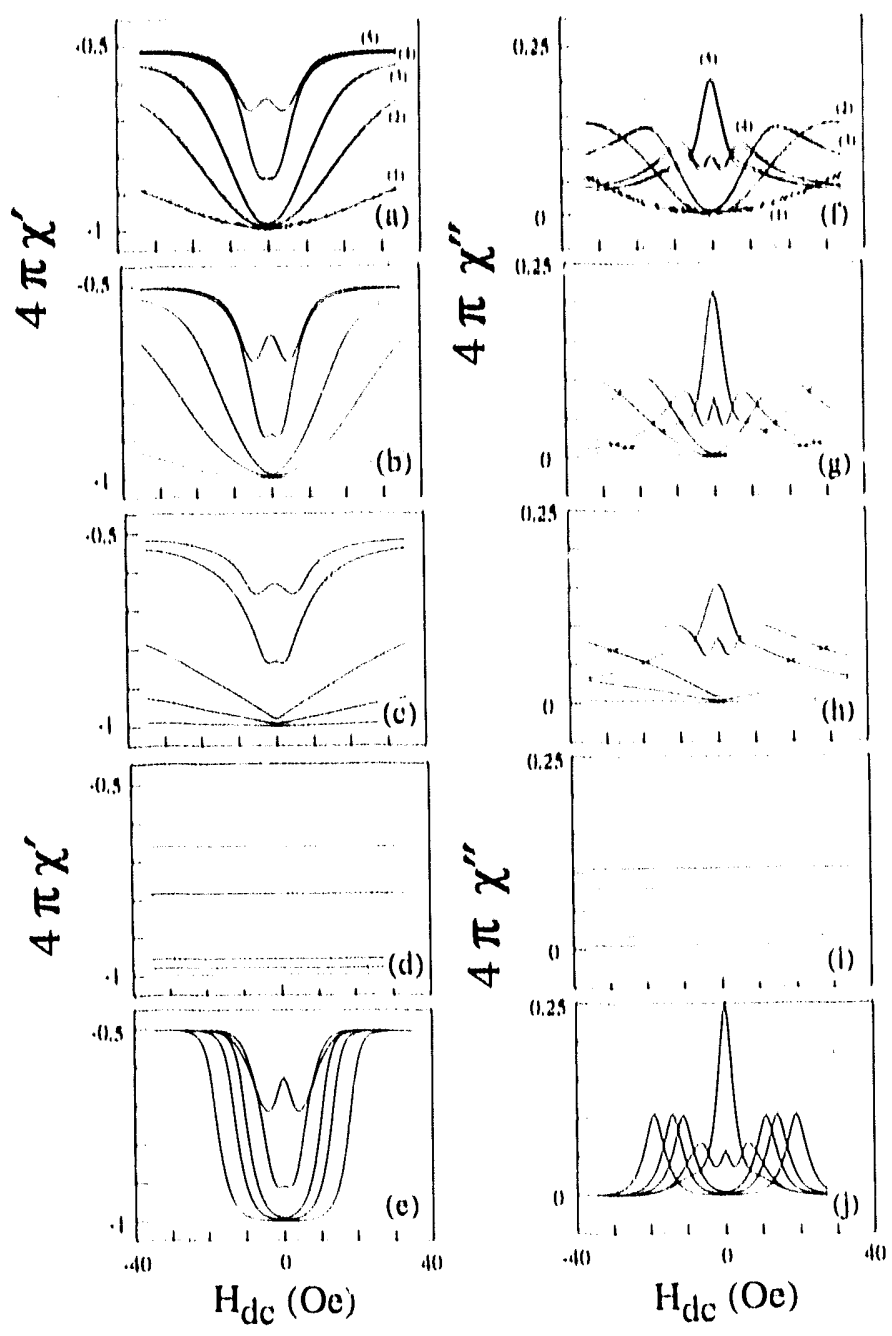

Figure 4

a) Moasurod ao suscoptlbillty for YBOO samplo al $78 \mathrm{~K}$ and $10 \mathrm{kH} / \mathrm{z}$ for values of the ao flold In Oo as llatod: (1) 0.03 , (2) 0.22 , (3) 0.71, (4) 4.0, (5) 7.8 .

b) modifled orliloal state model prdiotlon for the clata of a) using paramoters $B_{m}=2.25$ and $H_{0}=3 O_{0}$

o) same as b) but with $B=1,0$.

d) same as b) but with $B=0$.

o) orittoal state modol prediotlon for exponentlal dependence of $J_{0}(H)$.

f)-1) oorrespond to a)-0), but wlth the Imaginary rathor than real part of the susooptlbillity shown.

(XBL 907-2619)

apparatus permits convenient access to applied ac fields up to a few hundred Oe. Also, the harmonic response is monitored with a spectrum analyzer. Two peaks in the Imaginary part of the susceptibllity as a function of applied magnetic field occur at $15 \mathrm{Oe}$ and $250 \mathrm{Oe}$. The peak at $15 \mathrm{Oc}$ is interpreted as due to magnetic flux motion between the crystalline grains; the peak at 250) Oe is due to flux motion inside the grains. A powdered sample shows no peak at 1500 , as expected. These data, and the harmonic power measurements, are found to be well explained by a modified critical state model, which for flelds $\leq 50 \mathrm{Oe}$, is dominated by intergranular critical currents with the parametric form given above.

\section{Neutron-Induced Mlcrowave Loss In Ceramic $\mathrm{YBa}_{2} \mathrm{Cu}_{3} \mathrm{O}_{7}$

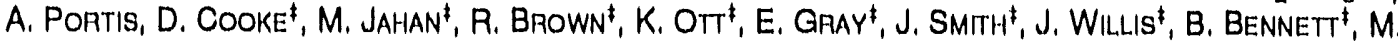

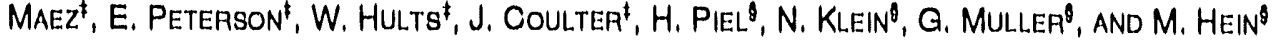

An increase by over three orders of magnitude from $0.6 \mathrm{~m} \Omega$ to $1.2 \Omega$ was observed in the $3 \mathrm{GHz}$ microwave surface resistance of ceramic $\mathrm{YBa}_{2} \mathrm{Cu}_{3} \mathrm{O}_{7}$, following exposure to neutrons. The irradiation was performed in the Los Alamos Omega West Reactor, for 42 minutes in the flux of approximately $10^{13}$ neutrons $\mathrm{cm}^{.2} \mathrm{~s}^{-1}$. The oxygen content of the sample (nominally 7.0 ) was reduced from 6.947 to 6.828 by this process. The transport resistivity of an unirradiated pellet was linear in temperature down to $T_{\text {c }}$ with a room temperature value of $2.1 \mathrm{~m} \Omega \mathrm{cm}$. Following irradiation, the resistivity rose with decreasing temperature from a room temperature value of $1.5 \Omega \mathrm{cm}$, with

\footnotetext{
toos Alamos National Laboratory ${ }^{B}$ Berglsohe Universitat-Wuppertal, Wuppertal, Germany
} 
little change at $\mathrm{T}_{\mathrm{a}^{\prime}}$ These results, in conjunction with eddy current, susceptibillty, lodomotric ttration, and thermally stimulated lumineseence moasurements on Irradiated and unirradiated samples, collectively suggest that the effect of noutron Irradiation has been to decrease intergranular coupling without the development of an insulating phase.

\section{Power- and Magnetlo Fleld-Induced Mlorowave Absorptlon in}

Tl-based High-T Superconducting Fllms

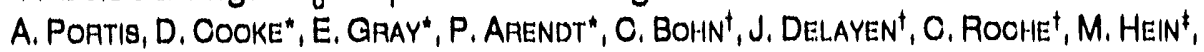
N. KLEIN ${ }^{\ddagger}, G$, MULLER ${ }^{\ddagger}$, S, ORBACH ${ }^{\ddagger}$, AND H, PIEL

The increase in the microwave surface resistance $R_{\mathrm{g}}$ of high- $\mathrm{T}_{\mathrm{C}}$ superconductors at elevated microwave power levels has been measured at $820 \mathrm{MHz}$ and $18 \mathrm{GHz}$ for both oriented and unoriented Tl-based films as a function of both $\mathrm{rf}$ and de magnetle flelds. Measurements are made by determining the $Q$ of a resonant microwave cavity. Simullaneous measurements of the shift in the resonant frequoncy, illustrated in Figure 5, permits determination of the surface reactance as well. The variation $\ln R_{g}$ with $\mathrm{rf}$ magnetic field is more pronounced than its variation with de magnetic ficld, which is taken as evidence that rf fields are more effective in decoupling the grains in the film from one another. The frequency dependence of $R_{S}$ is nearly linear, which is suggestive of ac loss in which magnetic work is performed over each period of the rf field. More extensive studies are required to definitively establish the nature of these rf loss mechanisms.

\section{Infrared Absorptivity Measurement on Thin Film $\mathrm{YBa}_{2} \mathrm{Cu}_{3} \mathrm{O}_{7}$ and $\mathrm{ErBa}_{2} \mathrm{Cu}_{3} \mathrm{O}_{7}$}

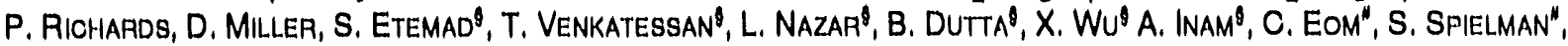
T. Geballe", N. Newman,"* and B. Col.."*

Direct absorptivity measurements have been made at $2 \mathrm{~K}$ from 25 to $700 \mathrm{~cm}^{-1}$ (wavenumbers) on thin films of $\mathrm{YBa}_{2} \mathrm{Cu}_{3} \mathrm{O}_{7}$ and $\mathrm{ErBa}_{2} \mathrm{Cu}_{3} \mathrm{O}_{7}$. It is in this spectral range one might expect to see the signature of a superconducting energy gap. The high quality c-axis oriented films are grown epitaxially on $\mathrm{SrTiO}_{3}, \mathrm{LaAlO}_{3}$, and $\mathrm{MgO}$ substrates by codeposition, off-axis sputtering, and laser deposition. In these measurements, the film acts as the absorbing element in a composite bolometric detector which is used with a Fourier transform infrared spectrometer. Despite the variety of sample deposition techniques and substrates all the films exhibit similar absorptivities. In contrast to the interpretation of some reflectivity measurements, the absorptivity is non-vanishing down to the lowest frequencies used. It is found that the absorptivity is approximately linear with frequency from 30 to $300 \mathrm{~cm}^{-1}$, and its magnitude is less than 0.01 for all frequencles less than $200 \mathrm{~cm}^{-1}$. No spectral feature has been found which can be identified with a superconducting energy gap.

Figure 5

Surface resistance $\mathrm{A}$, and cavity frequenoy measured near $18 \mathrm{GHz}$ for an orlented Tl-based film (sample 103), as a funotion of statlo magnetio field. The observed dependence on do fleld is simllar to that on if miagrietlo fleld, exoept that $P_{a}$ is less sensitive to the do field. The observed decrease in resonant frequenoy is a consequence of an increase in the surface reactance.

(XBL 918-1782)

\footnotetext{
"Los Alamos Natlonal Laboratory

'Berglsoh Universitat Wuppertal, Wuppertal, Germany

'Argonne National Laboratory

${ }^{B}$ Bellcore/Rutgers group

"Department of Applied Physics, Stanford Unlversity

" Conductus, Ino.
}

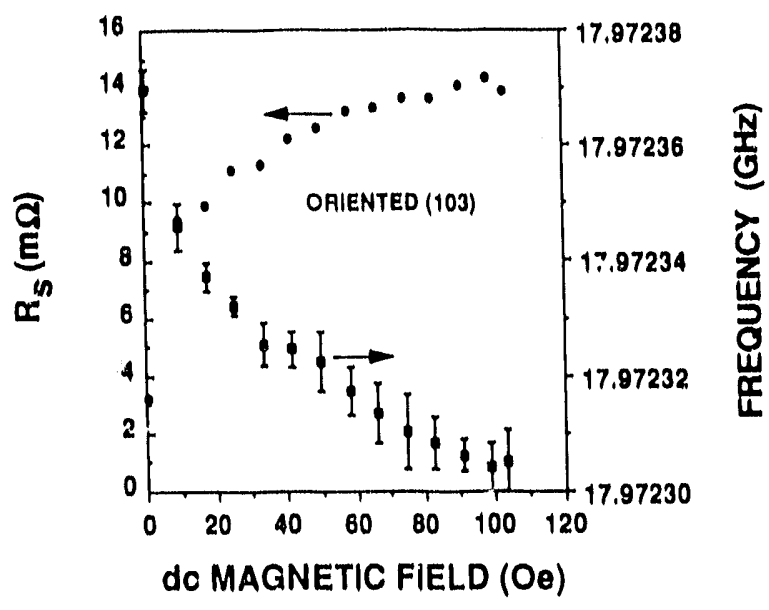

Center for Advanced Materials 


\section{Oxygen $17 \mathrm{NMR}$ of $\mathrm{Ba}_{2} \mathrm{Bi}_{2} \mathrm{O}_{6 \cdot x}$ \\ J. Reimer, S. AdLer, J. Michaels, AND J. Went}

Unlike diffraction techniques which require long-range order to determine solid structure, NMR probes the local environment of NMR-active nuclei, and can therefore provide local information about regions within highly defective or amorphous materials. In this work, ${ }^{17} \mathrm{O}-\mathrm{NMR}$ measurements are being employed to investigate the structure and properties of $\mathrm{Ba}_{2} \mathrm{Bi}_{2} \mathrm{O}_{6-x}$ an oxygen-deficient perovskite which has superconducting properties when doped with potassium or lead. Doping of this material changes it from a monoclinic semiconductor to a cubic metal, and the delocalization of electrons accompanying this phase transition is associated with superconductivity. We believe this phase transition occurs continuously by formation of a mixture of microdomains with spatially varying structure and electrical conductivity. Heating of the material also causes a phase change to cubic symmetry; neutron diffraction has already shown evidence that this phase transition occurs continuously, over a broad range of temperatures. The measurements of NMR lineshape as a function of doping and temperature (up to $1000^{\circ} \mathrm{C}$ ) should reveal which parts of the material are metallic and to what degree, which should in turn shed light on the nature of this phase transition and its effect on material properties.

\section{The Specific Heat of High-T Superconductors N.E. PHILLIPS, R.A. FISHER AND J.E. GORDON*}

For HTSC in general it is clear that fluctuations make significant contributions to the specific-heat anomaly at $\mathrm{T}_{\mathrm{c}}$. While in principle the fluctuation effects complicate the determination of the discontinuity $\Delta C\left(T_{c}\right)$, in practice the ideal value of $\Delta C\left(T_{c}\right)$, for fully superconducting samples, seems to be well established for $\mathrm{YBCO}$, and with a lower level of certainty for $\mathrm{La}_{1.25} \mathrm{Sr}_{0.15} \mathrm{CuO}_{4}$. The sample-to-sample variation $\Delta \mathrm{C}\left(\mathrm{T}_{\mathrm{c}}\right)$ can be understood in terms of in $r \pi$ t lete transitions to the superconducting state, or possibly gapless superconductivity.

There is no compelling evidence for a low-temperature, zero-field linear term that is intrinsic to the superconducting state in any HTSC. The observed linear terms can be attributed to impurity phases and incomplete transitions to the superconducting state or gapless superconductivity.

There is some indication of strong-coupling effects in the general temperature dependence of the superconducting-state specific heat, but these effects are most clearly evident in the specific heat near $T_{c}$ where they suggest extremely strong coupling. However, comparison of band-structure calculations with estimates of the normal-state electronic specific heat give small values of the electron-phonon interaction parameter that are not compatible with strong phonon coupling. Consistently with other considerations, for example the small isotope effects and high $T_{c}$ 's, this suggests the importance of a non-phonon mechanism.

\section{Specific Heat Evidence for Strong Coupling in $\mathrm{YBa}_{2} \mathrm{Cu}_{3} \mathrm{O}_{7}$ J.E. GORDON*, R.A. FISHER, S. KAMIN* AND N.E. PHILLIPS}

The specific-heat anomaly at $T_{C}$ for $Y B C O$ is fitted with expressions derived for a strong-coupling mode to obtain both normal and superconducting-state parameters. These results suggest the importance of strong-coupling effects. However, a comparison of the normal-state parameters with band-structure calculations suggest weak coupling. The discrepancy may be associated with a non-phonon contributions to this mechanism.

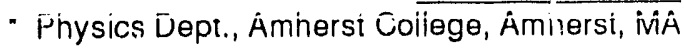




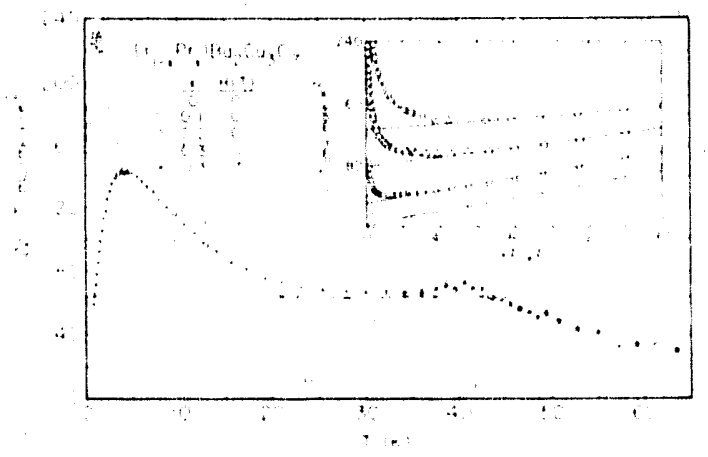

Figure 6

$\Delta C / T$ vs. $T$, where $\Delta C$ is the magnetic ordering plus "heavyfermion-like", go $T$, cor 'ributions to $\mathrm{C}$. The inset shows plots of $\mathrm{C} / \mathrm{T}$ vs $\mathrm{T} 2$ of the type applied to data for $T \geq 5 \mathrm{~K}$ that lod to overestimates of $g_{0}$. (XBL 909-3020)

Magnetic Ordering, Hypertine and "Linear" Contributions to the Low-Temperature Specific Heat of $\left(Y_{1 \cdot x} \mathrm{Pr}_{\mathrm{x}}\right) \mathrm{Ba}_{2} \mathrm{Cu}_{3} \mathrm{O}_{7-d}$ N.E. Phillips, R.A. Fisher, R. Caspary ${ }^{\circ}$, A. amato', H.B. Radousky", J.L. Peng', L. Zhang' and R.N. Sheltons

Among rare-earth substituted $Y B C O$ 's, the Pr-substituted materials exhibit unique properties that may contribute to an understanding of the mechanisms of superconductivity. New specifc heat measurements on $\left(\mathrm{Y}_{1 \cdot \mathrm{x}} \mathrm{Pr}_{\mathrm{x}}\right) \mathrm{Ba}_{2} \mathrm{Cu}_{3} \mathrm{O}_{7-\mathrm{d}} \mathrm{x}=0,0.1,0.2,0.3$ and $1,0.3 \leq \mathrm{T} \leq 65 \mathrm{~K}$ and including measuremen $1 \mathrm{~s}$ in magnetic fields to $7 \mathrm{~T}$ are reported. The combination of low-temperature and in-field data allows the separation of previously' unrecognized hyperfine and magnetic ordering contributions from the low-temperature linear term, $\gamma_{0} \mathrm{~T}$. The value of $\gamma_{0}, 200 \mathrm{~mJ} / \mathrm{mole} \operatorname{Pr} . \mathrm{K} 2$ for $\mathrm{x}=0.1,0.2$ and 0.3 , is substantially lower than deduced from carlier measurements, but the determination of a cut-off temperature of $\sim 50 \mathrm{~K}$ for this contribution adds to the appearance of "heavy-fermion-like" behavior.

\section{Pressure and Magnetic Field Dependence of the Specific Heat of Heavy Fermion $\mathrm{YbCu}_{4.5}$

\author{
A. Amato", R.A. Fisher, N.E. Phillips, D. Jaccard* and E. Walker*
}

The specific heat of a polycrystalline sample of $\mathrm{YbCu}_{4.5}$ has been measured between 0.3 and $20 \mathrm{~K}$ at pressures to $8.2 \mathrm{kbar}$, and, at zero pressure, in fields to $7 \mathrm{~T}$. Unlike cerium-based heavy-fermion compounds, an increase of $\mathrm{C} / \mathrm{T}$ is observed with increasing pressure, with the linear term enhanced by about $16 \%$ at $8.2 \mathrm{kbar}$. Above $7 \mathrm{~K},(\partial \mathrm{C} / \partial \mathrm{P})_{1}$ is negative. The nuclear contribution observed at $\mathrm{P}=0$ is increased by roughly a factor of two at $8.2 \mathrm{kbar}$. At zero field a minimum in $\mathrm{C} / \mathrm{T}$ is observed near $11 \mathrm{~K}$. Below that temperature $\mathrm{C} / \mathrm{T}$ increases and below $0.5 \mathrm{~K}$ exhibits an upturn ascibed to a hyperfine contribution. The increase in $\mathrm{C} / \mathrm{T}$ below $11 \mathrm{~K}$ is reduced by a factor 1.5 for $\mathrm{H}=7 \mathrm{~T}$, whereas the hyperfine term is enhanced due to the contribution of the ${ }^{63} \mathrm{Cu}$ and ${ }^{65} \mathrm{Cu}$ nuclei.

\section{Synthesis}

\section{lodine Intercalation of a High-Temperature Superconducting Oxide ${ }^{\star \star}$}

A. Zettt, M. Cohen, X. Xiang, S. McKernan, W. Vareka, J. Corkill, and T. Barbee III

We have intercalated iodine between the [Bi-O] planes of $\mathrm{Bi}_{2} \mathrm{Sr}_{2} \mathrm{CaCu}_{2} \mathrm{O}_{8}$, yielding a new (stage-1) compound in which the $\mathrm{c}$ axis is increased by $23 \%$ over the pristine unit-cell dimerision. The stoichiometry of the iodine-saturated material is $\mathrm{IBi}_{2} \mathrm{Sr}_{2} \mathrm{CaCu}_{2} \mathrm{O}_{y}$; it is a bulk superconductor with a transition temperature of $80 \mathrm{~K}$. The samples were prepared by placing iodine and high-quality single crystals of $\mathrm{Bi}_{2} \mathrm{Sr}_{2} \mathrm{CaCu}_{2} \mathrm{O}_{8}$ in evacuated pyrex tubes and annealing at temperatures in the range o. $1 \cup \mathrm{J}-200^{\circ} \mathrm{C}$ for $10-15$ days. Unilike most graphite intercalation compounds, this

\footnotetext{
* Institut fur Festkorperphysik, Technische Hochschule Darmstadt, Darmstadt, FRG

+ Laboratorium fur Festkorperphysik, ETH Honggerberg, Zurich, Switzerland

* Lawrence Livermore National Laboratory

$\S$ Dept. of Physics, UC Davis

\# Dept of Physics, Amherst College, Amherst, MA

* Supponted in part by tho National Sciones Foundation
} 
iodine intercalated superconductor is stable in air, which greatly simplifies characterization of physical properties and may be useful in applications. The $x$-ray diffraction patterns of highly oriented (along the c-axis) crystals of $\mathrm{Bi}_{2} \mathrm{Sr}_{2} \mathrm{CaCu}_{2} \mathrm{O}_{8}$ and $\mathrm{IBi}_{2} \mathrm{Sr}_{2} \mathrm{CaCu}_{2} \mathrm{O}_{8}$ are shown in Figure $7 \mathrm{a}$ and $\mathrm{b}$, respectively. The computed $x$-ray diffraction pattern of Figure $7 \mathrm{c}$ can be seen to agree quite well with the measured pattern of Figure $7 \mathrm{~b}$. Magnetic susceptibility measurements indicate that the transition temperature of the intercalated compound is $80 \mathrm{~K}$, and that the Meissner fraction is abolt $30 \%$, as it is for the unintercalated material. Thus $\mathrm{IBi}_{2} \mathrm{Sr}_{2} \mathrm{CaCu}_{2} \mathrm{O}_{\mathrm{y}}$ is a bulk superconductor.

The transition temperature is not greatly affected by the intercalation from initial values of 82 to $90 \mathrm{~K}$. Thus it appears that the iodine is not introducing additional holes into the $\mathrm{CuO}_{2}$ planes, which could raise $\mathrm{T}_{\mathrm{c}}$. The fact that $\mathrm{T}_{\mathrm{c}}$ is not greatly decreased by the intercalation also serves to confirm the two dimensional character of the superconducting processes in this material.

\section{Superconductivity in the Layered Compound $\mathrm{Li}_{x} \mathrm{NbO}_{2}{ }^{\#}$}

\section{A. Stacy, M. Geselbracht, and T. Richardson}

Whereas all of the copper oxide superconductors have very anisotropic structures, the superconducting oxides of early transition metals discovered prior to this work (e.g., $\mathrm{LiTi}_{2} \mathrm{O}_{4}$ ) have three-dimensional structures. "The new superconductors discovered in the course of this work. $\mathrm{Li}_{x} \mathrm{NbC}_{2}$, have a layered (i.e., twodimensional) hexagonal structure. The materials were prepared by deintercalation of lithium from the parent compound $\mathrm{LiNbO}_{2}$. Samples were prepared with $x=0.45,0.50$, and 0.62 . The samples with $x=0.45$ and 0.50 proved to be superconducting, with transition temperatures of 5.5 and $5.0 \mathrm{~K}$, respectively. Magnetic susceptibility data for $\mathrm{x}=0.45$ are shown in Figure 8.

Figure 8 Magnetic susceptibility versus temperature for a sample of the new superconductor $\mathrm{Li}_{0.45} \mathrm{NbO}_{2}$. The magnitude of the observed Meissner effect indicates a superconducting fraction of about $15 \%$.

(XBL 918-1783)

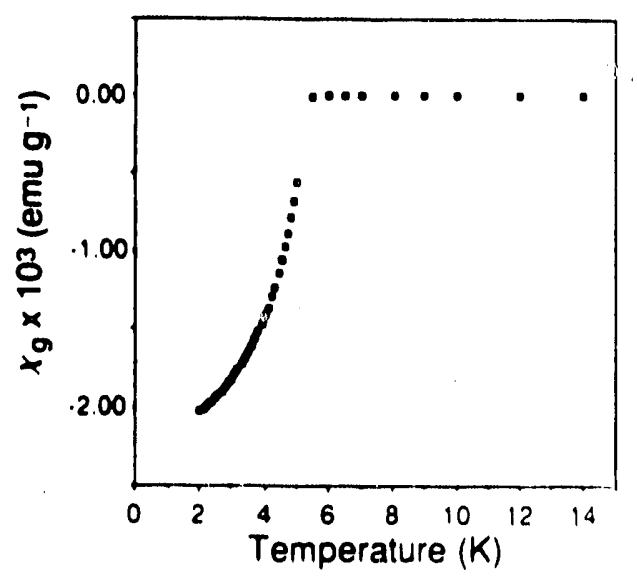


The discovery of superconductivity in these materials is significant for a number of reasons. Previously all of the known superconducting nloblum oxides contained niobium in a low formal oxidation state. In $\mathrm{Li}_{0.45} \mathrm{NbO}_{2}$ the formal oxidation state of niobium is +3.55 . Furthermore, we have seen superconductivity in a layered oxide containing an early transition metal; as the superconducting copper oxides also have layered structures, a comparison of the propertles of niobium oxide superconductors with those of the high- $\mathrm{T}_{\mathrm{c}}$ copper oxide materials will help clarify the mechanism of superconductivity in layered oxides.

Production of High Performance $\mathrm{YBa}_{2} \mathrm{Cu}_{3} \mathrm{O}_{7}$ using Nitrogen Dioxide

A. Stacy, S. Keller, K. Leafy*, H. JACOBSON*, N. LeVoY*, T. AsKeW*, AND R. Flippen*

Energy Dispersive X-ray Spectroscopy (EDS) was used to show that the elemental homogeneity of $\mathrm{YBa}_{2} \mathrm{Cu}_{3} \mathrm{O}_{7}$ powders can be improved substantially by heating the powder in a nitrogen dioxide-containing atmosphere (e.g., at $950{ }^{\circ} \mathrm{C}$ ), followed by annealing in oxygen at $950^{\circ} \mathrm{C}$, and slow cooling to room temperature. The improved homogeneity results in a substantially larger flux exclusion signal for the $\mathrm{NO}_{2}$-treated powder. The experimental results suggest a mechanism which involves the formation of a small amount of molten $\mathrm{Ba}\left(\mathrm{NO}_{3}\right)_{2}$, which acts as a flux that dissolves the constituents and reprecipitates them as high purity $\mathrm{YBa}_{2} \mathrm{Cu}_{3} \mathrm{O}_{7}$.

\section{Calcium-Substituted Y-Ba-Cu-O Superconductors ${ }^{\dagger}$ \\ D. Morais, P. Narwankar, A. Sinha K. Kakano, B. Fayn, and V. Shum}

We have investigated the effects of $\mathrm{Ca}$ substitution in the $\mathrm{Y}-\mathrm{Ba}-\mathrm{Cu}-\mathrm{O}$ system. Elevated oxygen pressure is found to increase the solubility range of $\mathrm{Ca}$. In the 123 phase, $\mathrm{Ca}_{x} \mathrm{Y}_{1-\mathrm{x}} \mathrm{Ba}_{2} \mathrm{Cu}_{3} \mathrm{O}_{y}$, the orthorhombic distortion decreases systematically as $\mathrm{Ca}$ increases, and $a, b$ and $c / 3$ become equal at $x=0.25$, as measured by $x$-ray diffraction. Then the structure remains tetragonal throughout the extended range of Ca solubility beyond $x=0.25$. 'The synthesis of the Ca-doped tetragonal 123 phase has been achieved in oxygen overpressures as small as 1 bar. Doping by $\mathrm{Ca}$ is compensated by a corresponding reduction in oxygen content, and $T_{c}$ remains consistently high (80$86 \mathrm{~K})$, comparable to orthorhombic 123 , and in striking contrast to the well-known oxygen deficient tetragonal 123 . This work establishes that the controlling factor in determining $T_{c}$ in this class of superconductors is the optimum oxidation (or formal average copper valency), and not any specific oxygen content, ordering into chains, or orthorhombic distortion.

The $T_{c}$ of 124 is enhanced by Ca substitution: $\mathrm{Ca}_{x} \mathrm{Y}_{1-x} \mathrm{Ba}_{2} \mathrm{Cu}_{4} \mathrm{O}_{\mathrm{y}}$ prepared at $200 \mathrm{bar}$ oxygen pressure at $930^{\circ} \mathrm{C}$ shows $\mathrm{T}_{c}=89 \mathrm{~K}$ for $\mathrm{x}=0.1$. The 124 phase remains stable with Ca substitution at oxygen pressures larger than 50 bar. At 2 to 16 bar, Ca substitution stabilizes the tetragonal 123 phase discussed above.

\section{THIN FILMS AND THIN-FILM DEVICES}

The thin-film research includes film synthesis, film characterization, and the investigation of thin-film devices such as bolometers and SQUIDs (Superconducting QUantum Interference Devices), for applications in electronics. Also underway is the development of thin films for tape conductors, for applications to electric power systems.

\footnotetext{
"E.I. du Pont de Nemours \& Co., Wilmington, Delaware

† Supported in part by Morris Research, Inc.
} 


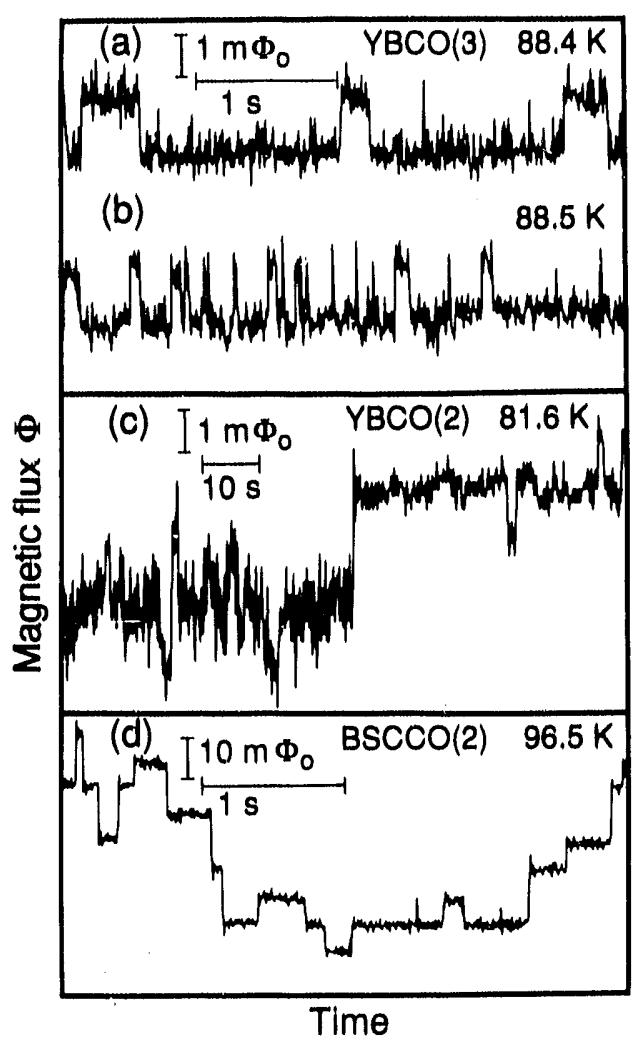

Flgure 9

Magnetlo flux through the measuring (low-To) SQUID vs, time for two YBCO films (a), (b), (o), and for a BSCCO flake (d). The magnetlo flux olearly "switohes" among discrete states. The vertloal bars show the size of one or ten thousandths of a flux quantum. (XBL 904-5484)

\section{Random Telegraph Signals in High-Temperature Superconductors ${ }^{\ddagger}$ J. Clatke, M. Johnson, M. Ferrari, F. Wellostood, M. Beasley", A. Inam", X. Wu",} L. NAZAR*", ANO T. Venkatesan"

The local magnetization of $\mathrm{YBa}_{2} \mathrm{Cu}_{3} \mathrm{O}_{7-x}\left(\mathrm{YBCO}\right.$ ) and $\mathrm{Bi}_{2} \mathrm{Sr}_{2} \mathrm{CaCu}_{2} \mathrm{O}_{8+y}$ (BSCCO), measured with a superconducting quantum interference device, has been found to exhibit random telegraph signals (RTS) over narrow ranges of temperature. We believe these signils arise from the thermally activated hopping of single magnetic vortices between tivo pinning sites. The data shown in Figures 9 (a) and (b) are from $\mathrm{YBCO}(3)$, a 0.3 micrumeter thick $\mathrm{c}$-axis film with $\mathrm{T}_{\mathrm{c}}=89.8 \mathrm{~K}$, grown epitaxially on a (100) $\mathrm{LaAlO}_{3}$ substrate by pulsed laser deposition. Over most of the range of temperatures in which noise was observable, 75 to $90.4 \mathrm{~K}$, the power spectrum was approximately $1 / \mathrm{f}$. Over a narrow range of temperatures, however $(88.4$ to $88.6 \mathrm{~K})$, the magnetic flux switched back and forth between two discrete levels at a rate that increased markedly with temperature. Figure 9 (c) shows similar data for a thin YBCO film deposited by sputtering on a (100) MgO substrate, while Figure 9 (d) shows flux versus time for a c-axis flake of BSCCO, about $0.15 \mathrm{~mm}$ thick. The spectral density of the RTS is Lorentzian, and from the temperature dependence of the characteristic time, we deduce pinning energies of 0.17 and $0.20 \mathrm{eV}$ for samples of $Y B C O$ and $B S C C O$, respectively, at reduced temperatures $\left(T / T_{c}\right)$ of 0.99 and 0.87 . The amplitudes of various RTSs imply flux hopping distances varying from 0.2 to 30 micrometers.

\footnotetext{
₹ Supported in part by the California Competitive Technology Program

'Department of Applied Physics, Stanford University

"Department of Physics, Rutgers University

"* Bellcore, Red Banks New Jersey
} 


\section{Superconducting Thin-Film Flux Transformers of $\mathrm{YBa}_{2} \mathrm{Cu}_{3} \mathrm{O}_{7}{ }^{*}$}

J. ClaAke, F. Wellstood, J, Kingston, and M. Ferrari

Using a three-layer $\mathrm{YBa}_{2} \mathrm{Cu}_{3} \mathrm{O}_{7}-\mathrm{SrTiO}_{3}-\mathrm{YBa}_{2} \mathrm{Cu}_{3} \mathrm{O}_{7}$ in situ laser deposition process, we have constructed thin-film flux transformers which have pickuploops $10 \mathrm{~mm}$ on a side and input colls with 10 turns. The device construction was based on last year's work in which multilayer, epitaxial high- $T_{\mathrm{c}}$ films were used to produce insulating crossovers. Each layer was patterned with a shadow mask or photolithography. The flux transformers were inductively coupled to a de Superconducting QUantum Interference Device (SQUID) at $4.2 \mathrm{~K}$ to determine their transition temperatures, the temperature dependence of the critical çurrent, and the coupling efficiency. The relative coupling efficiency for two transformers is shown in Figure 10. Above $T_{c}$ the unity coupling is just due to the rising inde of he low- $T_{c}$ SQUID; below $T_{c}$ the values of negative coupling observed it $\mathrm{T}$ twat the gain in signal produced by the flux transformers. Studies of noise in this configuration show that the dominant noise source is due to variations in flux transformer current caused by flux motion in the high- $\mathrm{T}_{\mathrm{f}}$ films. The present experiments yield a magnetic field sensitivity of about 0.9 pT Hz ${ }^{-1 / 2}$ at $1 \mathrm{~Hz}$ with the transformer at $60 \mathrm{~K}$. To realize the full potential of such magnetometers, it will be necessary to use high- $T_{c}$ films with lower levels of noise.

\section{Fabrication of an Infrared Bolometer with a High- $\mathrm{T}_{\mathrm{o}}$ Superconducting Thermometer ${ }^{\dagger}$ P. RICHARdS, S. Verghese, K. CHAR ${ }^{\ddagger}$, AND S. SACHTJEN}

A sensitive high- $T_{c}$ superconducting bolometer has been fabricated on a 20 micrometer thick sapphire substrate with a YBCO thin film transition edge thermometer. Optical measurements with a He-Ne laser gave a noise equivalent power of 2.4 $x 10^{-11} \mathrm{~W} \mathrm{~Hz}^{-1 / 2}$ at $10 \mathrm{~Hz}$ and a responsivity of $17 \mathrm{~V} / \mathrm{W}$ in good agreement with electrical bolometer measurements. Gold black smoke was then deposited on the back side of the assembled bolometer as an absorber.

Spectral measurements on a fourier transform spectrometer show that the bolometer has useful sensitivity from visible wavelengths to beyond 100 micrometers. This performance is clearly superior to that of a commercial room temperature pyroelectric detector, as was demonstrated by a direct comparison. Further improvement appears to be possible, by reducing degradation of the YBCO film during the gold black deposition.

Figure 10

Rolative response of a low-T, SQUID coupled to a high-T. Ilux transformer, vs. temperature of the transfornor. The circles and squares show values for two different transformers. Solid lines are guides to the eye. The inset shows schematically a flux transformer coupled to a de SQUID.

(XBL 906-5579)

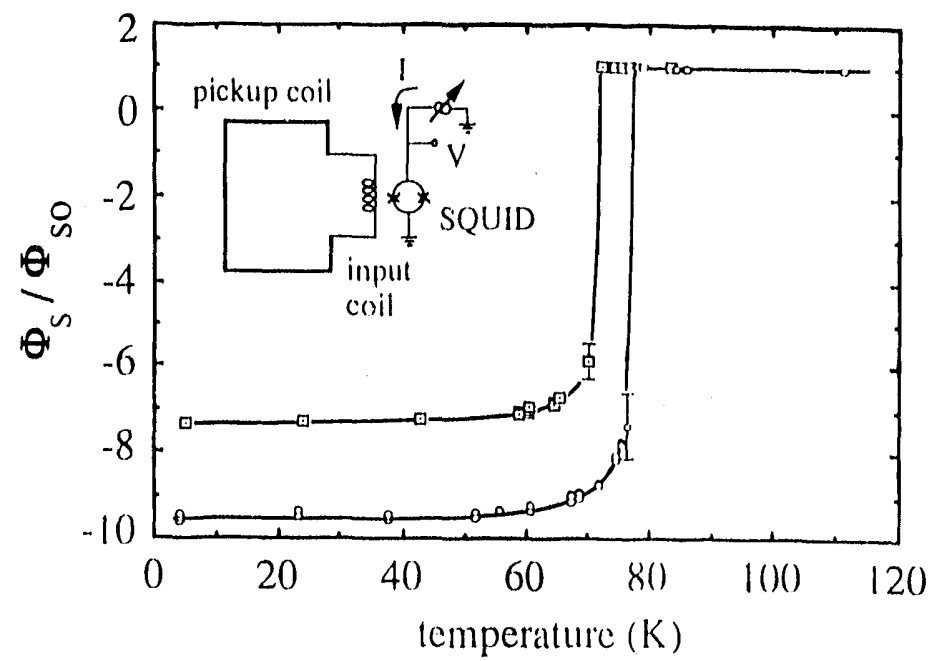

"Supported in part by the Callfornla Competitive Technology Program, and by Conductus, Inc.

'Supported in part by the Chemical Sciences Division of the DOE Office of Basic Energy Sciences, by Conductus, Inc., and by the U.S. Dept. of Energy

₹ Conductus, Inc., Sunnyvale, CA 


\section{Fabrication and Measurement of High-T, Mlcrobolometers $\$$

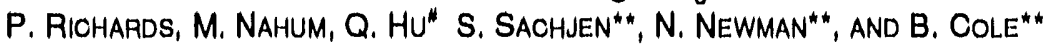

We have fabricated and measured the performance of antenna-coupled microbolometers based on the resistive transition of a high- $\mathrm{T}_{\mathrm{c}}$ superconducting film for use as detectors of far-infrared and millimeter waves. A planar lithographed antenna (log-periodic or log-spiral) is used to couple the radiation to a thin YBCO film with dimensions ( 6 by 13 micrometers) which are much smaller than the wavelength to be measured. This film acts both as the resistor to thermalize the rf currents and as a transition edge thermometer to measure the resulting temperature rise. Because of its small size, both the thermal conductance from the film into the bulk of the substrate and the heat capacity of the thermally active region are small. Consequently, the microbolometer has low noise, fast response, and a high voltage responsivity. We measured a phonon-limited electrical noise equivalent power of $4 \times 10^{-12} \mathrm{~W} \mathrm{~Hz}^{-1 / 2}$ at $10 \mathrm{kHz}$ modulation frequency and a responsivity of $480 \mathrm{~V} / \mathrm{W}$ at a bias of $0.55 \mathrm{~mA}$. Measurements of the optical efficiency are in progress.

\section{Sputtering of High-T, Superconducting Films ${ }^{\text {t† }}$ \\ M. RUBIN, M. DIXON, E. YIN, B. HOPPER}

The objective of this work is to develop a practical process for sputtering highcritical-current films on polycrystalline substrates. In conventional planar magnetron sputtering, negative oxygen ions are believed to be accelerated towards the substrate, causing deviations from stoichiometry, disorder, and even net resputtering of the film. The most common solution to this problem has been sputtering offaxis at high pressures to slow and avoid the directed beam. This situation is undesirable because of very slow deposition rates and loss of the easily scalable planar configuration. Biasing of the substrate holder and use of a secondary electrode on axis at lower pressure greatly increased the deposition rate, but significant damage still occurs from charge-exchanged and reflected neutrals. A combination of biasing and particle shields produced superconducting films on axis.

The above observations about sputtering conditions hold even for a single crystal substrate like strontlum titanate. When a metal tape substrate such as stainless steel or Hastelloy is used, however, superconducting films are never produced unless a buffer layer is introduced. Yttrium-stabilized zirconia and other materials with compatible thermal-expansion coefficients work well as buffers. Auger depth profiling shows that they block diffusion of harmful transition-metal elements from the substrate. There is a strong tendency for the grains to grow with c-axis orientation as revealed by $x$-ray diffraction, but random nucleation of the grains produces rotational misorientation and weak links. Thus, high transition temperatures can be obtained, but critical current densities fall to typical bulk levels. Future efforts will focus on alignment and recrystallization.

\section{Pulsed Laser Deposition of High- $\mathrm{T}_{\mathrm{c}}$ Thin Films}

\section{R. Russo, X. MAO, J. MCMILLAN, R. READE, B. OLSEN ${ }^{\ddagger \ddagger}, H . L^{88}$, AND J. Ho}

Pulsed laser deposition is by now a well-known technique for the synthesis of high-T filims with excellent electrical properties. In addition, it has advantages of high deposition rates, congruent material transfer, and simple target characteristics which make it attractive for the production of multilayer structures.

\footnotetext{
Supported by the Chemical Sclences Division of the DOE Office of Basic Energy Sclences * Department of Electrical Engineering and Computer Sclence and Research Laboratory of Electronics, MIT "* Conductus, Inc., Sunnyvale, CA
}

it Supported by the DOE Assistant Secretary for Conservation and Renewable Energy, Offlce of Energy Management, Advanced Utility Concepts Division

\# Lawrence Livermore National Laboratory 88 Department of Physics and Chemistry, Wichita State University, Wichita, KS 


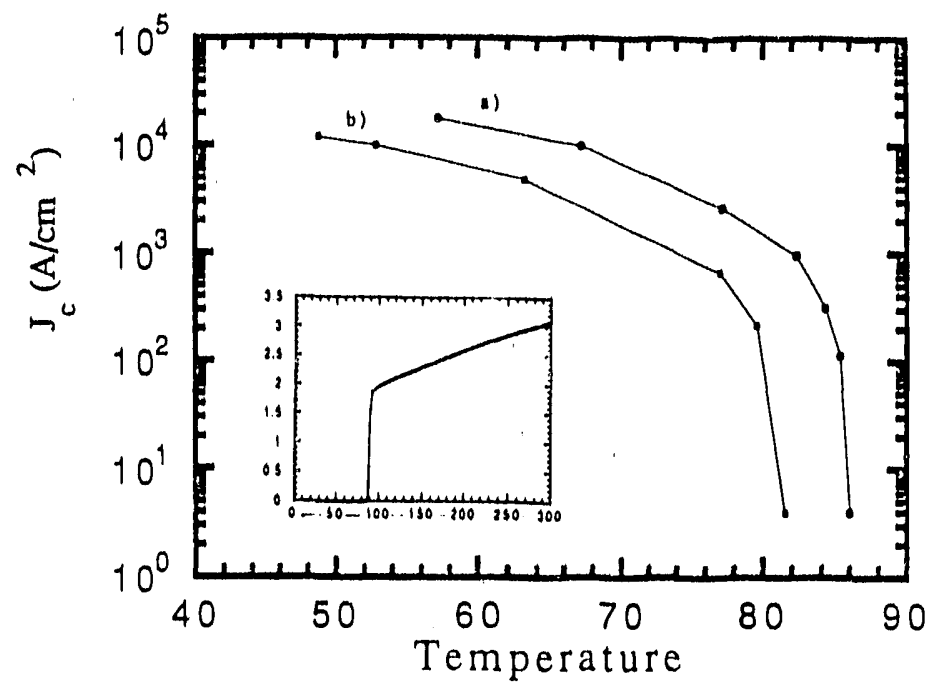

A number of buffered metal substrates have been coated by laser-deposited $Y B C O$ thin films. Surprisingly Ag showed potential as a buffer, for example on $\mathrm{Pt}$ and stainless steel substrates, in that it raised the zero-resistance temperature compared with unbuffered substrates. However Ag does not prevent the deleterious YBCO/ metal interaction and also led to the nucleation of unoriented superconducting films, instead of the more favorable c-axis orientation. As was the case for the sputtered films YSZ proved to be an excellent buffer. The best film produced to date, on YSZbuffered Haynes alloy $\# 230$, exhibited zero resistance at $86 \mathrm{~K}$ and $\mathrm{Jc}$ of $3,000 \mathrm{~A} \mathrm{~cm}^{-2}$ at $77 \mathrm{~K}$, as shown in Figure 11. The quality of the superconducting properties is closely related to the texture of the YSZ layer, which is in turn controlled by deposition conditions. Further study of this issue is in progress.

Laser deposition of $\mathrm{Bi}_{2} \mathrm{Sr}_{2} \mathrm{CaCu}_{2} \mathrm{O}_{8}$ films which are superconducting at $70 \mathrm{~K}$ without the usual subsequent anneal was made possible by doping with both $\mathrm{Pb}(\mathrm{a}$ standard approach) and $\mathrm{Sb}$ (a novel approach). Films were deposited on single crystal $\mathrm{MgO}$ substrates at substrate block temperatures of $800^{\circ} \mathrm{C}$ in 0.2 torr oxygen pressure. $X$-ray diffraction results show that the films are the "2212" phase with c-axis orientation. Scanning electron micrographs of films with and without $\mathrm{Sb}$ demonstrate that the $\mathrm{Sb}$ promotes the growth of larger crystal grains. Initial efforts to transfer this high- $T_{c}$ film process to buffered metal substrates yielded films which were superconducting but with wide resistive transitions.

\section{Electrical Characterization of High-T. Films* \\ P. Berdahl, J, McMillan, M. Nicholas}

In addition to routine electrical characterization of superconducting films deposited on metal substrates (resistance and critical current density vs. temperature, etc.), we perform novel characterization measurements to further elucidate dissipative mechanisms in high- $\mathrm{T}_{\mathrm{c}}$ superconductors.

One particularly interesting measurement has been angular magnetoresistance, in which sample resistance is determined as the sample is slowly rotated in a fixed magnetic field. The high- $\mathrm{T}_{\mathrm{c}}$ superconductors are all highly anisotropic, and this anisotropy is directly apparent in the angular magnetoresistance measurements. If the conductor is composed of randomly oriented cystallites, little dependence of resistance on orientation angle is seen. (Demagnetizing effects are nearly absent for fields above about 0.1 tesla, so the shape of the conductor cross section is not very important.) On the other hand, if the crystallites have a dominant orientation (i.e., the

\footnotetext{
"Supporied by the DOE Assistant Secretary for Conservation and Renewable Energy, Office of Energy Management, Advanced Utility Concepts Division
} 
conductor has texture), then a pronounced dependence on orientation angle is seen. A minimum in resistance is observed when the magnetic field is allgned parallel to the copper-oxide planes, as may be expected from free energy considerations. For our films, then, c-axis orientation produces a resistance minimum for fleld parallol to the film, whereas a-axis orientation produces a minimum with field perpendicular to the film. Both types of orientation have been observed in both epitaxial films on crystalline substrates and in films deposited on buffered metal substrates. Angular magnetoresistance measurements generally agree well with, and complement, $x$-ray diffraction.

\section{CERAMIC PROCESSING}

\section{Acoustic Emission Study of Microcracking In 123-type Ceramic Superconductors ${ }^{\dagger}$

\author{
L. DE JONGHE AND T. RICHARDSON
}

Acoustic emission from sintered ceramic $\mathrm{YBa}_{2} \mathrm{Cu}_{3} \mathrm{O}_{7}(\mathrm{YBCO})$ superconductor pellets provides a direct measure of microcracking behavior during processing. By detection and statistical analysis of acoustic events, the effects of cooling rates, processing atmosphere, average grain size, additives, and grain alignment on microcracking in YBCO have been studied. The onset temperature and duration of acoustic emission during cooling correlate well with the oxygen partial pressure in the furnace. Rapid changes in oxygen partlal pressure at constant temperature produce acoustic emission that is characteristic of microcracking. A reported critical grain size for microcracking in sintered polycrystalline $Y B C O$, of about 1 micrometer, has been confirmed. It is clear that microcracking must be held to a n inimum if YBCO ceramic superconductors are to be used in high-current applications. Grain alignment is the most effective means of both reducing microcracking and increasing critical currents. Slow cooling and avoidance of rapid changes in oxygen partial pressure are also effective, especially in large-grained materials.

\section{Traveling Reaction Zone Method for Preparation of Textured Ceramic Superconductor Thick Films ${ }^{\dagger}$ \\ L. DE JONGHE AND T. RICHARDSON}

Textured thick films of superconducting $\mathrm{YBa}_{2} \mathrm{Cu}_{3} \mathrm{O}_{7-x}$ have been prepared on ceramic substrates using a traveling reaction zone method. The technique utilizes the rapid reaction between $\mathrm{Y}_{2} \mathrm{Cu}_{2} \mathrm{O}_{5}$ and $\mathrm{BaCuO}_{2}$ to form the superconductor as the film passes through a steep temperature gradient furnace. The films consist of a single, continuous superconducting phase with strong c-axis orientation normal to the alumina substrate.

\section{Traveling Solvent Zone Texturing of Ceramic Superconductor Thick Films ${ }^{\dagger}$}

L. DE JONGHE AND T. RICHARDSON

Supported thick films of superconducting $\mathrm{YBa}_{2} \mathrm{Cu}_{3} \mathrm{O}_{7-x}$ have been prepared using a modified traveling solvent zone technique. The films consist of a strongly oriented, single superconducting phase with excellent connectivity and unusual microstructure. The technique utilizes a volatile flux $(\mathrm{KCl})$, which melts and evaporates as the

† Supported in part by the Electric Power Research Institute 
Figure 12

Eleotron mlorograph of a travellng solvent zone processed

$\mathrm{YBa}_{2} \mathrm{Cu}_{3} \mathrm{O}_{7}$ thlok film vlewed from direotly above the surface.

(XBB 890-10119)

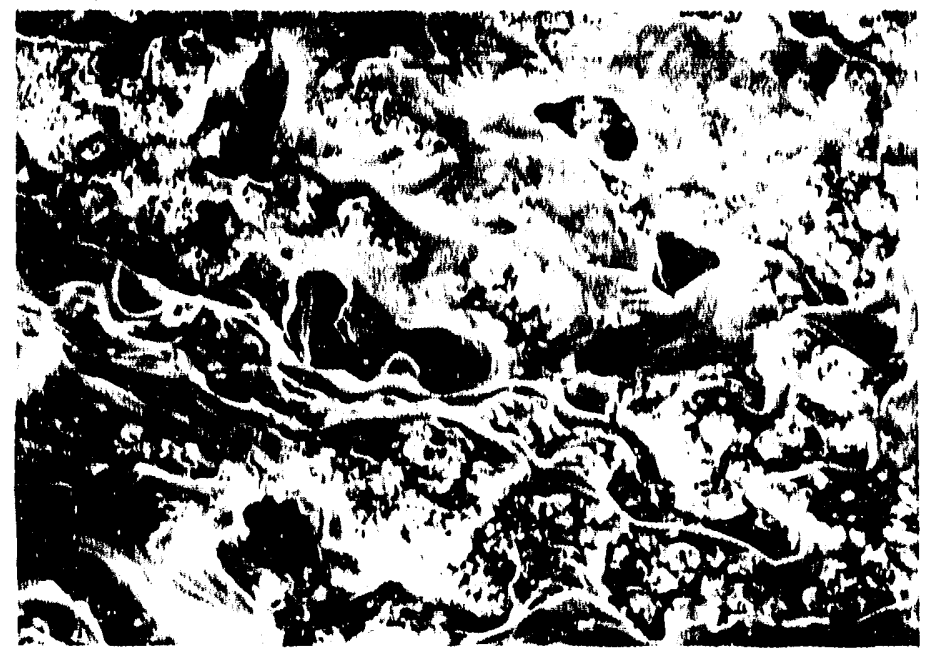

film passes through a steep temperature gradient furnace. Figure 12 shows a scanring electron micrograph of the resulting film surface. Although there is some impurity phase (believed to be barium cuprate) on the surface, the underlying material is dense, and c-axis oriented, as shown by $x$-ray diffraction. Sponge-like structures (not shown) are also observed and are attributed to uncontrolled evaporation of solvent $(\mathrm{KCl})$ from the molten film. Efforts to refine the processing parameters, to achieve reduced porosity and high critical current densities continue.

\section{ELECTRON MICROSCOPY}

The electrori microscopy research features atomic resolution imaging of cations, which enables defects, grain boundary structure, and composition to be analyzed and related to synthesis conditions and to physical properties. The state-of-the-art facilities of the National Center for Electron Microscopy, including the Atomic Resolution Microscope, are extensively utilized.

\section{Copper-Oxygen Intercalation and Related Phase Transformations in Y-Ba-Cu-O* R. GRonsky, M. Fendorf, C. BURMester AND L. WIILLE ${ }^{\dagger}$}

Phase transformations in the system $\mathrm{Y}_{2} \mathrm{Ba}_{4} \mathrm{Cu}_{6+x} \mathrm{O}_{14+x}$ have been investigated by high resolution transmission microscopy (TEM) and by static lattice Monte Carlo simulations. The calculations are based on an intercalation scheme where copper oxide "particles" are allowed to move from simulated (100) grain boundaries into the lattice, parallel to existing $\mathrm{CuO}(001)$ planes. Micrographs reveal dislocations and stacking faults associated with the diffusion of copper and oxygen as the stoichiometric parameter $x$ varies locally during a phase transformation, and these defects are accurately reproduced by the calculations in "snapshots" of the simulated structures. In addition, the simulations show the presence of the well-known 123 (i.e., $\mathrm{Y}_{1} \mathrm{Ba}_{2} \mathrm{Cu}_{3} \mathrm{O}_{7}$ ), 124 , and 247 phases and predict the formation of 249 and 125 structures at higher oxygen partial pressures. Based on experimental images and Monte Carlo results, an atomic mechanism involving the intercalation and removal of extra $\mathrm{CuO}$ planes by partial dislocation climb is proposed for changes in the layered crystal structure.

\footnotetext{
" Supported In part by a University of Houston subcontract from DARPA

† Department of Physles, Florida Atlantio University, Boca Raton, Florida
} 


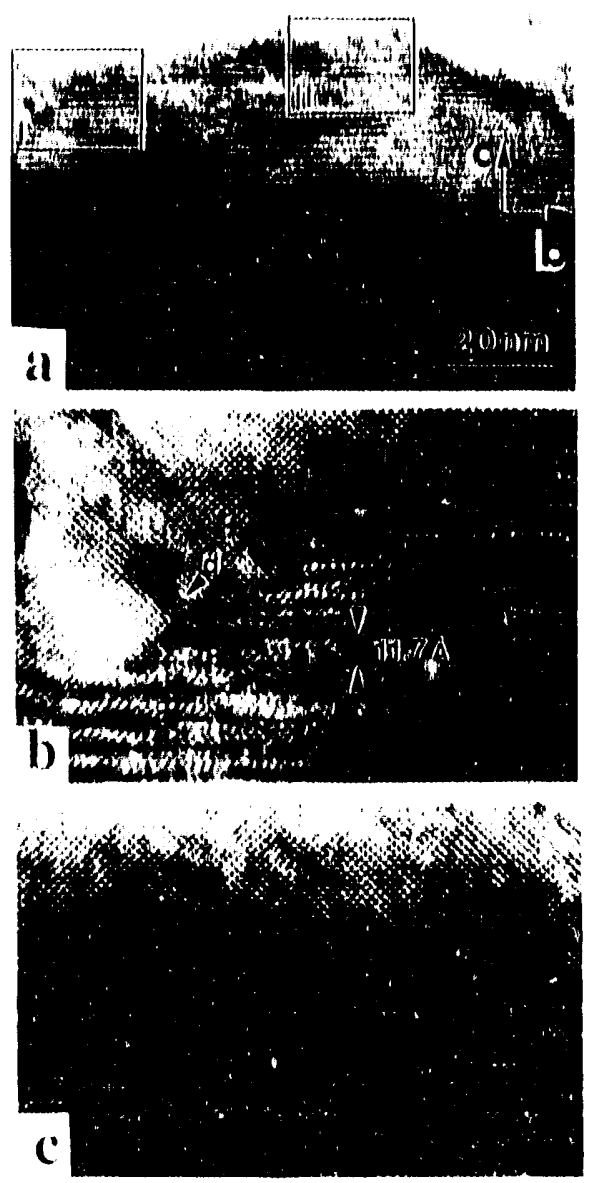

Figuro 13

a) Lattloe Iringe Image of $\mathrm{SrTIO}_{3}$ grown on $\mathrm{YBOO}$

b) Dotall of a stopped Interlaoe, showing an edge clislocatlon, labolod "d", In whloh tho assoolated extra hall plane is normal to the interface.

o) Detall of a complotoly flat intorlaco, (XBB 907-6401)

\section{Heteroeplaxial $\mathrm{YBa}_{2} \mathrm{Cu}_{3} \mathrm{O}_{7} \mathrm{SrTlO}_{3}-\mathrm{YBa}_{2} \mathrm{Cu}_{3} \mathrm{O}_{7}$ Trilayers Examined by Transmission Electron Microscopy \\ R. Gronsky, M. TIDJANI, J. Clarke, J. Kingston, and F. Wellstood}

We have performed high resolution transmission electron microscopy and electron diffraction studies of this heteroepitaxial super..... Juctor-insulator-superconductor system, depostted on polished (001) $\mathrm{MgO}$ substrates by in situ laser ablation. The resulting films grow epitaxially' and consistently preserve a parallel orientation between the close-packed ((001) $\mathrm{YB}_{\mathrm{i}_{2}} \mathrm{Cu}_{3} \mathrm{O}_{4}$ planes and (001) $\mathrm{SrTiO}_{3}$ planes over the entire trilayer, even in the presence. of ledges and/or steps along vicinal interfaces. A segment of the lower $\mathrm{YBCO}-\mathrm{SrTiO}_{3}$ interface is shown at high magnification in Figure 13. Both (010) and (001) cross fringes of $\mathrm{SrTiO}_{3}$ and $\mathrm{YBCO}$ layers are visible in the entire micrograph. Although both interface regions showed strain, occasionally relieved by stacking faults, they were free of disorder and any evidence of impurity phases. The observed epitaxial growth is very likely responsible for the excellent electrical properties found in similarly constructed multilayer interconnects.

\section{Monte Carlo Study of Domain Formation in $\mathrm{YBa}_{2}\left(\mathrm{Cu}_{1-\mathrm{x}} \mathrm{Fe}_{\mathrm{x}}\right) 3 \mathrm{O}_{2}$ R. GRONSKY, C. BURMESTER, AND L. WILLE}

Upon progressive doping with $\mathrm{Fe}$ the $\mathrm{YBa}_{2}\left(\mathrm{Cu}_{1 \cdot \times} \mathrm{Fe}_{\mathrm{x}}\right)_{3} \mathrm{O}_{\mathrm{z}}$ compound transforms from an orthorombic to a tetragonal structure without an accompanying loss of superconductivity. This behavior has been interpreted by assuming that the tetragonal structure consists of many conflicting orthorhombic microdomains pinned by the Fe atoms. Extending an Ising model previously used to model oxygen ordering in the

‡Department of Physlcs, Florida Atlantio University, Booa Raton, Florlda 


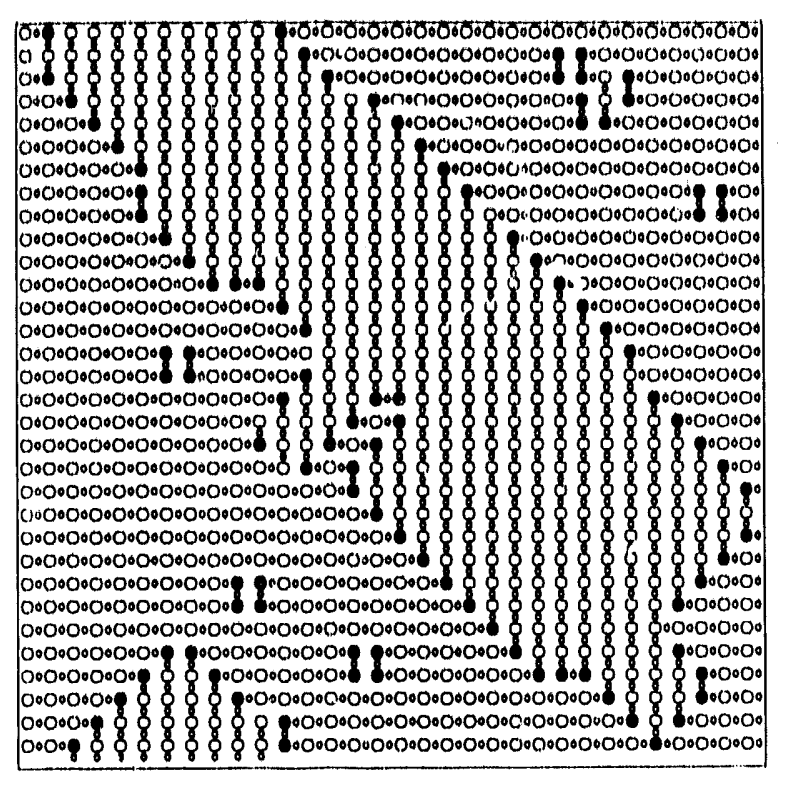

Figuro 14

Monto Oarlo almulatlon snapshot of basal plano conllguration obtained for 10 percont lron doplng, Large flllod olrolos roprosant lrons, largo unillod olrolos coppors, and amall dirolos oxygons. Noto how tho lion atoms lorm well-ordored linear <11> olustora, (X日L, 000-3047)

undoped compound, we show by Monte Carlo simulation that such microdomains do indeed occur. The oxygen content is allowed to vary in the simulations, while the Fe-Cu sublattice is handled in the canonical ensemble (fixed Fe content). The Fe atoms are mobile and found to cluster along the $<11>$ direction in precise agreement with experimental observations. Figure 14, a Monte Carlo simulation "snapshot," shows how the Iron atoms are distributed, resulting in microdomains containing oxygen chains in two orthogonal directlons. Thus, while the local atonile arrangement is orthogonal, the macroscopic symmetry of the configuration is tetragonal.

\section{Atomic Imaging and Spectroscopy of Blsmuth Cuprate High Temperature Superconductors \\ G. Thomas, C. Hetherington, R. Ramesh*, B. Bagley*, J. Tarasoon*, S. Gheen ${ }^{\dagger}$, M. Rudee ${ }^{\ddagger}$, and H. Luo ${ }^{\ddagger}$}

The bismuth cuprate superconductors belong to a general class of oxides that are termed polytypoids. The different polytypoids have the same general structure but the repeat sequence in the structure changes with the composition, thus the term polytypoid. In these materials, with the general formula of $\mathrm{Bi}_{2} \mathrm{Sr}_{2} \mathrm{Ca}_{n-1} \mathrm{Cu}_{n} \mathrm{O}_{y}$ (where $n=1,2,3$, or 4$)$, the supercor,ducting transitton temperature increnses with the value of $n$ (up to $n=3$ ). The details of the cationic stacking and defects in the structure of the different polytypoids have been characterized using atomic resolution electron microscopy in conjunction with image simulations, image processing, microdiffraction and fine probe $x$-ray analysis. In sintered samples, the microstructure and consequently the transport properties have been shown to be sensitive to the structural and microchemical details adjacent to grain boundaries.

In all the polytypoid bismuth cuprates, an incommensurate structural modulation has been observed. By carrying out a series of electron diffraction experiments on samples systematically doped with $\mathrm{Pb}$ we have traced the origin of the structural modulation to the intercalation of oxygen in the two BlO layers, this periodically distorting their planarity.

\footnotetext{
"Bellcore, Red Bank, New Jersey

'Department of Physles and Astronomy, Unlversity of Maryland

$\neq$ Unlversity of Callfornia, San Dlego
} 


\section{Mlorostructure of $(\mathrm{Bl}, \mathrm{Pb}) \mathrm{SrCaCuO}$ Superconduotors at Dlfferent Oxygen Pressures}

W. OAO, O. HETHERINGTON, AND G. THOMAS

The midrostructure of $(\mathrm{Bl}, \mathrm{Pb}) \mathrm{SrCaCuO}$ suporconductors annealed at different oxygen partial prossures has been studied by high resolution electron microsecopy (IITEM). Tho rosults are boing corrolated with the processing conditions and olectrical propertlos. Those compounds form a serios of polytypolds, each with a specifle critical tomperature. The $n=3$ polytypoid $\left(\mathrm{Bl}, \mathrm{Pb}_{2} \mathrm{Sr}_{2} \mathrm{Ca}_{2} \mathrm{Cu}_{3} \mathrm{O}_{4}\right.$ has the highest $\mathrm{T}_{4}$ (1)5K), and the $n=2$ polytypold $(\mathrm{Bl}, \mathrm{Pb})_{2} \mathrm{Sr}_{2} \mathrm{CaCu}_{2} \mathrm{O}_{y}$ has $\mathrm{T}_{\mathrm{a}}=85 \mathrm{~K}$. In particular since the oxy gen content is thought to play an important role in the structure and properties, curront work Involves the investigation of post-annoal troatments undor varying partial pressures of oxygen. Melssnor curves show that the $T_{c}$ of the superconductor is decrensed at higher oxygen partial pressures, with an optimal pressure boing 10 mbar. $X$-ray and TEM results confirm that the main phase in these samples is the $n=3$ polytypold. HREM results show that the lower $\mathrm{T}_{\mathrm{c}} \mathrm{n}=2$ phase occurs as defects in the $(n=3)$ grains and this phase incroases with increasing oxygen pressure. These results show that the na3 polytypold is unstable under highor oxygen pressure and reverts to the $n=2$ form. This case also is found along the grain boundaries in the samples annealed at higher oxygen pressure. The observation of relatively Bl-rich lower $\mathrm{T}_{\mathrm{c}}$ polytypolds near the grain boundary suggests a strong tendency for Bt to segregate near such interfaces. This growth process may be affected by the presence of excess oxygen near the boundarles. The decomposition of $n=3$ is probably one of the important roasons for the decrease of $T_{c}$ with increasing oxygen partial pressure.

Program Leader

Alox Zottl

Investigators

Paul Bordaht*

Marvin Cohon

John Clarko

Leo Falicov

Didier do Fontaine

Ronald Cronsky

Eugene Haller

Carson Joffrios

Lutgard Do Jonghe

Vladimir Kresin ${ }^{\dagger}$

Donald Olander

Norman Phillips

Alan Portis

Joffroy Relmer

Paul Richards

Michacl Rubin*

Richard Russo*

Angelica Stacy

Garoth Thomas

Jack Washburn

Elcke Weber

Potor Yu

Alox Zottl

Scientific Staff

Mehdi Balooch

Richard Dalven

Robert Fisher

William Hanson ${ }^{\ddagger}$

Crispin Hotherington

Thomas Richardson
Visiting Scientists

A. Amoto-Universitó Gonove

H. Bando-Electrotechnical Laboratory, Japan

R. Caspary-Technische Hochschule Dormstatdt

M. Colclough-Conductus, Inc.

E. Faulquos-Universito de Nantos

J.E. Gordon-Amhorst University, MA

S. Kamin-Amhorst Univorsity, MA

X.-L. Mao-University of Sclence and Technology, Hofol, PRC

S. Sachtion-Conductus, Inc.

H Svonsmark-Danish Tochnical University

Postdoctoral Fellows

Michaol Dixon*

Eric Kvam

Nancy Missort

Erik Salomons

Fredorick Wellstood

X.-D. Xlang

Graduate Students

Stuart Adler

M. Asta

K. Atwal

Troy Barbee, III

Gabriel Briceno

Brian Burk

Christopher Burmester

G. Ceder

Jennifer Corkill

William Creager

Michael Crommie

Mark Fendorf

Mark Ferrari

Kim Fortunati
"Applled Solence Dlvislón TChemlcal Solences Division ‡Englneering Division 
Ciralluate Students (comtimued)

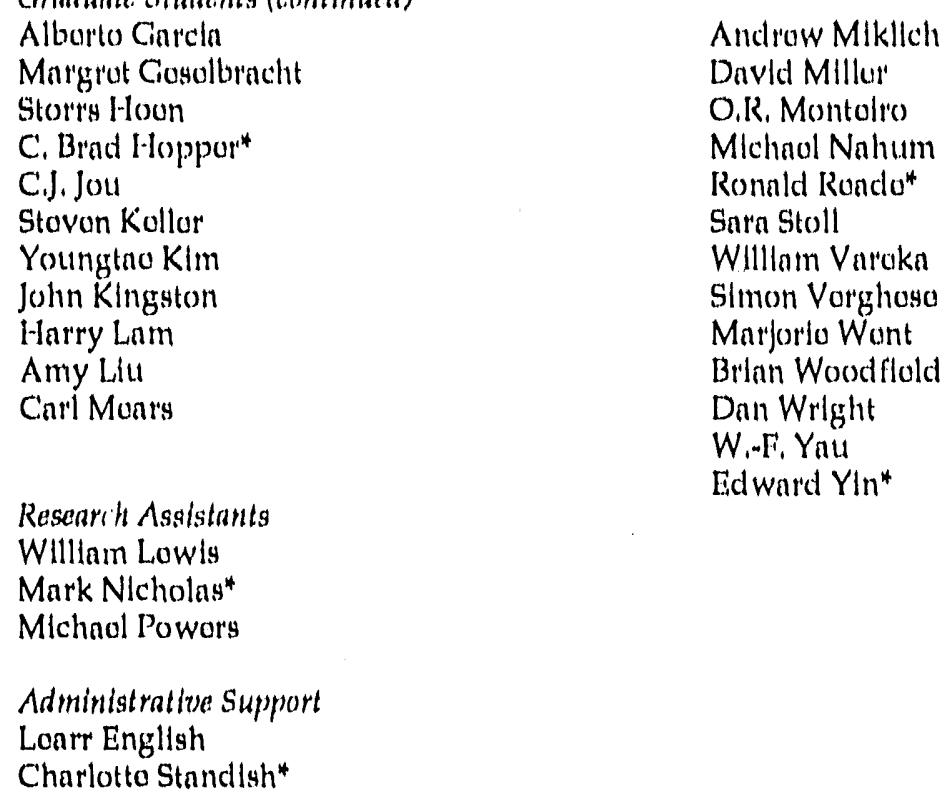

\section{Industry Interactions}

\section{Contracts}

- A grant from tho Callfornla Competitive T'echnology Program supports much of tho offort to dovolop commorcial high-T, SQUID magnotomotors. This work Incluctos collaborations with Stanford Univorsity and Conductus, Inc.

- Tho Electrle Powor Rosearch Instltuto (EPRI) provided support for resoarch on improved coramlcs for high-current applications, El'RI also supportod rosearch leading to tho discovory of the now suporconducting matorial $\mathrm{Li}_{x} \mathrm{NbO}_{2}$.

\section{Industrlal Collaborations}

- The group of 'T. Vonkatesan at Bollcore and N. Nowman and B. Cole of Conductus, Inc, are collaborating with P. Richard on studles of infrarod absorption in thin high$T_{\mathrm{c}}$ films. This group also collaboratos with J. Clarke on tho investigation of flux nolso in high- $T_{\mathrm{e}}$ matorials.

- M. Crawford and E. McCarron III of du Pont aro collaborating on specific hoat measuromonts with N. Phillips and A. Stacy.

- J. Torrance of IBM Almadon Research Center is collaborating on specific heat moasuromonts with N. Phillips.

- A group at du Pont (K. Leary, H. Jacobson, N. Lovoy, T. Askew, and R. Flippen) are collaborating with $\mathrm{A}$. Stacy on tho production of high quality $\mathrm{YBa}_{2} \mathrm{Cu}_{3} \mathrm{O}$, using nitrogon dloxide.

- N. Nowman, B, Cole, K. Char and S. Sachtjon of Conductus, Inc, collaborato with P. Richards in tho dovo,opmont of high- $T_{\mathrm{c}}$ bolomotors and microbolomoters.

- R. Ramesh, B. Bagley, and J, Tarascon of Bollcure collaborate with G. Thomas on atomic imaging and spectroscopy of bismuth cuprate superconductors. 
Bertram Batlogg

Theodore H. Geballe

Richard E. Howard

Arthur W. Sleight
AT\&T Bell Laboratories

Stanford University

AT\&T Bell Laboratories

Oregon State University

Review Panel

\section{Publications and Reports}

Refereed Journal Articles

Adler, S.B., J.N. Michaels, and J.A. Reimer, "A Compact, High-Temperature NMR Probe for use in a Narrow-Bore Superconducting Magnet," Rev. Sci. Inst, vol. 61, p. 3368, 1990.

Ceder, G., M. Asta, W.C. Carter, M.E. Mann, M. Kraitchman, and D. de Fontaine, "Phase Diagram and Low Temperature Behavior of Oxygen Ordering in $\mathrm{YBa}_{2} \mathrm{Cu}_{3} \mathrm{O}_{2}$ Using ab Initio Interactions," Phys Reo. B, vol. 41, p. 8698, 1990.

Cohen, M.L., "Theore'ical Overview of Proposed Mechanisms for High Temperature Superconductivity," Physica Scripta, vol. T3?, p. 267, 1990.

Cohen, M.L. and D.R. Penn, "Weak Versus Strong-Coupling Theory for $\mathrm{Bi}_{2} \mathrm{Sr}_{2} \mathrm{CaCu}_{2} \mathrm{O}_{g^{\prime}}$ " Phys. Rev. B, vol. 42, p. $8702,1990$.

Cohen, M.L., D.R. Penn, and T.W. Barbee, III, "Limitations on Electronic Mechanisms for High Temperature Superconducting Oxides," Solid State Comm., vol. 75, p. 971, 1990.

Cooke, D.W., E.R. Gray, P.N. Arendt, B.L. Bennett, D.E. Brown, N.E. Elliot, A.J. Klapetzky, G.A. Reeves, and A.M. Portis, "Microwave Surface Resistance and Power Dependence of Thallium-Based Films Deposited onto Large-Area Silver Substrates," J. Supercond., vol. 3, p. 261, 1990.

Cooke, D.W., E.R. Gray, P.N. Arendt, B.L. Bennett, D.R. Brown, N.E. Elliott, A.J. Klapetzky, G.A. Reeves, and A.M. Portls, "Microwave Surface Resistance and Power Dependence of Thallium-Based Films Deposited onto Large-Area Silver Substrates," I. Supercond., vol. 3, p. 261, 1990.

Cooke, D.W., M.S. Jahan, D.R. Brown, K.C. Ott, E.R. Gray, J.L. Smith, J.O. Willts, B.L. Bennett, M.A. Maez, E.J. Peterson, W.L. Hults, J.Y. Coulter, A.M. Portis, H. Piel, N. Klein, G. Muller, and M. Hein, 'Neutron-Induced Microwave Loss in Ceramic $\mathrm{YBa}_{2} \mathrm{Cu}_{3} \mathrm{O}_{7-8} "$ Appl. Phys. Lett., vol. 56, p. 2462, 1990.

Crommie, M.F., A.Y. Liu, M.L. Cohen, and A. Zettl, "Variable Normal-State Transport Properties of Bi2Sr2CaCu2O8-y," Phys. Reo. B, vol. 41, p. 2526, 1990.

Crommie, M.F., Y. Liu, M.L. Cohen, and A. Zettl, "Variable Normal-State Transport Properties of $\mathrm{Bi}_{2} \mathrm{Sr}_{2} \mathrm{CaCu}_{2} \mathrm{O}_{8-y^{\prime \prime}}$ " $\mathrm{Phys}$. Rev. $B$, vol. 41, p. 2526, 1990.

Crommie, M.F. and A. Zettl, "Thermai Conductivity of Single-Crystal Bi-Sr-Ca-Cu-O," Phys. Rev. B, vol. 41, p. $10978,1990$.

de Fontaine, D., "Comment on Structural Properties of the Tetragonal Superconductors $\mathrm{LaBaCaCu}_{3} \mathrm{O}_{7-8 \text { " }}$ " J. Less-Common Met., vol. 160, p. L5, 1990.

de Fontaine, D., G. Ceder, and M. Asta, "Low Temperature Long-Range Oxygen Order in $\mathrm{YBa}_{2} \mathrm{Cu}_{3} \mathrm{O}_{z^{\prime}}$ " Nature, vol. 34.3, p. $544,1990$.

de Fontaine, D., G. Ceder, and M. Asia, "Thermodynamics of Oxygen Ordering in $\mathrm{YBa}_{2} \mathrm{Cu}_{3} \mathrm{O}_{z^{\prime}}$ " J. Less-Common Metals, vol. 160, p. L5, 1990.

Fendorf, M., C.P. Burmester, L.T. Wille, and R. Gronsky, "Copper-Oxygen Intercalation and Related Phase Transformations in YBaCuO," Appl. Phys. Lett, vol. 57, p. 2481, 1990.

Ferarri, M.J., M. Johnson, F.C. Wellstood, J. Clarke, D. Mitzi, P.A. Rosenthal, C.B. Eom, T.H. Geballe, A. Kapitulnik, and M.R. Beasley, "Distribution of Flux Pinning Energies in $\mathrm{YBa}_{2} \mathrm{Cu}_{3} \mathrm{O}_{7.8}$ and $\mathrm{Bi}_{2} \mathrm{Sr}_{2} \mathrm{CaCu}_{2} \mathrm{O}_{8+8}$ from Flux Noise," Phys. Rev. Lett., vol. 64, p. 72, 1990.

Ferrari, M., M. Johnson, F.C. Wellstood, and J. Clarke, "Flux Pinning Energies in High-T, Superconductors: Ferrari, et al Reply," Phys. Rev. Lett., vol. 65, p. 279, 1990.

Freericks, J.K. and L.M. Falicov, "Exact Many-Body Solution of the Periodic-Cluster t-t'-J Modei for Cubic Systems: GroundState Properties," Phys. Reo. B, vol. 42, p. 4960, 1990.

Freericks, J.K. and L.M. Falicov, "Exact Many-Body Solutions of the Periodic Cluster t-t'-J Model for Cubic Systems: GroundState Properties," Phys. Reo. B, vol. 42, p. 4960, 1990. 
Geselbracht, M.J., T.J. Richardson, and A.M. Stacy, "Superconductivity in the Layered Compound $\mathrm{Li}_{x} \mathrm{NbO}_{2}$ " Nature, vol. 345 , p. 324, 1990.

Hu, Q., C.A. Mears, P.L. Richards, and F.L. Lloyd, "Observation of Non-Dissipative Quasiparticle Tunnel Currents in Superconducting Tunnel Junctions," Phys. Rev. Lett., vol. 64, p. 2945, 1990.

Johnson, M., M.J. Ferrari, F.C. Wellstood, and J. Clarke, "Random Telegraph Signals in High-Temperature Superconductors," Rapid Communication, vol, 42, p. 10792, 1990.

Khachaturyan, A.G. and J.W. Morris, Jr., "Diffuse Scattering from $\mathrm{YBa}_{2} \mathrm{Cu}_{3} \mathrm{O}_{7}$ Oxide Caused by Magnell-Type Plane Defects," Phys. Rev. Lett., vol. 64, p. 76, 1990.

Kijima, N., R. Gronsky", H. Endo, Y. Oguid, S. McKernan, and A. Zettl, "Superconductivity and Chemical Composition of the High-T, Phase in the Sb-Pb-Bi-Sr-Ca-Cu-O System," Ipn. J. Appl. Phys., vol. 30, p. L99, 1990.

Kingston, J.J., F.C. Wellstood, Ph. Lerch, A.H. Miklich, and J. Clarke, "Multilayer $\mathrm{YBa}_{2} \mathrm{Cu}_{3} \mathrm{O}_{\mathrm{x}}-\mathrm{SrTiO}_{3}-\mathrm{YBa}_{2} \mathrm{Cu}_{3} \mathrm{O}_{\mathrm{x}}$ Films for Insulating Crossovers," Appl. Phys. Lett., vol. 56, p. 189, 1990.

Kramer, M.J., L.S. Chumbley, R.W. McCallum, W.J. Nelles, S. Weir, and E.P. Kvam, "Deformation Induced Defects in $\mathrm{YBa}_{2} \mathrm{Cu}_{3} \mathrm{O}_{7-8}$ " Physica C, vol. 166, p. 115, 1990.

Kresin, V.Z. and H. Morawitz, "Carrier Concentration Dependence of High- $\mathrm{T}_{\mathrm{c}}$ Superconductivity in the Layered Copper Oxides," Solid State Comım., vol. 74, p. 1203, 1990.

Kresin, V.Z. and H. Morawitz, "High T Superconductor in an AC Field," J. Supercon., vol. 3, p. 177, 1990.

Kresin, V.Z. and H. Morawitz, "Positron-Annihilation Lifetime in the High-T ${ }_{c}$ Oxides," J. Supercon., vol. 3, p. $227,1990$.

Kresin, V.Z. and S.A. Wolf, "Major Normal and Superconducting Parameters of High-T $\mathrm{T}_{c}$ Oxides," Phys. Reo. B, vol. 41, p. 4278, 1990 .

Kresin, V.Z. and S.A. Wolf, "Multigap Structure in the Cuprates," Physica C, vol. 169, p. 476, 1990.

Kresin, V. and H. Morawitz, "Plasmon Spectrum in Layered Conductors," Phys. Lett. A, vol. 145, p. 368.

Lam, Q.H., Y. Kim, and C.D. Jeffries, "Nonlinear Electrodynamics in Granular $\mathrm{YBa}_{2} \mathrm{Cu}_{3} \mathrm{O}_{7}$ : Measurements and Models of Complex Permeability," Phys. Rev. B, vol. 42, 1990.

Leary, K.J., H.W. Jacobson, N.F. Levoy, R.A. Lapalomento, T.R. Askew, R.B. Flippen, S.W. Keller, and A.M. Stacy, "The Production of High Performance $\mathrm{YBa}_{2} \mathrm{Cu}_{3} \mathrm{O}_{7}$ Using Nitrogen Dioxide," J. Mat. Res., vol. 5, p. 22, 1990.

Monteiro, O.R. and J.W. Evans, "In Situ Observation of the Orthorhombic-Tetragonal Phase Transformation in $\mathrm{YBa}_{2} \mathrm{Cu}_{3} \mathrm{O}_{7-8}$ " $J$. Appl. Phys., vol. 69, p. 2414, 1990.

Morris, D.E., A.P. Marathe, and A.P.B. Sinha, "Destabilisation of 124 and 247 Phases of Y-Ba-Cu-O by Fe Substitution at Elevated Oxygen Pressures," Physica C, vol. 169, p. 386, 1990.

Morris, D.E., A.G. Markelz, and J.H. Nickel, Conversion of 124 into $123+\mathrm{CuO}$, and 124, 123, and 247 Phase Regions in the $Y$-BaCu-O System, 168, p. 153, 1990.

Morris, D.E., P.K. Narwankar, and A.P.B. Sinha, "Lanthanum-Substituted Y-Ba-Cu-O Superconductors Synthesized at Elevated Oxygen Pressures," Appl. Phys. Lett, vol. 57, p. 715, 1990.

Morris, D.E., P. Narwankar, A.P.B. Sinha, K. Takano, B. Fayn, and V.T. Shum, "Calcium Substituted Y-Ba-Cu-O Superconductors with Enhanced T Synthesized at Elevated Oxygen Pressures," Phys. Rev. B, vol. 41, p. 4118, 1990.

Olander, D.R., "Laser-Pulse Vaporization of Refractory Materials," Pure E Appl. Chem., vol. 62, p. 123, 1990.

Pasternak, M.P., R.D. Taylor, A. Chen, C. Meade, L.M. Falicov, A. Giesekus, R. Jeanloz, and P.Y. Yu, "Pressure Induced Metallization and the Collapse of the Magnetic State in Antiferromagnetic Insulator Nil ${ }_{2}$ " Phys. Reo. Lett., vol. 65, p. 790, 1990.

Phillips, N.E., R.A. Fisher, J.E. Gordon, S. Kim, A.M. Stacy, M.K. Crawford, and E.M. McCarron III, "Specific Heat of $\mathrm{YBa}_{2} \mathrm{Cu}_{3} \mathrm{O}_{7}$ : Origin of the 'Linear' Term, Volume Fraction of Superconductivity," Phys. Reo. Lett, vol. 65, p. $357,1990$.

Portis, A.M., D.W. Cooke, and E.R. Gray, "RF Properties of High-Ternperature Superconductors: Cavity Methods," I. Supercond., vol. 3, p. 297, 1990.

Ramesh, R., D.M. Hwang, T. Venkatesan, T.S. Ravi, L. Nazar, A. Inam, X.D. Wu, B. Dutta, G. Thomas, A.F. Marshall, and T.H. Geballe, "Direct Observation of Structural Defects in Laser-Deposited Superconducting YBaCuO Thin Films," Science, vol. 247, p. 57, 1990.

Richardson, T.J. and L.C. De Jonghe, "Traveling Reaction Zone Method for Preparation of Textured Ceramic Superconductor Thick Films," J. Am. Ceram. Soc, vol. 73, p. 3511. (In press.) 
Richardson, T.J. and L.C. De Jonghe, "Accoustic Emission Study of Microcracking in 123-Type Ceramic Superconductors," I. Mat. Res., vol. 5, p. 2066, 1990.

Robbes, D., A.H. Miklich, J.J. Kingston, Ph. Lerch, F.C. Wellstood, and J. Clarke, "Josephson Weak Links in Thin Films of $\mathrm{YBa}_{2} \mathrm{Cu}_{3} \mathrm{O}_{7-\mathrm{x}}$ Induced by Electrical Pulses," Appl. Phys. Lett., vol. 56, p. 2240, 1990.

Salomons, E. and D. de Fontaine, "Monte Carlo Study of Tracer and Chemical Diffusion of Oxygen in $\mathrm{YBa}_{2} \mathrm{Cu}_{3} \mathrm{O}_{6+2 \mathrm{c}}$ " $P$ hys. Rev. B, vol. 41, p. 11159, 1990.

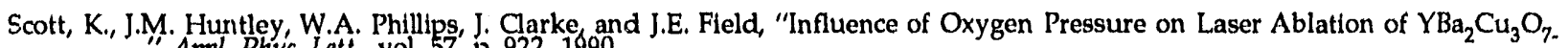
$\mathrm{x}^{\prime \prime}$ Appl. Phys. Lett., vol. 57, p. 922, 1990.

Svensmark, H. and L.M. Falicov, "Superconducting Vortex-Line Configurations in Materials with Twin Boundaries," Phys. Rev. B, vol. 42, p. 9957, 1990.

Verghese, S., P.L. Richards, K. Char, and S.A. Sachtjen, "Fabrication of a Sensitive High-T Superconducting Microbolometer," Applied Superconductivity Conf. Proc., IEEE Trans. Mag, vol. 1292, p. 137, 1990. (Submitted.)

VerNooy, P.D., M.A. Dixon, F.J. Hollander, and A.M. Stacy, "Novel $\mathrm{Cu}_{6} \mathrm{O}_{15}$ 'Bowls' in Seven New Barium Copper Oxides," Inorg. Chem., vol. 29, p. 2837, 1990.

Wellstood, F.C., J.J. Kingston, and J. Clarke, "Superconducting Thin Film Multiturn Coils of $\mathrm{YBa}_{2} \mathrm{Cu}_{3} \mathrm{O}_{7-\mathrm{x}^{\prime}}$ " Appl. Phys. Lett., vol. 56, p. 2336, 1990.

Wellstood, F.C., J.J. Kingston, M.J. Ferrari, and J. Clarke, "Superconducing Thin-Film Flux Transformers of $\mathrm{YBa}_{2} \mathrm{Cu}_{3} \mathrm{O}_{7-x^{\prime}}$ " $A p p l$. Phys. Lett, vol. 57, p. 1930, 1990. (In press.)

Went, M.S. and J.A. Reimer, "Oxygen-17 Nuclear Magnetic Resonance Studies of Lanthanum Strontium Copper Oxygen," Chemistry of Materials, vol. 2, p. 389, 1990.

Xiang, X.-D., S. McKernan, W.A. Vareka, A. Zettl, J.L. Corkill, T.W. Barbee, III, and M.L. Cohen, "Iodine Intercalation of a High-Temperature Superconducting Oxide," Nature, vol. 348, p. 145, 1990.

Zhang, H., J.W. Lynn, W. Li, T.W. Clinton, and D.E. Morris, "Two and Three-Diminsional Magnetic Order in $\mathrm{RBa}_{2} \mathrm{Cu}_{4} \mathrm{O}_{8}$ " Phys. Rev. B, vol. 41, p. 11229, 1990.

Thomas, G. and R. Ramesin, "Atomic Imaging and Microanalysis of Ceramics at the NCEM, Berkeley, California", Ceramic Transactions vol.5,p.287,1990. (ed. W.Young, G.McVay and G.Pike)

Salcimons, E. and D. de Fontaine, "Monte Carlo Study of Tracer and Chemical Diffusion of Oxygen in $\mathrm{YBa}_{2} \mathrm{Cu}_{3} \mathrm{O}_{6+2 \mathrm{c}}$ " Phys. Rev. $B$, vol. 41, p. 11159, 1990.

de Fontaine, D., G. Ceder, and M. Asta, "Thermodynamics of Oxygen Ordering in $\mathrm{YBa}_{2} \mathrm{Cu}_{3} \mathrm{O}_{\mathrm{Z}}$ " J. Less-Common Metals, vols. 164 \& 165, p. 108; 1990.

Ferrari, M. J., M. Johnson, F. C Wellstood, J. Clarke, D. Mitzi, P. A. Rosenthal, C. B. Eom, T. H. Geballe, A. Kapitulnik, and M. R. Beasley, "Distribution of Flux Pinning Energies in $\mathrm{YBa}_{2} \mathrm{Cu}_{3} \mathrm{O}_{7-\mathrm{d}}$ and $\mathrm{Bi}_{2} \mathrm{Sr}_{2} \mathrm{CaCu}_{2} \mathrm{O}_{8+\mathrm{d}}$ rom Flux Noise," Phys. Rev. Lelt. 64,72 (1990).

Kingston, J. J., F. C. Wellstood, Ph. Lerch, A. H. Miklich and J. Clarke, "Multilayer $\mathrm{YBa}_{2} \mathrm{Cu}_{3} \mathrm{O}_{\mathrm{X}}-\mathrm{SrTiO}_{3}-\mathrm{YBa}_{2} \mathrm{Cu}_{3} \mathrm{O}_{\mathrm{X}}$ Films for Insulating Crossovers," Appl. Phys. Lett. 56, 189 (1990).

Robbes, D., A.H. Miklich, J. J.Kingston, Ph. Lerch, F. C.Wellstood, and J. Clarke,"Josephson Weak Links in Thin Films of YBa2 $\mathrm{Cu}_{3} \mathrm{O}_{7-x}$ Induced by Electrical Pulses," Appl. Phys. Lett. 56, 2240 (1990); erratum 57, 1169 (1990).

Wellstood, F. C., J. J. Kingston, and J. Clarke, "Superconducting Thin Film Multiturn Coils of YBa2 $\mathrm{Cu}_{3} \mathrm{O}_{7-\mathrm{x}}$ " Appl, Phys. Lett. 56, 2336 (1990).

Scott, K., J. M. Huntley, W. A. Phillips, J. Clarke, and J. E. Field, "Influence of Oxygen Pressure on Laser A.blation of $\mathrm{Yba}_{2} \mathrm{Cu}_{3} \mathrm{O}_{7-\mathrm{x}}$ " Appl. Phys. Lett. 57, 922 (1990).

Cohen, M. L., D. R. Penn, and T. W. Barbee III, "Limitations on Electronic Mechanisms for High Temperature Superconducting Oxides," Solid State Comm., vol. 75, p. 971, 1990.

Barbee III, T. W., A. Garcia, and M. L. Cohen, "Theoretical Study of High Pressure Metallic Hydrogen," Mat. Res. Soc. Symp. Proc., vol. 193, p. 15, 1990.

Cohen, M. L. and D. R. Penn, "Weak- Versus Strong-Coupling Theory for $\mathrm{Bi}_{2} \mathrm{Sr}_{2} \mathrm{CaCu}_{2} \mathrm{O}_{8}$," Phys. Rev. B, vol. 42, p. $8702,1990$.

Cohen, M. L., "Some Theories of High Temperature Superconductivity," Mat. Res. Soc. Symp. Proc., vol. 169, p. 13, 1990.

Amato, A., R.A. Fisher, R. Caspary, N.E. Phillips, H.B. Raduusky, J. Peng, L.Zhang and R.N. Shelton, "Specific Heat of $\left(Y_{1-x} P r_{x}\right)$ $\mathrm{Ba}_{2} \mathrm{Cu}_{3} \mathrm{O}_{7}$ : Magnetic Ordering; Magnatic Hyperfine Fields", Physica B, vol. 165-166, p. 1347, 1990.

Amato, A., R.A. Fisher, N.E. Phillips and J.B. Torrance, "Specific Heat of La2-x $\mathrm{Sr}_{x} \mathrm{CuO}_{4}$ : Volume Fraction of Superconductivity; Possible Structural Transition at 45K", Physica B, vol, 165-166, p. 13371990. 
Clarke, J., "SQUIDs: Principles, Noise and Applications," in Superconducting Devices, ed. S.T. Ruggiero and D. A. Rudman, p. 51, Academic Press, 1990.

Kresin, V.Z., "Proximity Effect and High- $\mathrm{T}_{\mathrm{c}}$ Superconductivity," in Advances in Superconductivity, ed. T. Ishiguro and K. Kajimura, p. 969, 1990.

Kresin, V.Z. and S. Wolf, Fundamentals of Superconductivity, Plenum Press, 1990.

Portis, A.M., "Microvaves and Superconductivity: Processes in the Intergranular Medium," in Earlier and Recent Aspects of Superconductivity, ed. J.G. Bednorz, K.A. Mueller, vol. 90, p. 278, Springer-Verlag, 1990.

Ceder, G., M. Asta, and D. de Fontaine, "Oxygen Ordering in $\mathrm{YBa}_{2} \mathrm{Cu}_{3} \mathrm{O}_{\mathrm{Z}}$ at Low Temperature," in Mat. Res. Soc. Symp. Proc., vol. 169. p. 189, 1990.

Hu, Qing, and Richards, P. L., "Quasiparticle Mixers and Detectors," in Modern Superconducting Devices, eds, Steven T. Ruggiero and David A. Rudman, pp. 169-196, Academic Press, San Diego, California 1990, ${ }^{\dagger}$

Balooch, M., D.R. Olander, R.E. Russo, and W.J. Siekhaus, "Long Laser-Pulse Method of Producing Y-Ba-Cu-O Superconducting Films," Materials Research Society Symposium, in Proceedings on High Temp. Superconductors; Fundamental Properties and Novel Material Processing, eds. D.Christen, J. Narayan and L. Schneemeyer, vol. 169, p. 447, 1990.

Theses

Fortunatl, K., Electron Microscopy Study of Transition Metal BiCaSrCuO Superconductors. (Masters Thesis, April 1990, U.C. Berkeley, Advisor: R. Gronsky)

Kim, Y., Quasiperiodic Transition to Chaos in Ge; and Magnetic Susceptibility of High- $T_{c}$ Superconductors. (Ph.D. Thesis, U.C. Berkeley.)

LBL Reports

Amato, A., R. Caspary, R.A. Fisher, J.L. Peng, N.E. Phillips, H.B. Radousky, R.N. Shelton, and L. Zhang, "The Low Temperature and High Field Heat Capacity of $\mathrm{Y}_{1-x} \mathrm{Pr}_{x} \mathrm{Ba}_{2} \mathrm{Cu}_{3} \mathrm{O}_{7}$ : Magnetic Order and Hyperfine Fields," Phys. Rev. B. (Submitted.)

Burmester, C.P., S. Quong, L.T. Wille, R. Gronsky, B.T. Ahn, V.Y. Lee, R. Beyers, T.M. Gur, and R.A. Huggins, LBL 29215, "High Resolution Transmission Electron Microscopy of Partial States of Oxygen Order in $\mathrm{YBa}_{2} \mathrm{Cu}_{3} \mathrm{O}_{z^{\prime}}$ " Mat. Res. Soc. Proc. (In press.)

Burmester, C.P., L.T. Wille, and R. Gronsky, "Monte Carlo Study of Domain Formation in $\left.\mathrm{YBa}_{21-\mathrm{x}} \mathrm{Fe}_{\mathbf{x}}\right) \mathrm{O}_{z}$ " Solid State Comm. (Submitted.) Burmester, C.P., L.T. Wille, and R. Gronsky, "Monte Carlo Study of Oxygen Ordering in $\mathrm{YBa}_{2} \mathrm{Cu}_{3} \mathrm{O}_{7 . y}$ " Mat. Res. Soc. Proc. (In
press.)

Chandrachood, M.R., A.P.B. Sinha, and D.E. Morris, "Lithium Substituted Supersonducting $\mathrm{Y}_{1} \mathrm{Ba}_{2} \mathrm{Cu}_{4} \mathrm{O}_{8}$ Formed in Elevated Oxygen Pressure," Physica C. (Submitted.)

Chandrachood, M.R., A.P.B. Sinha, and D.E. Morris, "Phase Diagram and New Phases in the Y-Ba-Cu-O System at Filgh Oxygen Pressure," Physica $C$.

Cooke, D.W., P.N. Arendt, E.R. Gray, A. Mayer, D.R. Brown, N.E. Elliott, G.A. Reeves, and A.M. Portis, "High-Frequency Properties of Tl-based Superconductors Deposited onto Large-Area Metallic Substrates," IEEE Trans. Magn. (In press.)

Cooke, D.W., P.N. Arendt, E.R. Gray, R.E. Meunchausen, B.L. Bennett, S.R. Foltyn, R.C. Estler, X.D. Wu, G.A. Reeves, N.E Elliot, N.E. Elliott, D.R. Brown, A.M. Portis, R.C. Taber, and A. Mogrocampero, "Microwave Properties of HTS Films," Proc. 2nd Int. Conf. on Elec. Mats.. (In press.)

Crommic, M.F. and A. Zettl, "Anisotropic Thermal Conductivity of Bi-Sr-Ca-Cu-O," Phys. Rev. B. (In press.)

Fendorf, M., C.P. Burmester, L.T. Wille, and R. Gronsky, LBL 28669, "Experimental and Theoretical Characterization of the $\mathrm{YBa}_{2} \mathrm{Cu}_{3} \mathrm{O}_{7} / \mathrm{YBa}_{2} \mathrm{Cu}_{3} \mathrm{O}_{8}$ Phase Transformation," Mat. Res. Soc. Proc. (In press.)

Ferrari, M.J., J.J. Kingston, F.C. Wellstood, and J. Clarke, "Flux Noise from Superconducting $\mathrm{YBa}_{2} \mathrm{Cu}_{3} \mathrm{O}_{7 \cdot \mathrm{x}}$ Flux Transformers," Appl. Phys, Lett. (Submitted.)

Hu, Q., C.A. Mears, P.L. Richards, and F.L. Lloyd, "Quantum Susceptance and its Effects on the High Frequency Response of Superconducting Tunnel Junctions," Phys, Rev. B. (Submitted.)

Hu, Q., C.A. Mears, P.L. Richards, and F.L. Lloyd, "Observation of Quantum Susceptance in Superconducting Tunnel Junctions," Bull. Am. Phys. Soc., vol. 35, p. 202, 1990.

Jou, C.J. and J. Washburn, Relationship between $T_{c}$ and Electronegativity Differences in Compound Superconductors. Barbee III, T. W., A. Garcia, and M. L. Cohen, "Prediction of Possible High-T T Superconductivity in Metalic Hydrogen," Bull. A.P.S.,
vol. 35, p. 196, 1990. 
Mao, X., R.E. Russo, H.B. Liu, and J. Ho, "As-Deposited Superconducting Sb Doped Bi-Pb-Sr-Ca-Cu-O Thin Films Prepared by Pulsed Laser Deposition," Appl. Phys. Lett. (Submitted.)

Mears, C.A., Q. Hu, and P.L. Richards, "The Effect of the Quantum Susceptance on the Gain of Superconducting Quasiparticle Mixer," Applied Superconductivity Conf. Proc., IEEE Trans. Mag. (Submitted.)

Mears, C.A., Q. Hu, P.L. Richards, A. Worsham, and D.E. Prober, "Quantum Limited Quasiparticle Mixers at $100 \mathrm{GHz}$," Applied. Superconductivity Conf. Proc., IEEE Trans. Mag.

Mears, C.A., Q. Hu, P.L. Richards, A. Worsham, D.E. Prober, and A.V. Raisanen, "Quantum Limited Heterodyne Detection of Millmeter Waves Using Superconducting Tantalum Tunnel Junctions," Appl. Phys. Lett. (Sumbitted.)

Morawitz, M., I Bozovic, and V.Z. Kresin, "Layer Plasmons and the Optical Response of Superconducting Films of $\mathrm{YBa}_{2} \mathrm{Cu}_{3} \mathrm{O}_{7}$ " Phys. Reo. B. (Submitted.)

Morris, D.E., M.R. Chandrachood, and A.P.B. Sinha, "Synthesis of Thalljum Superconductors with Improved Properties in Elevated Oxygen Pressure," Physica C. (Submitted.)

Morris, D.E., J. Nickel, B. Feyn, A. Markelz, R. Gronsky, M. Fendorf, and C.P. Burmester, "Introduction of Defects and Strain Fields for Flux Pinning by Conversion of 124 into 123 Superconductor and CuO," Mat. Res. Soc. Proc. (In press.)

Nahum, M., Q. Hu, P.L. Richards, N. Newman, and S.A. Sachtjen, "Fabrication and Measurement of a High-T ${ }_{c}$ Superconducting Microbolometer," Applied Superconductivity Conf. Proc., IEEE Trans. Mag. (Submitted.)

Nahum, M., Q. Hu, P.L. Richards, and S.A. Sachtjen, "Fabrication and Measurement of a High-T ${ }_{c}$ Superconducting Microbolometer," Bull. Am. Phys. Soc., vol. 35, p. 719, 1990.

Nahum, M. and P.L. Richards, "Design Analysis of a Novel Low Temperature Bolometer," Applied Superconductivity Conf. Proc., IEEE Trans. Mag. (Submitted.)

Narwankar, P.K., M.R. Chandrachood, D.E. Morris, and A.P.B. Sinha, "Enhanced Critical Current Density in Ca Doped $\mathrm{Y}_{1} \mathrm{Ba}_{2} \mathrm{Cu}_{4} \mathrm{O}_{8}{ }^{\prime \prime}$ Appl. Phys. Lett. (Submitted.)

Narwankar, P.K., A.P.B. Sinha, and D.E. Morris, "124 Superconductor Stabilized by Hole Donor (Ca) Along with Acceptor (La) Substitution," Physica C. (In press.)

Phillips, N.E., R.A. Fisher, and J.E. Gordon, "The Specific Heat of High-T ${ }_{c}$ Superconductors," in Progress in Low-Temperature Physics 13, ed. D. Brewer, Elsevier.

Portis, A.M., D.W. Cooke, E.R. Gray, P.N. Arendt, C.L. Bohn, J.R. Delayen, C.T. Roche, M. Hein, N. Klein, G. Muller, S. Orbach, and H. Piel, "Power and Magnetic Fleld-Induced Microwave Loss in Tl-based High- $T_{c}$ Superconducting Films," Appl. Phys. Let. (Submitted.)

Portis, A.M., W.F. Yau, E.R. Weber, and N. Newman, "Microwave Properties of High Quality in-situ Sputtered Y-Ba-Cu-O Thin Films," Proc. 7th CIMTEC-World Ceramics Congress and Satellite Symposia, Trieste. (In press.)

Richardson, T.J, and L.C. De Jonghe, LBL 28720, "Traveling Solvent Zone Texturing of Ceramic Superconductor Thick Films," J. Mat. Sci. Let.

Russo, R.E., R.P. Reade, P. Berdahl, J.M. McMillan, and B.L. Olsen, "Fabrication and Characterization of YBaCuO Thin Films on Stainless Steel Substrates," Proc. 2nd Int. Symp. on High- $T_{c}$ Superconducting Compounds: Processing and Supercond. Props., (TMS Annual Meeting). (In press.)

Russo, R.E., R.P. Reade, J.M. McMillan, and B.L. Olsen, "Metal Buffer Layers and YBaCuO Thin Films on Pt and Stainless Steel Using Pulsed Laser Deposition," I. Appl. Phys. (In press.)

Tidjani, M.E., R. Gronsky, J.J. Kingston, F.C. Wellstood, and J. Clarke, "Heteroepitaxial $\mathrm{YBa}_{2} \mathrm{Cu}_{3} \mathrm{O}_{7 \cdot x}-\mathrm{SrTiO}_{3}-\mathrm{YBa}_{2} \mathrm{Cu}_{3} \mathrm{O}_{7 \cdot x}$ Trilayers Examined by Transmission Electron Microscopy," Appl. Phys. Lett. (Submitted.)

Verghese, S., P.L. Richards, K. Char, and S.A. Sachtjen, "Fabrication of a High-T Superconducting Bolometer," SPIE Proc. (Submitted.)

Wille, L.T., C.P. Burmester, P.A. Sterne, R. Gronsky, B.T. Ahn, V.Y. Lee, R. Beyers, T.M. Gur, and R.A. Huggins, LBL. 29216, "Oxygen Ordered Superstructures and Domain Formation in $\mathrm{YBa}_{2} \mathrm{Cu}_{3} \mathrm{O}_{7-x^{\prime}}$ " Int. Cryog. Topical Mats. Conf. Proc. (In press.)

Wille, L.T., P.A. Sterne, C.P. Birmester, and R. Gronsky, "First-Principles Calculation and HREM Study of Oxygen Ordering and Domain Formation in $\mathrm{YBa}_{2} \mathrm{Cu}_{3} \mathrm{O}_{7 \cdot y}$ " Mat. Res. Soc. Proc. (In press.)

Yamamoto, L. and R. Gronsky, "Grain Boundary Structure and Critical Currents in YBCO," Mat. Res. Soc. Proc. (In press.)

Asta, M., D. de Fontaine, G. Ceder, E. Salomons, and M. Kraitchman, "One- and Two-Dimensional Oxygen Ordering in $\mathrm{YBa}_{2} \mathrm{Cu}_{3} \mathrm{O}_{x}$ " LBL-28802, J. Less-Common Metals. (In press.)

Johnson, M., M.J. Ferrari, F. C. Wellstood, and J. Clarke, LBL-29510, "Random Telegraph Signals in High Temperature Superconductors," Phys. Reo. Rapid Communication (In press.) 
Tidjani, M. E., R. Gronsky, J.J. Kingston, F. C. Wellstood, and J. Clarke, LBL-29667, "Heteroepitaxial YBa2 $\mathrm{Cu}_{3} \mathrm{O}_{7 \times x} \mathrm{SrTiO}_{3}$ $\mathrm{YBa}_{2} \mathrm{Cu}_{3} \mathrm{O}_{7-x}$ Trilayers Examined by Transmission Electron Microscopy," Appl. Phys. Lett. (Submitted.)

Clarke, J., LBL-30088, "Superconducting Devices," Encyclopedia of Physics. Submitted.)

Wellstood, F. C., J. J. Kingston, M. J. Ferrari, and J. Clarke, LBL-28890, "Thin-Film Flux Transformers of YBa2 $\mathrm{Cu}_{3} \mathrm{O}$ 7-x," IEEE Trans. Magn. (Submitted.)

Kingston, J. J., F. C. Wellstood, Du Quan, and John Clark, LBL-28889, "Photolithographically Patterned Thin-Film Multilayer Devices of $\mathrm{YBa}_{2} \mathrm{Cu}_{3} \mathrm{O}_{7}, "$ IEEE Trans. Magn. (Submitted.)

Bindslev Hansen, J., T. Holst, F. C. Wellstood, and J. Clarke, LBL-28891, "Low Frequency Noise in Resonant Josephson Soliton Oscillators," JEEE Trans. Magn. (Submitted.)

Miklich, A. H., F. C. Wellstood, J. J. Kingston, J. Clarke, M. S. Colclough, A. H. Cardona, L. C. Bourne, W. L. Olson, and M. M. Eddy, LBL-28892, "High-TC Thin-Film Magnetometer," IEEE Trans. Magn. (Submitted.)

Ferrari, M., M. Johnson, F. C. Wellstood, and J. Clarke, LBL-30087, "Comment on "Theory of $1 / \mathrm{f}$ Magnetic Flux Noise in High-T Superconductors," Phys. Rev. Lett. (Submitted.)

Clarke, J., M.S. Colclough, Du Quan, M.J. Ferrari, J.J. Kingston, A.H. Miklich, and F.C. Wellstood, LBL.-29794, "Fligh-T ${ }_{\mathrm{C}}$ Thin-Film Microelectronics," Proc. ISS'90, Springer-Verlag (Submitted.)

Brunel, L. C., S. G. Loude, G. Martinez, S. Labdi, and H. Raffy, LBL-29442, "Superconducting Gapin $\mathrm{Bi}_{2} \mathrm{Sr}_{2} \mathrm{CaCu}_{2} \mathrm{O}_{8}$," Phys. Reo. Lett. (Submitted.)

Barbee III, T. W., M. L. Cohen, and D. R. Penn, LBL-29765, "Experimental Constraints on Some Mechanisms for High Temperature Superconductivity," Phys. Rev. (In Press.)

Crespi, V. H., M. L. Cohen, and D. R. Penn, LBL-29786, "Anharmonic Phonons and the Isotope Effect in Superconductivity," Phys. Rev. (In Press.)

Cohen, M. L., LBL-30171, "Limitations on the Theories of High Temperature Superconductors," in New Horizons in Low Dimensional Electron Systems. (In Press.)

Xiang, X.-D., A. Zettl, W. A. Vareka, J. L. Corkill, T. W. Barbee III, and M. L. Cohen, LBL-30172, "Expitaxial Intercalation of the BISr-Ca-Cu-O Superconductor Series," Phys. Rev. (In Press.)

Xiang, X.-D., A. Zettl, W. A. Vareka, J. L. Corkill, T. W. Barbee III, and M. L. Cohen, LBL-30046, "lodine Intercalated Stage II Superconducting Compound $\mathrm{I}-\mathrm{Bi}_{2} \mathrm{Sr}_{2} \mathrm{CaCu}_{2} \mathrm{O}_{\mathbf{x}}$, Science. (Submitted.)

Barbee III, T. W. and M. L. Cohen, LBL-29717, "Prediction of HIgh Temperature Superconductivity in Hexagonal and Rhombohedral Phases of Metallic Hydrogen," Phys. Reo. (In Press.)

Gordon, J.E., R.A. Fisher, S. Kim and N.E. Phillips, LBL-28305, "Thermal and Magnetic Measurements on YBa2 $\mathrm{Cu}_{3} \mathrm{O}_{7} \mathrm{y}^{\prime}$, presented at the International Conference on Superconductivity (ICSC), Bangalore, India, Jan. 10-14, 1990. (In press)

Lee, W.C., K. Sun, L.L. Miller, D.C. Johnston, C.A. Swenson, R.A. Klemm, S. Kim, R.A. Fisher and N.E. Phillips, LBL-29825, "Heat Capacity of High Purity $\mathrm{YBa}_{2} \mathrm{Cu}_{3} \mathrm{O}_{7}$ from $0.4 \mathrm{~K}$ to $400 \mathrm{~K}$ in Applied Magnetic Fields of Zero and 70 KG", Phys. Rev. B. (Submitted)

Phillips, N.E., and R.A. Fisher, LBL-28863, "Effect of Cu2+ Magnetic Moments on the Superconductivity of YBa2 $\mathrm{Cu}_{3} \mathrm{O}_{7}$. The Origin of the "Linear" Term in the Specific Heat; The Volume Fraction of Superconductivity", presented at Yamada Conference XXV on Magnetic Phase Transitions, Osaka, Japan, April 1990. (In press)

Gordon, J.E., R.A. Fisher, S. Kamin and N.E. Phillips, LBL-29411, "Specific Heat Evidence for Strong Coupling in $\mathrm{YBa}_{2} \mathrm{Cu}_{3} \mathrm{O}_{7}$, presented at the High Temperature Superconductivity Conference, Cambridge, U.K., Aug. 1990. (In press),

Phillips, N.E., R.A. Fisher, R. Caspary, A. Amato, H.B. Radousky, J.L. Peng, L. Zhang and R.N. Shelton, LBL-29695, " Magnetic Ordering, Hyperfine and "Linear" Contributions to the Low-Temperature Specific Heat of $\left(\mathrm{Y}_{1-x} \mathrm{Pr}_{x}\right) \mathrm{Ba}_{2} \mathrm{Cu}_{3} \mathrm{O}_{7-\delta}{ }^{\prime}, \mathrm{Phys}_{\text {, }}$ Reo. B. (Submitted)

Phillips, N.E. and R.A. Fisher, LBL-28751, “Low-Temperature Specific Heat Measurements: Application to High-T $\mathrm{C}$ Superconductors", presented at the Minerals, Metals and Materials (TMS) Meeting, Anaheim, CA Feb. 1990. (In press)

Cleland, A. N., I. M. Schmidt, and J. Clarke, LBL-29364, "Resonant Tunneling in Small Current-Blased Josephson Junctions," Phys. Reo. B1 (In press.)

de Fontaine, D., Thermodynamics of One-, Two- and Three Dimension Oxygen Ordering in $\mathrm{YBa}_{2} \mathrm{Cu}_{3} \mathrm{O}_{x}$, TMS Annual Meeting, Araheim, CA, February 1990; California Institute of Technology, Pasadena, CA, February 1990; Condensed Matter Seminar, Physics Department, University of California, Santa Cruz, CA, May 1990.

de Fontaine, D., Thermodyramics of Oxygen Ordering in $\mathrm{YBa}_{2} \mathrm{Cu}_{3} \mathrm{O}_{x}$, plenary lecture, E-MRS Spring Meeting, Strasbourg, France, MayJune 1990

Ceder, G., Low Temperature Oxygen Ordering in $\mathrm{YBa}_{2} \mathrm{Cu}_{3} \mathrm{O}_{z}$ High Temperature Superconductivity Workshop, University of Chicago, IL, September 1990.

de Fontaine, D., Thermodynamics of Oxygen Ordering in YBCO, Japanese Institute of Metals, Sendal, Japan, September 1990.

de Fontaine, D., Oxygen Ordering in the $Y B C O$ High $T_{c}$ Superconductor, Physics Department, Hokkaido University, Sapporo, Japan, September 1990. 
Hu, Qing, Mears, C. A., Richards, P. L., and Lloyd, F. L., "Observation of Quantum Susceptance in Superconducting Tunnel Juncti/ons," Bull. Am. Phys. Soc., vol. 35, p. 202, 1990 †

Richards, P.L., High $T_{C}$ Superconductive Bolometers as Infrared Detectors, American Physical Society March Meeting, Anaheim, CA, March, 1990.

Richards, P.L., Superconducting Detectors: Low $T_{c}$ and High $T_{c}$, Applied Physics Seminar, Yale University, New Haven, CT, April , 1990.

Nahum, M., Fabrication of Sensitive High $T_{C}$ Bolometers, Workshop on Innovative Long Wavelength Infrared Detectors, Pasadena, CA, April, 1990.

Clarke, J., Prog,ress Towards a Technology for Electronics with Thin Films of High Temperature Superconductors, SC Global 90, Long Beach, California, January 1990.

Clarke, J., Flux Noise and Pinning Energies in High Temperature Superconductors, colloquium at Physics Department, University of California, San Diego, San Diego, February 1990.

Ferrarl, M. J., Flux Noise and Pinning Energies in High-T $T_{c}$ Superconductors, March Meeting of the American Physical Society, Anaheim, CA, March 1990.

Clarke, J., Progress Towvards a Technology for Electronics with Thin-film High- $T_{c}$ Superconductors, seminar at Bellcore, Red Bank, New Jersey, April 1990.

Clarke, J., Flux Noise and Pinning Energies in High-T $T_{C}$ Superconductors, colloquium at AT\&T Bell Labs, Murray Hill, New Jersey, April 1990.

Wellstood, F. C., Crossovers, Flux Transformers, Pick-up Coils and HTSC SQUIDs, seminar at Conductus, Inc., Sunnyvale, California, April 1990.

Wellstood, F. C., YBCO Thin-film Coils and Flux Transformers, colloquium at University of Maryland, College Park, Maryland, April 1990.

Progress Towards Superconducting Electronics with High- $T_{c}$ Thin Films, Conference on the Sctence and Technology of Thin-film Superconductors, Denver, Colorado, May 1990.

Clarke, J., High-T $T_{C}$ Superconducting Devices, presentation to the Science and Education Advisory Committee, LBL, May 1990.

Clarke, J., l/f Noise in High- $T_{C}$ Superconductors, colloquium at Applied Science Department, UCDavis, Livermore, California, May 1990.

Clarke, J., Multilayer Thin-film Coils and Flux Transformers, SQUID 90, Dubna, USSR, May 1990.

Clarke, J., Current Dependence of Flux Noise and Pinning Energies in $\mathrm{YBa}_{2} \mathrm{Cu}_{3} \mathrm{O}_{7-x}$ Films, LT-Satellite Conference on High- $\mathrm{T}_{\mathrm{C}}$ Superconductivity, Cambridge, England, August 1990.

Clarke, J., Closing Address at LT-Satellite Conference on High-T $\mathrm{T}_{\mathrm{C}}$ Superconductivity, Cambridge, England, August 1990.

Clarke, J., Progress towards an Electronics Technology with Thin Films of High-T $T_{C}$ Superconductors, LBL Review Meeting, Berkeley, CA, September 2, 1990.

Wellstood, F. C., Vortex Motion and Noise in YBCO Flux Transformers, Condensed Matter Colloquium, Dept. of Physics and Astronomy, University of Maryland, College Park, MD, September 1990.

Clarke, J., Thermally Activated Noise Processes in High Transition Temperature Superconductors, NATO Advanced Research Workshop Rate Processes in Dissipative Systems: 50 Years after Kramers, Tutzing, Germany, September 1990.

Clarke, J., SQUID Magnetometers, Applications of Metallic and Ceramic Superconductivity, NATO Advanced Study Institute, Fort Collins, CO, September 1990.

Kingston, J. J., High $T_{C}$ Thin Film Multilayer Structures, seminar at San Francisco State University, San Francisco, CA, October 1990.

Wellstood, F. C., YBCO Thin-film Coils and Flux Transformers, Condensed Matter Collogium, Dept. of Physics, University of California, Davis, Davis, CA, October 1990.

Clarke, J., An Electronics Technology with Thins Films of High- $T_{C}$ Superconductors, Review Meeting for the media organized by the California Competitive Technology Program, San Francisco, CA, October 1990.

Wellstood, F. C.,YBCO Thin-film Coils and Flux Transformers, seminar at Superconducting Technologies, Inc., Santa Barbara, CA, October 1990.

Clarke, J., An Electronics Technology with Thin Films of High-T, Superconductors, seminar at NEC, Tsukuba, Japan, November 1990.

Clarke, J., Progress towards an Electronics Technology with Thin Films of High-T $T_{C}$ Superconductors, opening plenary address at Third International Symposium on Superconductivity, Sendai, Japan, November 1990.

Clarke, J., Closing summary at Third International Symposium on Superconductivity, Sendai, Japan, November 1990.

Clarke, J., Flux Noise and Pinning Energies in High-T $T_{C}$ Superconductors, seminar at IBM Almaden, San Jose, CA, December 1990.

Clarke, J., YBa $\mathrm{Cu}_{3} \mathrm{O}_{7-x}$ Insulated Multilayer Siructures, Fall Meeting of the Materials Research Society, Boston, MA, November 1990.

Cohen, M. L., Predicting New Solids and Superconductors, International Conference on Total Energy Methods and Physics of III-V Semicondcutors, Paris, France, January 1990.

Cohen, M. L., Some Perspective on High Temperature Superconductivity, Department of Physics, University of Generva, Geneva, Switzerland, January 1990.

Cohen, M. L., Predicting Properties of Solids and Superconductors, Ecolé Polytechnique de Lausanne, Lausanne, Switzerland, January 1990. 
Cohen, M. L., Predicting Properties of Sollds, Clusters, and Supercondiuctors, Lawrence Livermore Laboratory, Livermore, CA, February 1990.

Cohen, M. L., Some Perspectives on High Temperature Superconductivily, Greater Washington Solid State Physics Colloquium, University of Maryland, College Park, MD, May 1990.

Cohen, M. L., Experimental Constraints on Theories of High Temperature Superconductors, Review of High Temperature Superconductivity, Lawrence Berkeley Laboratory, Berkeley, CA, October, 1990.

Cohen, M. L., Predicting Properties of Solids, Clusters, and Superconductors, Dupont Central Research and Development Department, Experimental Station, Wilmington, DE, November 1990.

Cohen, M. L., Predicting Properties of Solids, Clusters, and Superconductors, Geophysical Laboratory, Carnegie Institution of Washington, Washington, D. C., November 1990.

Phillips, N.E., "The Specific Heat of $\mathrm{YBa}_{2} \mathrm{Cu}_{3} \mathrm{O}_{7}$ : The origin of the Linear Term and the Volume Fraction of Superconductivity", CNRS/ CRTBT, Grenoble, France, October 1989.

Phillips, N.E., "Linear Term in the Specific Heat of $\mathrm{YBa}_{2} \mathrm{Cu}_{3} \mathrm{O}_{7}$ ", Technische Hochschule Darmstadt, Federal Republic of Germany, January 1990.

Phillips, N.E., "Specific Heat of High- $T_{c}$ Superconductors", Universite de Geneve, Geneva, Switzerland, January 1990.

Phillips, N.E., and R.A. Fisher, "Low-Temperature Specific-Heat Measurements: Application to High-Tc Superconductors", Minerals, Metals and Materials (TMS) Meeting, Anaheim, CA, February 1990.

Phillips, N.E., "A Review of Specific-Heat Measurements on High-T $T_{c}$ Superconductors", Gordon Conference on Superconductivity, Ventura, CA, March 1990.

Phillips, N.E., "Specific-Heat of High-T $T_{c}$ Superconductors", Seminar on Low-Temperature Physics, Nara, Japan, April 1990.

Phillips, N.E., and R.A. Fishar, "Effect of $\mathrm{Cu}^{2}+$ Magnetic Moments on the Superconductivity of $\mathrm{YBa}_{2} \mathrm{Cu}_{3} \mathrm{O}_{7}$ : The Origin of the Linear Term in the Specific Heat; The Volume Fraction of Superconductivity", Yamada Conference XXV on Magnetic Phase Transitions, Osaka, Japan, April 1990.

Phillips, N.E., "Specific-Heat of High-T ${ }_{C}$ Superconductors", Lawrence Livermore National Laboratory, Livermore, CA, April 1990.

Contributed Talks

de Fontaine, D., G. Ceder, and M. Kraitchman, Thermodynamics of One-, Two-, and Three-Dimenstonal Oxygen Ordering in $\mathrm{YBa}_{2} \mathrm{Cu}_{3} \mathrm{O}_{x_{1}}$ March Meeting of the American Physical Society, Anaheim, CA, March 1990.

Nahum, M., Fabrication and Measurement of a High $T_{c}$ Superconducting Microbolometer, American Physical Society, March Meeting, Anaheim, CA, March, 1990.

Miller, D., Infrared Absorptivity Measurement on Thin Film $\mathrm{YBa}_{2} \mathrm{C}^{\mathrm{i}} \mathrm{3}_{3} \mathrm{O} 7-d$, American Physical Society March Meeting, Anaheim, CA, March, 1990.

Richards, P.L., Obseroation of Quantum Susceptance in Superconducting Tunnel Junctions, 19th International Conference on Low Temperature Physics (LT-19), Brighton, England, August, 1990.

Verghese, S., Fabrication of an Infrared Bolometer with a High $T_{C}$ Superconducting Thermometer, Applied Superconductivity Conference, Snowmass Village, Aspen, CO, September, 1990.

Verghese, S., Fabrication of a High $T_{c}$ Superconducting Bolometer, SPIE's Technical Symposium on Optical Engineering and Photonics in Aerospace Sensing, Superconductivity Applications for Infrared and Microwave Devices, Orlando, FL, April, 1990.

Pheips, R. B., Heat Capacity of Adsorbed $H_{2}$ on Evaporated Ag Films, NATO Advanced Study Institute "Phase Transitions in Surface Films," Erice, Sicily, Italy, June, 1990.

Richards, P.L., Observation of Quantum Susceptance in Superconducting Tunnel Junctions, 19th International Conference on Low Temperature Physics (LT-19), Brighton, England, August, 1990.

Nahum, M, Fabrication and Measurement of High $T_{C}$ Superconducting Microbolometers, Applied Superconductivity Conference, Snowmass Village, Aspen, CO, September, 1990.

Hu, Qing, The Effect of the Quantum Susceptance on the Gain of Superconducting Quasiparticle Mixers, Applied Superconductivity Conference, Snowmass Village, Aspen, CO, September, 1990.

Kingston, J.J., F. C. Wellstood, Ph. Lerch, A. H. Miklich and J. Clarke, $\mathrm{YBa}_{2} \mathrm{Cu}_{3} \mathrm{O}_{x} \mathrm{SrTiO}_{3}-\mathrm{YBa}_{2} \mathrm{Cu}_{3} \mathrm{O}_{x}$ Trilayer Insulating Crossovers, March Mecting of the American I'hysical Society, Anaheim, CA, March 1990.

Schmidt, J. M., A. N. Cleland and J. Clarke, Resonant Tunneling in Small Current-Biased Josephson Junctions, March Meeting of the American Physical Society, Anaheim, CA, March 1990.

Wellstood, F. C., J. J. Kingston, and J. Clarke, YBCO Thin-film Multi-turn Coits, March Meeting of the American I'hysical Society, Anaheim, CA, March 1990.

Miklich, A. H., J. J. Kingston, Ph. Lerch, F. C. Wellstood, J. Clarke, and D. Robbes, Formalion of Weak Links via Electrical Spikes in Thin Films of $\mathrm{YBa}_{2} \mathrm{Cu}_{3} \mathrm{O}_{7-d}$, March Meeting of the American Physical Society, Anaheim, CA, March 1990.

Wellstood, F. C., J. J. Kingston, M. J. Ferrari, and J. Clarke, Thin-Film Flux Transformers of $\mathrm{YBa}_{2} \mathrm{Cu}_{3} \mathrm{O}_{7-x}$, Applied Superconductivity Conference, Snowmass, CO, September 1990.

Kingston, J. J., F. C. Wellstood, Du Quan, and J. Clarke I'hotolithographically Palterned Thin-Film Multilayer Devices of $\mathrm{YBa}_{2} \mathrm{Cu}_{3} \mathrm{O}_{7-x_{1}}$ Applied Superconductivity Conference, Snowmass, CO, September 1990. 
Bindslev Hansen, J., T. Holst, F. C. Wellstood, and J. Clarke Low Frequency Noise in Resonant Josephson Soliton Oscillators, Applled Superconductivity Conference, Snowmass, CO, September 1990.

Miklich, A. H., F. C. Wellstood, J. J. Kingston, J. Clarke, M. S. Colclough, A. H. Cardona, L. C. Bourne, W. L. Olson, and M. M. Eddy, High-TC Thin-Film Magnetometer, Applied Superconductivity Conference, Snowmass, CO, September 1990.

Robbes, D., A. H. Miklich, J. J. Kingston, F. C. Wellstood, J. Clarke, and Ph. Lerch, Growth of Josephson Weak Links in Microbridges of YBCO Thin Films Using Electrical Pulses, Spring Conference of the European Materials Research Sodety, Strasbourg, France, June 1990. 
Anisotropic Polymeric Materials

Polymer-Surface Interactions

Enzymatic Synthesis of Materials

\section{Polymers and Composites Program}

The CAM Polymers and Composites Program is concerned with the prediction and control of structure development in high-performance polymers and the enzymatic synthesis of novel polymeric and related types of materials. The program focuses on three areas.

ANISOTROPIC POLYMERIC MATERIALS are characterized by a "domain" structure in the melt-micron-scale regions of high local order, interconnected by submicron regions of rapid change in local orientation. The orientation and flow of the molecules in a given domain have a major effect on the macroscopic properties of the polymer product. During the past year:

- Rheological measurements established that the flow properties of a crystalline polymer solution which can be formed into materials with outstanding physical properties are gel-like under processing conditions, with a small breaking strain. Such a material might exhibit heterogeneous flow in a processing operation.

- Thermal, microscopic and rheological measurements on a blend of a liquid crystalline polymer with a flexible polymer suggest mutual solubility and a possible explanation of the ability of liquid crystalline polymers to serve as processing aids.

POLYMER-SURFACE INTERACTIONS play a significant role in the development of bulk structure during processing and of the mechanical properties of the manufactured object, failure and fatigue of composite materials, the properties of thin films for microelectronics and food packaging applications, and in performance areas such as tribology and biomedical applications such as implant wear. During the past year:

- Quantum mechanical calculations of energy hypersurfaces of oligomers of poly (methylmethacrylate) with aluminum surfaces showed the development of glass-like non-equilibrium structures at the interface.

- Molecular dynamics simulations of the surface region of the glassy polymer were used to probe segmental displacement, orientational relavation of bonds, and conformational isomerization in the neighborhood of a polymer surface. Estimates of the surface tension of the glass polymer were obtained.

- SIMS measurements of metal and metal-oxide surfaces following the peeling of polyethylene films revealed a complete surface coverage of residual polymer. 
Enzymes catalyze reactions in a manner that makes them ideally suited to the synthesis of materials. They produce highly uniform products at low temperatures and pressures. They allow only one of the many possible reactions of a given substrate, thus greatly limiting the production of side products that might be toxic or wasteful. The CAM Project on ENZYMATIC SYNTHESIS OF MATERIALS seeks to explore the application of recently developed techniques in molecular biology, biochemistry and bioorganic chemistry to the synthesis of materials and to understand and exploit the expected enhanced properties of these materials. Research is focused on using enzymes as they are found in nature; on engineering enzymes through genetic and chemical means, and on creating new enzymes-all for the purpose of allowing them to catalyze reactions with non-biological substrates and to produce materials with interesting and important properties. Target products include modified polyamides, polysaccharides, and nonbiological materials including those polymerized through carbon-carbon linkages. Recent work has expanded the interests of the program to include enzymatic and chemical synthesis of multi-functional monomers. These can modify surface properties or self-assemble into thin films which can act as components of detectors and sensors and also as materials for the modification of surfaces.

During the past year there have been several significant highlights:

- The enzymes phosphorylase, lysozyme and subtilisin have been used in the synthesis of polymers through techniques involving the modification of the enzyme, substrate or reaction conditions. In the case of phosphorylase, non-natural monomers have been used in the synthesis of novel polymers.

- An antibody has been generated that catalyzes a reaction for which there is no known enzyme. This result demonstrates that enzymatic synthesis need not be confined to "biological" materials.

- Additional progress has been achieved in engineering enzymes for increased stability in reactors and in understanding factors that play a role in thermal stability.

- A new class of peptide-derivatized lipids was synthesized for self assembly into monomolecular films for the control of surface and interfacial properties 


\section{ANISOTROPIC POLYMERIC MATERIALS}

The processing of liquids which are anisotropic at rest is common in the manufature of advanced polymeric materials. The anisotropy might be a consequence of the presence of fibers, ais in fiber-filled composite materials, or of the rigid backbone structure of a liquid crystalline polymer. Prediction and control of orientation development of anisotropic liquids during processing remains a major outstanding technical problem.

Our work in prior years has focused on structure development in melt-processible liquid crystalline polymers, where we have used rheology, nuclear magnetic resonance spectroscopy, and thermal analysis as complementary tools. This work is continuing, with particular attention to the problem of obtaining reliable data for these temperature-sensitive polymers over a long time (which is necessary for the low deformation rate experiments that reveal structure) and to the rheology of the solid phase. We do not have new concrete results to report in these areas, although they have occupied a considerable amount of our time during the past year. We have expanded our focus to include liquid-crystalline polymer blends and a solutionprocessed (1yotropic) system which is known to have exceptional mechanical properties. The rheology of the lyotropic system is highly unusual and is indicative of a gel-like structure; such a structure would have important consequences during processing.

As part of our continuing work on the analysis of structure development we have simulated a new experimental procedure which appears promising for the measurement of extensional properties of polymer solutions.

\section{Lyotropic Liquid Crystalline Polymers \\ B. Ennst, M.M. DenN, P. Pierini*, W.E. Rochefort*}

Liquid crystalline solutions of cis-poly (p-phenylenebenzobisoxazole) in polyphosphoric acid can be formed into fibers with outstanding mechanical properties and are being studied in novel forming operations that could lead to shaped objects with excellent mechanical and barrier properties. We have studied the rheology of this system at concentrations in the isotropic and liquid crystalline regimes. "Timetemperature superposition," in which properties at different temperatures can be superimposed by a temperature-dependent scaling of the time axis, is found to apply. Time-temperature superposition is commonly observed for flexible-backbone polymers but is unusual in a liquid-crystalline system. The linear viscoelastic storage $\left(G^{\prime}\right)$

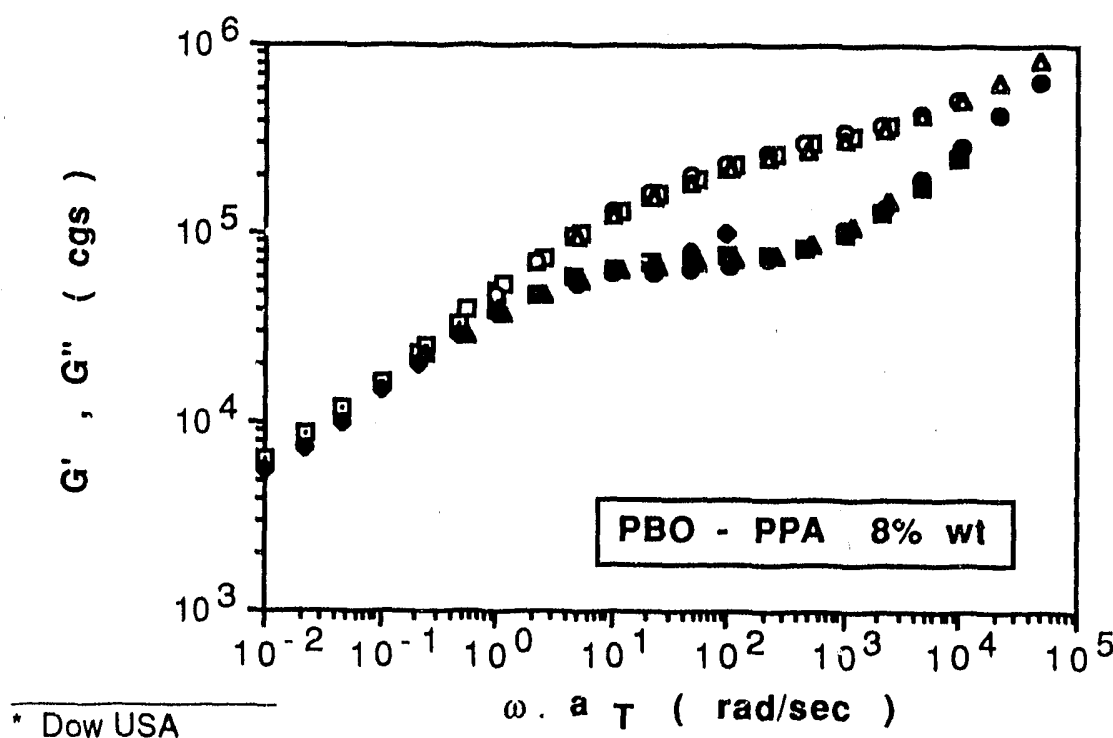

Figure 1

Storage, or elastic, modulus (G', open symbols) and loss, or viscous, modulus (G", closed symbols in dynes/cm 2 for and $8 \%$ liquid-crystalline solution of a rigid-rod polymer as a function of reduced frequency of mechanical oscillation. The data are shifted along the frequency axis using "timetemperature" superposition, in which a single activation energy enables data at temperatures from 100 to $239^{\circ} \mathrm{C}$ to be superimposed. The large reglon of overlap of storage and loss modull, which is sean at all concentrations, is usually interpreted as indicating a gel-like structure. (XBL 918-1785) 
Figure 2

Scanning electron micrograph of a blend of $20 \%$ Vectra, a liquid-crystalline polymer, with $80 \%$ polyethylene terephthalate). The picture is typical of a phaseseparated system, but the large change in the melting temperature of the poly(ethylene terephthalate) component in the blend, found with differential scanning calorimetry, is suggestive of a small degree of mutual solubility. This could be associated with a plasticizing effect which has been reported in the patent literature. (ХBB 918-6799)

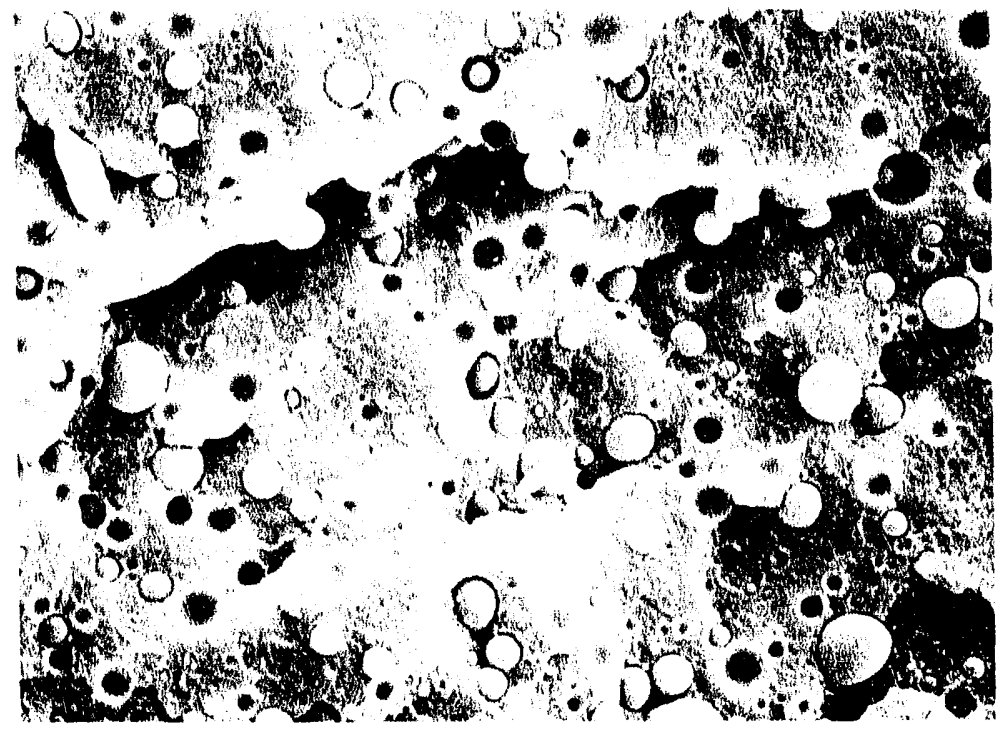

and loss $\left(G^{\prime \prime}\right)$ moduli are shown in Figure 1. The superposition of the curves for $G^{\prime}$ and $G^{\prime \prime}$ is characteristic of the rheological behavior of gel-like materials and is not seen in other liquid crystalline systems. Othıer measurements are consistent with this observation, leading to a picture of a material that is gel-like under processing conditions with a possible low yield stress and very small breaking strain. Such a material might exhibit heterogeneous flow in a processing operation, with unknown consequences regarding the backbone orientation distribution and macroscopic physical properties.

Blends of liquid crystalline polymers both with other rigid-rod molecules and with flexible chains show considerable promise for enhanced properties. We initiated a study of structure development in liquid crystalline polymer blends during the fourth quarter of FY90. We have found a striking change in the melting temperature of the poly(ethylene terephthalate) component in blends with Vectra, a thermotropic liquid crystalline copolyester of hydroxybenzoic acid and hydroxynaphthoic acid. Such systems are generally presumed to be incompatible, and the scanning electron micrograph in Figure 2 looks like that of a phase-separated system, but the large change in the melting temperature is suggestive of the possible existence of a small degree of mutual solubility. Such mutual solubility would lead to a plasticizing effect that could be associated with the observation in the patent literature that small amounts of liquid crystalline polymers added to flexible systems can serve as processing aids which bring about a substantial reduction in viscosity.

\title{
Flow Simulation of an Extensional Rheometer
}

\author{
R. KEUnings, M. M. DENN, R. W. G. SHIPMAN
}

The extensional properties of polymer solutions are exceedingly difficult to measure because of the low viscosities under processing conditions. We have analyzed a new falling-plate extensional rheometer with the specific objective of understanding the connection betwenn the macroscopic measurements (which are 

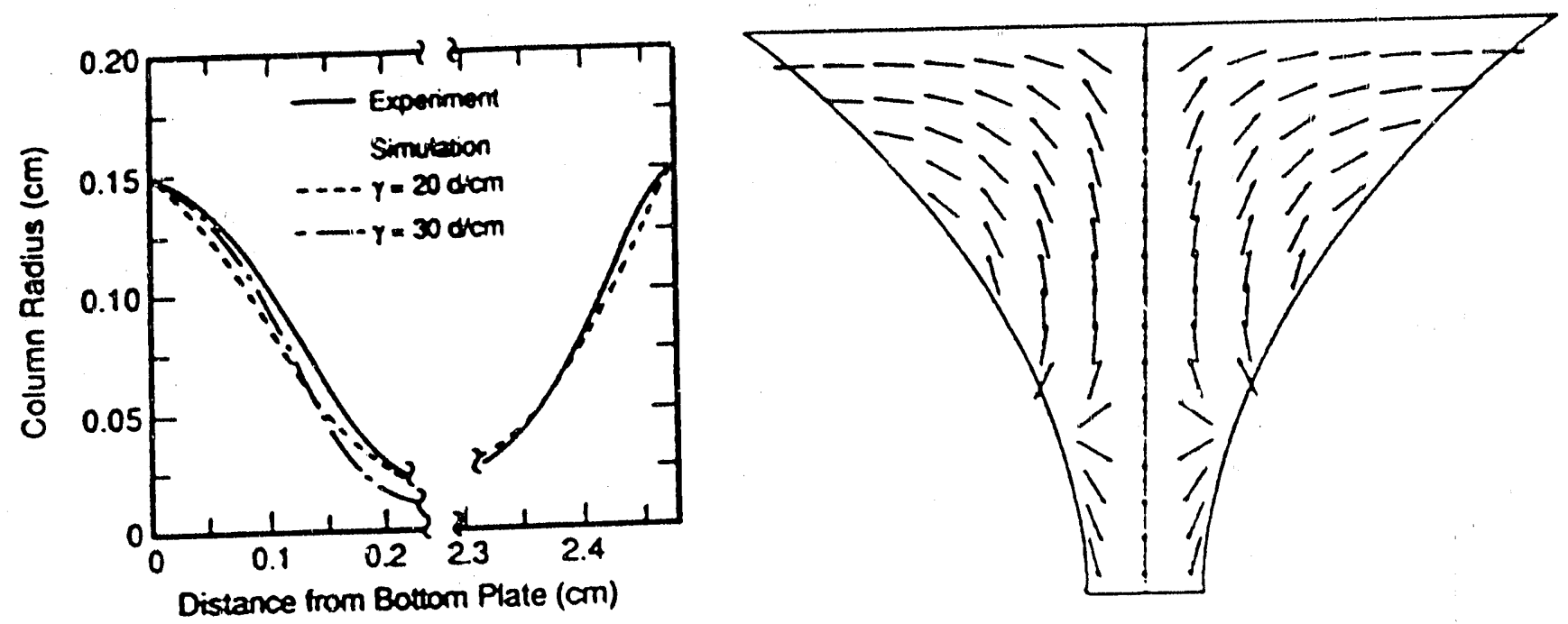

Figure 3

Simulation (a) of an experiment using the "falling-plate" rheometer, in which a coiumn of liquid contained between tow plates is deformed in extension by rapid separation of the plates. The flow pattern near the plates (b, top plate) shows an unexpected revers, $\theta$ flow, whlch explains the experimental observation that the macroscopic stretch rate is not equal to the local stretch rate during the early stages of the experiment. (XBL 918-1;86; XBL 918-1787)

based on photographs of the temporal evolution of the free-surface) and the rheological properties of the solution. Figure 3 a shows a simulation of an experiment by Sridhar, using independent measurements of the rheological properties of the polymer solution. The large amount of curvature in the neighborhood of the plate is caused by a surface tensicn-driven reverse flow, as shown in Figure $3 \mathrm{~b}$. The presence of this reverse flow precludes use of a macroscopic analysis until the filament has been stretched to a substantial length and explains the experimental observation that the macroscopic strain rate is not reflected in the local deformation until late in the measurement.

\section{POLYMER-SURFACE INTERACTIONS}

The physical or chemicai interaction between a polymer and a non-polymeric surface results in conformational changes of the polymer in the neighborhood of the interface, making it different from that in the bulk. Interaction during melt processing between the melt and the metal shaping surface is known to affect adhesion and the onset of flow instabilities, and hexce the throughput and bulk material properties. The properties of polymer composites are determined by the nature of the interaction between the matrix and the particulate or fiber filler; the interaction affects not only interface adhesion, but such properties as failure and fatigue as well. The interactions of thin polymer films with metal and metal oxide interfaces are of importance in a variety of applications

Our activities during the past year include simulations using both quantum mechanical methods and Molecular Dynamics, as well as experimental studies utilizing a varicty of spectroscopic tools. The theoretical work is providing information about expected conformational states, including the likely existence of a quasi two-dimensional surface "glass" when there is a reactive interaction between a functional group on the polymer and the metal or oxide surface. The spectroscopic information about surface conformational states and exchange between the surface and the bulk in a melt has come largely from infrared spectroscopy. SIMS has been useful in examining metal and oxide surfaces after removal of a polymer film, with particular relevance to adhesion and the relation to melt flow instabilities. We have devoted considerable effort to perfecting NMR techniques to examine polymers at oxide surfaces, but concrete results here are not yet in hand. 
We are studying interfaces where chernical bonding can occur between specific functional groups of the organic polymer and the substrate species. The interplay between the strong and specific enthalpic interactions that are characteristic of chemical bonding at the segment level and the entropic constraints associated with confining long chain molecules near a solid substrate determines the near-surface structure and strorgly influences interfacial properties.

We have used quantum mechanical density functional theory to calculate the energy hypersurfaces for the interactions of oligomers of poly(methylmethacrylate) (PMMA) with "jellium" and cluster representations of aluminum surfaces. The energetics are highly dependent on the orientation in which the oligomer approaches the metal surface. Last year we reported some early results; we have now completed the calculation of the energy ypersurfaces for monomers and dimers of PMMA interacting with aluminum, as shown in Figure 4. Comparison of these energy hypersurfaces with rotational isomeric state calculations of PMMA in the bulk show that PMMA should adsorb on aluminum surfaces in locally strained conformations. The existence of deep minima that are separated from each other and the global mininum by barricrs that are large relative to $\mathrm{kT}$ leads us to believe that PMMA chains adsorb on aluminum surfaces in rather flat, locally strained (compared to the bulk), non-equilibrium conformations. Our picture of the near-surface structure may be referred to as a quasi two-dimensional "glass". (The word glass is used only in the sense that the structure is characterized by a collection of non-equilibrium structures; there is no connection with the bulk glass transition temperature of the polymer.)

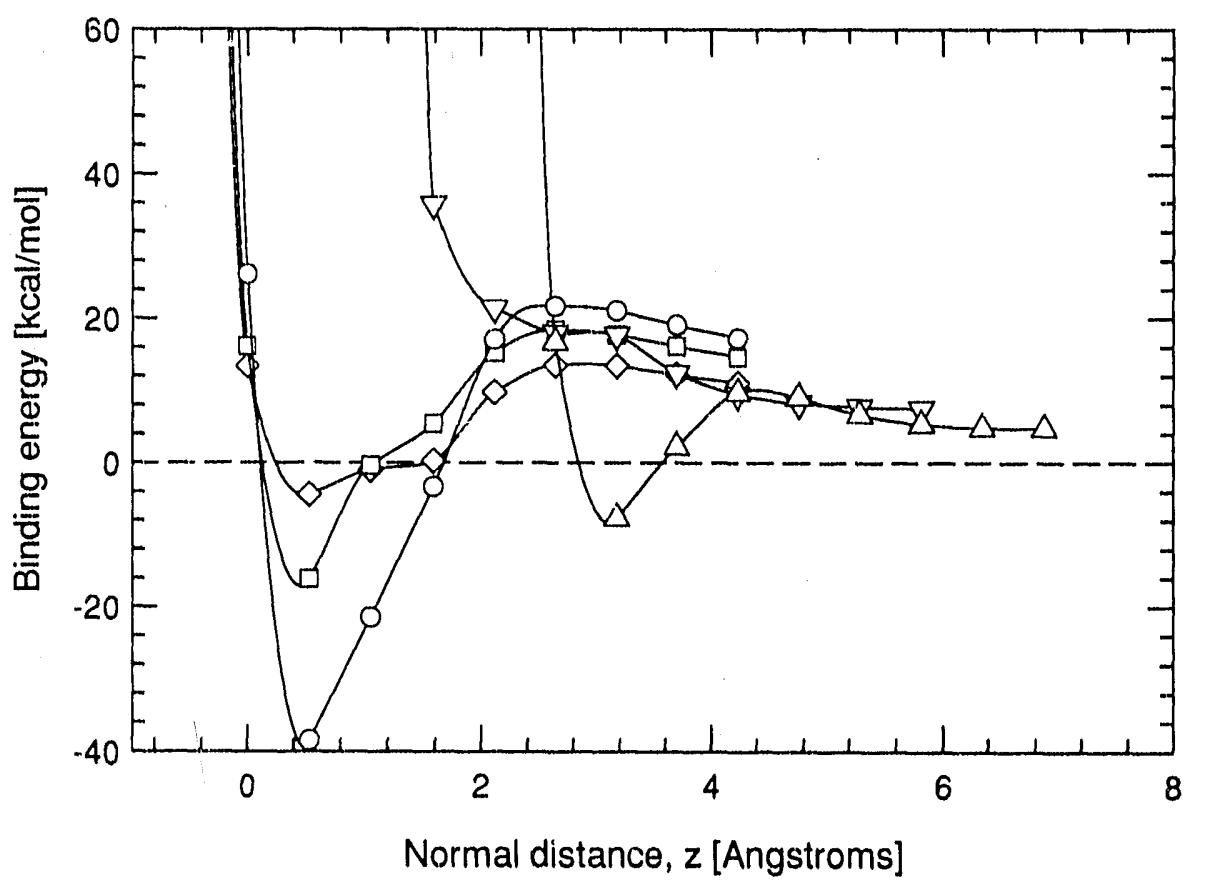

Figure 4

Binding energy of a PMMA monomer on the jellum representation on an aluminum surface. The distance coordinate is the normal distance of the carbonyl oxygen atom from the jellium edge. Diamonds correspond to an orientation in which the carbonyl bond is perpendicular to the surface with the carbonyl oxygen atom closer to the surface than the carbonyl carbon; squares correspond to an orientation in which the carbonyl bond makes a $30^{\circ}$ angle with the surface normal. In the first two cases bonding occurs primarily with the carbonyl functional group. Upside-down triangles correspond to an orientation in which the carbonyl group is parallel to the surface; both the carbonyl group and the methoxy oxygen atom are sterically hindered from approaching the surface and no bonding occurs. Triangles correspond to an orientation in which the carbonyl group is sterically blocked from the surface while bonding occurs with the methoxy oxygen atom. Circles correspond to an orientation in which the carbonyl group makes a $60^{\circ}$ angle with the surface normal and the methoxy oxygen atom approaches the surface; bonding occurs with both the carbonyl group and the methoxy oxygen atom. 
Molecular Simulations

D. THEOdOROU, K. MANSFIELD

The objective of this work is to develop statistical-mechanics-based computer simulation methods for the prediction of polymer interfacial properties from chemical constitution. During this year we have been working on a Molecular Dynamics simulation approach that aims at clucidating molecular mobility in the surface region of a glassy polymer. The method tracks the trajectory of a microscopic model of a thin glassy polymer film in phase space under given thermodynamic constraints by solving Newton's equations of motion for all constituent atoms. Initial configurations for the simulations are generated via our Molecular Mechanics method described previously. The production phase of the simulations is conducted in the microcanonical ensemble.

The duration of the dynamic simulations is confined to times on the order of 100 picoseconds. Short-time dynamical processes of segmental displacement, orientational relaxation of bonds, and conformatinnal isomerization are probed as a function of position within the polymer film. This allows one to identify regions at the free surfaces in which the mobility of chains is enhanced relative to the bulk glass and thus determine the depth from the free surfaces at which the thermal motion of polymer chains becomes truly glass-like. Structural information in the presence of thermal motion is accumulated and compared against our earlier static simulation results. In addition, an estimate of the surface tension of the glassy polymer (including entropic contributions) is obtained.

\section{Adhesion and Melt Fracture}

M. M. DENN, D. HILL

We reported last year on the apparent connection between the onset of melt flow instabilities at high stress levels ("melt fracture") and the adhesion between the polymer melt and the metal surface of the extrusion die. We have since improved the predictive ability of our analysis by incorporating estimates of the glass transition behavior of the melt in the presence of small amounts of crystalline material. We have now initiated a study of the surfaces that are created during the adhesion experiment using spectroscopic techniques in an ultra-high vacuum system. SIMS measurements of metal and metal oxide surfaces following the peeling of deuterated polyethylene films reveal a complete surface coverage of residual polymer following a peel test. This observation is paradoxical with respect to the apparent adhesion energetics associated with our previous experiments.

\section{FTIR/ATR Study of Polymer Surfaces}

A. T. BelL, M. M. DenN, L. R. Dietsche

We have been using infrare $\mathbb{A}$ light absorption with attenuated total reflection (FTIR/ATR) in a flow cell to study the interactions between a polymer melt and the solid surface, particularly surface exchange kinetics with hexadecane and 1-hexadecene to simulate polyolefins and trichlorotrifluoroethane (R-113) to simulate common additives. We have two $\mathrm{ZnSe}$ crystals for the flow system, one bare and the other coated with a 150-200 $\AA$ layer of chrome at the reflecting surface. Displacement experiments using R-113 and hexadecane on both surfaces scale in a way that is indicative of diffusion control. Exchange experiments between hexadecene and hexadecane do not scale in the way that would be expected for a diffusion process, however, and data for the uncoated and coated crystals no longer overlap. These experiments are indicative of the types of surface effects that we believe are relevant in phenomena associated with melt flow in metal and metal oxide shaping dies. 


\section{ENZYMATIC SYNTHESIS OF MATERIALS*}

The concept of using purified enzymes in the synthesis of materials is a relatively new one. Its validity rests on the demonstration that recent advances in molecular biology and biochemistry allow the manipulation of the substrate and reaction specificity of enzymes. Considerable research remains to be done, however, before these advances can be routinely applied to the synthesis of useful materials. In support of this goal, the CAM program has focused on:

- understanding the fundamental properties of enzymes and enzymecatalysed reactions that could be involved in the synthesis of materials.

- engineering enzyme structure, activity and reaction conditions to allow the synthesis of materials from novel substrates.

- determining the structure/function relationships of enzyme-synthesized materials, predicting properties from structure, and designing structure to achieve target properties.

\section{Enzymatic Synthesis of Polymers \\ Polysaccharides}

Polysaccharides perform a wide range of functions, and there is therefore a great deal of interest in the properties of unusual derivatives. Fluorinated polysaccharides may, for example, find commercial use as lubricants, adhesives or plastic additives. Chemical methods for constructing these regular and uniform polymers do not exist. It would therefore be attractive to be able to make these polymers enzymatically. One of the most important obstacles to be overcome in using enzymes in the synthesis of polysaccharides lies in the fact that in many cases, degradative hydrolysis rather than synthesis is thermodynamically favored. Recent work has focused on solutions to that problem using the enzymes lysozyme and phosphorylase.

\section{Synthesis Using Lysozyme \\ M. BEDNARSKI, C. HOBBS}

The goal of this project is to use a combination of site-directed mutagenesis, synthetic substrates and unusual solvents to allow the use of the enzyme lysozyme in polymer synthesis. A tetramer of $\mathrm{N}$-acetylglucosamine (Figure 5 ) was selected as a substrate since it would have a greater binding energy than any smaller oligomers. The synthesis of both the monobenzyl and dibenzyl phosphates of the tetrasaccharide was completed with the expectation that this would further improve binding to the enzyme and also solubility in organic solvents. Incubation of these compounds with lysozyme was performed with the enzyme coupled to a new polymeric material developed by the program for the stabilization of enzymes in organic solvents (see $p$. 210). Coupling allowed the reaction to proceed in organic solvents such as dimethyl formamide, reducing the activity of water which would otherwise have led to hydrolysis of the product. Under these conditions, polymer synthesis was achieved for the monobenzyl derivative. The synthesis was repeated with additional modifications on a large scale to construct a useful amount of the new substrate. The polymerization reaction was monitored by NMR spectroscopy and after $3 \mathrm{~h}$ a new peak appeared, preliminarily identified as corresponding to liberated monobenzylphosphate. In addition, a precipitate appeared, tentatively identified as an insoluble polymer of $\mathrm{N}$-acetylglucosamine. The material is in the process of being characterized and the preparation of the pure substrate is being repeated on a larger scale.

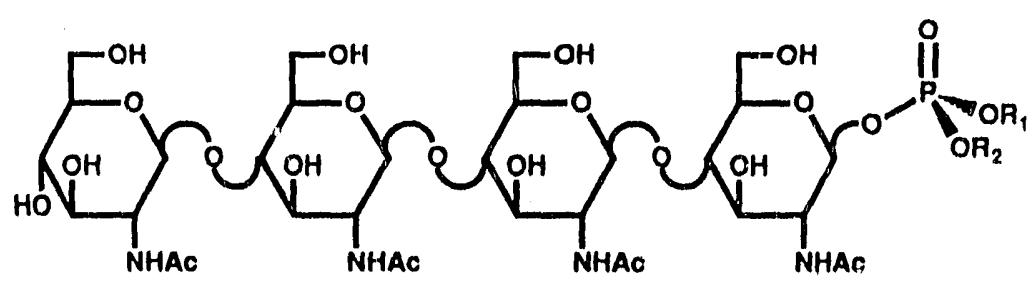

Figure 5 Modified chitin-like substrate for lysozyme allows for use of enzyme in the synthesis of polymer. $R_{1}, R_{2}=H_{1}$ $H_{1}=H_{1} R_{2}=$ benzyl $R_{1}, R_{2}=$ benzyl. (XBL 919-2057)

"Additional support from the Division of Energy Biosciences, U.S. Department of Energy 
Lysozyme-Binding of Natural and Unnatural Substrates

J. KIASCH AND M. COREY

Once synthesis using lysozyme has been achieved, the enzyme will be used to polymerize non-natural polymers. A critical aspect of this effort is the understanding of how the enzyme binds its substrates; which amino acids of the enzyme active site are involved in binding; and, how they bind the natural (and therefore the unnatural) substrate and with what energy. Also needed is an understanding of how enzymes with modified active sites would bind substrates. Three carboxylate residues $\left(\mathrm{RCOO}^{-}\right)$(at positions 52,35, and 101) which are located in the active site of lysozyrne have been shown to make hydrogen bonds to bound oligosaccharide inhibitors, nonreactive compounds with structures similar to that of the substrate. Their lack of reactivity allows them to be used as model compounds for the study. Through sitedirected mutagenesis, their anionic side chains have been neutralized by substituting their corresponding amides. The free energy contributions of each one has been evaluated singly and in combination. It was shown that they each contribute between $1.5-4 \mathrm{kcal} / \mathrm{mol}$ in the free energy of association of the substrate with the enzyme. Continuing studies should provide a more complete understanding of the nature of the binding of lysozyme to its substrates and of the types of unnatural substrates that could bind and the types of active site modifications that would be required for binding of those that do not.

\section{Synthesis Using Phosphorylase \\ M. BEDNARSKI AND L. OEHLER}

The enzyme phosphorylase was chosen as another system for the study of enzymatic polymerization reactions. Phosphorylases are enzymes that normally catalyze the reversible cleavage of the polymer glycogen to form glucose-1-phosphate. As reported last year, formation of polymer can be achieved if the reaction includes a mechanism for the consumption of inorganic phosphate formed as a byproduct. In an attempt to force the enzyme to make novel polymers using unnatural monomers, a variety of glucose-1-phosphate derivatives were synthesized. The choice of these derivatives was based upon information available from the enzyme's crystal structure. A number of fluorine-substituted polymers have been synthesized. Kinetic constants, $k_{c a t} / K_{m}$, and the $K_{i}$ for those derivatives which act as inhibitors, will be studied.

Current work involves the synthesis of glucose derivatives with the thiol in the 5 and 6 position and azide in the 6 and 3 position. Using phosphorous NMR, the 5-thio derivative has been shown to be a substrate for the enzyme. Synthesis of the 6-thiol derivative is near completion and will be tested as a substrate using phosphorous NMR. High molecular weight polymer has been synthesized with the thiol-substituted monomer.

Polyamides

Polypeptides with well defined primary or secondary structure have great potential for the development as novel materials. The variety of side chains available and the effect of sequence on structure and function suggest that control of synthesis of these materials should be a significant ad vance. Structures such as helices, sheets, and turns exist in many proteins and are involved in the formation of higher-order protein structures and biological antivities. Polypeptides which mimic these regular structures may thus have properties useful for a number of applications. Incorporation of functional groups into such regular polypeptides will create a new class of molecules which could find use in materials science, biology, and chemistry.

\footnotetext{
"Research performed at Scripps Research Institute, La Jolla, CA
} 

residue that are practical targets for further modifications are shown.

(CBB 918-5592)

Chemical synthesis of polypeptides has traditionally been dependent on the anhydride method using phosgene. The need for the milder, stereoselective, racemization-free, catalytic procedure achievable through the use of enzymes is timely and impor-

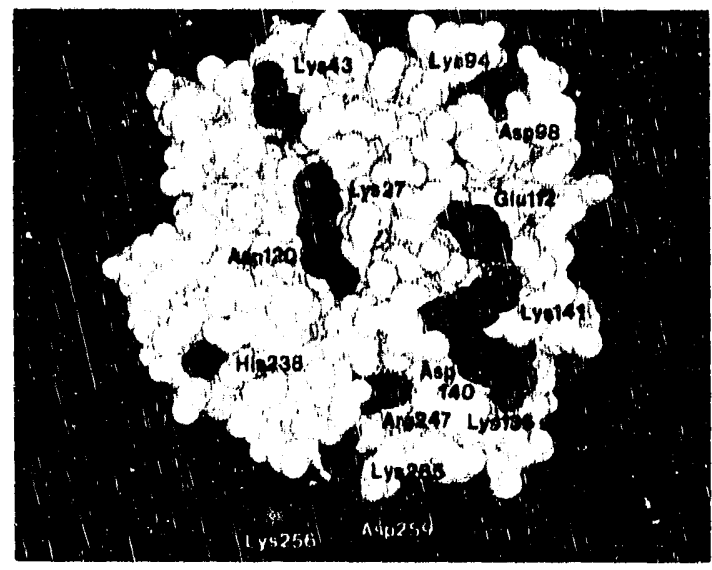
tant. Work in this area is currently focused on two enzymes, subtilisin and HAV protease. In the case of subtilisin, the focus of the research is on the use of the enzyme in synthesis rather than degradation. In the case of HAV protease, the focus is on the binding of the enzyme to its substrate, and by extension, to unnatural substrates.

\section{Subtilisin \\ C. H. WONG and D. Dumas"}

The enzyme subtilisin is a protease able to break or make peptide bonds of olyamide materials. Through the use of site-directed mutagenesis, a highly stableand active mutant of the enzyme, subtilisin 8397,(Figure 6) has been made in collaboration with Genex Corporation. This new enzyme has enhanced lifetimes (20-100 x) both in aqueous solution and anhydrous dimethylformamide (DMF). Activity in organic solvents, an important attribute for synthesis of materials soluble only in organic media, was illustrated by regioselective acylation of sugars and nucleosides, enantioselective hydrolysis of unnatural amino acid esters, and synthesis of peptides in DMF (or DMF- $\mathrm{H}_{2} \mathrm{O}$ ). Kinetic analysis of the enzyme with selected substrates and a transition-state-based inhibitor indicates that the mutant enzyme has approximately the same substrate specificity and catalytic efficiency as the wild-type enzyme. The enzyme should therefore have great value in performing the various reactions shown previously to be catalyzed only poorly if at all by the wild-type enzyme.

The mutant enzyme was made by substitutions involving $\mathrm{H}$-bonding, hydrophobic interactions, configurational entropy, van der Waals interactions, and $\mathrm{Ca}^{++}$ binding. Other mutations have also been examined and correlations between structure and function drawn from these studies should aid in the rational design of more stable enzymes.

Various methyl arylalkane sulfonates have also been developed for selective methylation of the e2- $\mathrm{N}$ of the active-site histidine. Detailed kinetic studies have established the preliminary results reported last year that under proper conditions, the methylated enzyme loses most of the amidase activity while the esterase activity is still significant; thereby promoting bond synthesis at the expense of degradation. A mechanism involving ring-flipping of the active-site imidazole was proposed to explain methylsubtilisin-cataiyzed reaction. A similar situation was observed in a related enzyme, chymotrypsin.

Thiol Proteases

\section{J. KIRSCH, J. PETITHORY, S. ROSENBERG ${ }^{\dagger}$, B. MALCOLM ${ }^{\dagger}$}

A collaboration has been recently established with scientists at Protos Corporation to investigate the large substrate binding domain of a thiol protease HAV which is potentially able to synthesize polyamides of defined monomer sequence. HAV

\footnotetext{
"Scripps Research Institute, La Jolla, CA
}

'Protos Corporation, Emeryville, CA 
protease appears to recognize up to eight amino acids in a peptide substrate. Initial work is focused on the determination of the specificity at each of the eight positions. Materials were provided by the Protos collaborators Steve Rosenberg and Bruce Malcolm for enzymatic analysis. A satisfactory assay for the enzyme has been developed. An accelerated method for analysis of substrate specificity has also been developed.

\section{Proteases in Organic Solvents}

M. BEDNARSKI, M. CALLSTROM*, P. WANG

A novel polysaccharide-based polymer has been developed which stabilizes a wide variety of proteolytic enzyme in organic solvents. With apparent retention of stability and specificity. In preliminary experimental results the enzymes chymotrypsin, trypsin and subtilisin, when coupled to the polymer, have been used in the synthesis of polyamides from amino acids or short peptides.

\section{"Non Blological" Polymers}

Traditional views of materials synthesized enzymatically focus only on the "biological" polymers, polyamides, polysaccharides, polyesters, polynucleotides and the like. Three projects in the program are focused on expanding the applicability of enzymes to the synthesis of polymeric materials that are normally regarded as "chemical" rather than biological. The goal here is the use of enzymes to make "classical" polymers with properties that are enhanced by the nature of the control of structure or the low temperature synthesis achieved only through the use of enzymes.

\section{Polysaccharide-Based Polyacrylamides and Acrylates \\ -Chemical Linkage of Sugart \\ M. Bednarski, M. Callstrom*, P. Wong}

In a project funded by the Cargill Corporation, enzymatically and chemically modified sugars have been linked to methacrylate and acrylamide monomers which were then polymerized. The resulting high molacular weight polymers have shown very interesting properties (Figure 7). They are water soluble and are hydrogels and continuing work involves investigating these and other solution properties. Most of the work on these materials during the past year has, however, focused on their remarkable ability to stabilize enzymes under unusual conditions. When bound to
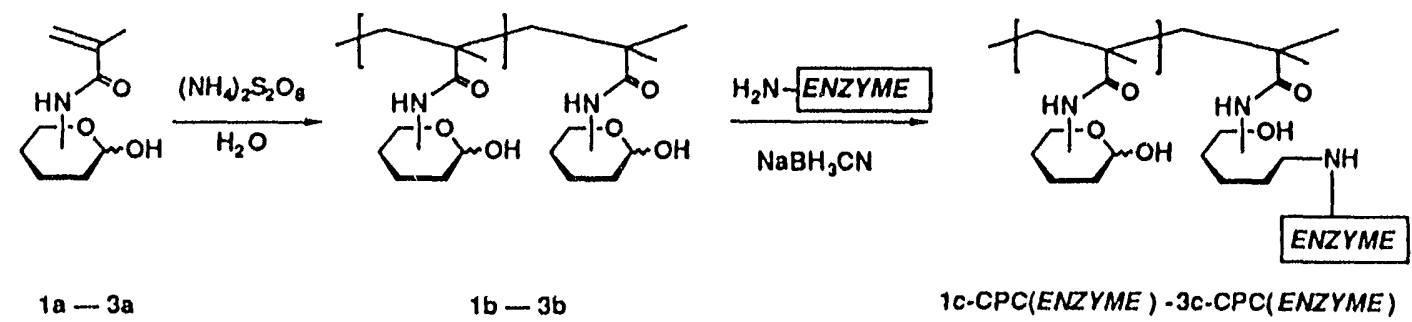

$1 a-3 a$
$1 b-3 b$

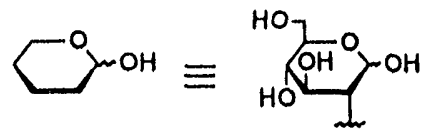

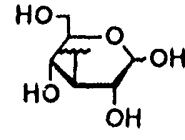

Figure 7

Scheme for synthesis of polysaccaride-based polymer and its coupling to enzymes. (XBL 919-2058)

"The Ohio State University

${ }^{\dagger}$ Funded by Cargill Corporation, Minneapolis, MN 


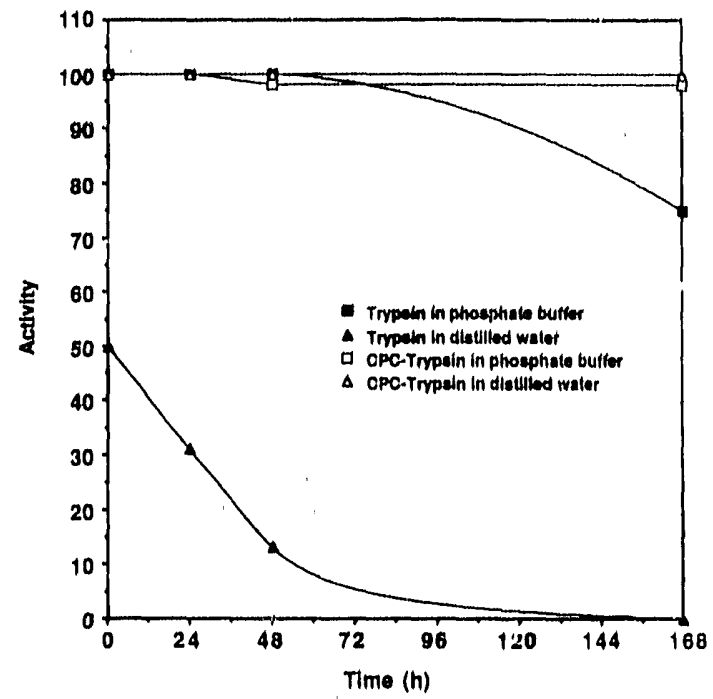

this polymer, a wide variety of enzymes has been shown to retain activity in distilled water (without the buffering agents usually required) (Figure 8). This is of great importance to industrial reactions involving enzymes since the usual purification step to rid the product of the buffers usually required to maintain enzyme stability is no longer required. The coupled enzymes are also stable at high temperatures (see $p$. 214) and in organic solvents (see above).

In addition, novel carbohydrate-based hydrophilic gels and water soluble biopolymers have been synthesized through the use of the enzyme $\beta$-Galactosidase. This enzyme, one of a class of glycosidases, is known to transfer sugar residues from disaccharides to primary and secondary alcohols. The enzyme was used to attach carbohydrate structures to the primary hydroxyl $(\mathrm{OH})$ group of polymerizable monomers. Subsequent polymerization yielded a polymer with C-1-linked carbohydrate pendant groups (Figure 9). Glycosylated polymers and copolymers of allyl alcohol, hydroxyl-alkyl-methacrylates, hydroxy-alkyl-acrylates, or any monomer with primary hydroxyl groups can be modified in this method. This single step enzymatic conversion can be accomplished without the requirement of protection and deprotection of other potentially reactive groups that is often required in chemical routes to the same product. Further, the synthesis of a single anomer is easily achieved, in comparison to the presence of both anomers after most chemical syntheses.

$\beta$-Galactosidase effected the transfer of galactose to 2-hydroxyethyl-methacrylate (HEMA) using either lactose or phenyl-galactose as a substrate. The resulting monomer, a galactose derivatized HEMA, was then polymerized and molded into plano contact lenses $0.1 \mathrm{~mm}$ thick. The lenses were transparent and of high water content $(80 \% \mathrm{w} / \mathrm{w})$ and are expected to have improved wettability and lower protein adsorption, two important characteristics of improved contact lenses.

Figure 9

Enzymatic linkage of sugar to polymerizable monomer, followed by polymerization, yields novel carbohydrate derivatized polymers and gels.

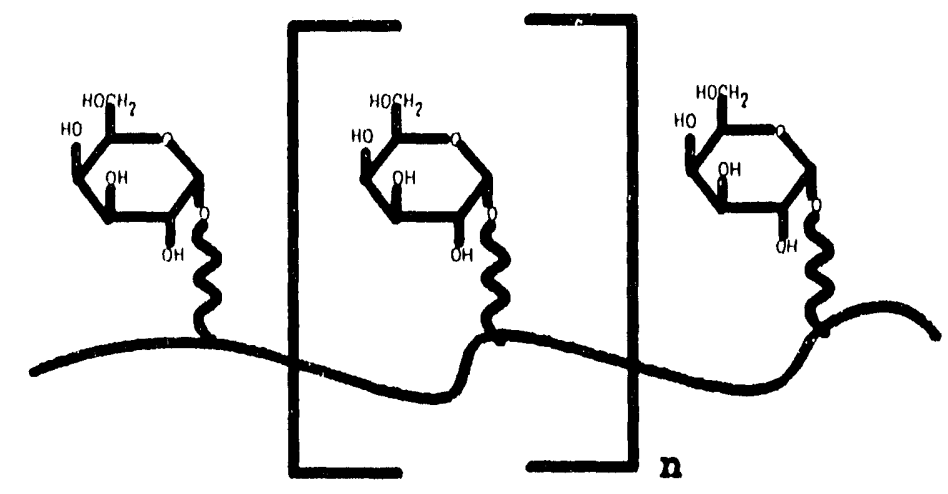




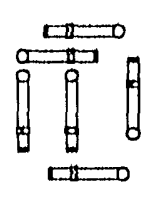

(a)

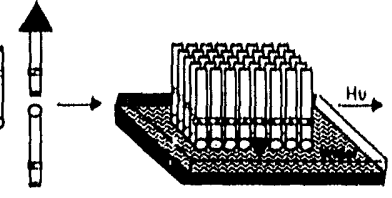

(b)

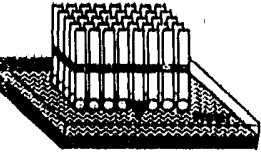

(9)

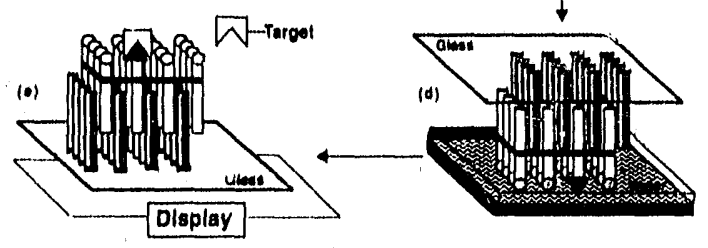

Figure10

Multifunotional organio moleoules are synthesised, some with "receptor" site ( A ) designed for speciflo binding of a target (a). These mc leoules "self-assemble" on a water surface (b) and are polymerlzed when Irradiated ' 0 ). The film is lifted onto a sultably prepared /ilass slide (d) which is then exposed to a solution possibly contalning the target moleoule (W). Binding of target to receptor is recorded inrough the resulting changes in the opto-electronic propertles of the polymerized film $\langle\theta\}$, ! $\times 3 L$ 819-2060)

\title{
Catalytic Antibodies \\ P. SCHULTZ, A. BRAIS TED
}

With the advent of technologies to produce monoclonal antibodies, it has become possible to generate proteins that selectively recognize virtually any given target substrate. Research described last year demonstrated that it now is reasonable to expect that catalytic antibodies can be created even for those reactions that involve substrates that are not "biological" in nature. These antibodies could then be used in an almost unlimited range of reactions leading to the synthesis of the full breadth of organic materials.

Completing preliminary work described last year, antibodies generated against a 12.2.2] bicyclic transition state analogue proved to be effective catalysts for a bimolecular Diels-Alder reaction. One of these antibodies catalyzed the reaction with a $k_{\text {cat }}$ value of $0.67 \mathrm{sec}^{-1}$ and $\mathrm{K}_{\mathrm{m}}$ values of $1130 \mu \mathrm{M}$ and $740 \mu \mathrm{M}$ for the diene and dienophile, respectively. The dissociation constant $\left(K_{D}\right)$ for the Diels-Alder reaction product is 10 $\mu \mathrm{M}$ which compares favorably to the $\mathrm{K}_{\mathrm{D}}$ of $126 \mu \mathrm{M}$ for the transition state analogue. The strategy used should be generally applicable to Diels-Alder reactions involving acyclic dienes, thereby providing a methodology for producing catalytic antibodies to control the stereochemistry and regiochemistry in a variety of Diels-Alder reactions.

\section{Control of Interfacial Properties of Surfaces Using Biological Coatings}

\author{
Peptide Films \\ M. BEDNAFSKI, T. W/ILSON, J. NAGY
}

As part of the investigation into the design and control of interfacial properties using biological materials, a convenient method to attach peptides to a variety of surfaces was developed. To accomplish these goals a new class of peptide-derivatized lipids (PDL's) was synthesized and characterized. These PDLs can be self-assembled into monom.olecular films which can be used to control interfacial properties such as wetting and adhesion, and provide a simple method to coat surfaces with polyamides.

Self-assembled PDL films are formed using a modified Langmuir-Blodgett procedure. The lipids are first spread at the air water interface and then crystallized by inducing a differential cooling gradient across the interface. The crystalline monolayer film is then polymerized using UV irradiation and transferred onto other surfaces by simply forming a contact between the two interfaces. Peptide derivatized surfaces containing alanine, phenylalanine, glycine, serine and ethanolamine have been synthesized. These surfaces were characterized by contact angle measurements, $X$-ray photoelectron spectroscopy, ellipsometry, fluorescence microscopy and scanning probe microscopy. Four major applications of these materials are under investigation: 1) catalyst design/molecular recognition, 2) bioelectronic devices, 3) tribology and adhesion and 4) microlithography. 


\section{Sensors/Detectors}

M. BEDNARSKI, T. WILSON, J. NAGY

In a project supported by the California Competitive Technology Program, designed to transfer technology derived from fundamental research at public institutions to Californla corporations, films similar to those described above have been modified to $\mathrm{cr}$ y designed, specific binding sites on their surfaces. Binding of target molecules to those sites causes a detectable change in the opto-electronic properties of the film (Figure 10). Collaboration with Blocircuits Corporation is focused on binding sites for detection of disease-causing microorganisms.

\section{Enzyme Design and Engineering}

\section{Thermostability of Enzymes \\ J. KIRSCH, P. SHIH, M. CALlstrom*, M. Bednarski, C.-H. Wong}

Roaction rates approximately double with a $10^{\circ}$ increase in temperature. Thus, the stabilization of enzymes so that they can function effectively at elevated temperatures will be an important advantage in bioreactors. Site-directed mutagenesis technology coupled with $x$-ray crystallographic structure analysis offers the opporti:ulty to deal with this problem by explicit protein design.

Experiments described last year were extended in order to test the hypothesis that simple nydrophobic packing could significantly increase the thermostability of lysozyme. An excellent correlation was shown for 11 proteins prepared by sitedirected mutagenesis. Nearly $3^{\circ} \mathrm{C}$ increases in $\mathrm{T}_{m}$ are produced by each added $-\mathrm{CH}_{2}-$ group. It was suggested in last year's report that there would be a limit to the degree of packing that could accommodated without seriously straining the enzyme structure. Two mutants have now been prepared adding the very large amino acids phenylalanine and tyrosine. Results with these substantiate the hypothesis. They yield active enzymes but ones which are significantly less stable than the variants made with smaller amino acids in these positions. An exciting new finding is that thermostable mutations in different parts of the protein can be combined to give the most stable proteins yet realized. For example, the mutant protein D101S is $2.8^{\circ} \mathrm{C}$ and $\mathrm{S} 91 \mathrm{~T}$ is $2.7^{\circ} \mathrm{C}$ more stable than wild type, respectively. The combined mutant, D101S/ $S 91 \Gamma$, is $5^{\circ} \mathrm{C}$ more stable than wild type.

The enzymes coupled to the polysaccharide based polymer (see page 12) have been shown to have significantly increased stability at normal and high temperatures (Figure 11). Continued exploitation of this material and its novel properties will be pursued in the DOE program.

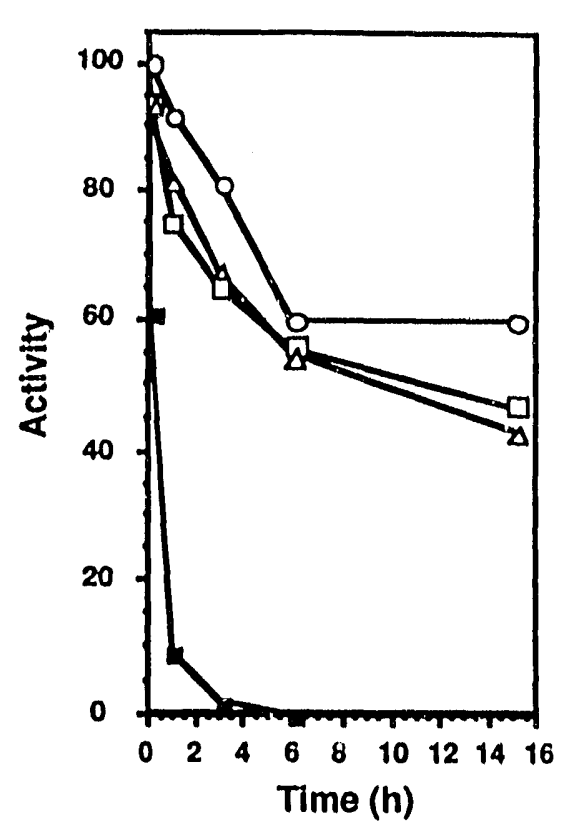

Figure 11

Stability of enzymes at elevated temperature $\left(50^{\circ}\right)$ through their coupllng to polysaccharidebased polymer. Solld symbols: uncoupled enzyme. Open symbols: a variety of coupled enzymes. (XBL 919-2061) 


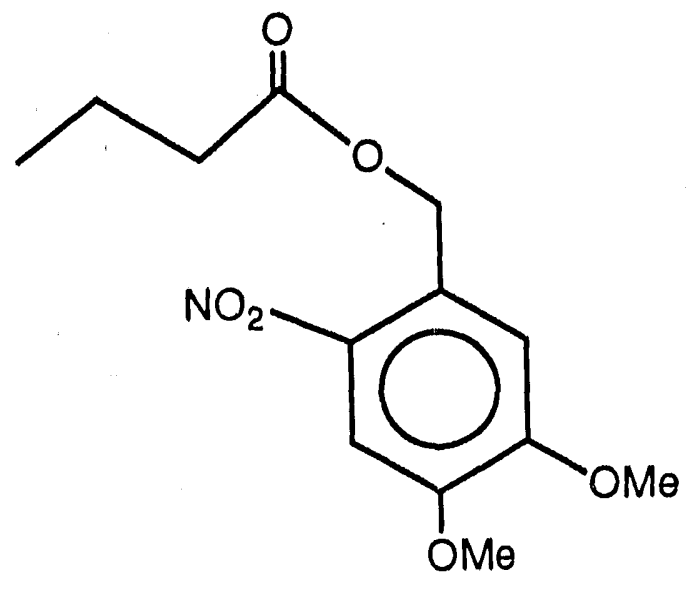

Figure12

Nonnatural amino acid asparty'l- $\beta$-nitrobenzyl ester has been Incorporated site-specifloally into the enzyme T4 lysozyme. The resulting enzyme is inactive untll photoaotlvated by exposure to light of $\lambda>315 \mathrm{~nm}$.<smiles>CC(C)CC(=O)O</smiles><smiles>CC(C)CCC(=O)O</smiles><smiles>CC(C)CCCC(=O)O</smiles>

Figure13

Amino acids of gradually increasing size have been inserted slte-specifloally into the enzyme T4 lysozyme. Amino acids (a), aspartio acid and givtamio aold (b) are naturally occurring. Amino aoid $(0)$ does not naturally occur in protelns.

\section{Seml-Synthetic Enzymes}

P.G. Schultz, S.A. Robertson, J. ElLman, D. Mendel.

Site-directed mutagenesis, although promising in its potentlal to help redesign enzymes, is restricted to the use of the 20 naturally occurring amino acids, thus limiting the fine tuning of geometry and functionality. As reported last year, this problem has been overcome by the development of a technique that allows the sitespecific substitution of virtually any alpha amino acid that can be synthesized in the laboratory. Technical aspects of the process have been significantly improved during the past year and the techniques has been applied to the erixyme T4 lysozyme.

A general and expedient procedure for the synthesis of aminoacyl tRNA has been developed. The system was also modified to involve preparation and photodeprotection of aminoacyl pdCpA derivatives containing nitroveratryl (NVOC) N-protected amino acids. The resulting tRNA was shown to be competent in an in vitro protein biosynthesis system. These protocols greatly simplify the procedure.

Unnatural amino acid mutagenesis has been applied to the construction of a photoactivatable enzyme. A stop codon was introduced into the active site $\pi$ of phage T4 lysozyme by means of oligonucleotide-directed mutagenesis. Suppressor tRNA aminoacylated with the photocleavable aspartyl- $\beta$-nitrobenzyl ester (NB-asp) (Figure 12) was constructed and found to efficiently suppress the stop signal in a cell-free coupled tranccription-translation system. The full length polypeptide produced under these conditions was catalytically inactive until irradiated at $\lambda>315 \mathrm{~nm}$ whereupon full catalytic activity was restored. This method can be extended to other amino acids within proteins to study a variety of biochemical problems.

The procedure has also been demonstrated to allow control of the size of active site amino acids through the successful incorporation of carboxylic acids with 1,2, and 3 methylene groups (Figure13). 
Program Leader

Morton M. Denn

Project Leaders

Mark D. Alper-Enzymatic Synthesls of Materials

Morton M. Denn-Anisotropic Polymeric Materials

Doros N. Theodorou-Polymer-Substrate Interactlons

Investigators

Mark D. Bednarski

Alexis T. Bell

Willlam S. Blalek

Harvey W. Blanch

Matthew Callstrom (The Ohlo State University)

Arup K. Chakraborty

Douglas S. Clark

Jack F, Kirsch

Jon D. Nagy

Bruce Novak

Jeffrey A. Relmer

Peter G, Schultz

C.-H. Wong (Scripps Research Institute)

Postdoctoral Fellows

Larry R. Dodd

David P. Durnas

Christopher J. Hobbs

Clemens Lamberth
Graduate Students

Claudla M. Bachmann

Andrew C. Braisted

Douglas A. Dovens, Jr.

Laura J. Dletsche

Mirtha M, Fernandez

Karen Fu

David Glles

Veronica K. Lim

Kovin F. Mansflold

Steven P. Musarra

Stephanie Robertson

James S. Shaffer

Phoobe F. Shlh

Spiridon S. Skourtis

Robecca E. Taylor

Albert Y. Wang

Peng Wang

Technical Assistants

Lynn Oehler

Whitney T, Carrico

Undergraduate Student

Troy E. Wilson

Nancy Lacrolx

- Peter Schultz was elected to the American Academy of Arts and Sciences.

- Harvey Blanch was elected Fellow of the International Institute of Blotechnology (UK).

- A polysaccaride based polymer for enzyme stabilization was developed in collaboration with Cargill Corporation.

- Substrate specificit!' of HAV protease was studied in collaboration with Protos, Inc.

- Thin film-based sensors and detectors were developed in collaboration with Biocircults.

Industrial Fellow

- Todd Guion of Cargill Corporation worked with Mark Bednarski's group on the production of novel carbohydrate-based polymers from carbohydrate residues. This exchange was supported by the Department of Energy's Industry Laboratory Technology Exchange Program.

Gifts

- Mark Bednarski's group received a 10K gift from Biucryst.

\section{Fellowships}

- The Enzyme project received a 20K fellowship from Hoechst Celanese.

\section{Contracts}

- Mark Bednarski's group recoived a $66 \mathrm{~K}$ contract from Cargill Corporation for the study of polysaccharide-based polymers.

- A grant from the California Competitive Technology Program supports work with Biocircuits, Inc., of Burlingame, $\mathrm{CA}$, on novel molecular self assembly systems for bioclectronics. 


\section{Patents}

- Self-Assembled Molecular Films; M.D. Bednarski, T.W. Wilron; U.S. Patont 07617 988 .

- Stabilized Proteins; P. Cruber, M.D. Bednarski, M. Callstrom; U.S. Patont 07613 224. (Cargill Corporation)

\section{Publications and Reports}

\section{Polymers and Composites}

\section{Referead journal Arlicles}

Chakraborty, A.K., H.T. Davis, and M. Tirrell, "A Molecular Orbital Study of the Intoractions of Acrylic Polymors with Aluminum: Implications for Adhesion," J. Polym. Sci., Polym. Chem. Ed, vol. 28, p. 3185, 1990.

Denn, M.M., "Issues in Viscoelastic Fluid Mechanics," Ann. Reo. Fl. Mech., vol. 22, p. 13, 1990.

Freeman, B.D., D.S. Soane, and M.M. Denn, "Effect of Hydrostatic Pressure on Polystyrene Diffusivity in Toluene," Macromolecules, vol, 23, p. 245, 1990.

Glles, D.W. and M.M. Denn, "Strain-Measurement Error In a Constant-Stress Rheometer," I. Rheology, vol. 34, p. 603, 1990.

HIII, D.A., T. Hasegawa, and M.M. Denn, "On the Apparent Relation Between Adhestve Fallure and Melt Fracture," 1. Rheolosy, vol. 34, p. 891, 1990 .

Kalika, D.S, D.W. Glles, and M.M. Denn, "Shear and Time-Dependent Rheology of a Fully-Nematic Thermotropic Liquild Crystalline Copolymer," I. Rheology, vol, 34, p. 139, 1990.

Kallka, D.S., L. Nuel, and M.M. Denn, "Gap-Dependence of the Viscosity of a Thermotrople Liquld Crystalline Polymer," /. Rheology, vol. 33, p. 1059, 1990.

Kallka, D.S., M.-R. Shen, X.-M. Yu, M.M. Denn, P. lannelli, N. Mascioocchi, D. Yoon, W, Parrish, C, Friedrich, and C. Noel, "Structural, Dielectric, and Rheological Characterization of a Thermotropic Polyester Displaying Smectic $A$, Nematic, and Isotropic Phases," Macromolecules, vol. 23, p. 5192, 1990.

Mansfield, K.F, and D.N. Theodorou, "Atomistic Simulation of a Glassy Polymer Surface," Macromolecules, vol. 23, p. 4430, 1990.

Rosenberg, J., R. Keunings, and M.M. Denn, "Slmulation of Non-Recirculating Flows of Dilute Flber Suspensilons," J. NonNewtonian Fluid Mech., vol. 37, p. 317, 1990.

Refereced Conference Proceedings

Kounings, R. and S. Musarca, "Numerical Simulation of Viscoelastic Stratified Flow in Complex Gcometries," Proc, 2nd World Congress on Computational Mechanics, p. 611, 1990.

Shaffer, J.S, and A.K. Chakraborty, "Energetics and Near-Surface Structure at Polymer-Metal Interfaces," Polymer Preprints, vol. 31, p. 546, 1990.

Other Publicalions

Denn, M.M. and E.T. Samulski, (Chairman), "Liquid Crystalline Polymers," National Materials Adoisory Board: Committee on Liquid Crystalline Polymers, NMAB-453, National Academy Press, 1990.

1.BL Reports (including journal articles submitted or in press)

Amundson, K.R., J.A. Reimer, and M.M. Denn, "Investigation of Microstructure in Poly(p-hydroxybenzole acld co-ethylene terephthalate) Using Nuclear Magnetic Resonance Spectroscopy," Macromolecules. (In press.)

Dodd, L.R. and D.N. Theodorou, "Analytical Treatment of the Volume and Surface Area of Molecules Formed by an Arbitrary Collection of Unequal Spheres Intersected by Planes," Molec. Phys. (In press.)

Mansfield, K.F. and D.N. Theodorou, "Molecular Mechanics Simulation of Glassy Polymers at Interfaces," in Computer Simulation of Polymers (In press.), ed. R.-J. Roe.

Nuel, L. and M.M. Denn, "Effect of Processing and Particulate Flllors on the Rheology of a Nematic Polymer Melt," Rheol. Acta. (In press.)

Rosenberg, J.R. and R. Keunings, "Numerical Integration of Differentlal Viscoelastlc Models," 1. Non-Newtonian Fluid Mech. (In press.)

Shipman, R.W.G., R. Keunings, and M.M. Denn, "Free-Surface Effects in Torsional Parallel-Plate Rheometry," Ind. ling. Chem. Res, (In press.) 
Thakkar, B., F. Konstandinidis, A.K. Chakraborty, R. Tannenbaum, L.W. Polts, J.F. Evans, and M. Tirrell, "Interfacial Bonding and Chain Conformations at PMMA-Native Aluminum Oxide Surfaces: IR, XPS, and NMR Sudies," Langmuir. (In press.)

Denn, M.M., Stress-Induced Wall Effects and Polymer Flow Instabilities, Presented at University of Wisconsin, Chemical Engineering Dept., March 1990; Unversity of Illinois, Urbana, Cinemical Engineering Dept., March 1990; North Carolina State University, Chemical Engineering Dept., March 1990; University of Florida, Chemical Engineering Dept., March 1990.

Denn, M.M., Flow Instabilities in Polymer Melt Processing, 17th Annual Stanley Katz Memorial Lecture, City College, New York, NY, April 1990.

Denn, M.M., Polymer/Surface Interactions, Union Carbide Chemicals and Plastics Company, Specialty Chemicals Division, Tarrytown, NY, February 1990.

Denn, M.M., Rheology of Thermotropic Liquid Crystallirie Polymers, 33rd IUPAC International Symposium on Macromolecules, Montreal, July 1990.

Denn, M.M., Liquid Crystalline Polymers, NATO Workshop on Defects, Singularities and Patterns in Nematic Liquid Crystals, Orsay, France, May 1990.

Keunings, R., Progress and Challenges in Computational Rheclogy, Third European Rheology Conference, Keynote Paper, Edinburgh, Scotland, September 1990.

Rosenberg, J.R., M.M. Denn, and R. Keunings, Numerical Simulation of Fiber Suspension Flow in Complex Geometries, 6th Meeting of the Polymer Processing Society, Nice, France, 1990.

Theodorou, D.N., Molecular Modeling of Polymers at Interfaces, Presented at: Polymer Science Lecture Series, Institute of Polymer Science, University of Akron, January 1990; BIOSYM Seminar on Computer Simulation of Polymers and Polymeric Systems, Irvine, TX, Apri!! 1990; Makromolekulare Chemie, Institut fur Polymere, ETH Zurich, Switzerland, June 1990; BIOSYM Polymer Project Consortium Meeting, Paris, France, June 1990; and Symposium on Models for Polymer Thermodynamics, 1990 Annual Meeting of the American Institute of Chemical Engineers, Chicago, IL, November 1990.

Theodorou, D.N., Elements of Statistical Mechanics and Introduction to Techriques for the Molecular Simulation of Materials, National Research Center for the Physical Sciences "Democritus," Aghia Paraskevi, Athens, Greece, July 1990.

Theodorou, D.N., Molecular Simulation of Polymers: Prediction of Thermodynamic, Mechanical Interfacial and Rheological Properties, National Center for the Physical Sciences "Democritus," Aghia Paraskevi, Athens, Greece, July 1990.

Theodorou, D.N., Molecular Modeling of Interfacial Structure and Thermodynamics of Polymers, Third Workshop of the American Chemical Society on Polymer Surfaces and Interfaces, Pacific Grove, CA, October 1990.

Dodd, L.R. and D.N. Theodorou, PVT Properties of Polymer Liquids from Detailed Chain Ceometry and Energetics, Symposium on Models for Polymer Thermodynamics, 1990 Annual Meeting of the American Institute of Chemical Engineers, Chicago, IL, November 1990.

Giles, D.W. and M.M. Denn, Rheometer Strain and Strain-Rate Errors, Golden Jubilee Meeting of the British Society of Rheology and 3rd European Rheology Conference, Edinburgh, Scotland, September 1990.

Keunings, R. and S. Musarra, Numerical Simulation of Viscoelastic Stratified Flow in Complex Geometries, 2nd World Congress on Computational Mechanics, Stuttgart, Germany, 1990.

Mansfield, K.F. and D.N. Theodorou, Atomistic Molecular Dynamics Simulation of a Polymer/Vacuum Interface, Symposium on Polymer Surfaces and Interfaces, 1990 Annual Meeting of the American Institute of Chemical Engineers, Chicago, IL, November 1990.

Theodorou, D.N., Molecular Modeling of Structure and Thermodynamic Properties of Polymers at Interfaces, 33rd IUPAC Symposium on Macromolecules, Montreal, Quebec, July 1990. 


\section{Enzymatic Synthesis of Materials}

Refereed Journal Articles

Braisted, A. and P.G. Schultz, "An Antbody-Catalyzed Biomolecular Diels-Alder Reaction," J. Am. Chem. Soc., vol. 112, p. 7430, 1990.

Chen, S.T., J.A. Bibbs, W.J. Hemmen, Y.F. Wang, J. Liu, M.W. Pantollano, M. Whitlow, P.N. Bryan, and C.-H. Wong, "Enzymes in Organic Synthesis: Use of Subtlisin and a Highly Stable Mutant Derived from Site-Specific Mutations," I. Am. Chem. Soc., vol. 112, p. 945, 1990.

Malcolm, B.A., K.P. Wilson, B.W. Matthews, J.F. Kirsch, and A.C. Wilson, "Ancestral Lysozymes Reconstructed, Neutrality Tested, and Thermostability Linked to Hydrocarbon Packing," Nature, vol. 345, p. 86, 1990.

Mastandrea, M. and M. Bednarski, "The Use of Self-Assembled Organic Films for Controlling Biological Adhestion," J. Mater. Educ., vol. 11, p. 529, 1990.

West, J.B., W.J. Hennen, J.L. Lalonde, J.A. Blbbs, Z. Zhong, E.F. Meyer, and C.-H. Wong, "Enzymes as Synthetic Catalysts: Mechanistic and Active-Site Considerations of Natural and Modified Chymotrypsin," J. Am. Chem. Soc,, vol. 112, p. $5313,1990$.

Wong, C.-H., S.T. Chen, W.J. Hennen, J.A. Bibbs, Y.-F. Wang, J.L.-C. Liu, M.W. Pantoliano, M.Whitlow, and P.N. Bryan, "Enzymes in Organic Synthesis: Use of Subtilisin and a Highly Stable Mutant Derived from Multiple Site-Specific Mutations," J. Am. Chem. Soc., vol. 112, p. 945, 1990.

Refereed Conference Proceedings

Bibbs, J.A., Z. Zhong, and C.-H. Wong, "Modification of Proteases for Peptide Synthesis," Mat. Res. Soc. Proc., vol. 174, p. 223, 1990.

Callstrom, M.R., \ 1.D. Bednarski, T.G. Hiil, L.M. Oehler, and P. Gruber, "New Carbohydrate-Based Materials," Mat. Res. Soc. Proc., vol. 174, p. 259, 1990.

Mastandrea, M. and M. Bednarski, "Sugar-Coated Semiconductors: Model Surfaces to Study Biological Adhesion," Mat. Res. Soc. Proc., vol. 174, p. 277, 1990.

Rieke, P.C., P.D. Calvert, and M.D. Alper, eds., Materials Synthesis Using Biological Processes, 174, Materials Research Society, 1990.

LBL Reports (including joumal articles submitted or in press)

Braisted, A.C. and P.G. Schultz, "An Antibody-Catalyzed Biomolecular Diels-Alder Reaction," J. Am. Chem. Soc. (Submitted.)

Mastandrea, M., T. Wilson, and M.D. Bednarski, "The Use of Self-Assembled Organic Films for Controlling Biological Adhesion," J. Mat. Edu. (Submitted.)

Wong, A., D.S. Clark, and H.W. Blanch, "Enzymatic Synthesis of Carbohydrate-Derivatized Monomers," Macromolecules. (Submitted.)

Irvited Talks

Alper, M.D., Enzymatic Synthesis of Materials, Presented at Xerox PARC, Palo Alto, CA, November 1990; Materials Research Society, Boston, MA, November 1990; Sandia National Laboratory, Albuquerque, NM, August 1990; U.S. Department of Commerce, Federal Technology Transfer Series, Washington, D.C., Jily 1990; DOE Bloenergy Coordinating Committee, Washington, D.C., June 1990.

Bednarski, M.D., Synthesis of Carbon-Linked Glycosides that Ininibit the Binding of Pathogenic Bacteria to Cells, XVth International Carbohydrate Symposium, Yokohama, Japan, August 1990.

Bednarski, M.D., Carbon-Clycosides Bind to Cell-Surface Receptors and can be Used to Change the Antigenic Properties of Pathogenic Bacteria, National Science Foundation Workshop on Organic Synthesis and Natural Products Chemistry, Ft. Collins, CO, July 1990.

Bednarski, M.D., The Synthesis of Polymerized Polypeptide-Lipid Films to Control Interfacial Properties, NSF Biomolecular Materials Workshop, Washington, D.C., October 1990.

Bednarski, M.D., L. Oehler, and C. Hobbs, The use of Proteins in the Synthesis of Polysaccharides and Polypeptide based Polymers, MRS Meeting, Boston, MA, November 1990.

Kirsch, J., Enzyme Design: The Lysozyme Paradigm, National Academy of Sciences Workshop on Catalysis, Washington, D.C., April 1990.

Kirsch, J., Protein-Protein Recognition: Lysozyme and its Complexes with Antibodies, Harvard Medical School, Boston, MA, June 1990.

Kirsch, J., Lysozyme: Binding and Thermostability, Center for Advanced Research in Biotechnology, College Park, MD, March 1990. 
Kirsch, J.F., Site-Directed Mutagenesis of Aspartate Aminotransferase, Presented at University of North Carolina, March 1990; University of Maryland, March 1990.

Kirsch, J.F., The Circe Effect in Enzyme Catalysis, Boston, MA, Pfizer Symposium in honor of James A. Wells, Art.erican Chemical Sodety Meeting, April 1990.

Kirsch, J.F., The Aspartate Aminotransferase Mechanism, Syntex Corporation, Palo Alto, CA, January 1990.

Kirsch, J.F., Site-Directed Mutagenesis Analysis of the Aspartate Aminotransferase Mechanism, Ann Arbor, MI, Parke.Davis Company, May 1990.

Schultz, P.G., Directed Mutagenesis with Unnatural Amino Acids, Mack Lectureship, Ohio State University, February 1990.

Schultz, P.G., New Opportunities at the Interface of Chemistry and Biology, Mack Lectureship, Ohio State University, Fcbruary 1990.

Schultz, P.G., Catalytic Antibodies, Denkewalter Lecture, Loyola University, May 1990.

Schultz, P.G., Mutagenesis with Unnatural Amino Acids, Irving S. Segal Memorial Lecture, October 1990. 


\section{High-Performance Metals Program}

The CAM program in HIGH-PERFORMANCE METALS is intended to advance metallurgical science in those directions that are critical to the development of new metals and alloys with exceptional properties. The research addresses problems that are relevant to industry, and is done in close collaboration with industrial or national laboratory groups who are the potential users of the research. The program includes three tasks: Metals for Advanced Applications (J.W. Morris, Jr.), Mechanical Behavior of Materials (R.O. Ritchie), and Materials Characterization (G. Thomas).

The overall aim of research in METALS FOR ADVANCED APPLICATIONS is to understand and exploit mechanisms of microstructural evu ution to suggest new alloys or processing techniques that establish useful engineering properties. This is accomplished through fundamental research on the nature of microstructure, its evolution, and ways in which microstructure can be engineered to control properties. Current research particularly concentrates on functionally unstable materials, whose properties are strongly affected by microstructural instabilities during service.

Highlights of recent research include:

- The use of combined analytic and computer simulation techniques to clarify the preferred shapes of coherent precipitates in solids and the configurations of groups of elastically interacting precipitates.

- Demonstration of the relevance of diffuse scattering from random faults in determining the diffraction pattern of non-stoichiometric $\mathrm{YBa}_{2} \mathrm{Cu}_{3} \mathrm{O}_{7-\gamma}$.

- Development of an analytic solution for the low-temperature growth of the intermetallic layer at a $\mathrm{Cu}-\mathrm{Sn}$ interface.

- Demonstration that dislocation cell formation does not significantly affect work hardening in low-carbon sheet steel deformed near ronm temperature.

- A collaborative work with DEC which showed that thin solder joints may be made superplastic in the as-cast condition, with a dramatic improvement in resistance to thermal fatigue.

- Determination of the influence of strain-induced martensite on fatigue crack growth in metastable austenitic steels, and developed an appropriate constitutive equation.

- Establishment of the normal mechanism of electromigration failure in thin $\mathrm{Al}-\mathrm{Cu}$ conductors is transgranular, and showed that the mechanism can be suppressed by appropriate aging treatments, yielding a substantial increase in electromigration life.

- Demonstration that the fracture toughness of metastable austenitic steel is affected by high magnetic fields to a degree that depends on the stability of the austenite phase.

- Demonstration that loss of solderability of pre-tinned $\mathrm{Cu}$ electrical contacts can be caused by $\mathrm{Cu}$ diffusion to react with $\mathrm{Sn}$ in the pre-tinned layer. 
- A collaborative work with Hewlett Packard which found thickness limits for Au coatings on $\mathrm{Cu}$ contacts to prevent mechanical deterioration of the solder.

The aim of the MECHANICAL BEHAVIOR OF MATERIALS project is to develop a fundamental mechanistic understanding of fracture processes in order to provide guidelines for improved life prediction and the design of superior fracture-critical materials. It provides direct support to other CAM projects studying materials with important and interesting fracture properties. Work during the past year includes:

- Characterization of cyclic fatigue-crack propagation behavior in ceramics under variable-amplitude loading.

- The first reported documentation of cyclic fatigue-crack growth rate behavior along glass/copper and alumina/aluminum ceramic/metal interfaces.

- The identification of the mechanisms underlying the unique fracture-toughness and fatigue-crack growth behavior of advanced aluminum-lithium alloys scheduled for aerospace and cryogenic applications.

- The development of extrinsic methods for toughening ceramic/metal interfaces, and identifying mechanisms of cyclic fatigue and environmentallyassisted crack growth along such interfaces (in collaboration with R.M. Cannon of the CAM Electronic Materials Program), with specific emphasis of microelectronic packaging applications.

The aim of research in MATERIALS CHARACTERIZATION is to utilize highresolution techniques in materials characterization to clarify microstructural features and phase transformations in advanced metal alloys, and to determine their consequences for alloy properties. Research during the past year includes:

- Characterization of weld and heat-affected-zone properties of weldments in the aluminum alloy 2090 at room and cryogenic temperature.

- Demonstration that the coefficient of friction during forming of electrogalvanized sheet steel is proportional to the area of contact between sheet and tool irrespective of coating microstructure. Found that the coating surface recrystallizes during contact with the toolpiece.

- Identification of the mechanism underlying the unique fracture toughness and fatigue crack growth behavior of Al-Li alloys intended for aerospace and cryogenic applications.

- Experimental establishment of the two alternate mechanisms for the formation of $\delta^{\prime}$ precipitates in Al-Li alloys: spontaneous ordering on fast cooling, nucleation and growth on slow cooling.

- Characterization of the matrix-particle interface in $\mathrm{Al} / \mathrm{SiC}$ metal matrix composites, and showed the presence of a thin reaction layer of disordered alumino-silicide. 


\section{METALS FOR ADVANCED APPLICATIONS}

This research project includes work on the theory of microstructural evolution, microstructural effects in plastic deformat:on, microstructural influences on friction and wear, microstructural instabilities in fatigue and fracture, microstructural changes induced by electromagnetic fields, and microstructural consequences of welding and joining.

\section{Theory of Microstructural Evolution}

Almost all materials of engineering interest have microstructures that are thermodynamically unstable, and evolve continuously as the material is processed or used. These instabilities are intentionally utilized in processing to control the microstructure, and hence the properties, of the product. However, the microstructure continues to evolve as the material is used. Microstructural change during service usually induces undesirable changes in material properties, and is, hence, studied to learn how it can be avoided or forestalled. But microstructural instabilities can also be useful; they' can provide valuable defense mechanisms that are triggered by incipient failure and help to defeat it. The theory of microstructural evolution in solids is mede difficult by the kinetic constraints imposed by the solid state. Chemical diffusion is relatively slow, and structural changes are inhibited by the elastic constraint of the surrounding material. The development of the theory of microstructural evolution is essential to the understanding and control of material behavior.

The Equilibrium Shapes of Cubic Precipitates in Cubic Media with Negative Elastic Anisotropy M. McCormack AND J. W. MORRIS, JR.

Precipitates that form in the solid state ordinarily begin as coherent particles that are elastically connected to the surrounding matrix. Their preferred shapes are determined by a balance between surface energy, which creates a preference for spherical or equiaxed figures, and elastic energy, which is minimized when the particle is a thin plate with a definite crystallographic habit. Since the elastic energy is proportional to particle volume while the surface energy varies with area, the preferred shape changes as the particle grows. We showed some years ago that when the elastic anisotropy factor, $\Delta=c_{11}-c_{12}-2 c_{44}$, is negative, as it is for most materials, the preferred shape of a cubic precipitate evolves from sphere to cube to split cube to thin plate as the particle coarsens. The present work treated the case of positive anisotropy, and showed that, for isotropic surface energy, the preferred shape changes from sphere to tetrahedron to thin plate. The results apparently explain the tetrahedral shape preference of small precipitates in common ceramic systems.

\section{The Shape Evolution of Coherent Precipitates in Cubic Media}

M. MICCORMACK AND J.W. MORFIS, JR.

Distributions of precipitates in cubic media tend to adopt stable configurations that coarsen very slowly. Prior work suggests that the stabilization is due to long-range elastic interactions. To explore this phenomenon, we developed a computer simulation procedure that calculates the change in surface and elastic energy during to an arbitrary reconfiguration of small precipitate particles in two dimensions. The simulation shows that square precipitates spontaneously split in to parallel rectangles when they coarsen to a critical size, and that distributions of precipitates evolve into metastable configurations, stabilized by elastic interactions, in which particles align as split pairs. The morphological patterns of the metastable configurations are very sensitive to the interfacial tension of the product phase. 
Ordering in FCC-based systems is investigated using the pair potential approximation in the ground state and mean field limits. It is shown that the stability of noninteger domain sizes in long-period superstructures such as $\mathrm{Al}_{3} \mathrm{Ti}$ and $\mathrm{Ag}_{3} \mathrm{Mg}$ may result from a tendency of the system to reduce the number of non-dominant ordering waves in its final structure; the common long-period structures can be obtained as special cases of Khachaturyan's Maximum Amplitude Principle. Using this kinematic condition in conjunction with previously suggested forms for the Fourierspace pair potential, $V(k)$, leads to a simple interpretation of the dependence of the long-period domain size on electron concentration and temperature.

\section{Analysis of Low-Temperature Intermetallic Growth in Copper-Tin Diffusion Couples}

Z. MEI, A. SUNWOO, AND J. W. MORRIS, JA.

The properties of solder joints in microelectronic devices are strongly affected by the nature of the intermetallic layer at the interface. In the most common case, $\mathrm{Pb}-\mathrm{Sn}$ solder on $\mathrm{Cu}$, the intermetallic is a composite of two intermetallics: $\varepsilon$-phase, $\mathrm{Cu}_{3} \mathrm{Sn}$, and $\eta$-phase, $\mathrm{Cu}_{6} \mathrm{Sn}_{5}$. A multi-phase diffusion model was constructed and used to analyze the growth of the $\varepsilon$ - and $\eta$-phase intermetallic layers at a plane $\mathrm{Cu}-\mathrm{Sn}$ interface in a semi-infinite diffusion couple. The higher interdiffusivity in the $\eta$ phase has the consequcince that the $\eta$-phase predominates in the intermetallic bilayer. However, the lower activation energy for interdiffusion in the $\eta$-phase has the result that the $\varepsilon$-phase fills an increasing fraction of the intermetallic layer at higher temperature. The results successfully predict experimental observations on intermetallic growth at solder-Cu interfaces.

\section{Diffuse Scattering from $\mathrm{YBa}_{2} \mathrm{Cu}_{3} \mathrm{O}_{7 \ni}$}

A.G. KhaChaturyan" AND J.W. MORRIS, JR.

This work was motivated by the observation of diffuse maxima in diffraction patterns obtained from $\mathrm{YBa}_{2} \mathrm{Cu}_{3} \mathrm{O}_{7-\delta}$ of intermediate stoichiometry $(\delta<0.5)$ in the absence of macroscopic domains of the ordered phases corresponding to the observed maxima. Using a simple structural model that assumes the deviation from stoichiometry is accommodated by non-neighboring, random faults in the ordered pattern of oxygen in the basal plane of the unit cell, we showed that such random faulting would produce diffuse maxima tat shift with composition in a manner similar to that which is experimentally observed.

\section{Microstructural Effects on Work Hardening and Plastic Deformation}

Normal plastic deformation is caused by the motion of dislocations, and strongly influenced by the interaction of dislocations with one another and with microstructural obstacles such as precipitates and grain boundaries. Since both dislocations and microstructural barriers are densely distributed in a normal metal and evolve together, the theory of plastic deformation is formidable. To make progress in understanding it one tries to separate the effects of different microstructural elements and identify or control those particular features that have the most dominant effect. The separation can be subtle. Often the most obvious features of the microstructure are not the most important. 
The Influence of Dislocation Cell Formation on Work Hardening in Low-Carbon Steel

P.E. JOHNSON, J.H. SCHMmT AND J.W. MORRIS, JR.

The most striking microstructural change during the large plastic deformation of sheet steel at room temperature is the development of well-defined dislocation cells within the grains. It has long been assumed that cell formation dominates work hardening. To test this hypothesis steels were deformed to the same room-temperature strength level by straining at room temperature, which creates a well-developed cell structure, and by straining at lower temperatures, which creates a nearly random dislocation distribution. The subsequent work hardening behavior of the steel was found to be independent of the dislocation structure, showing that the cell structure has, at most, a secondary effect on deformation behavior. Further studies, including in situ deformation in a high-voltage electron microscope, suggests that the rate of deformation is dominated by the local motion of screw dislocations, on a scale that is small compared to cell size.

The Influence of Grain Morphology on Work Hardening in Al-LI-Cu Alloys

D. ChU, C. Tseng, D. YAO and J.W. MorRIS, JA.

$\mathrm{Al}-\mathrm{Li}-\mathrm{Cu}$ alloys can be processed to have two rather different grain structures: an equiaxed structure obtained by recrystallization, or a "pancake" structure obtained by severely deforming the alloy without recrystallization. At room temperature the two structures have similar work hardening characteristics. However, at cryogenic temperatures the pancake structure has a significantly higher work hardening rate. The change is apparently due to the difficulty of transmitting strain across grain boundaries at lower temperature; grain boundaries are much more densely distributed in the glide plane of the dislocation in the pancake structure.

Superplastic Al-Sc-LI Alloys

T. BRADLEY AND J.W. MORRIS, JR.

The alloying element $S c$ is well known to be both a very potent strengthener and a good grain refiner in $\mathrm{Al}$ alloys. $\mathrm{Al}-\mathrm{Mg}-\mathrm{Sc}$ alloys have been made with excellent superplastic formability at moderate temperature. To decrease the density of the alloys it is desirable to add $\mathrm{Li}$. To combine strength and superplasticity it is necessary to use a double heat treatment in which Sc precipitates are formed and coarsened at a temperature above the $\mathrm{Li}$ solvus to stabilize a fine grain structure, and $\mathrm{Li}$ precipitates are formed by subsequent heat treatment to impart strength. Using these principles, a variety of Al-Li-Sc-based alloys have been cast and heat treated, generating promising combinations of strength and formability.

\section{Microstructural Influences on Friction and Wear}

In most practical cases, friction between metals is not a simple interfacial phenomenon. It is governed by the mechanical properties of the material adjacent to the interface, which is polished, scored or locally welded during metal-to-metal contact. We have recently been engaged in research on one important example of this behavior: friction during the forming of electrogalvanized steel. The work is done in collaboration with the Ford Motor Company, LTV Steel, Rouge Steel, and the Keil Chemical Division of Ferro Corporation.

\section{The Sources of Friction in Forming Electrogalvanized Sheet Steel*}

S. SHAFFER AND J.W. MORRIS, JR.

The source of friction during the forming of electrogalvanized sheet steel were investigated by examining a series of steels, including both commercial product and steels electrogalvanized under controlled, laboratory conditions, that had been tested for friction by draw-bead simulation. The electrogalvanized layers were

\footnotetext{
"Research supported by Ford Motor Company, LTV
} 
characterized for grain size, crystallographic texture, and surface morphology. The results suggest that draw-bead friction is simply proportional to the fractional area of contact established between the bead and the coating layer during the abrasive drawing operation. The microstructure of the layer is relevant in two respects: it affects the effective hardness of the coating, and it influences the local roughness of the co :ting. Both factors influence the fractional area of contact.

\section{Changes in Crystallographic Texture During Forming of Electrogalvanized Sheet*}

S. SHAFFER, R. WENK ${ }^{\dagger}$ AND J.W. MORAIS, JA.

$\mathrm{X}$-ray and metallographic analyses were used to study the change in microstructure and crystallographic texture of the coated layer near the interface of contact during the forming of electrogalvanized sheet. The results iluggest that the nearsurface material is recrystallized by the severe deformation caused by contact with the tool piece. Recrystallization establishes a final crystallographic texture that is nearly independent of the initial texture of the coating, and apparentiy explains the simple proportionality between the coefficient of friction and the area of contact.

\section{Microstructural Instablities in Fatigue and Fracture}

Mechanical failure may be promoted or inhibited by microstructural instabilities. We have been studying two interesting examples of fatigue in materials with unstable microstructures: eutectic alloys that undergo recrystallization or polygranular reconfigurations when they are deformed, and metastable austenitic steels that transform martensitically during plastic deformation. The first problem is relevant to the thermal fatigue of soldered contacts in electronic devices the second is relevant to crack growth in the structures of high field superconducting magnets that are made of nonmagnetic steels and used at liquid helium temperature. Recent research includes the following.

The Mechanlsm of Thermal Fatigue in Eutectic Pb-Sn Solder

D. Tribula, Z. Mei, D. Gaivas, D. Frear ${ }^{\ddagger}$ and J.W. Morris, Jr.

Soldered contacts in microelectronic devices are liable to thermal fatigue failure in cyclic shear, caused by the difference in thermal expansion between the surfaces joined by the solder joint. In the case of eutectic $\mathrm{Pb}$-Sn solder, which is the most common solder material, the fatigue is driven by a microstructural instability which should be observed in many eutectic alloys. In the as-cast condition the solder has a lamellar eutectic microstructure. At high homologous temperatures, deformation is inhomogeneous, and concentrates in bands that cut through the microstructure. The material within the bands recrystallizes into a new microstructure of fine, equiaxed grains. The recrystallized material is relatively soft, so cyclic deformation is further concentrated in the recrystallized bands. The concentrated local deformation nucleates fatigue, and provides a preferential path for fatigue crack growth to failure. Recent research shows that this is the usual mechanism of fallure in solder joints of reasonable thickness.

\section{The Use of Alloy Additions to Inhiblt Thermal Fatigue in Eutectic Solder}

D. TFilBula AND J.W. MOARIS, Ja.

One method for inhibiting thermal fatigue in eutectic alloys is to introduce alloy additions that disturb the regularity of the lamellar eutectic microstructure and inhibit the formation of concentrated bands of deformation. An exploration of possible alloy additions to eutectic $\mathrm{Pb}$-Sn solder shows that minor additions of In or $\mathrm{Cd}$ refine the eutectic colonies and broaden the intercolony material with the consequence that high-temperature deformation is relatively diffuse. Tests of In-or Cd-modified solder joints show an improvement of more than $50 \%$ in the thermal fatigue life.

tDept, of Geology, University of California, Berkeley †Sandla National Laboratory, Albuquerque 
The Use of Grain Reflinement to Inhiblt Thermal Fatigue in Eutectlo Solder*

Z, MEl, C. SHINE ${ }^{\dagger}$ AND J.W. MORAI8, JA.

When a cutectic $\mathrm{Pb}$-Sn alloy is rapldly solidifled it develops a finc-grained, nearly equiaxed microstructure that deforms superplastically at moderate stresses. Research has shown that such a microstructure can be formed naturally in thin solder foints of the dimensions that are commonly used in microclectronic devices. Measurements of thermal fatigue in such foints shows that cyclic superplastic deformation is nearly "free"; there is little or no fatigue damage so long as the cyclic load is kept within the superplastic regime. Solder joints solidified at a sufficient rate to establish a superplastic microstructure have thormal fatigue lives that are several hundred percent greater than those of similar joints that are slowly cooled to create a cutcetic microstructure. These results apply not only to $\mathrm{Pb}-\mathrm{Sn}$ eutectic alloys, but also to other solder materials than can be solidified into a fine-gratned structure including In-Sn and In-Pb-Sn alloys.

\section{The Use of Second-Phase Particles to Inhibit Thermal Fatigue in Eutectlo Solder}

T. S. SUMMERS AND J.W. MORAIS, Ja.

The normal mechanism of thermal fatigue in eutectic solder can be frustrated by introducing second-phase particles that prevent the formation of continuous deformation bands. One simple way to accomplish this is to use off-eutectic compositions. Research on the fatigue life of slow-cooled $\mathrm{Pb}$-Sn solder as a function of composition shows that the fatigue life is maximum at about the $50 \mathrm{~Pb}-50 \mathrm{~S} n$ composition, where the microstructure is about one-third pro-eutectic $\mathrm{Pb}$. The islands of $\mathrm{Pb}$ prevent the formation of continuous deformation bands that cause recrystallization and fallure, while the surrounding eutectic material prevents early failure of the $\mathrm{Pb}$ islands.

The Influence of Deformation-Induced Martensite on Fatigue Crack Propagation in Metastable Austenitic Stee/s ${ }^{\ddagger}$

Z. MEI AND J.W. MORRIS, JR.

This research in'restigated the influence of the mechanically induced martensitic transformation on the fatigue crack growth rate in metastable austenitic stainless steels. The steels $304 \mathrm{~L}$ and $304 \mathrm{LN}$ were used to test the influence of composition, the tescing temperatures $298 \mathrm{~K}$ and $77 \mathrm{~K}$ were used to study the influence of test temperature, and various load ratios were used to determine the influence of the mean stress. It was found that decreasing the mechanical stability of the austenite by changing composition or lowering temperature reduces the fattgue crack growth rate and increases the threshold stress intensity for crack growth. However this beneficial effect diminishes as the load ratio increases, even though increasing the load ratio increases the martensite transformation. Several mechanisms that may affect this phenomenon are discussed, including the perturbation of the crack-tip stress field, crack deflection, and the work hardening characteristics and relative brittleness of the transformed material. The perturbation of the stress ficld seems the most important; by modifying previous models we develop a quantitative analysis of the crackgrowth rate that provides a reasonable fit to the experimental results.

\section{Microstructural Changes Induced by Electromagnetic Flelds}

Comparatively little research has been done on the influence of electromagnetic phenomena on microstructure and properties of engineering alloys. However, the subject is becoming increasingly important, as modern devices employ very high current densities or operate in high magnetic fields. We have been studying two examples of these phenomena: microstructural evolution and fallure due to elec-

\footnotetext{
"Research supported by the Digltal Equipment Corporation

tolgltal Equipment Corporation, Cupertino, $\mathrm{Ca}$.

tResearch supported by the Offlce of Magnetlo Fusion
} 
tromigration in thin aluminum alloy conductors, and changes in transformation behavior fracture toughness when metastable austenitic steds are stressed in high magnetic fiolds, Recent research includes the following.

\section{The Mechanism of Eleotromigration Fallure In Thin Aluminum Alloy Lines J.E. SANOHEZ, T. MONALLY AND J.W. MORRIS, JA.}

When a polygranular aluminum or $\mathrm{Al}$ alloy conductor ( $\mathrm{Al}-\mathrm{Cu}$ or $\mathrm{Al}-\mathrm{Cu}-\mathrm{Sl}$ ) is subjected to to a high current density, the current induces accelerated diffusion (electromigration) in the allny, and eventually causes fallure by the nucleation and juncture of volds that forn in the grain boundaries. However, modern microclectronic devices use conducting lines that are a micron or less in width. These have a "bamboo" structure in which single grains span the line. The mechanism of electromigration fallure in these lines was explored by following exposure to high current density with high-resolution transmission electron microscopic studies of the failure site. The results show a very different mechanism of fallure; the lines usually fall by a transgranular mechanism in which thin, slit-like volds or cracks nucleate at the boundarles of the line and propagate across it. The details of the transgranular fallure mechanism are under investigation.

\section{Accelerated Coarsening and Fallure in Artiflclally Aged Al-Cu Conductors}

C. KIM AND J.W. MORRIS, JR.

$\mathrm{Cu}$ is commonly added to $\mathrm{Al}$ conducting lines to inhibit electromigration fallure, though the mechanism by which $\mathrm{Cu}$ improves performance is not well understood. We have used electromigration testing and high-resolution transmission electron microscopy to study microstructural evolution and fallure in such conductors. The results show that $\mathrm{Cu}$ is present in the form of fine precipitates is as-deposited lines. When the current is imposed the fine precipita tes in the interior of the grains dissolve, while those at the grain boundaries coarsen. The mechanism of dissolution is the direct replacement of $\mathrm{Cu}$ by vacancles, with the consequence that the fine, intragranular precipitates are replaced by volds. The intragranular volds grow and join to produce transgranular fallure of thin lines. This result suggests that the electromigration life of thin lines can be improved by artificially aging the lines to control the precipitate distribution. Aging treatments that substantially reduce the density of intragranular precipitates increase electromigration life by a full order of magnitude, and change the mechanism of fallure to a diffuse mechanism in which the line gradually thins until it finally pinches off. Overaging causes a loss of electromigration resistance, apparently because $\mathrm{Cu}$ is fully depleted from long lengths of line, which then behave as pure $\mathrm{Al}$ conductors.

\section{The Influence of High Magnetic Fields on the Fracture Toughness of Metastable Austenitic Steels \\ J. CHAN AND J.W. MORRIS, JA.}

If a material is ferromagnetic, or if it is liable to transform into a ferromagnetic phase, one must be concerned about the influence of a high magnetic field on its mechanical properties. An important example is the structure of a high field superconducting magnet. To test this issue we have studied the tensile and fracture toughness of high strength steels at $4 \mathrm{~K}$ in high magnetic fields. The results, which have been reproduced in Japan, show that the tensile properties of common metastable austenitic steels are only slightly affected by fields as large as $18 \mathrm{~T}$. However, the fracture toughness changes significantly, in a direction and by an amount that depends on the degree of the martensitte transformation. Relatively stable alloys, such as nitrided $304(304 \mathrm{LN})$, increase in toughness by up to $30 \%$ in an $8 \mathrm{~T}$ ficld. Alloys that are less stable, such as $304 \mathrm{~L}$, decrease in toughness to a similar degree. The results

${ }^{\text {SResearch supported by the Offloe of Magnetic Fuslon }}$ 
show that the change in toughnoss is assoclated with the extent of martensitic transformation at the crack tip. However, the results cannot be quantitativaly fit to any existing theoretical treatment of transformatton toughening, which shows that there are quantitatively important elements missing from the current theories.

\section{Mlorostruotural Effects in Metals Jolning}

Metal alloys are welded or bratsed by foining them with a thin, molten layer that solidifies to create the joint. The properties of the joint are ordinarily deteriorated over those of the bulk metal for two reasons: the freshly solidified material in the joint has an as-cast microstructure that may have poor mechanical propertles, and the heat from the joining operation creates a heat-affected zone in the base material whose mechanical properties may be relative!y poor. We have been engaged in research on the welding of $\mathrm{Al}-\mathrm{Li}$ alloys, which have promising properties for cryogenic structural use but can only be used effectively if these properties can be at least partly preserved in the welded condition. We have also been researching the solderability of copper foints, which is a major problem in the manufacturing of electronic devices.

\section{Microstructural Consequences of Welding Al-LI-Cu Alloys}

A.J. Sunwoo, J. Chan and J.W. Morals, Ja.

The microstructure of the weldment and heat-affected zone in the Al-Li-Cu alloy 2090 were investigated. Welding disturbs the grain structure and distribution of hardening precipitates in the heat-affected zone and produces a relatively weak, ascast structure in the fusion zone, leading to a significant loss of strength and toughness, particularly at cryogenic temperatures. The problem can be partly overcome by changes in the welding procedure (electron beam welding is preferred to other techniques because of the thinner weld zone), by changes in the chemical composition of the weldment (raising the $\mathrm{Cu}$ content improves strength and toughness), or by post-weld heat treatments that re-establish the precipitate distribution in the weld region.

\section{Effect of Surface Conditions on the Solderabillty of Pre-tinned Cu Sheet*}

A.J.SUNWOO, J.W. MORRIS, JR. AND G.K. LUCEY, JR. ${ }^{\dagger}$

Copper contacts on printed circuit boards are often "pre-tinned" by coating with a thin layer of $\mathrm{Sn}$ or solder to maintain solderability during storage prior to manufacture. The solderability of the pre-tinned layer may be lost if the Cu-Sn intermetallics grow to penetrate the layer. We have investigated this issue by artificially aging $\mathrm{Cu}$ sheets pre-tinned with eutectic $(63 \mathrm{Sn}-37 \mathrm{~Pb})$ or $\mathrm{Pb}$-rich $(95 \mathrm{~Pb}-5 \mathrm{Sn})$ solders. In both cases the penetration of the intermetallic is due to diffusion of $\mathrm{Cu}$ into the solder and its subsequent reaction with $\mathrm{Sn}$-rich islands in the solder. In the case of the eutectic the intermetallic converts to the \%o-phase $\left(\mathrm{Cu}_{3} \mathrm{Sn}\right)$ and the $\mathrm{Pb}$ withdraws into discrete islands on the surface, so that the layer is poorly wet on subsequent exposure to molten solder. In the case of $95 \mathrm{~Pb}-5 \mathrm{Sn} \mathrm{Cu}$ diffusion leads to isolated pockets of the $\mathrm{Sn}$ rich $\eta$-phase $\left(\mathrm{Cu}_{6} \mathrm{Sn}_{5}\right)$ and solderability is maintained even after relatively long aging at high temperature.

\section{Effect of Gold on the Rellabillty of Fine Pitch Surface Mount Solder Joints ${ }^{*}$ \\ J. Glazer', P. Kramer and J.W. Morais, JR.}

The effect of Au pre-coating on the reliability of surface mount solder joints between plastic quad flat packs and $\mathrm{Cu}-\mathrm{Ni}$-Au printed circuit boards was investigated. Thin $\mathrm{Au}$ layers protect the $\mathrm{Cu}-\mathrm{Ni}$ metallization and preserve solderability. While the $\mathrm{Au}$ layer is dissolved into the solder, and re-precipitated into a dense

\footnotetext{
"Work supported by the U.S. Army, Harry Diamond Laboratories

U.S. Army, Harry Dlamond Laboratorles

† Supported by Hewlett Packard

${ }^{\$}$ Hewlett Packard Corporatlon, Palo Alto, Calfornia
} 
distribution of Au-Sn intermetallics, accelerated service simulation tests suggest that moderately thick Au layers do not cause carly joint failures. However, excessive concentrations of $A u$ in the solder joint induces void formation during soldering. For this reason, it is concluded that the thickness of the Au protectlve layer should be constrained so that the Au concentration in the layer does not exced $3 \mathrm{wt} . \%$.

\section{The Use of Au Proteotive Coatings in Fluxless Solder Joints"}

R. CINOUE AND J.W. MORAIS, JR.

Protective layers of Au were deposited on Ni substrates by electroplating and by physical vapor deposittion, and the resulting joints were tested for their solderability in the absence of flux. The electroplated substrates proved to be solderable, while the deposited ones did not. Auger analysis shows that the electrodeposition process successfully eliminates oxide at the Ni/Au interface. Physical vapor deposition deposits All over the surface contaminant, which reappears when the Au is dissolved into the solder and inhibits solderability.

\section{MECHANICAL BEHAVIOR}

The principal emphasis of this project over the past year has been to examine in greater detail the fatigue, fracture and cryogenic toughness behavior of advanced aluminum-lithium alloys, with special emphasis on the role of powder-metallurgy processing and sheet material.

\section{Fatigue and Fracture}

Designers of modern commercial and military aerospace vehicles and space launch systems are constantly in search for new materials with lower density, and high strength, stiffness and stability at elevated or cryogenic temperatures. To meet these challenges, much effort has been directed toward developing intermetallics, ceramics and composites as structural and engine materials for future applications. However, for structural airframes, age-hardened 2000 and 7000 series aluminum alloys have long been preferred for many commercial transport and military aircraft by virtue of their high strength-to-weight ratio, although the use of composite materials, particularly for secondary structures, is rapidly increasing. To meet the competition from composite materials, the aluminum industry has recently introduced a new generation of aluminum-lithium alloys, by additionally incorporating ultra-low density lithium into traditional aluminum alloys; these alloys represent a new class of light-weight, high-modulus, high-strength, monolithic structural materials, which are cost-effectlve compared to the more expensive composites. The emphasis of this project has been to fully understand the micro-mechanisms underlying the behavior of these materials, with special emphasis on their performance under fatigue conditions.

\section{Fatigue Properties of Aluminum-Lithium Alloys \\ K. T. Venkateswara Rao, R. O. Ritchie}

Lithium-containing aluminum alloys constitute a family of low-density, highstrength, monolithic metallic materials, which have been identified as inexpensive alternatives to graphite-epoxy, reinforced metal-matrix and ARALL-laminate com. posites for many advanced structural aerospace applications. With added benefits from improved elastic modulus and attractive combinations of fracture toughness and fatigue properties, the alloys have been considered as prime candidates for replacing 2000 and 7000 series aluminum alloys currently used in commercial and military aircraft. In this work, the cyclic fatigue strength and fatigue-crack propagation characteristics of aluminum-lithium alloys has been reviewed with emphasis on

\footnotetext{
"Supported by Sandia National Laboratory, Albuquerque
} 
the underlying micromechanisms associated with crack advance and their implications to damage-tolerant design and lifetime computations. Specifically, results on the initlation and growth of fatigue cracks in binary Al-Li, experimental Al-Li-Cu, and near-commercial $\mathrm{Al}-\mathrm{LI}-\mathrm{Cu}-\mathrm{Zr}$ and $\mathrm{Al}-\mathrm{LI}-\mathrm{Cu}-\mathrm{Mg}-\mathrm{Zr}$ systems have been examined in detail, as a function of microstructure, crack size, wrought product form, plateorientation, temperature, environment, load ratio and loading sequence; behavior is contrasted with that of traditional aerospace aluminumalloys. Observations strongly suggest a prominent role of crack-tip shiclding during fatigue-crack propagation in these alloys, princlpally due to deflected and tortuous crack-path morphologies, induced by the shearable nature of coherent $\delta^{\prime}$ strengthening precipttates, pronounced crystallographic texture and strongly anisotropic grain structures.

\section{Fatlgue-Crack Propagation Behavlor in 2090-T8X and 2091-T8 Shieet and Plate Alloys K. T. Venkateswara Rao, R. J. Bucol*, K. V. Jata ${ }^{\dagger}, R, O$. Ritchie}

The influence of wrought product form on the fatigue-crack propagation resistance of aluminum-lithium alloys has been examined; specifically, results on the growth kinetics of long $(>10 \mathrm{~mm}$ ) fatigue cracks in peak-aged $\mathrm{Al}-\mathrm{LL}-\mathrm{Cu}-\mathrm{Zr}$ 2090-T8X and $\mathrm{Al}-\mathrm{Li}-\mathrm{Cu}-\mathrm{Mg}-\mathrm{Zr} 2091-\mathrm{T} 8$ alloys, fabricated as sheet and plate, were analyzed as a function of microstructure, load ratio and specimen orientation. Contrary to popular belief, it was found that fatigue-crack growth rates at equivalent stressintensity levels were significantly faster and less dependent on specimen orientation in sheet than in plate. Such differences were attributed to the prominent role of cracktip shielding during fatigue in these alloys, resulting from crack deflection and consequent crack closure from wedging of fracture-surface asperities (Figure 1), which microstructurally is related to variations in the degree of recrystallization, grain morphology and texture between the two product forms.

Comparison of fatigue-crack path and fracturesurface morphologles in 2090 alloy processed as

T83 sheet and T81 plate, showing $(a, b)$ crack paths along the crack-growth direction, $(0, d)$ craok profiles across the specimen thickness and $(\theta, f)$ fracture surfaces. Arrows indicate the general direction of crack growth. (XBB 890-10708)
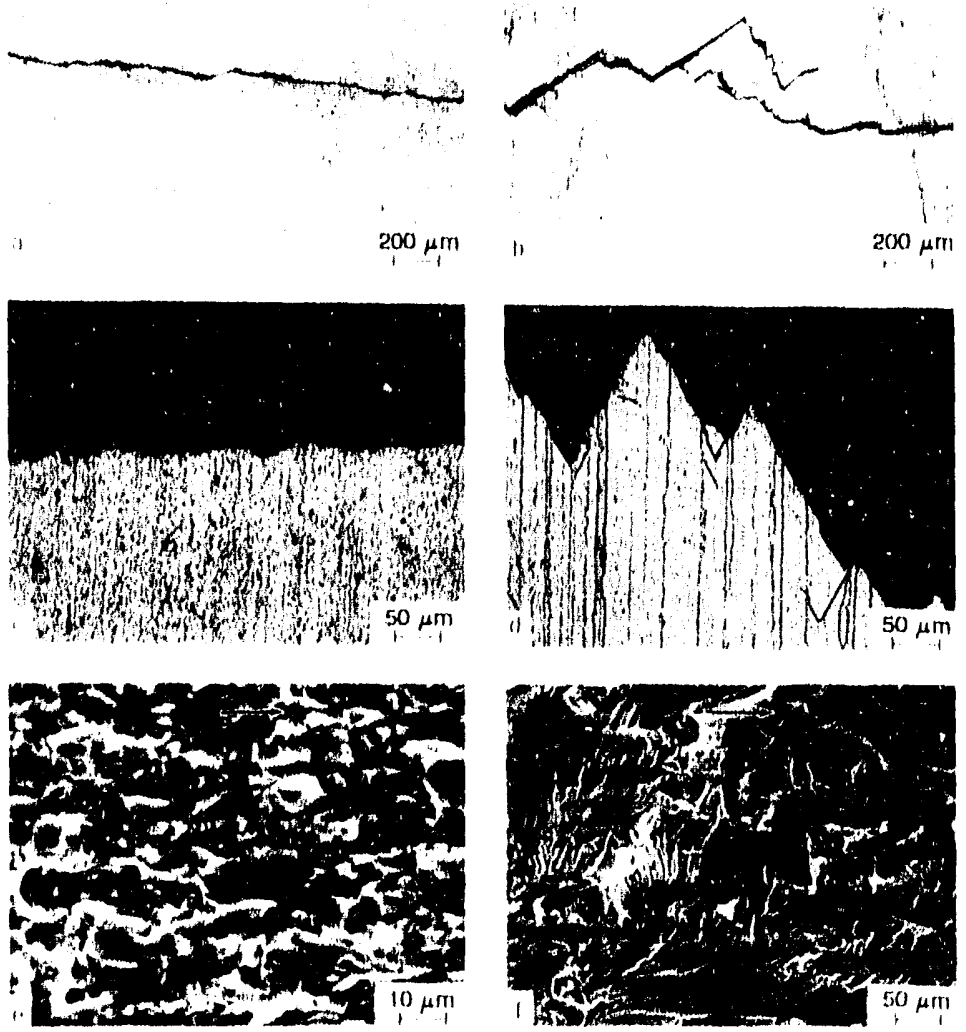

\footnotetext{
"Alcoa Laboratorles, Alcoa Center, Pittsburgh, PA

$\dagger$ University of Dayton Research Institute, OH

National Center for Electron Microscopy

$\S$ Allod Signal, Metals and Ceramics Laboratory, Morristown, NJ
} 


\section{MATERIALS CHARACTERIZATION Microstructure and $\alpha-A /$ Base Matrix/SiC Particulate Composites V. RADMILOVIC ${ }^{\ddagger}$ G. THOMAS ${ }^{\ddagger}$, AND S. K. DAS}

The microstructures of monolithi= Al-Fe-V-Si alloy and $\alpha-\mathrm{Al}$ base matrix/SiC particulate composites (MMC) have been characterized by conventional and high resolution transmission electron microscopy, microdiffraction and $x$-ray spectroscopy techniques. Silicide particles of average composiition $\mathrm{Al}_{12}(\mathrm{Fe}, \mathrm{V})_{4} \mathrm{Si}$ are present in both of these materials. These particles are unstable under the electron beam at voltages above $200 \mathrm{kV}$, and exhibit radiation induced disordering. SiC particulates present in the $\mathrm{MMC}$ structure are predominantly of the hexagonal $6 \mathrm{H}$ polytype, but the hexagonal $5 \mathrm{H}$ polytype is also observed. A very thin reaction layer is present between the matrix and $\mathrm{SiC}$ particles. No segregation of alloying elements such as $\mathrm{Fe}$, $\mathrm{V}$, or $\mathrm{Si}$ at the $\mathrm{m} / \mathrm{SiC}$ interface has been observed. The second phase present at the $\alpha-$ $\mathrm{Al} / \mathrm{SiC}$ interface seems to be a disordered silicide.

\section{Early Microstructural Evolution and Deformation Behavior in Solution Heat Treated Aluminum-Lithium Alloys}

S. MIYASATO

The binary aluminum-lithium system is age-hardened by the metastable phase $\delta^{\prime}$ $\left(\mathrm{Al}_{3} \mathrm{Li}\right)$. The $\delta^{\prime}$ precipitates are present in volume fractions of $\sim 0.2$ in commercial Al$\mathrm{Li}$ based alloys and thus affect many of the mechanical properties. Diffraction evidence from $\delta^{\prime}$ is present after solution heat treating and rapid quenching; therefore, $\delta^{\prime}$ either forms during the quench or immediately afterwards. In this investigation, the formation of $\delta^{\prime}$ during rapid quenching is compared with the precipitation behavior during slower quenching in alloys with commercially important $\mathrm{Cu}$ and $\mathrm{Mg}$ additions. The alloys used were in wt. $\% \mathrm{Al}-2.4 \% \mathrm{Li}-0.11 \mathrm{Zr}, \mathrm{Al}-2.45 \mathrm{Li}-3.15 \mathrm{Cu}-0.12 \mathrm{Zr}$, and $\mathrm{Al}-2.6 \mathrm{Li}-1 \mathrm{Cu}-0.5 \mathrm{Mg}-0.5 \mathrm{Zr}$. The formation of the microstructures in different alloys during different quench rates, and the effect of the microstructural features on the tensile deformation behavior was correlated.

Conventional transmission electron microscopy and high resolution electron microscopy showed that fine, irregularly shaped $\delta^{\prime}$ domains were present in very high volume fractions after rapid water quenching irrespective of additional solute species present. The formation of $d^{\prime}$ during a low air cool from solution heat treatment is shown to be a combination of heterogeneous nucleation at $\beta^{\prime}\left(\mathrm{Al}_{3} \mathrm{Zr}\right)$ dispersoid particle/matrix interfaces and homogeneous nucleation of discrete particles. The effect of the microstructure produced by slow air cooling was an increase in both tensile elongation and strength as compared with the microstructure produced by rapid water quenching. The superiority of the air cooling was lost with subsequent artificial aging, as both strength and elongation fell below the values of water quenched specimens due to the copious precipitation of coarse, equilibrium $\delta$ phase intermetallics.

A regime of zero strain hardening at very small plastic strains was obseved in the $\mathrm{Al}-\mathrm{Li}-\mathrm{Cu}-\mathrm{Mg}-\mathrm{Zr}$ alloy in the as-quenched conditions and at $77 \mathrm{~K}$ testing temperature. The yield plateau was attributed to the presence of a high volume fraction of $\beta^{\prime}\left(\mathrm{Al}_{3} \mathrm{Zr}\right)$ dispersoid particles which pin dislocations until a critical stress causes dislocations to cross-slip around the obstacles. The extent of the yield plateau was observed to decrease with slower quench rates and artificial aging. Direct observation of the dislocation substructure developed during ex-situ tensile straining revealed that the plateau was not caused by the planar slip of dislocations through the ordered $\delta^{\prime}$ particles. 
Effect of Cooling Rate on the Formaion of $\delta^{\prime}\left(\mathrm{Al}_{3} \mathrm{Li}\right)$ in Aluminum-Lithium Based Alloys S. MiYasato, V. Radmilovic and G. THOMAS

The ordered nature of the $\delta^{\prime}\left(\mathrm{Al}_{3} \mathrm{Li}\right)$ precipitate is known to encourage planar slip and hence shear failure in aluminum-lithium alloys. The effect of cooling rate on the formation mechanisms of $\delta^{\prime}$ and the degree of planar slip was investigated. Rapid water quenching and slow air cooling from solution heat treatment temperatures were evaluated in $\mathrm{Al}-\mathrm{Li}-\mathrm{Zr}, \mathrm{Al}-\mathrm{Li}-\mathrm{Cu}-\mathrm{Zr}$ and $\mathrm{Al}-\mathrm{Li}-\mathrm{Cu}-\mathrm{Mg}-\mathrm{Zr}$ alloys. Air cooling was found to increase the total elongation to failure in tension tests due to a bimodal distribution of $\delta^{\prime}$ size in a high $Z \mathrm{r}$ content alloy. When rapidly quenched, $\delta^{\prime}$ forms by a homogeneous formation mechanism; when slowly cooled $\delta^{\prime}$ forms by heterogeneous and homogeneous nucleation.

Program Leader

J.W. Morris, Jr.

Project Leaders

J.W. Morris-Metals for Advanced Applications

Robert O.Ritchie-Mechanical Behavior

Investigators and Scientific Staff

Gareth Thomas

Anne J. Sunwoo

K. T. Venkateswara Kao

P. N. Spencer

Postdoctoral Fellow

Xiaoguang Zhang

Visiting Researcher

Zequn Mei

Graduate Students

Edwin L. Bradley, III

Jin W. Chan

David Chu

Russell B. Cinque

Lawrence H. Edelson

Julia L. Freer

Hiroaki Hayashigatani

Seongil Im

Carl H. Iwashita

Patricia B. Johnson

Abby Kavner

Anthony G. Keslinke

Choongun Kim

Pamela A. Kramer

Christophe S. Kumai

Undergraduate Students

Desi Kovar

John McNulty

Sabrina K. Kwong

Timothy Lindsey

Stuart MacAdam

Mark T. McCormack

Andre McFayden

James M. McNaney

Shelly Miyasato

Wendy E. Nojima

Aneta Nowakowska

Steven J. Shaffer

Jian K. Shang

Peter N. Skarpelos

Tammy E. Summers

Carol Tseng

Ping $X_{u}$

Administrative Support

Jane Fortado

Madeleine Penton 
- Desi Kovar won First Prize in the National Aluminum Association 1990 Charles Martin Hall Award for best undergraduate research paper on Aluminum and its Alloys.

- John McNulty won First Prize in the National TMS-AIME 1990 Best Undergraduate Research Paper Award, sponsored by the Minerals, Metals and Materials Society.

- John McNulty won Second Prize in the National Aluminum Association 1990 Charles Martin Hall Award for best undergraduate research paper on Aluminum and its Alloys.

- S. Miyasato won the Student Award, Electron Microscopy Society of America.

\section{Contracts and Collaborations}

- Naval Air Development provided partial support for a program on the mechanisms of corrosion fatigue in commercial Al-Li alloys.

- Northrop provided support for an experimental evaluation of the high-temperature fatigue properties of $\mathrm{Al}-\mathrm{Li}$ alloys.

- Research on friction during sheet metal forming was supported by an indus..ial consortium including Ford Motor Company, LTV Steel, Rouge Steel and Keil Chemical Division of Ferro Corporation.

- Research on the fatigue of surface mount solder joints was done in collaboration with the Digital Equipment Corporation, and supported by them.

- Research on the use of Au coatings to permit fluxless soldering was supported by the Sandia National Laboratory.

- Research on the influence of Au coatings on surface mount soldered contacts was done in collaboration with Hewlett Packard, and supported by them.

- Research on intermetallic growth and its influence on the solderability of pretinned contacts was supported by the US Army Harry Diamond Laboratories as part of their manufacturing technology program.

- Materials for research on advanced aluminum alloys were provided by Alcoa.

- LBL light alloy melting facilities were used by Alcoa to cast and process research alloys for their use.

- Research on high strength steels for applications in aircraft landing gear is supported by the Naval Air Development Center and done in collaboration with Carpenter Steel.

- R. J. Bucci of Alcoa collaborated with the Mechanical Behavior group on the fatigue of $\mathrm{Al}-\mathrm{Li}$ alloy sheet.

- G. Thomas received support from Allied-Signal for research in the microscopy of advanced aluminum alloys.

Publications and Reports

Metals for Advanced Applications

Referred Journal Articles

Morris, Jr., J.W., (with J. W. Chan and A. J. Sunwoo) High-Mn Steel Weldment Mechanical Properties at 4K, Welding Journal, Research Supplement, Vol 69:1, January 1990, pp. 30S - 38S

Morris, Jr., J.W., (with A. G. Khachaturyan) Diffuse Scattering from $\mathrm{YBa}_{3} \mathrm{Cu}_{2} \mathrm{O}_{7 . \partial}$, Physical Review Letters, Vol 64:1, January 1, 1970, pp. 76-79

Morris, Jr., J.W., (with J. Glazer) On the Theory of Strengthening by Coherent Ordered Precipitates,. Philosophical Magazine Letters, Vol 62:1, 1990, pp. 33-36

Morris, Jr., J.W., (with J. W. Chan, J. Glazer, Z. Mel and P.A. Kramer) Fracture Toughness Of 304 Stainless Steel In An 8 Testla Field, Acta Metallurgical Vol 38:6, May 1990, pp. 479-487

Morris, Jr., J.W., (with Z. Mei) Mossbauer Spectrum Curve Fitting With A Personal Computer, Nuclear Instruments and Methods in Physics Research, B47, May 1990, pp. 181-186

Morris, Jr., J.W., (with T.S.E. Summers), Isothermal Fatigue Behavior of Sn-Pb Solder Joints, Journal of Electronic Packaging, Vol 112, June 1990, pp. 94-99 
Morris, Jr., J.W.,. (with D. Tribula), Creep in Shear of Experimental Solder Joints, Journal of Electronic Packaging, Vol 112, June 1990, pp. 87-93

Morris, Jr., J.W., (with J. Glazer), On the Theory of Strengthening by Coherent Ordered Predipitates, Philasophical Magazine Letters, Vol 62:1, 1990, pp. 33-36

Morris, Jr, J.W., (with Z. Mei) Influence of Deformation-Induced Martensite on Fatigue Crack Propagation in 304-Type Steels, Metallurgical Transactions A, Vol 21A:12, December 1990, pp. 3137-3152

Morris, Jr., J.W., (with A. J. Sunwoo and E. L. Bradley, III), Effects of Heat Affected Zone Peak and Temperatures on the Microstructure and Properties of 2090 Alloy, Metallurgical Transactions, Vol 21A:10, October 1990, pp. 2795-2804

Morris, Jr., J.W., (with A. G. Khachaturyan) A Possibility of Experimental Determination of a Nonequillbrium Free Energy of an Ordered Alloy, Scripta Metallurgical et Materialia, Vol 24, April 1990, pp. 391-394

Morris, Jr., J.W., (with P. E. Johnson, J.-H. Schmitt and S. A. Vincent, The Effect of Prestrain Temperatures On Dislocation Cell Formation and Subsequent Tensile Behavjor in Low Carbon Steel Sheets, Scripta_Met, Vol 24, 1990, pp. 1447-1452

Morris, Jr., J.W., (with Z. Mel, D. Grivas and M. C. Shine) Superplastic Creep of Eutectic Tin-Lead Solder Joints, Journal of Electronic Materials, Vol 19:11, November 1990, pp. 1273-1280

Morris, Jr., J.W., (with John E. Sanchez, Jr. and L. T. McKnelly, Jr) Morphology of Electromigration-Induced Damage and Failure in Al Alloy Thin Film Conductors, Journal of Electronics Materials, Vol 19:11, November 1990, pp. 1213-1220

Refereed Conference Proceedings

Morris, Jr., J.W., (with A. J. Sunwoo), Effects of Precipitate Distribution on 293K and 77K Properties of 2090-T81 Weldments, Advances in Cryogenic Engineering Materials '89, Vol 36B, June 1990, pp. 1167-1173

Morris, Jr., J.W., (with S. L. Verzasconi), Cryogenic Mechanical Properties of Low Density Superplastic Al-Mg-Sc Alloys, Advances in Cryogenic Engineering Materials '89, Vol 36B, June 1990, pp. 1127-1130

Morris, Jr., J.W., (with J. Glazer and J. W. Chan), The Metallurgical Determinants of Toughness at Cryogenic Temperature, Advances in Cryogenic Engincering Materials '89, Vol 36B, June 1990, pp. 777-785

Morris, Jr, J.W., (with Z. Mei), The Effects of Temperature on Fatigue Crack Propagation in 310 Austenitic Stainless Steel, Advances in Cryogenic Engineering Materials '89, Vol 36B, June 1990, pp. 1241-1247

Morris, Jr., J.W., J. W. Chan, J. Glazer and Z. Mei) 4.2K Fracture Toughness of 304 Stainless Steel in A Magnetic Field, Adrances in Cryogenic Engineering Materials '89, Vol 36B, June 1990, pp. 1299-1306

Morris, Jr., J.W., (with D. Chu), The Effect of Hydrogen Charging on the Mechanical Properties of Aluminum-Lithium Alloy 2090, Adoances in Cryogenic Engineering Materials '89, Vol 36B, June 1990, pp. 1151-1157

Morris, Jr., J.W., (with S. K. Hwang, H.S. Ryoo and H. Y. Lee) Effect Of Phase Transformation And Recrystallization On The Texture Of Zircaloy, Proceedings of Recrystallization '90 Conference (ed. T. Chandra), 1990, pp. 163-168

Morris, Jr., J.W., (with S. J. Shaffer, W. E. Nojima, P.N. Skarpelos) Research on the Metallurgical Determinants of Formability in Electrogalvanized Sheet, Zinc-Based Steel Coating Systems: Metallurgy and Performance, G. Krauss \& D. K. Matlock, eds, TMS, Warrendale, PA, October 1990, pp. 251-261

Morris, Jr., J.W., (with R. A. Emigh, E. L. Bradley, III, S. Miyasato) Superplastic Studies In The Al-Li-Sc-Mg System Superplasticity in Aerospace II, edited by Terry R. McNelley and H. Charles Heikkenen, The Minerals, Metals and Materials Society, July 1990, pp. $303-315$

Morris, Jr., J.W., (with S. J. Shaffer, W. E. Nojima, P.N. Skarpelos) Research on the Metallurgical Determinants of Formability in Electrogalvanized Sheet Zinc-Based Steel Coating Systems: Metallurgy and Performance, G. Krauss \& D. K. Matlock, eds, TMS, Warrendale, PA, October 1990, pp. 251-261

Morris, Jr., J.W., (with S. J. Shaffer and H. -R. Wenk) Textural Characterization and Its Application on Zinc Electrogalvanized Steels Zinc-Based Steel Coating Systems: Metallurgy and Performance, G. Krauss \& D. K. Matlock, eds, TMS, Warrendale, PA, October 1990, pp. 129-140

Radmilovic, V., S. Miyasato and G. Thomas, "Subgrain Boundary Structure in Al-Li-Cu-Zr Alloy", Conf. Proc. Athens, Greece III Balkan Congress on Electron Microscopy, p.478, 1989.

Kusinski, J. and G. Thomas, "Microstructure of the Deformed Al-Li-Cu-Zr Alloy", Proc. VII Conf. E.M., Krakuw, Poland, VII Konferencja Mikroskopii Electronowej Ciala Stalego, p.285,1989.

Other Publications

Morris, Jr., J.W., "The Science Of Thermomechnalcal Processing," Proceeding 1st Japan International SAMPE Symposium, January 1990, pp. 787-792

Morris, Jr., J.W., (with D. Tribula, T.S.E. Summers and D.I Grivas) The Metallurgical Mechanisms of Solder Fatigue, NEPCON'90 Proceedings, 1990

Morris, Jr., J.W., (with John J. Sanchez, Jr., and James R. Lloyd), Electromigration Fallure of Circuit-Level Interconnections, The Journal of The Minerals, Metals \& Materials Society, Vol 42:9, September 1990, pp, 41-45 
Thesis

Miyasato,S.M.,Microstructural Evolution in Al-Li Alloys,(Th.D.Thesls, Department of Materials Science and Mineral Engineering, U.C. Berkeley. Advisor: G. Thomas.

Invited Talks

Morris, Jr, J. W. "The Metallurgical Mechanisms of Solder Fattgue, NEPCON West '90, Anaheim, Callfornia, February 26-March 1,1990

Morris, Jr., J. W. "Research on Electrogalvanization of Steel Sheets," Surface and Metal Formability Conference, Chicago, IL., February 8-9, 1990

Morris, Jr., J. W. "Microstructural Mechanisms of Failure in Solder Contacts," Eighteenth Annual Electronic Materials Symposium of the Northern Californla Section of TMS, Santa Clara, CA March 26, 1990

Morris, Jr., J. W. "Microstructural Mechanisms of Creep and Fatigue in Eutectic Pb-Sn Solders" First International Workshop of Materials and Mechanics Issues of Solder Alloy Applications, Santa Fe, NM, June 6-8, 1990

Morris, Jr. J. W. "Toward New' Solders with Exceptional Resistance in Thermal Fatigue, TMS Annual Meeting, New Orleans, February 1991

Morris, Jr, J. W. "Influence of High-Magnetic Fieids and Other Electromagnetic Phenomena On The Mechanical Properties of Structural Materials," National Research Institute for Metals, Tokyo, Japan, December 10, 1990

Morris, Jr, J. W. "New Solders With Exceptional Resistance in Thermal Fatigue," Hitachi, Ltd, Production Engineering Research Lab, Yokohama, Japan, December 11, 1990

Morris, Jr, J. W. "Research of High Strength Steels," Kyushu University, Department of Iron and Steel Metallurgy, Fukuoka, Japan, December 13, 1990

Morris, Jr, J. W. "Research of Electronic Packaging and Superconductivity," Kobe Steel, Ltd, Superconducting and Cryogenic Technology Center, Kobe, Japan, December 15, 1990

Morris, Jr, J. W. "High T, Materials Magneticmechanical Behavior" (1) Toshiba, Tsurumi, Ohkura, (2) Toshiba, Ukishima, Decernber 17,1990

Morris, Jr., J. W. "Advanced Cryogenic Materials and Topics," Tohoku University, Sendai, December 18, 1990

Morris, Jr., J. W. "Deformation and Fracture Behavior of Advanced Cryogenic Materials, National Research Institute for Metals, Tsukuba, Japan, December 21, 1990.

Mechanical Behavior of Materials

Refereed Journal Articles

Dauskardt, R.H., F. Haubensak, and R.O. Ritchie, "On the Interpretation of the Fractal Character of Fracture Surfaces," Acta Metall. Mater., vol. 38, p. 143, 1990.

Venkateswara Rao, K.T. and R.O. Ritchie, "Mechanisms Influencing the Cryogenic Fracture-Toughness Behavior of Aluminum-Lithium Alloys," Acta. Metall. Mater, vol. 38, p. 2309, 1990.

Refcreed Conference Proceedings

Venkateswara Rao, K.T., R.J. Bucci, and R.O. Ritchie, "On the Micromechanisms of Fatigue-Crack Propagation in AluminumLithium Alloys: Sheet vs. Plate Material," in Fatigue 90, ed. H. KItagawa, and T. Tanaka, vol. 2, p. 936, 1990.

Venkateswara Rao, K.T. and R.O. Ritchie, "Fatigue-Crack Propagation in Advanced Aerospace Materials: Aluminum-Lithium Alloys," in Proc. 7th Int. Conf on Fracture: Adoances in Fracture Research, ed. K. Salama, K. Ravi-Chandar, D.M. R. Taplin, and P.Rama Rao, vol. 5, p. 3787, 1990.

LBL. Reports

Venkateswara Rao, K.T., R.J. Bucci, K.V. Jata, and R.O. Ritchie, LBL 29514, "A Comparison of Fatigue-Crack Propagation Behavior in Sheet and Plate Aluminum-Lithium Alloys," Materials Science and Engineering A. (Submitted.)

Venkateswara Rao, K.T., N.J. Kim, P.P. Pizzo, and R.O. Ritchie, LBL 28517, "Fatgue-Crack Propagation in Aluminum-Lithlum Alloys Processed by Powder and Ingot Metallurgy," Adoanced Aluminum and Magnesium Alloys. (Submitted.)

Venkateswara Rao, K.T. and R.O. Ritchie, LBL 28440, "Cryogenic Fracture Toughness and Fatigue-Crack Propagation Behavior in Powder-Metallurgy Aluminum-Lithium Alloys," Metall. Trans, A. (Accepted for publication.)

Venkateswara Rao, K.T. and R.O. Ritchie, LBL 28964, "Development of Microstructures with Improved Cryogenic Toughness through Variations in Stress State: Aluminum-Lithium Alloys," Alloys Phase Stability and Design, Mat. Res. Soc. Proc. (Submitted.) 
Ritchle, R.O, Cyclic Behavior of Advanced Structural Materials, DARPA Meeting on Fatigue and Reliabllity of Advancod Structural Materials, La Jolla, CA, July 1990.

Ritchie, R.O., Fatigue of Advanced Materials, Fourth International Conference on Fatigue and Fatigue Thresholds: Fatlgue '90, Honolulu, IHA, July 1990.

Ritchie, R.O., Overview of the Small-Crack Problem in Fatigue, ASTM Symposium on Small-Crack Test Methods, San Antonio, TX, Novomber 1990.

Ritchie, R.O., Design of Analysis Methods for Advanced Materials, Sixth Annual North American Welding Research Conforence on Design and Fitness for Service of Welded Structures, Columbus, OH, October 1990.

Ritchie, R.O., Fracture Mechanics and Fatigue, ASM Annual Conference: Materials Week, Detrolt, MI, October 1990.

Ritchie, R.O. and K.T. Venkateswara Rao, Cryogenic Fracture Toughness Behavior of I/M and P/M. Aluminum-Lithium Alloys, ASTM Spring Meeting, San Francisco, CA, April 1990.

Ritchie, R.O. and K.T. Venkateswara Rao, The Design of Materials with Enhanced Cryogenic Toughnessi Commercial AluminumLithium Alloys, Spring MRS Annual Meeting, San Francisco, CA, April 1990.

Ritchie, R.O. and K.T. Venkateswara Rao, Mechanisms of Cryogenic Toughness in Conmercial Alumirum-Lithium Alloys, 119th TMS Annual Meeting, Anaheim, CA, February 1990.

Ritchie, R.O., K.T. Venkateswara Rao, and R.J. Bucci, Micromechanisms of Cyclic Crack Extension in Al-Li Alloys, Fourth International Conference on Fatigue and Fatigue Thresholds: Fatlgue '90, Honolulu, HA, July 1990.

Ritchie, R.O., K.T. Venkateswara Rao, and W. Yu, Fatigue-Crack Propagation in Al-Li Alloys: Effects of Tensile and Compression Overloads, 119th TMS Annual Meeting, Anaheim, CA, February 1990. 


\section{Industry Participation}

CAM's mission statement calls for basic research in materials science. The research programs described in the preceding sections of this report are devoted to increasing our understanding of the fundamental properties of materials and materials systems. The mission statement also states that this research should support U. S. industry and that there be direct and continuing collaboration between CAM and U. S. industrial research laboratories. The selection of CAM research topics and the design of its programs are governed by the basic materials research needs of industry and a major thrust of the programs involves information flow to and from industry. This includes discussions, research collaborations, gifts, contracts, industrial fellowships, visits, publication of results in the scientiic journals, and publications from the Center, such as Research Notes, and this Annual Report.

The CAM Industry Participation Office, in the office of the CAM Director, is charged with the development and management of these interactions with industry. Activities supported by that office include:

- program advisory board meetings

- industry participation workshops

- research collaborations

- CAM industrial fellowships

- research contracts, gifts and fellowships

- publications

- visits of industry scientists and research managers

Each CAM program, and some projects, are supported by an advisory board made up of industrial research managers serving two or three year renewable terms. The boards meet formally once each year to review the focus and goals of the program and the research progress made since the last meeting. A report is prepared on these aspects of the program with specific suggestions and criticisms, primarily focused on the question of which research directions are appropriate to CAM and of greatest potential benefit to U.S. industry. Members of the advisory board also consult with the program and project leaders informally throughout the year. Listings of the advisory board members follow each chapter of this report. 
Each CAM program holds, at two to three ycar intervals, a formal workshop for industry. These are open to all interested representatives of U. S. Industry. The workshops, which usually run for two days, involve presentations by the CAM investigators of the research of their programs, and their planned directions for the following few years. Industrial scientists attending the workshop are invited to discuss the research and to express their views on appropriate directions of the research programs-directions that will produce beneficial results for their own companies and for U.S. industry in general. The workshops also include visits to the CAM laboratories and informal discussions with its scientists and students.

\section{Research Collaborations}

CAM programs have established research collaborations with scientists in many U.S. industrial laboratories. These are described in detall in the preceeding sections of this report and involve companies in areas from petrochemical to automobile manufacturing to blotechnology. In some cases, the collaboration involves exchange of proprietary information or materials. Results of this work are published in the open literature by University of Callfornia and Lawrence Berkeley Laboratory policy, but only after protection of the proprietary information is assured.

\section{Industrial Fellows}

The Industrial Fellows Program at CAM is one of our most effective means of technology transfer to industry. Under the program, industrial scientists come to CAM to spend from three months to a year as integral members of one of the research programs. The fellowships can also be arranged for one week each month for a year, or, with local companies, for one or two days each week during the year. Industrial Fellows not only pursue research projects while in residence, adding their own background and experience to that of the programs staff, but also serve as excellent technology transfer agents when they return to their company's laboratories. Some of the Fellows devote their time at CAM to the development and design of collaborative research programs between their laboratories and the CAM Program. Two Industrial Fellows worked at CAM during 1990. Two are scheduled for appointment in 1991 and more are now being planned for 1992.

\section{0 industrial Fellows}
M. Colclough
Conductus, Inc.
High $T_{c}$ Superconductivity Program
T. Guion
Cargill, Inc.
Enzymatlc Synthesls of Materlals Project

The value of this program has been recognized by the Department of Energy. Arrangements have been made for DOE support of the laboratory, living, and travel expenses of many of the Industrial Fellows while at work at CAM through the Industry-Laboratory Technology Exchange Program of the DOE Office of Energy Research. In 1990, both M. Colclough T. Guion were supported under this program. 
Unrestricted gif ts to CAM during 1990 totalod $\$ 204,000$, ralsing the seven year total to $\$ 836,000$. This type of funding is the most valuable to the CAM programs because it gives them the required flexibility to deal with important and unexpected research needs as they arise.

\section{Gifts of Materials and Equipment}

Programs at the Center benofit groatly from donations of usod or new processing or analytical equipment, or materials that are unavallable commercially. This year, Chevron Corporation donated a Varian $\mathrm{XL} \cdot \mathrm{MH}_{\mathrm{z}}$ Nuclear Magnetlc Resonance Spectrometer with a replacoment value of $115 \mathrm{~K}$. The value of donated materials for the past seven years exceeds two million dollars.

\section{Research Contracts}

1990 rescarch contracts totaled $\$ 402,000$, bringing that seven yoar total to $\$ 1,196,00()$. The contracts allow for focused work on specific projects of direct interest to the company involved, and enable the sponsors to maintain close contact with the investigators and students.

\section{California Competitive Technology Program}

Two CAM programs have been selected to participate in the Californla Competitive Technology Program. The program on High- $T_{c}$ Superconductivity, with support from the U.S. Department of Energy, is continuing its collaborative effort with the State of Callfornia and Conductus, Inc, a start-up company in California's SilliconValley. "The goal of the project is to transfer to Conductus results of the fundamental research supported by DOE that will allow the development of Superconducting QUantum Interference Devices (SQUIDs) using the new high- $T_{c}$ superconducting materials. The CAM program on Enzymatic Synthesis of Materials has also received a grant from the California Competitive Technology Program for a collaborative effort with Blocircuits, Inc., (Burlingame, CA), for work on novel molecular selfassembly systems for bloelectronics. The focus of the work is on designing and synthesizing novel self-assembling organic films with application to the production of bloclectronic sensors.

Publications

All CAM work is published in the open literature. This year CAM researchers published 211 articles in books, fournals and conference proceedings, 146 invited papers, 49 contributed papers. An additional 188 journal articles are now in press. The Center also produces a number of its own publications throughout the year. These include this Annual Report, and the triannual Research Notes describing recent research highlights. Research Notes also includes the list of recent journal articles. These CAM publications are sent, along with announcements of workshops and other meetings, to those on our mailing list. The attached form should be used for adding names to that list.

Industrial Visitors

Representatives from U.S. industrial companies are encouraged to visit the Center; visits range from one day to a week or more. First visits usually involve discussions with CAM management, industry participation officials, and selected program leaders. Subsequent visits are focused on more detailed scientific discussions with 
program staff and often load to continuing rolationships including porlodic exchanges of idoas and rosults, or active, formal collaborations.

\section{Students and Postdoctoral Fellows}

During the past seven years, 108 students received their masters or doctoral degrees (18 in 1990) or completed postdoctoral fellowships. Of this group, 56 have moved on to industrial research positions, and 12 more have taken University teaching positions. Others continuod their studies after loaving CAM.

\section{Degree Recipjents}

Name

R. Bicrnath

S. Anthony-Cahill

L. Chan

M. Corcy

J. Ding

R. Enilgh

D. Kapolnck

C. Kumai

S. Lombardo

L. McKnelly, Jr.

Z. Mel

A. Michiels

C. Noren

J. Rosenberg

C. Sheu

R. Shipman

D. Tribula

D. Zeglinski

\section{Degree Current Employer}

PhD

Phd

Masters

PhD

PhD

PhD

Masters

PhD

PhD

PhD

$\mathrm{PhD}$

Masters

PhD

PhD

Masters

PhD

PhD

PhD
AT\&T Boll Laboratories

DuPont Central R\&D

Intel Corporation

University of Colorado

Applied Materials

Precision Cast Parts Corporation

Superconductor Technologles, Inc.

Postdoctoral Fellow, LBI.

Max Planck Institute

Vitesse Semiconductor

Postdoctoral Fellow, LBL

Applied Magnetics Corporation

Postdoctoral, LBL

Postdoctoral, LBL

¿ urthrup Aircraft

Postdoctoral Fellow, LBL

Lam Research

Surface Science Labnratory
CAM Program

Polymors and Composites

Tolymers and Composites

Electronics Materials

Polymers and Composites

Electronic Materials

High Performance Motals

Ceramic Science

High Performance Metals

Surface Sclence and Catalysis

High Performance Metals

High Performance Metals

Polymers and Composites

Polymers and Composites

Polymers and Composites

Ceramic Sclence

Polyrners and Composites

High Performance Metals

Polymers and Composites 
Blanoh, $H_{1}$ 211

Bednarskl, M. .......140, 207-208, 210,212,213

Bell, A. $122 \cdot 124,128 \cdot 131,206$

Burdahl, $P$..... .184

Bourett, E., $107 \cdot 109$

Brewer, $L$ $69 \cdot 70$

Cannon, $R$ .163

Chakraborty, A.....................................205

Clark, D. 211

Clarke, J... $49-51,139,181-182$

Cohen, M $59-61,170,173,178$

Dahmen, U

$4,21,22,24-25$

de Fontalne,

$20-28,171$

Dejonghe, L.. 159-162, 185

Denn, M 202-204, 206

Evans, J $34-35,91,162$

Falloov, $52.54,171$

Glaeser, A. .158

Gronsky, R. $186 \cdot 187$

Haller, E 104-106

Helnemann, H..................................133

Jakelevlo, J........................................104

Jeffrles, C ...174

Kirsch, J $208-209,213$

Kortright, J 114,116

Kresin, $V$ $170-171$

Krishnan, $K$. $29-33$

Levy, A. 109-110

Lillental-Weber, Z $55-58,141$

Loule, S. 222-229

Morris, J.W., Jr.... $75-77,92-95$

Muller, R. $.98-100$

Newman, J. $71-74$

Olander, D 113,115

Olmstead, M.... $64-65,177-178$

Phillips, N $78 \cdot 88$

Plnes, $A$.
Porter, J......................................114, 116

Portis, A.....................................174.176

Relmer, J............................... 123, 177, 203

Rlohards, P...................36.40, 176, 182.183

Piltohle, $A_{1}$ O......................163-165, 229.230

Rosenblatt, G. .............................143.146

Ros8, P................................62.63, 89.90

Salmeron, M.........128, 134, 137-138, 140.141

Sohultz, P.

212,214

Shen, $R$

$41-45,142-143$

Somorjal, G..........125-128, 131, 133.138, 141

Staoy, A. .....................................179.180

Theodorou, D.............................. 131, 205

Thomas, G...... 3-4, 6, 14-19, 188-189, 231-232

Toblas, C $.66-68,96-97$

Van Hove, $M$ $131-132,134-136$

Waluklewioz, W., 104-106, 112

Washburn, J $.109 \cdot 111$

Wober, E $106,109-110$

Westmacott, K $4,20-23$

Wong, C.H. 209,213

Yu, P. $46-48$

Zettl, A $139,173-174,178$ 

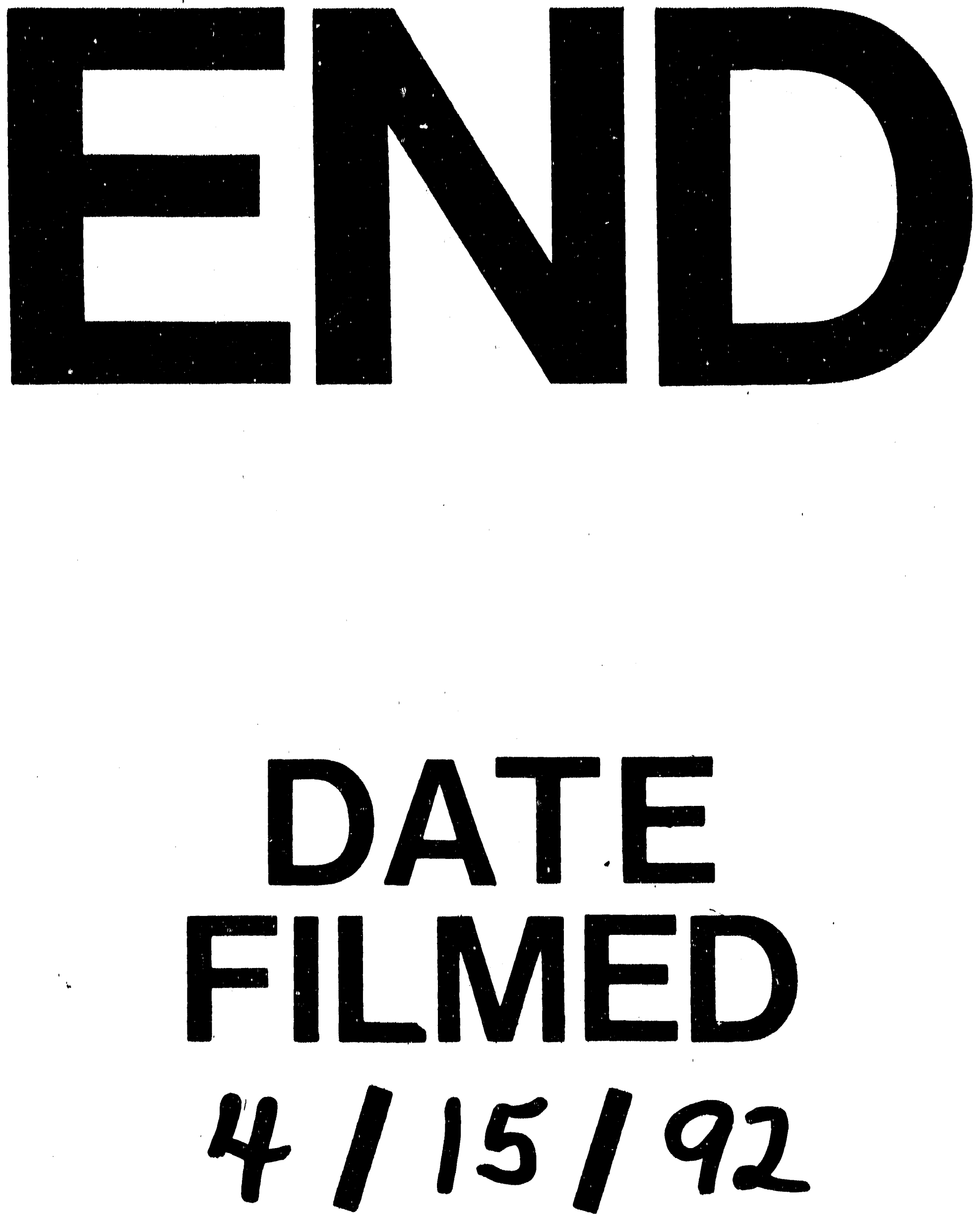

1 


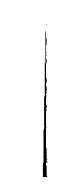

